University of Louisville

ThinkIR: The University of Louisville's Institutional Repository

Electronic Theses and Dissertations

8-2011

\title{
A study of the behavior of veneer wall systems in medium rise buildings under seismic loads.
}

Niranjan Desai 1979-

University of Louisville

Follow this and additional works at: https://ir.library.louisville.edu/etd

\section{Recommended Citation}

Desai, Niranjan 1979-, "A study of the behavior of veneer wall systems in medium rise buildings under seismic loads." (2011). Electronic Theses and Dissertations. Paper 337.

https://doi.org/10.18297/etd/337

This Doctoral Dissertation is brought to you for free and open access by ThinkIR: The University of Louisville's Institutional Repository. It has been accepted for inclusion in Electronic Theses and Dissertations by an authorized administrator of ThinkIR: The University of Louisville's Institutional Repository. This title appears here courtesy of the author, who has retained all other copyrights. For more information, please contact thinkir@louisville.edu. 


\title{
A STUDY OF THE BEHAVIOR OF VENEER WALL SYSTEMS IN MEDIUM RISE BUILDINGS UNDER SEISMIC LOADS
}

\author{
By \\ Niranjan Desai \\ B.TECH., The Indian Institute of Technology - Delhi, 2003 \\ M.E.S., The University of Sydney, 2004 \\ A Dissertation \\ Submitted to the Faculty of the \\ Department of Civil and Environmental Engineering of the University of Louisville \\ In Partial Fulfillment of the Requirements \\ For the Degree of \\ Doctor of Philosophy \\ Department of Civil and Environmental Engineering \\ University of Louisville \\ Louisville, Kentucky
}

August, 2011 


\title{
A STUDY OF THE BEHAVIOR OF VENEER WALL SYSTEMS IN MEDIUM RISE BUILDINGS UNDER SEISMIC LOADS
}

\author{
By \\ Niranjan Desai \\ B.TECH., The Indian Institute of Technology - Delhi, 2003 \\ M.E.S., The University of Sydney, 2004
}

A Dissertation Approved on

June 3, 2011

By the Following Dissertation Committee:

Dissertation Director (Mark McGinley)

William P. Hnat

Zhihui Sun

Thomas D. Rockaway 


\section{ACKNOWLEDGEMENTS}

I would like to thank my advisor, Dr. Mark McGinley for his guidance and patience. Working under his supervision provided me with an excellent opportunity to understand the process involved in performing academic research. Furthermore, he was always easily accessible and approachable, and created a very comfortable and congenial working environment. At the same time, he was exacting and professional, thereby creating the ideal balanced atmosphere for me to work within. I would also like to thank Dr J.P. Mohsen for his understanding and patience, and providing me with the funds needed to complete this research endeavor, at the time at which I was close to finishing, but had insufficient funds. Finally, I would like to thank Dr. Hussein Okail and Dr. Seongwoo Jo for their significant contributions to the development of my analytical models, which greatly accelerated the pace of my research effort. 


\title{
ABSTRACT \\ A STUDY OF THE BEHAVIOR OF VENEER WALL SYSTEMS IN MEDIUM RISE BUILDINGS UNDER SEISMIC LOADS
}

\author{
Niranjan Desai
}

May 26, 2011

This dissertation presents an analytical investigation that examined the seismic performance of steel stud backed and Concrete Masonry Units (CMU) backed masonry veneer wall systems, under in and out - of - plane loads, in medium rise building frames. The investigation was prompted by recently observed damage to brick veneer wall systems due to strong earthquake and wind events. Prior research on these systems had focused on veneer walls built using older construction practices, or on residential wood stud backed veneer wall systems, or wall systems in low rise building frames.

In this investigation, analytical models of the wall systems were attached to models of medium rise building frames, and the combined models were dynamically analyzed under the action of carefully selected ground motions, using the state of the art OpenSees framework. The preliminary designs of the building frames were performed on the STAAD.Pro software, according to American Building Code provisions. The member sizes were selected by the software using its inbuilt design algorithms, so as to be 
representative of those commonly used in earthquake resistant design in the United States, in regions falling under seismic category D. These members were then transferred into the OpenSees framework, on which the dynamic analysis was performed. The Sylmar and Tarzana ground motion histories were appropriately scaled and used in the dynamic analysis.

A parametric study was conducted in order to understand the effect of different parameters on the response of the combined system comprising the veneer walls and the main building frame. The parameters were selected so as to create systems that represented the masses and stiffnesses of a vast majority of systems used in construction practice. For the mainframe systems, these included the steel moment resisting and braced frames, and the reinforced concrete moment resisting and shear wall systems. For the veneer wall systems, the parameters varied included the type of backing wall, namely, the steel stud backing wall and the CMU backing wall, and the type of tie system, namely, a stiff tie system and a flexible tie system.

All the models developed in this investigation were calibrated against experimental results. During the calibration process, models were developed on OpenSees that replicated experimental observations and the model parameters were adjusted till the results predicted by the models closely matched observations. 
To begin with, the results of this investigation describe the effect of modeling the wall systems, under in and out - of - plane loads, as their representative masses, and as analytical models, on the frame systems, at the Design Based Earthquake (DBE) and Maximum Considered Earthquake (MCE) levels of the Sylmar and Tarzana ground motions. Subsequently, they describe the effect of the mainframes on the veneer wall systems, under out - of - plane loads, at the MCE level of the same ground motions. Finally, the results of a collapse analysis of the wall systems under out - of - plane loads is presented, showing the intensity of the ground shaking which caused failure of the wall system, and the reason for the observed failure. 


\section{TABLE OF CONTENTS}

PAGE

SIGNATURE PAGE

vii

ACKNOWLEDGEMENTS

ABSTRACT

TABLE OF CONTENTS vii

LIST OF TABLES Xi

LIST OF FIGURES Xiv

\section{CHAPTER 1}

INTRODUCTION

1.1 Background

1.2 Overview of Research Program

1.3 Scope and Objectives

\section{CHAPTER 2}

LITERATURE REVIEW 6

2.1 Introduction 6

2.2 Performance Based Earthquake Engineering 7

2.3 Veneer Wall System Behavior 9

2.4 An Overview of the Existing Research on Veneer Wall Systems 13

2.4.1 Lafave et al.: Investigations

2.4.2 Hussein et al.: Investigations 23

2.4.3 Seongwoo Jo et al.: Investigations 29

2.5 Summary 33

CHAPTER 3

MODELING DESCRIPTION AND CALIBRATION, PARAMETRIC STUDY

3.1 Introduction 
3.3 Main Frame Design 41

3.3.1 Vertical Loads $\quad 42$

3.3.2 Lateral Loads: Equivalent Lateral Force Procedure $\quad 44$

3.3.2.1 Seismic Base Shear Determination 46

3.3.2.2 Vertical Distribution of Seismic Forces 51

3.3.2.3 Computation of Storey Deflections 51

3.3.3 Load Combinations

3.3.4 STAAD.Pro 3-D Frame Models and Frame Design 53

3.3.4.1 Steel Moment Resisting Frame 53

3.3.4.2 Steel Braced Frame

3.3.4.3 Reinforced Concrete Moment Resisting Frame 56

3.3.4.4 Reinforced Concrete Shear Wall System 57

3.4 Nonlinear (OpenSees) Modeling of the Main Frames 66

3.4.1 Development of the Equivalent Sections 67

3.4.2 Steel Moment Resisting Frame $\quad 71$

3.4.3 Steel Braced Frame $\quad 77$

$\begin{array}{ll}\text { 3.4.4 Reinforced Concrete Moment Resisting Frame } & 79\end{array}$

3.4.5 Reinforced Concrete Shear Wall System 85

3.5 Nonlinear (OpenSees) Modeling of Veneer Wall Systems 96

3.5.1 Out - of - Plane Veneer Wall Model: Flexible Backing Wall 98

3.5.1.1 Steel Stud Backing Wall Model 98

3.5.1.2 Veneer Model 99

3.5.1.3 Tie Model 102

3.5.1.4 Attachment of the Veneer Wall System to the Main Frame 105

3.5.2 Out - of - Plane Veneer Wall Model: Stiff Backing Wall 107

3.5.2.1 CMU Backing Wall Model 107

3.5.2.2 Inelastic Veneer Element Model $\quad 110$

3.5.2.3 Tie Models 110

3.5.2.4 Attachment of the Veneer Wall System to the Main Frame 113

3.5.3 Wall Model: Flexible Backing Wall Under In - Plane Loads 114

3.5.3.1 Steel Stud Backing Wall 114

3.5.3.2 Veneer Model 118

3.5.3.3 Wall Tie Models: In - Plane Loading $\quad 120$

3.5.3.4 Attachment of the Wall System to the Main Frame for In - Plane Loading 122

3.5.4 Wall Model: Stiff Backing Wall Under In - Plane Loads $\quad 124$

3.5.4.1 Backing Wall $\quad 125$

3.5.4.2 Veneer Model 126

3.5.4.3 Tie Models 127

3.5.4.4 Attachment of the Wall System to the Main Frame for In - Plane Loading 129

$\begin{array}{lr}3.6 \text { Verification/Calibration } & 130\end{array}$

3.6.1 Frame Models 131

3.6.1.1 Frame Models: Pushover Analysis Results $\quad 131$

3.6.1.2 Steel Moment Resisting Frame $\quad 132$

3.6.1.3 Steel Braced Frame 134

3.6.1.4 Reinforced Concrete Moment Resisting Frame 136

3.6.1.5 Reinforced Concrete Shear Wall System 137

3.6.2 Out of Plane Behavior of Veneer Wall System: Flexible Backing Wall 139

viii 
3.6.3 Out of Plane Wall: Stiff Backing

3.6.4 Inplane Wall: Flexible Backing

3.6.5 Inplane Wall: Stiff Backing

3.7 Selection of Ground Motions

3.7.1 Scaling of the Ground Motions

\section{CHAPTER 4}

\section{RESULTS OF THE ANALYSES AND PARAMETRIC STUDIES}

4.1 Comparison of Structural Frame Accelerations

4.3 Comparison of Structural Frame Accelerations and Deformations with the in - plane veneer walls analyzed as a mass, or analyzed as a system

\section{CHAPTER 5}

DISCUSSION OF THE RESULTS

5.1 Effects of the CMU Backed Wall Systems Loaded in their Out - of - Plane Direction, on the Reinforced Concrete Moment Frame

5.2 Effects of the Steel Stud Backed Wall Systems Loaded in their Out - of - Plane Direction, on the Reinforced Concrete Moment Frame

5.3 Effects of the CMU Backed Wall Systems Loaded in their Out - of - Plane Direction, on the Reinforced Concrete Frame with Shear Walls

5.4 Effects of the Steel Stud Backed Wall Systems Loaded in their Out - of - Plane Direction, on the Reinforced Concrete Frame with Shear Walls

5.5 Effects of the CMU Backed Wall Systems Loaded in their Out - of - Plane Direction, on the Steel Braced Frame

5.6 Effects of the Steel Stud Backed Wall Systems Loaded in their Out - of - Plane Direction, on the Steel Braced Frame

5.7 Effects of the CMU Backed Wall Systems Loaded in their Out - of - Plane Direction, on the Steel Moment Frame

5.8 Effects of the CMU Backed Wall Systems Loaded in their Out - of - Plane Direction, on the Steel Moment Frame

5.9 Effects of the CMU Backed Wall Systems Loaded in their In - Plane Direction, on the Reinforced Concrete Braced Frame 228

5.10 Effects of the Steel Stud Backed Wall Systems Loaded in their In - Plane Direction, on the Reinforced Concrete Braced Frame 229

5.11 Effects of the CMU Backed Wall Systems Loaded in their In - Plane Direction, on the Steel Moment Resisting Frame

5.12 Effects of the Steel Stud Backed Wall Systems Loaded in their In - Plane Direction, on the Steel Moment Resisting Frame

5.13 Effects of the Frames on the CMU Backed Wall Systems (Stiff and Flexible Ties), Loaded in their Out - Of - Plane Direction

5.14 Effects of the Frames on the Steel Stud Backed Wall Systems (Stiff and Flexible Ties), Loaded in their Out - Of - Plane Direction 


\section{CHAPTER 6}

SUMMARY AND CONCLUSIONS

6.1 Summary

6.2 Conclusions

6.3 Recommendations for further research

REFERENCES

APPENDIX A

APPENDIX B 


\section{LIST OF TABLES}

TABLE

PAGE

Table 3.1: Frame Response Modification Factors 48

Table 3.2: Frame Coefficients $C_{t}$ and $x \quad 50$

Table 3.3: Fundamental Period of the Frames 50

Table 3.4: Frame Deflection Amplification Factors $\quad 52$

Table 3.5: STAAD.Pro Exterior Steel Moment Resisting Frame Section Sizes $\quad 59$

Table 3.6: STAAD.Pro Interior Steel Moment Resisting Frame Section Sizes 60

Table 3.7: STAAD.Pro Exterior Reinforced Concrete Moment Resisting Frame Section Sizes 62

Table 3.8: STAAD.Pro Interior Reinforced Concrete Moment Resisting Frame Section Sizes 62

Table 3.9: STAAD.Pro Peripheral Steel Braced Frame Section Sizes 64

Table 3.10: STAAD.Pro Peripheral Reinforced Concrete Braced Frame Column Section Sizes 65

Table 3.11: STAAD.Pro Peripheral Reinforced Concrete Braced Frame Beam Section Sizes 65

Table 3.12: Concrete Material Model Parameter Values $\quad 83$

Table 3.13: Equivalent Steel Moment Resisting Frame Section Sizes 89

Table 3.14: Equivalent Steel Moment Resisting Frame Masses 90

Table 3.15: OpenSees Equivalent RC Moment Resisting Frame Beam Sections 92

Table 3.16: OpenSees Equivalent RC Moment Resisting Frame Column Sections 93

Table 3.17: Equivalent Reinforced Concrete Moment Resisting Frame Masses 94

Table 3.18: Peripheral Steel Braced Frame Masses 99

Table 3.19: Peripheral Reinforced Concrete Braced Frame Masses 96 
Table 3.20: Veneer Model

Table 3.21: Breakpoints of the Diagonal Truss Element Hysteretic Material Model

Table 3.22: Experimental Loading Protocol (Hikita, 2006)

Table 3.23: Loading Protocol Applied To Analytical Model

Table 3.24: Hysteretic Material Model Assigned To Diagonal Truss Elements

Table 3.25: Frame Spectral Response Acceleration Based Upon Design Response Spectrum

Table 3.26: Frame Spectral Response Acceleration Based Upon Response Spectrum of Sylmar Ground Motion

Table 3.27: Frame Spectral Response Acceleration Based Upon Response Spectrum of Tarzana Ground Motion

Table 3.28: DBE Scaling Factors

Table 3.29: MCE Scaling Factors

Table 3.30: Simulations Performed on Concrete Moment Resisting Frame, Veneer Wall Loaded in Out - of - Plane Direction

Table 3.31: Simulations Performed on Concrete Shear Wall System, Veneer Wall Loaded in Out - of Plane Direction

Table 3.32: Simulations Performed on Steel Braced Frame, Veneer Wall Loaded in Out - of - Plane Direction

Table 3.33: Simulations Performed on Steel Moment Resisting Frame, Veneer Wall Loaded in Out - of Plane Direction

Table 3.34: Simulations Performed on Reinforced Concrete Shear Wall System, Veneer Wall Loaded in In - Plane Direction

Table 3.35: Simulations Performed on Steel Moment Resisting Frame, Veneer Wall Loaded in In - Plane Direction

Table 3.36: Explanation of Symbols Used

Table 4.1: Comparison between the Peak Accelerations and Base Shears for the Steel Moment Resisting Frame, with Mass and Analytical Model Representations of the Out of Plane Wall System, and a Mass Representation of the In Plane Wall System

Table 4.2: Comparison between the Peak Accelerations and Base Shears for the Steel Braced Frame, with Mass and Analytical Model Representations of the Out of Plane Wall System, and a Mass Representation of the In Plane Wall System

Table 4.3: Comparison between the Peak Accelerations and Base Shears for the Reinforced Concrete Moment Resisting Frame, with Mass and Analytical Model Representations of the Out of Plane Wall System, and a Mass Representation of the In Plane Wall System

Table 4.4: Comparison between the Peak Accelerations and Base Shears for the Reinforced Concrete Braced Frame, with Mass and Analytical Model Representations of the Out of Plane Wall System, and a Mass Representation of the In Plane Wall System

Table 4.5: Comparison between the Peak and Average Displacements for the Steel Moment Resisting Frame, with Mass and Analytical Model Representations of the Out of Plane Wall System, and a Mass Representation of the In Plane Wall System

185

Table 4.6: Comparison between the Peak and Average Displacements for the Steel Braced Frame, with Mass and Analytical Model Representations of the Out of Plane Wall System, and a Mass Representation of the In Plane Wall System

Table 4.7: Comparison between the Peak and Average Displacements for the Reinforced Concrete Moment Resisting Frame, with Mass and Analytical Model Representations of the Out of Plane Wall System, and a Mass Representation of the In Plane Wall System 
Table 4.8: Comparison between the Peak and Average Displacements for the Reinforced Concrete Braced Frame, with Mass and Analytical Model Representations of the Out of Plane Wall System, and a Mass Representation of the In Plane Wall System

Table 4.9: Comparison between the Peak Accelerations and Base Shears for the Steel Moment Resisting Frame, with Mass and Analytical Model Representations of the In Plane Wall System, and a Mass Representation of the Out of Plane Wall System

Table 4.10: Comparison between the Peak Accelerations and Base Shears for the Reinforced Concrete Braced Frame, with Mass and Analytical Model Representations of the In Plane Wall System, and a Mass Representation of the Out of Plane Wall System

Table 4.11: Comparison between the Peak and Average Displacements for the Steel Moment Resisting Frame, with Mass and Analytical Model Representations of the In Plane Wall System, and a Mass Representation of the Out of Plane Wall System

Table 4.12: Comparison between the Peak and Average Displacements for the Reinforced Concrete Braced Frame, with Mass and Analytical Model Representations of the In Plane Wall System, and a Mass Representation of the Out of Plane Wall System

Table 4.13: Comparison between the Peak and Average Veneer and Backup Accelerations for the Out of Plane Wall Systems In the Steel Moment Frame

Table 4.14: Comparison between the Peak and Average Veneer and Backup Accelerations for the Out of Plane Wall Systems In the Steel Braced Frame

Table 4.15: Comparison between the Peak and Average Veneer and Backup Accelerations for the Out of Plane Wall Systems In the Reinforced Concrete Moment Frame

Table 4.16: Comparison between the Peak and Average Veneer and Backup Accelerations for the Out of Plane Wall Systems In the Reinforced Concrete Braced Frame

Table 4.17: Comparison between the Peak and Average Veneer and Backup Displacements for the Out of Plane Wall Systems In the Steel Moment Frame

Table 4.18: Comparison between the Peak and Average Veneer and Backup Displacements for the Out of Plane Wall Systems In the Steel Braced Frame

Table 4.19: Comparison between the Peak and Average Veneer and Backup Displacements for the Out of Plane Wall Systems In the Reinforced Concrete Moment Resisting Frame

208

Table 4.20: Comparison between the Peak and Average Veneer and Backup Displacements for the Out of Plane Wall Systems In the Reinforced Concrete Braced Frame

Table 4.21: Peak Tie Forces in the Out of Plane Walls in the $10^{\text {th }}$ Storey of the Mainframes at MCE, at the Time Instant at Which the Veneer Acceleration Reached Its Maximum Value

Table 4.22: Time Instants at Which the Veneer Acceleration at MCE, Reached Its Maximum Value208

Table 4.23: Level of Tarzana Ground Motion Corresponding to Collapse of Wall Systems $\quad 210$

Table 4.24: Level of Sylmar Ground Motion Corresponding to Collapse of Wall Systems

Table 4.25: Comparison Between the Collapse Level and MCE Level of the Tarzana Ground Motion, for all the Systems Analyzed

212

Table 4.26: Comparison Between the Collapse Level and MCE Level of the Sylmar Ground Motion, for all the Systems Analyzed 


\section{LIST OF FIGURES}

Figure 1.1: Typical Brick Veneer Steel Stud Wall Cross Section, BIA Tech. Note 28 (BIA,2002) 2 Figure 2.1: An Illustration of Performance Based Earthquake Engineering (The Applied Technology Council, 2004)

Figure 2.2: Components of a Typical Veneer Wall System (Adapted from Okail, 2010)

Figure 2.3: Some Commonly Used Veneer Anchors (Adapted from Okail, 2010)

Figure 2.4: A Section View of the Brick - Tie - Wood Specimen (Subassembly) Setup. (Reneckis et al, 2004)

Figure 2.5: Behavior of 28 ga. Ties Under Monotonic Tension and Compression From the Subassembly Tests (Reneckis et al, 2004)

Figure 2.6: Elevation Views of the Wall Test Structure (Reneckis and Lafave, 2005)

Figure 2.7: Wall Test Structure Set Up On a Shake Table (Reneckis and Lafave, 2005)

Figure 3.1: Plan View of the Building Frames

Figure 3.2: Elevation View of the Building Frames In Their Short Direction 38

Figure 3.3: Elevation View of the Building Frames In Their Long Direction 39

Figure 3.4: Steel and Reinforced Concrete Moment Frames in 3-D

Figure 3.5: Locations of the Braces in the Peripheral Frames of the Steel Braced Frame System

Figure 3.6: Locations of the Shear Walls in the Peripheral Frames of the Reinforced Concrete Shear Wall System

Figure 3.7: Base Shear applied to the Support Nodes of the Mainframe

Figure 3.8: Equivalent Static Load Distribution Applied to the Mainframe

Figure 3.9: Member Labels for Typical Steel and Reinforced Concrete Moment Resisting, Exterior and Interior Frames, Designed Using STAAD.Pro

Figure 3.10: Typical Staad.Pro Reinforced Concrete Column Section

Figure 3.11: Typical Staad.Pro Reinforced Concrete Beam Section

Figure 3.12: Member Labels for a Typical Peripheral Steel Braced Frame (STAAD.Pro)

Figure 3.13: Frame Transformation From 3-D to 2-D

Figure 3.14: Equivalent Section of the Steel Moment Resisting Frame 
Figure 3.17: Boundary Conditions and Locations of Seismic Masses for the 2-D Frames

Figure 3.18: Typical Braced Frame Connection Model Between the Beam and Column 77

Figure 3.19: Typical Reinforced Concrete Section 80

Figure 3.20: Concrete Model in Compression $\quad 83$

Figure 3.21: Concrete Model in Tension $\quad 84$

Figure 3.22: Steel Reinforcement Material Model 85

Figure 3.23: Attachment of the Shear Wall Elements to the Mainframe 86

Figure 3.24: OpenSees Member and Mass Labels for Equivalent Steel and Reinforced Concrete Moment Resisting, Exterior and Interior Frames $\quad 88$

Figure 3.25: Typical OpenSees Reinforced Concrete Section 91

$\begin{array}{ll}\text { Figure 3.26: Veneer Element Dimensions and Fiber Layout } & 100\end{array}$

Figure 3.27: Compression Model for the Veneer in the Steel Stud Backed Wall System Under Out - of Plane Loading

Figure 3.28: Tension Model for the Veneer in the Steel Stud Backed Wall System Under Out - of - Plane Loading

Figure 3.29: Flexible Tie Model for the Steel Stud Backed Wall System, Out - of - Plane Loading 103

Figure 3.30: Stiff Tie Model for the Steel Stud Backed Wall System, Out - of - Plane Loading 104

Figure 3.31: Attachment of the Base of the Steel Stud Backed Wall Under Out - of - Plane Loading, to the Mainframe 106

Figure 3.32: Attachment of the Top of the Steel Stud Backed Wall Under Out - of - Plane Loading, to the Mainframe

Figure 3.33: Moment - Curvature Relationship for Out - Of - Plane Behavior of the Stiff Backing Wall, in the Moment Frames

Figure 3.34: Double Eye and Pintle Tie Model Used in the CMU Backed Wall System Under Out - of Plane Loading

Figure 3.35: Triwire Tie Model Used in the CMU Backed Wall System, Out - of - Plane Loading 113

Figure 3.36: Equivalent Single Bay Braced Frame Representation of the Backing Wall of the Steel Stud Backed System, Under In - Plane Loading

Figure 3.37: Diagonal Truss Element Material Model

118

Figure 3.38: Locations of the Veneer Elements of the Stud Backed System, In - Plane Loading

119

Figure 3.39: Shear Behavior of the Double Eye and Pintle Tie System

Figure 3.40: Attachment of the Base of the Backing Wall of the Steel Stud Backed Wall Under In - Plane Loading, to the Mainframe

Figure 3.41: Locations of the Veneer and Backup of the CMU Backed Wall System, Under In - Plane Loading

Figure 3.42: Shear Behavior of the Triwire Tie System

Figure 3.43: Attachment of the Base of the CMU Backed Wall System Under In - Plane Loading, to the Mainframe

Figure 3.44: Calibration of the Steel Moment Resisting Frame

Figure 3.45: Calibration of the Steel Braced Frame

135

Figure 3.46: Calibration of the Reinforced Concrete Moment Resisting Frame 
Figure 3.50: Finite Element Model of Wood Stud Backed Wall System Loaded in its Out - of - Plane Direction (Adapted From (Okail et al., 2009))

Figure 3.51: Flexible Tie Model (Calibration Of Out - Of - Plane Wood Stud Backed Wall)

Figure 3.52: Comparison Between Deformation Profiles of the Experimental Wall System, and that Predicted by Analytical Model, Before Veneer Cracking (Adapted From (Mcginley et al., 2011)) 144

Figure 3.53: Comparison Between Deformation Profiles of the Experimental Wall System, and that Predicted by Analytical Model, After Veneer Cracking (Adapted From (Mcginley et al., 2011)) 145

Figure 3.54: OpenSees Model for CMU Out - of - Plane Wall Specimens (Jo, 2010)

Figure 3.55: Diagonal Truss Element Hysteretic Model

Figure 3.56: Comparison Between Experimental and Analytical Model Response of Steel Stud Backing Wall, Under In - Plane Loading

Figure 3.57: Comparison Between Response of Analytical Model of Actual Steel Stud Backing Wall, and Equivalent Steel Stud Backing Wall, Under In - Plane Loading

Figure 4.1: Acceleration profile along the height of the main frame for the stiffest and most flexible systems analyzed, with a mass representation and an analytical model representation of the out of plane wall system, and a Mass Representation of the In Plane Wall System

Figure 4.2: Displacement profile along the height of the main frame for the stiffest and most flexible systems analyzed, with a mass representation and an analytical model representation of the out of plane wall system, and a Mass Representation of the In Plane Wall System

Figure 4.3: Acceleration Profile Along the Height of the Main Frame for the Stiffest and Most Flexible Systems Analyzed, With a Mass Representation and an Analytical Model Representation of the In Plane Wall System, and a Mass Representation of the Out of Plane Wall System

Figure 4.4: Displacement Profile Along the Height of the Main Frame for the Stiffest and Most Flexible Systems Analyzed, With a Mass Representation and an Analytical Model Representation of the In Plane Wall System, and a Mass Representation of the Out of Plane Wall System

Figure 4.5: Acceleration Profile of the Out of Plane Veneer, Along the Height of the Main Frame for the Most Flexible System Analyzed, At the Time Instant At Which the Veneer Acceleration Reached Its Maximum Value

Figure 4.6: Acceleration Profile of the Out of Plane Veneer, Along the Height of the Main Frame for the Stiffest System Analyzed, At the Time Instant At Which the Veneer Acceleration Reached Its Maximum Value

Figure 4.7: Acceleration Profiles of the Out of Plane Veneer and Backup at MCE, for the Stiffest and Most Flexible Wall Systems on the $10^{\text {th }}$ Storey of the Mainframe, at the Time Instant at Which the Veneer Acceleration Reached Its Maximum Value

Figure 4.8: Displacement Profiles of the Out of Plane Veneer and Backup at MCE, for the Stiffest and Most Flexible Wall Systems on the $10^{\text {th }}$ Storey of the Mainframe, at the Time Instant at Which the Veneer Acceleration Reached Its Maximum Value

Figure 4.9: Tie Forces for the Stiffest and Most Flexible Wall Systems on the $10^{\text {th }}$ Storey of the Mainframe, at the Time Instant at Which the Veneer Acceleration Reached Its Maximum Value 


\section{CHAPTER 1}

\section{INTRODUCTION}

\subsection{Background}

This dissertation describes a study of the behavior of brick veneer wall systems in medium height buildings, under seismic loading. To date, the seismic performance of the brick veneer wall system has been examined in detail only in isolation and in single story structures. Information on its performance in multistory structures is needed since brick veneer wall systems are commonly used in multistory construction across the United States and elsewhere. The results obtainedfrom this investigation are intended to improve the understanding of this system making it easier to develop cost effective strategies to strengthen these systems and reduce the likelihood of their failure in severe events.

Brick veneer wall systems are comprised of an exterior clay masonry layer separated from an interior backup wall system by an air cavity and connected to the backup by metal ties. Figure 1.1 shows the components of a veneer wall system. Wood and steel studs, reinforced concrete or concrete masonry units are typically used to construct the backup wall. The exterior masonry veneer is used because of its pleasing appearance and 
durability. The air cavity functions as a drainage system and a thermal barrier. The backup wall supports the brick veneer and can support loads from the structure. The metal ties transfer laterals loads from the exterior veneer to the interior backup, while accommodating in - plane differential movements. The recent performance of these wall systems under seismic loading has prompted a number of investigations.

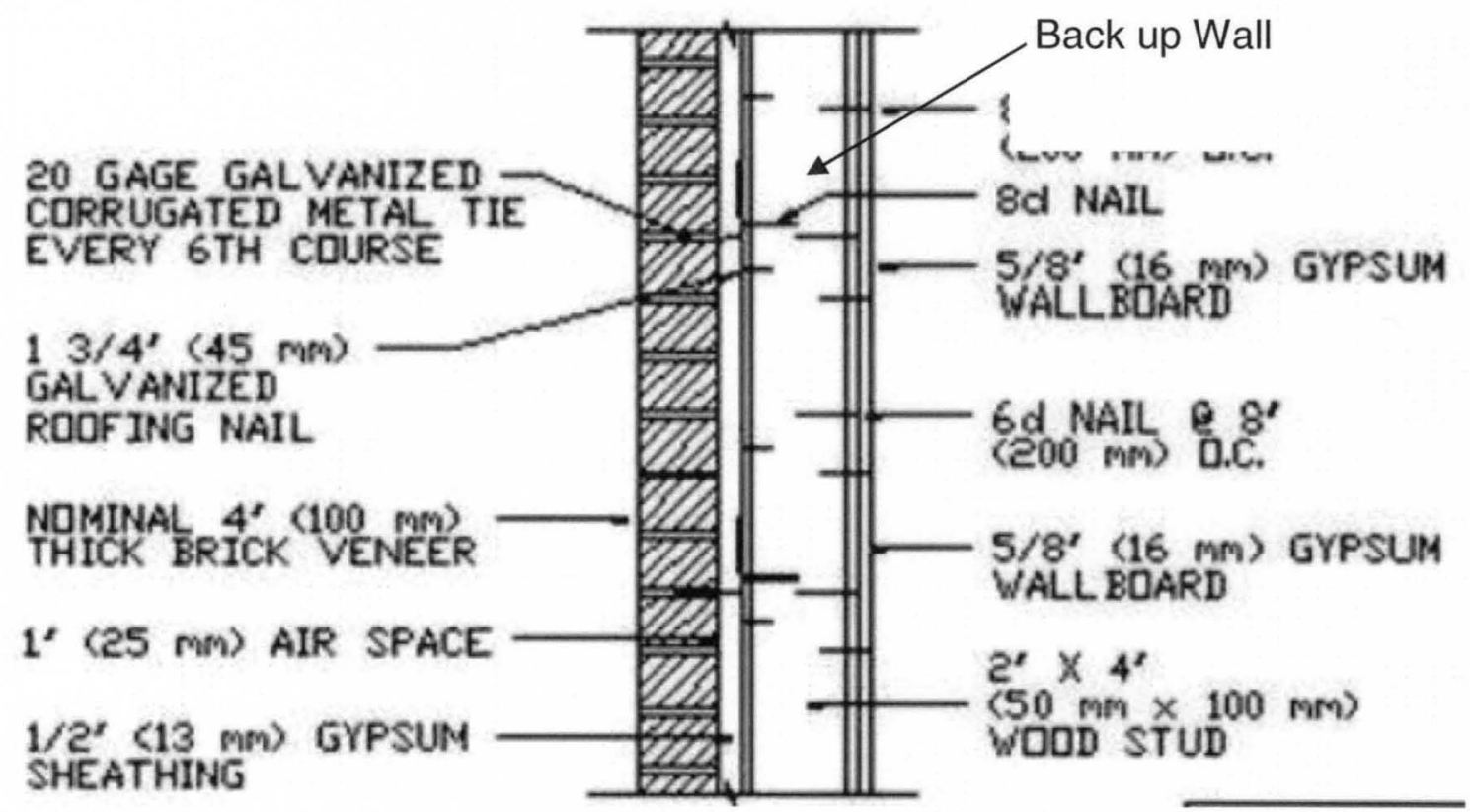

Figure 1.1 Typical Brick Veneer Steel Stud Wall Cross Section From BIA Tech. Note 28 (BIA, 2002)

Predicting the performance of a brick veneer wall system under seismic loads is complicated since not only is it hard to accurately predict the amount and frequency of the seismic ground acceleration, but the properties (stiffness, material properties, section properties) of the structure are hard to predict accurately as well. An accurate model of the overall system behavior is, however, critical in the effectiveness of the performance based analysis and the development of fragility curves for these systems 


\subsection{Overview of Research Program}

In this project, analytical models of brick veneer wall systems in medium rise building frames were developed using the OpenSees software program. The plan dimensions of the building frames used in the analysis and the loads acting on them were considered to be representative of a standard office building. The properties of the materials used in the veneer wall systems were those used in standard construction practice. The tie types used in the wall systems were obtained from the databases of companies supplying these products to the masonry construction industry in the United States.

In order to gain a better understanding of the interaction of the different parts of the system and to shed light on the seismic performance of the wall systems in medium rise buildings, a parametric study was conducted on the models by varying the building frame type, the backing wall type, the tie type, and the applied ground motion, the details of which aredescribed in the next section. Results of this research will be used to evaluate current building code requirements for these wall systems in medium rise buildings.

\subsection{Scope and Objectives}

This dissertation focuses on the description of the investigation conducted into the behavior of veneer wall systems in medium rise buildings under the influence of seismic loads. The investigation includes the development of combined analytical models of the veneer wall systems attached to the medium rise building frames. These models were 
subjected to the Sylmar and Tarzana seismic ground motions, since they have been observed by others (Okail, 2010; Jo, 2010) to have the worst effect on the wall systems in single story constructions. The models were shaken at levels corresponding to the Design Base Earthquake (DBE) and the Maximum Considered Earthquake (MCE). Information about the earthquake ground motions used in the analysis, and the process used to scale them and derive the DBE and MCE levels is presented later. In view of the end goal of this research, a parametric study was conducted using these analytical models, in order to understand the influence of the different components of the systems on the system behavior. The study exercised the models using the aforementioned ground motions at both the DBE and MCE levels, while varying the following parameters within the models:

1) Frame type (Steel Moment Frame, Steel Braced Frame, Reinforced Concrete Moment Frame, and Reinforced Concrete Shear Wall system)

2) Wall system backing type (Steel Stud Backup, and CMU Backup)

3) Tie type (Stiff and Flexible)

Finally, each model was subjected to increasing levels of loading until collapse occurred, by incrementally increasing the intensity of the ground motion, until a component of the concerned system failed. 
In support of the ultimate goal of developing an understanding of the behavior of in and out - of - plane veneer wall systems in medium rise buildings under seismic loads, the objectives of this investigation are:

a. To develop analytical models that can be used to predict the load - deformation performance of brick veneer wall systems in medium rise construction under seismic loads from varying ground motion intensities and frequencies.

b. To investigate how the different components of the systems; the building frame, the backup wall, the ties, and the veneer interact with each other.

c. To investigate how this interaction affects how seismic loads are distributed between the components of the system, and the building frame.

d. To investigate the effects different component characteristics have on the overall performance of the system. The properties of the structure (such as damping, stiffness, etc.) may have a significant effect on the response of the system and the load distribution to all the components.

e. Determine whether the current prescriptive building code provisions for Brick veneer wall systems are adequate for medium rise building applications. 


\section{CHAPTER 2}

\section{LITERATURE REVIEW}

\subsection{Introduction}

The following chapter summarizes related research into seismic behavior and masonry veneer wall system's. It begins by describing the concept of the Performance Based Design Method applied to seismic design. Following this, it describes the basic features of a masonry veneer wall system, the individual components of which it is comprised, and the functions of these components. It then summarizes a number of investigations that have been conducted on masonry veneer wall systems to date. These sumamries describe the specific systems that were investigated, the reasons for conducting the investigations, the method of investigation, the results obtained, and conclusions arrived at. Most of the investigations conducted had an experimental and analytical component, and both of these components are described in this chapter. 


\subsection{Performance Based Earthquake Engineering}

In order to assess, predict and improve the seismic performance of structures, a method known as "Performance Based Earthquake Engineering" has been developed in the US by a number of groups (The Applied Technology Council, 2004). In this method, the physical condition of a structural component is characterized by the peak level of stress that the component experiences under seismic loading, reflected on a response curve for the component. The component stress levels are then correlated to structural system damage, the number of lives lost, and economic loss. Structural system performance levels have been defined as "Fully Operational - Immediate Occupancy" (the structure is undamaged), "Operational" or "Damage Control" (the structure is moderately damaged and requires repair), "Life Safety" (a damage state near collapse and implies that the structure is irreparable, or severely damaged), and finally, "Collapse" (The Applied Technology Council, 1996; Federal Emergency Management Association, 1997a, 1997b). Figure 2.1 provides a visual representation of the different performance limit states defined above. The goal of the methodology is to be able to design a structure to perform at a specified level for a given ground acceleration. 


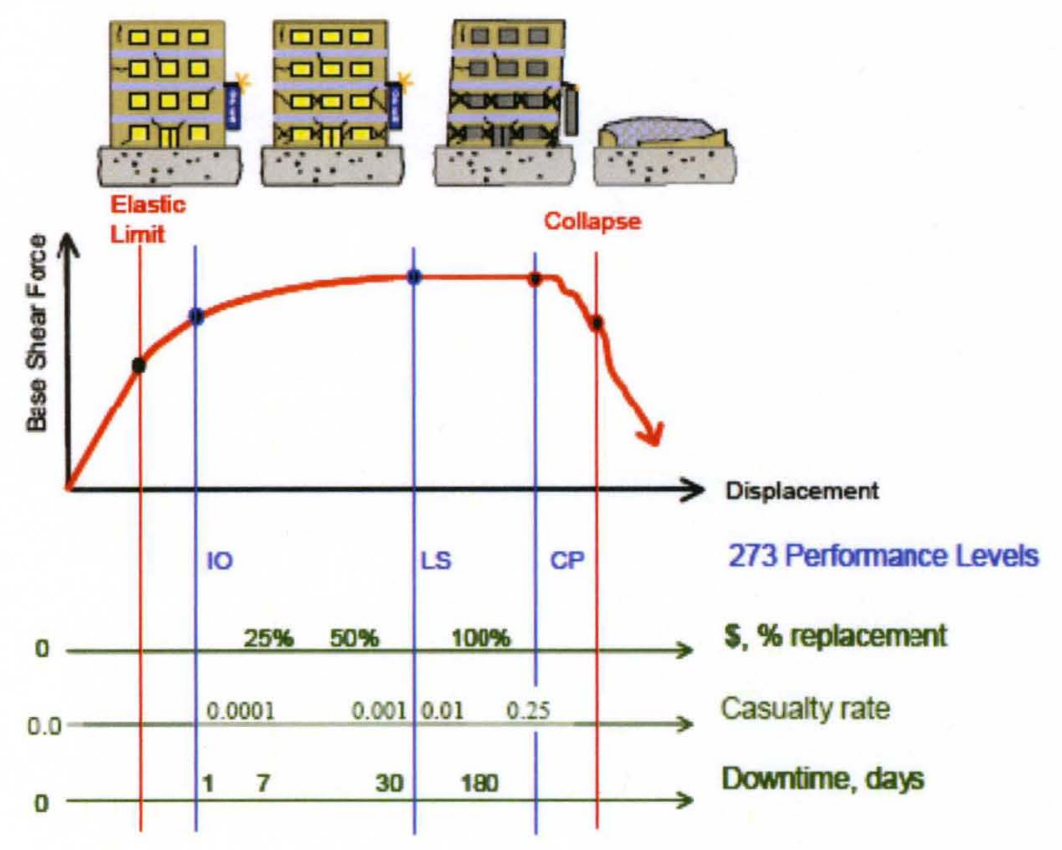

\section{Figure 2.1: An Illustration of Performance Based Earthquake Engineering (The Applied Technology Council, 2004)}

As part of the performance based design procedures, fragility functions are developed for the components of the system. These fragility functions are mathematical relationships that define the probability that a component or a system will experience a given level of damage at, or in excess of, a specific level for a level of demand (eg: interstory drift ratio, shear force, etc). This procedure attempts to take into account the inherent uncertainty present in seismic design and makes it possible to predict the performance of a structure with a specific confidence level. 
However, predicting the performance of a component like a brick veneer wall system under seismic loads is complicated since it is hard to accurately predict the amount and frequency of the seismic ground acceleration. In addition the properties of the structure that have an effect on the acceleration response of the structure (such as damping, stiffness, etc.), are hard to predict accurately as well. However, having an accurate model of the overall system behavior is critical in the effectiveness of the performance based analysis and the development of fragility curves for these systems. Being able to

predicting system response under a give seismic event is a fundamental requirement of the performance based earthquake design methodology.

\subsection{Veneer Wall System behavior}

The majority of research work performed on the behavior of masonry veneer wall systems has been done on wood stud backed systems, which are primarily used in residential construction. This section will thus first describe the important features of wood stud backed veneer wall systems.

Wood stud - framed structures are typically connected to clay brick masonry veneer by corrugated sheet metal ties. These wall systems are commonly used in residential construction, particularly in the central and southeastern United States, where there is low to moderate seismic activity (Reneckis and LaFave, 2005). Some of the reasons for using brick veneer in this type of construction are:

1) It is visually appealing and durable 
2) It has an excellent thermal performance

3) It provides good resistance to water penetration.

Figure 2.2 shows a wood stud backed veneer wall system.

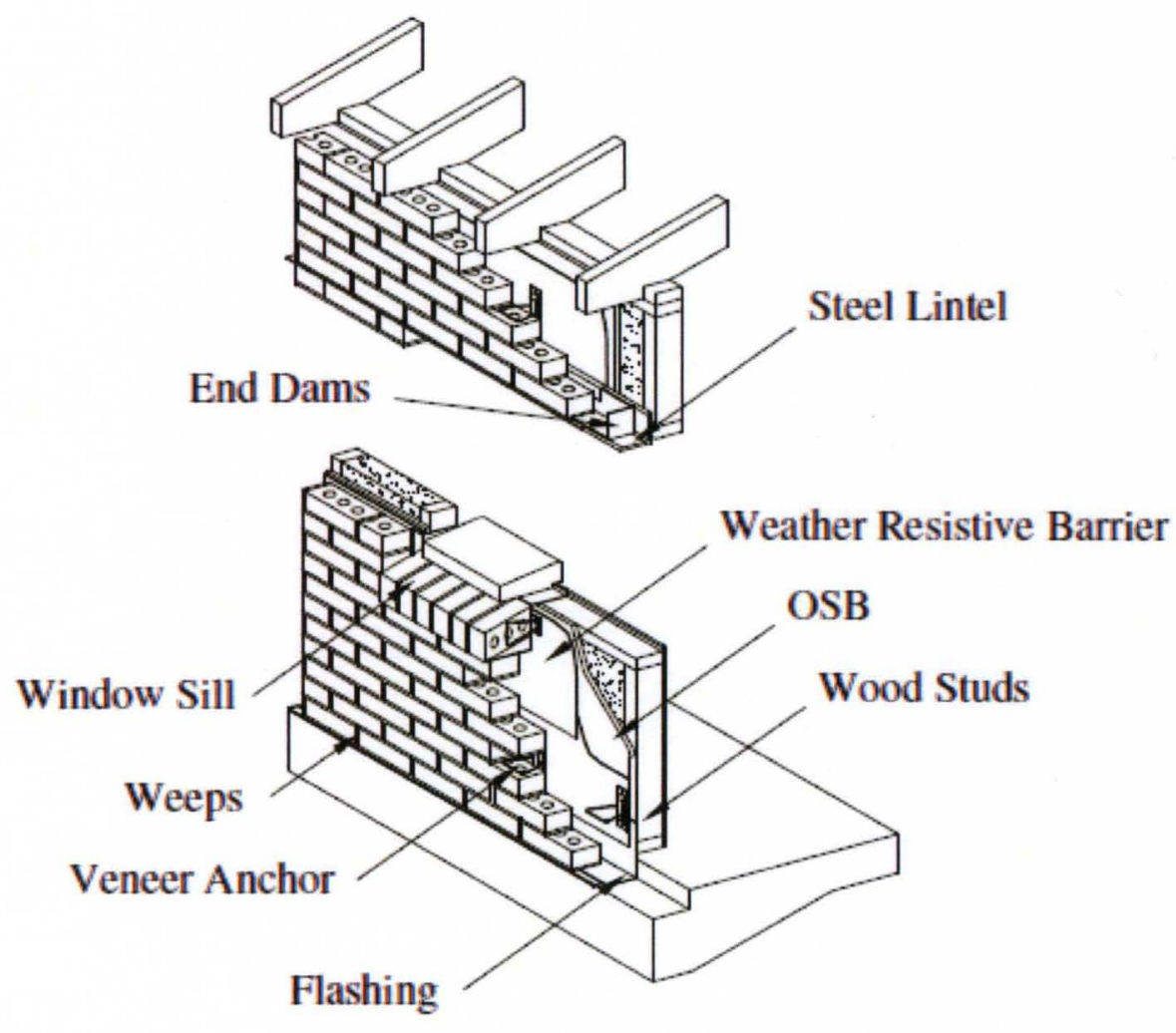

Figure 2.2: Components of a Typical Wood Stud Backed Veneer Wall System (Adapted from Okail, 2010)

A typical wood stud backed veneer wall system consists of the following components:

An exterior clay brick veneer wall.

An interior wood stud backup wall, which has sheathing on both sides, insulation, a vapor barrier, and a moisture barrier.

An air cavity between the veneer and the backup wall. 
Regularly spaced tie connectors attach the exterior veneer to the interior backup.

Figure 2.3 shows some ties that are commonly used in veneer wall systems today.
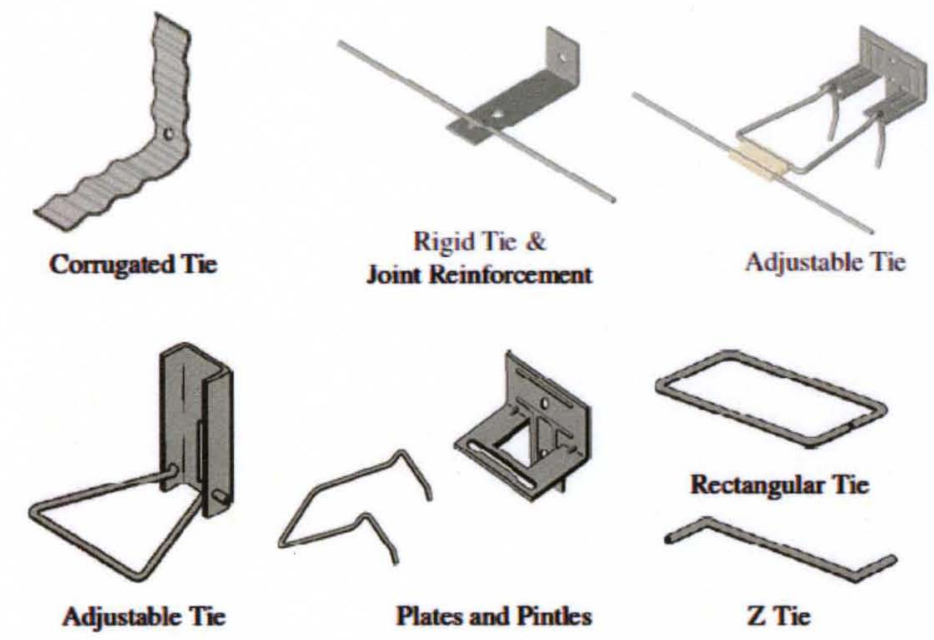

Figure 2.3: Some Commonly Used Veneer Anchors (Adapted from Okail, 2010)

The primary functions of the individual components of the wall system are stated below:

The veneer is used for its pleasing appearance, provides a partial moisture barrier and wearing surface.

The ties transmit lateral forces from the veneer to the backup wall.

The air cavity functions as a thermal barrier and also provides for drainage.

The backup resists all the gravity loads (with the exception of the brick self - weight) and the lateral loads (Reneckis et al., 2004). This wall component also provides the primary moisture, thermal, vapor and air barriers for the wall system. 
The ties are a very crucial component of the system since they transmit the lateral loads from the veneer to the backup wall. Hence, their properties can have a significant effect on the overall performance of the wall system under seismic loading. In general, the ties must satisfy the following performance requirements:

They must have adequate strength and stiffness (in tension and compression) to transfer the lateral loads from the veneer to the backup wall.

They must have sufficient transverse flexibility to accommodate differential movements between the veneer and backup wall.

They must possess a good resistance to corrosion. (Reneckis and Lafave, 2005; Reneckis et al., 2004; Choi and Lafave, 2004; Lafave and Reneckis, 2005)

A variety of design codes and recommended practices, such as the Brick Industry Association's (BIA) Technical Note 28 on Brick Construction (BIA, 1991), the Masonry Standards Joint Committee's (MSJC) Building Code Requirements for Masonry Structures (MSJC, 2002) and the International Code Council's International Residential Code (IRC) for one and two - family dwellings (ICC, 2000), provide specifications for the use of corrugated sheet metal ties on wood framing. These provisions define such wall system characteristics as the minimum tie dimensions and the maximum tie spacings. However, these provisions are not always adhered to in actual residential construction. 


\subsection{An Overview of the Existing Research on Veneer Wall Systems}

\subsubsection{Lafave et al.: Investigations (Reneckis and Lafave, 2005; Reneckis et al., 2004;}

Choi and Lafave, 2004; Lafave and Reneckis, 2005)

Damage to brick veneer wall systems has been observed in recent years as a result of strong earthquake and wind events (Reneckis et al., 2004). This damage included cracking of the veneer wall, excessive differential movement, and even collapse of the veneer under out of plane loading. In most cases, this damage occurred when the veneer moved away from the backup wall under out of plane loading, creating very high demand on the tensile force and displacement capacities of the tie connectors, eventually leading to them to pull out of the backup wall. Some of the possible causes for damage are listed below:

1) The ties were placed too far apart

2) The ties were too flexible

3) The ties were insufficiently anchored to the veneer or backup wall

4.) Ties were missing or badly corroded.(Reneckis et al., 2004).

Although this damage prompted research into the behavior of masonry veneer wall systems, most of this research focused on veneer wall systems built using a narrow range of construction practices, and did not generally investigate the cyclic behavior and strength limits of the tie connectors. This lack of information on the behavior and performance of masonry veneer wall under out - of - plane loads using modern 
construction practices led to an investigation that was undertaken at the University of Illinois (UIUC), at the Mid - America Earthquake Center (MAE). This study focused on the out of plane behavior of wood stud backed veneer wall systems. The investigation initially involved static and cyclic load tests that were performed on brick - tie - wood stud subassemblies, (Reneckis et al., 2004). A diagrammatic representation of a typical tie and wall subassembly is shown in Figure 2.4.

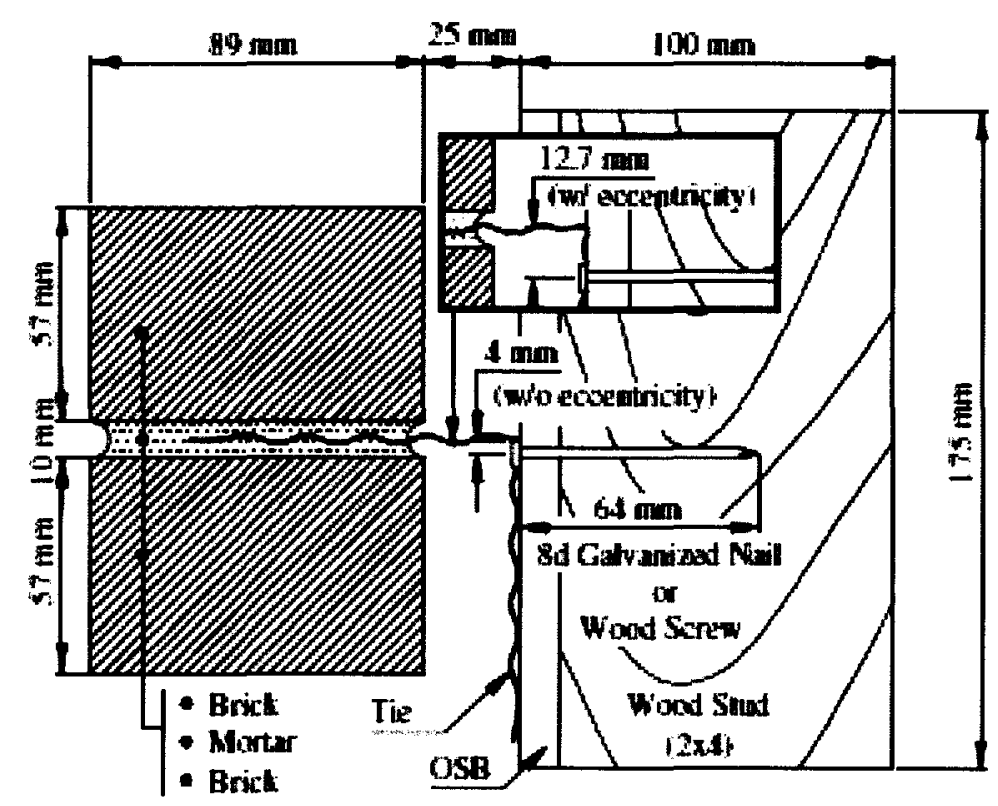

Figure 2.4: A Section View of the Brick - Tie - Wood Specimen (Subassembly) Setup. (Reneckis et al, 2004)

Since the subassemblies included the veneer, the tie connector, and the backup wall, the tests captured the interaction between these components of the system. A variety of the typical tie and wall configurations that would meet the prescriptive construction requirements of the BIA Technical Notes (BIA, 1991), the MSJC Code (MSJC, 2002), and the IRC for One - and - Two Family Dwellings (IRC, 2000) were investigated. The 
effects of different tie thicknesses $(16,22$, and 28 ga.), tie attachment methods (nail or screw), presence or absence of an eccentricity between the nail or screw and the bend location, and of different tie embedment lengths into the mortar joint, on the load response of the subassemblies, were examined. Furthermore, the subassemblies were subjected to various different types of loading, namely, monotonic tension, monotonic compression, cyclic tension - compression, monotonic shear, and cyclic shear. Based upon the response of the subassemblies under these loading regimes, tie assembly strengths and stiffnesses were obtained for the different types of loading. Figure 2.5 shows the idealized behavior of a typical tie specimen in monotonic tension and compression, with and without an eccentricity between the nail and the tie bend.

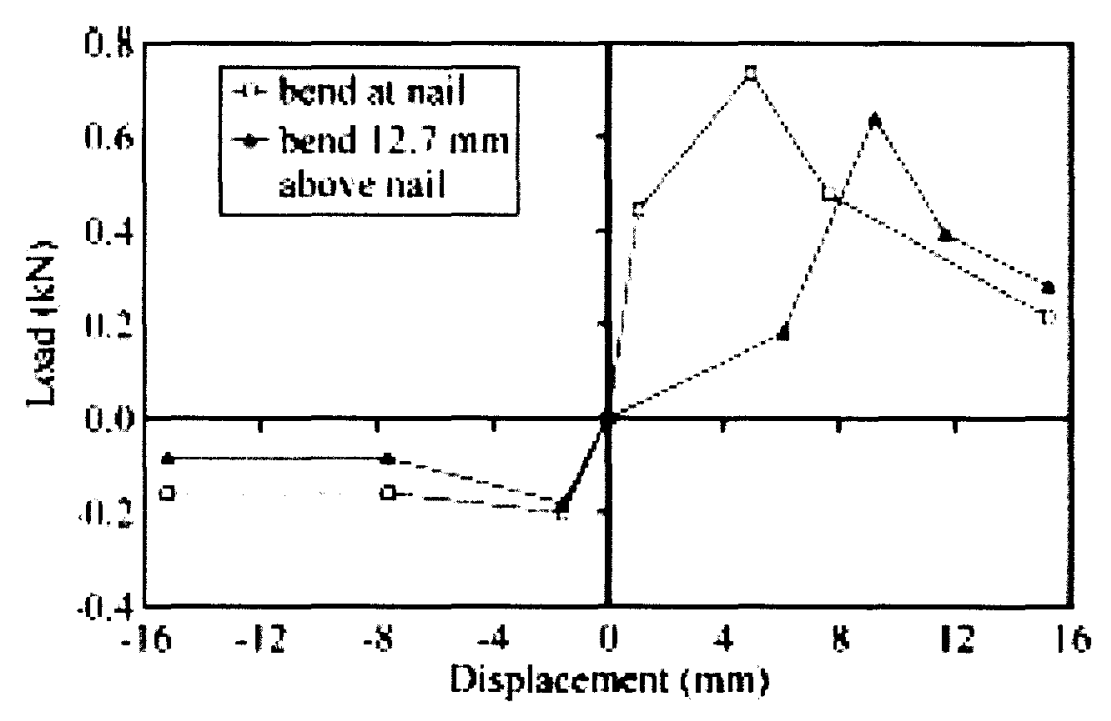

Figure 2.5: Behavior of 28 ga. Ties Under Monotonic Tension and Compression From the Subassembly Tests (Reneckis et al, 2004). 
During the subassembly tests, the ties were shown to fail in a number of different ways. In monotonic tension, after the straightening of the tie bend and the tie corrugations, the following failure modes were observed depending on wall configuration:

1. Pullout of the nail from the wood stud backup wall

2. Pullout of the tie from the mortar joint.

3. Yielding and tearing of the tie in the vicinity of the nail hole and/or push through of the nail or screw, through the tie hole

4. Tie buckling (Reneckis and Lafave, 2005).

During monotonic compression loading, buckling of the tie was the dominant failure mode. In the cyclic tension - compression tests, fracture of the ties was the predominant failure mode, while the remainder failed in a manner similar to that observed in the monotonic tests.

The envelope or backbone curve defining the cyclic response of the ties was similar to that of the monotonic tests. It was observed that ties in actual masonry veneer walls exhibited similar failure modes as those displayed in the subassembly tests (Reneckis and Lafave, 2005). Based on the subassembly test results, it was concluded that the tie and wall connection could be modeled as axial links, with nonlinear material properties that represented their experimentally observed behavior. 
After examining the effects of different parameters on the subassembly behavior, the researchers (Choi and Lafave, 2004) made the following observations:

1. The specimens that used 28 gage corrugated ties failed within the tie itself, due to the low thickness of material. For the thickest 16 gage ties tested, failure predominantly occurred by pullout of the tie from the mortar. For the 22 gage ties, an intermediate thickness, failure was through a variety of different modes as discussed previously.

2. The increased thickness of the 16 gage ties affected thecompression behavior, and they were observed to have significantly more strength and stiffness than the 22 gage ties. The 28 gage ties did not show much difference in behavior compared to the 22 gage ties. However, the initial stiffness of the system was considerably larger for the 22 gage ties.

3. The presence of an initial in plane offset displacement reduced the tension strength of the screw connected specimens to half its value without an offset displacement. The failure mode in this situation was the pullout of the tie due to a loss in bond strength in the mortar. The offset had a negligible effect on either the strength, or the stiffness of the nail connected specimens in tension, and reduced the values of the aforementioned quantities by a maximum of 20 percent in compression.

4. The presence of an eccentricity between the 90 degree tie bend and the point of attachment of the nail or the screw, predictably reduced the stiffness of the specimens in which this eccentricity was present. This reduction in stiffness occurred predominantly for tension loading. 
5. In general, increasing the length of the tie embedded in the veneer, led to an increase in the maximum load carrying capacity of the system, until the mode of failure shifted to fastener failure.

In the second phase of testing, a full - scale brick veneer and wood frame test structure was designed and tested. This structure was designed to represent a portion of a single story wall system in a single family home, and was subjected to static and dynamic out - of - plane lateral loading on a shake table (Reneckis and Lafave, 2005). The test structure is shown in Figure 2.6, and the setup on the shake table is shown in Figure 2.7.

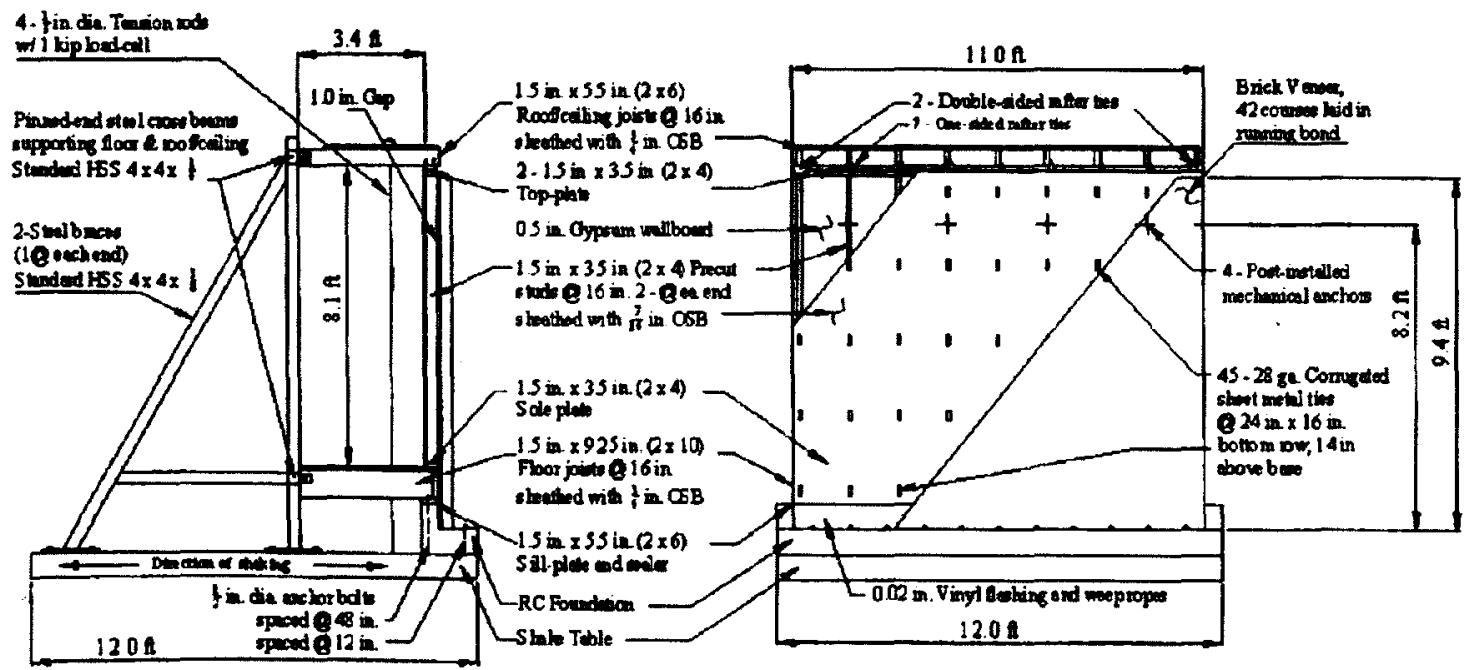

Figure 2.6: Elevation Views of the Wall Test Structure (Reneckis and Lafave, 2005). 


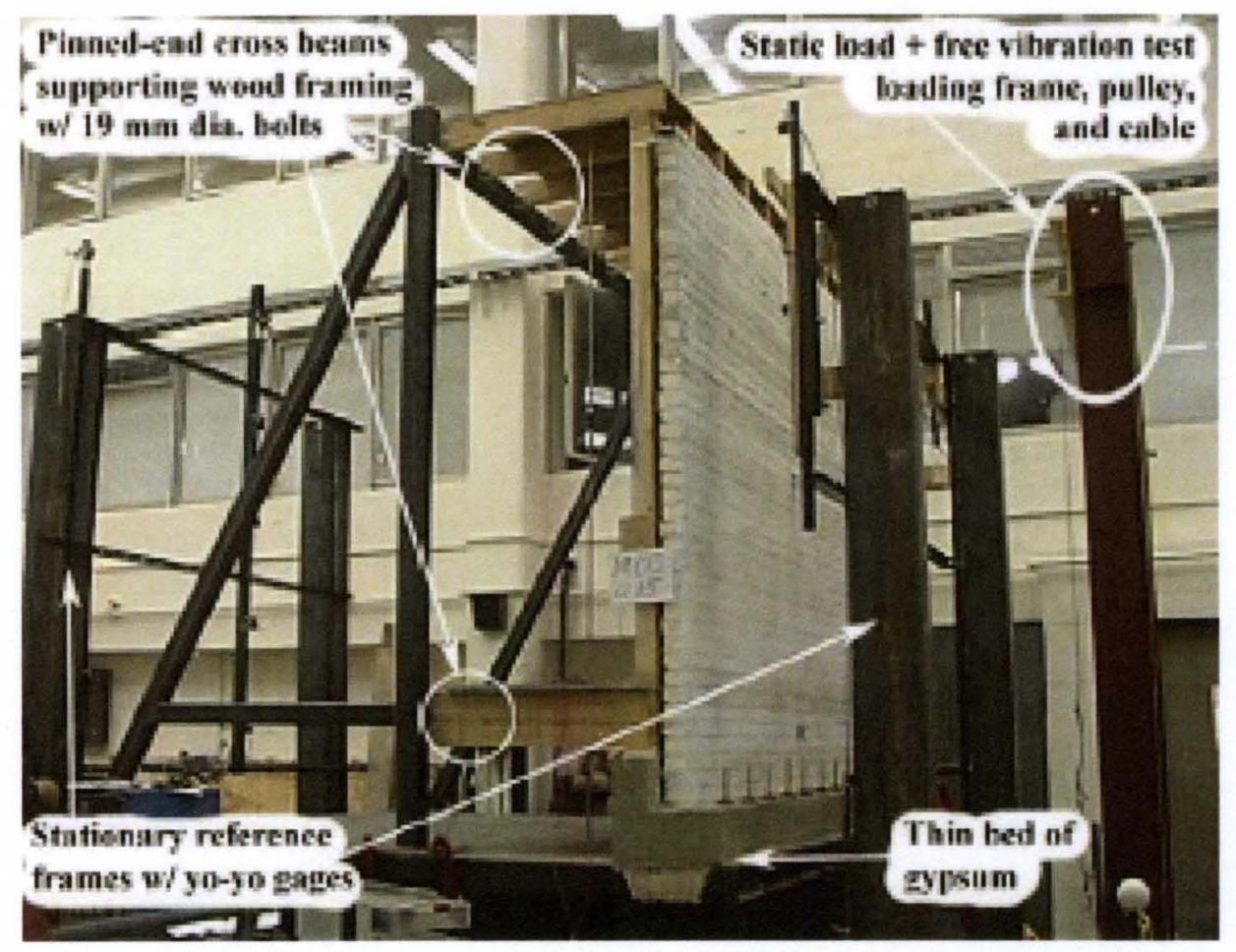

\section{Figure 2.7: Wall Test Structure Set Up On a Shake Table (Reneckis and Lafave, 2005).}

These tests provided information on the overall behavior of the wall systems. The specimens were designed to meet the provisions listed in the BIA Technical Notes on Brick Construction 28, 28A, and 44B (BIA, 1988; BIA, 1991), the IRC for one and twofamily dwellings (ICC, 2000), and the MSJC's Building Code Requirements for Masonry Structures (MSJC, 2002). Two different tie installation techniques were implemented in two separate series of wall panel tests. The first series of wall panel tests involved the application of low level of static load and then dynamic loads to the test structure in which all of the ties were installed using a zero eccentricity between the 90 degree tie bend and the nail (or close to zero). The dynamic loads were applied until partial collapse of the veneer occurred. Following this, the collapsed portion of the veneer from the wall 
system just tested was rebuilt with new brick masonry, and attached to the backing wall with ties that explored the use of the maximum offset permitted by the MSJC and IRC of $12.7 \mathrm{~mm}$.

These tests provided valuable information on the interaction and load transfer between the veneer, backup and ties. The configurations tested progressed through three levels of response: the elastic level, in which there was no visible damage, followed by the intermediate level, in which damage to the ties and veneer had just commenced, and, finally, the ultimate level, which corresponded to the collapse of the wall system due to the accumulation of damage to the ties or the veneer. It was observed that the ties located near stiffer regions of the backup experienced the highest deformations and hence were damaged first. Some of the tie connection failure modes that were observed were (Reneckis and Lafave, 2005):

1. Fracture of the ties

2. Tearing at the nail hole

3. Nail pullout

4. Tie pullout from the mortar joint

5. Yielding at the nail - hole leading to the push through of the nail.

These failure modes were similar to those observed in the tie subassembly tests. The tie properties (strength and stiffness) had a significant effect on the overall response of the wall system. 
The results from the experimental phase of the research were used to develop and calibrate 3-D analytical finite element models that represented the full-scale experimental brick veneer wall panel specimens. The FE model defined the wood stud backup and brick veneer as linear elastic beams and nonlinear inelastic material models were used to describe the behavior of the tie connectors. These tie models were primarily based upon the brick - tie - wood subassembly test results.

After the analytical models were calibrated against the experimental results under static and dynamic load levels, a parametric study was conducted using the FE wall models. The parameters, such as, the tie connection sizes (28 and 22 ga.), the installation methods (with and without eccentricity of the tie bend, nail versus screw attached) and layouts were varied. The results from these parametric studies provided valuable information on the performance limits of residential brick veneer wall construction for different tie connection and loading conditions. Reneckis and Lafave (Reneckis and Lafave, 2005) concluded that the various stages of veneer wall system damage (such as, the onset of tie failure, the spread of tie failure across the top row, and ultimately, collapse) could be captured by examining whether the tie connections at key locations in the models exceeded their ultimate load and/or displacement capacities. They also learned that the different installation methods had little effect on the performance of the 22 gage ties. The 28 gage ties without an eccentricity from the nail at the tie bend performed as well as the 22 gage ties, whereas 28 gage ties with an eccentricities performed poorly. In general, they found that the stiffness of the ties, not strength, had a greater effect on the overall performance of the wall system. Stiffer ties improved the 
overall strength of the wall system for the range of tie systems evaluated. It appeared that this veneer in this analytical model was not allowed to crack.

For the different tie connections studied, it was observed that there was no significant difference between the level of ground shaking at which first tie damage occurred, and at which complete collapse occurred. The top row of ties played a vital role in the ultimate load capacity of the wall system. Amongst the different tie layouts investigated in the parametric study, it was seen that adding another row of ties at every other stud, between the top two rows of ties significantly improved the overall strength of the wall system. Using a checker - board pattern for the arrangement of the connectors resulted in the removal of the top row of ties at every other stud, and led to a reduction of the overall wall panel strength by a third of its initial value with top row ties at every stud, despite satisfying the prescriptive code provisions.

Another interesting observation that made by Reneckis and Lafave was that the veneer wall model incorporating the 28 ga. ties, installed with an offset eccentricity, had a uniform wind suction capacity that was lower than the minimum design unfactored leeward wind pressure (suction) commonly used for the design of wall components and cladding for standard residential structures in the coastal regions of the United States(Reneckis and Lafave, 2005).

Based upon these studies, the researchers recommended that a minimum of 22 gage corrugated ties, should be used. This recommendation was based upon the fact that the 
analysis revealed that the 28 gage ties performed as well as the 22 gage ties only for a zero eccentricity between the 90 degree tie bend and the nail fasteners. For all other cases in which an eccentricity was present, the overall strength of the wall system deteriorated. Furthermore, they recommended that the spacing of ties on the top row of the walls should be reduced to provide a higher veneer - to - backup connection stiffness and strength where it was most needed to resist the out - of - plane loading. Finally, they support using a screw instead of a nail to attach the tie to the backup wall.

\subsubsection{Hussein Okail et al.: Investigations.}

Hussein Okail, in his dissertation titled "Experimental and Analytical Investigation of the Seismic Performance of Low - Rise Masonry Veneer Buildings", (Okail, 2010) described a study on the seismic performance of clay masonry veneer in wood framed construction. He utilized the experimental results of tests conducted at North Carolina State University (McGinley and Hamoush, 2008) to calibrate the nonlinear finite element models that he used in his investigation. In these tests, quasi - static, cyclic out - of plane loads were applied to four wood stud backed, brick veneer wall systems, using a wiffle tree apparatus. The setup of the wall specimens included the use of different tie spacings and stiffnesses (a flexible corrugated tie system, and a stiff tie system), and the presence and absence of joint reinforcement. The specimens were loaded with a quasi static cyclic loading pattern, the peaks of which were gradually increased so as to take the wall system through its different stages of response, starting from an initial elastic stage, 
to the stage at which the veneer cracked, followed by a collapse of the system due to pull - out of an entire row of ties.

In these tests, it was observed that the veneer always cracked around its mid - height. Furthermore, the stiffness and the arrangement of the ties were parameters that affected the response of the veneer. The ultimate failure of the walls was always related to the ties, and was observed to occur either due to a pullout of the ties from the wood stud backing, or, in the case of the lighter gauge corrugated ties, by fatigue cracking of the ties, or, in the case of the systems incorporating stronger, screw connections between the ties and the stud walls, by a pullout of the tie from the veneer bed joint. The effect of the use of joint reinforcement was another parameter that was explored and it was observed joint reinforcing did not have a significant effect on the response of the wall system.

Over the course of his investigation (Okail, 2010), Okial also tested eleven wall segment specimens dynamically on a shake table. Seven of these specimens were tested in their out - of - plane direction, and four were tested, in their in - plane direction. Furthermore, a full - scale single - storey prototypical masonry veneer building was tested on the shaking table under uni - directional shaking. All the wall assemblies and the prototype building were designed and constructed in accordance with theSeismic Design Category D and E provisions of the MSJC code (MSJC, 2008) for masonry veneer, and the IRC (ICC, 2006) for timber structures, and satisfied the serviceability requirements of the BIA Technical Notes (BIA, 2002). 
Some of the parameters that were investigated in the testing of the wall segments were:

\section{Tie types}

2. Tie spacing

3. The wall aspect ratio

4. The presence and absence of mortar joint reinforcement and window openings.

5. Mortar type.

The shake table tests showed that the overall out - of - plane dynamic response of the wall system was primarily governed by the behavior of the tie connectors, specifically, the pull out strength of the anchors. The failure mode observed in the corrugated tie specimens involved a gradual pullout of the attaching nail from the backup wall, and the failure mode observed in the rigid tie systems generally involved a sudden pullout of the anchor from the mortar joint. The wall specimens endured ground motions significantly in excess of those that define the design basis earthquake (DBE) and maximum considered earthquake (MCE) levels for seismic design categories D and E. The presence or absence of joint reinforcement did not have much of an effect on the in plane or on a plane seismic response of the wall systems, nor did mortar type.

The essential feature in the response of the in - plane wall systems was the sliding of the veneer along the base flashing for the squat veneer walls, and a combined rocking / sliding motion for the more slender walls. It was observed that the in - plane walls could 
withstand a higher level of ground shaking as compared to the out - of - plane wall systems.

In the prototype building that was tested, two tie types were used in the out - of plane walls, namely, a flexible corrugated tie system, and a rigid tie system. For the in plane walls that were tested, only corrugated ties were used. One of the in - plane walls was designed using joint reinforcement, and the other was not. It was found that most of the systems performed well under levels of ground shaking that exceeded the MCE for Seismic Design Category D. It was observed that the in - plane veneer walls helped contributed to the overall stability to the wood frame. However, short walls that had a high height / length ratio underwent a rocking motion and applied additional seismic forces on the wood frame at high levels of ground shaking. Furthermore, it was observed that continuous veneer corners helped support the out - of - plane veneer segments. It was observed that the joint reinforcement in the veneer had no effect on the seismic performance of the system.

The analytical phase of the research involved the development of nonlinear finite element models to simulate the behavior of the veneer wall systems. Non - linear displacement based beam - column elements were used to model the veneer, elastic beam elements were used to model the wood stud backup wall, nonlinear truss elements with an appropriate hysteretic model were used to model the tie connectors. Two types of tie 
models were considered, a flexible tie model and a stiff tie model. The analytical models displayed good correlation with the experimental data (Okail et al., 2009).

These models were used to develop an understanding of the distribution of tie forces along the height of the wall. It was found that the condition of the veneer had a strong effect on the tie force distribution; for an uncracked veneer, the distribution was influenced by the flexibility of the backing wall and the wall boundary conditions, whereas, for a cracked veneer, the tie forces near the region of the crack were observed to be higher than in other regions. The use of nonlinear hysteretic material models for the ties permitted a redistribution of tie forces, thereby spreading anchor forces. This behavior was observed in the tests where flexible ties were used. Rigid ties allowed for less force redistribution.

A parametric study on these analytical models revealed the effect of the strength and stiffness of the anchors on the overall out - of - plane response of the walls. Anchors having a low strength led to a premature collapse of the wall characterized by the veneer leaning away from the backup wall. The use of higher strength anchors gave rise to a behavior where the veneer cracked at around mid - height, leading to a redistribution of forces in the anchors. The initial stiffness of the anchors did not have a significant effect on the response after cracking. Slack existing in corrugated ties adversely affected the wall performance, with the generation of acceleration spikes, which led to a higher localized dynamic acceleration, and in some cases premature collapse (Okail, 2010). 
The next phase of the modeling involved the development of an analytical model to simulate the in - plane behavior of the wall system. In order to model the veneerin plane behavior, a "Masonry Element" was developed which involved the use of a combination of nonlinear beam - column elements and truss elements to model the behavior of the masonry. The model used to simulate the behavior of the wood stud backup wall involved the use of elastic beam and truss elements, and nonlinear diagonal truss elements. The diagonal elements were assigned a nonlinear hysteretic material model that was calibrated against the results of racking tests on wood shear walls, and captured the nonlinearities that developed in the fasteners used in the wood shear wall. The model showed an excellent match with the experimental (Okail, 2010) data obtained from tests conducted on the wall segments.

A parametric study was conducted using the in - plane wall model, in an effort to understand the effect of the veneer on the in-plane behavior of the wood stud shear wall. The effect of veneers with different aspect ratios was considered and it was concluded that squat veneers had a positive restraining effect on the backup frame, whereas slender veneers had a tendency to rock and increase the forces in the wood stud backup wall, thereby having a negative effect on the system. The study also proved that modeling the behavior of the veneer in plane as just a mass was overly conservative, and led to an overestimation of lateral drift of the shear wall. 
Hussein et al., also conducted a parametric study on the behavior of a two-story veneer under out of- plane seismic loading. Here the nonlinear finite element vener wall system models were used to evaluate the current prescriptive requirements of the MSJC (MSJC, 2008) and found they are adequate. It was shown that a minimum value of anchor strength of $667 \mathrm{~N}$ was necessary for adequate performance under the design based earthquake and the maximum considered earthquake.

\subsubsection{Seongwoo Jo et-al.: Investigations}

In his dissertation titled "Seismic Behavior and Design of Low - Rise Reinforced Concrete Masonry with Clay Masonry Veneer", Seongwoo Jo (Jo, 2010) described an investigation that studied the seismic behavior of clay masonry veneer walls backed by concrete masonry walls. A total of $12 \mathrm{CMU}$ backed veneer wall specimens were designed, constructed and tested. Six of these were tested in the out - of - plane direction and the remainder, in the in - plane direction. For each set of six walls, three were tested quasi - statically, and three, dynamically, on a shake table. Finally, a full scale single storey CMU building specimen was also tested on a shake table.

Jo observed that the seismic response of low - rise masonry structures was governed by the response of the in - plane masonry shear walls, which controlled the horizontal movement of the roof diaphragm. The out - of - plane walls were excited at their base and at their top, which was supported by the roof diaphragm. He studied the in - plane response of CMU backed veneer wall systems by subjecting veneer walls to in - plane 
quasi - static loads. With the help of shake table tests conducted on in - plane CMU backed wall systems, he also investigated the in - plane rocking and base sliding behavior of the veneer and the in - plane shear behavior of the tie connectors.

As part of this investigation, a CMU building, which was designed and constructed to meet the Seismic Design Category D provisions of the MSJC code (MSJC, 2008), was subjected a series of ground motions on a shake table. It was shown that the building was able to resist earthquakes well above the MCE level. The veneer acting in the in plane direction did not have a significant effect on the response of the CMU building. Furthermore, it was seen that the veneer of the wall specimens subjected to in plane loading displayed a rigid body response, and rotated and slid at their bases. The aspect ratio (the ratio of the height of the wall to its plan length) of the veneer determined whether it would rock, or slide. Walls with a lower aspect ratio displayed a tendency to slide, whereas those with a higher aspect ratio tended to rock. The frictional resistance at the base of the veneer depended upon the coefficient of friction between the veneer and the shelf angle at its base. This frictional force, combined with the in - plane resistance of the connectors, provided the resistance to the sliding of the veneer. The in - plane resistance of the connectors resisted the rocking motion of the veneer.

The out of plane load tests conducted proved that the specimens were able to perform adequately under the MCE level of ground motion. It was observed that as the intensity of ground shaking exceeded the MCE level, flexural hinges formed at the base and at mid 
- height of the CMU backup. The flexibility of the roof diaphragm had an effect on the out - of - plane response of wall. The use of a laterally flexible roof diaphragm prevented the formation of a flexural hinge at mid - height in the CMU backup. Veneer cracking resulted in its flexural resistance dropping to zero. Prior to the cracking of the cracking of the veneer, the significantly higher stiffness of the backup wall led to it resisting most of the imposed bending moments. Thus, after cracking the out - of - plane veneer acted as a mass attached to the backing wall. Furthermore, it was observed that the out - of - plane tie connectors performed well, and securely connected the veneer to the backup wall in all the tests conducted.

Jo also developed a nonlinear analytical model for CMU backed masonry veneer wall systems within the OPENSEES software framework that were calibrated using the test results. It was found that the models simulated the in and out - of - plane wall system behavior well. The parametric study conducted using these models provided general information about the general response of low - rise CMU buildings with clay masonry veneer.

On the completion of his research, Jo arrived at the following conclusions:

1. Regularly shaped low - rise CMU buildings, that are designed using the provisions of the MSJC code (MSJC, 2008) for a region falling under Seismic Category E, will perform well if they are designed so that the flexural capacity of the CMU wall 
segments is significantly higher than the flexural demand. These wall systems can perform adequately well above the MCE level.

2. The seismic response of the building is governed by the flexural hinging or sliding of the in - plane CMU shear walls.

3. The clay masonry veneers, and the tie connectors, performed well under in plane and out of plane loading.

4. The parameters that are crucial to the seismic response of low - rise concrete masonry buildings were accurately simulated by the nonlinear dynamic model and analysis performed on the building, and the results that this type of analysis can provide serve as a reliable set of guidelines to the designer. The models accurately represented the flexural hinging and sliding at the base of the CMU shear walls, the rocking and sliding behavior of the veneer under in plane loading, the flexural hinging at the base and around mid - height of the CMU walls loaded onto plane, and the inelastic behavior the ties.

Based upon his research, Jo recommended that the MSJC code should introduce provisions to limit the in plane sliding of the base of CMU walls at the MCE level, and should recommend the prevention of sliding at the DBE level. The sliding of the in plane CMU wall can lead to the fracture of the vertical reinforcement bars. Furthermore, he concluded that the current provisions in the MSJC Code (MSJC, 2008) document that recommend the representation of the anchored veneer by its mass, are inaccurate, since the veneer rocks and slides and thus assists in energy dissipation during an earthquake. Finally, he stated that the use of joint reinforcement in the veneer made no difference to its response, and hence it was unnecessary. 


\subsection{Summary}

It appears that masonry veneer wall systems in low rise buildings can perform well under severe seismic events if designed and constructed using appropriate code provisions. It is unclear though, whether these code provisions are sufficient to ensure good seismic performance of these wall systems in taller structures. This needs to be investigated further. 


\section{CHAPTER 3}

\section{MODELING DESCRIPTION AND CALIBRATION, PARAMETRIC STUDY}

\subsection{Introduction}

This chapter describes the approach used to model the wall and frame systems during the analytical investigation of the seismic performance of veneer wall systems in medium rise buildings.

To achieve this objective, in and out - of - plane analytical models of the veneer wall systems were developed and attached to analytical models of the medium rise building frames. The building frame systems were designed to be representative of those used in typical medium rise buildings in higher seismic areas in the United States. These combined veneer wall - building frame models were calibrated using test results, and then analyzed dynamically under the effect of appropriately scaled ground motions. These ground motions were selected to create the worst effect on the wall systems. 
Additionally, selected parameters were varied in the models in order to understand their influence on the seismic performance of the system.

Section 3.2 of this chapter describes the building frames that were used in this study and how the different types of frames were selected. The next section in this chapter describes the process used to design the main building frames (to which the veneer wall systems would be subsequently attached). Following this, Section 3.4 describes the conversion of the 3-D building frames designed above, into 2-D frames.

Section 3.5 describes the technique used to model the veneer wall systems, both in and out - of - plane, with both steel stud and CMU backing systems. This section also explains the modeling techniques developed to represent the connection of the wall systems to the main building frames.

Section 3.6 discusses the process used to calibrate both the frame models and the veneer wall system models using work of other researchers. Section 3.7 describes the ground motions used in the dynamic analysis and the reasons for selecting them. In this section, the process used to scale the ground motions to establish the Design Basis Earthquake (DBE) and Maximum Considered Earthquake (MCE) for each of the systems being analyzed is described. 
Then finally, Section 3.9 of this chapter describes the parametric study that was conducted.

\subsection{Building Frames}

A range of medium rise structures was investigated, the dimensions and configuration of which were chosen to be representative of the range of typical construction. These representative dimensions and configurations were selected based upon the recommendations of engineers in the industry, who were consulted for their input.

The following dimensions were selected for the four building frames investigated:

1) A $125 \mathrm{ft}$ length

2) A $75 \mathrm{ft}$ width

3) 10 stories in height with a $12 \mathrm{ft}$ height per story

4) A $25 \mathrm{ft}$ bay spacing

Figures $3.1,3.2$, and 3.3 show the plan and elevation views of the building frames. 


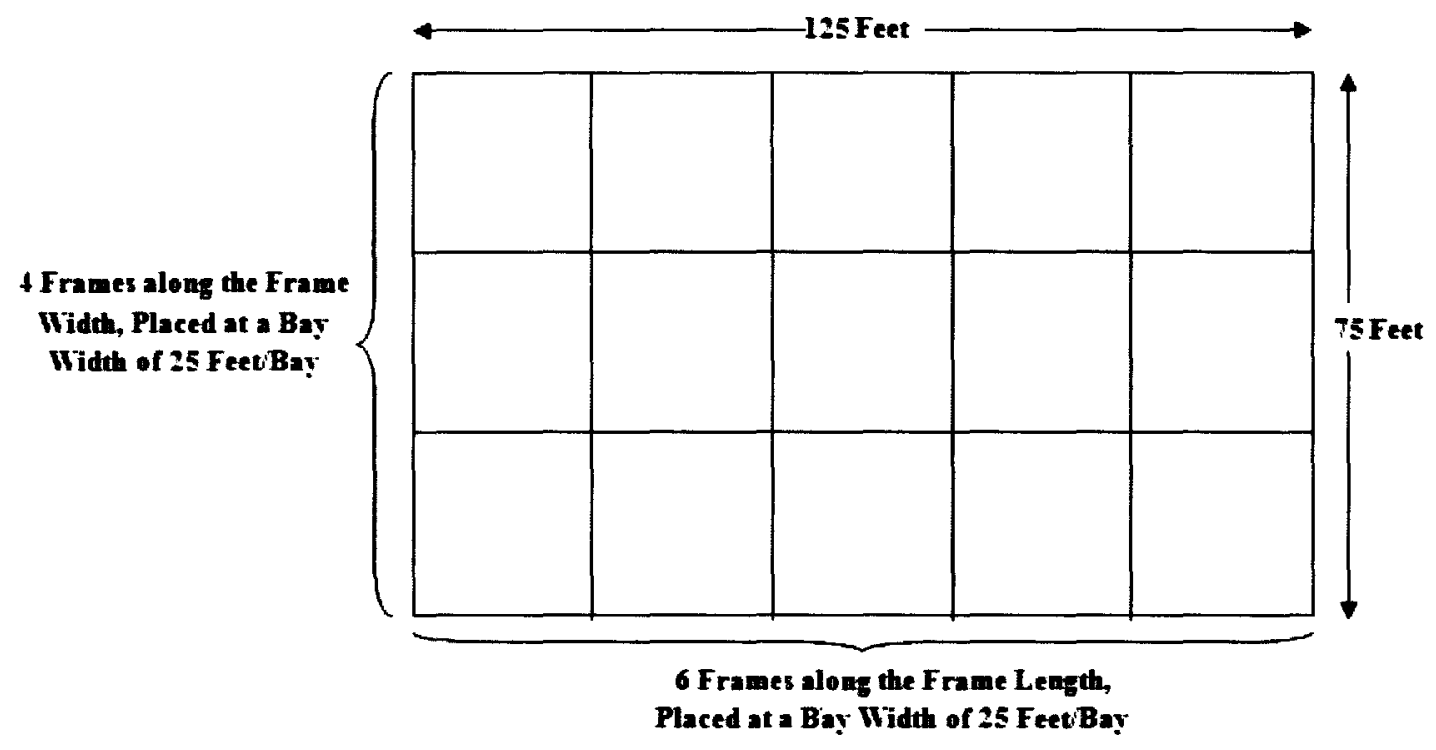

Figure 3.1: Plan View of the Building Frames 


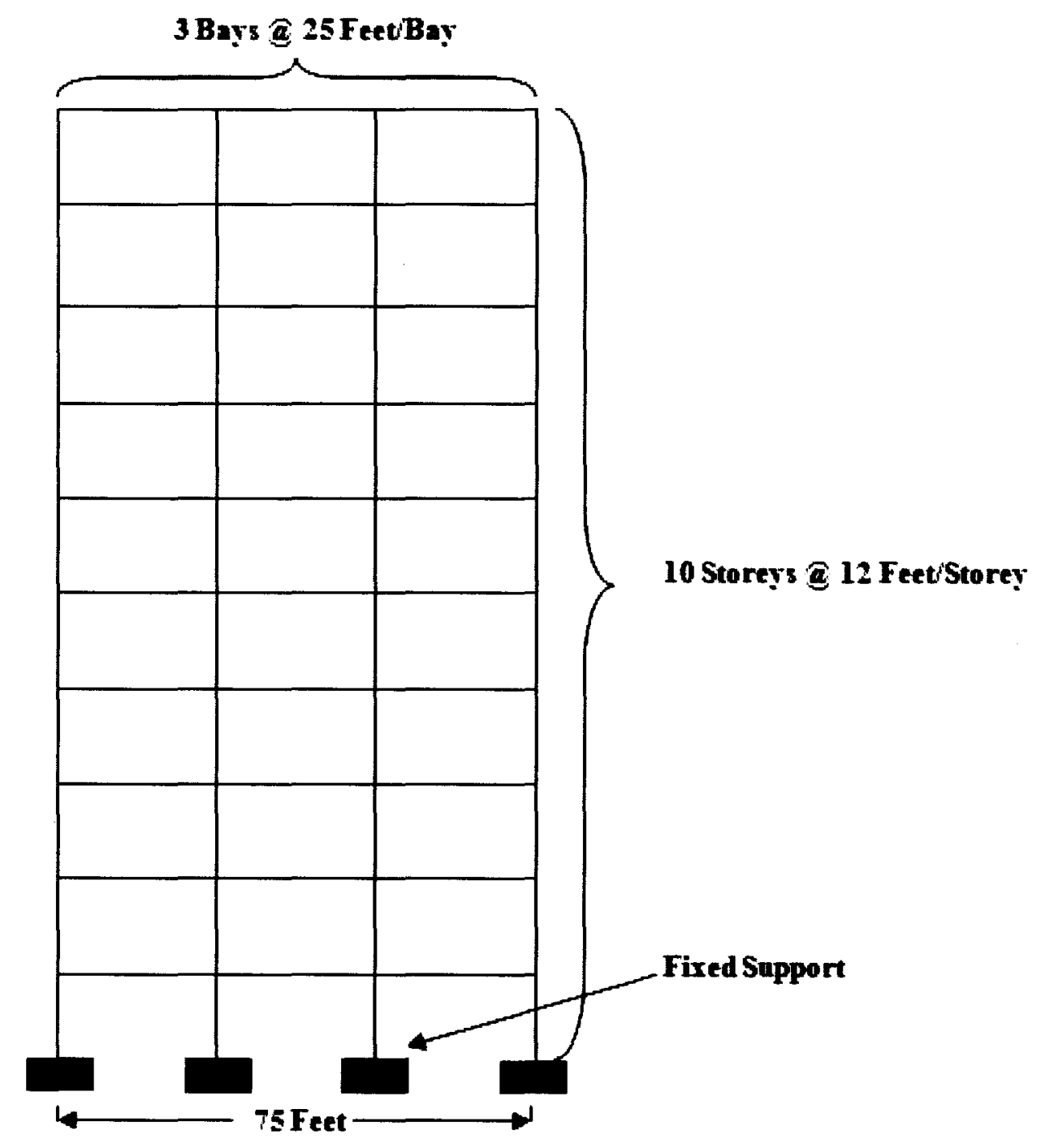

Figure 3.2: Elevation View of the Building Frames In Their Short Direction 


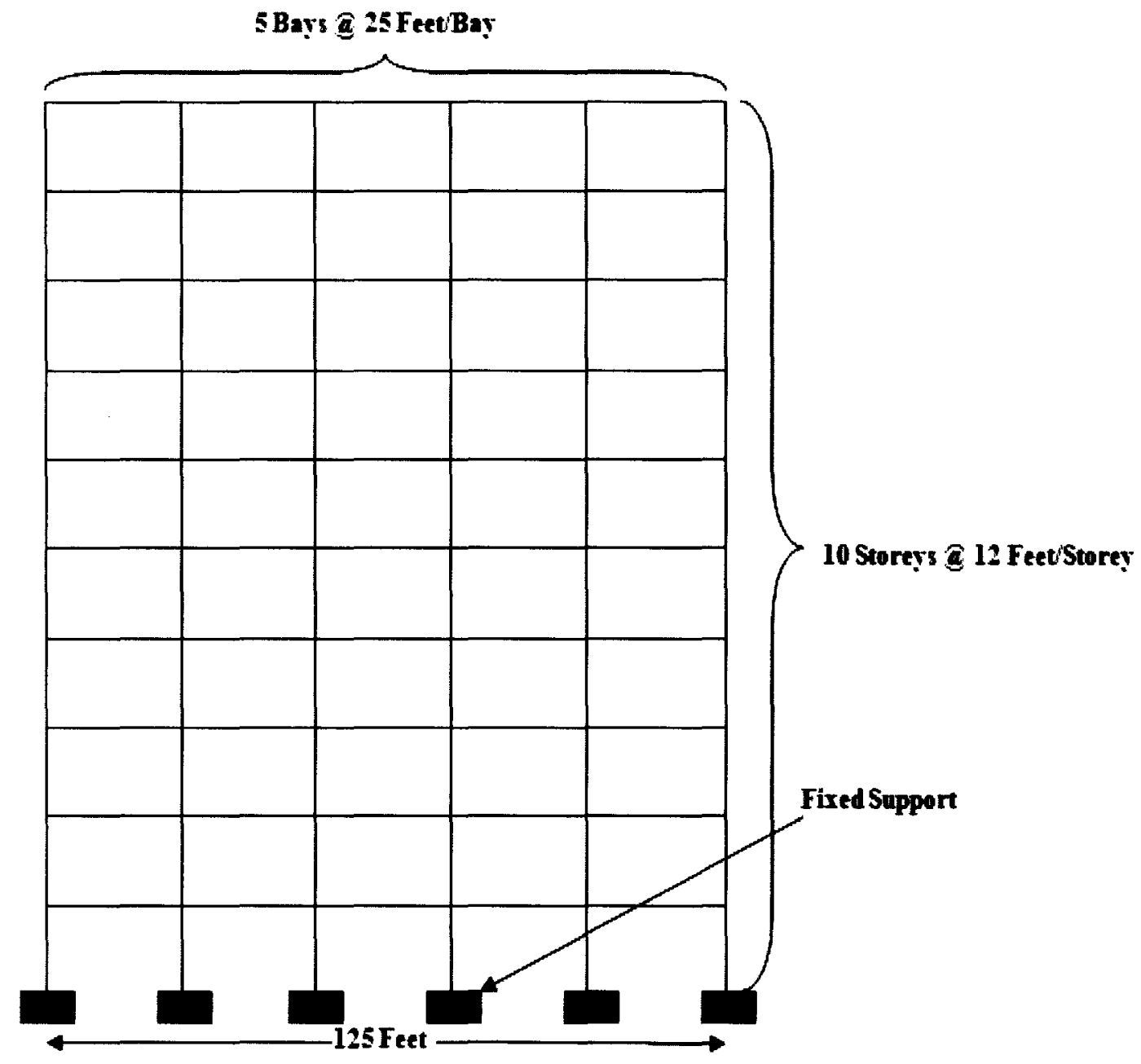

Figure 3.3: Elevation View of the Building Frames In Their Long Direction

The following four types of building frame systems (Figures 3.4, 3.5 and 3.6) were considered in this study:

1) Steel Moment Resisting Frame

2) Reinforced Concrete Moment Resisting Frame

3) Steel Braced Frame

4) Reinforced Concrete Frame with Shear Walls. 
These systems encompassed the range of stiffnesses and masses of the different types of basic framing systems likely to be used for these types of structures. The steel moment resisting frame would be the most flexible, and the reinforced concrete shear wall system would be the stiffest. The floor system used for all the structures was comprised of a concrete slab, supported by floor beams, which, in turn, were supported by floor girders.

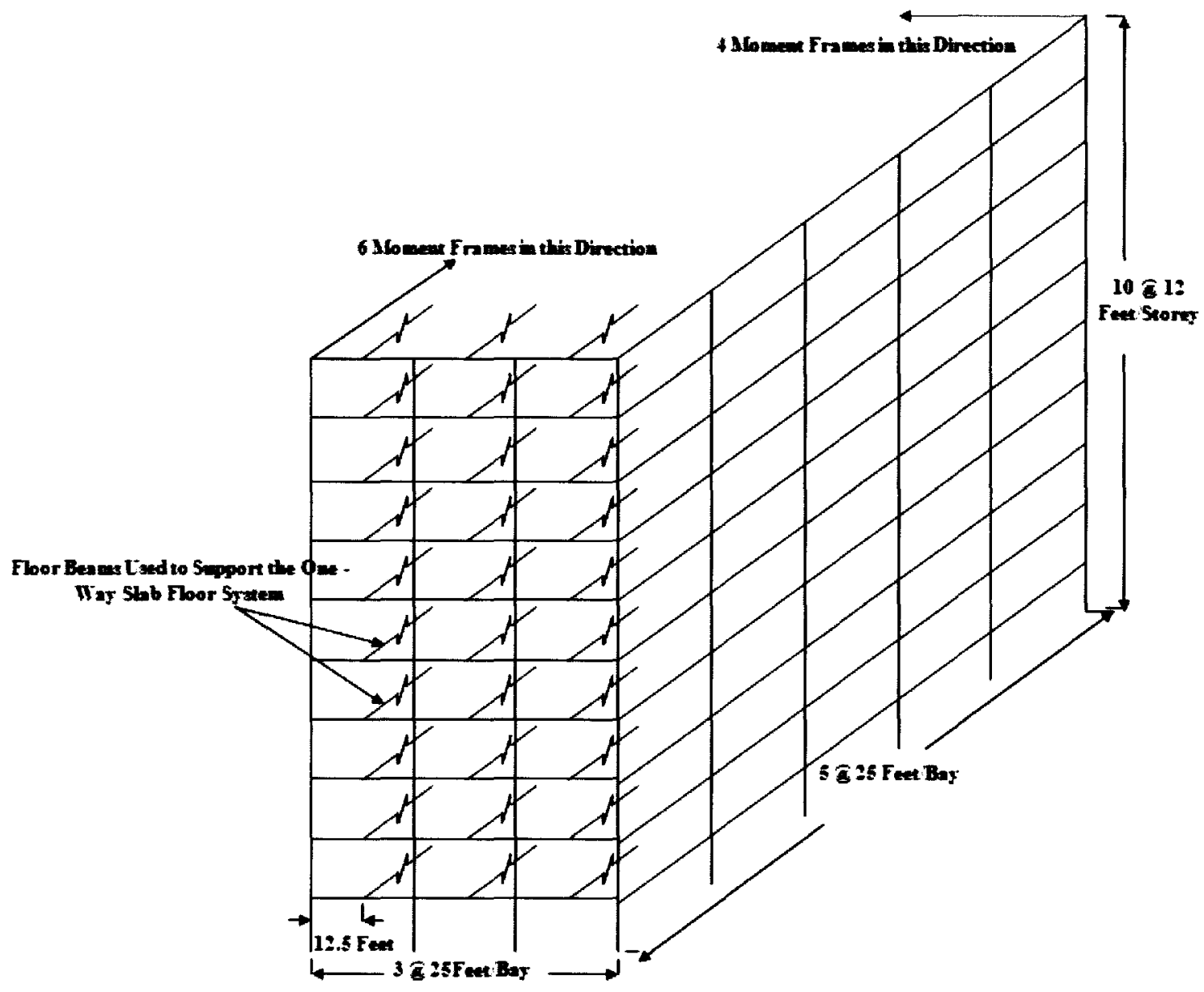

Figure 3.4: Steel and Reinforced Concrete Moment Frames in 3-D 

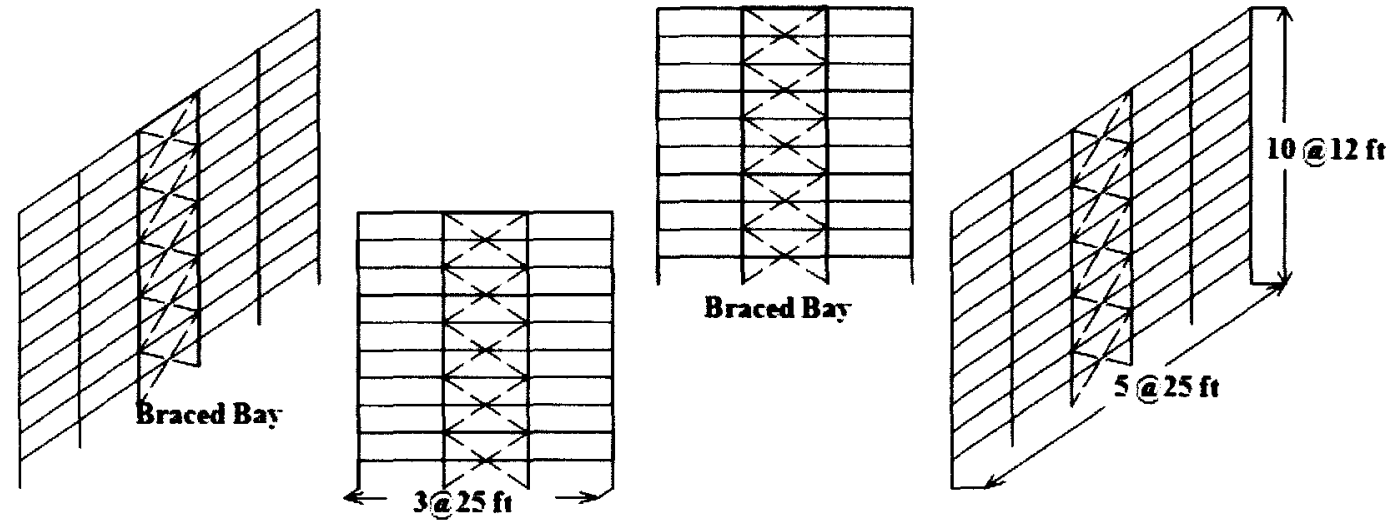

Figure 3.5: Locations of the Braces in the Peripheral Frames of the Steel Braced Frame System

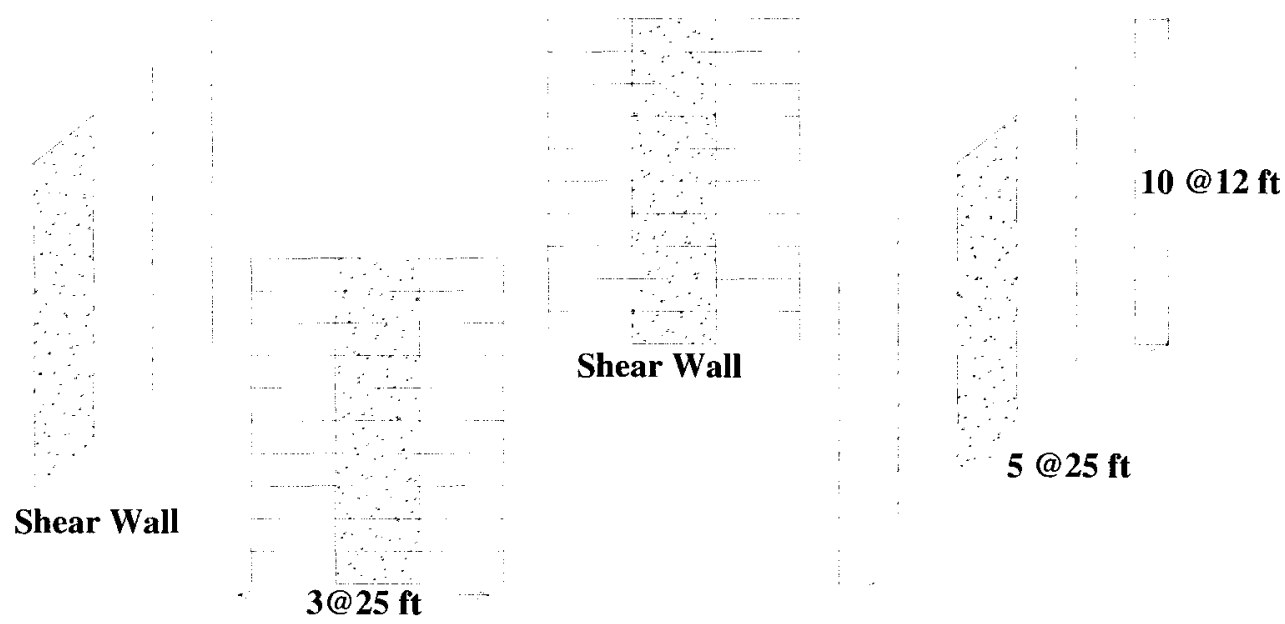

Figure 3.6: Locations of the Shear Walls in the Peripheral Frames of the Reinforced Concrete Shear Wall System

\subsection{Main Frame Design}

The member sizes of the main building frames that were used in the dynamic analysis were obtained by designing the 3-D frames (whose configurations and dimensions were described in Section 3.2) using the STAAD.Pro software package, developed by Bentley (http://www.bentley.com/en-US/Products/STAAD.Pro/), and the equivalent static load 
method. The steel moment resisting and braced frames were designed in accordance with the American Institute of Steel Construction (AISC) Load and Resistance Factor Design (LRFD) method (AISC, 2005). The reinforced concrete frames, both moment and shear wall systems, were designed according to the American Concrete Institute (ACI) provisions (ACI, 2008). STAAD.Pro is equipped to select the minimum sizes of the members in keeping with the United States steel and concrete code provisions, in accordance with its design algorithms, given the building configuration, material properties, and code specified loads. The purpose of designing the 3-D frames using STAAD.Pro was to obtain building frame member sizes that are representative of those used in the seismic construction of typical medium rise buildings in the United States.

\subsubsection{Vertical Loads}

The unfactored static vertical loads that were assumed to act on the building frames were:

1) A floor Dead Load of 60 psf. This load included the weights of different components of the floor system. An assumed 4 inch deep reinforced concrete slab contributed 50 psf (a value of 150 pound-force per cubic foot (pcf) was assumed for the density of concrete), the mechanical and electrical components were assumed to weigh about 5 psf, the metal deck was assumed to weigh approximately $3 \mathrm{psf}$, and the carpet and underlayment, approximately 2 psf.

2) The roof Dead Load was assumed to be $10 \mathrm{psf}$ in the steel buildings and $60 \mathrm{psf}$ in the reinforced concrete buildings, the difference being due to absence of a reinforced 
concrete slab in the steel framed buildings and the presence of the same in the reinforced concrete buildings.

3) The floor live load was assumed to be 65 psf. This number is the sum of two terms, namely, a 50 psf live load prescribed for standard office buildings in ASCE - 07 - 05 (ASCE, 2005), and an additional 15 psf partition load.

4) An additional dead load of 77 pound-force per square foot (psf) or 924 pound-force per foot $(\mathrm{lb} / \mathrm{ft})$ was applied to the peripheral floor girders of the frame on every story (since each story height was 12 feet). This load would be produced by the weight of the CMU backed veneer wall system, which encloses the building frame. It was assumed that the clay brick veneer weighs 40 psf and the CMU backing wall weighs 37 psf. The steel stud backed wall systems were assumed to weigh $48 \mathrm{psf}$, once again, with a 40 psf contribution from the brick veneer, and, an 8 psf contribution from the steel stud backing. However, for the subsequent dynamic analysis, the frame that was designed for the heavier CMU backed system for both the CMU and stud backed systems was used, since the difference between the two frames was only in the peripheral floor girders.

5) A load of $200 \mathrm{lb} / \mathrm{ft}$ was applied to the peripheral roof girders. This load was produced by the weight of a $4 \mathrm{ft}$ high parapet wall, which was assumed to weigh approximately 50 psf. 


\subsubsection{Lateral Loads: Equivalent Lateral Force Procedure}

The lateral seismic loads acting on the main building frames were approximated by the Equivalent Lateral Force Procedure, as prescribed in Section 12.8 of ASCE - $07-05$ (ASCE, 2005). In the equivalent lateral force procedure, static loads are applied to a structure, with magnitudes and directions that approximate the peak effects of dynamic seismic loading on the structure. These concentrated lateral seismic forces are assumed to occur at floor and roof levels in buildings, where there is the highest concentration of mass. Typically, the largest lateral accelerations, forces and displacements occur at the top storey of a structure, particularly in the case of tall buildings. In general, the distribution of lateral storey forces is associated with the first fundamental mode of vibration of a cantilevered structure. This is reasonable for low to medium rise buildings, whose response is generally dominated by their first mode. These effects are modeled in the equivalent lateral force procedure by distributing lateral forces at each storey level with the sum of these lateral forces equal to the seismic base shear. This is explained in more detail subsequently in this section. Figures 3.7 and 3.8 show the application of the seismic base shear and the resultant loads, distributed according to the equivalent lateral force procedure, to the building. 


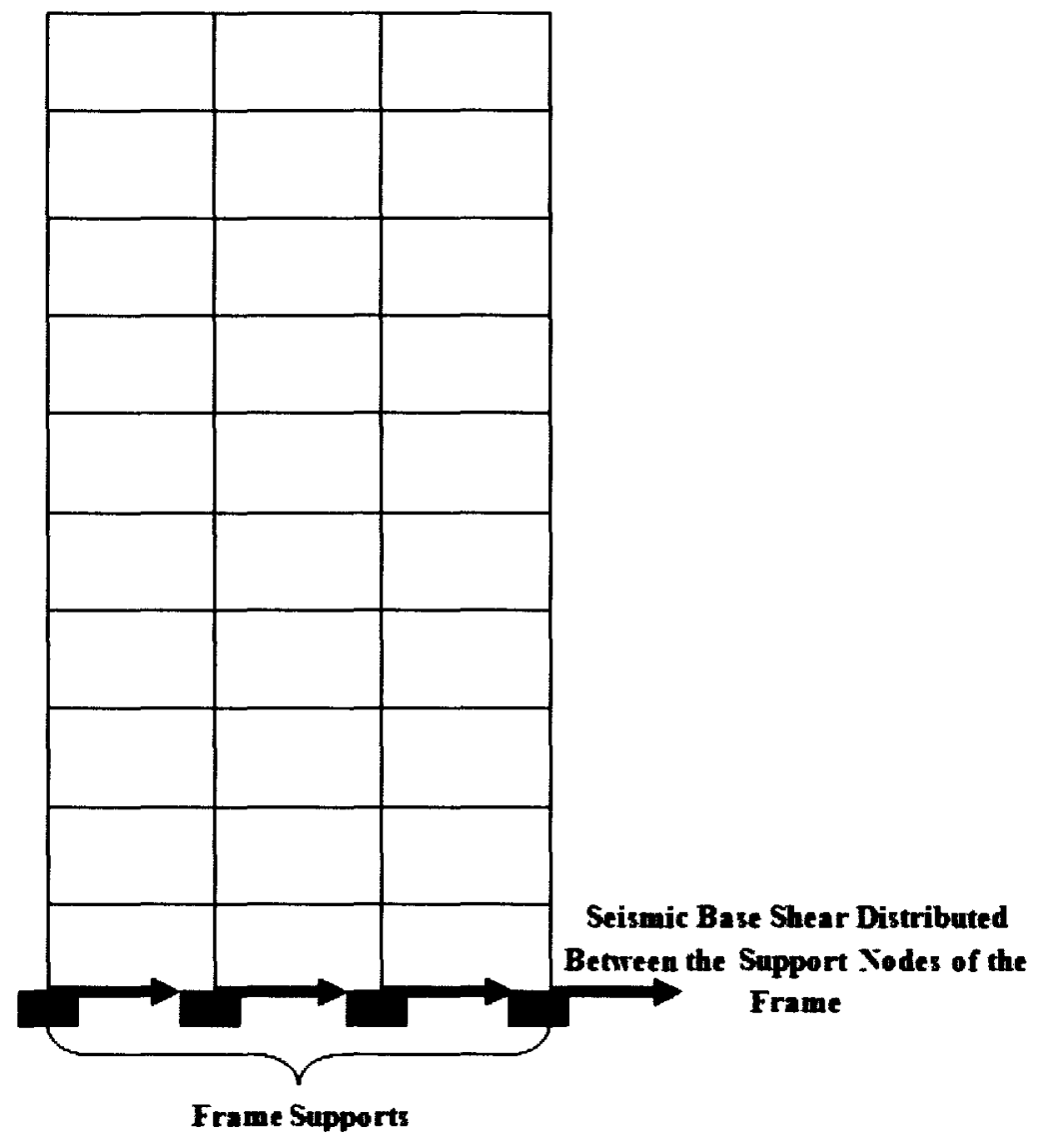

Figure 3.7: Base Shear Applied to the Support Nodes of the Mainframe 


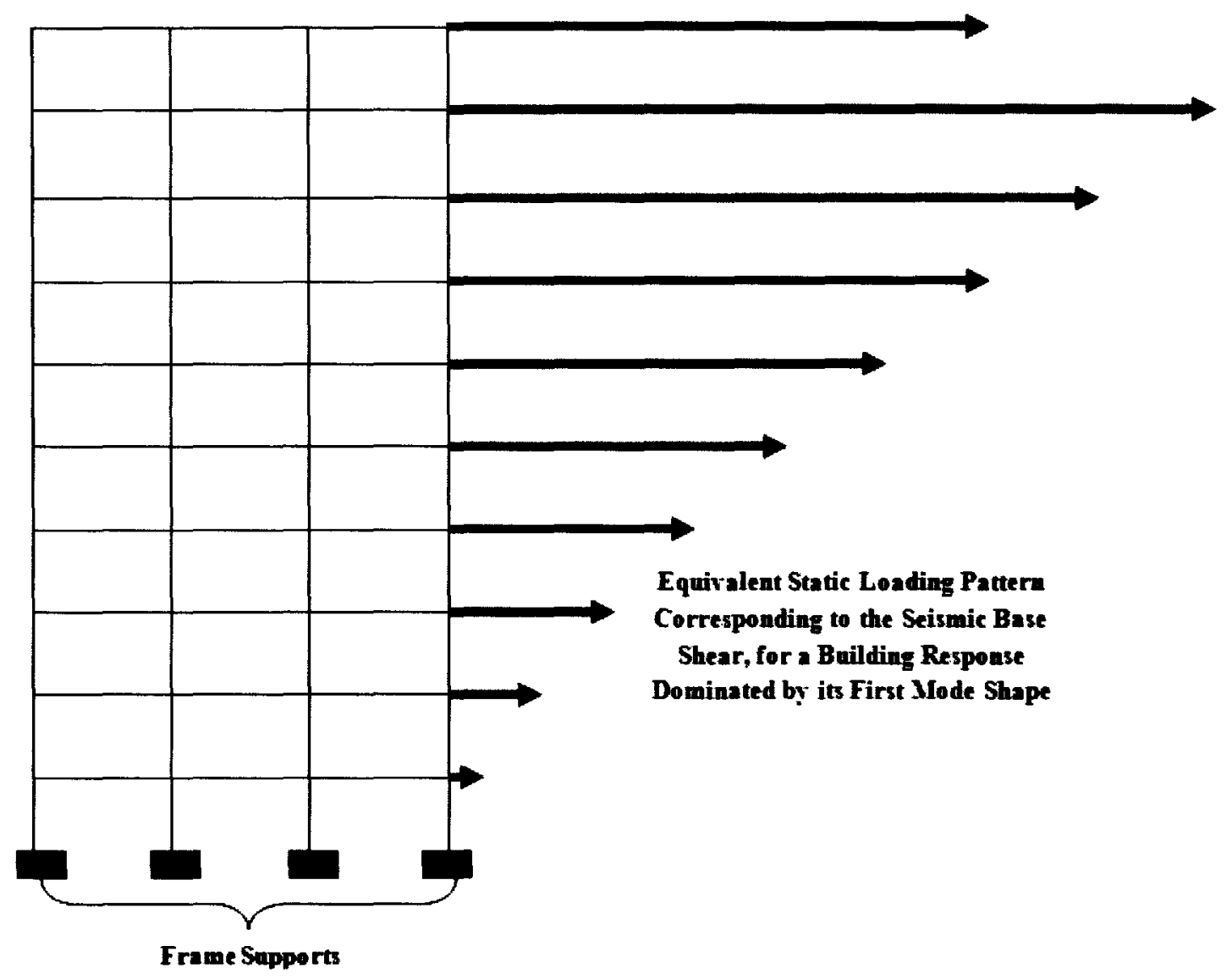

Figure 3.8: Equivalent Static Load Distribution Applied to the Mainframe

\subsubsection{Seismic Base Shear Determination}

According to Section 12.8.1 of ASCE - 07 - 05, the seismic base shear, $V$, in a given direction is given by:

$V=C_{s} W$

where,

$V=$ seismic base shear 
$C_{s}=$ the seismic response coefficient, determined in accordance with Section 12.8.1.1 of ASCE $-07-05$, and

$W=$ the effective seismic weight of the building, determined in accordance with Section 12.7.2 of ASCE - $07-05$.

The seismic response coefficient, $C_{s}$, determined using Eq. 12.8-2 of ASCE - 07 - 05, is given by:

$$
C_{S}=\frac{s_{D S}}{\left(\frac{R}{I}\right)}
$$

where,

$S_{D S}=$ the design spectral response acceleration parameter in the short period range, determined from Table 11.6.1 of ASCE - 07-05, $R=$ the response modification factor in Table 12.2-1 of ASCE $-07-05$, and $I=$ the occupancy importance factor, determined in accordance with section 11.5.1 of ASCE - $07-05$.

The value of $C_{s}$, computed in accordance with Eq. 12.8-2 of ASCE - $07-05$ need not exceed the following:

$C_{s, \text { max }}=\frac{S_{D 1}}{T\left(\frac{R}{I}\right)}$ for $T \leq T_{L}$

$C_{s, \max }=\frac{S_{D 1} T_{L}}{T^{2}\left(\frac{R}{I}\right)}$ for $T>T_{L}$

Furthermore, $C_{s}>0.01$

where,

$S_{D 1}=$ the design spectral response acceleration parameter at a period of $0.1 \mathrm{~s}$, as determined from Section 11.4.4 of ASCE - 07-05, 
$T=$ the fundamental period of the structure (s), determined in Section 12.8.2 of ASCE $07-05$, and

$T_{L}=$ long - period transition period (s), determined in Section 11.4.5 of ASCE $-07-05$.

The buildings being investigated were assumed to be located in Seismic Design Category D. Buildings in this category (Table 11.6.1 of ASCE - $07-05$ ) have values of $S_{D S}$ greater than 0.5 . A value of 0.55 was selected for all the building frame systems being designed, since this was considered to be reasonably representative of buildings in the maximum design conditions. The values of the response modification factor, $R$, which were selected for the frames, from Table 12.2.1 of ASCE - $07-05$ are shown in Table 3.1.

Table 3.1: Frame Response Modification Factors

\begin{tabular}{cl}
\hline Frame Type & R \\
\hline Steel moment resisting frame & 8 \\
Steel braced frame & 6 \\
RC moment resisting frame & 8 \\
RCshear wallsystem & 6 \\
\hline
\end{tabular}

The $R$ values above correspond to frames whose connections are detailed in such a way as to result in "special" frames, as opposed to "ordinary" frames. In this investigation, the frames were assumed to be detailed as special frames because the provisions in ASCE - $07-05$ do not permit the construction of ordinary steel and reinforced concrete moment frames, and ordinary reinforced concrete shear wall systems, 
in Seismic Category D regions. Furthermore, the code restricts the height of ordinary steel concentrically braced frames in a Seismic Category D region to 35 feet, which is less than the 120 feet height of the frames being designed, thereby making it necessary to detail the steel braced frame as a special concentrically braced steel frame.

All the buildings were assumed to be in Occupancy Category I, resulting in an importance factor of 1 (Table 11.5-1 of ASCE - 07 - 05).

The effective seismic weight, $W$, of each building frame being designed was computed in accordance with the provisions in Section 12.7.2 of ASCE - $07-05$. These weights included the total unfactored floor and roof dead load, the load due to the floor partitions, the veneer wall loads, the roof parapet wall load, and the self weight of the members of the frame. The detailed weight and base shear calculations are shown in Appendix A.

The approximate fundamental period of each building, $T_{a}$, in seconds, was determined using Eq. 12.8-7 of ASCE - $07-05$ :

$$
T_{a}=C_{t} h_{n}{ }^{x}
$$

where, $h_{n}=$ the height in feet above the base to the highest level of the structure and 
$C_{t}, x=$ building period paramters determined from Table 12.8-2 of ASCE $-07-05$. These vary for different types of frame. They account for variations in the modal response period of the frames with changes in stiffness and mass.

All the buildings considered had a height of 120 feet. The values of $C_{t}$ and $x$ that were used are tabulated in Table 3.2

Table 3.2: Frame Coefficients $C_{t}$ and $x$

\begin{tabular}{ccc}
\hline Frame Type & $\mathbf{C}_{\mathbf{t}}$ & $\mathbf{x}$ \\
\hline Steel Moment Resisting Frame & 0.028 & 0.8 \\
Steel Braced Frame & 0.02 & 0.75 \\
RC Moment Resisting Frame & 0.016 & 0.9 \\
RC Shear Wall System & 0.02 & 0.75 \\
\hline
\end{tabular}

The resulting values of the fundamental periods of the structures are shown in Table 3.3.

Table 3.3: Fundamental Period of the Frames

\begin{tabular}{cc}
\hline Frame Type & $\mathbf{T}_{\mathbf{a}}(\mathbf{s})$ \\
\hline Steel Moment Resisting Frame & 1.2897 \\
Steel Braced Frame & 0.7251 \\
RC Moment Resisting Frame & 1.1895 \\
RC Shear Wall System & 0.7251 \\
\hline
\end{tabular}




\subsubsection{Vertical Distribution of Seismic Forces}

The lateral seismic force, $F_{x}$, induced at each storey level, was computed in accordance with Equations 12.8-11 and 12.8-12 of ASCE - 07 - 05, as follows:

$$
\begin{array}{r}
F_{x}=C_{v x} V \\
C_{v x}=\frac{w_{x} h_{x}{ }^{k}}{\sum_{i=1}^{n} w_{i} h_{i}{ }^{k}}
\end{array}
$$

Where

$C_{v x}=$ vertical distribution factor, $V=$ total base shear (in kip or $\mathrm{kN}$ ). In this investigation, base shear was measured in kips, $w_{i}$ and $w_{x}=$ the portion of the total effective seismic weight, $W$, allocated to storey $i$ or $x$, $h_{i}$ and $h_{x}=$ the height (in feet or meters) from the base to level $i$ or $x$, and $k=$ an exponent related to the structure period as follows:

For structures with $T_{a} \leq 0.5 \mathrm{~s}, k=1$; for

$$
T_{a} \geq 2.5 \mathrm{~s}, k=2 \text {; and for }
$$

$0.5 \mathrm{~s}<T_{a}<2.5 \mathrm{~s}, \mathrm{k}$ is determined by linear interpolation between 1 and 2 .

\subsubsection{Computation of Storey Deflections}

The actual deflections, $\delta_{x}$, at a particular level $x$ in the building, were computed in accordance with Eq. 12.8-15 of ASCE - 07 - 05, as:

$$
\delta_{x}=\frac{C_{d} \delta_{x e}}{I}
$$

where,

$C_{d}=$ the deflection amplification factor (dimensionless) in Table 12.2 - 1 of ASCE-7-05, 
$\delta_{x e}=$ the deflections determined by an elastic analysis, and

$I=$ the importance factor, discussed in section 3.2.2.1.1 above.

Table 3.4 displays the $C_{d}$ values used for the buildings in this analysis.

Table 3.4: Frame Deflection Amplification Factors

\begin{tabular}{cc}
\hline Frame Type & $\mathbf{C}_{\mathbf{d}}$ \\
\hline Steel Moment Resisting Frame & 5.5 \\
Steel Braced Frame & 5 \\
RC Moment Resisting Frame & 5.5 \\
RC Shear Wall System & 5 \\
\hline
\end{tabular}

Table 12.12-1 of ASCE - 07 - 05 limits the permissible design storey drift for any storey in steel braced frame and reinforced concrete shear wall system to $0.02 h_{s x}$, where $h_{s x}$ is the storey height below level $x$. The design storey drift was computed as the largest difference of the deflections along any edges of the structure (the computation of the deflections was described in Section 3.3.2.4 above), at the top and bottom of the storey under consideration, in accordance with 12.12 .1 of ASCE - $07-05$.

\subsubsection{Load Combinations}

The following basic load combinations were used in the design of the frames (Section

2.3.2, ASCE - 07-05):
a) $\quad 1.2 \mathrm{D}+1.6 \mathrm{~L}+0.5 \mathrm{R}_{\mathrm{L}}$
b) $\quad\left(1.2+0.2 \mathrm{~S}_{\mathrm{DS}}\right) \mathrm{D}+\mathrm{E}+\mathrm{L}$
c) $\quad\left(0.9-0.2 \mathrm{~S}_{\mathrm{DS}}\right) \mathrm{D}+\mathrm{E}$ 
where,

$\mathrm{D}=$ Dead Load

$\mathrm{L}=$ Live Load

$\mathrm{R}_{\mathrm{L}}=$ Roof Live Load

$\mathrm{E}=$ Earthquake load (computed by the equivalent lateral force procedure described above)

With $S_{D S}$ taken as 0.55 , the above load combinations reduce to:
a) $\quad 1.2 \mathrm{D}+1.6 \mathrm{~L}+0.6 \mathrm{RL}$
b) $\quad 1.31 \mathrm{D}+\mathrm{E}+\mathrm{L}$
c) $\quad 0.79 \mathrm{D}+\mathrm{E}$

\subsubsection{STAADPRO 3-D Frame Models and Frame Design}

This section describes the four 3 - dimensional frame models developed using STAAD.Pro. These models included a steel moment resisting frame, a steel braced frame, a reinforced concrete moment resisting frame, and a reinforced concrete frame and shear wall system. Included in the description are the element models used, the material properties used, the design assumptions, and other details specific to the models performance.

\subsubsection{Steel Moment Resisting Frame}

The important features incorporated in the steel moment resisting frame models on the STAAD.Pro framework were: 
1) Elastic beam elements were used to model the beams and columns of the frame. They were assigned the elastic modulus, poisson's ratio, and density of steel, namely 29000 ksi, 0.3, 490 pcf, respectively. The steel used was assumed to have a yield stress of 50 ksi.

2) Connections of all beams and column elements are continuous.

3) 4 inch thick elastic concrete plate elements were used to model the slabs. These slabs elements were not designed but were incorporated to obtain an accurate representation of the stiffness of the system, and to provide connectivity for load transfer between the different components of the frame, as well as stability. They were assigned a negligible density, since their self weight was already incorporated in the floor dead loads. The slab elements were assumed to have a modulus of elasticity of $3150 \mathrm{ksi}$ and a poisson's ratio of 0.17 . Due to the limitation of this investigation, there is no experimental data to show the modulus directly. Hence, the expression prescribed in the ACI provisions (ACI, 2008) was used to get an approximate value. In reality, the static and dynamic modulii of concrete are different. For the purpose of this investigation only an approximate representation of the frame behavior is required, and hence, the ACI values are used as a reference.

4) The columns were oriented so that they would be bending about their strong axis (major principal axis of a cross section), when the building was subjected lateral loads parallel to the short direction.

5) All the supports at the column base were fixed.

6) The factored vertical and lateral loads obtained were applied, and combined as described previously. 
7) The beams and columns were designed according to the AISC provisions (AISC, 2005). The columns at every storey were grouped into three sets, namely, the interior columns, the corner columns, and the columns along the edges. Furthermore, within the above mentioned groups, the same columns were used on the $1^{\text {st }}$ and $2^{\text {nd }}$ storeys, the $3^{\text {rd }}$ and $4^{\text {th }}$ storeys, the $5^{\text {th }}, 6^{\text {th }}$ and $7^{\text {th }}$ storeys, and the $8^{\text {th }}$ and $9^{\text {th }}$ storeys.

\subsubsection{Steel Braced Frame}

The steel braced frame was modeled in a similar manner to the steel moment frame described previously, except:

1) The connections between the beams and columns were modeled as pinned connections.

2) The columns were assumed to be pinned at the base of the building and at the locations at which the column section sizes underwent a transition, namely, the $3^{\text {rd }}, 5^{\text {th }}$, $8^{\text {th }}$, and $10^{\text {th }}$ storeys.

3) Axial truss elements were used to model the cross brace members. These members were designed to function in tension only, and had no compressive force carrying capacity. Initially, the intention was to use circular sections for the braces. However, as it turned out, the circular members selected by the software were impractically large, which led to the use of steel wide flange sections for the braces. A single set of cross braces extended over 2 storeys of the building. 


\subsubsection{Reinforced Concrete Moment Frame}

The reinforced concrete moment frame was modeled almost identically to the steel moment frame. The aspects unique to the reinforced concrete moment frame model are presented below:

1) The beams and columns of the frame were designed using concrete that had a modulus of elasticity of $3150 \mathrm{ksi}$ and a density of $150 \mathrm{pcf}$.

2) The reinforcing bars were limited to 1.25 in diameter (\# 10).

3) The reinforcing bars were designed assuming $60 \mathrm{ksi}$ steel.

4) The compressive strength of concrete was assumed to be $4 \mathrm{ksi}$. In the dynamic analysis (described subsequently) conducted using the frame sections obtained from this static design, an additional simulation was performed using a high strength concrete having a compressive strength of $8 \mathrm{ksi}$, in order to determine the effect of the concrete compressive strength on the frame response under dynamic earthquake loads. The peak acceleration of the concrete frame modeled using $8 \mathrm{ksi}$ concrete was less than $5 \%$ lower than that of the frame using 4 ksi concrete. Since the primary goal of this investigation is to understand the behavior of the wall system attached to the frame, and theexact behavior of the frame is not required, changing the concrete strength has a neglible effect of the accelerations of the frame and thus will have a negible effect on the wall system response, and hence only $4 \mathrm{ksi}$ concrete was used in this investigation. 


\subsubsection{Reinforced Concrete Shear Wall System}

The reinforced concrete shear wall system was modeled in a manner similar to that of the steel braced frame, except for the following:

1) The beams and columns were made of reinforced concrete instead of steel. The material properties of the concrete and reinforcing steel used for this purpose, and the maximum size of the reinforcing bars, was identical to that used for the reinforced concrete moment frame described previously.

2) Shear walls were used as the lateral force resisting system. The shear wall was not designed by the STAAD.Pro program. This design was done by hand. Shear wall elements were incorporated into the STAAD model provide a realistic representation of the lateral stiffness of the system. For the sake of modeling, shear wall elements were represented by 2 beam - column elements, at every storey of the frame. These elements extended over the height of the frame, at locations identical to the column lines on either side the central bay located on each of the 4 edges of the frame. These columns were dimensioned in such a way that the sum of their individual stiffnesses was identical to that of the shear wall in that bay. The columns were continuous over the height of the building, and were fixed at their base. The joints connecting the shear wall elements to the main frame were modeled to transmit only the lateral load from the main frame to the columns, but no vertical loads. 
Tables 3.5 through 3.11 present the sizes of the sections recommended by Staad.Pro for the steel moment resisting and braced frames, and the reinforcement details (bar sizes and the number of bars) for the reinforced concrete moment resisting and shear wall systems, modeled in accordance with the process described in Sections 3.3.4.1 through 3.3.4.4. For the steel and reinforced concrete braced frame systems, only the sizes for the peripheral frames of the 3-D structure are presented, since only these frames constitute the lateral force resisting system in these cases. Figures 3.9, 3.10, and 3.11 explain the labels and symbols appearing in the tables (assume B - beam; C - column)

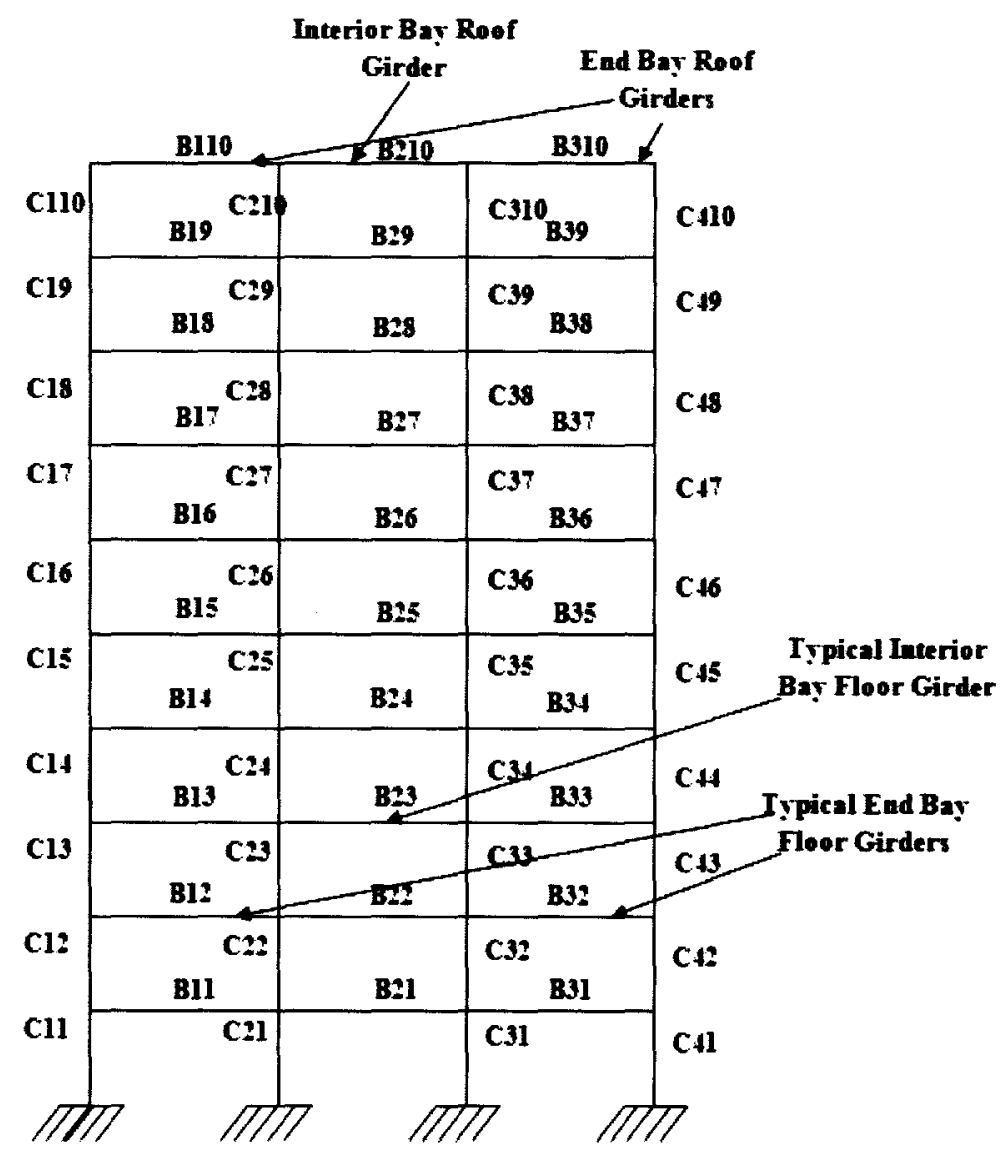

Figure 3.9: Member Labels for Typical Steel and Reinforced Concrete Moment Resisting, Exterior and Interior Frames, Designed Using STAAD.Pro 
Table 3.5: STAAD.Pro Exterior Steel Moment Resisting Frame Section Sizes (Refer to Figure 3.9 for Explanation of Symbols)

\begin{tabular}{|c|c|}
\hline Member Label & Section \\
\hline $\mathrm{C} 11, \mathrm{C} 12, \mathrm{C} 41, \mathrm{C} 42$ & W $18 \times 97$ \\
\hline $\mathrm{C} 21, \mathrm{C} 22, \mathrm{C} 31, \mathrm{C} 32$ & $\mathrm{~W} 21 \times 122$ \\
\hline $\mathrm{C} 13, \mathrm{C} 14, \mathrm{C} 43, \mathrm{C} 44$ & W $14 \times 82$ \\
\hline $\mathrm{C} 23, \mathrm{C} 24, \mathrm{C} 33, \mathrm{C} 34$ & W $18 \times 86$ \\
\hline $\mathrm{C} 15, \mathrm{C} 16, \mathrm{C} 17, \mathrm{C} 45, \mathrm{C} 46, \mathrm{C} 47$ & $\mathrm{~W} 12 \times 65$ \\
\hline $\mathrm{C} 25, \mathrm{C} 26, \mathrm{C} 27, \mathrm{C} 35, \mathrm{C} 36, \mathrm{C} 37$ & $\mathrm{~W} 12 \times 72$ \\
\hline $\mathrm{C} 18, \mathrm{C} 19, \mathrm{C} 48, \mathrm{C} 49$ & $\mathrm{~W} 10 \times 49$ \\
\hline $\mathrm{C} 28, \mathrm{C} 29, \mathrm{C} 38, \mathrm{C} 39$ & $\mathrm{~W} 12 \times 45$ \\
\hline $\mathrm{C} 110, \mathrm{C} 410$ & $\mathrm{~W} 8 \times 24$ \\
\hline C 210, C 310 & W6×15 \\
\hline $\mathrm{B} 11, \mathrm{~B} 12, \mathrm{~B} 31, \mathrm{~B} 32$ & $\mathrm{~W} 21 \times 50$ \\
\hline $\mathrm{B} 21, \mathrm{~B} 22$ & $\mathrm{~W} 21 \times 50$ \\
\hline $\mathrm{B} 13, \mathrm{~B} 14, \mathrm{~B} 33, \mathrm{~B} 34$ & $\mathrm{~W} 21 \times 50$ \\
\hline $\mathrm{B} 23, \mathrm{~B} 24$ & $\mathrm{~W} 21 \times 50$ \\
\hline В 15, B 16, B 17, B 35, B 36, B 37 & W $14 \times 48$ \\
\hline $\mathrm{B} 25, \mathrm{~B} 26, \mathrm{~B} 27$ & W $14 \times 48$ \\
\hline B 18, B 19, B 38, B39 & $\mathrm{W} 16 \times 40$ \\
\hline B28, B29 & $\mathrm{W} 16 \times 40$ \\
\hline $\mathrm{B} 110, \mathrm{~B} 310$ & W6×15 \\
\hline B210 & W6 $6 \times 15$ \\
\hline
\end{tabular}


Table 3.6: STAAD.Pro Interior Steel Moment Resisting Frame Section Sizes (Refer to Figure 3.9 for Explanation of Symbols)

\begin{tabular}{|c|c|}
\hline Member Label & Section \\
\hline $\mathrm{C} 11, \mathrm{C} 12, \mathrm{C} 41, \mathrm{C} 42$ & $\mathrm{~W} 21 \times 122$ \\
\hline $\mathrm{C} 21, \mathrm{C} 22, \mathrm{C} 31, \mathrm{C} 32$ & W24×117 \\
\hline $\mathrm{C} 13, \mathrm{C} 14, \mathrm{C} 43, \mathrm{C} 44$ & $\mathrm{~W} 18 \times 86$ \\
\hline $\mathrm{C} 23, \mathrm{C} 24, \mathrm{C} 33, \mathrm{C} 34$ & $\mathrm{~W} 18 \times 86$ \\
\hline $\mathrm{C} 15, \mathrm{C} 16, \mathrm{C} 17, \mathrm{C} 45, \mathrm{C} 46, \mathrm{C} 47$ & $\mathrm{~W} 12 \times 72$ \\
\hline $\mathrm{C} 25, \mathrm{C} 26, \mathrm{C} 27, \mathrm{C} 35, \mathrm{C} 36, \mathrm{C} 37$ & W $18 \times 76$ \\
\hline $\mathrm{C} 18, \mathrm{C} 19, \mathrm{C} 48, \mathrm{C} 49$ & $\mathrm{~W} 14 \times 48$ \\
\hline $\mathrm{C} 28, \mathrm{C} 29, \mathrm{C} 38, \mathrm{C} 39$ & $\mathrm{~W} 18 \times 50$ \\
\hline $\mathrm{C} 110, \mathrm{C} 410$ & $\mathrm{~W} 8 \times 18$ \\
\hline $\mathrm{C} 210, \mathrm{C} 310$ & W6× 15 \\
\hline $\mathrm{B} 11, \mathrm{~B} 12, \mathrm{~B} 31, \mathrm{~B} 32$ & $\mathrm{~W} 21 \times 50$ \\
\hline $\mathrm{B} 21, \mathrm{~B} 22$ & $\mathrm{~W} 21 \times 50$ \\
\hline $\mathrm{B} 13, \mathrm{~B} 14, \mathrm{~B} 33, \mathrm{~B} 34$ & $\mathrm{~W} 18 \times 50$ \\
\hline $\mathrm{B} 23, \mathrm{~B} 24$ & $\mathrm{~W} 21 \times 50$ \\
\hline $\mathrm{B} 15, \mathrm{~B} 16, \mathrm{~B} 17, \mathrm{~B} 35, \mathrm{~B} 36, \mathrm{~B} 37$ & $\mathrm{~W} 21 \times 50$ \\
\hline $\mathrm{B} 25, \mathrm{~B} 26, \mathrm{~B} 27$ & $W 21 \times 50$ \\
\hline B18, B19, B38, B39 & $\mathrm{W} 16 \times 40$ \\
\hline B28, B29 & $\mathrm{W} 16 \times 40$ \\
\hline $\mathrm{B} 110, \mathrm{~B} 310$ & W6×15 \\
\hline B210 & W6 $6 \times 15$ \\
\hline
\end{tabular}




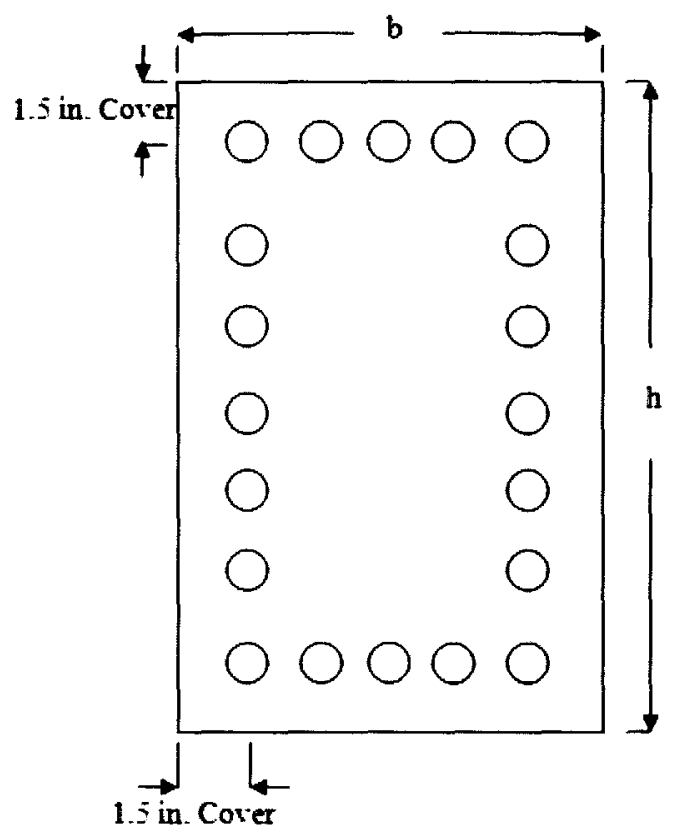

Figure 3.10: Typical Staad.Pro Reinforced Concrete Column Section

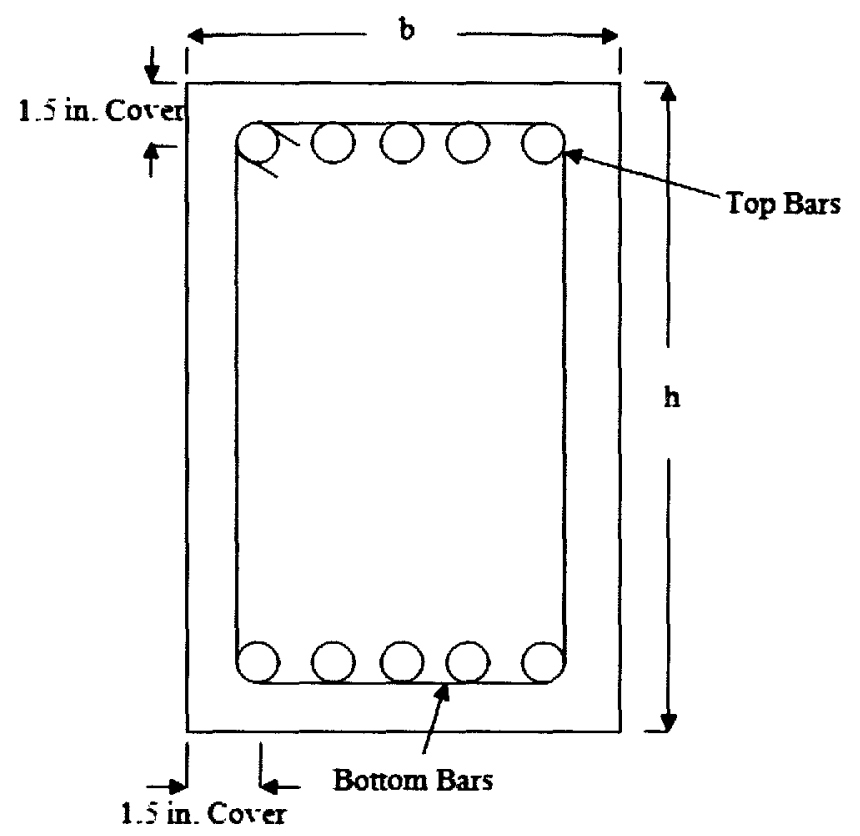

Figure 3.11: Typical Staad.Pro Reinforced Concrete Beam Section 
Table 3.7: STAAD.Pro Exterior Reinforced Concrete Moment Resisting Frame Section Sizes (Refer to Figures 3.9 and 3.10 for Explanation of Symbols)

\begin{tabular}{cllll}
\hline Member & b (ft.) & h (ft.) & Bar Size & No. of Bars \\
\hline C11, C12, C41, C42 & 1.33 & 1.33 & $\# 10$ & 12 \\
C21, C22, C31, C32 & 1.5 & 1.5 & $\# 10$ & 12 \\
C13, C14, C43, C44 & 1.33 & 1.33 & $\# 10$ & 12 \\
C23, C24, C33, C34 & 1.5 & 1.5 & $\# 8$ & 20 \\
C15, C16, C17, C45, C46, C47 & 1.5 & 1.5 & $\# 9$ & 12 \\
C25, C26, C27, C35, C36, C37 & 1.33 & 1.33 & $\# 9$ & 16 \\
C18, C19, C48, C49 & 1.16 & 1.16 & $\# 10$ & 8 \\
C28, C29, C38, C39 & 1.16 & 1.16 & $\# 8$ & 12 \\
C110, C410 & 1.0 & 1.0 & $\# 7$ & 12 \\
C210, C310 & 0.67 & 0.67 & $\# 7$ & 4 \\
\hline
\end{tabular}

Table 3.8: STAAD.Pro Interior Reinforced Concrete Moment Resisting Frame Section Sizes(Refer to Figures 3.9 and 3.10 for Explanation of Symbols)

\begin{tabular}{cllll}
\hline Member & b (ft.) & h (ft.) & Bar Size & No. of Bars \\
\hline C11, C12, C41, C42 & 1.67 & 1.67 & $\# 8$ & 24 \\
C21, C22, C31, C32 & 1.83 & 1.83 & $\# 8$ & 24 \\
C13, C14, C43, C44 & 1.5 & 1.5 & $\# 10$ & 12 \\
C23, C24, C33, C34 & 1.67 & 1.67 & $\# 8$ & 24 \\
C15, C16, C17, C45, C46, C47 & 1.33 & 1.33 & $\# 9$ & 12 \\
C25, C26, C27, C35, C36, C37 & 1.5 & 1.5 & $\# 10$ & 12 \\
C18, C19, C48, C49 & 1.16 & 1.16 & $\# 9$ & 8 \\
C28, C29, C38, C39 & 1.16 & 1.16 & $\# 8$ & 12 \\
C110, C410 & 0.83 & 0.83 & $\# 7$ & 8 \\
C210, C310 & 0.67 & 0.67 & $\# 7$ & 4 \\
& & & & \\
\hline
\end{tabular}




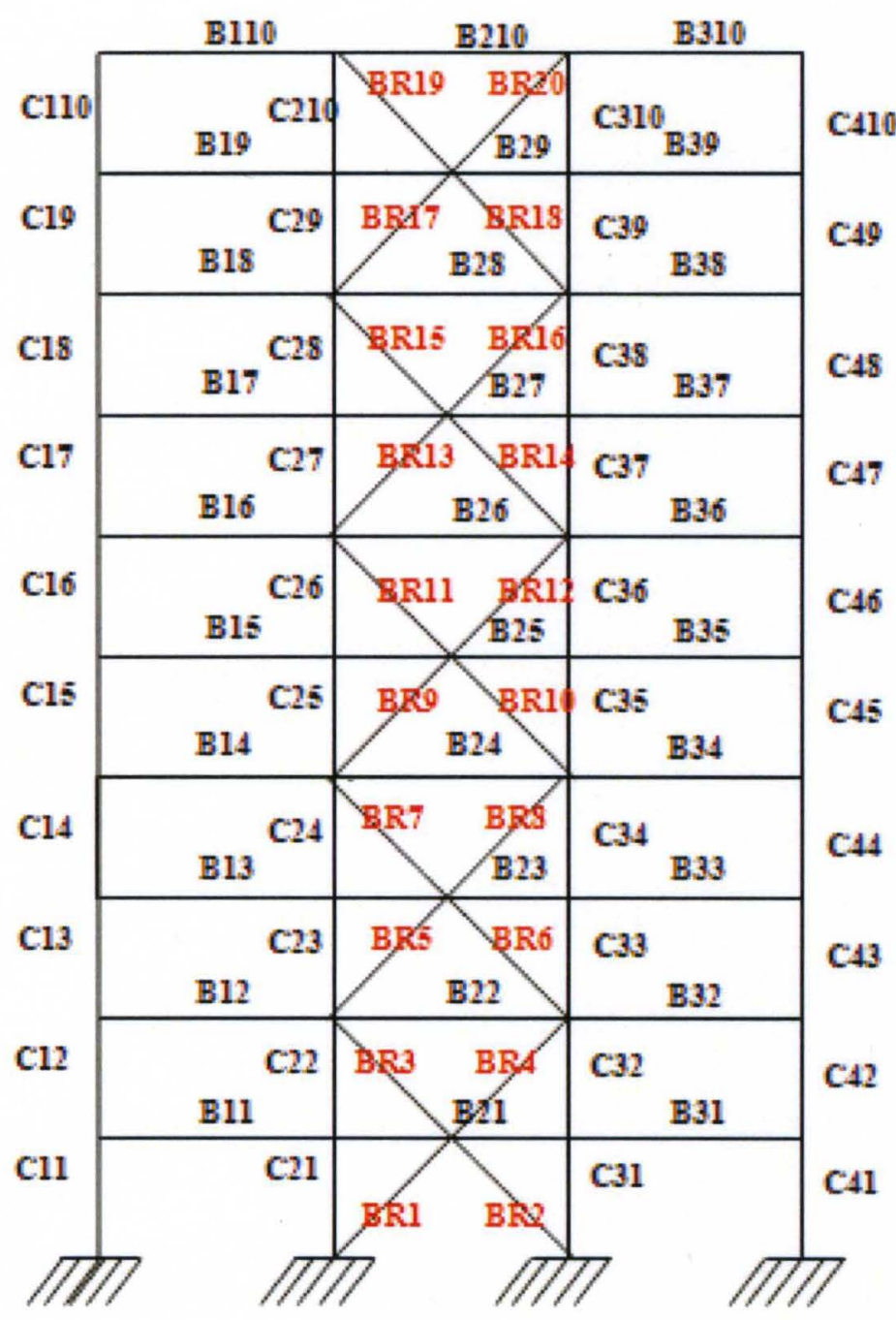

Figure 3.12: Member Labels for a Typical Peripheral Steel Braced Frame, Designed Using STAAD.Pro 
Table 3.9: STAAD.Pro Peripheral Steel Braced Frame Section Sizes (Refer to Figure 3.12 for Explanation of Symbols)

\begin{tabular}{|c|c|}
\hline Member Label & Section \\
\hline $\mathrm{C} 11, \mathrm{C} 12, \mathrm{C} 41, \mathrm{C} 42$ & $\mathrm{~W} 12 \times 58$ \\
\hline $\mathrm{C} 21, \mathrm{C} 22, \mathrm{C} 31, \mathrm{C} 32$ & W24×207 \\
\hline $\mathrm{C} 13, \mathrm{C} 14, \mathrm{C} 43, \mathrm{C} 44$ & W $10 \times 49$ \\
\hline $\mathrm{C} 23, \mathrm{C} 24, \mathrm{C} 33, \mathrm{C} 34$ & $\mathrm{~W} 18 \times 175$ \\
\hline $\mathrm{C} 15, \mathrm{C} 16, \mathrm{C} 17, \mathrm{C} 45, \mathrm{C} 46, \mathrm{C} 47$ & $\mathrm{~W} 12 \times 45$ \\
\hline $\mathrm{C} 25, \mathrm{C} 26, \mathrm{C} 27, \mathrm{C} 35, \mathrm{C} 36, \mathrm{C} 37$ & W14×99 \\
\hline $\mathrm{C} 18, \mathrm{C} 19, \mathrm{C} 48, \mathrm{C} 49$ & $W 8 \times 24$ \\
\hline $\mathrm{C} 28, \mathrm{C} 29, \mathrm{C} 38, \mathrm{C} 39$ & W10 1049 \\
\hline C110, C410 & W6×12 \\
\hline $\mathrm{C} 210, \mathrm{C} 310$ & W6×20 \\
\hline $\mathrm{B} 11, \mathrm{~B} 12, \mathrm{~B} 31, \mathrm{~B} 32$ & W $16 \times 45$ \\
\hline $\mathrm{B} 21, \mathrm{~B} 22$ & $\mathrm{~W} 16 \times 45$ \\
\hline $\mathrm{B} 13, \mathrm{~B} 14, \mathrm{~B} 33, \mathrm{~B} 34$ & $\mathrm{~W} 16 \times 45$ \\
\hline B23, B24 & W $16 \times 45$ \\
\hline B $15, \mathrm{~B} 16, \mathrm{~B} 17, \mathrm{~B} 35, \mathrm{~B} 36, \mathrm{~B} 37$ & W16 1645 \\
\hline $\mathrm{B} 25, \mathrm{~B} 26, \mathrm{~B} 27$ & W $16 \times 45$ \\
\hline $\mathrm{B} 18, \mathrm{~B} 19, \mathrm{~B} 38, \mathrm{~B} 39$ & $\mathrm{~W} 16 \times 45$ \\
\hline $\mathrm{B} 28, \mathrm{~B} 29$ & $\mathrm{~W} 16 \times 45$ \\
\hline $\mathrm{B} 110, \mathrm{~B} 310$ & $\mathrm{~W} 12 \times 14$ \\
\hline B210 & $\mathrm{W} 12 \times 14$ \\
\hline $\mathrm{BR} 1, \mathrm{BR} 2$ & $\mathrm{~W} 14 \times 43$ \\
\hline $\mathrm{BR} 3, \mathrm{BR} 4$ & $\mathrm{~W} 21 \times 44$ \\
\hline BR5, BR6 & $\mathrm{W} 21 \times 44$ \\
\hline $\mathrm{BR} 7, \mathrm{BR} 8$ & $W 8 \times 48$ \\
\hline BR9, BR10 & W14 1438 \\
\hline BR 11, BR 12 & W $10 \times 39$ \\
\hline BR13, BR14 & W8×21 \\
\hline $\mathrm{BR} 15, \mathrm{BR} 16$ & $W 8 \times 24$ \\
\hline BR17, BR 18 & W6×9 \\
\hline $\mathrm{BR} 19, \mathrm{BR} 20$ & W6x9 \\
\hline
\end{tabular}


Table 3.10: STAAD.Pro Peripheral Reinforced Concrete Braced Frame Column Section Sizes (Refer to Figure 3.9 for Explanation of Symbols)

\begin{tabular}{cllll}
\hline Member & b (ft.) & h (ft.) & Bar Size & No. of Bars \\
\hline C11, C12, C41, C42 & 1.33 & 1.33 & $\# 5$ & 20 \\
C21, C22, C31, C32 & 1.5 & 1.5 & $\# 8$ & 16 \\
C13, C14, C43, C44 & 1.0 & 1.0 & $\# 9$ & 8 \\
C23, C24, C33, C34 & 1.16 & 1.16 & $\# 10$ & 12 \\
C15, C16, C17, C45, C46, C47 & 0.83 & 0.83 & $\# 8$ & 8 \\
C25, C26, C27, C35, C36, C37 & 1.0 & 1.0 & $\# 8$ & 12 \\
C18, C19, C48, C49 & 0.67 & 0.67 & $\# 5$ & 4 \\
C28, C29, C38, C39 & 0.67 & 0.67 & $\# 9$ & 4 \\
C110, C410 & 0.67 & 0.67 & $\# 4$ & 4 \\
C210, C310 & 0.67 & 0.67 & $\# 4$ & 4 \\
\hline
\end{tabular}

Table 3.11: STAAD.Pro Peripheral Reinforced Concrete Braced Frame Beam Section Sizes (Refer to Figure 3.9)

\begin{tabular}{ccccccc}
\hline Member & b (ft.) & h (ft.) & $\begin{array}{c}\text { Bar Size } \\
\text { (Top) }\end{array}$ & $\begin{array}{c}\text { No. of Bars } \\
\text { (Top) }\end{array}$ & $\begin{array}{c}\text { Bar Size } \\
\text { (Bottom) }\end{array}$ & $\begin{array}{c}\text { No. of } \\
\text { Bars } \\
\text { (Bottom) }\end{array}$ \\
\hline & & & & & & \\
End Bay Floor Girders & 1.0 & 2.0 & $\# 6$ & 2 & $\# 10$ & 3 \\
Interior Bay Floor Girders & 1.0 & 2.0 & NA & 0 & $\# 10$ & 3 \\
End Bay Roof Girders & 1.33 & 0.67 & $\# 4$ & 2 & $\# 8$ & 2 \\
Interior Bay Roof Girders & 1.33 & 0.67 & $\# 4$ & 2 & $\# 8$ & 2 \\
\hline
\end{tabular}

The shear wall was designed using \#6 bars at 48" on Center. This reinforcement configuration extended over the entire height of the building. 


\subsection{Nonlinear (OPENSEES) Modeling of the Main Frames}

This section describes the process that was followed in developing four, two dimensional nonlinear frame models. These models were designed to be incorporated into a nonlinear finite element modeling program, OpenSees. The OpenSees platform was developed by the Pacific Earthquake Engineering Research (PEER) Center at the University of California at Berkeley (http://opensees.berkeley.edu/). The OpenSees analyses were performed on 2-D frames that had an equivalent strength and stiffness as the elastic (STAAD.Pro) 3-D building frame in the weak direction of the building. The 3$\mathrm{D}$ building frame was comprised of three bays in one direction and five bays in the orthogonal direction. In the case of the moment resisting frames, all 6 frames participated in carrying the lateral seismic loads, and in the case of the braced frames, it was assumed that only the two peripheral braced frames resisted the lateral loads. The 3-D frames and equivalent 2-D frames both consisted of three bays in the short direction and ten storeys. This three to two dimensions simplification is commonly done and is permitted according to the provisions of Section 16.2.2 in ASCE - 07 - 05, for a structure that has a regular shape and independent orthogonal seismic force resisting systems. In a symmetrical building, little is to be gained from a 3-D analysis and large stability problems can occur with 3-D systems. A visual representation of the transformation of the steel and reinforced concrete moment resisting frames from three to two dimensions is shown in Figure 3.13. In the case of the steel braced frame and reinforced concrete shear wall systems, one peripheral frame was directly used in the two - dimensional analysis, with appropriate apportioning of loads. 
The following sections describe the procedures used to obtain the 2 dimensional systems from the 3 dimensional systems. All of these key modeling aspects are described for the four frames separately.

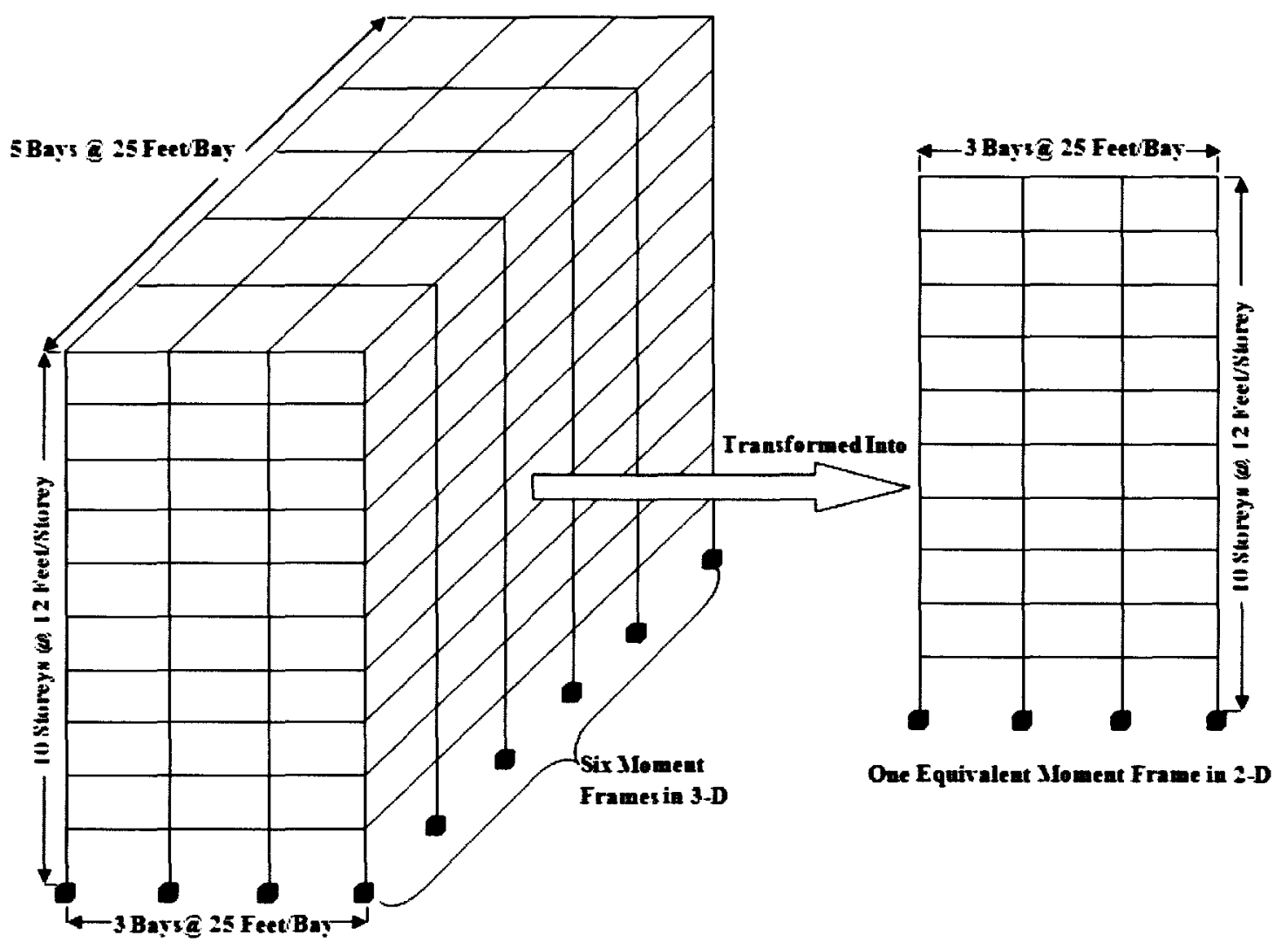

Figure 3.13: Frame Transformation From 3-D to 2-D

\subsubsection{Development of the Equivalent Sections}

As described earlier, the moment resisting framed buildings involved in this investigation had six frames in the weak direction of the building, all of which participate in supporting the lateral seismic loads. The braced frames had only two peripheral frames in either orthogonal direction that carried lateral loads. These peripheral frames contained either the cross braced systems, or shear walls. Thus, for the moment frames, the 
properties of the six frames were combined to obtain a single equivalent 2-D frame. This equivalent frame carried the full seismic mass of the original 3-D building frame. Using symmetry in the case of the braced frames, one of the two peripheral frames was used, with half of the building's seismic mass attached to it.

To ensure the 2-D and 3-D models produced the same performance, plastic section modulii, moments of inertia about the major axis, and cross - sectional areas of the members in the 3-D structure were added. Dimensions for the equivalent members of the 2-D frame were selected so that the section properties would be the same as the total for the 3D systems. The equations showing the relationship between the section properties of the six frames, and the conglomerate section properties of the equivalent 2-D frame, are presented on the next page. Figure 3.14 shows the relevant section properties of a typical steel wide flange section that were used in this transformation. 


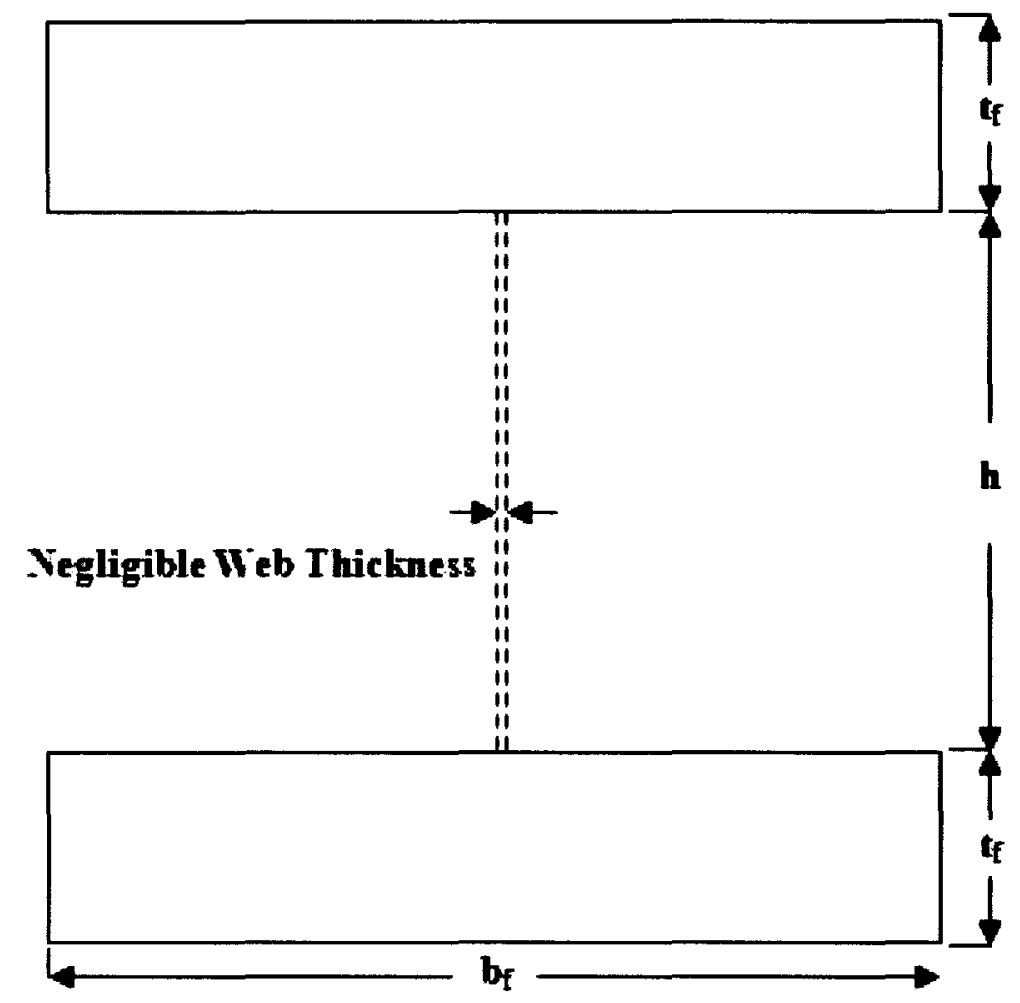

Figure 3.14: Equivalent Section of the Steel Moment Resisting Frame BeamColumns

$$
A_{\text {sum }}=2 b_{f} t_{f}, Z_{\text {sum }}=b_{f} t_{f}\left(h+t_{f}\right), \text { and } I_{\text {sum }}=\frac{b_{f}}{12}\left[\left(h+2 t_{f}\right)^{3}-h^{3}\right]
$$

where,

$A_{\text {sum }}=$ Sum of the cross - sectional areas of the members of the six frames (3D),

$Z_{\text {sum }}=$ Sum of the plastic section modulii of the members of the six frames (3D),

$I_{\text {sum }}=$ Sum of the moments of inertia about the strong axis of the members of the six frames (3D),

$b_{f}=$ Width of the flange of a section of a member of the equivalent frame,

$t_{f}=$ Thickness of the flange of a section of a member of the equivalent frame, and 
$h=$ Depth of a section of a member of the equivalent frame, excluding the flange thicknesses.

The solution of the above system of equations completely defined the sections for the equivalent 2-D steel moment frame. The parameters $b_{f}, t_{f}, t_{w}$ (web thickness), and $h$ were used to define the cross - section of each member of the equivalent frame. In the process of developing the above equations, the thickness of the web of the equivalent section in the 2-D frame was ignored since it would have significantly less effect on the section properties. This assumption made it possible to solve the system of equations for the composite sections in the equivalent frame since the reduction of one unknown (the thickness of the web of the equivalent section) converted it from a system of three equations (shown above) and four unknowns $\left(b_{f}, t_{f}, t_{w}\right.$, and $\left.h\right)$ to a system of three equations and three unknowns $\left(b_{f}, t_{f}\right.$, and $\left.h\right)$. To simply the analysis, $t_{w}$, was assumed to be zero and hence does not appear in the equations. However, during the dynamic analyses, to ensure numerical stability, a small value (of the order $10^{-8}$ inches) was assigned to the web thickness. This very small web thickness did not significantly affect the calculated section properties.

For the equivalent 2-D concrete moment frames, widths of the sections were taken as six times the individual elements, keeping the depth constant. The total number and area of longitudinal steel reinforcement bars was also simply added up. The same number of 
reinforcement bars were used in tension and compression, in order to account for the loading reversals that occur in a typical earthquake.

The following sections describe additional features of the modeling of the four 2-D frames.

\subsubsection{Steel Moment Resisting Frame}

Nonlinear beam - column elements were used to model the beams and columns of the frame. The beams and columns were represented by a fiber section identified by a section tag at each integration point. Each fiber section consisted of a grouping of separate uniaxial fibers that were distributed in two dimensional space in such a way that they take the desired shape of the section being modeled. In this case, each beam and column was an I - shaped section that represented the combined properties of the wide flange sections from the six different frames. A material model was associated with each fiber of the section. Five Gauss integration points (Figure 3.15) were used for the nonlinear curvature distribution.

For the steel moment frame, an elastoplastic material model (Figure 3.16) was used to simulate the behavior of steel in tension and compression. The values of the yield stress and elastic modulus were the same as those selected in the elastic design, $29000 \mathrm{ksi}$ and 
$50 \mathrm{ksi}$, respectively. Since a collapse analysis of the models is one of the objectives of this investigation, and a condition of zero lateral stiffness at a storey of the structure is required in order to form a collapse mechanism, an elastoplastic model was used to simulate the behavior of steel. In the elastoplastic representation, after an initial zone of elastic behavior, the plastic behavior is comprised of a region of zero stiffness. If a hardening material model that had some plastic stiffness was used, it would never satisfy the condition of zero stiffness needed for collapse, even at very high values of load, in the subsequent incremental dynamic analysis performed on the models. Hence an elastoplastic approximation was used to simulate the behavior of steel. An elastoplastic model was used to describe the behavior of steel by Lourdes Amelia Mieses Hernández (Hernandez, 2007).

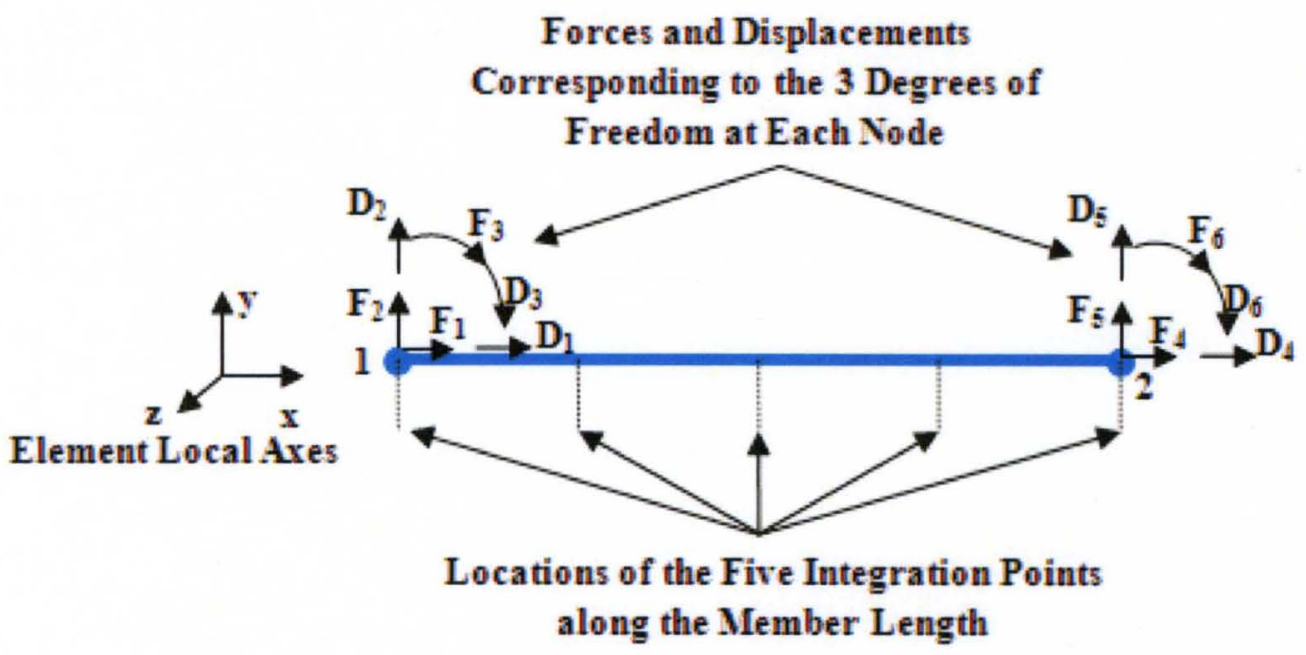

Figure 3.15: Typical Beam - Column Element 


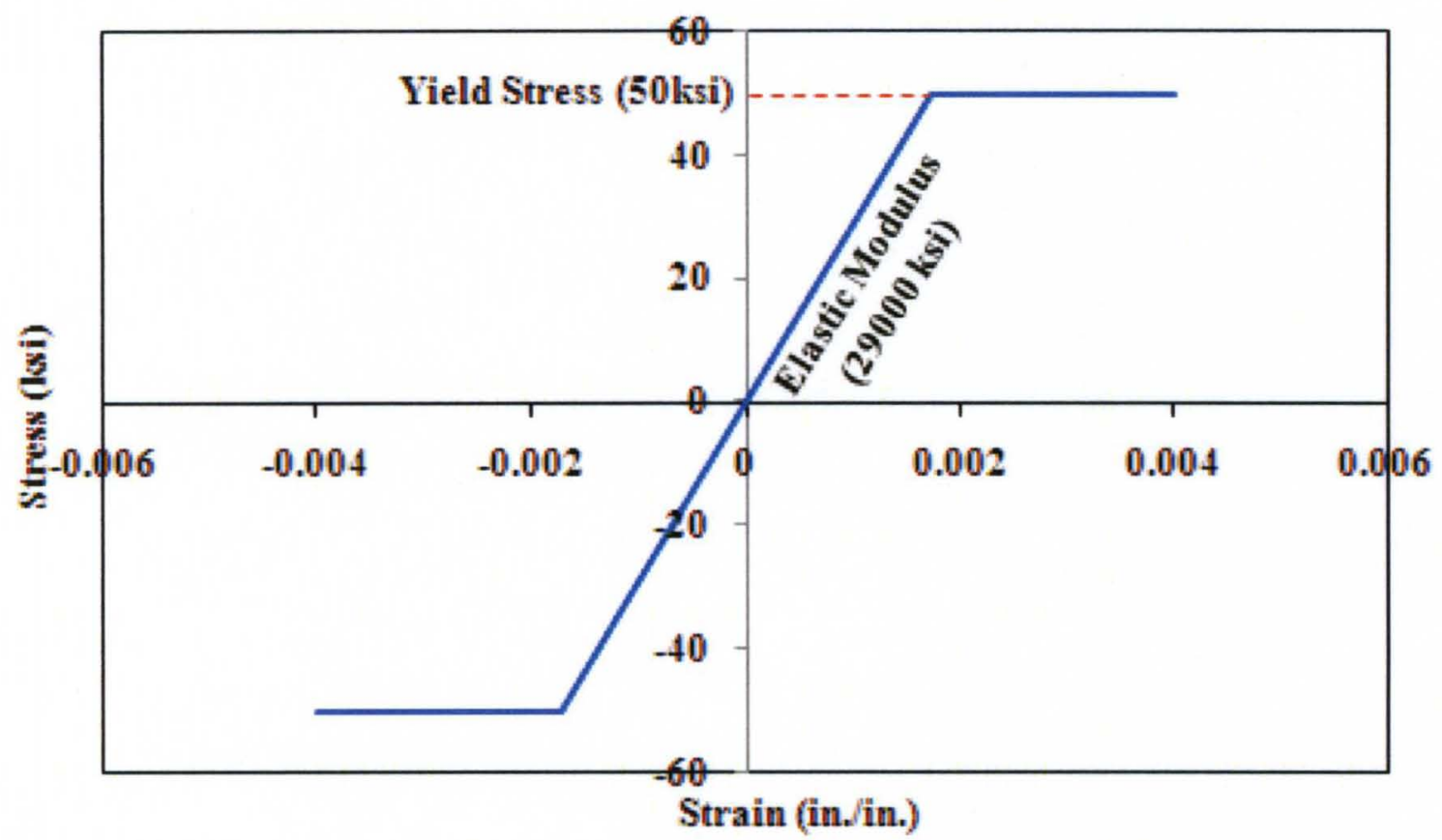

Figure 3.16: Elastoplastic Model Steel Model Used in the Steel Moment Resisting Frame

Based upon work by others[add references] summarized in the OPENSEES manual, the following fiber layout was used for all wide flange beam - columns: sixteen fibers were used along the depth and width of the beam and column sections, 46 fibers were used along the thickness of the flange, and two fibers were used along the thickness of the web. As discussed earlier, the web of the equivalent section was assigned a negligible thickness to simplify calculations, and the use of two fibers was sufficient to approximate its relatively insignificant contribution to the overall section behavior. These beam column element configurations were selected based upon those used in the models developed on the OpenSees software homepage (Mazzoni and McKenna, 2006), which were found to give an accurate prediction of the nonlinear behavior of steel frame 
systems. They were scaled according to the relative dimensions of the hypothetical sections versus those of the actual sections modeled on the OpenSees homepage.

The vertical loads acting on the 2-D frame were derived from the unfactored loads acting on the 3-D frame, and converted to equivalent point loads on the 2-D frame using tributary areas. The dead load, live load, and the out of plane wall loads were converted into point loads acting on the 2-D frame nodes. The combined weight of the two in plane veneer walls were uniformly distributed to the beams at each storey level of the 2D frame. The dead and live vertical loads were combined according to Equation 3-2 in Section 3.2.8 of the Federal Emergency Management Agency (FEMA) document titled FEMA 273: NEHRP Guidelines for the Seismic Rehabilitation of Buildings (FEMA, 1997). This equation defines the loads that should be applied to the building system during a seismic analysis. The total gravity load combination is given by:

$$
Q_{G}=1.1\left(Q_{D}+Q_{L}\right)
$$

where,

$Q_{D}=$ Dead load effect ( action), and

$Q_{L}=$ Effective live load effect (action), equal to $25 \%$ of the unreduced design live load, but not less than the measured live load.

The self weights of the frame members were applied in the form of a load. The weights of the beams and columns were assumed to be uniformly distributed across their lengths, and were computed using a density of 490 pounds/cubic foot for steel.

The base supports of the columns in the 2-D frame were modeled as fixed. 
Seismic masses were attached to the beam and column junctions at every storey level. These seismic masses were computed by considering the contributions from the factored dead and live loads, in and out of plane veneer walls, and the member self weights. Each nodal seismic mass was determined using the tributary lengths, widths or areas from the 3-D system. The mainframe with attached seismic masses is shown in Figure 3.17. 


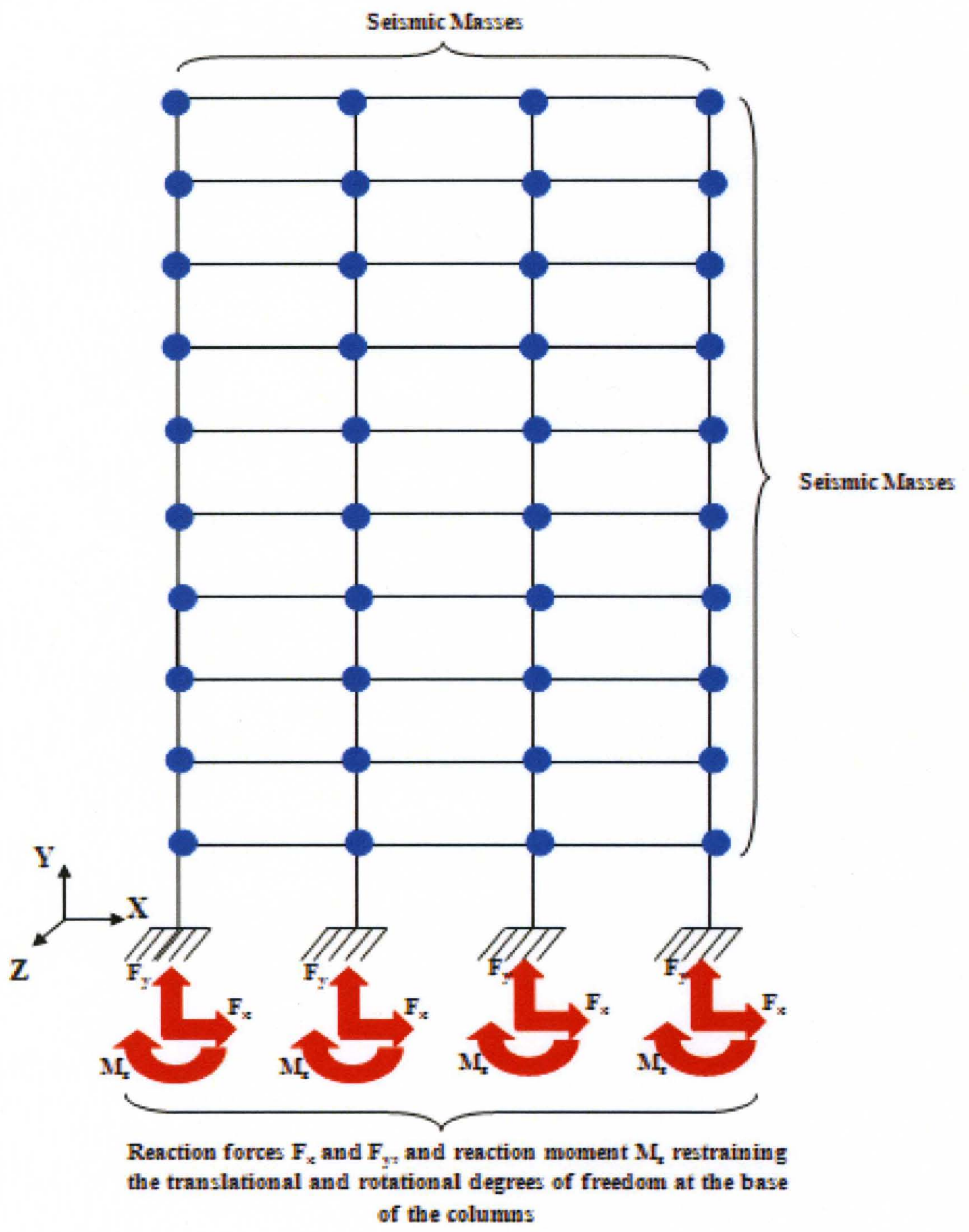

Figure 3.17: Boundary Conditions and Locations of Seismic Masses for the 2-D Frames 


\subsubsection{Steel Braced Frame}

The 2-D steel braced frame model was identical to the steel moment frame model, except for the following:

1) The beam column element models for the steel braced frame were identical to those used in the steel moment frame, except for the number of fibers used in each cross section. In this case, there were 16 fibers used across the depth of the section, 2 across the thickness of the web, 16 across the width of the flange, and 4 across the thickness of the flange. The section sizes used in the steel moment resisting and braced frames were different, and hence, the number of fibers used in the two were also different.

2) The joint between the orthogonally intersecting beams and columns was changed to a pinned connection. This was accomplished by incorporating a zero length element between the column and the beam in such a way that the end of the column was attached to the zero length element and the end of the beam was also attached to the zero length element. Thus, the ends of the column and beam were not directly connected to each other. The modeling of this connection is shown in Figure 3.18.

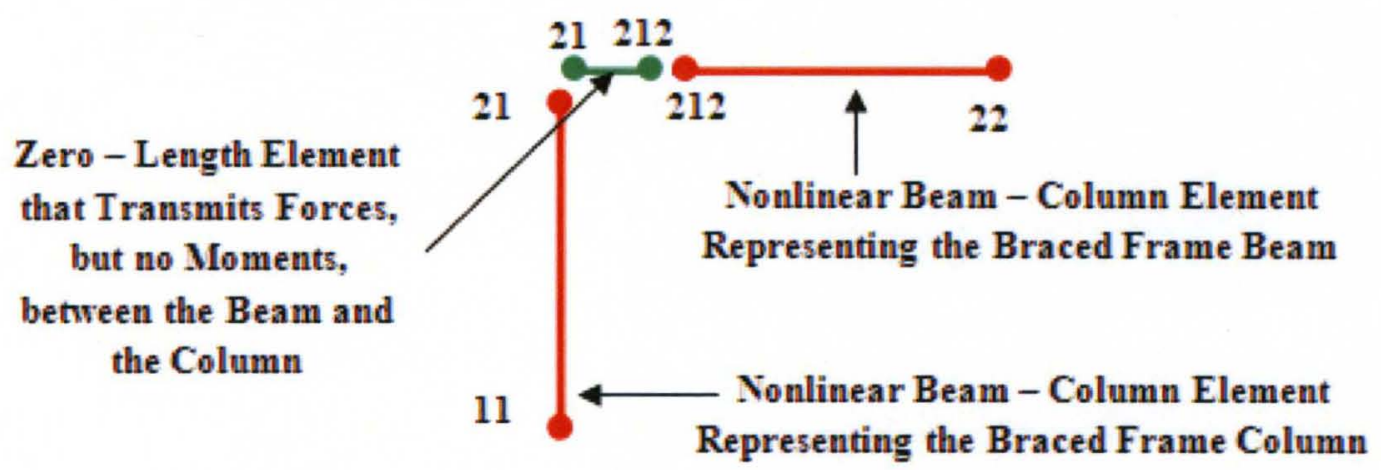

Figure 3.18: Typical Braced Frame Connection Model Between the Beam and Column 
A zero length element within the OpenSees software is an element that is defined by two nodes at the same location. The two nodes are connected by uniaxial material models corresponding to the different degrees of freedom at the nodes. Linear elastic material models were associated with the zero length element corresponding to the three degrees of freedom at the joint, including the rotation about an axis perpendicular to the two dimensional plane. The models corresponding to the translational degrees of freedom were assigned a very high stiffness and the model corresponding to the rotational degree of freedom at the joint was assigned a negligible stiffness, thereby ensuring a transfer of vertical and horizontal forces from the beam to the column and negating a similar transfer of moments.

The lateral braces were modeled using axial truss elements. A fiber section model was associated with the brace elements. Since the braces were designed as tension only members in the 3-D frame, the material model associated with the fibers was assigned an extremely low stiffness in compression. This was accomplished by using an uniaxial bilinear hysteretic model. In tension, an elastoplastic material model was used to approximate the behavior of a steel fiber, with a yield stress and Young's modulus identical to that used in the 3-D system.

Only half the width of a single bay in a direction perpendicular to the two dimensional plane under consideration was used to determine the loads on the braced frame. Furthermore, the weight of only one in - plane wall was applied to the floor beams 
of the 2-D frame, due to symmetry and the fact that there are only two lateral resisting frames.

3) The seismic masses were computed by considering the tributary area of the dead, live, in and out of plane wall loads in the 3-D configuration. A tributary width of half the length of the 3-D building in a direction perpendicular to the 2-D frame was used for each 2-D frame being considered.

\subsubsection{Reinforced Concrete Moment Resisting Frame}

The approach employed to model the reinforced concrete moment frame shared several similarities with the approach used to model the behavior of the steel moment frame. The differences are listed below:

1) The fibers comprising the element section were arranged so as to create a rectangular shape. The dimensions of this shape were obtained from the equivalent sections for the reinforced concrete moment frame. Five groups of concrete fibers (patches) were defined, namely, four cover patches and one core patch. The cover patches had a thickness equal to the reinforcement cover distance ( 1.5 inches), and were arranged in the form of a rectangle, enclosing the core. The core patch included the remainder of the section, enclosed within these four peripheral cover patches. The steel reinforcement bars were represented by fibers arranged in layers at the top, bottom, and vertical edges of the section, along the inside edge of the cover patches. A typical reinforced concrete section is shown in Figure 3.19. Material models were assigned to the fibers used to model the 
concrete and material models were assigned to the fibers used to model the steel reinforcement. Modeling of the reinforced concrete sections in this manner was recommended on the OpenSees homepage and it was found that when they were modeled in this manner, they give an accurate representation of the frame behavior.

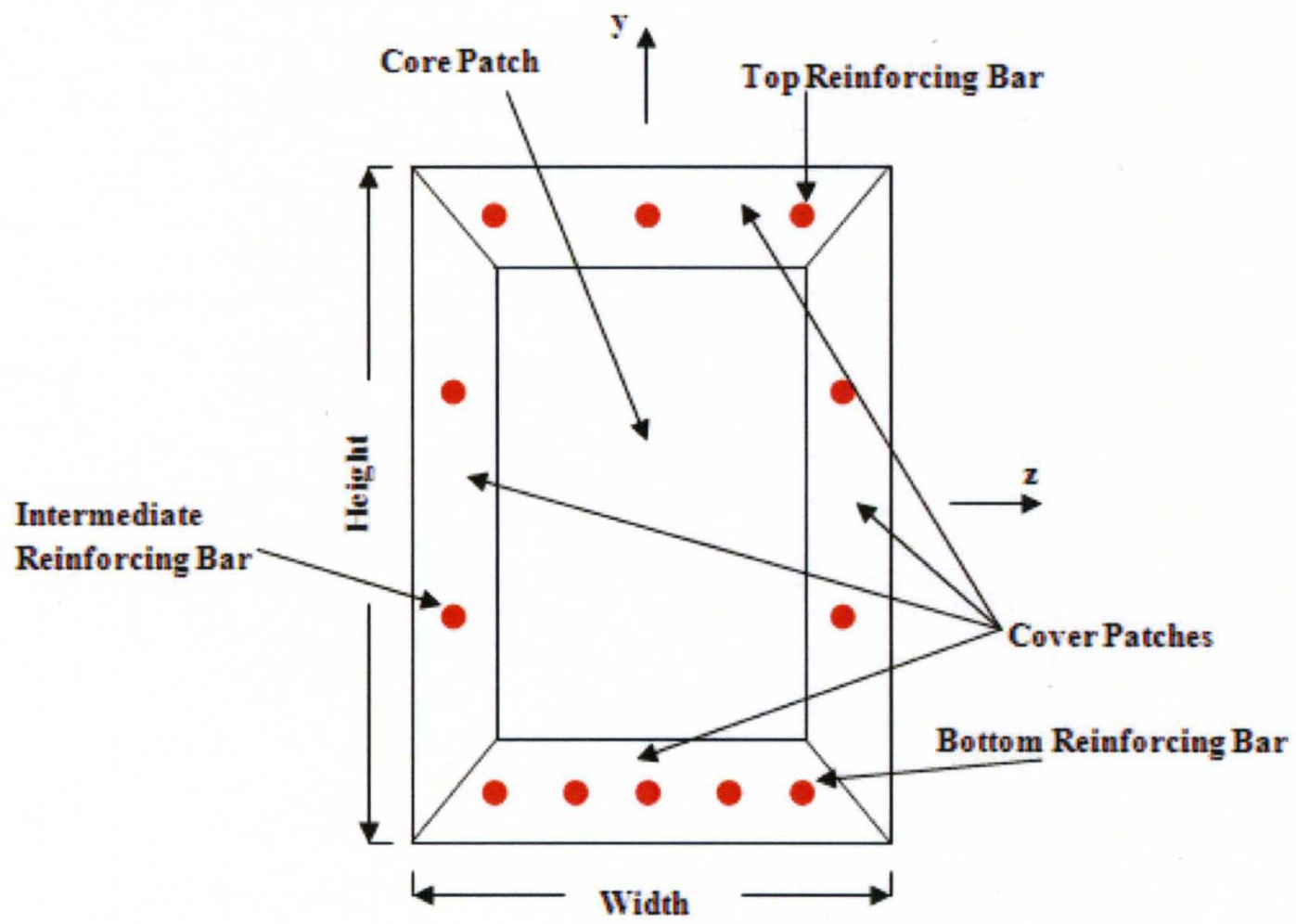

Figure 3.19: Typical Reinforced Concrete Section

2) The uniaxial material model that governed the behavior of each concrete fiber was selected from the models in the OpenSees library of material models. A "Concrete02 Linear Tension Softening" model was used. The input parameters that defined the material model were partly obtained from research work performed by Anthony Wolanski (Wolanski, 2004), and partly from values recommended in the developed 
models on the OPENSEES homepage. This model requires the following parameters to be input:

a) The concrete compressive strength at 28 days, $f_{c}$.

b) The compressive strain at the compressive strength defined above, $e_{c}$.

c) The concrete crushing strength, $f_{c r}$.

d) The concrete strain at the crushing strength, $e_{c r}$.

e) The ratio of the unloading slope at the crushing strain and the initial slope, $\lambda$.

f) The tensile strength, $f_{t}$.

g) The slope of linear tension softening branch, $E_{t s}$.

Concrete was assumed to have a compressive strength of 4000 psi. The elastic modulus, $E_{c}$, was related to the compressive strength by (ACI, 2008):

$$
E_{c}=57000 \sqrt{f_{c}}
$$

The initial elastic modulus was thus taken as $3605000 \mathrm{psi}$ (see Figure 3.16).

The elastic modulus was related to the strain at peak compressive stress by (ACI, 2008):

$$
E_{c}=\frac{2 f_{c}}{e_{c}}
$$

Based upon this, the strain at the compressive strength was computed to be 0.002219 in/in.

The concrete compressive stress at peak compressive strain $\left(f_{c r}\right)$ was taken as $0.2 f_{c}$, as recommended by the researchers who developed the model on the OpenSees 
homepage. The value for the crushing strain used was $0.003 \mathrm{in} / \mathrm{in}$, as recommended by Wolanski (Wolanski, 2004).

A value of 0.1 was used for $\lambda$, was found to give good predictions of behavior by the developers of OpenSees. The tensile strength was obtained using (ACI, 2008):

$$
f_{t}=7.5 \sqrt{f_{c}}
$$

and resulted in a value of 475 psi. Cracks were assumed to develop in the concrete if the tensile stress in the material crossed this value.

The slope of the unloading portion of the tension model was related to the tensile strength as:

$$
E_{t s}=\frac{f_{t}}{a}
$$

This relationship was recommended for use with the concrete model. The value of the parameter "a" was selected as 0.017 . This value did not have a very large effect on the response, and was selected to ensure numerical stability of the model after cracking.

The material models used for concrete in compression and tension are shown in Figures 3.20 and 3.21 respectively. The numerical values of the parameters derived above are summarized in Table 3.12 . 
Table 3.12: Concrete Material Model Parameter Values

\begin{tabular}{cc}
\hline Concrete Model Parameter & Value \\
\hline$f_{c}$ & $4000 \mathrm{psi}$ \\
$e_{c}$ & 0.002219 \\
$f_{c r}$ & $800 \mathrm{psi}$ \\
$e_{c r}$ & 0.003 \\
$\Lambda$ & 0.1 \\
$f_{t}$ & $475 \mathrm{psi}$ \\
$E_{t s}$ & $27941 \mathrm{psi}$ \\
\hline
\end{tabular}

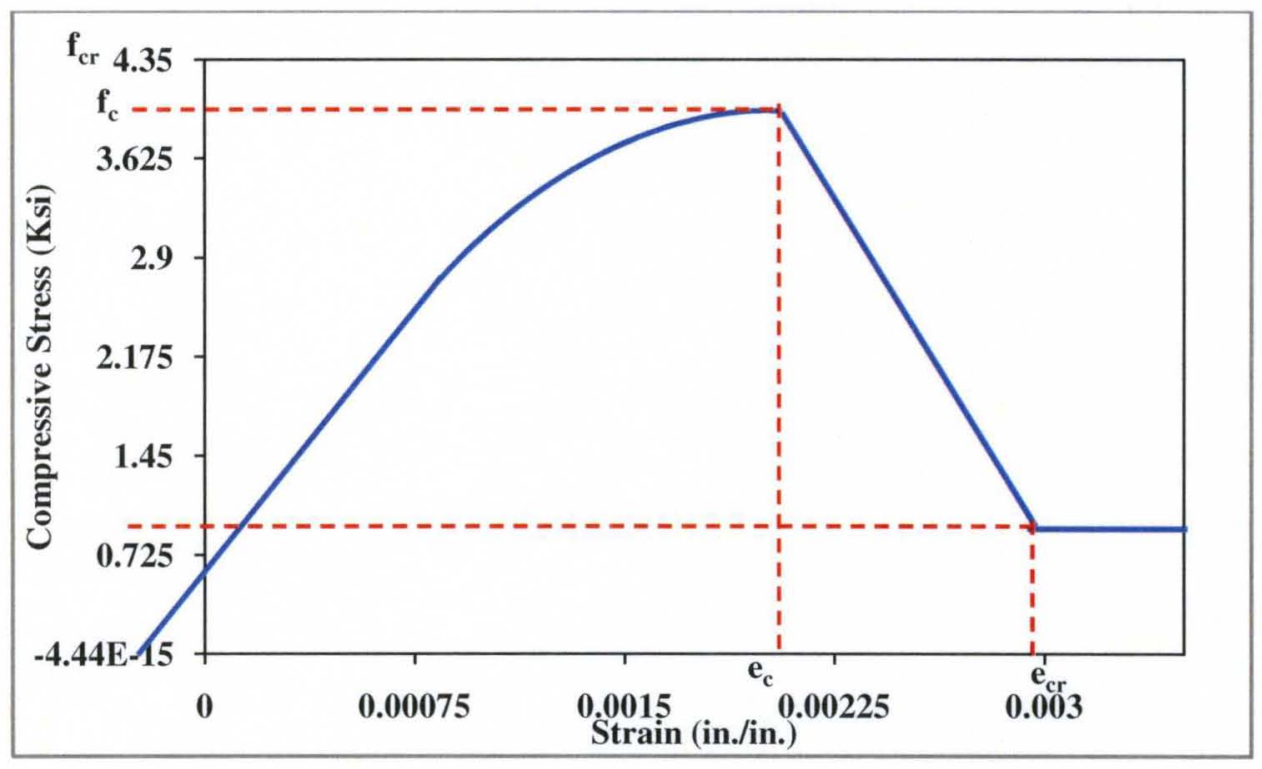

Figure 3.20: Concrete Model in Compression 


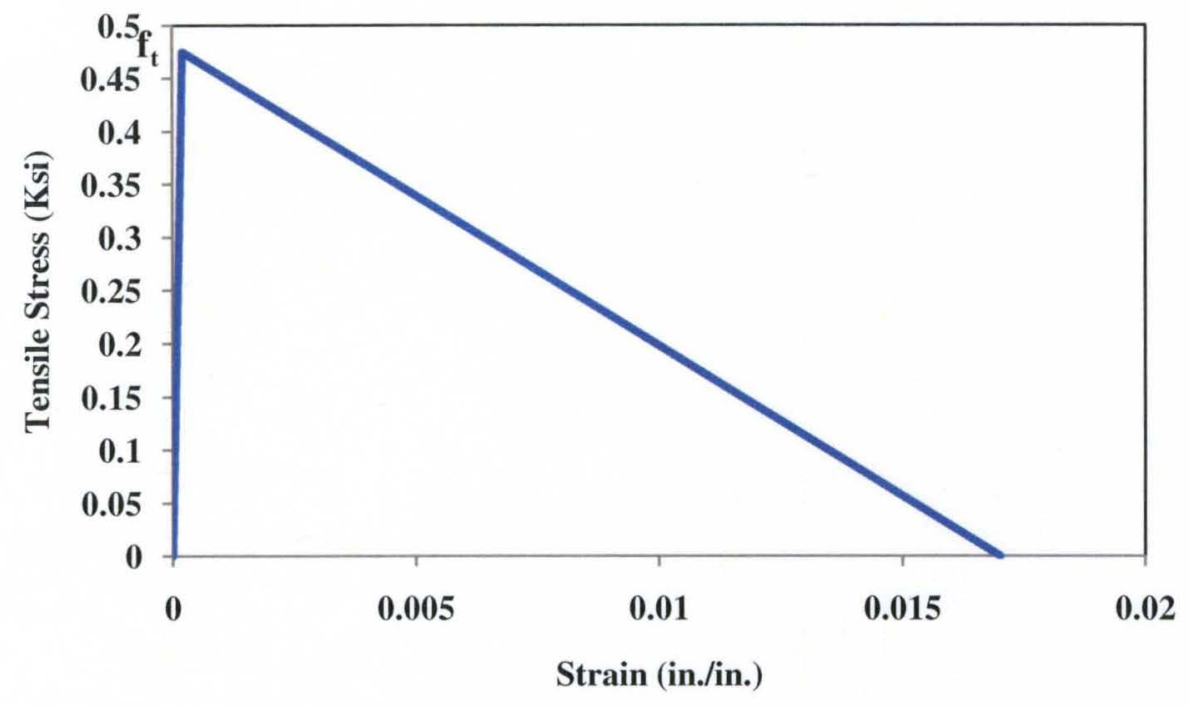

Figure 3.21: Concrete Model in Tension

3) Similarly, the material model of the steel reinforcement bars was also obtained from the OpenSees library, and an "Elastic Perfectly Plastic" material model was used, as recommended by Lourdes Amelia Mieses Hernández (Hernandez, 2007). The Young's modulus and yield stress of the steel (see Figure 3.22) was the same as that used for the designs of the reinforced concrete frames in STAAD.Pro. Twenty fibers were used for both the core and cover patches, along the vertical and horizontal orthogonal directions at each section. The number of fibers was obtained from that recommended to model reinforced concrete moment resisting frames on the OpenSees homepage, after adjusting for the section dimensions, as it was observed to provide an accurate representation of the frame behavior. 


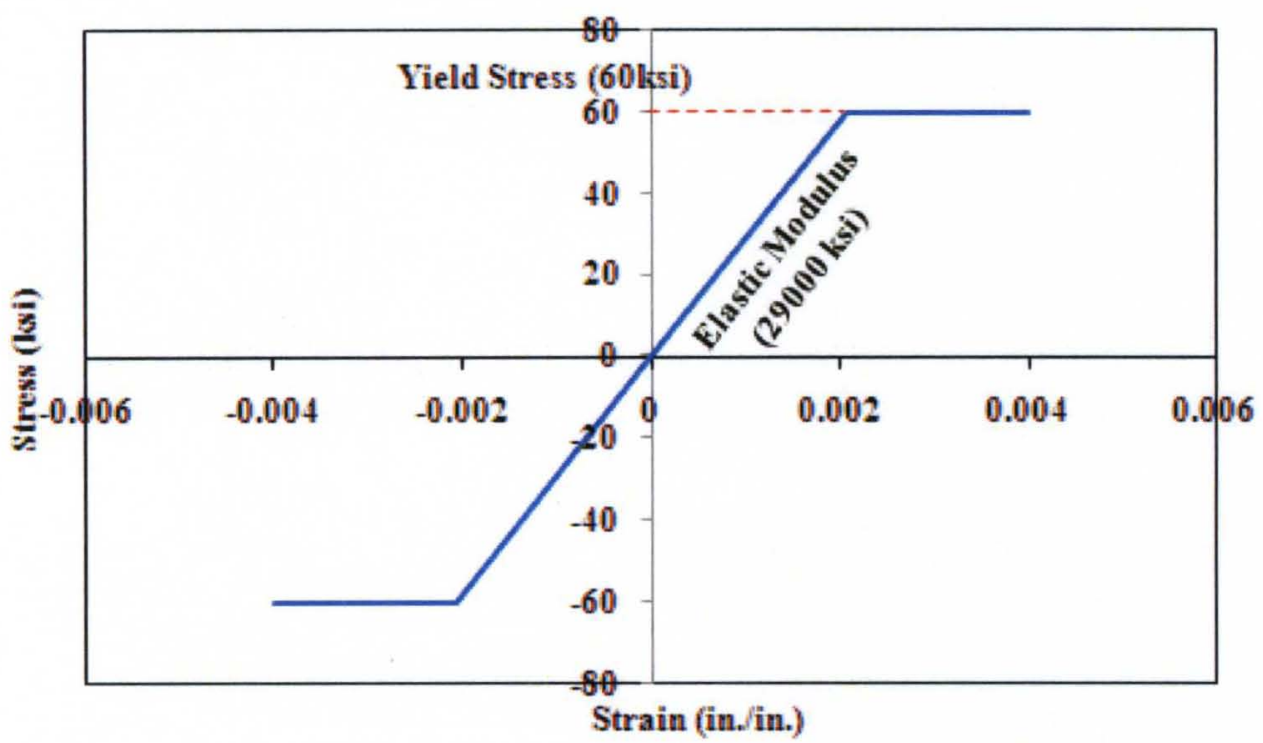

Figure 3.22: Steel Reinforcement Material Model

4) A value of 150 pound-force/cubic foot was used as the density of concrete, and 490 pound-force/cubic foot as the density of steel. These values were used to compute the seismic masses.

\subsubsection{Reinforced Concrete Shear Wall System}

The analytical model of this frame was developed from the models used to simulate the behavior of the steel braced frame. The differences between the two models are presented below:

1) The fiber model used for the beams and columns was developed in an identical manner to that described for the reinforced concrete moment frame. The material models used to describe the behavior of the concrete and reinforcing steel, the number of fibers, 
and the reinforcement cover distances, were also the same as those used in the reinforced concrete moment frame.

2) The shear wall was also represented by nonlinear beam column elements, with fiber sections. The shear wall elements were modeled in a manner similar to that used for the elastic analysis. The shear walls were represented by two separate beam - columns, that had $1 / 2$ the strength and stiffness of the shear walls, at each storey level. Furthermore, zero length elements were used to connect the shear wall elements to the main frame, in such a way as to prevent any vertical load transfer, but to ensure complete horizontal load transfer. This was accomplished by using an elastic joint material model with a very high stiffness in the horizontal direction, and a very low stiffness in the vertical direction. The shear wall and it attachment to the mainframe is shown in Figure 3.23.

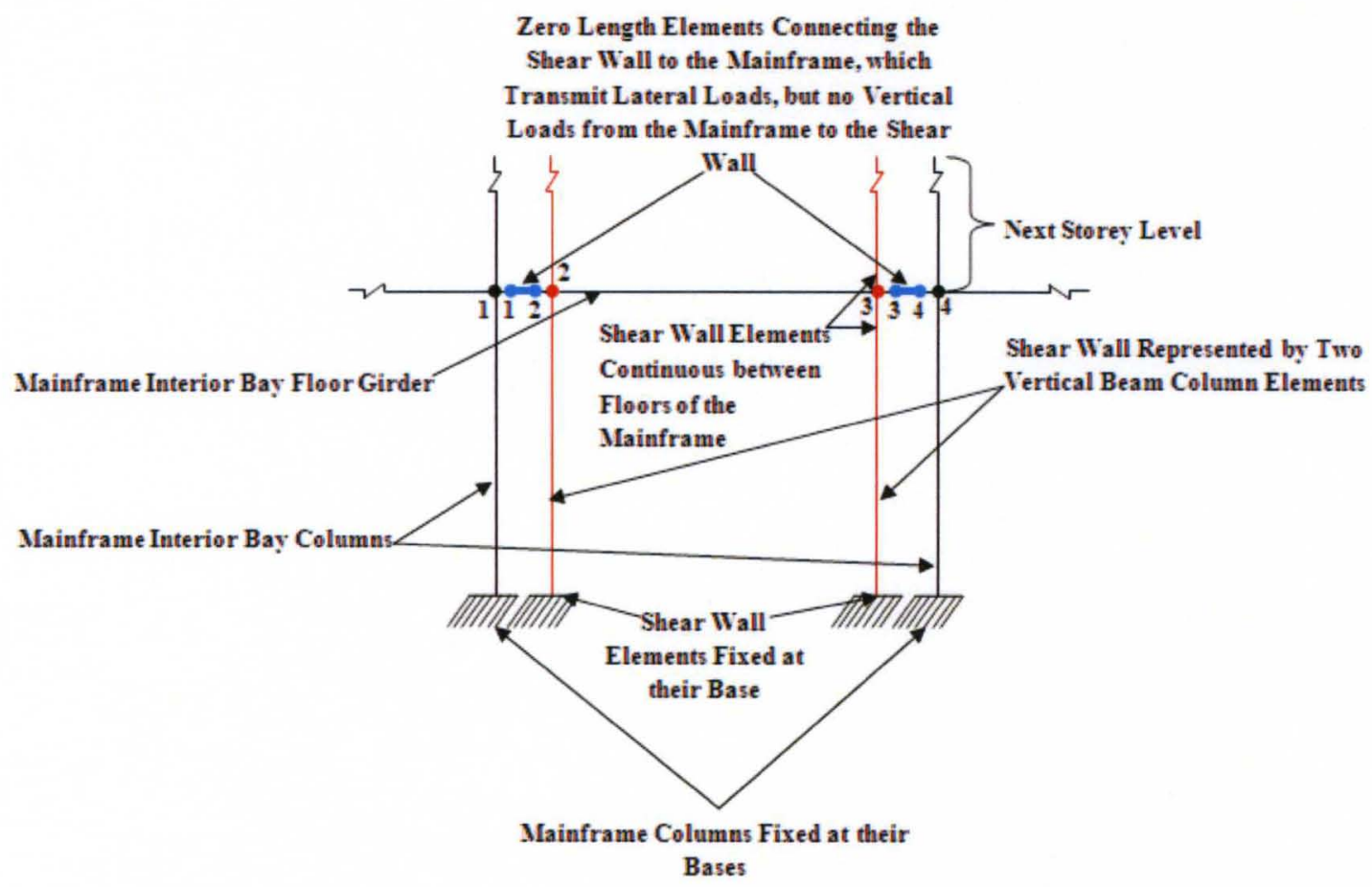

Figure 3.23: Attachment of the Shear Wall Elements to the Mainframe 
Tables 3.13 through 3.19 present the sizes of the equivalent sections for the steel and reinforced concrete moment resisting, the reinforcement details (bar sizes and the number of bars) for the reinforced concrete moment resisting frame, and the magnitudes of the seismic masses attached to the steel and reinforced concrete moment resisting and braced frames, used in the OpenSees analyses. The section sizes for the steel and reinforced concrete braced frames are identical to those presented earlier for the Staad.Pro sections, since these sections were a part of the peripheral lateral force resisting frames in the 3-D structures that were subsequently directly incorporated into OpenSees. Figures 3.14, 3.24, and 3.25 explain the labels and symbols appear in the tables. 


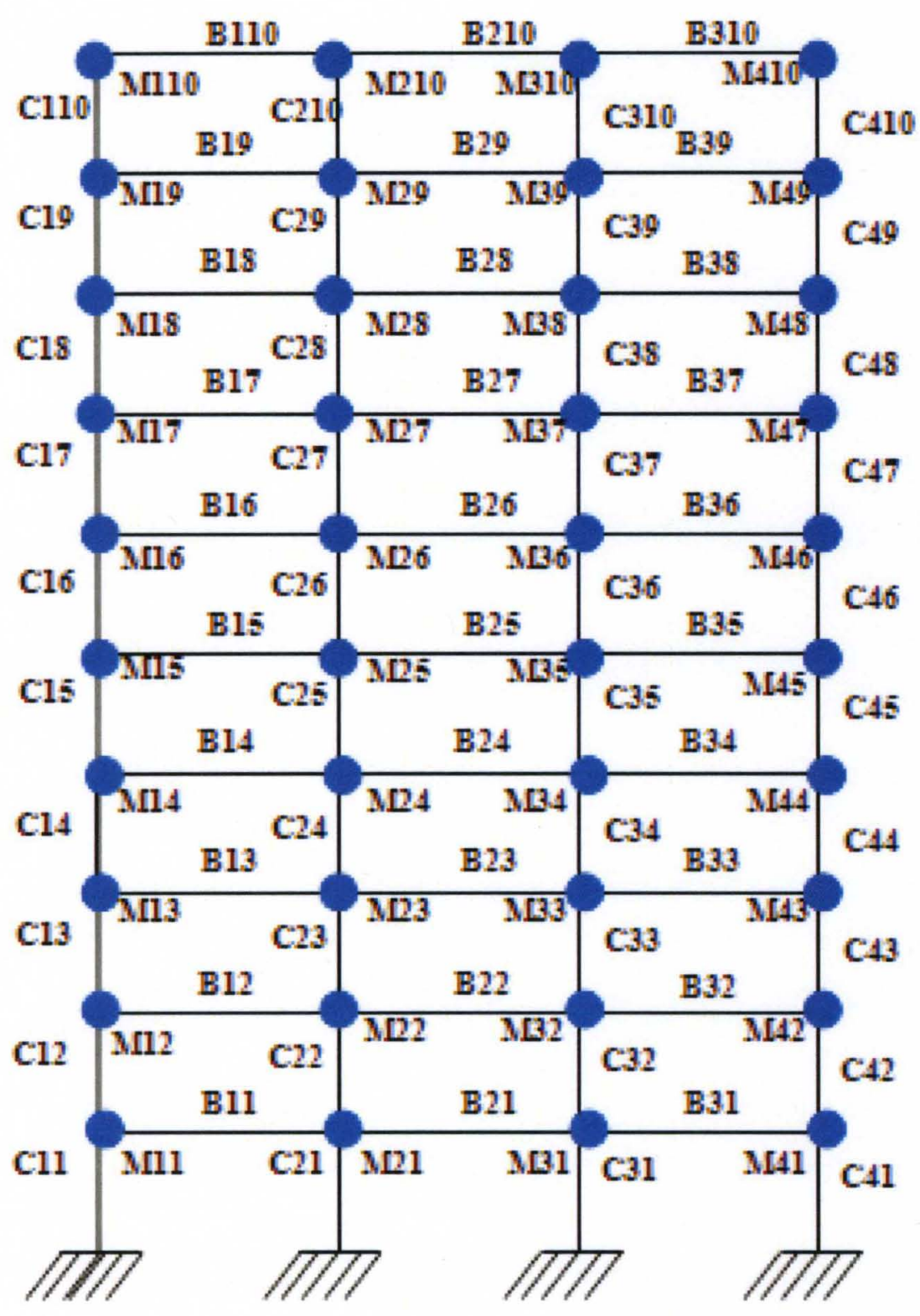

Figure 3.24: OpenSees Member and Mass Labels for Equivalent Steel and Reinforced Concrete Moment Resisting, Exterior and Interior Frames 
Table 3.13: Equivalent Steel Moment Resisting Frame Section Sizes (Refer to Figures 3.14 and 3.24 for Explanation of Symbols)

\begin{tabular}{cccc}
\hline Member Label & h (in.) & b $_{\mathbf{f}}$ (in.) & $\mathbf{t}_{\mathbf{f}}$ (in.) \\
\hline C11, C12, C41, C42 & 26.7 & & \\
C21, C22, C31, C32 & 30.2 & 9.75 & 10.3 \\
C13, C14, C43, C44 & 22.2 & 8.86 & 11.82 \\
C23, C24, C33, C34 & 23.5 & 8.64 & 8.47 \\
C15, C16, C17, C45, C46, C47 & 15.3 & 12.1 & 8.78 \\
C25, C26, C27, C35, C36, C37 & 21.7 & 7.78 & 5.06 \\
C18, C19, C48, C49 & 16.4 & 6.92 & 8.44 \\
C28, C29, C38, C39 & 21.41 & 4.8 & 6.16 \\
C110, C410 & 10.3 & 4.68 & 8.88 \\
C210, C310 & 7.62 & 4.85 & 3.75 \\
B11, B12, B31, B32 & 26.4 & 3.85 & 2.74 \\
B21, B22 & 26.4 & 3.85 & 11.5 \\
B13, B14, B33, B34 & 24.3 & 4.35 & 11.5 \\
B23, B24 & 26.4 & 3.85 & 10.1 \\
B15, B16, B17, B35, B36, B37 & 24.3 & 4.11 & 11.5 \\
B25, B26, B27 & 24.3 & 4.11 & 10.6 \\
B18, B19, B38, B39 & 20.7 & 4.27 & 10.6 \\
B28, B29 & 20.7 & 4.27 & 8.3 \\
B110, B310 & 7.62 & 4.85 & 8.3 \\
B210 & 7.62 & 4.85 & 2.74 \\
& & & \\
\hline
\end{tabular}


Table 3.14: Equivalent Steel Moment Resisting Frame Masses (Refer to Figure 3.24 For Explanation of Symbols)

\begin{tabular}{cc}
\hline Mass Label & Value (lbs) \\
\hline M21, M24 & 8861 \\
M31, M34 & 8952 \\
M41, M44 & 9064 \\
M51, M54 & 9192 \\
M61, M64 & 9333 \\
M71, M74 & 9486 \\
M81, M84 & 9650 \\
M91, M94 & 9823 \\
M101, M104 & 10005 \\
M11, M114 & 4636 \\
M22, M23 & 9774 \\
M32, M33 & 9866 \\
M42, M43 & 9978 \\
M52, M53 & 10106 \\
M62, M63 & 10247 \\
M72, M73 & 10400 \\
M82, M83 & 10563 \\
M92, M93 & 10736 \\
M102, M103 & 10918 \\
M112, M113 & 3556 \\
\hline
\end{tabular}




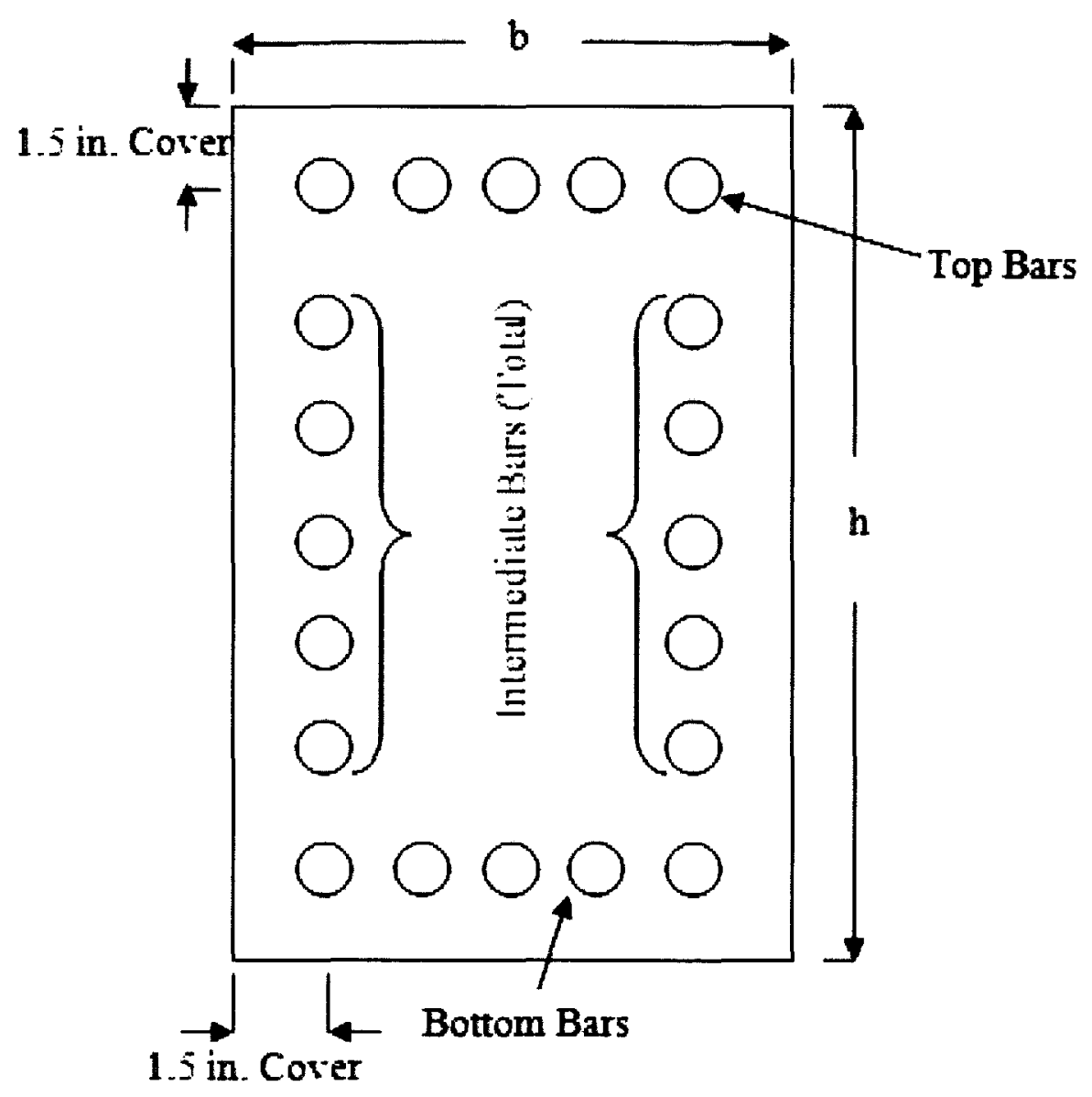

Figure 3.25: Typical OpenSees Reinforced Concrete Section 
Table 3.15: OpenSees Equivalent Reinforced Concrete Moment Resisting Frame Beam Sections (Refer to Figures 3.24 and 3.25 For Explanation of Symbols)

\begin{tabular}{|c|c|c|c|c|c|c|c|c|}
\hline Member & b (in.) & $h$ (in.) & $\begin{array}{l}\text { No. of } \\
\text { Bars } \\
\text { (Top) } \\
\end{array}$ & $\begin{array}{l}\text { Area I } \\
\text { Bar } \\
\text { (Top) } \\
\end{array}$ & $\begin{array}{l}\text { No. of Bars } \\
\text { (Intermediate) }\end{array}$ & $\begin{array}{l}\text { Area / Bar } \\
\text { (Intermediate) }\end{array}$ & $\begin{array}{l}\begin{array}{l}\text { No. of } \\
\text { Bars } \\
\text { (Bottom) }\end{array} \\
\end{array}$ & $\begin{array}{l}\text { Area } \\
\text { Bar } \\
\text { (Bottom) } \\
\end{array}$ \\
\hline $\begin{array}{l}\text { B11, B12, } \\
\text { B31, B32 }\end{array}$ & 83.52 & 27.96 & 26 & 1.056 & NONE & N/A & 18 & 1.02 \\
\hline $\mathrm{B} 21, \mathrm{~B} 22$ & 83.52 & 27.96 & 26 & 1.056 & NONE & N/A & 22 & 0.74 \\
\hline $\begin{array}{l}\text { B13, B14, } \\
\text { B33, B34 }\end{array}$ & 91.7 & 24.0 & 28 & 1.227 & NONE & N/A & 30 & 0.68 \\
\hline B23, B24 & 91.7 & 25.92 & 28 & 1.227 & NONE & N/A & 32 & 0.65 \\
\hline $\begin{array}{l}\text { B15, B16, } \\
\text { B17, B35, } \\
\text { B36, B37 }\end{array}$ & 83.52 & 24.0 & 24 & 1.227 & NONE & N/A & 18 & 1.07 \\
\hline $\begin{array}{l}\text { B25, B26, } \\
\text { B27 }\end{array}$ & 79.7 & 24.0 & 24 & 1.15 & NONE & N/A & 18 & 0.86 \\
\hline $\begin{array}{l}\text { В18, B19, } \\
\text { B38, B399 }\end{array}$ & 72.0 & 20.0 & 22 & 1.06 & NONE & N/A & 22 & 0.87 \\
\hline B28, B29 & 72.0 & 20.0 & 18 & 1.227 & NONE & N/A & $1^{16.0}$ & 0.99 \\
\hline B1 $10, B 310$ & 48.24 & 15.96 & 12 & 0.6 & NONE & N/A & 12 & 0.55 \\
\hline B210 & 48.24 & 15.96 & 12 & 0.55 & NONE & N/A & 14 & 0.34 \\
\hline
\end{tabular}


Table 3.16: OpenSees Equivalent Reinforced Concrete Moment Resisting Frame Column Sections (Refer to Figures 3.24 and 3.25 For Explanation of Symbols)

\begin{tabular}{|c|c|c|c|c|c|c|c|c|}
\hline Member & b (in.) & $\begin{array}{l}\mathrm{h} \\
\text { (in.) }\end{array}$ & $\begin{array}{l}\text { No. of } \\
\text { Bars } \\
\text { (Top) } \\
\end{array}$ & $\begin{array}{l}\text { Area l } \\
\text { Bar } \\
\text { (Top) } \\
\end{array}$ & $\begin{array}{l}\text { No. of Bars } \\
\text { (Intermediate) }\end{array}$ & $\begin{array}{l}\text { Area I Bar } \\
\text { (Intermediate) }\end{array}$ & $\begin{array}{l}\begin{array}{l}\text { No. of } \\
\text { Bars } \\
\text { (Bottom) }\end{array} \\
\end{array}$ & $\begin{array}{l}\begin{array}{l}\text { Area } \\
\text { Bar } \\
\text { (Bottom) }\end{array} \\
\end{array}$ \\
\hline $\begin{array}{l}\mathrm{C} 11, \mathrm{C} 12 \\
\mathrm{C} 41, \mathrm{C} 42\end{array}$ & 112.1 & 20.0 & 36 & 0.883 & 40 & 1.03 & 36 & 0.88 \\
\hline $\begin{array}{l}\mathrm{C} 21, \quad \mathrm{C} 22 \\
\mathrm{C} 31, \mathrm{C} 32\end{array}$ & 123.8 & 22.0 & 36 & 0.883 & 48 & 0.86 & 36 & 0.88 \\
\hline $\begin{array}{l}\mathrm{C} 13, \quad \mathrm{Cl} 4 \\
\mathrm{C} 43, \mathrm{C} 44\end{array}$ & 104.0 & 18.0 & 24 & 1.227 & 24 & 1.227 & 24 & 1.23 \\
\hline $\begin{array}{l}\text { C23, C24 } \\
\text { C33, C34 }\end{array}$ & 116.2 & 20.0 & 40 & 0.785 & 56 & 0.785 & 40 & 0.79 \\
\hline $\begin{array}{l}\mathrm{C} 15, \quad \mathrm{C} 16 \\
\mathrm{C} 17, \quad \mathrm{C} 45 \\
\mathrm{C} 46, \mathrm{C} 47\end{array}$ & 99.84 & 18.0 & 24 & 0.993 & 24 & 0.993 & 24 & 0.99 \\
\hline $\begin{array}{ll}\mathrm{C} 25, & \mathrm{C} 26 \\
\mathrm{C} 27, & \mathrm{C} 35 \\
\mathrm{C} 36, \mathrm{C} 37\end{array}$ & 103.9 & 18.0 & 26 & 1.137 & 28 & 1.126 & 26 & 1.14 \\
\hline $\begin{array}{l}\text { C18, C19 } \\
\text { C } 48 \text { C } 49\end{array}$ & 83.52 & 13.9 & 18 & 1.071 & 12 & 1.071 & 18 & 1.07 \\
\hline $\begin{array}{l}\mathrm{C} 28, \quad \mathrm{C} 29 \\
\mathrm{C} 38, \mathrm{C} 39\end{array}$ & 83.52 & 13.9 & 24 & 0.785 & 24 & 0.785 & 24 & 0.79 \\
\hline $\mathrm{C} 110, \mathrm{C} 410$ & 63.84 & 12.0 & 20 & 0.6 & 16 & 0.6 & 20 & 0.6 \\
\hline C210,C310 & 48.24 & 8.04 & 12 & 0.6 & NONE & N/A & 12 & 0.6 \\
\hline
\end{tabular}


Table 3.17: Equivalent Reinforced Concrete Moment Resisting Frame Masses (Refer to Figure 3.24 For Explanation of Symbols)

\begin{tabular}{cc}
\hline Mass Label & Value (lbs) \\
\hline M21, M24 & 9189 \\
M31, M34 & 9780 \\
M41, M44 & 10486 \\
M51, M54 & 11281 \\
M61, M64 & 12147 \\
M71, M74 & 13076 \\
M81, M84 & 14060 \\
M91, M94 & 15093 \\
M101, M104 & 16173 \\
M111, M114 & 16214 \\
M22, M23 & 10102 \\
M32, M33 & 10693 \\
M42, M43 & 11400 \\
M52, M53 & 12194 \\
M62, M63 & 13061 \\
M72, M73 & 13989 \\
M82, M83 & 14973 \\
M92, M93 & 16007 \\
M102, M103 & 17086 \\
M112, M113 & 17002 \\
\hline
\end{tabular}


Table 3.18: Peripheral Steel Braced Frame Masses (Refer to Figure 3.24 For Explanation of Symbols)

\begin{tabular}{lc}
\hline Mass Label & Value (lbs) \\
\hline M21, M24 & 4492 \\
M31, M34 & 4595 \\
M41, M44 & 4706 \\
M51, M54 & 4819 \\
M61, M64 & 4937 \\
M71, M74 & 5057 \\
M81, M84 & 5179 \\
M91, M94 & 5304 \\
M101, M104 & 5430 \\
M111, M114 & 2458 \\
M22, M23 & 4948 \\
M32, M33 & 5052 \\
M42, M43 & 5162 \\
M52, M53 & 5276 \\
M62, M63 & 5393 \\
M72, M73 & 5514 \\
M82, M83 & 5636 \\
M92, M93 & 5761 \\
M102, M103 & 5887 \\
M112, M113 & 1728 \\
\hline
\end{tabular}


Table 3.19: Peripheral Reinforced Concrete Braced Frame Masses (Refer to Figure 3.24 For Explanation of Symbols)

\begin{tabular}{cc}
\hline Mass Label & Value (lbs) \\
\hline M21, M24 & 4611 \\
M31, M34 & 4931 \\
M41, M44 & 5314 \\
M51, M54 & 5745 \\
M61, M64 & 6215 \\
M71, M74 & 6719 \\
M81, M84 & 7252 \\
M91, M94 & 7813 \\
M101, M104 & 8398 \\
M11, M114 & 3728 \\
M22, M23 & 8910 \\
M32, M33 & 9231 \\
M42, M43 & 9614 \\
M52, M53 & 10045 \\
M62, M63 & 10515 \\
M72, M73 & 11018 \\
M82, M83 & 11552 \\
M92, M93 & 12112 \\
M102, M103 & 12698 \\
M112, M113 & 10334 \\
\hline
\end{tabular}

\subsection{Nonlinear (OpenSees) Modeling of the Veneer Wall Systems}

This section describes the approach employed to model the veneer wall systems and their attachments to the main frame models, under both in-plane and out-of-plane loading. The behavior of the following components was simulated by these models:

1) The backup wall system

2) The veneer

3) The ties 


\section{4) The supports}

Two types of veneer wall system backing walls and ties were considered, one flexible, and the other stiff. In the case of the backing walls, the steel stud backing wall was considered to be flexible and the CMU backing wall, stiff. For attachment of the veneer to the steel stud backing wall, double eye and pintle ties were considered. It was also assumed that the range of tie stiffness possible for these systems was representative of the range of tie stiffest possible in the field. The vertical eccentricity between the eyes and pintles determined the tie stiffness for the double eye and pintle system under out-ofplane wall loading. For the stud backed wall systems under in-plane loading, only one stiffness level was considered for the double eye and pintle ties, assuming a zero eccentricity between the eyes and the pintles since this defines critical conditions for this loading.

In an effort to bound the possible stiffnesses of tie systems that are commonly used to connect brick veneer and CMU backing walls two tie types were considered, namely, the triwire and the double eye and pintle systems.

This approach made it possible to bound the likely behavior of masonry veneer wall systems. It was assumed that the response of typical veneer wall systems would lie between the stiffest and most flexible simulations. The material properties and the stiffness of the unreinforced clay masonry veneer was assumed to be the same in all the models. 


\subsubsection{Out of Plane Veneer Wall Model: Flexible Backing Wall}

This section describes the approach employed to simulate the out of plane behavior of the veneer wall systems backed by a flexible steel stud backing wall. As discussed earlier, two types of ties were used; a flexible tie system and a stiff tie system. The material models used to approximate the behavior of these ties are shown in Figures 3.29 and 3.30. The way in which the veneer was modeled is described and these system models were based upon models developed by Hussein Okail (Okail, 2010), which have been calibrated against experimental results. Finally, the modeling of the attachments of the wall to the main supporting building frame is discussed.

\subsubsection{Steel Stud Backing Wall Model}

The out of plane stud backed system was modeled using an elastic beam column element. This was considered appropriate since the studs typically remain elastic at loads that result in tie or veneer failure. The behavior of the studs was restricted to simply bending about their major axis. Since yielding was not considered, the material was assumed to remain elastic.

All steel studs were assumed to have the same material properties as that described for the standard steel stud section (600\$137-43) from the Steel Stud Manufacturers Association (SSMA) Tech Catalog (SSMA, 2010). These section properties are as follows: 
1) Depth: 6 in

2) Flange width: 1.37 in

3) Material thickness: 0.043 in

4) Cross sectional area: $0.413 \mathrm{in}^{2}$

5) Moment of inertia about the strong axis: $2.042 \mathrm{in}^{4}$

This member size is commonly used in commercial masonry veneer wall system construction.

Each stud element loaded in the out-of-plane direct in the 2-D model had an elastic modulus of $29000 \mathrm{ksi}$ and the combined area and moment of inertia of all the studs along the 125 feet length of the wall for the moment frames, and a 62.5 feet length of the wall for the braced frame and shear wall systems. The studs were assumed to be spaced at 16 inches on center, so, over a length of 125 feet, 95 steel studs were assumed to be present for the steel and reinforced concrete moment frames, and half that number for the braced frame and shear wall systems.

\subsubsection{Veneer Model}

A nonlinear beam column element was used to model the behavior of the clay brick veneer. A fiber section model was used with this element in order to simulate the spread of cracking across the section. The clay brick element was modeled with elements with a depth of 3.625 inches, a width of 1500 inches. The width of the section was the same as the length of the wall, for the moment frames, and half that value for the braced frames. 
Thirty fibers were used across the depth of the section and only 1 fiber across the width. This was done because the veneer bends only one axis. A cross - sectional view of the veneer, and the layout of the fibers at the section is shown in Figure 3.26.

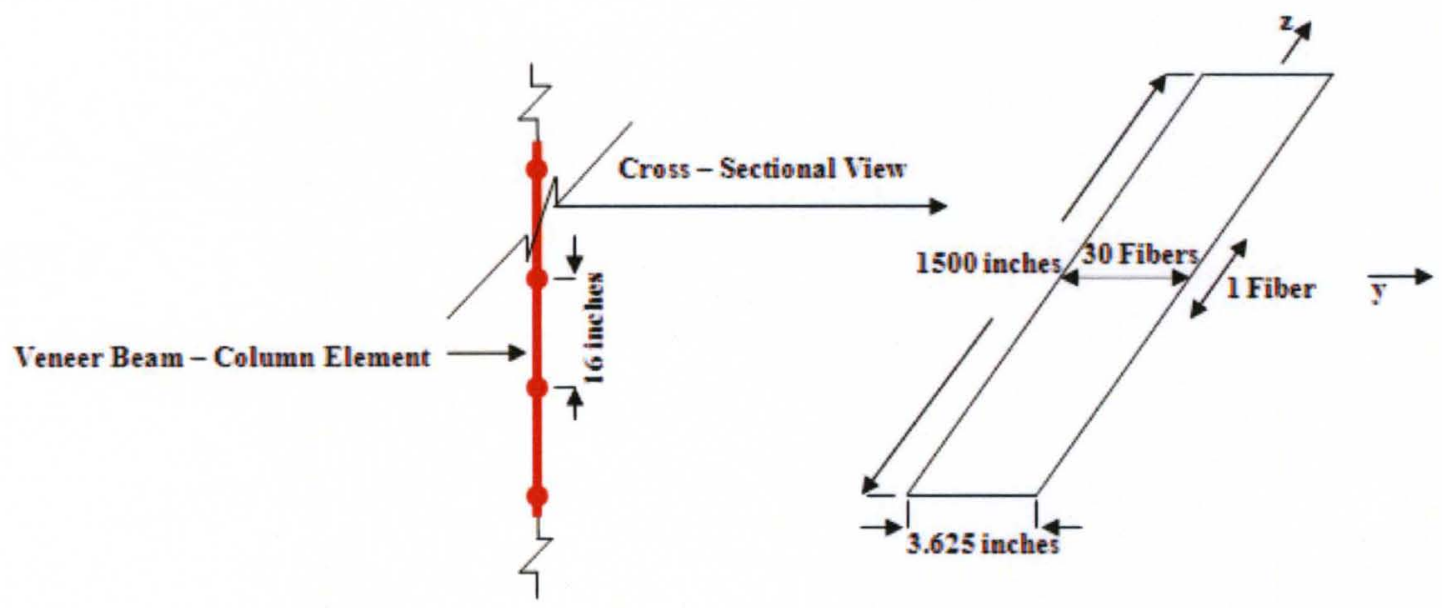

Figure 3.26: Veneer Element Dimensions and Fiber Layout

The Concrete02 model from the OpenSees library of material models (Yassin, 1994), the input parameters of which have been discussed earlier, was used to model the veneer material properties since it can be used to account for cracking. The break points that characterized this model are shown in Table 3.20 and Figures 3.27 and 3.28. It should be noted that since the flexural tension strength of the veneer is low, the compression behavior of the veneer did not have a significant effect its behavior. 
Table 3.20: Veneer Model

\begin{tabular}{cc}
\hline Concrete Model Parameter & Value \\
\hline$f_{c}$ & $1500 \mathrm{psi}$ \\
$e_{c}$ & 0.0029 \\
$f_{c r}$ & $300 \mathrm{psi}$ \\
$e_{c r}$ & 0.01 \\
$\Lambda$ & 0.1 \\
$f_{t}$ & $70 \mathrm{psi}$ \\
$E_{t s}$ & $4118 \mathrm{psi}$ \\
\hline
\end{tabular}

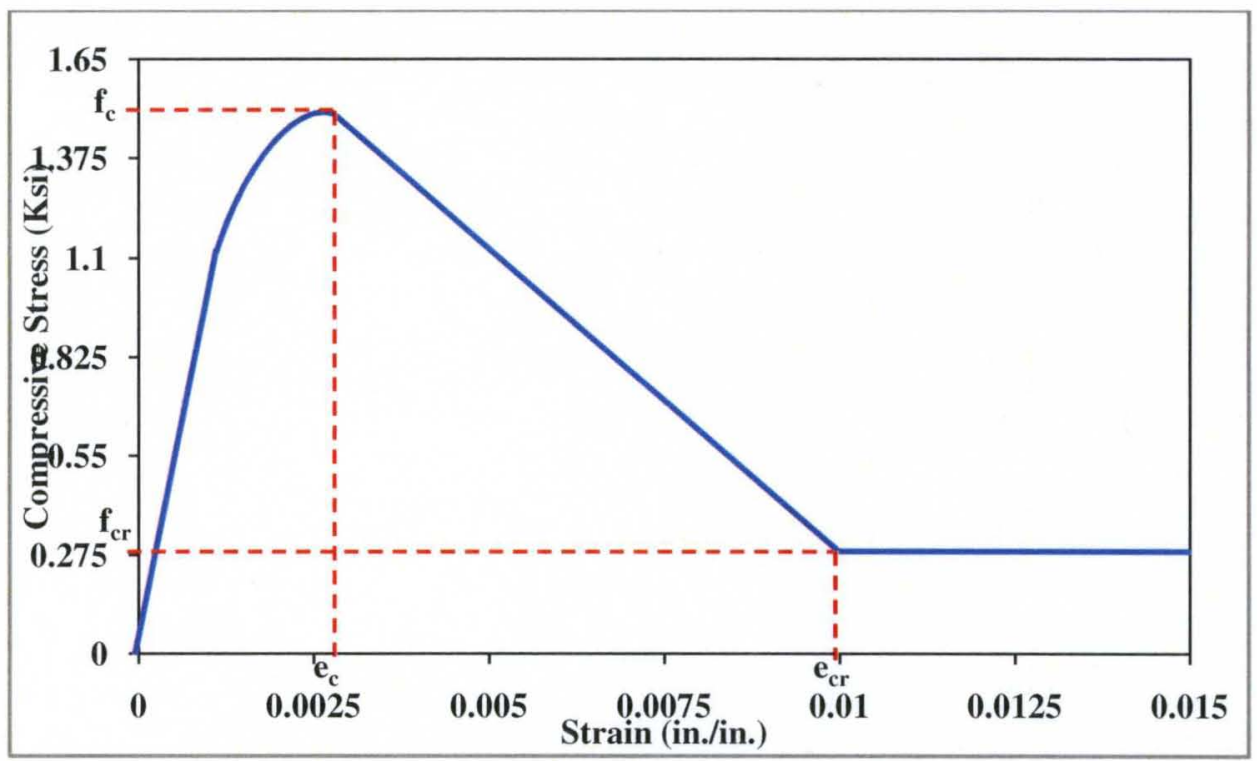

Figure 3.27: Compression Model for the Veneer in the Steel Stud Backed Wall System Under Out - of - Plane Loading 


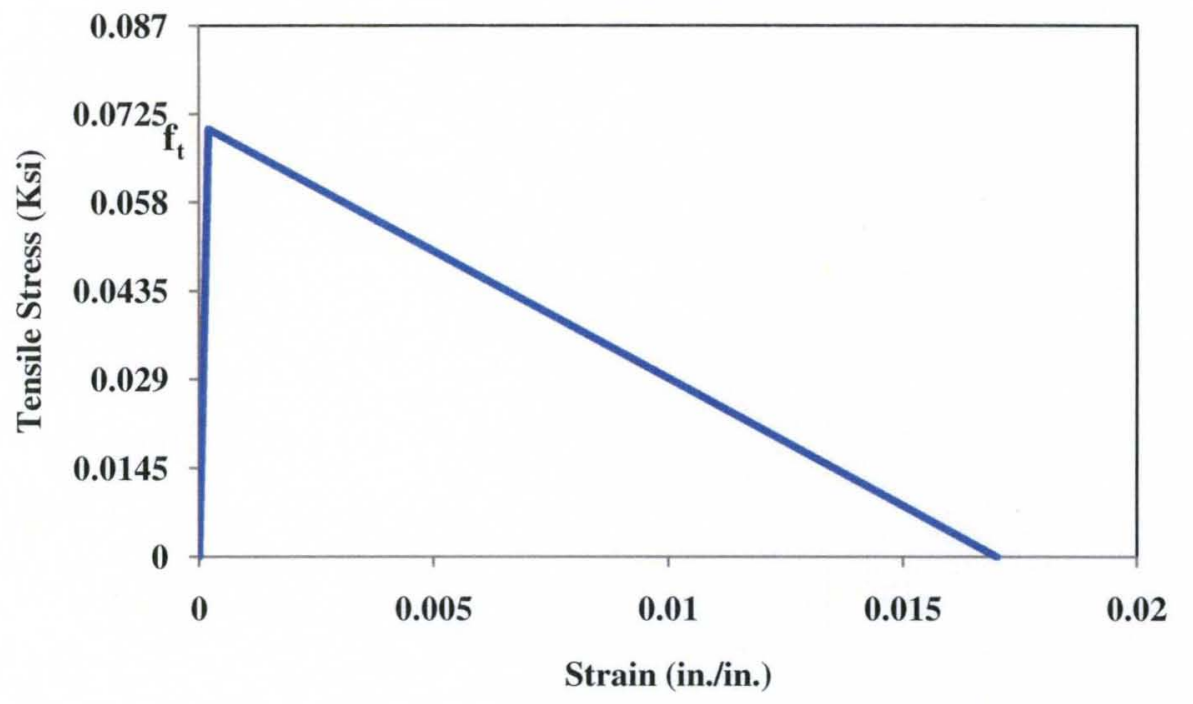

Figure 3.28: Tension Model for the Veneer in the Steel Stud Backed Wall System Under Out - of - Plane Loading

\subsubsection{Tie Model}

Axial truss elements were used to model the veneer wall system ties. A hysteretic material model was used to describe the backbone curve of the ties. As shown in Figures 3.29 and 3.30, the model included a linear loading branch until the first break point was reached, namely, the peak tension load of the tie. The initial loading slope and pullout force of the stiff and flexible ties was obtained from test data, details of which are included later in the description of the model calibration. For the flexible ties, an initial loading stiffness in tension of $0.965 \mathrm{kip} / \mathrm{inch}$, a pullout force of $0.152 \mathrm{kip}$, and a loading stiffness in compression of $3.03 \mathrm{kip} / \mathrm{inch}$ were used for each tie. For the stiff ties, an initial loading stiffness in tension of $5.0292 \mathrm{kip} / \mathrm{inch}$, a pullout force of $0.792 \mathrm{kip}$, and a loading stiffness in compression of $5.029 \mathrm{kip} / \mathrm{inch}$ were used for each tie. Compression tie behavior was modeled with a linear function since it was assumed that mortar 
droppings stiffen the ties and help support the ties (this will be discussed further in the calibration section)

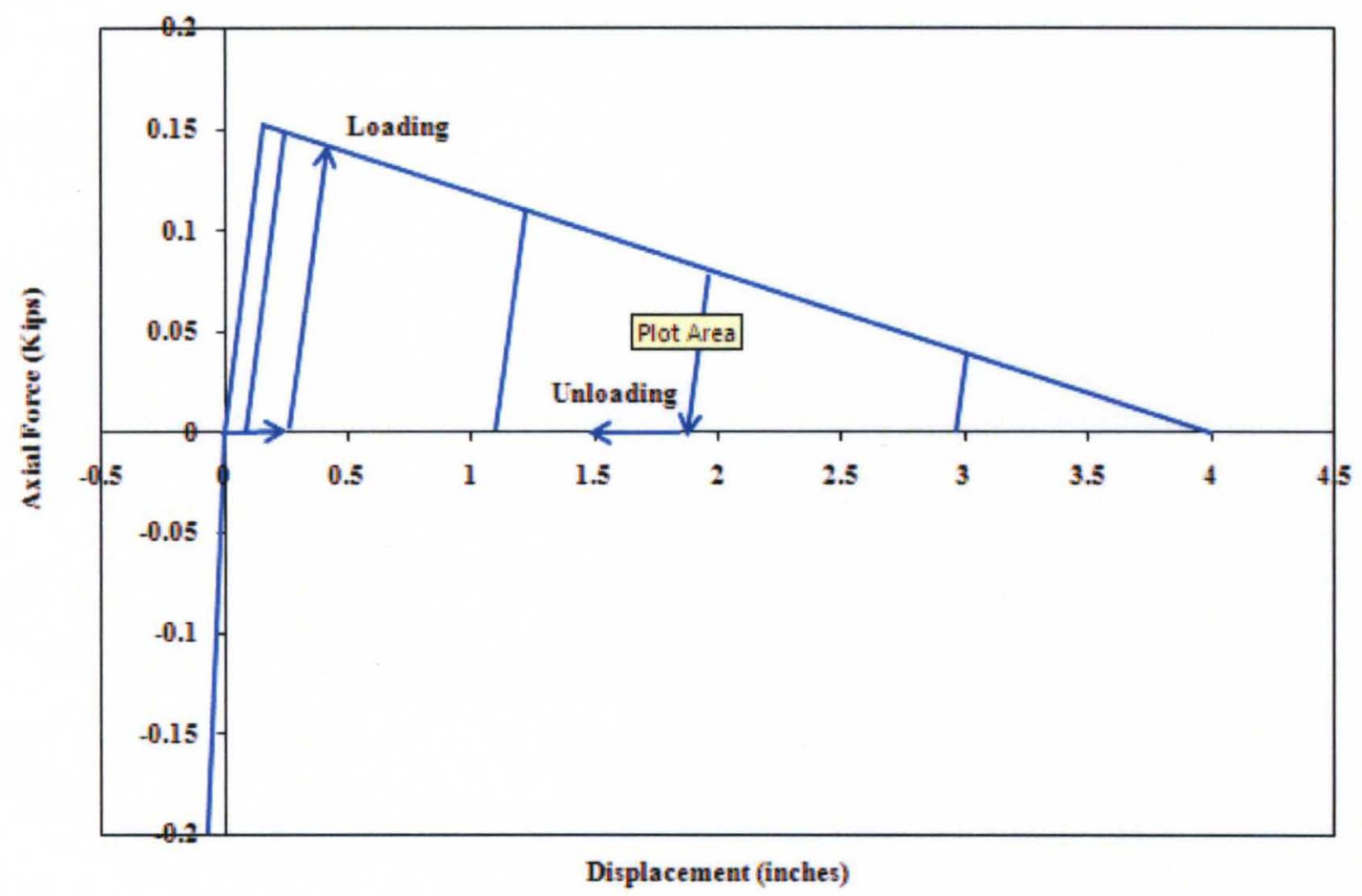

Figure 3.29: Flexible Tie Model for the Steel Stud Backed Wall System Under Out of - Plane Loading 


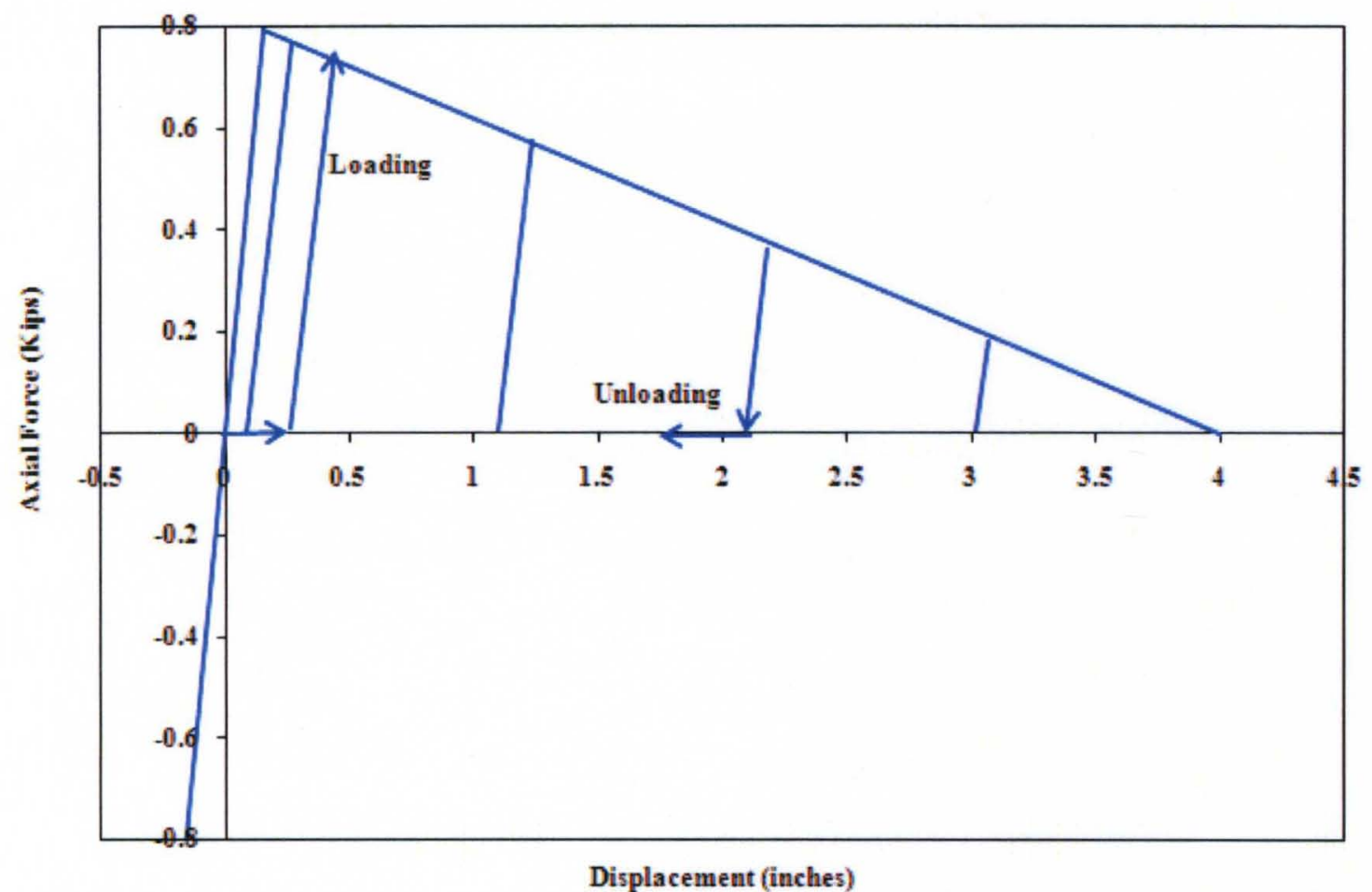

Figure 3.30: Stiff Tie Model for the Steel Stud Backed Wall System Under Out of - Plane Loading

Both ties were assumed to have reached a peak tension load when they showed an elongation of $4 \mathrm{~mm}$. This value was obtained from the Canadian code (CSA, 2004). After the peak tension load was reached, the load - deflection curve followed a linear unloading path until the tie load dropped to zero. The unloading slope was adjusted to obtain numerical stability. The displacement at no tension load was set as 4 inches.

The strengths and stiffnesses of the ties were multiplied by the number of ties present over the length of the wall system, in order to convert the 3-D wall system to a 2-D model. For the moment frames, there were 95 ties at each level used along a 125 feet long wall, with ties spaced at 16 inches on center. The 2-D braced frame model used half this value, since only one of the frames was considered in the analysis. 


\subsubsection{Attachment of the Veneer Wall System to the Structural Frame}

In order to attach the out of plane stud backed wall system to the building structural frame, three elastic beam column elements having a very high stiffness were used at each storey level as shown in Figure 3.31. The first beam column element was a short 0.05 inch long element, protruding horizontally outward from the storey level. This element was rigidly connected to the floor girder at that storey level. The node at the other end of this element was connected to two more beam column elements, one of them vertical, that is, perpendicular to this element, and the other horizontal. The vertical element was 2.73 inches long, and the horizontal element was 1 inch long. The vertical element was used to allow the attachment of the base of the steel stud backing wall to occur the typical elevation above the beams. The horizontal element was used to provide the 1 inch, or $25.4 \mathrm{~mm}$ air gap between the veneer and the backup. The base of the veneer was attached to the free end of the one inch long supporting elastic beam column element via a zero length element. The zero length element was used to allow the transmission of vertical forces between the veneer and the support, but negligible moment. The zero length elements were also used to account for the friction force between the base of the veneer and the shelf angle by using an elastoplastic material model corresponding to the horizontal translational degree of freedom at that node. The model had a single breakpoint corresponding to the frictional force, $f=\mu R$, at which sliding of the veneer would begin, and a very high initial stiffness before the breakpoint was reached. This allowed almost no movement of the base of the veneer in the horizontal direction until the horizontal force exceeded the frictional resistance. The coefficient of friction, $\mu$, between the base of the veneer and the shelf angle below it, was taken to be 0.5 (Jo, 
2010). An additional zero length element was also attached to the base of the veneer. This additional zero length element was assumed to have a very low stiffness and was used to provide numerical stability if slipping occurred.

The base of the steel stud backup was connected to the free end of the vertical 2.73 inch long elastic beam column element, once again, via a zero length element. The material models associated with the two translational degrees of freedom and one rotational degree of freedom at the nodes of the zero length element were selected to simulate a pin connection. The top end of the backing wall was attached to the beam column elements at this level by an axial truss element having a very high stiffness, thus permitting a transfer of lateral, horizontal load into the frame from the top of the backing wall, as shown in Figure 3.32. The top of the veneer was unsupported.

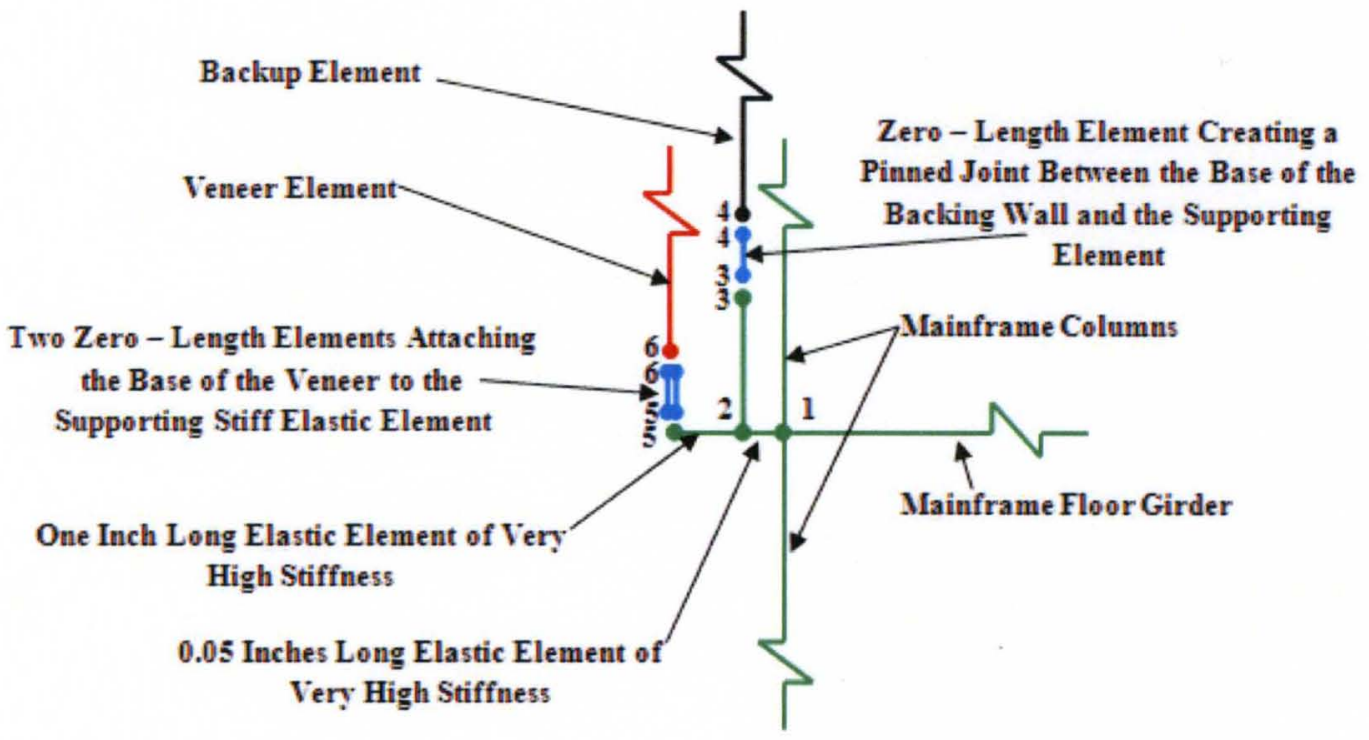

Figure 3.31: Attachment of the Base of the Steel Stud Backed Wall Under Out - of Plane Loading, to the Mainframe 


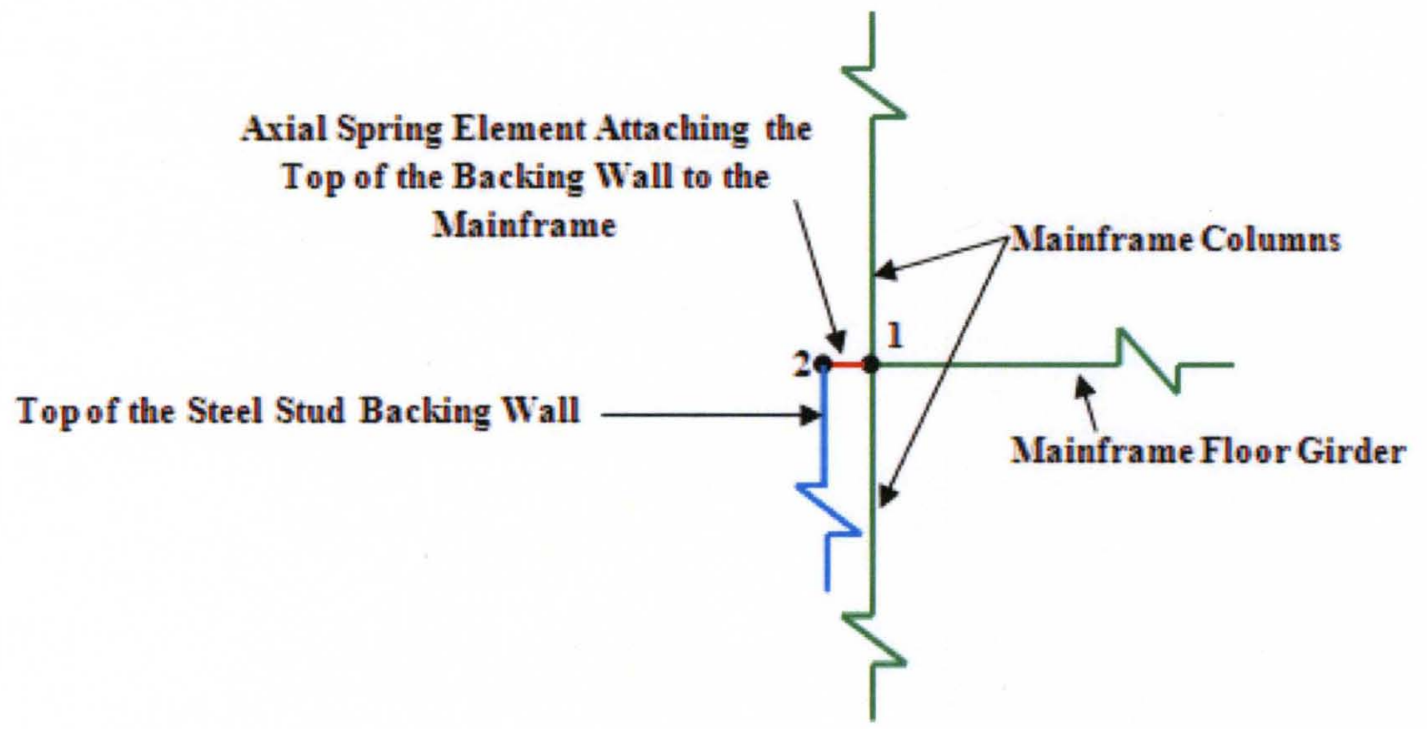

Figure 3.32: Attachment of the Top of the Steel Stud Backed Wall Under Out - of Plane Loading, to the Mainframe

\subsubsection{Out of Plane Veneer Wall Model: Stiff Backing Wall}

This section describes the modeling of the CMU backed out of plane veneer wall system. The technique used to model these walls was based upon work done by Jo (Jo, 2010). In a way similar to the description of the stud backed wall system, the models used for the backup, veneer, and the tie systems, and attachments of the wall system to the building structural frame are discussed in this section.

\subsubsection{CMU Backing Wall Model}

The reinforced CMU backing wall was assumed to be already be cracked at the maximum moment location at its mid - height. In addition, the translational degrees of freedom of the nodes at the junction of the elements immediately above and below the mid - height of the wall were coupled. A zero length element that produced a moment 
curvature relationship identical to that of a section at the center of the backing wall, corresponding to the rotational degree of freedom of the nodes at the junction of the upper and lower halves of the backing wall, was used to connect its two halves. This moment curvature relationship ignored the initial uncracked behavior of the backing wall.

The backing wall was assumed to be cracked to simplify the analysis, since the intention of this research was to model the inelastic behavior of the wall system; the consequence of this assumption was to underestimate the initial uncracked stiffness of the wall, but this would only have a small effect on the low load behavior and was ignored. All other sections of the backing wall were assumed to behave in an elastic, uncracked manner, and were modeled using elastic beam column elements.

As mentioned in the previous paragraph, the upper and lower halves of the backing wall, (above and below the crack location, respectively) were connected by zero length elements. The material model associated with these zero length elements simulated the moment - curvature behavior of a section at the center line of the reinforced backing wall. For simplicity, the material model used to simulate backing wall behavior ignored the initial uncracked phase of the response. A bilinear moment curvature relationship was used (see Figure 3.33). The initial linear cracked section response until reinforcement yield, and then a post yield behavior with a slope of $1 \%$ that of the initial slope. The yield rotation was obtained from the crack width at yield. The crack width at yield was found to be 0.025 inches, from quasi - static testing of CMU wall specimens done by Jo (Jo, 2010). Hence, the yield rotation, $\theta$, for a 7.625 inches deep CMU unit, was computed as: 
$\theta=\tan ^{-1} \frac{0.025}{(0.5 \times 7.625)} \cong \frac{0.025}{(0.5 \times 7.625)}($ small angle assumption $)=0.0065$ radians

The values that were used for the yield moments at the base, $M_{b}$, and the midpoint $M_{m}$, of the CMU wall are:

$M_{b}, M_{m}=19 \times 15.625=296.875 \mathrm{kip}-$ feet, for the steel and reinforced concrete moment frames, and

$M_{b}, M_{m}=19 \times 7.8125=148.4375 \mathrm{kip}-$ feet, for the steel and reinforced concrete braced frames.

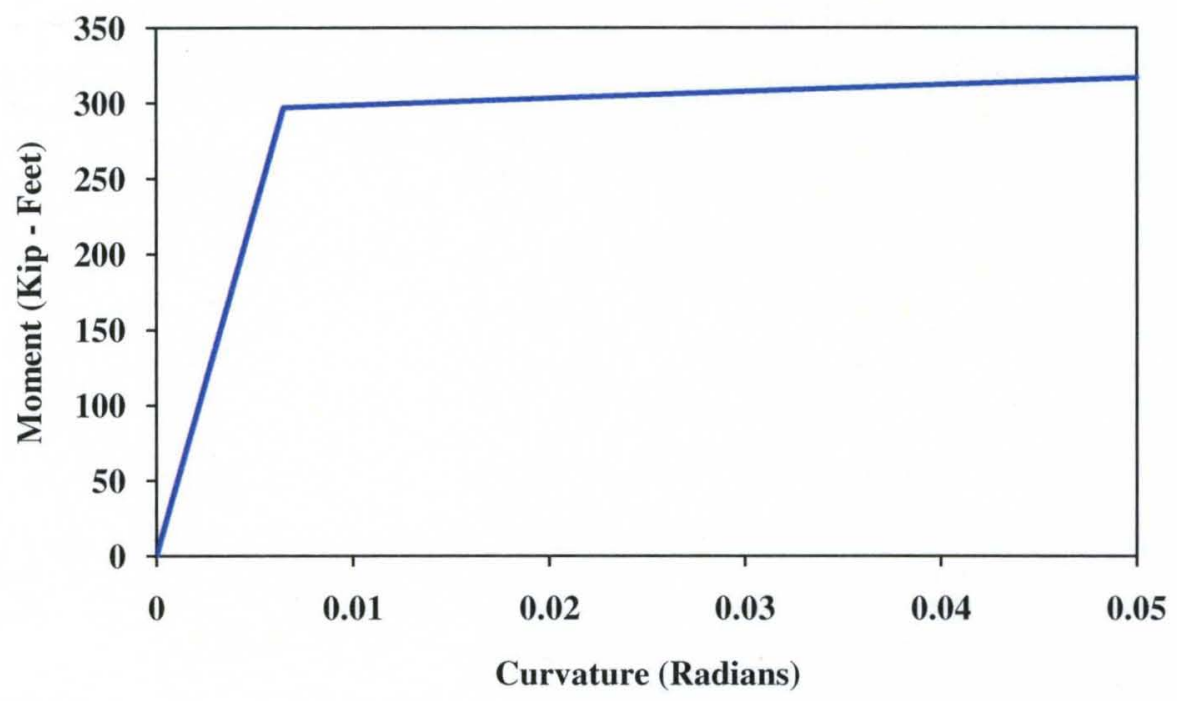

Figure 3.33: Moment - Curvature Relationship for Out - Of - Plane Behavior of the CMU Backing Wall.

Work by Jo (Jo, 2010) showed an 8" CMU wall with \#5 reinforcement bars at 10" on center, had a yield moment capacity of $19 \mathrm{kip}$ - in, and this was used in this investigation, in a manner described in the expressions above. It was assumed that a similar CMU backing wall configuration would be used in this application. The capacity was adjusted 
to account for the tributary width of 125 feet for the moment frames and 62.5 feet for the braced frame and shear wall models.

The cross sectional area and moment of inertia values of the backing wall elements were derived from the actual width and depth of the wall. For the moment frames, a width of 125 feet was used and for the braced frames, half of this value was used. The depth of the sections was taken to be 7.625 inches, which is the depth of standard 8 inch concrete masonry units. The modulus of elasticity of the concrete masonry units was assumed to be $900 \mathrm{f}_{\mathrm{m}}$, (MSJC, 2008). An assumed masonry compressive strength of 1.5 ksi was used in this study, since this is a lower bound of the values available in the field. The density of the concrete masonry units was taken to be $120 \mathrm{pcf}$.

\subsubsection{Inelastic Veneer Element Model}

The veneer was modeled in a way similar to that for the flexible backup system.

\subsubsection{Tie Models}

Two types of veneer ties were modeled for the (stiff) CMU backed veneer wall systems: a double eye and pintle system, and a triwire system. The analytical models were based upon work done by Jo (Jo, 2010) and his models were calibrated against experimental results. 
Jo's model's describe loading regions in tension and compression for the double eye and pintle tie model (Figure 3.34) that are comprised of two segments, the first being a short segment having a low initial stiffness and the another segment having a much higher stiffness. Jo estimated the initial tie stiffness to be $1.7 \mathrm{kip} / \mathrm{inch}$, for up to 0.03 inches of displacement in both directions. The second tie stiffness was estimated to be $16.0 \mathrm{kip} / \mathrm{inch}$. The maximum capacity of the ties in tension and compression was set at $0.56 \mathrm{kip}$, at a displacement of 0.055 inches.

For the sake of simplicity, in the current investigation, the loading region of the double eye and pintle ties (Figure 3.34) in tension was represented by only a single loading segment instead of two. The initial low stiffness region was ignored, both in tension and in compression. This simplification was introduced in order to reduce the likelihood of numerical instabilities in the dynamic analysis. As a result of this approximation, the model showed a slightly higher stiffness in the initial elastic phase of the response. However, under the loads acting on the system in this investigation, the ties would most likely show an inelastic response, and hence this approximation would not create any significant inaccuracies in the results predicted by the model. The tie system was assumed to have the same stiffness in tension and compression up to a load of 0.56 kips. The stiffness was such that a deflection of 0.055 inches would result at the peak 0.56 kips. After the tension deformation of 0.055 inches was exceeded, the load was assumed to be constant at 0.56 kips, until a peak deformation of 0.1 inches occurred, which was assumed to be the peak tensile deformation capacity of the tie system. 


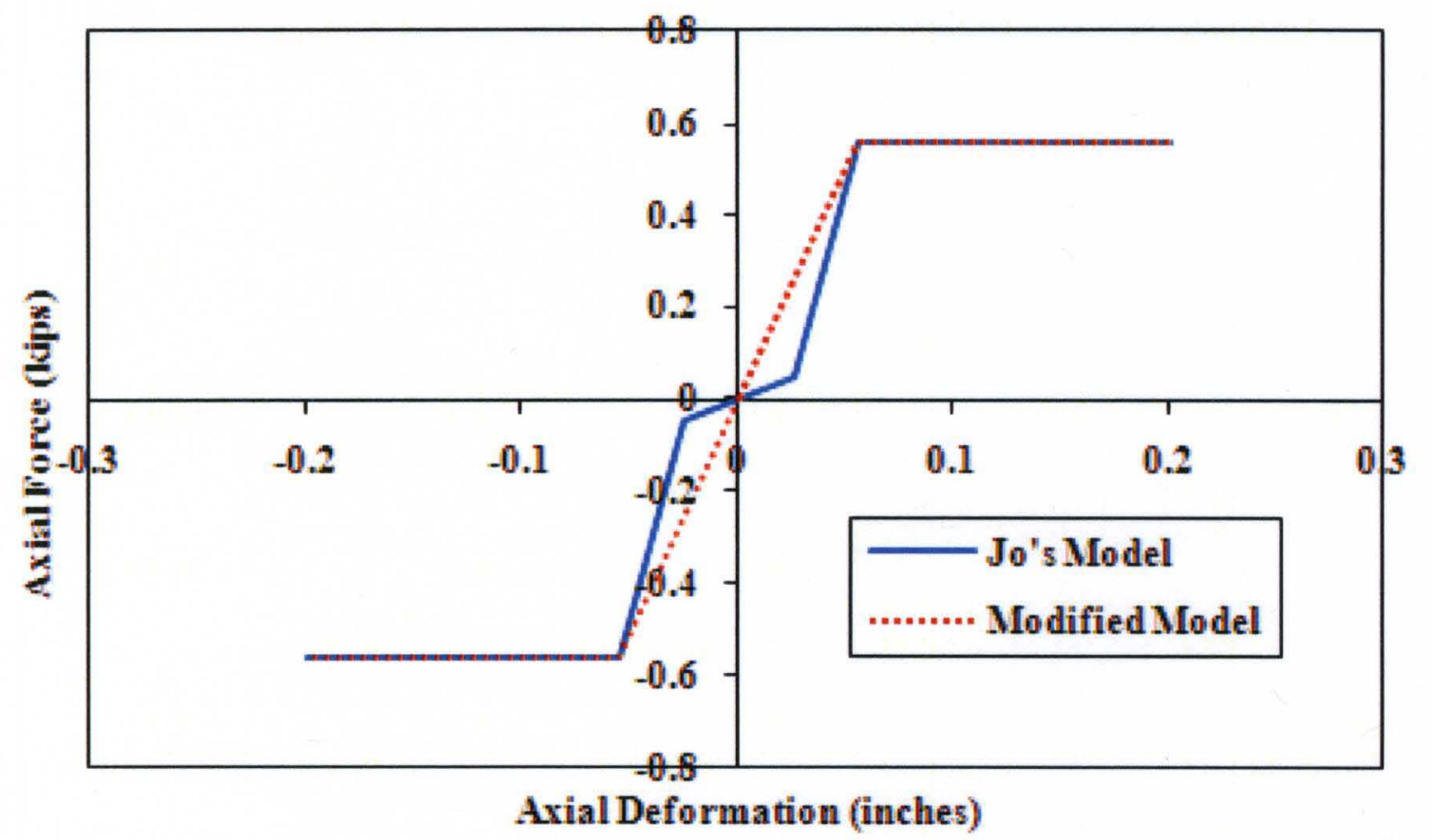
Figure 3.34: Double Eye and Pintle Tie Model Used in the CMU Backed Wall
System Under Out - of - Plane Loading

The envelope curve used to model the behavior of the triwire connectors in tension and compression was obtained from work done by Jo (Jo, 2010). This curve is shown in Figure 3.35. His analytical models were calibrated against experimental results and he proposed a triwire tie model that had an initial stiffness of $36 \mathrm{kips} / \mathrm{in}$ in tension, with a peak load of 0.71 kips. In compression, a peak load of 0.56 kips produces a displacement of 0.014 inches. The peak load in compression was assumed to be governed by buckling. The residual strength after buckling was taken as 0.33 kips. This value was reached at a displacement of about 0.2 inches. Furthermore, 0.09 inches was defined as the deformation capacity of the triwire connectors in tension and 1.0 inch was defined maximum deformation capacity of these connectors in compression. 


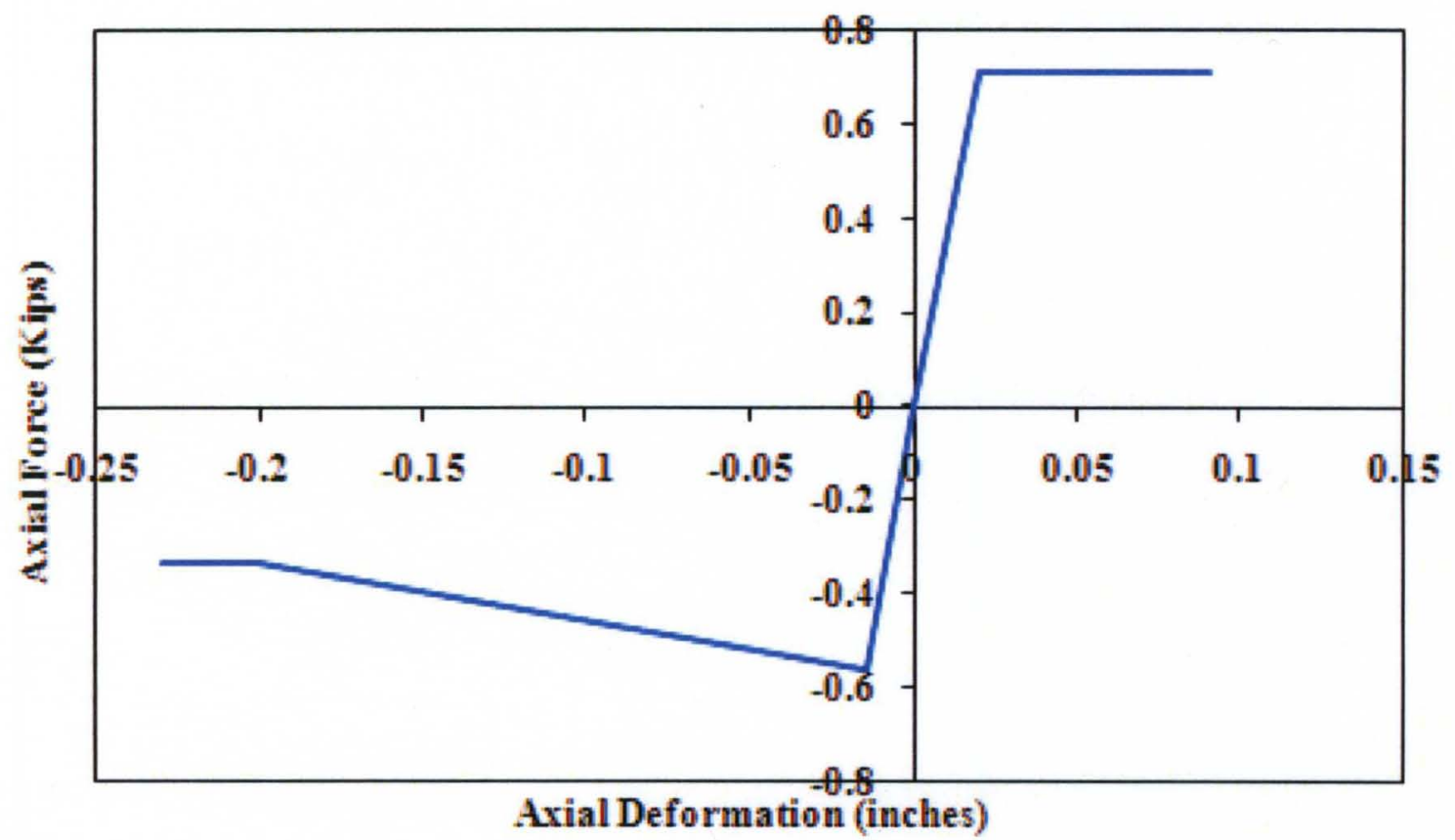

Figure 3.35: Triwire Tie Model Used in the CMU Backed Wall System Under Out of - Plane Loading

\subsubsection{Out - of - Plane Attachment of the Veneer Wall System to the Main Frame}

The out-of-plane attachment of the CMU backed out of plane wall system was similar to that of the stud backed wall system. The only difference for this backing system was the absence of the vertical 2.73 inch long vertical elastic beam column element. Instead, base of the CMU backing wall was attached to the node at the junction of the 0.05 inch long elastic beam column element using a zero length element. This zero length element was also attached to the main building frame, and the one inch horizontal element which was attached to the base of the veneer. The material models assigned to each of the degrees of freedom of the nodes of this zero length element were such that they simulated a fixed base condition at the bottom of the backing wall. The translational degrees of freedom used elastic models having a very high modulus of elasticity. The rotational 
degrees of freedom used a material model similar to that used to connect the lower and upper halves of the backup at its precracked midsection. This simulated the bending moment - curvature relationship at the base of the backing wall. The breakpoint for this model was slightly modified to account for the small change in the moment curvature relationship caused by the slight increase in self weight of the backing wall acting on its base as compared to its midsection (Jo, 2010).

\subsubsection{Wall Model: Flexible Backing Wall Under In - Plane Loads}

This section describes the modeling approach employed to simulate the behavior of the steel stud backed wall system under in - plane loading. This model was developed in the same way as the out of plane wall models. The following sections describe this model development.

\subsubsection{Steel Stud Backing Wall}

The steel stud backing wall was modeled as a braced frame as per Okail [Okail, 2010]. The response of the backing wall was calibrated against an experimentally tested steel stud system under racking loads. The details of this calibration are presented in a later section.

A typical steel stud backing wall has attached sheathing and acts like a shear wall. The sheathing carries the lateral load and transmits it to the steel studs via the attaching 
screws. To model the in - plane behavior of the steel wall, a 2-D braced frame was set up to represent the steel stud backing wall. In this frame, the vertical columns modeled the steel studs. The cross braces were axial truss elements, and were used to model the sheathing and the sheathing screws. The beams were axial truss elements which were used to transfer lateral loads into the cross braces. The cross braces transferred the lateral loads to the base. Thus, the combined system of the horizontal axial truss elements and the cross braces was intended to replicate the lateral force carrying ability of the sheathing and the screws used to attach it to the steel studs.

The in - plane veneer wall systems are present in each bay of the exterior structural frames. However, using the braced frame representation of the in - plane veneer wall system with studs spaced at 16 inches on center would creati 18 braced frames along each of the 25 feet girder lengths of the structural frame. This modeling method was computationally inefficient and increased the likelihood of numerical instability in the model. Thus, the stud backing wall of each wall system under the action of in - plane loads, was approximated as a single bay braced frame (Figure 3.36). The width of the frame was taken as 8.33 feet. Thus, the braced frame was assumed to occupy the middle third of each of the 25 feet wide bays on each storey of the main building frame. The storey heights in the braced frame representation of the backing wall were taken as 8 inches per storey. The steel stud columns of the braced frames were modeled using elastic beam column elements. The horizontal beam elements of the frame and the 
diagonal elements that constituted the cross braces, were all modeled using axial truss elements.

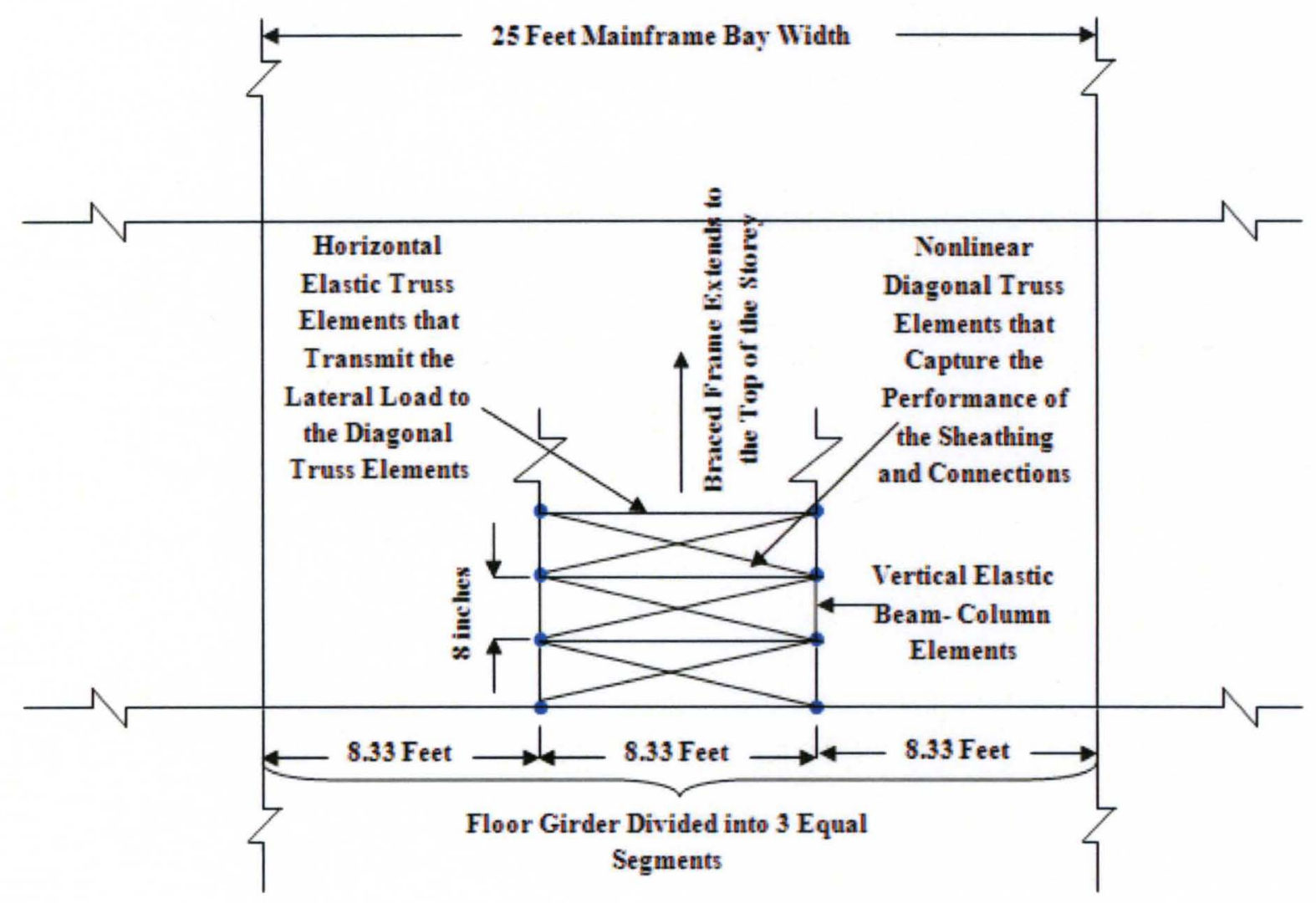

Figure 3.36: Equivalent Single Bay Braced Frame Representation of the Backing Wall of the Steel Stud Backed System, Under In - Plane Loading

The areas and moments of inertia of the vertical beam column elements, and the areas of the axial truss horizontal and cross braced elements of the equivalent single bay frame were selected so that the in plane veneer backing wall frame model behaved like a 25 feet long backing wall under in - plane racking load. The methodology used to obtain these values is described later, in the calibration section of this document. 
The post calibration values of these parameters for the equivalent single bay braced frame representation of the steel stud backing wall are presented below:

Cross sectional area of the vertical elastic beam column elements: $16.52 \mathrm{in}^{2}$

Moment of Inertia of the vertical elastic beam column elements: $3.48 \mathrm{in}^{4}$

Elastic modulus of the vertical elastic beam column elements: $29000 \mathrm{ksi}$

Cross sectional area of the horizontal truss elements: $40 \mathrm{in}^{2}$

Elastic modulus of the horizontal truss elements: $1500 \mathrm{ksi}$

Cross sectional area of the diagonal truss elements: $31.42857 \mathrm{in}^{2}$

The break points of the hysteretic material model associated with the diagonal truss elements are presented in Table 3.21. The envelope curve developed using these breakpoints is shown in Figure 3.37. The same model was used for both compression and tension

Table 3.21: Breakpoints of the Diagonal Truss Element Hysteretic Material Model

\begin{tabular}{ccc}
\hline Breakpoint & Stress (ksi) & Strain (in./in.) \\
\hline 1 & 0.45 & 0.00024 \\
2 & 0.698366 & 0.001021 \\
3 & 0.0 & 0.0045 \\
\hline
\end{tabular}




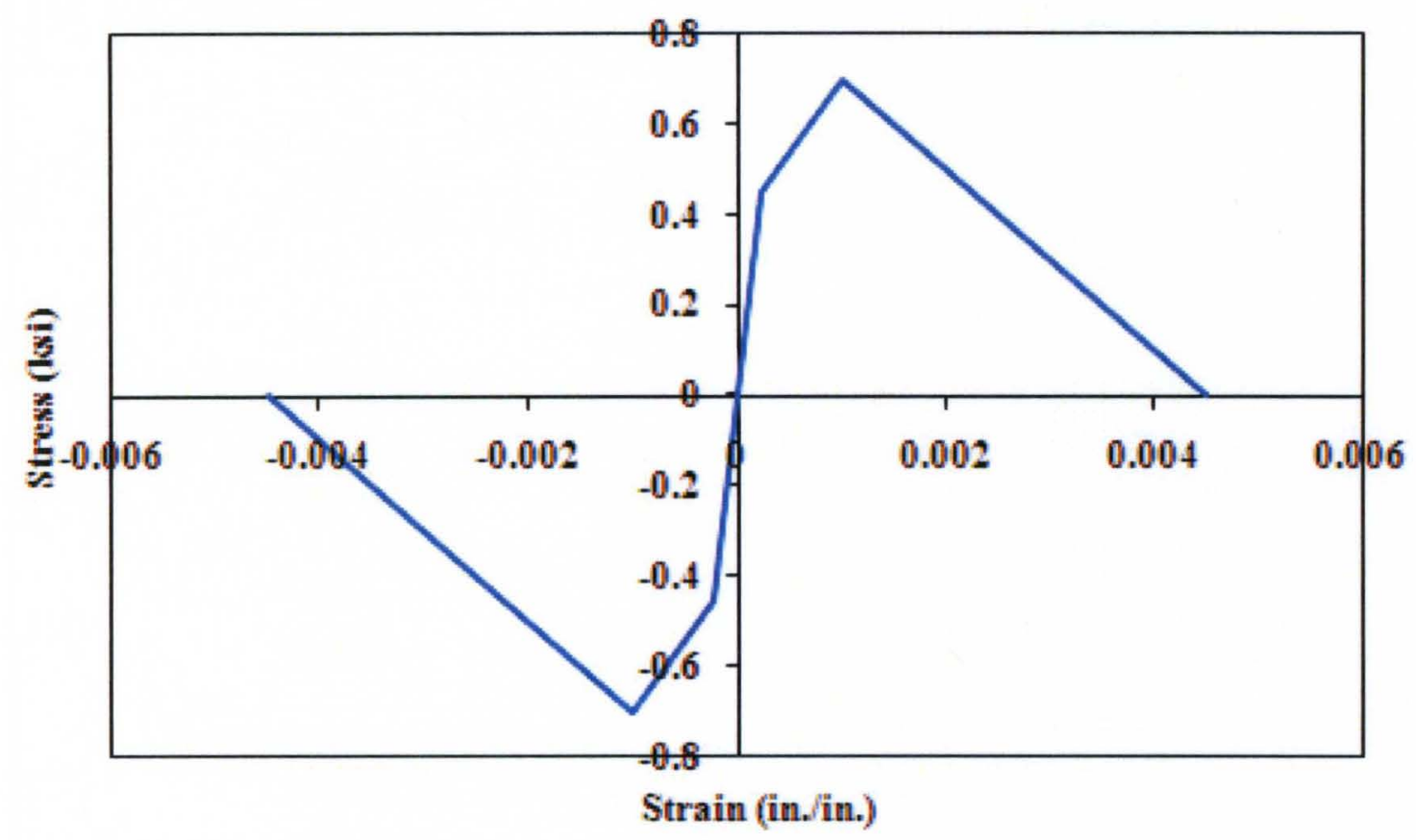

Figure 3.37: Diagonal Truss Element Material Model

\subsubsection{Veneer Model}

Elastic beam column elements were used to model the veneer in the in - plane direction. The veneer was assumed to remain in its uncracked state, under in - plane loads. This assumption justified using elastic elements, since inelastic post cracking behavior was not expected. This type of behavior was suggested by Jo (Jo, 2010), who used elastic beam column elements to model the in - plane behavior of clay brick veneer. Two vertical columns of these elastic elements were used to represent a veneer in each bay of the 2-D frame (Figure 3.38). These columns coincided with the column lines of the vertical columns of the equivalent, single bay, backing braced frame. At each storey level, the beam column veneer elements and the backup were connected to each other at 
their nodes by zero length elements representing the in - plane ties. In reality, each in plane veneer section spanned 25 feet in the main frame, and had a depth of 3.625 inches. The cross sectional area and moment of inertia of the elastic beam column representations of the veneer were assigned half the values of the actual veneer, to account for the use of a two column representation of the veneer. The moment of inertia of the actual veneer was computed about an axis passing through the center line of the veneer and perpendicular to the plane of the in - plane wall. Thus, the width of the cross section was 3.625 inches and the depth was 25 feet. The modulus of elasticity assigned to the elastic beam column elements was that of the clay brick masonry assembly.

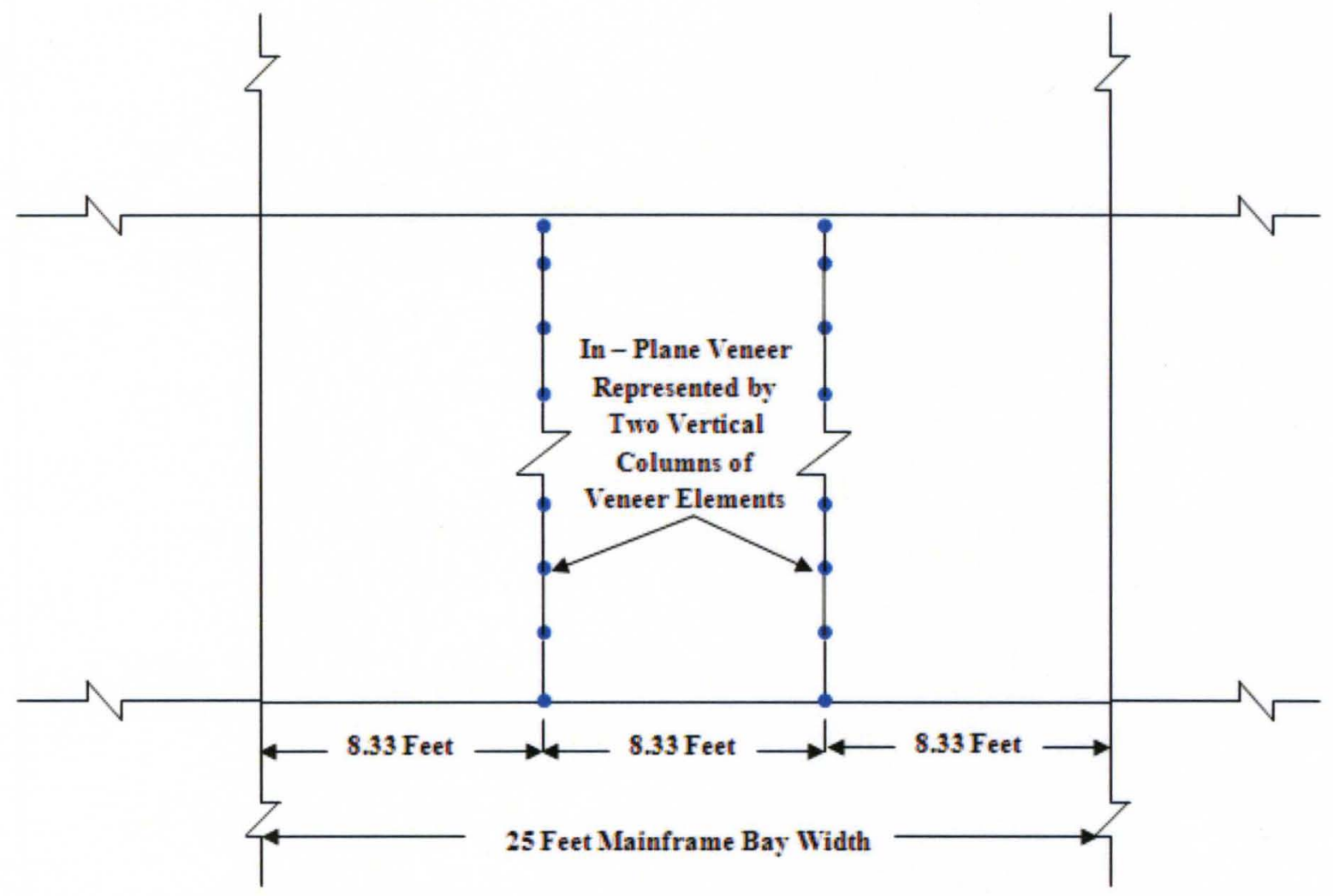

Figure 3.38: Locations of the Veneer Elements of the Steel Stud Backed System, Under In - Plane Loading 


\subsubsection{Wall Tie Models: In - plane Loading}

For the steel stud backed veneer wall system loaded in the plane of the wall, only the double eye and pintle tie was considered. The model for this tie system was obtained from work done by Jo (Jo, 2010). As mentioned in the previous section, the in - plane behavior of the wall ties were represented by zero length elements connecting the veneer and the backup. A material model representing the shear behavior of the double eye and pintle ties was assigned to the zero length tie elements in the horizontal translational direction, which is the direction in which the shear force on the in - plane wall ties acted, when the in - plane wall system was subjected to a lateral load. The model that represented the shear behavior of the in - plane wall ties was developed by Jo (Jo, 2010) assuming that the two pintles act as cantilever beams. The parameters that effect the in plane stiffness of the ties are the amount of mortar droppings present, the difference between the diameters of the pintles and eyes, the vertical eccentricity of the tie pieces, and the protrusion of the eyes. These vertical eccentricities are typically caused by construction tolerance, and the in - plane rocking of the veneer.

The maximum shear strength of the system is related to the amount of vertical eccentricity, wire diameter, and the amount of protrusion of the eyes. In his work, Jo (Jo, 2010) computed the horizontal shear stiffness and strength of the tie systems as two cantilevered beams, using:

$$
\text { Stiffness }=2 \times \frac{E I}{L^{3}}, \text { and }
$$




$$
\text { Strength }=2 \times \frac{f_{y} \times S}{L}
$$

The basic relationship between load and displacement is:

$$
\Delta_{y}=\frac{\text { Strength }}{\text { Stiffness }}
$$

Using this basic relationship, and the strength and stiffness computed using the formulae above,Jo (Jo, 2010) computed the displacement at yield to be about 0.039 inches. These values of shear strength and deformation at yield, upon which the envelope curve of the connectors was based, assumed that the connectors undergo only elastic deformation. Jo (Jo, 2010) also indicated that the maximum capacity of the ties would be some multiple of the yield strength and found a multiplier of 1.4 best modeled the test data. A backbone curve for the load - deflection in - plane behavior of the ties was constructed based upon these calculations. As shown in Figure 3.39, the first break point was at a force of 0.071 kips. The stiffness of the connectors was the same as that computed above. For these values of strength and stiffness, the deformation at which the first break point occurred was 0.055 inches. An elastic-plastic model from the library of material models in OpenSees was selected to simulate this behavior, using the above defined break points. 


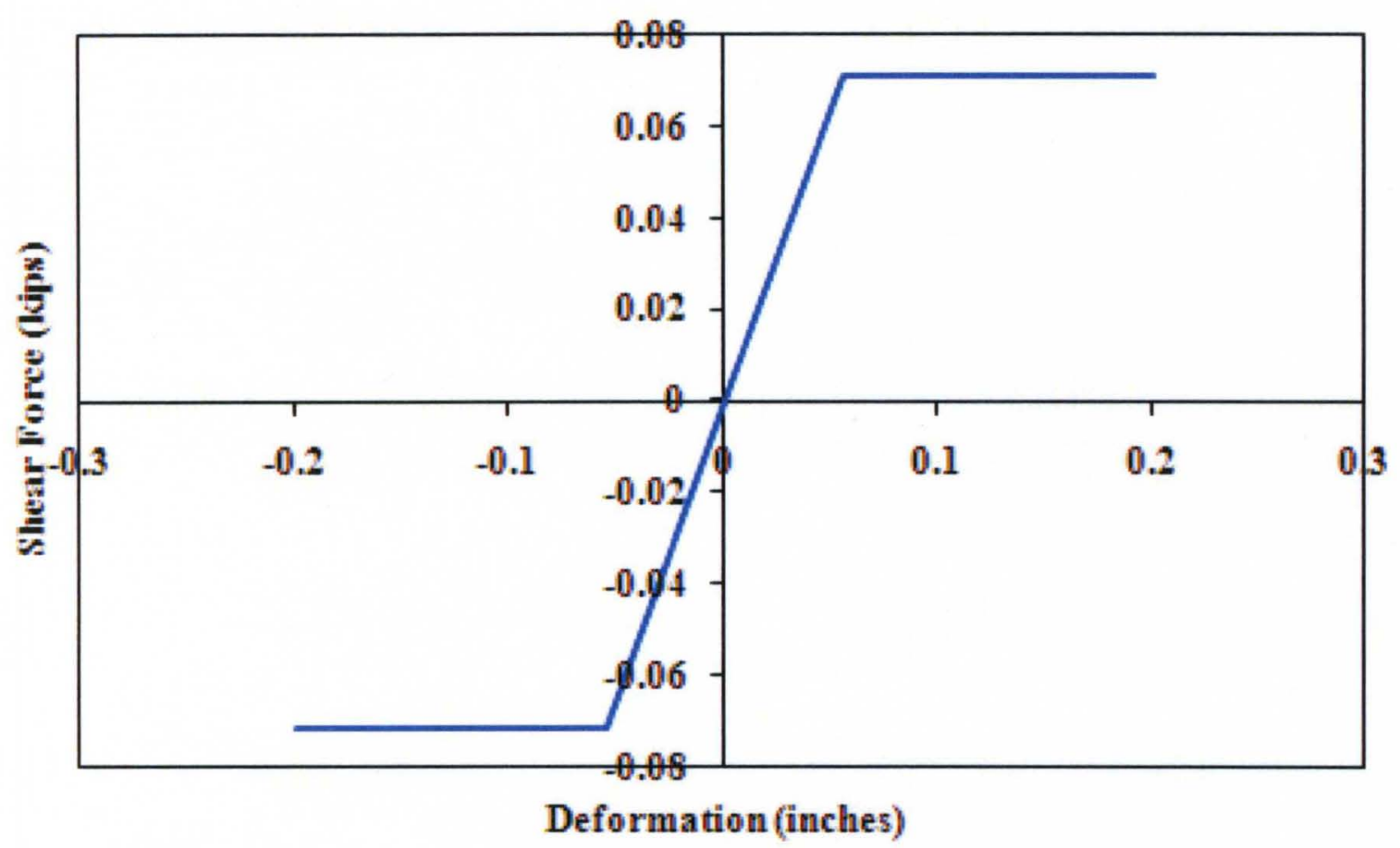

Figure 3.39: Shear Behavior of the Double Eye and Pintel Tie System

\subsubsection{Attachment of the Wall System to the Main Frame for In - plane Loading}

This section discusses the attachment of the steel stud backed wall system to the floor girder of the main frame of the building for in - plane loading.

A vertical 2.73 inch long elastic beam column element of a very high flexural stiffness was attached to the one third points of the floor girders at every bay of each storey of the building frame. The bases of the two vertical column lines of the braced frame representation of the steel stud backing wall were attached to the free ends of these vertical beam column elements via zero length elements (Figure 3.40), whose material 
models in the three degrees of freedom (two translational and one rotational) were selected to permit the transfer of vertical and horizontal forces between the backing wall and the supporting elements, but did not permit moment transfer, thereby simulating a pin support. This was accomplished by assigning a high stiffness elastic material model to the translational degrees of freedom, and a low stiffness elastic material model to the rotational degree of freedom at the node.

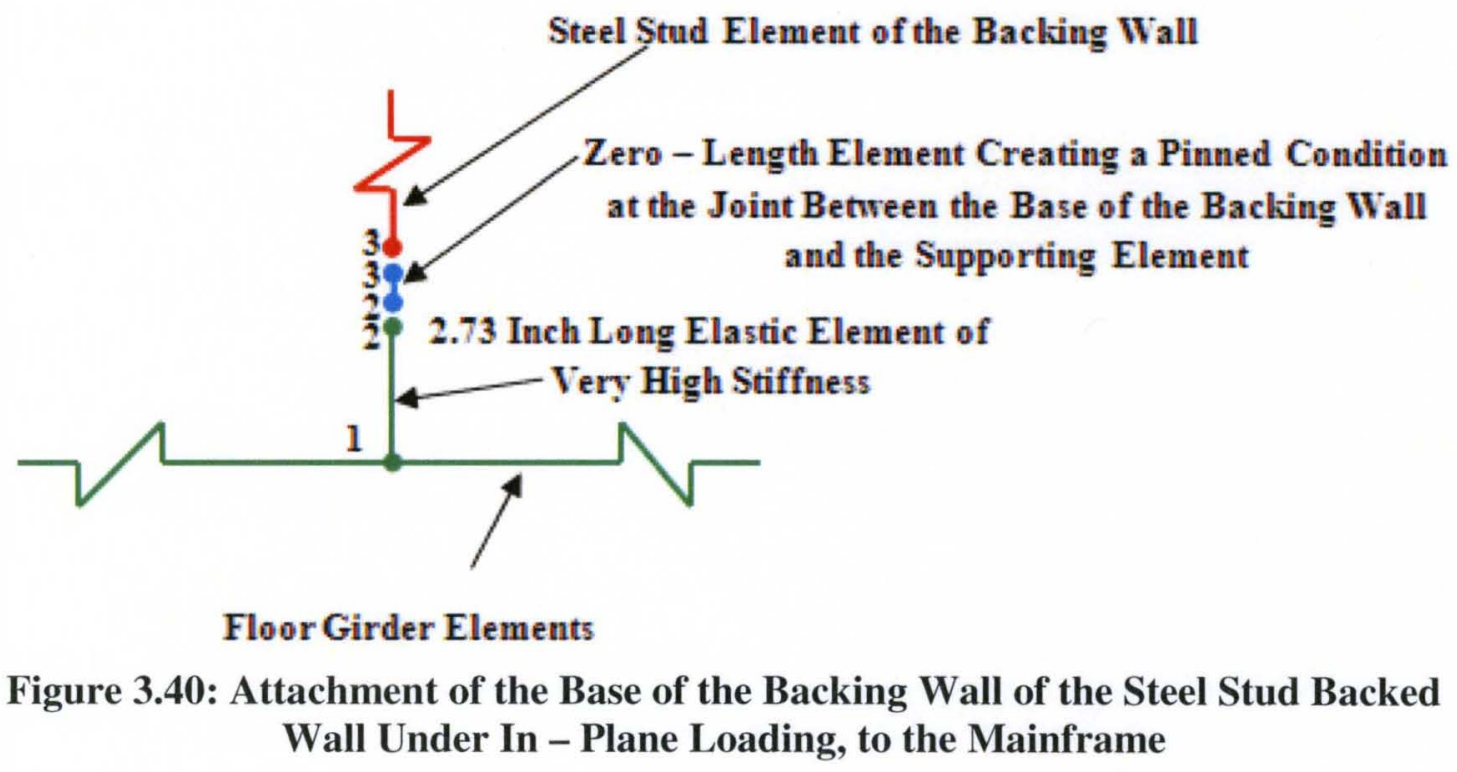

The backing wall braced frame models were attached to the corresponding one third points of the floor girder at the next higher storey level, once again, through zero length elements. A simple elastic material model was assigned to these zero length elements with an extremely high stiffness for horizontal translational degrees of freedom, and a low stiffness for the vertical translational and rotational degrees of freedom. This idealization permitted a transfer of horizontal lateral seismic forces from the girder into 
the steel stud backing wall, while preventing the transfer of vertical loads and moments into the backing wall.

The veneer is represented by two vertical columns of elastic beam column elements located at the one third points of the floor girder. The base of each of these columns was connected to the girder through a zero length element that was configured to fully transmit the vertical force between the veneer and the floor girder, but not to transmit any moment. The connection also allowed for a sliding frictional resistance at the base of the veneer by assigning an elastic-plastic spring in horizontal translational degree of freedom direction at the base of the veneer. This spring was configured to have high initial stiffness until a breakpoint load corresponding to the frictional force, $f=\mu R$, was reached, thereby ensuring little to no movement of the base of the veneer until the sliding frictional resistance was overcome. The top of the veneer was unsupported.

\subsubsection{Wall Model: Stiff Backing Wall Under In - Plane Loads}

This section describes the models used to simulate the behavior of the rigid, CMU

backed veneer wall system under in - plane loads. The components of the system are dealt with separately. 


\subsubsection{Backing Wall}

Based upon work done by Jo (Jo, 2010), a single vertical column of elastic beam column elements were used to model the CMU backing wall system underin-plane loading,. The CMU backing wall does not experience inelastic behavior under in - plane loads. Thus, an elastic model was adequate to describe its response under lateral in plane loading. It was assumed that the masonry had a specified compressive strength of $1500 \mathrm{psi}$, and an elastic modulus of 900f'm (MSJC, 2008). Figure 3.41 shows the locations along the floor girder at which the veneer and backup elements of the wall system were attached. The vertical column of beam column backing wall elements was attached near the center of the floor girder of the building frame. The section properties of the beam column elements were computed based upon a cross sectional width of 7.625 inches (for an 8 inch CMU specimen) and a cross sectional depth of 25 feet. A value of 120 pcf was used for the density of the CMU in the backing wall. 


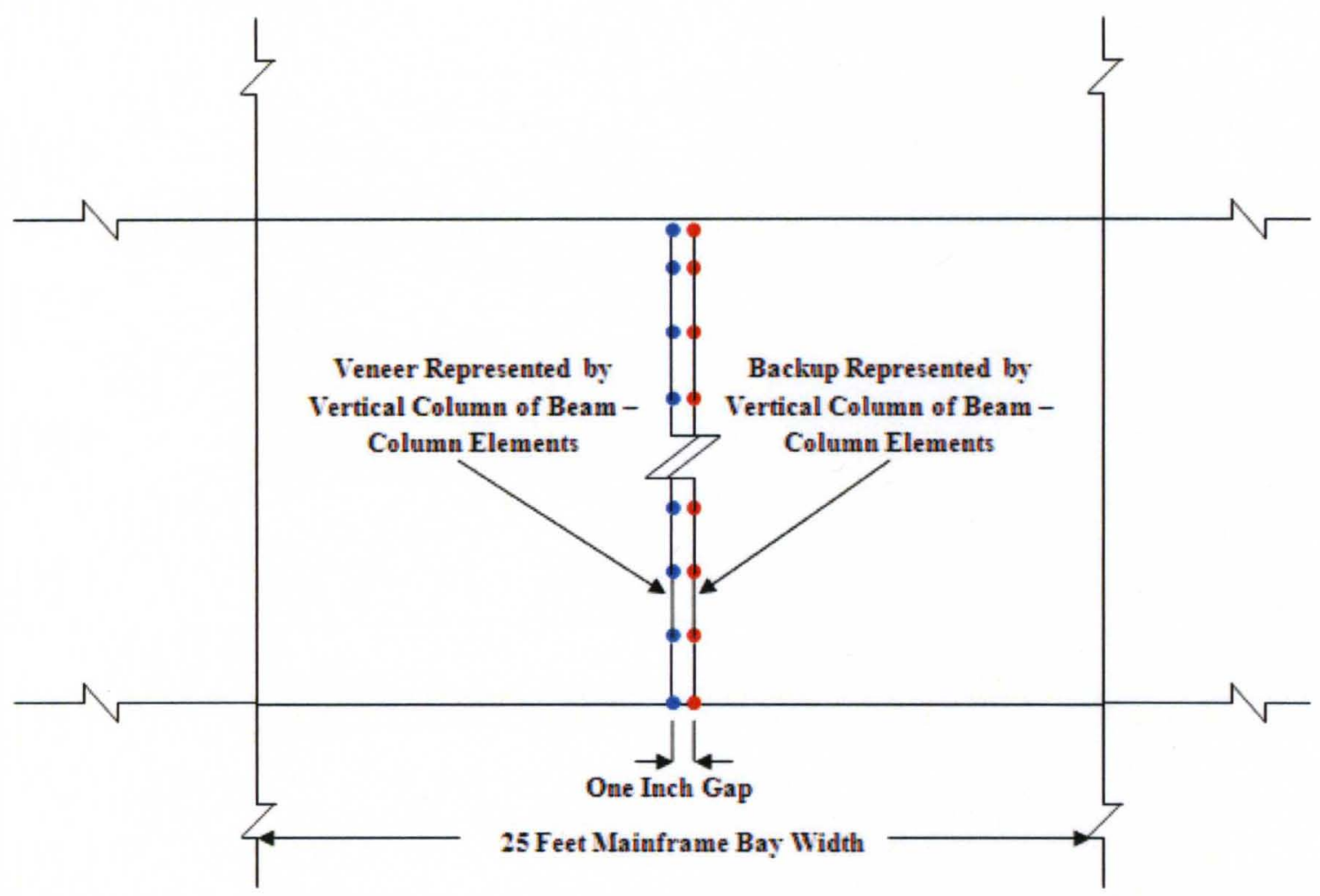

Figure 3.41: Locations of the Veneer and Backup of the CMU Backed Wall System, Under In - Plane Loading

\subsubsection{Veneer Model}

The veneer was also idealized using a single vertical column of elastic beam column elements under in - plane loads. This model was based upon work done by Jo (Jo, 2010). A value of 1500 psi was used for the specified compressive strength of the clay brick veneer, since this is typical for this type of wall system, and $700 \mathrm{f}$ 'm (MSJC, 2008), for the elastic modulus. 
The rocking behavior of the veneer was found to be negligible for a 12 feet long wall (Jo, 2010). Consequently, rocking is likely to be insignificant for a 25 feet long wall and was ignored in this analysis.

\subsubsection{Tie Models}

Two different types of tie systems connecting the veneer and the CMU backing were modeled for in-plane loading. The double eye and pintle system and a triwire tie systems were modeled using axial truss elements. These tie models were developed by Jo (Jo, 2010) in his research and were calibrated against experimental results.

The double eye and pintle tie system has already been described in Section 3.5.3.3. This section will focus on the triwire tie system. The approach used by Jo (Jo, 2010) to develop the tie model for the triwire tie system was similar to that used for the double eye and pintle system. Jo idealized the shear behavior of the connector as that of a fixed-fixed beam with a sidesway displacement of one end. It was acknowledged that mortar droppings influenced the effective length of the beam, and thus, its strength and stiffness. However, this effect only occurs in the initial stages of loading, for this loading direction, Since the critical wall system behavior is at the higher load levels, Jo (Jo, 2010) suggested ignoring the influence of the mortar droppings on the connector response. Based upon this assumption, and from mechanics, the elastic shear stiffness of the beam representation of the connector was computed using: 


$$
\text { Stiffness }=\frac{12 E I}{L^{3}}
$$

Furthermore, the shear strength, which is governed by flexural yielding at the ends of the beam, can be estimated as:

$$
\text { Strength }=\frac{2 f_{y} S}{L}
$$

Using the computed values of shear strength and stiffness, the displacement at yield can be computed as approximately 0.025 inches. As with the double eye and pintle system, Jo applied a multiplication factor of 1.4 to the theoretically computed shear strength to account for the inelastic effects and residual stresses. Jo (Jo, 2010) selected this value based on experimental results.

Thus, an elastic-plastic material model for the triwire connectors, shown Figure 3.42, was used. This model incorporates the first break point at a force of $0.035 \mathrm{kip}$ (the ultimate shear strength), with a displacement of 0.035 inches. The displacement of 0.035 inches was obtained using the elastic stiffness computed above, and the shear strength of 0.035 kips. 


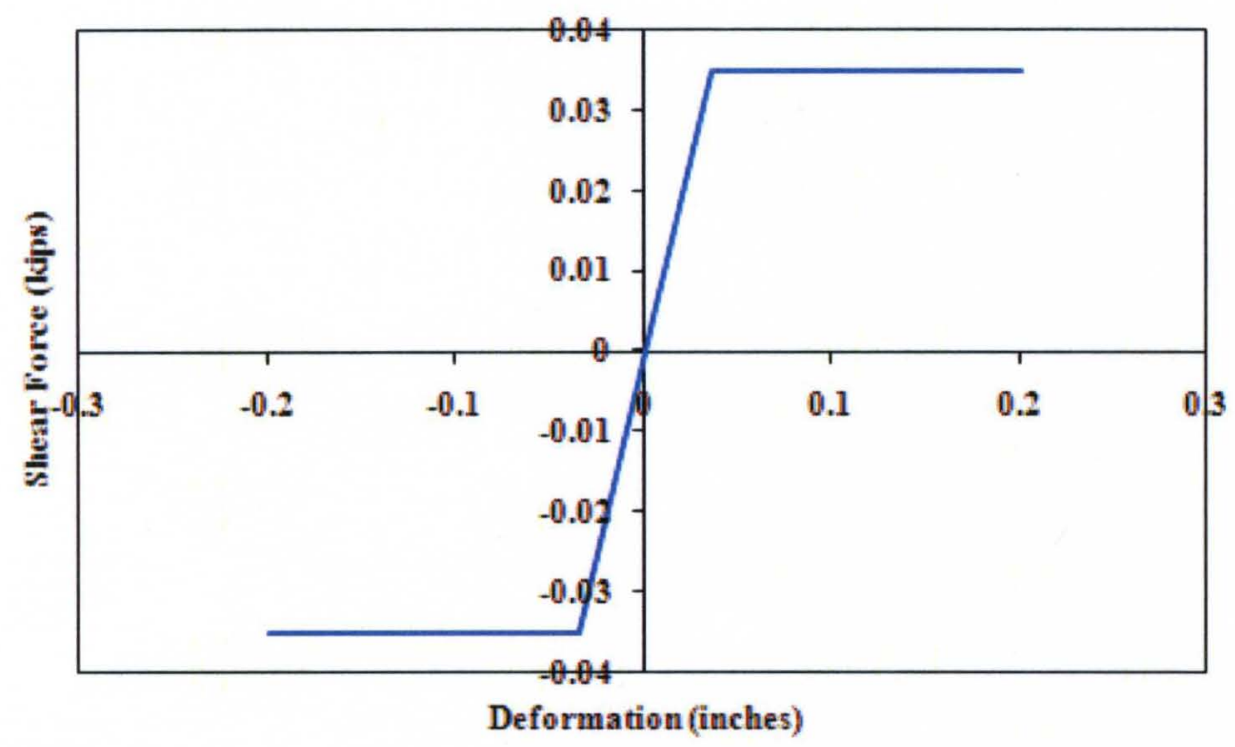

Figure 3.42: Shear Behavior of the Triwire Tie System

\subsubsection{Attachment of the Wall System to the Main Frame Under In - plane Loading}

The attachment of the CMU backed veneer wall system under in - plane loading to the main building frame girder (Figure 3.43) was similar to that used with the steel stud backed wall system. However, the veneer and backup were each represented by only a single vertical column of elastic beam column elements, and the floor girder was not divided at its one third points. It was divided into three segments, with the first and third segment being equal in length and the central segment being one inch in length, corresponding to the gap between the veneer and backup, across which the tie connectors span. The vertical column representing the CMU backing wall was attached to one end of the central floor girder element, and the vertical column representing the veneer was attached to the other end. The veneer was attached at its base in a manner similar to that 
in which it was attached in the case of the stud backed system. The base element of the CMU backing wall was attached to the floor girder using a zero length element that fully transferred the horizontal and vertical forces and transferred bending moments from the backing wall to the floor girder. These moments were assumed to correspond to the in plane moment curvature relationship of the section at the base of the backing wall, thereby simulating a cantilevered condition. The top of the backing wall was unsupported, unlike the top of the steel stud backing wall.

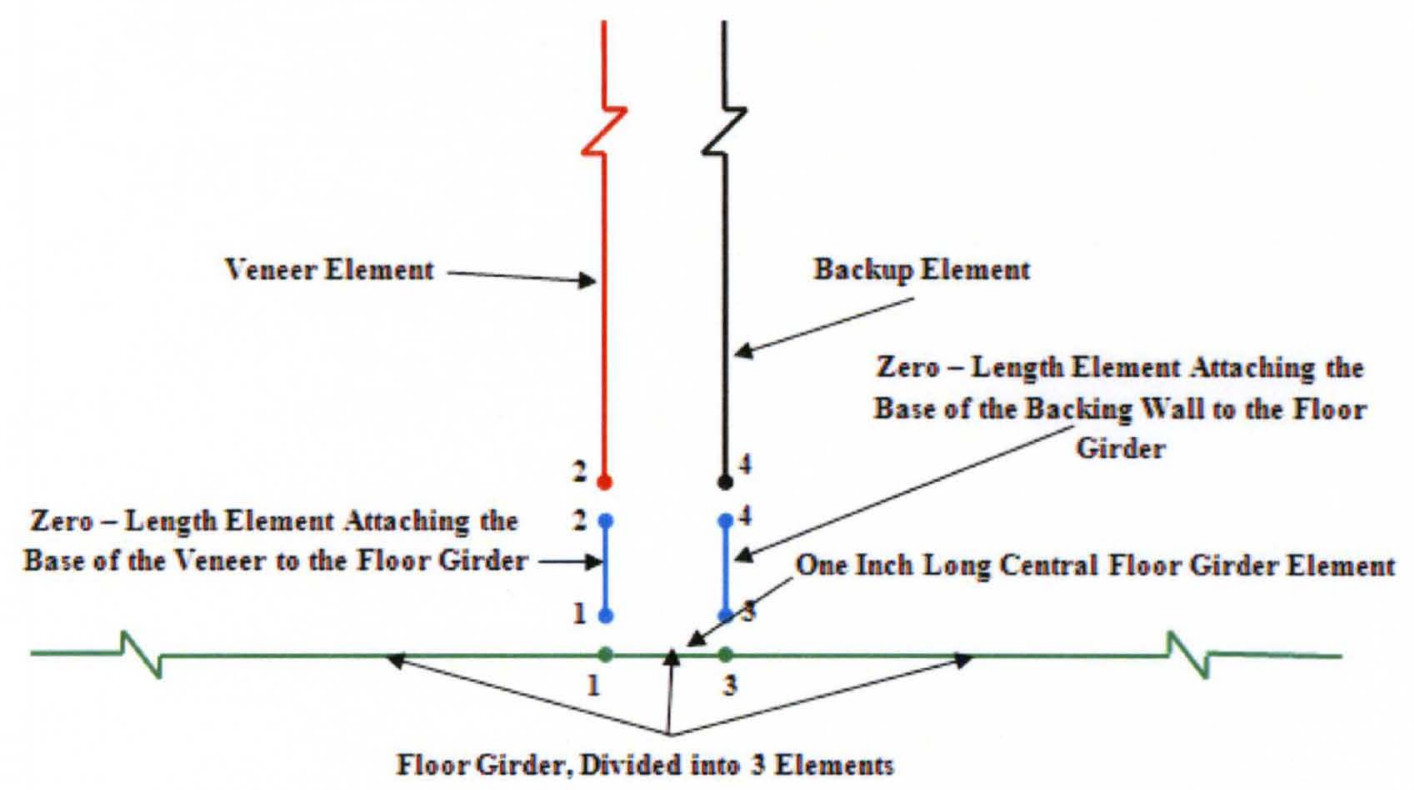

Figure 3.43: Attachment of the Base of the CMU Backed Wall System Under In Plane Loading, to the Mainframe

\subsection{Verification/Calibration}

This section addresses the verification of the structural building frame models and the calibration of the veneer wall system models. 


\subsubsection{Frame Models}

This section validates the element, section, and material models used in the structural building frames used in the investigation. A pushover analysis was conducted on these frames,as stipulated in the FEMA 273 document (FEMA, 1997) provisions, and compared to the expected behavior of such frames, based upon the work of other researchers (mentioned in Sections 3.6.1.2 through 3.6.1.5). This process was used to further validate the frame models. The models of the frames used in this investigation were calibrated by others using experimental results. Since the objective of this investigation was to understand the behavior of the veneer wall system in the main frame an exact representation of the main frame behavior was not required. However, for the veneer walls, the prime focus of this investigation, a detailed calibration of the models against experimental results was conducted. This calibration is described in the subsequent sections (Sections 3.6.2 through 3.6.5).

\subsubsection{Frame Models: Pushover Analysis Results}

In addition to using material and frame models that others have shown to predict the behavior of similar frame systems, the validity of the two dimensional steel and reinforced concrete, moment resisting and braced frame models used in this investigation was further demonstrated by comparing their response to standard, documented response of such frames under the action of a quasi static pushover analysis. 
A pushover analysis involves subjecting the nonlinear model of the building to monotonically increasing lateral forces or displacements until either a target displacement is exceeded, or the building collapses. Appropriate gravity loads are applied and combined according to Equation 3-2 of the FEMA 273 (FEMA, 1997) document. The control node at which the lateral displacement is applied is the center of mass at the roof of the building. Different profiles of lateral load can be applied to the building along its height, but they are required to represent the likely inertia forces in the building during an earthquake. For this analysis, a load pattern corresponding to the equivalent static loading pattern described earlier was applied to the building in increasing increments, until it collapsed. A comparison between the nonlinear pushover response of the frames considered in this investigation and their expected response is presented in the next four subsections.

\subsubsection{Steel Moment Resisting Frame}

As a part of his dissertation titled "Evaluation of the Seismic Level of Protection of Steel Moment Resisting Frame Building Structures", Aiman Mahmoud Samy Biddah (Biddah, 1998) studied the nonlinear pushover response of a ten storey steel moment resisting frame system. The building configuration that was considered is almost identical to that used in the ongoing investigation. The building was a three - bay by four - bay rectangular steel office building. The bay width in both directions was 26.64 feet (8 meters). The storey height for the buildings was 15 feet ( 4.5 meters) for the first floor, and 12 feet ( 3.6 meters) for the remaining storeys. The total height of the building was 
122.877 feet (36.9 meters). The lateral force resisting system was comprised of two peripheral steel moment resisting frames.

The comparison between the response of this frame, for bending about the weak axis of the building, in a nonlinear pushover analysis (Biddah, 1998), and that of the steel moment resisting frame using the models developed in the current investigation (but adjusted to match the Biddah configuration) is presented in Figure 3.44. In the figure, the base shear is normalized with respect to the design base shear of the structure, while the roof deflection is represented as a percentage of the structure heights. It is seen in the figure that the responses are very similar. The response of the frame considered in the current investigation is slightly more flexible, in regions of higher deflection, once inelastic response occurs. In the elastic region of response, the frames showed an identical response. In the inelastic region, Biddah's frame was about $2 \%$ stiffer than the frame used in the current investigation. . Considering that the primary goal of the investigation is to understand the behavior of the veneer wall in the frame, an exact behavior of the frame is not needed. The likely reason for difference this is that in Biddah's investigation, the increase in the lateral deflection due to P-Delta effects was felt only in the two peripheral frames of the building, which carried half the total vertical loads that acted upon the end bays of the building, whereas in the current investigation, the P-Delta effects increased the deflections of the six moment resisting frames that constituted the lateral force resisting system of the building. The material model used by Biddah in his investigation to simulate the behavior of steel accounted for strain 
hardening, whereas the model used in the ongoing investigation did not. This is another reason why Biddah's model showed a slightly stiffer performance than that of the model used in the current investigation.

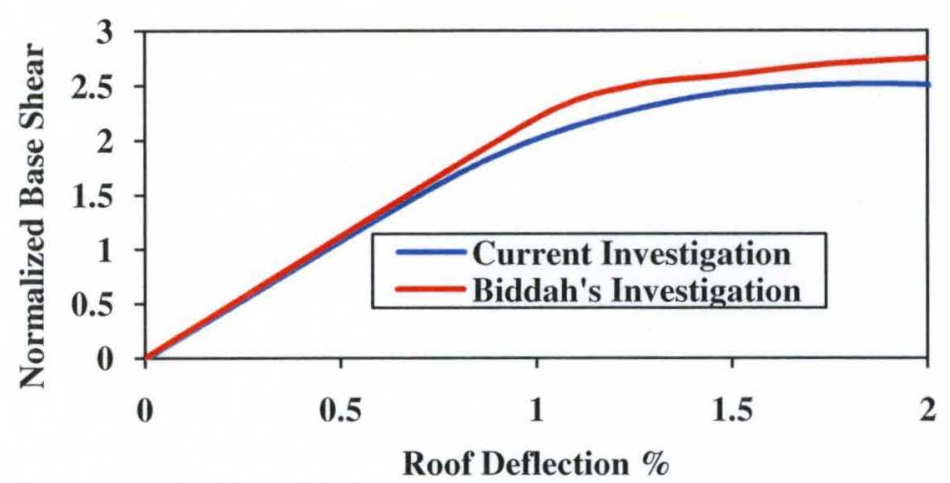

Figure 3.44: Calibration of the Steel Moment Resisting Frame

\subsubsection{Steel Braced Frame}

As a part of his dissertation titled "Performance - Based Seismic Engineering of Low and Medium Rise Frames", Saeid Rashidi (Rashidi, 2000) studied the nonlinear pushover response of a 12 storey steel braced frame system. The system that he investigated had a similar configuration to that considered in this research endeavor. It had a 150 feet by 150 feet square plan, and a height of 150 feet. The first storey was 18 feet high, and the remaining 11 storeys were each 12 feet high. The perimeter steel concentrically braced frames constituted the lateral force resisting system of the building. A comparison between the responses of this frame and an identical frame simulated using the models from the current investigation is shown in Figure 3.45. In the figure, the base shear is normalized with respect to the weight of the structures, while the global drift is defined as the roof horizontal displacement divided by the height of the building. In a nonlinear 
pushover analysis, the frame response obtained from Rashidi's investigation (Rashidi, 2000 ) is slightly stiffer (about 3\%) than that of the frame using the models developed in the current investigation.

The slight difference in stiffness of the frames is most likely due to the fact that Rashidi accounted for the effect of the compression braces to a greater extent than they were accounted for in the current investigation.

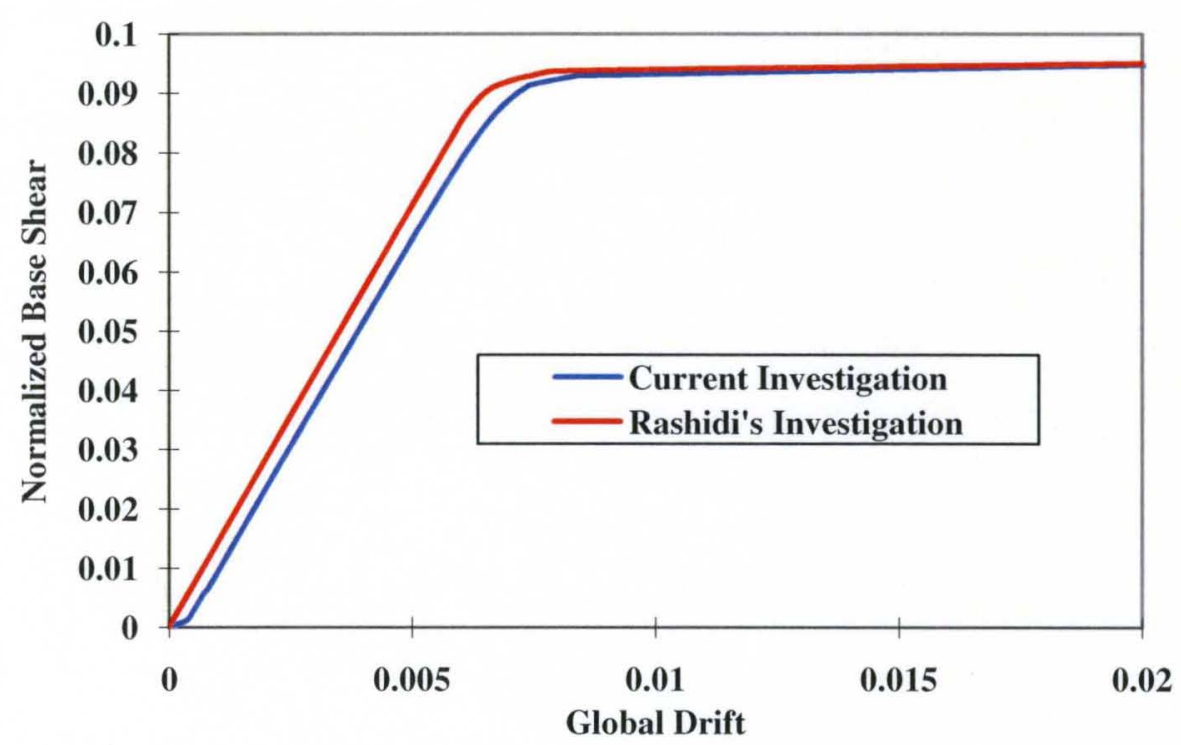

Figure 3.45: Calibration of the Steel Braced Frame

Considering that the primary goal of the investigation is to understand the behavior of the veneer wall in the frame, an exact behavior of the frame is not needed. 


\subsubsection{Reinforced Concrete Moment Resisting Frame}

As a part of his dissertation titled "Performance - Based Plastic Design of Earthquake Resistant Reinforced Concrete Moment Frames”, Wen Cheng Liao (Liao, 2010) studied the nonlinear pushover response of a 3-D, 12 storey reinforced concrete moment frame building system. The building had a square shaped plan and consisted of 3 bays, each having a width of 20 feet, in each direction. The height of the first storey of the building was 15 feet, and that of the remaining storeys was 13 feet, resulting in a total building height of 158 feet. A comparison between the responses of this frame and the frame used in the current investigation is shown in Figure 3.46. The response of both the frames was comprised of three linear segments. The first segment corresponded to the initial phase of the response, when the concrete was uncracked. Following this, the concrete cracked and the steel reinforcement participated in carrying the tensile load, represented by the second segment of the response. Finally, the third segment of the response corresponded to the region in which the steel in the reinforcement had crossed its yield point. It is seen from the figure that the response of the frame used in the current investigation was very similar to that of Liao's. The frame used in this investigation was about $11 \%$ stiffer in the first segment of the response, and about $13 \%$ stiffer in the second segment of the response. In the third segment of the response, both frames had an identical stiffness. Considering that the primary goal of the investigation is to understand the behavior of the veneer wall in the frame, an exact behavior of the frame is not needed. 


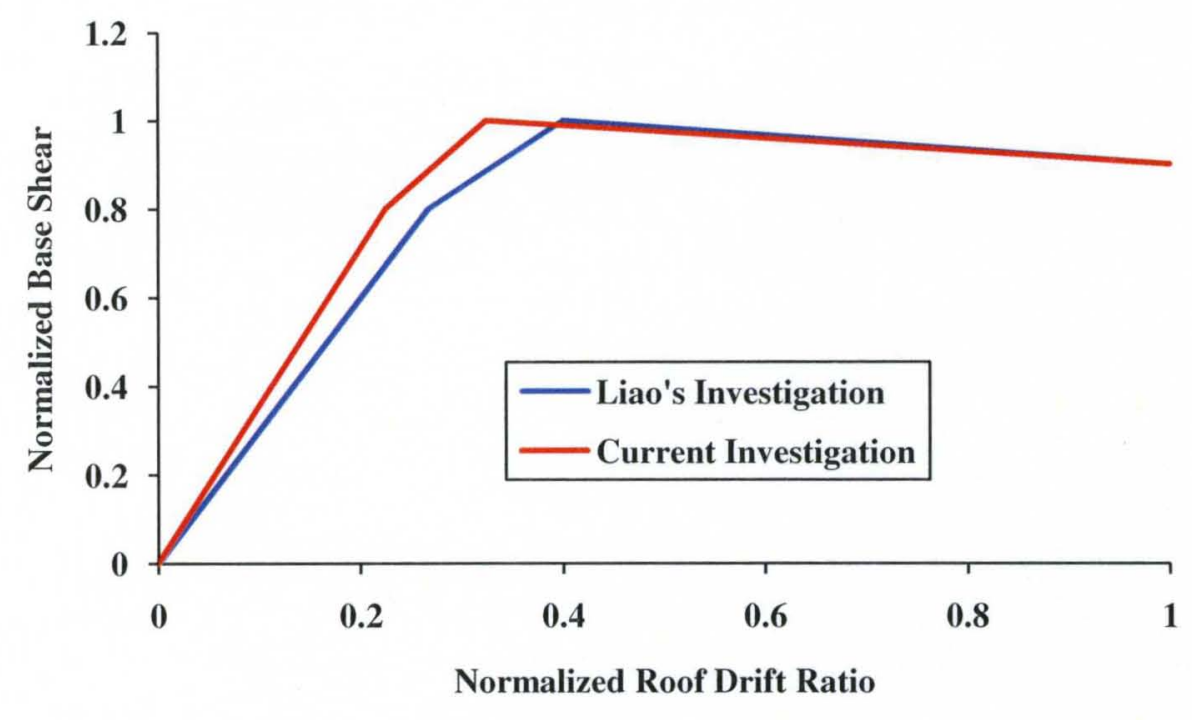

Figure 3.46: Calibration of the Reinforced Concrete Moment Resisting Frame

\subsubsection{Reinforced Concrete Shear Wall System}

As a part of his dissertation titled "Nonlinear Analysis of Reinforced Concrete Shear Wall Structures", Dilip Khatri (Khatri, 1998) studied the nonlinear pushover response of a 14 storey, 2-D reinforced concrete shear wall system. The shear wall that was individually tested was part of a 14 storey reinforced concrete shear wall structure. Prior to the work done by Khatri, William Gates had performed an elastic dynamic analysis of this building, and a complete description of this building can be obtained from the report prepared by him (Gates, 1973).

For the purpose of this discussion, the depth of the shear wall was 57 feet, and the width (thickness) was 12 inches. A comparison between the response of this shear wall, and the shear wall used in the current investigation can be seen in Figure 3.47. It can be 
seen from the figure that the response of the frame used in the current investigation was very similar to that of Khatri's. In the region of the response curves corresponding to that post cracking of the concrete, Khatri's frame stiffness was about $10 \%$ less than that of the frame used in the current investigation. In the region corresponding to that corresponding to post yield of the steel rebars, Khatri's frame stiffness was nearly identical to that of the frame used in the current investigation (about $2.9 \%$ stiffer). Considering that the primary goal of the investigation is to understand the behavior of the veneer wall in the frame, an exact behavior of the frame is not needed.

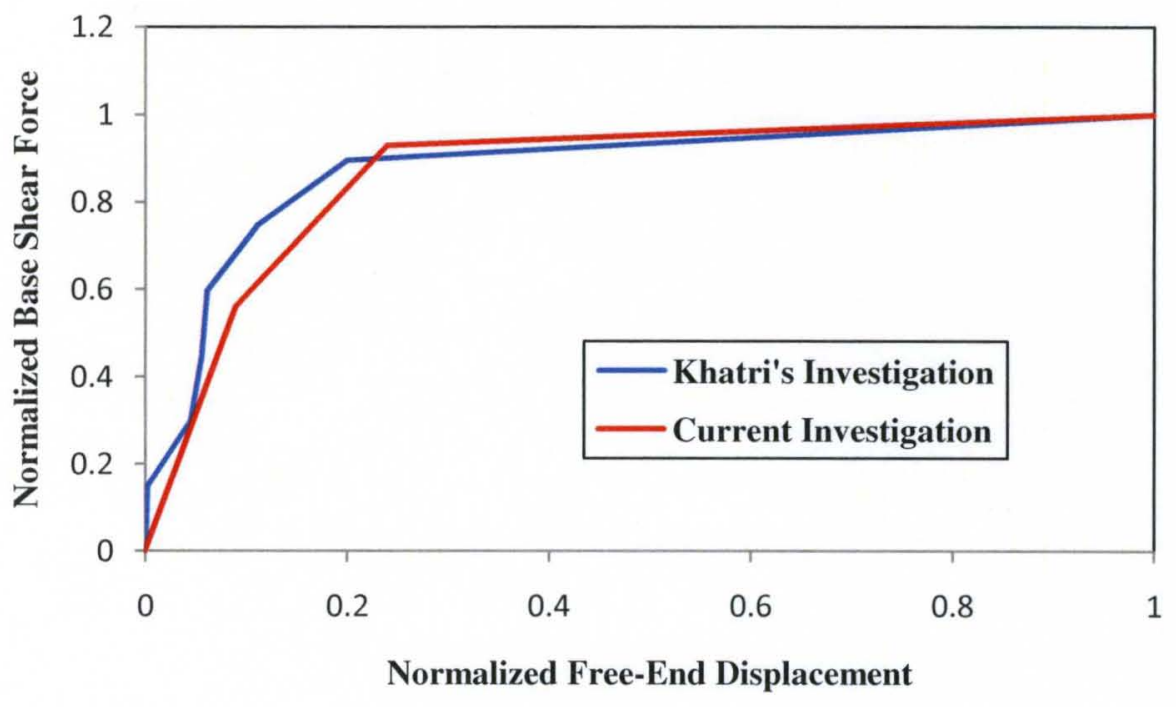

Figure 3.47: Calibration of the Reinforced Concrete Shear Wall System 


\subsubsection{Out of Plane Behavior of Veneer Wall System: Flexible (Steel Stud) Backing Wall}

Analytical models for the wood stud backed veneer wall systems loaded in their out of - plane directions, incorporating both flexible and stiff tie systems (Okail, 2010), were calibrated using the results of quasi - static cyclic tests veneer wall systems conducted at North Carolina A and T State University (McGinley and Hamoush, 2008) and both small and large scale dynamic testing. This section describes the tests conducted and the calibration of the models representing the steel stud backed wall systems loaded in their out - of - plane direction using the test data.

During McGinley's tests, a total of four $4 \mathrm{ft} \times 8 \mathrm{ft}$, full scale clay brick veneer wall specimens with a wood stud backing (Figures 3.48 and 3.49) were tested under quasi static cyclic out - of - plane loading using a whiffle tree apparatus. A whiffle tree is a mechanism that is used to create a number of uniform point loads on a surface. The backing wall consisted of nominal $2 \times 4$ inches wood studs, spaced at 16 inches on centers. The veneer consisted of nominal 4 inch standard modular clay units, and type $\mathrm{N}$ masonry cement mortar. $8 \mathrm{~d}$ nails were used to fasten the $7 / 16$ in. exterior grade Oriental Strand Board (OSB) to the wood studs, at a spacing of 6 inches on center on the edge studs, and 12 inches on center on the interior studs. A 0.5 inches thick gypsum wallboard was attached to the interior of the wood studs, using drywall screws spaced at 12 inches on center. 


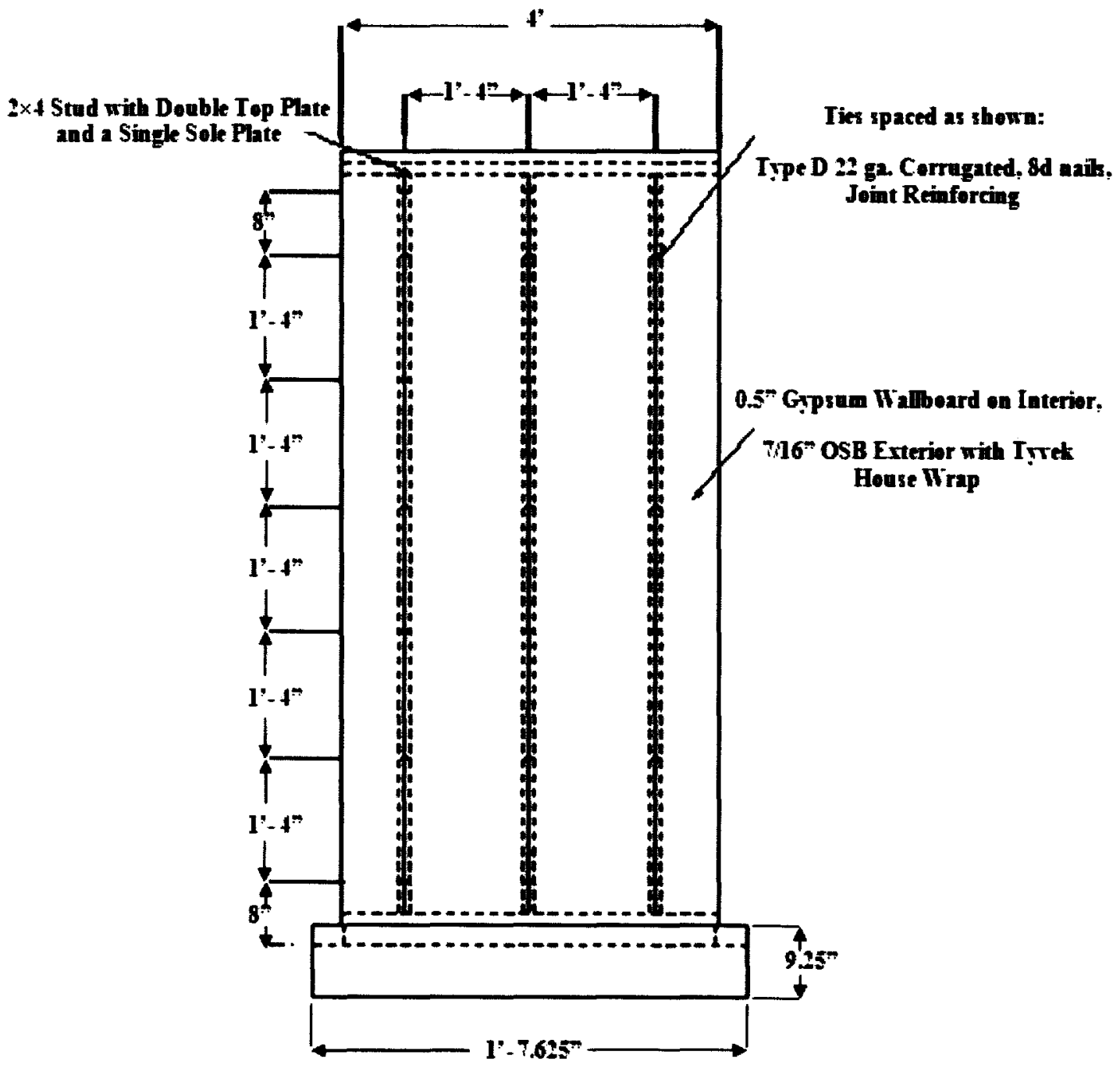

Figure 3.48: Elevation View of the Backing System (Adapted From (McGinley et al., 2011)) 


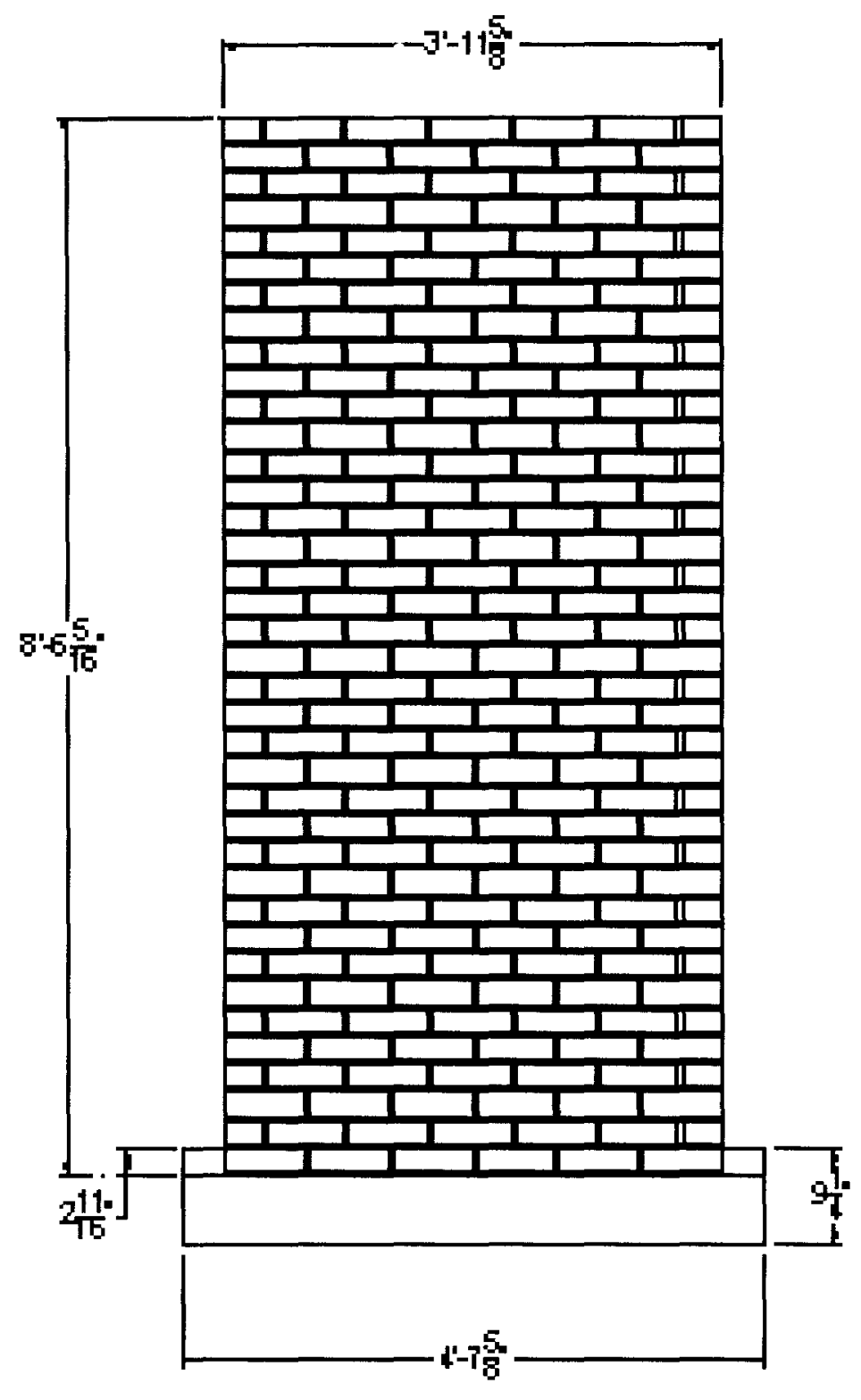

Figure 3.49: Elevation View of the Veneer (Adapted From (McGinley et al., 2011))

In the tests, a cyclic load was applied to the specimens. The loading protocol consisted of three cycles at a load of $250 \mathrm{lbs}$ (one cycle included both the pushing of the 
veneer towards the backing wall, and the pulling of the veneer away from the backing wall), followed by three more cycles at a load of $500 \mathrm{lbs}$. Following this, the load was increased in increments of $500 \mathrm{lbs}$ until the specimen collapsed.

Figure 3.50 shows the wood stud backed veneer wall system model developed by Okail (Okail, 2009) for out-of-plane loading. This model depends on a tie system model that is largely informed by the brick - tie - wood subassembly tests performed by Young - Hwan Choi and James Lafave (Choi and Lafave, 2004). The tie model suggested by Chio and adapted by Okail is shown in Figure 3.51. This model was found to provide a good estimate of the response of flexible tie systems to monotonic and cyclic loads, and when incorporated into a veneer wall system model, gives good agreement between predicted and measured response, under quasi-static (see Figures 3.52 and 3.53) and dynamic loads (Okail, 2009). 


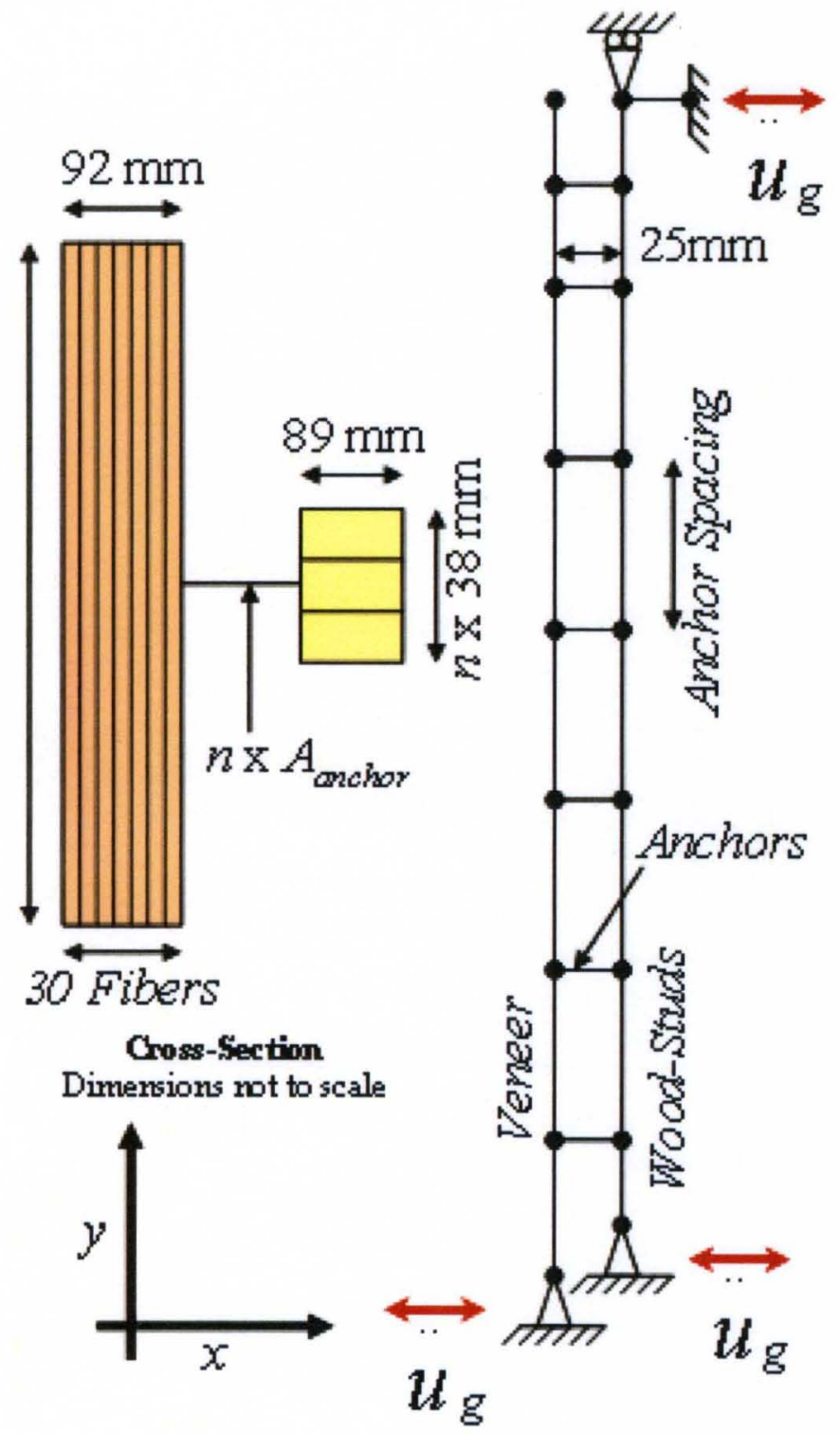

Figure 3.50: Finite Element Model of Wood Stud Backed Wall System Loaded in its Out - of - Plane Direction (Adapted From (Okail et al., 2009)) 


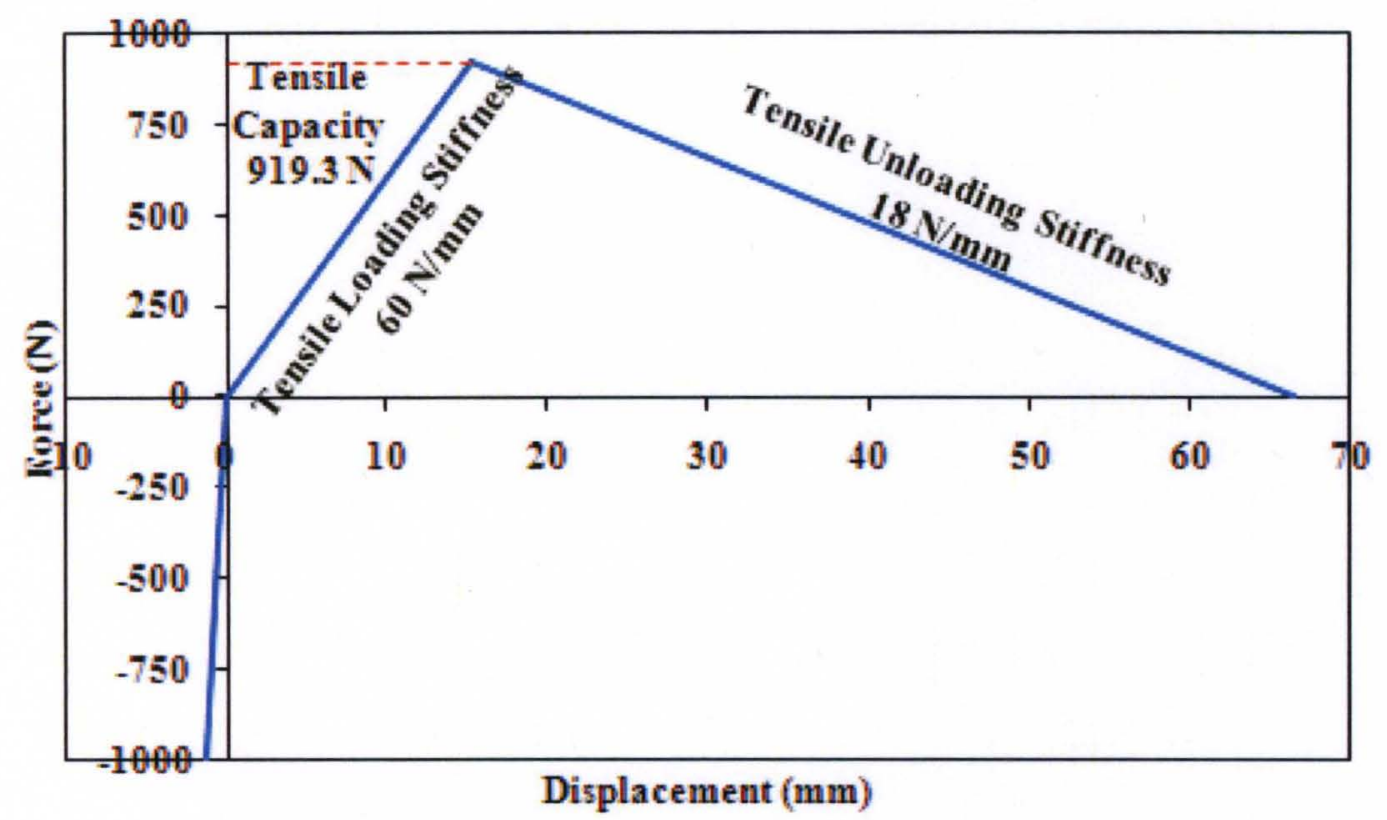

Figure 3.51: Flexible Tie Model, Used In Calibration Of Out - Of - Plane Wood Stud Backed Wall System

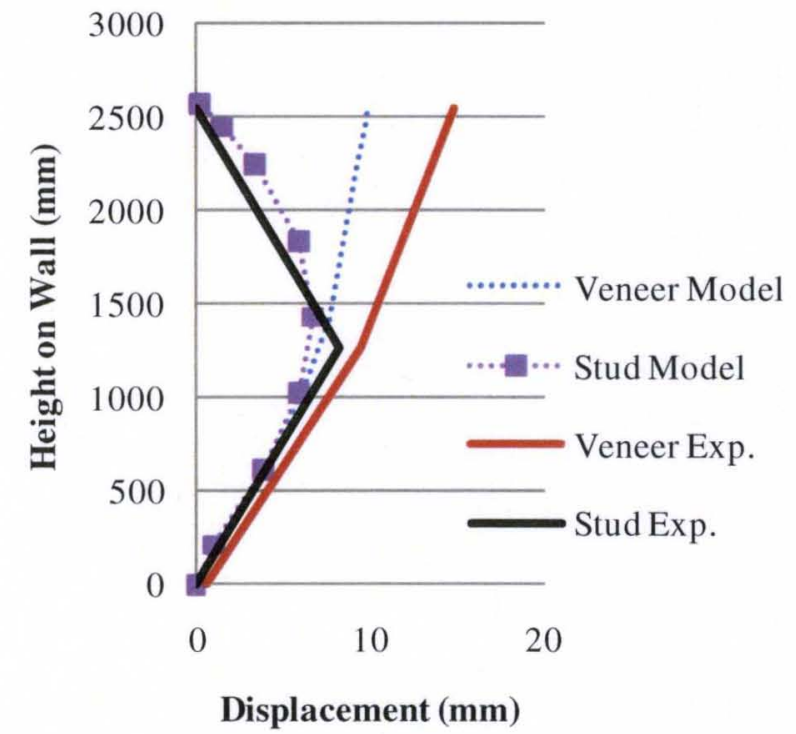

Figure 3.52: Comparison Between the Deformation Profiles of the Experimental Wall System, and that Predicted by the Analytical Model, Before Veneer Cracking (Adapted From (McGinley et al., 2011)) 


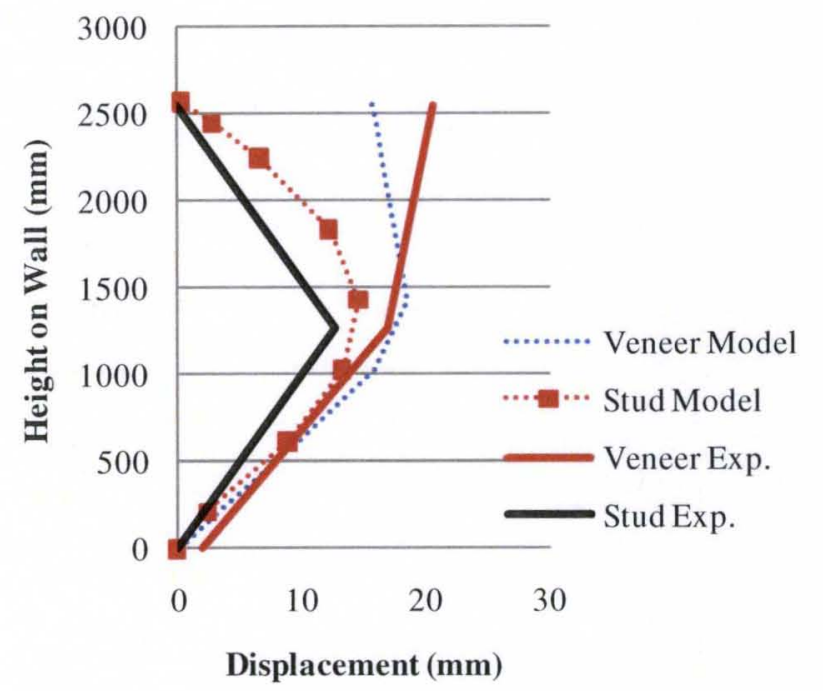

Figure 3.53: Comparison Between the Deformation Profiles of the Experimental Wall System, and that Predicted by the Analytical Model, After Veneer Cracking (Adapted From (McGinley et al., 2011))

In this investigation, the selection of the type of element and, the number of element integration points for the stud backed veneer wall system under out-of-plane loading was modeled based upon his work (Okail, 2010). Although Okail et-al investigated the seismic behavior of wood stud backed veneer wall systems, and the current investigation evaluated steel stud backed veneer wall systems, Okail's backup model can be used for the steel stud backed systems as well. The wood stud backup and the steel stud backup were both expected to have a very similar behavior, since both of them display a linear elastic response. 
The pullout strength of the ties in the wood studs was found to be critical and ranged from $460 \mathrm{~N}$ to $970 \mathrm{~N}$ (Okail et al., 2009), (Choi and Lafave, 2004). Okail also suggested that in tension, a loading stiffness of $60 \mathrm{~N} / \mathrm{mm}$ to $263 \mathrm{~N} / \mathrm{mm}$ be used for tie modeling, although, based on their test results, Choi and Lafave (Choi and Lafave, 2004) recommended a loading branch in tension comprising two segments, the first having a stiffness lying between $0.377 \mathrm{kip} / \mathrm{inch}(66 \mathrm{~N} / \mathrm{mm})$ and $0.8 \mathrm{kip} / \mathrm{inch}(139 \mathrm{~N} / \mathrm{mm})$, and the second, lying between 0.12kip/inch (21 N/mm) and 0.59kip/inch (104 N/mm).

The flexible ties in this investigation used a peak tension loading of 0.152 kips (676 N) to account for the higher capacity of the pintel systems and is based on the published capacities from these systems from manufacturer's literature (WIRE-BOND, 2011). Similarly, the tension capacity of the stiff ties was 0.792 kips $(3523 \mathrm{~N})$. The initial stiffness of the flexible ties were derived from the flexibility of the pintel legs at the code maximum extension of 1.25 inch and was $0.965 \mathrm{kip} /$ inch $(169 \mathrm{~N} / \mathrm{mm})$ and the stiff ties was based on the pintel leg flexibility at zero extension and resulted in a stiffness of 5.03 kip / inch ( $881 \mathrm{~N} / \mathrm{mm})$.

Results of the tests conducted by Choi and Lafave (Choi and Lafave, 2004) displayed a tensile unloading stiffness lying between $0.114 \mathrm{kip} / \mathrm{inch}(20 \mathrm{~N} / \mathrm{mm})$ and $1.04 \mathrm{kip} / \mathrm{inch}$ $(182 \mathrm{~N} / \mathrm{mm}$ ). The range of values recommended by Hussein (Hussein et al., 2009) for the 
same lay between $0.165 \mathrm{kip} /$ inch $(29 \mathrm{~N} / \mathrm{mm})$ and $0.228 \mathrm{kip} / \mathrm{inch}(40 \mathrm{~N} / \mathrm{mm})$. The value used for this in this investigation fell in this range.

For the wood stud backed wall systems, the tie model in elastic compression range was assumed to have a single loading segment in compression, with a slope of 700 $\mathrm{N} / \mathrm{mm}$, (Okail et al., 2009). These values provided a good correlation with the results of the quasi - static, cyclic experimental tests performed by McGinley and Hamoush (McGinley and Hamoush, 2008). For this investigation the flexible ties were assumed to have a compression slope of $3.03 \mathrm{kip} /$ inch $(531 \mathrm{~N} / \mathrm{mm})$ and the stiff ties a slope of 5.03 kip / inch $(881 \mathrm{~N} / \mathrm{mm})$. These values are based on the published capacities from these systems from manufacturer's literature (WIRE-BOND, 2011).

Section 3.5.1 of this dissertation described the models used in this investigation, for the steel stud backed wall systems loaded in their out - of - plane directions. These models were obtained by adjusting the out-of-plane wood stud models to account for difference in material and section properties, and wall dimensions. 


\subsubsection{Out of Plane Wall: Stiff Backing}

The analytical models for the CMU backed veneer wall system were obtained from Jo (Jo, 2010), as described in Section 3.5.2. These models were shown to produce good agreement with measured results (Jo, 2010).

Figure 3.54 shows the models of the CMU backed veneer wall system used for this investigation. The elastic CMU backing wall had a specified masonry compressive strength $\left(\mathrm{f}^{\prime} \mathrm{m}\right)$ of $1500 \mathrm{psi}$, and an elastic modulus of $900 \mathrm{f}^{\prime} \mathrm{m}$, as prescribed by the MSJC code (MSJC, 2008). The clay masonry veneer was assigned an elastic modulus,

$\mathrm{E}_{\mathrm{m}}=700 \mathrm{f}_{\mathrm{m}}(\mathrm{MSJC}, 2008)$.

Jo's models were adjusted for minor differences in materials and wall dimensions. 


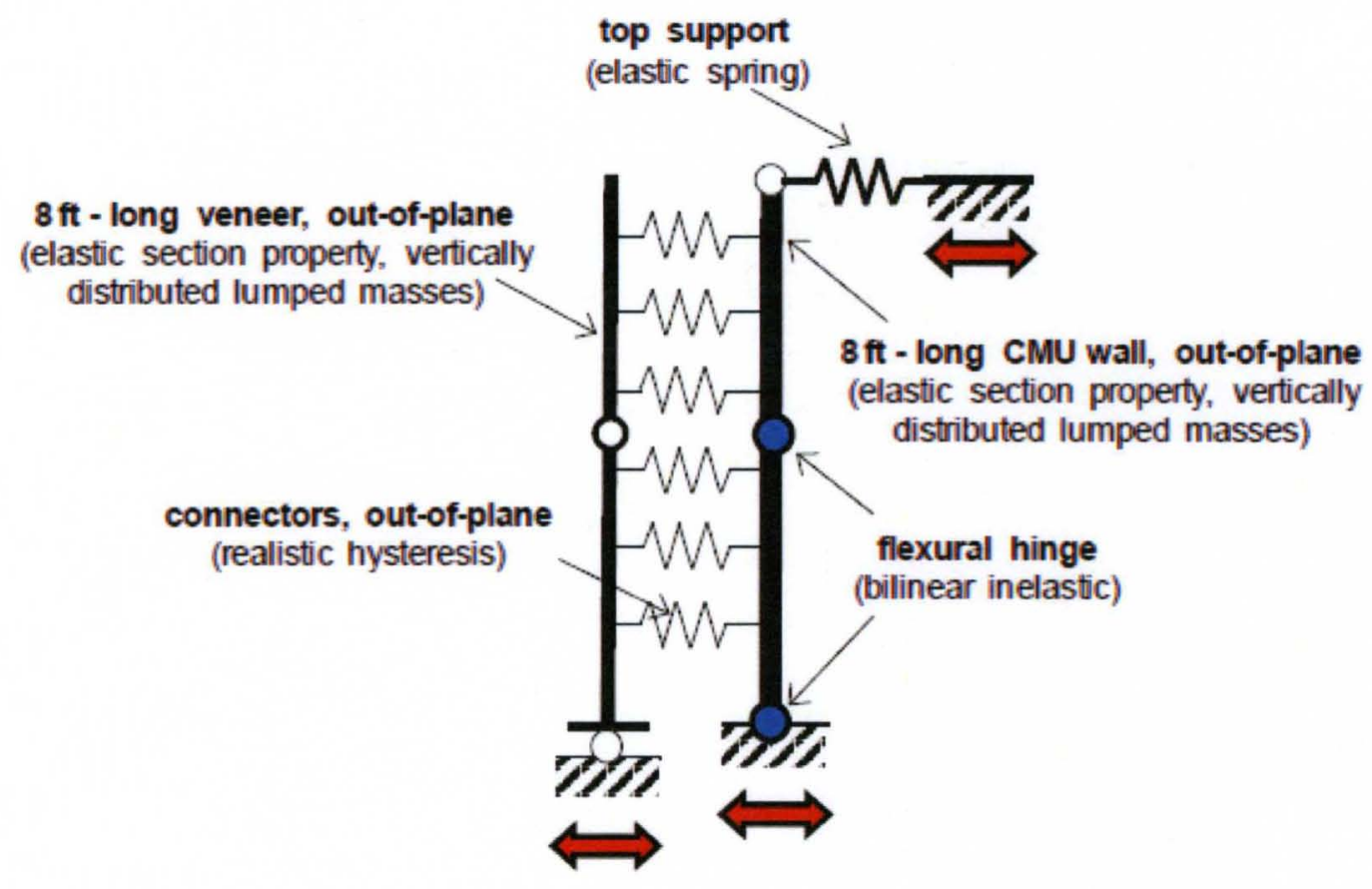

Figure 3.54: OpenSees Model for the CMU Out - of - Plane Wall Specimens (Adapted from Jo, 2010)

\subsubsection{In - plane Wall: Flexible Backing}

The models used for the in - plane stud backed wall system were obtained from a combination of sources. The in - plane veneer and tie models were directly taken from Jo's work (Jo, 2010). Only one tie type was considered for the in - plane stud backed wall system, the double eye and pintle system. In addition, it was assumed that there was a zero eccentricity between the pintle and the eyes. However, the in-plane response of the steel stud backing wall was calibrated against experimental evidence, as part of this investigation. 
As discussed earlier, the stud backing wall of the veneer wall system under in-plane loads was represented by a single bay braced frame attached to the structural building frame in each bay and every storey. The properties of this braced frame, and the nonlinear hysteretic material model assigned to its diagonal brace elements were obtained by first developing a braced frame stud wall model with a bay width of 16 inches. The section and material properties, and the nonlinear hysteretic material model assigned to the diagonal brace elements of this frame were obtained from the test results.This braced frame model was extrapolated to represent the 18 sections of studs over the 25 feet building frame bay width. This 18 bay model was then simplified into a single braced frame model that was then attached to the building frame floor girders as described in Section 3.5.3.1.

As a part of her research work, Katherine Hikita (Hikita, 2006) tested a total of 32 light gauge steel frame / wood panel shear walls. Amongst the different specimens that were tested, one of them included a $1220 \mathrm{~mm}$ long and $2440 \mathrm{~mm}$ high light gauge steel stud wall with an $11 \mathrm{~mm}$ thick OSB for wall sheathing, attached to it on one side via self drilling screws. Three 0.043 " thick steel studs were used in this specimen, at a spacing of $610 \mathrm{~mm}$ on center. This specimen was tested under the Consortium of Universities for Research in Earthquake Engineering (CUREE) reversed cyclic protocol for ordinary ground motions (Krawlinker et al., 2000; ASTM E2126, 2005). Based upon this protocol, the target displacement peaks and the number of cycles at each peak that were applied to the specimen tested in the research project are presented in Table 3.22. Additional details 
of this experiment can be accessed in the dissertation titled "Combined Gravity and Lateral Loading of Light Gauge Steel Frame / Wood Panel Shear Walls", by Katherine Hikita (Hikita, 2006).

Table 3.22: Experimental Loading Protocol (Hikita, 2006)

\begin{tabular}{cc}
\hline Target Displacement (in.) & Number of Cycles \\
\hline 0.067638 & 6 \\
0.101496 & 1 \\
0.076102 & 6 \\
0.135315 & 1 \\
0.101496 & 6 \\
0.27063 & 1 \\
0.202953 & 3 \\
0.405945 & 1 \\
0.304449 & 3 \\
0.54126 & 1 \\
0.405945 & 2 \\
0.947205 & 1 \\
0.710394 & 2 \\
1.35315 & 1 \\
1.014843 & 2 \\
2.029724 & 1 \\
1.522283 & 2 \\
2.706299 & 1 \\
2.029724 & 2 \\
\hline
\end{tabular}

An analytical model was developed on the OpenSees framework to replicate the behavior of the steel stud backed shear wall described above, under a nearly identical loading protocol. Some minor changes were incorporated in order to reduce the computational time. The loading protocol used to load the analytical model used only one cycle at each displacement peak within the region of elastic response of the system. An observation of the experimental results showed that the response of the system for a given 
displacement peak in the region of its inelastic response was nearly the same for each cycle at that peak, and hence, only one cycle at each displacement peak in the inelastic region should give a good approximation of the system behavior. The slightly modified loading protocol that was applied to the analytical model is shown in Table 3.23.

The braced frame stud model used to replicate the experiment discussed above (Hikita, 2006), used the 24 inch stud spacing of the experimental specimen. The height of each storey of the braced frame was 8 inches. As was discussed earlier in Section 3.5.3.1, the vertical column elements of the frame were modeled using steel elastic beam column elements, the horizontal beam elements were modeled using elastic truss elements, and the diagonal cross braces, using nonlinear truss elements. The vertical elastic beam - column elements were assigned a standard elastic modulus of steel, 29000 ksi. The horizontal truss elements were assigned a simple linear elastic material model, as their sole role was to transmit horizontal forces to the braces, and were assumed to have an elastic modulus of $1500 \mathrm{ksi}$. The diagonal truss elements had a tri -linear hysteretic material model associated with them and the characteristics of this model were determined based on the test results. The break points of this model are presented in Table 3.24 and the model itself is shown in Figure 3.55. A comparison between the analytical model and experimental results is shown in Figure 3.56. The model showed an initial stiffness that was identical to the experimental stiffness. The inelastic response in the model also started at the same level of loading as it did in the experiment. The peak 
load reached was also the same for both the analytical model and experimental specimen, as was the unloading slope.

Table 3.23: Loading Protocol Applied To Analytical Model

\begin{tabular}{cc}
\hline Target Displacement (in.) & Number of Cycles \\
\hline 0.067638 & 1 \\
0.101496 & 1 \\
0.135315 & 1 \\
0.27063 & 1 \\
0.405945 & 1 \\
0.304449 & 1 \\
0.54126 & 1 \\
0.405945 & 1 \\
0.947205 & 1 \\
0.710394 & 1 \\
1.35315 & 1 \\
1.014843 & 1 \\
2.029724 & 1 \\
1.522283 & 1 \\
2.706575 & 1 \\
2.029724 & 1 \\
\hline
\end{tabular}

Table 3.24: Hysteretic Material Model Assigned To Diagonal Truss Elements

\begin{tabular}{ccc}
\hline Breakpoint & Stress (ksi) & Strain (in./in.) \\
\hline 1 & 0.45 & 0.00054 \\
2 & 0.803933 & 0.005453 \\
3 & 0.0 & 0.02 \\
\hline
\end{tabular}

Additionally, the following parameters were used to completely define the model:

Pinching parameter for the $\mathrm{x}$ axis: 0.6

Pinching parameter for the y axis: 0.15 
Damage due to energy parameter: 0.25

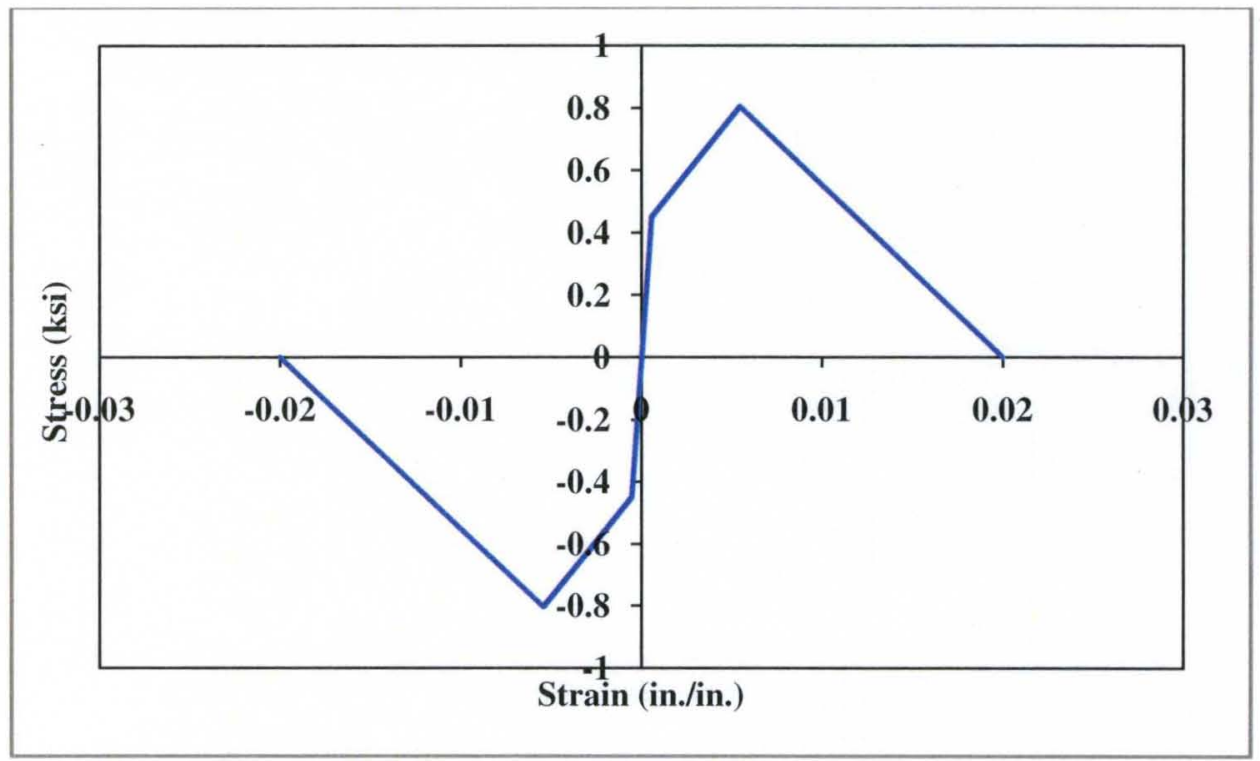

Figure 3.55: Diagonal Truss Element Hysteretic Model

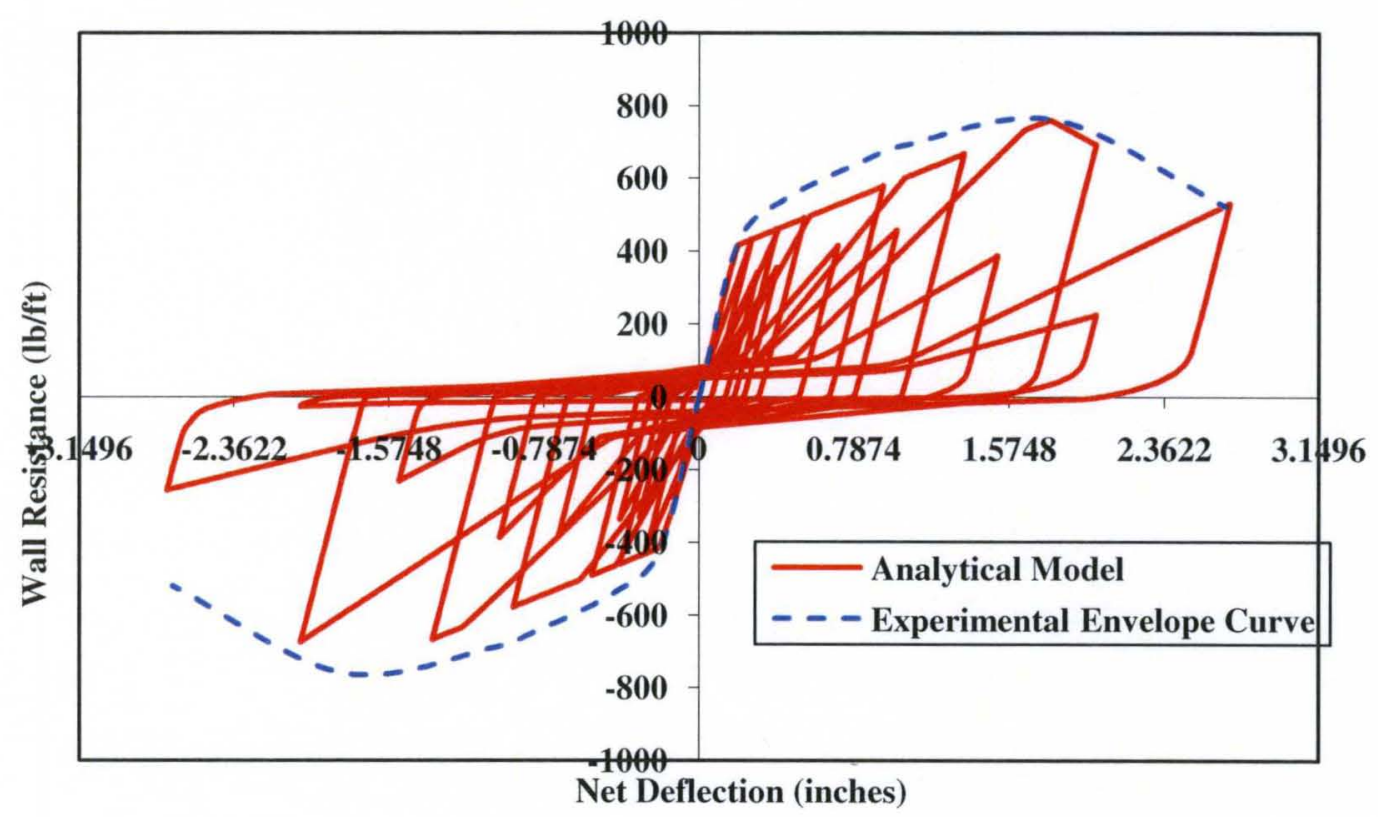

Figure 3.56: Comparison Between Experimental and Analytical Model Response of Steel Stud Backing Wall, Under In - Plane Loading 
The braced frame stud wall model was then developed from the test results was then extrapolated into the 18 stud spaced wall system that occurs in each bay of the building frame. This representation of the stud backed veneer wall system was loaded in its in plane direction to obtain its base shear versus roof displacement backbone curve under the effect of an incrementally increasing lateral pushover load. The following properties were used for the vertical elastic beam column elements and the horizontal and diagonal truss elements of the braced frame model (with the studs at 16 inches on center):

Area of each vertical element: $2 \times 0.413=0.826 \mathrm{in}^{2}$

Moment of Inertia about the minor axis of each vertical element: $0.087 \times 2=0.174 \mathrm{in}^{4}$

Area of each horizontal truss element: $2 \times 1.0=2.0 \mathrm{in}^{2}$

Area of each diagonal truss element: $2 \times 1.0=2.0 \mathrm{in}^{2}$

The material properties assigned to the vertical elastic beam - column elements, the horizontal elastic truss elements, and the nonlinear diagonal truss elements were the same as those obtained in the calibration process described earlier.

The final step of the stud backing wall model development process involved converting the 18 bay braced frame model into an equivalent single bay braced frame. For the equivalent single bay braced frame, to start with, arbitrary values of cross sectional area and moment of inertia of the elements were selected, and, during the calibration process, these were adjusted till the response of the equivalent single bay 
braced frame and that of the 18 bay braced frame, to an in - plane pushover loading, were nearly identical. For the sake of simplicity, each of the edge columns were assigned half of the computed sum of the areas and moments of inertia of all the elements at a storey level of the actual frame model. Furthermore, since there was only one diagonal truss element in the equivalent frame used to represent all the diagonal elements inclined in the same direction at that storey in the multi-stud frame, each diagonal truss element of the equivalent frame was assigned the sum of the areas and moments of inertias of all those elements in the mutli-stud frame. The same process was followed while assigning section properties to the horizontal truss elements that were intended to transfer the lateral load to the braces in the equivalent frame. Initially, the material model assigned to the diagonal truss elements of the equivalent frame was the same model used for the diagonal truss elements of the multi-stud braced frame. A pushover analysis on both the frames was conducted and the single frame system was the cross sectional areas and moments of inertia of the elements of the equivalent frame, and the break points of the hysteretic model assigned to the diagonal elements of the equivalent frame, were adjusted until a good match the base shear versus roof displacement response curve of the equivalent and actual frames was obtained. The comparison between the response of the muti-stud braced frame and the equivalent single bay braced frame to the lateral pushover load, is shown in Figure 3.57. The section properties and material models that were finally used for the equivalent single bay braced frame were presented earlier in this chapter. 


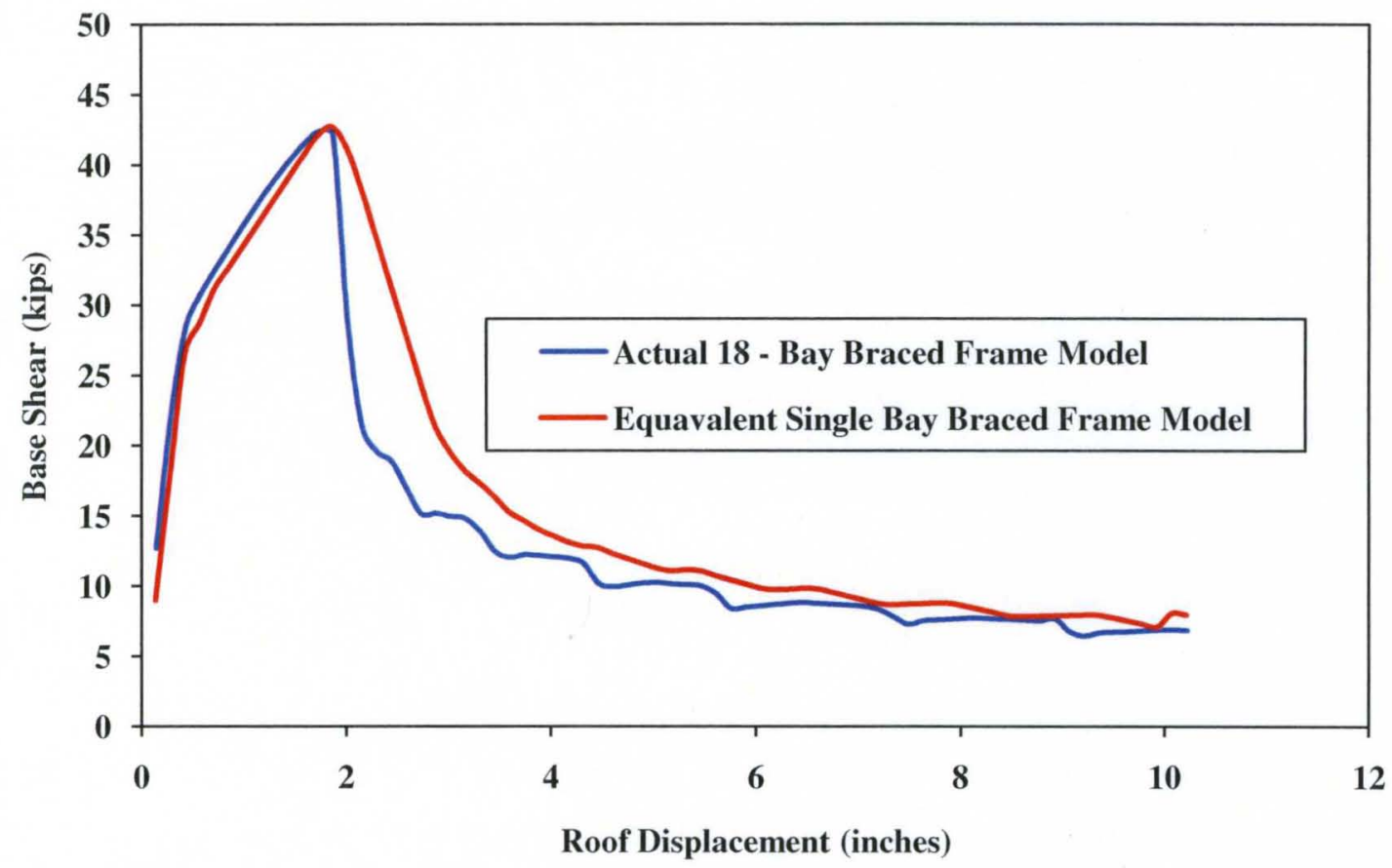

Figure 3.57: Comparison Between Response of Analytical Model of Actual Steel Stud Backing Wall, and Equivalent Steel Stud Backing Wall, Under In - Plane Loading

\subsubsection{In - plane Wall: Stiff Backing}

The in-plane CMU backing wall and veneer model developed by Jo (Jo, 2010) showed good agreement between predicted and measured behavior. These models for the in - plane CMU backed wall system were used and adjusted to account for differences wall dimensions and material properties. 


\subsection{Selection of Ground Motions}

The Sylmar and Tarzana ground motions (Figures 3.58 and 3.59) were chosen for evaluating the frames and veneer wall systems in this investigation. Both these ground motions were recorded during the 1994 Northridge earthquake. The total duration of the Sylmar ground motion was 40 seconds and the Tarzana ground motion was 60 seconds. To save computational time, the dynamic analysis was performed over only that time interval of the ground motion where the accelerations were not negligible. For the Sylmar ground motion, this time interval extended from 2 to 13 seconds, and for the Tarzana ground motion, from 3 to 18 seconds.

The Sylmar record has a peak ground acceleration of $0.84 \mathrm{~g}$ in one direction and 0.59 $\mathrm{g}$ in the other. For the Tarzana ground motion, the corresponding values are $1.79 \mathrm{~g}$ and $1.59 \mathrm{~g}$. The Tarzana record is very rich in high frequency content and has a higher ratio of peak ground acceleration to peak ground velocity or peak ground displacement than the Sylmar ground motion. It was used by $\mathrm{Jo}_{\mathrm{O}}(\mathrm{Jo}, 2010)$ in his shake table tests on $\mathrm{CMU}$ wall specimens precisely for this reason, since it made it possible for the shaking table to apply higher peak ground accelerations without exceeding its velocity or displacement limits. The ground motions were applied to the equivalent two - dimensional three bay frames, which were obtained from the transformation of the buildings from three to two dimensions. Hence, they were applied along the short direction of the building. 


\section{Sylmar}

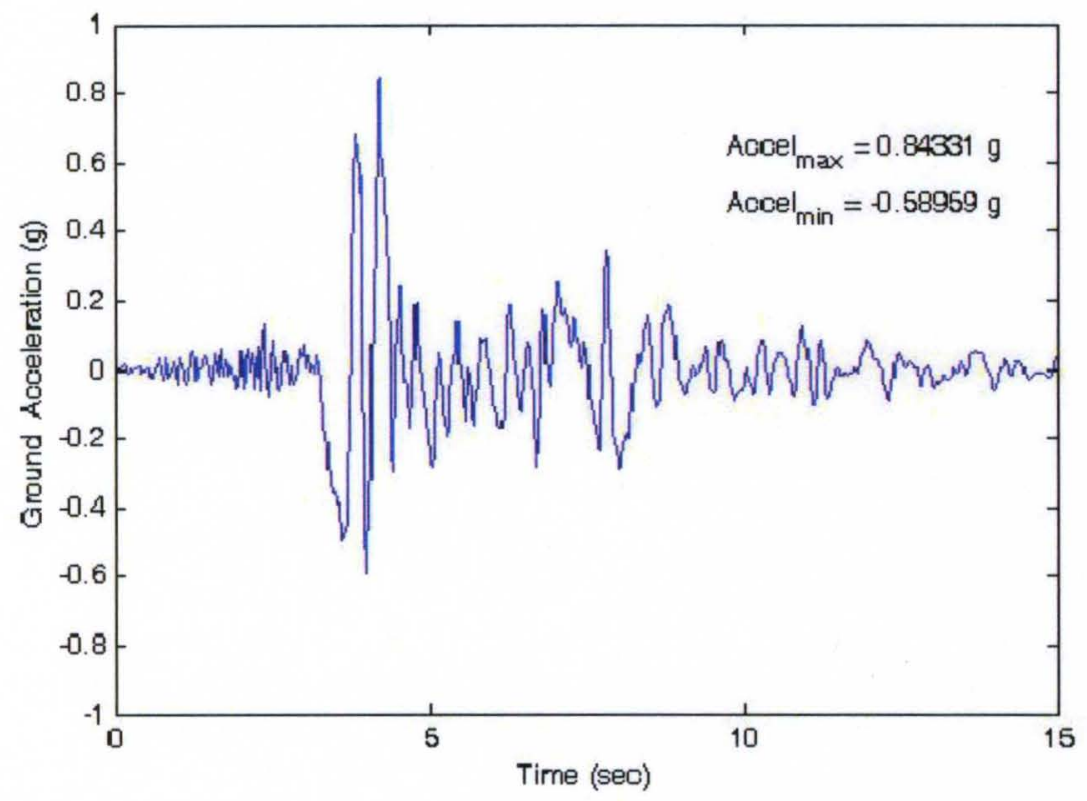

Figure 3.58: Sylmar Ground Motion Record (Adapted From (Jo, 2010))

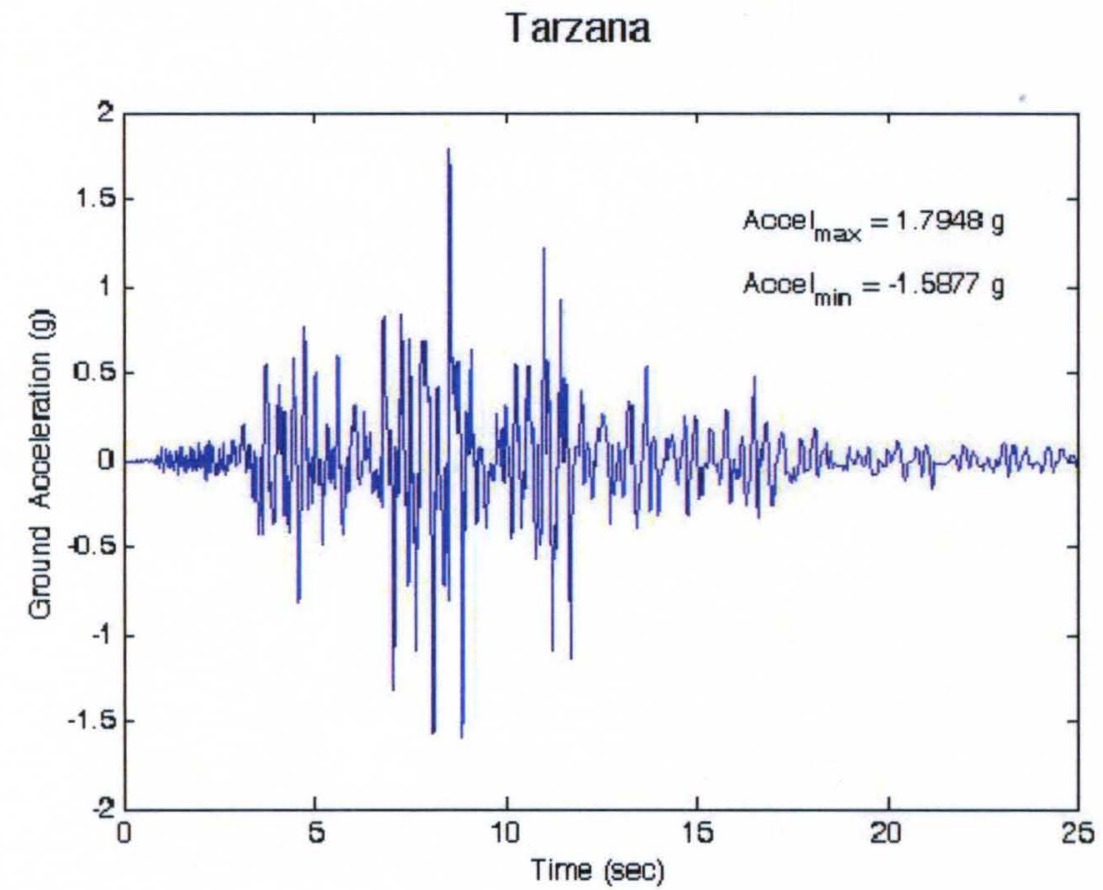

Figure 3.59: Tarzana Ground Motion Record (Adapted From (Jo, 2010)) 159 


\subsubsection{Scaling of the Ground Motions}

The Design Basis Earthquake (DBE) is an earthquake that has a $10 \%$ probability of occurrence in 50 years. Such an earthquake creates repairable damage to a structure. The systems crucial to the safety of the structure must remain functional and operable. From the point of view of design, this level of earthquake loading is defined for the economic design of structures whose damage or failure would not lead to a catastrophic loss. The DBE includes earthquake effects that are two - thirds of the corresponding Maximum Considered Earthquake (MCE) effects. The MCE is defined as that earthquake that has a $2 \%$ probability of occurrence in 50 years. The MCE includes the most severe effects considered in a building provision. Many building codes require non - essential buildings to be designed in such a way that they do not collapse in a MCE, whereby the building remains standing, permitting the safe exit of its occupants.

In order to define the $\mathrm{DBE}$ and MCE levels of each of the ground motions, they were scaled in a manner described by Hussein (Okail, 2010). The scaling process involved a sequence of steps. These included:

1) The response spectrum for each frame and ground motion were developed using the SEISMOSIGNAL software package developed by SEISMOSOFT (http://www.seismosoft.com/en/SeismoSignal.aspx). A damping ratio value of 5\% was used for the steel frames and one of $2 \%$ was used for the reinforced concrete frames for the calculation of the spectral acceleration values. 
2) A design response spectrum was constructed according to the provisions of Section 11.4.5 of ASCE - 07-05 (ASCE, 2005), for a location in Seismic Category D. For reasons mentioned earlier in Section 3.3.2.1, a value of 0.55 was used for the design earthquake spectral response acceleration parameter at short periods $\left(\mathrm{S}_{\mathrm{DS}}\right)$. A value of $\mathrm{S}_{\mathrm{Dl}}=0.22$ was selected for this analysis, since this is reasonably representative of an upper bound of locations in Seismic Category D.

3) Using these values described above, the expressions for the spectral accelerations $\left(S_{\mathrm{a}}\right)$ corresponding to the different fundamental periods of design response spectrum for a location in Seismic Category D was developed from Equations 11.4-5 to 11.4-7 of Section 11.4.5 of ASCE - 07 - 05 (ASCE, 2005), as:

For $T_{a}<T_{0}$

$$
S_{a}=S_{D S}\left(0.4+0.6 \frac{T_{a}}{T_{0}}\right)
$$

For $T_{0} \leq T_{a} \leq T_{S}$

$$
S_{a}=S_{D S}
$$

For $T_{S} \leq T_{a} \leq T_{L}$

$$
S_{a}=\frac{S_{D 1}}{T_{a}}
$$

For $T_{a}>T_{L}$

$$
S_{a}=\frac{S_{D 1} T_{L}}{T_{a}^{2}}
$$


where,

$T_{a}=$ the approximate fundamental period of the structure (calculated earlier).

$T_{0}=0.2 \frac{S_{D 1}}{S_{D S}}$

$T_{S}=\frac{S_{D 1}}{S_{D S}}$

$T_{L}=$ Long Transition Period, obtained from Figures $22-15$ to $22-19$ of ASCE $-07-05$ (ASCE, 2005). Inspection of the contour maps available in the figures mentioned above, show that these values were significantly larger than $T_{a}$ for all the frames.

Using the approximate time periods of the four building frames, the values of the spectral accelerations were extracted from the response spectra of the individual ground motions, and from the design response spectrum derived in accordance to the provisions of ASCE 07-05. Based upon the technique used by Hussein (Okail, 2010), the scaling factor applied to the ground motion to obtain the DBE was the ratio of the spectral acceleration obtained from the provisions of ASCE - 07-05 (ASCE, 2005), to the spectral acceleration obtained from the response spectrum of the individual ground motions, at the fundamental period of the system being considered. This value was multiplied by a factor of 1.5 to get the scaling factor that was used to determine the MCE, in accordance with the provisions of Section 11.4.6 of ASCE - 07-05 (ASCE, 2005). 
Based upon the equations shown above, and using the values of $S_{D 1}$ and $S_{D S}$ mentioned earlier (in point number 2 of this Section), the values of $T_{0}$ and $T_{S}$ are 0.08 and 0.4. From an inspection of the approximate time periods of the frames, $\mathrm{T}_{\mathrm{a}}$ is greater than $T_{S}$ for all the frames. Hence, the value of the spectral response acceleration $S_{a}$, for all four frames being considered in this investigation is obtained from the equation $S_{a}=S_{D 1} / T_{a}$. These values of $S_{a}$, obtained from the design response spectrum developed using the provisions of ASCE - $07-05$, are shown in Table 3.25.

Table 3.25: Frame Spectral Response Acceleration Based Upon Design Response Spectrum

\begin{tabular}{cc}
\hline Frame Type & $\mathbf{S}_{\mathbf{a}}(\mathbf{g})$ \\
\hline Steel Moment Resisting Frame & 0.1706 \\
Steel Braced Frame & 0.3034 \\
RC Moment Resisting Frame & 0.185 \\
RC Shear Wall System & 0.3034 \\
\hline
\end{tabular}

The approximate site specific design response spectrum and the approximate response spectra for the Sylmar and Tarzana ground motions using a damping value of $5 \%$ for the steel frames and $2 \%$ for the reinforced concrete frames are shown in Figure 3.60. 


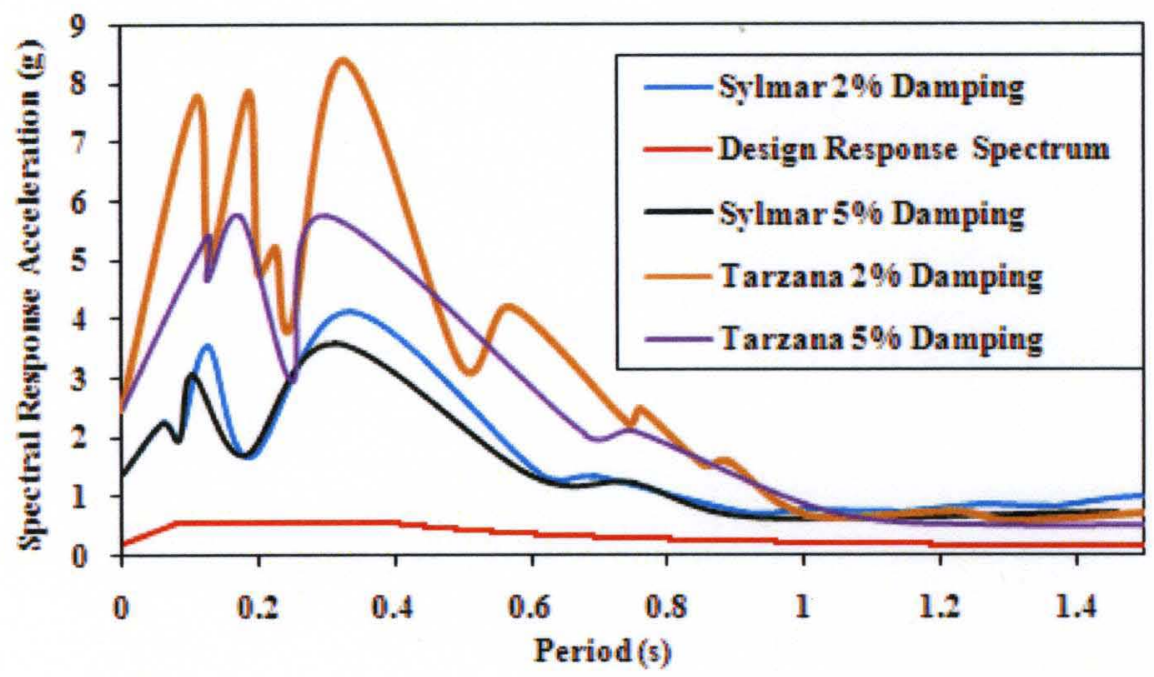

Figure 3.60: Approximate Response Spectra

The values of $S_{a}$, obtained from the response spectra of the Sylmar and Tarzana ground motions, for the time periods of the four different frames, are shown in Tables 3.26 and 3.27 .

Table 3.26: Frame Spectral Response Acceleration Based Upon Response Spectrum of Sylmar Ground Motion

\begin{tabular}{cc}
\hline Frame Type & $\mathbf{S}_{\mathbf{a}}(\mathbf{g})$ \\
\hline Steel Moment Resisting Frame & 0.72 \\
Steel Braced Frame & 1.12 \\
RC Moment Resisting Frame & 0.77 \\
RC Shear Wall System & 1.36 \\
\hline
\end{tabular}

Table 3.27: Frame Spectral Response Acceleration Based Upon Response Spectrum of Tarzana Ground Motion

\begin{tabular}{cc}
\hline Frame Type & $\mathbf{S}_{\mathrm{a}}(\mathbf{g})$ \\
\hline Steel Moment Resisting Frame & 0.52 \\
Steel Braced Frame & 2.08 \\
RC Moment Resisting Frame & 0.8 \\
RC Shear Wall System & 2.25 \\
\hline
\end{tabular}


Using these values, the scaling factors that correspond to the DBE and MCE earthquake levels of the four frames are shown in Tables 3.28 and 3.29. Based upon the ASCE 7 provisions, the MCE level is simply 1.5 times the DBE level.

Table 3.28: DBE Scaling Factors

\begin{tabular}{ccc}
\hline Frame Type & Scaling Factor (Sylmar) & Scaling Factor (Tarzana) \\
\hline Steel Moment Resisting Frame & 0.2369 & 0.3281 \\
Steel Braced Frame & 0.271 & 0.1458 \\
RC Moment Resisting Frame & 0.24 & 0.2312 \\
RC Shear Wall System & 0.2231 & 0.1348 \\
\hline
\end{tabular}

Table 3.29: MCE Scaling Factors

\begin{tabular}{ccc}
\hline Frame Type & Scaling Factor (Sylmar) & Scaling Factor (Tarzana) \\
\hline Steel Moment Resisting Frame & 0.3553 & 0.4922 \\
Steel Braced Frame & 0.4065 & 0.2187 \\
RC Moment Resisting Frame & 0.36 & 0.3468 \\
RC Shear Wall System & 0.3346 & 0.2022 \\
\hline
\end{tabular}

\subsection{Parametric Study}

In order to understand the influence of different characteristics of the veneer wall and building structural frame systems on the overall response of the systems, a parametric study was conducted using the nonlinear models and the OpenSees software. The parameters that were varied were:

1) The type building structural frame system. 
2) The backing wall used to support the veneer, both in the in and out - of - plane loading directions.

3) The type of ties used in the veneer wall systems loaded, both in - plane and out - of plane.

4) The ground motion used to shake the combined building frame and veneer wall systems.

Each of the analytical models were subjected to ground shaking with the Sylmar and Tarzana ground motions, at two levels, the DBE and the MCE. The results of this parametric study are presented in the next chapter. After being subjected to MCE level ground motions, each model was subjected to increasing amplitude ground motions until collapse, or a component of the system failed. The failure mode and level of ground shaking were recorded. The list of simulations performed are shown in Tables 3.30 to 3.35. The interpretation of each symbol used in the Table is shown in Table 3.36. 
Table 3.30: Simulations Performed on Concrete Moment Resisting Frame, Veneer Wall Loaded in Out - of - Plane Direction

\begin{tabular}{|c|c|}
\hline Serial Number & Model ID \\
\hline $\begin{array}{l}1 \\
2 \\
3\end{array}$ & $\begin{array}{l}\text { cmrf/op-mass/cmu/none/ip-mass/cmu/none/syl/dbe } \\
\text { cmrf/op-am/cmu/de/ip-mass/cmu/none/syl/dbe } \\
\text { cmrf/op-am/cmu/tw/ip-mass/cmu/none/syl/dbe }\end{array}$ \\
\hline $\begin{array}{l}4 \\
5 \\
6\end{array}$ & $\begin{array}{l}\text { cmrf/op-mass/cmu/none/ip-mass/cmu/none/syl/mce } \\
\text { cmrf/op-am/cmu/de/ip-mass/cmu/none/syl/mce } \\
\text { cmrf/op-am/cmu/tw/ip-mass/cmu/none/syl/mce }\end{array}$ \\
\hline $\begin{array}{l}7 \\
8 \\
9\end{array}$ & $\begin{array}{l}\text { cmrf/op-mass/cmu/none/ip-mass/cmu/none/tar/dbe } \\
\text { cmrf/op-am/cmu/de/ip-mass/cmu/none/tar/dbe } \\
\text { cmrf/op-am/cmu/tw/ip-mass/cmu/none/tar/dbe }\end{array}$ \\
\hline $\begin{array}{l}10 \\
11 \\
12\end{array}$ & $\begin{array}{l}\text { cmrf/op-mass/cmu/none/ip-mass/cmu/none/tar/mce } \\
\text { cmrf/op-am/cmu/de/ip-mass/cmu/none/tar/mce } \\
\text { cmrf/op-am/cmu/tw/ip-mass/cmu/none/tar/mce }\end{array}$ \\
\hline $\begin{array}{l}13 \\
14 \\
15\end{array}$ & $\begin{array}{l}\text { cmrf/op-mass/studs/none/ip-mass/studs/none/syl/dbe } \\
\text { cmrf/op-am/studs/de-flex/ip-mass/studs/none/syl/dbe } \\
\text { cmrf/op-am/studs/de-stiff/ip-mass/studs/none/syl/dbe }\end{array}$ \\
\hline $\begin{array}{l}16 \\
17 \\
18\end{array}$ & $\begin{array}{l}\text { cmrf/op-mass/studs/none/ip-mass/studs/none/syl/mce } \\
\text { cmrf/op-am/studs/de-flex/ip-mass/studs/none/syl/mce } \\
\text { cmrf/op-am/studs/de-stiff/ip-mass/studs/none/syl/mce }\end{array}$ \\
\hline $\begin{array}{l}19 \\
20 \\
21\end{array}$ & $\begin{array}{l}\text { cmrf/op-mass/studs/none/ip-mass/studs/none/tar/dbe } \\
\text { cmrf/op-am/studs/de-flex/ip-mass/studs/none/tar/dbe } \\
\text { cmrf/op-am/studs/de-stiff/ip-mass/studs/none/tar/dbe }\end{array}$ \\
\hline $\begin{array}{l}22 \\
23 \\
24\end{array}$ & $\begin{array}{l}\text { cmrf/op-mass/studs/none/ip-mass/studs/none/tar/mce } \\
\text { cmrf/op-am/studs/de-flex/ip-mass/studs/none/tar/mce } \\
\text { cmrf/op-am/studs/de-stiff/ip-mass/studs/none/tar/mce }\end{array}$ \\
\hline
\end{tabular}




\section{Table 3.31: Simulations Performed on Concrete Shear Wall System, Veneer Wall}

Loaded in Out - of - Plane Direction

Serial Number

25

26

27

28

29

30

31

32

33

34

35

36

37

38

39

40

41

42

43

44

45

46

47

48 cb/op-mass/cmu/none/ip-mass/cmu/none/syl/dbe cb/op-am/cmu/de/ip-mass/cmu/none/syl/dbe cb/op-am/cmu/tw/ip-mass/cmu/none/syl/dbe

cb/op-mass/cmu/none/ip-mass/cmu/none/syl/mce cb/op-am/cmu/de/ip-mass/cmu/none/syl/mce $\mathrm{cb} / \mathrm{op}-\mathrm{am} / \mathrm{cmu} / \mathrm{tw} / \mathrm{ip}-\mathrm{mass} / \mathrm{cmu} / \mathrm{none} / \mathrm{syl} / \mathrm{mce}$

cb/op-mass/cmu/none/ip-mass/cmu/none/tar/dbe cb/op-am/cmu/de/ip-mass/cmu/none/tar/dbe cb/op-am/cmu/tw/ip-mass/cmu/none/tar/dbe

cb/op-mass/cmu/none/ip-mass/cmu/none/tar/mce $\mathrm{cb} / \mathrm{op}-\mathrm{am} / \mathrm{cmu} / \mathrm{de} / \mathrm{ip}-\mathrm{mass} / \mathrm{cmu} /$ none/tar/mce $\mathrm{cb} / \mathrm{op}-\mathrm{am} / \mathrm{cmu} / \mathrm{tw} / \mathrm{ip}-\mathrm{mass} / \mathrm{cmu} /$ none/tar/mce

cb/op-mass/studs/none/ip-mass/studs/none/syl/dbe cb/op-am/studs/de-flex/ip-mass/studs/none/syl/dbe cb/op-am/studs/de-stiff/ip-mass/studs/none/syl/dbe

cb/op-mass/studs/none/ip-mass/studs/none/syl/mce cb/op-am/studs/de-flex/ip-mass/studs/none/syl/mce cb/op-am/studs/de-stiff/ip-mass/studs/none/syl/mce

cb/op-mass/studs/none/ip-mass/studs/none/tar/dbe cb/op-am/studs/de-flex/ip-mass/studs/none/tar/dbe cb/op-am/studs/de-stiff/ip-mass/studs/none/tar/dbe

cb/op-mass/studs/none/ip-mass/studs/none/tar/mce cb/op-am/studs/de-flex/ip-mass/studs/none/tar/mce cb/op-am/studs/de-stiff/ip-mass/studs/none/tar/mce 
Table 3.32: Simulations Performed on Steel Braced Frame, Veneer Wall Loaded in Out - of - Plane Direction

\begin{tabular}{|c|c|}
\hline Serial Number & Model ID \\
\hline $\begin{array}{l}49 \\
50 \\
51\end{array}$ & $\begin{array}{l}\mathrm{sb} / \mathrm{op}-\mathrm{mass} / \mathrm{cmu} / \mathrm{none} / \mathrm{ip}-\mathrm{mass} / \mathrm{cmu} / \mathrm{none} / \mathrm{syl} / \mathrm{dbe} \\
\mathrm{sb} / \mathrm{op}-\mathrm{am} / \mathrm{cmu} / \mathrm{de} / \mathrm{ip}-\mathrm{mass} / \mathrm{cmu} / \text { none/syl/dbe } \\
\text { sb/op-am/cmu/tw/ip-mass/cmu/none/syl/dbe }\end{array}$ \\
\hline $\begin{array}{l}52 \\
53 \\
54\end{array}$ & $\begin{array}{l}\text { sb/op-mass/cmu/none/ip-mass/cmu/none/syl/mce } \\
\text { sb/op-am/cmu/de/ip-mass/cmu/none/syl/mce } \\
\text { sb/op-am/cmu/tw/ip-mass/cmu/none/syl/mce }\end{array}$ \\
\hline $\begin{array}{l}55 \\
56 \\
57\end{array}$ & $\begin{array}{l}\mathrm{sb} / \mathrm{op}-\mathrm{mass} / \mathrm{cmu} / \mathrm{none} / \mathrm{ip}-\mathrm{mass} / \mathrm{cmu} / \text { none/tar/dbe } \\
\mathrm{sb} / \mathrm{op}-\mathrm{am} / \mathrm{cmu} / \mathrm{de} / \mathrm{ip}-\mathrm{mass} / \mathrm{cmu} / \text { none/tar/dbe } \\
\mathrm{sb} / \mathrm{op}-\mathrm{am} / \mathrm{cmu} / \mathrm{tw} / \mathrm{ip}-\mathrm{mass} / \mathrm{cmu} / \text { none/tar/dbe }\end{array}$ \\
\hline $\begin{array}{l}58 \\
59 \\
60\end{array}$ & $\begin{array}{l}\text { sb/op-mass/cmu/none/ip-mass/cmu/none/tar/mce } \\
\text { sb/op-am/cmu/de/ip-mass/cmu/none/tar/mce } \\
\text { sb/op-am/cmu/tw/ip-mass/cmu/none/tar/mce }\end{array}$ \\
\hline $\begin{array}{l}61 \\
62 \\
63\end{array}$ & $\begin{array}{l}\text { sb/op-mass/studs/none/ip-mass/studs/none/syl/dbe } \\
\text { sb/op-am/studs/de-flex/ip-mass/studs/none/syl/dbe } \\
\text { sb/op-am/studs/de-stiff/ip-mass/studs/none/syl/dbe }\end{array}$ \\
\hline $\begin{array}{l}64 \\
65 \\
66\end{array}$ & $\begin{array}{l}\text { sb/op-mass/studs/none/ip-mass/studs/none/syl/mce } \\
\text { sb/op-am/studs/de-flex/ip-mass/studs/none/syl/mce } \\
\text { sb/op-am/studs/de-stiff/ip-mass/studs/none/syl/mce }\end{array}$ \\
\hline $\begin{array}{l}67 \\
68 \\
69\end{array}$ & $\begin{array}{l}\text { sb/op-mass/studs/none/ip-mass/studs/none/tar/dbe } \\
\text { sb/op-am/studs/de-flex/ip-mass/studs/none/tar/dbe } \\
\text { sb/op-am/studs/de-stiff/ip-mass/studs/none/tar/dbe }\end{array}$ \\
\hline $\begin{array}{l}70 \\
71 \\
72\end{array}$ & $\begin{array}{l}\text { sb/op-mass/studs/none/ip-mass/studs/none/tar/mce } \\
\text { sb/op-am/studs/de-flex/ip-mass/studs/none/tar/mce } \\
\text { sb/op-am/studs/de-stiff/ip-mass/studs/none/tar/mce }\end{array}$ \\
\hline
\end{tabular}


Table 3.33: Simulations Performed on Steel Moment Resisting Frame, Veneer Wall Loaded in Out - of - Plane Direction

\begin{tabular}{|c|c|}
\hline Serial Number & Model ID \\
\hline $\begin{array}{l}73 \\
74 \\
75\end{array}$ & $\begin{array}{l}\text { smrf/op-mass/cmu/none/ip-mass/cmu/none/syl/dbe } \\
\text { smrf/op-am/cmu/de/ip-mass/cmu/none/syl/dbe } \\
\text { smrf/op-am/cmu/tw/ip-mass/cmu/none/syl/dbe }\end{array}$ \\
\hline $\begin{array}{l}76 \\
77 \\
78\end{array}$ & $\begin{array}{l}\text { smrf/op-mass/cmu/none/ip-mass/cmu/none/syl/mce } \\
\text { smrf/op-am/cmu/de/ip-mass/cmu/none/syl/mce } \\
\text { smrf/op-am/cmu/tw/ip-mass/cmu/none/syl/mce }\end{array}$ \\
\hline $\begin{array}{l}79 \\
80 \\
81\end{array}$ & $\begin{array}{l}\text { smrf/op-mass/cmu/none/ip-mass/cmu/none/tar/dbe } \\
\text { smrf/op-am/cmu/de/ip-mass/cmu/none/tar/dbe } \\
\text { smrf/op-am/cmu/tw/ip-mass/cmu/none/tar/dbe }\end{array}$ \\
\hline $\begin{array}{l}82 \\
83 \\
84\end{array}$ & $\begin{array}{l}\text { smrf/op-mass/cmu/none/ip-mass/cmu/none/tar/mce } \\
\text { smrf/op-am/cmu/de/ip-mass/cmu/none/tar/mce } \\
\text { smrf/op-am/cmu/tw/ip-mass/cmu/none/tar/mce }\end{array}$ \\
\hline $\begin{array}{l}85 \\
86 \\
87\end{array}$ & $\begin{array}{l}\text { smrf/op-mass/studs/none/ip-mass/studs/none/syl/dbe } \\
\text { smrf/op-am/studs/de-flex/ip-mass/studs/none/syl/dbe } \\
\text { smrf/op-am/studs/de-stiff/ip-mass/studs/none/syl/dbe }\end{array}$ \\
\hline $\begin{array}{l}88 \\
89 \\
90\end{array}$ & $\begin{array}{l}\text { smrf/op-mass/studs/none/ip-mass/studs/none/syl/mce } \\
\text { smrf/op-am/studs/de-flex/ip-mass/studs/none/syl/mce } \\
\text { smrf/op-am/studs/de-stiff/ip-mass/studs/none/syl/mce }\end{array}$ \\
\hline $\begin{array}{l}91 \\
92 \\
93\end{array}$ & $\begin{array}{l}\text { smrf/op-mass/studs/none/ip-mass/studs/none/tar/dbe } \\
\text { smrf/op-am/studs/de-flex/ip-mass/studs/none/tar/dbe } \\
\text { smrf/op-am/studs/de-stiff/ip-mass/studs/none/tar/dbe }\end{array}$ \\
\hline $\begin{array}{l}94 \\
95 \\
96\end{array}$ & $\begin{array}{l}\text { smrf/op-mass/studs/none/ip-mass/studs/none/tar/mce } \\
\text { smrf/op-am/studs/de-flex/ip-mass/studs/none/tar/mce } \\
\text { smrf/op-am/studs/de-stiff/ip-mass/studs/none/tar/mce }\end{array}$ \\
\hline
\end{tabular}


Table 3.34: Simulations Performed on Reinforced Concrete Shear Wall System, Veneer Wall Loaded in In - Plane Direction

\begin{tabular}{|c|c|}
\hline Serial Number & Model ID \\
\hline $\begin{array}{l}97 \\
98 \\
99\end{array}$ & $\begin{array}{l}\text { cb/op-mass/cmu/none/ip-mass/cmu/none/syl/dbe } \\
\text { cb/op-mass/cmu/none/ip-am/cmu/de/syl/dbe } \\
\text { cb/op-mass/cmu/none/ip-am/cmu/tw/syl/dbe }\end{array}$ \\
\hline $\begin{array}{l}100 \\
101 \\
102\end{array}$ & $\begin{array}{l}\text { cb/op-mass/cmu/none/ip-mass/cmu/none/syl/mce } \\
\mathrm{cb} / \text { op-mass/cmu/none/ip-am/cmu/de/syl/mce } \\
\text { cb/op-mass/cmu/none/ip-am/cmu/tw/syl/mce }\end{array}$ \\
\hline $\begin{array}{l}103 \\
104 \\
105\end{array}$ & $\begin{array}{l}\text { cb/op-mass/cmu/none/ip-mass/cmu/none/tar/dbe } \\
\text { cb/op-mass/cmu/none/ip-am/cmu/de/tar/dbe } \\
\text { cb/op-mass/cmu/none/ip-am/cmu/tw/tar/dbe }\end{array}$ \\
\hline $\begin{array}{l}106 \\
107 \\
108\end{array}$ & $\begin{array}{l}\mathrm{cb} / \text { op-mass/cmu/none/ip-mass/cmu/none/tar/mce } \\
\mathrm{cb} / \text { op-mass/cmu/none/ip-am/cmu/de/tar/mce } \\
\mathrm{cb} / \text { op-mass/cmu/none/ip-am/cmu/tw/tar/mce }\end{array}$ \\
\hline $\begin{array}{l}109 \\
110\end{array}$ & $\begin{array}{l}\text { cb/op-mass/studs/none/ip-mass/studs/none/syl/dbe } \\
\mathrm{cb} / \text { op-mass/studs/none/ip-am/studs/de/syl/dbe }\end{array}$ \\
\hline $\begin{array}{l}111 \\
112\end{array}$ & $\begin{array}{l}\mathrm{cb} / \text { op-mass/studs/none/ip-mass/studs/none/syl/mce } \\
\mathrm{cb} / \mathrm{op}-\mathrm{mass} / \mathrm{studs} / \text { none/ip-am/studs/de/syl/mce }\end{array}$ \\
\hline $\begin{array}{l}113 \\
114\end{array}$ & $\begin{array}{l}\text { cb/op-mass/studs/none/ip-mass/studs/none/tar/dbe } \\
\mathrm{cb} / \text { op-mass/studs/none/ip-am/studs/de/tar/dbe }\end{array}$ \\
\hline $\begin{array}{l}115 \\
116\end{array}$ & $\begin{array}{l}\text { cb/op-mass/studs/none/ip-mass/studs/none/tar/mce } \\
\mathrm{cb} / \text { op-mass/studs/none/ip-am/studs/de/tar/mce }\end{array}$ \\
\hline
\end{tabular}


Table 3.35: Simulations Performed on Steel Moment Resisting Frame, Veneer Wall Loaded in In - Plane Direction

\begin{tabular}{ll}
\hline Serial Number & Model ID \\
117 & smrf/op-mass/cmu/none/ip-mass/cmu/none/syl/dbe \\
118 & smrf/op-mass/cmu/none/ip-am/cmu/de/syl/dbe \\
119 & smrf/op-mass/cmu/none/ip-am/cmu/tw/syl/dbe \\
& \\
120 & smrf/op-mass/cmu/none/ip-mass/cmu/none/syl/mce \\
121 & smrf/op-mass/cmu/none/ip-am/cmu/de/syl/mce \\
122 & smrf/op-mass/cmu/none/ip-am/cmu/tw/syl/mce \\
123 & smrf/op-mass/cmu/none/ip-mass/cmu/none/tar/dbe \\
124 & smrf/op-mass/cmu/none/ip-am/cmu/de/tar/dbe \\
125 & smrf/op-mass/cmu/none/ip-am/cmu/tw/tar/dbe \\
126 & smrf/op-mass/cmu/none/ip-mass/cmu/none/tar/mce \\
127 & smrf/op-mass/cmu/none/ip-am/cmu/de/tar/mce \\
128 & smrf/op-mass/cmu/none/ip-am/cmu/tw/tar/mce \\
129 & smrf/op-mass/studs/none/ip-mass/studs/none/syl/dbe \\
130 & smrf/op-mass/studs/none/ip-am/studs/de/syl/dbe \\
131 & smrf/op-mass/studs/none/ip-mass/studs/none/syl/mce \\
132 & smrf/op-mass/studs/none/ip-am/studs/de/syl/mce \\
133 & smrf/op-mass/studs/none/ip-mass/studs/none/tar/dbe \\
134 & smrf/op-mass/studs/none/ip-am/studs/de/tar/dbe \\
135 & smrf/op-mass/studs/none/ip-mass/studs/none/tar/mce \\
136 & smrf/op-mass/studs/none/ip-am/studs/de/tar/mce \\
&
\end{tabular}


Table 3.36: Explanation of Symbols Used

\begin{tabular}{|c|c|}
\hline Symbol & Interpretation \\
\hline $\mathrm{cmrf}$ & Reinforced Concrete Moment Resisting Frame \\
\hline $\mathrm{cb}$ & Reinforced Concrete Braced Frame (Shear Wall System) \\
\hline $\mathrm{sb}$ & Steel Braced Frame \\
\hline smrf & Steel Moment Resisting Frame \\
\hline op-mass & Out - of - Plane Wall Represented by Mass Only \\
\hline ip-mass & In - Plane Wall Represented by Mass Only \\
\hline op-am & Out - of - Plane Wall Represented by Analytical Model \\
\hline ip-am & In - Plane Wall Represented by Analytical Model \\
\hline $\mathrm{cmu}$ & Concrete Masonry Unit Backing Wall \\
\hline studs & Steel Stud Backing Wall \\
\hline de & $\begin{array}{c}\text { Double Eye and Pintle Tie System, Used in the CMU Backed In } \\
\text { and Out - of - Plane Wall Systems, and Stud Backed In - Plane } \\
\text { Wall System }\end{array}$ \\
\hline tw & $\begin{array}{c}\text { Triwire Tie System, Used in the CMU backed In and Out - of - } \\
\text { Plane Wall Systems }\end{array}$ \\
\hline de-stiff & $\begin{array}{l}\text { Stiff Double Eye and Pintle Tie System, for the Stud Backed Out - } \\
\text { of - Plane Wall System }\end{array}$ \\
\hline de-flex & $\begin{array}{l}\text { Flexible Double Eye and Pintle Tie System, for the Stud Backed } \\
\text { Out - of - Plane Wall System }\end{array}$ \\
\hline syl & Sylmar Ground Motion \\
\hline $\operatorname{tar}$ & Tarzana Ground Motion \\
\hline dbe & Design Basis Earthquake Level \\
\hline mce & Maximum Considered Earthquake Level \\
\hline none & $\begin{array}{c}\text { No Analytical Model Used for the Tie System, Since the Wall } \\
\text { System was Represented by its Mass }\end{array}$ \\
\hline
\end{tabular}




\section{CHAPTER 4}

\section{RESULTS OF THE ANALYSES AND PARAMETRIC STUDIES}

This chapter presents the results of the seismic analyses and parametric studies described in the previous chapter. The results are grouped into seven sections that include effects on the structural frame accelerations, structural frame deformations, analytical modeling of the in - plane veneer wall system and effects on the out - of- plane behavior of the veneer wall system.

\subsection{Comparison of Structural Frame Accelerations}

This section presents a comparison between the accelerations of representative nodes on the structural building with the attached veneer wall systems represented by concentrated masses lumped at their nodes (the common modelling approach), and the accelerations of the same points on the frame when the veneer walls are modeled as separate systems. These comparisons included variations in the structural frame configurations, variations in the intensity of ground shaking, and variation in the veneer 
wall system configurations. Under seismic loading, the accelerations of the nodes of the frames are directly proportional to the dynamic forces that act at the nodes, the nodal mass being the proportionality constant. Thus, the accelerations induced in the frame due to an earthquake define the loads that the frame must resist. Consequently, a comparison of accelerations will be essentially a comparison of the design forces in the frame.

Accelerations on nodes located on the first column of each of the frame models were used for all comparisons. This was done since it was observed that the accelerations of the corresponding nodes on the second, third, and fourth columns of the frames were virtually identical to those of the first column line.

The nodal response accelerations were plotted at the instant of time at which the frame nodal acceleration reached a maximum value. This maximum acceleration typically occurred at, or near, the top of the frame, in most configurations.

Figure 4.1 shows the peak frame accelerations for the most flexible frame system (the steel moment resisting frame $(\mathrm{smrf} /))$ with the in - plane and out - of - plane steel stud backed veneer walls represented by mass only (../op-mass/.../ip-mass/.../stud/), under the MCE level (/mce/) of the Tarzana ground motion (/tar/). Also presented in this figure are the frame accelerations for the concrete braced frame systems $(\mathrm{cb} /)$, with in - plane and out - of - plane concrete masonry backed veneer wall systems represented by masses 
only (../op-mass/.../ip-mass/.../cmu/), under the DBE level (/dbe/) of the Sylmar ground motion (/syl/). These plots provide the response of the most flexible and stiffest systems analyzed, and thus define the range of system behavior. Also shown on this graph is the response of each of these systems when the out - of - plane behavior of the veneer wall system is modeled as a system, instead of just masses (/op-am/). The peak values of the frame acceleration and the peak base shear are tabulated in Tables 4.1 through 4.4 for all four frame configurations. Also listed in these tables are the ground motion time steps where peak acceleration was observed.

The base shear serves as a good indicator of the modal response of the building under the effect of an earthquake. Referring to the discussion on base shear in Chapter 3 , it can be seen that the base shear depends upon the effective seismic weight of the structure, and the seismic response coefficient. The seismic response coefficient depends upon the design spectral response acceleration parameter in the short period range, the response modification factor for the building, and its occupancy importance factor. The design spectral response acceleration parameter in the short period range is directly proportional to the MCE spectral response acceleration for short periods, which, in turn, is proportional to the $0.2 \mathrm{~s}$ spectral response acceleration, adjusted for site effects. When the representation of the veneer wall is changed from a mass to system formulation, the modal response period of the combined veneer wall/building frame system changes, thereby changing the response acceleration of the system and thus producing a change in the base shear. If the change in the base shear is not significant, it would imply that the period of vibration of the structure and its mode of response has not changed significantly 
either. The acceleration plots of all the wall system and frames, with variations in out-ofplane wall system configurations and modeling are contained in Appendix B.

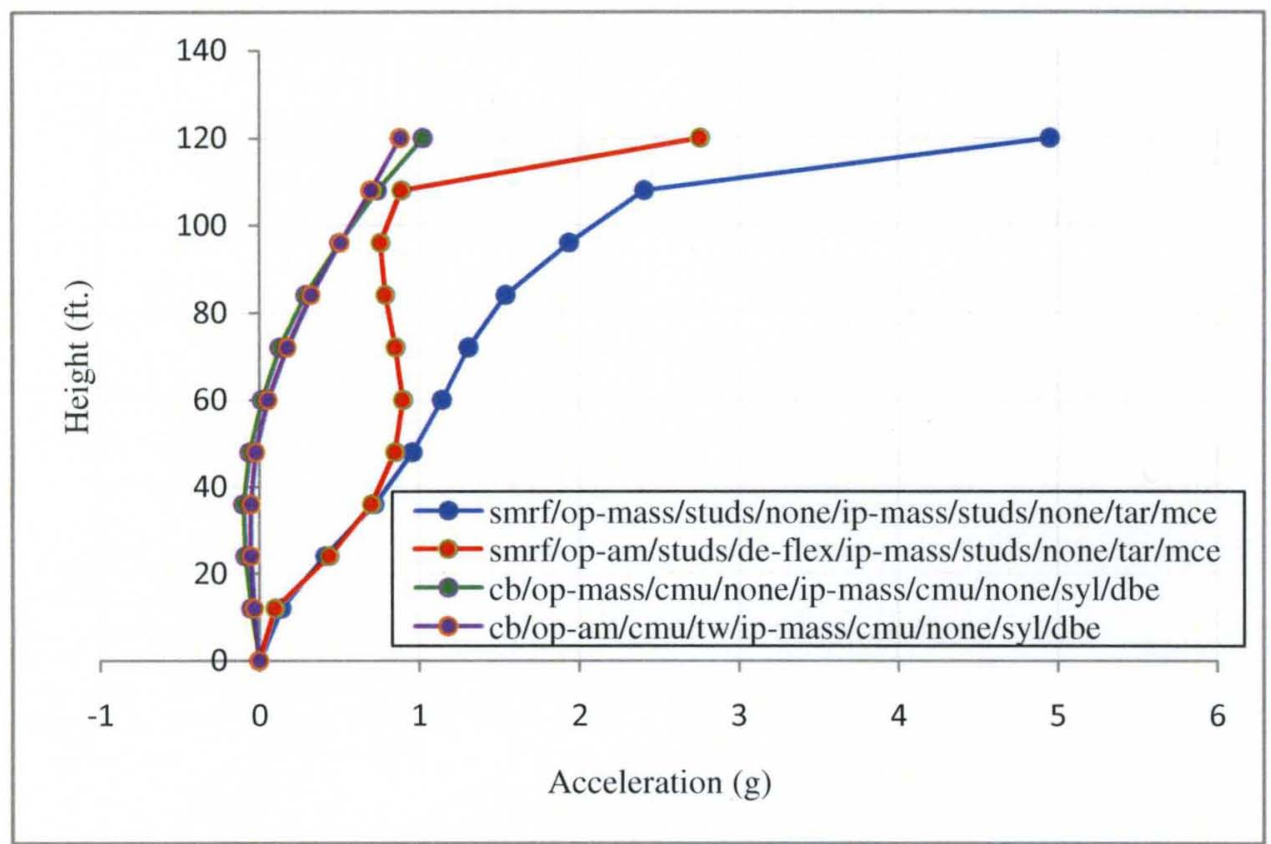

Figure 4.1: Acceleration profile along the height of the main frame for the stiffest and most flexible systems analyzed, with a mass representation and an analytical model representation of the out of plane wall system, and a Mass Representation of the In Plane Wall System (Refer to Table 3.22 for an Explanation of the Simulation Labels) 
Table 4.1: Comparison between the Peak Accelerations and Base Shears for the Steel Moment Resisting Frame, with Mass and Analytical Model Representations of the Out of Plane Wall System, and a Mass Representation of the In Plane Wall System (Refer to Table 3.22 for an Explanation of the Simulation Labels)

\begin{tabular}{|c|c|c|c|}
\hline Peak Model ID & $\begin{array}{c}\text { Peak } \\
\text { Acceleration } \\
\text { (g) }\end{array}$ & $\begin{array}{c}\text { Peak } \\
\text { Base } \\
\text { Shear } \\
\text { (kip) }\end{array}$ & $\begin{array}{c}\text { Time } \\
\text { (s) }\end{array}$ \\
\hline smrf/op_mass/cmu/none/ip_mass/cmu/none/syl/dbe & 1.53 & 289 & 3.25 \\
\hline smrf/op_am/cmu/de/ip_mass/cmu/none/syl/dbe & 1.39 & 231 & 3.13 \\
\hline smrf/op_am/cmu/tw/ip_mass/cmu/none/syl/dbe & 1.32 & 226 & 3.13 \\
\hline smrf/op_mass/cmu/none/ip_mass/cmu/none/syl/mce & 2.30 & 401 & 3.25 \\
\hline smrf/op_am/cmu/de/ip_mass/cmu/none/syl/mce & 1.99 & 352 & 3.13 \\
\hline smrf/op_am/cmu/tw/ip_mass/cmu/none/syl/mce & 1.99 & 331 & 3.13 \\
\hline smrf/op_mass/cmu/none/ip_mass/cmu/none/tar/dbe & 3.08 & 350 & 5.15 \\
\hline smrf/op_am/cmu/de/ip_mass/cmu/none/tar/dbe & 3.02 & 291 & 5.52 \\
\hline smrf/op_am/cmu/tw/ip_mass/cmu/none/tar/dbe & 3.01 & 283 & 5.52 \\
\hline smrf/op_mass/cmu/none/ip_mass/cmu/none/tar/mce & 4.97 & 450 & 5.15 \\
\hline smrf/op_am/cmu/de/ip_mass/cmu/none/tar/mce & 3.79 & 398 & 5.52 \\
\hline smrf/op_am/cmu/tw/ip_mass/cmu/none/tar/mce & 3.77 & 387 & 5.52 \\
\hline smrf/op_mass/studs/none/ip_mass/studs/none/syl/dbe & 1.50 & 203 & 3.23 \\
\hline smrf/op_am/studs/de_flex/ip_mass/studs/none/syl/dbe & 1.45 & 156 & 2.85 \\
\hline smrf/op_am/studs/de_stiff/ip_mass/studs/none/syl/dbe & 1.35 & 147 & 2.85 \\
\hline smrf/op_mass/studs/none/ip_mass/studs/none/syl/mce & 1.88 & 303 & 3.23 \\
\hline smrf/op_am/studs/de_flex/ip_mass/studs/none/syl/mce & 1.79 & 248 & 2.85 \\
\hline smrf/op_am/studs/de_stiff/ip_mass/studs/none/syl/mce & 1.74 & 236 & 2.85 \\
\hline smrf/op_mass/studs/none/ip_mass/studs/none/tar/dbe & 2.55 & 255 & 5.98 \\
\hline smrf/op_am/studs/de_flex/ip_mass/studs/none/tar/dbe & 2.51 & 214 & 5.79 \\
\hline smrf/op_am/studs/de_stiff/ip_mass/studs/none/tar/dbe & 2.22 & 209 & 5.79 \\
\hline smrf/op_mass/studs/none/ip_mass/studs/none/tar/mce & 3.99 & 428 & 5.75 \\
\hline smrf/op_am/studs/de_flex/ip_mass/studs/none/tar/mce & 3.13 & 369 & 5.79 \\
\hline smrf/op_am/studs/de_stiff/ip_mass/studs/none/tar/mce & 2.91 & 357 & 5.80 \\
\hline
\end{tabular}


Table 4.2: Comparison between the Peak Accelerations and Base Shears for the Steel Braced Frame, with Mass and Analytical Model Representations of the Out of Plane Wall System, and a Mass Representation of the In Plane Wall System

\begin{tabular}{|c|c|c|c|}
\hline Model ID & $\begin{array}{c}\text { Peak } \\
\text { Acceleration } \\
\text { (g) }\end{array}$ & $\begin{array}{c}\text { Peak } \\
\text { Base } \\
\text { Shear } \\
\text { (kip) }\end{array}$ & $\begin{array}{c}\text { Time } \\
\text { (s) }\end{array}$ \\
\hline sb/op_mass/cmu/none/ip_mass/cmu/none/syl/dbe & 1.32 & 275 & 3.12 \\
\hline sb/op_am/cmu/de/ip_mass/cmu/none/syl/dbe & 1.15 & 265 & 3.13 \\
\hline sb/op_am/cmu/tw/ip_mass/cmu/none/syl/dbe & 1.04 & 274 & 3.13 \\
\hline sb/op_mass/cmu/none/ip_mass/cmu/none/syl/mce & 1.74 & 357 & 3.12 \\
\hline $\mathrm{sb} / \mathrm{op} \_a \mathrm{am} / \mathrm{cmu} / \mathrm{de} / \mathrm{ip} \_\mathrm{mass} / \mathrm{cmu} / \mathrm{none} / \mathrm{syl} / \mathrm{mce}$ & 1.64 & 361 & 3.13 \\
\hline sb/op_am/cmu/tw/ip_mass/cmu/none/syl/mce & 1.62 & 353 & 3.13 \\
\hline sb/op_mass/cmu/none/ip_mass/cmu/none/tar/dbe & 1.53 & 236 & 5.86 \\
\hline sb/op_am/cmu/de/ip_mass/cmu/none/tar/dbe & 1.68 & 238 & 5.82 \\
\hline sb/op_am/cmu/tw/ip_mass/cmu/none/tar/dbe & 1.64 & 232 & 5.82 \\
\hline sb/op_mass/cmu/none/ip_mass/cmu/none/tar/mce & 2.29 & 321 & 5.5 \\
\hline $\mathrm{sb} / \mathrm{op}$ am/cmu/de/ip_mass/cmu/none/tar/mce & 2.42 & 329 & 5.47 \\
\hline sb/op_am/cmu/tw/ip_mass/cmu/none/tar/mce & 2.51 & 329 & 5.82 \\
\hline sb/op_mass/studs/none/ip_mass/studs/none/syl/dbe & 1.00 & 204 & 3.4 \\
\hline sb/op_am/studs/de_flex/ip_mass/studs/none/syl/dbe & 1.05 & 210 & 3.43 \\
\hline sb/op_am/studs/de_stiff/ip_mass/studs/none/syl/dbe & 1.03 & 202 & 3.43 \\
\hline sb/op_mass/studs/none/ip_mass/studs/none/syl/mce & 1.66 & 296 & 3.2 \\
\hline sb/op_am/studs/de_flex/ip_mass/studs/none/syl/mce & 1.53 & 317 & 3.85 \\
\hline sb/op_am/studs/de_stiff/ip_mass/studs/none/syl/mce & 1.51 & 295 & 3.2 \\
\hline sb/op_mass/studs/none/ip_mass/studs/none/tar/dbe & 1.32 & 210 & 5.88 \\
\hline sb/op_am/studs/de_flex/ip_mass/studs/none/tar/dbe & 1.40 & 213 & 5.77 \\
\hline sb/op_am/studs/de_stiff/ip_mass/studs/none/tar/dbe & 1.33 & 202 & 5.75 \\
\hline sb/op_mass/studs/none/ip_mass/studs/none/tar/mce & 1.87 & 296 & 5.9 \\
\hline sb/op_am/studs/de_flex/ip_mass/studs/none/tar/mce & 1.96 & 290 & 5.77 \\
\hline sb/op_am/studs/de_stiff/ip_mass/studs/none/tar/mce & 2.05 & 276 & 5.76 \\
\hline
\end{tabular}


Table 4.3: Comparison between the Peak Accelerations and Base Shears for the Reinforced Concrete Moment Resisting Frame, with Mass and Analytical Model Representations of the Out of Plane Wall System, and a Mass Representation of the In Plane Wall System

\begin{tabular}{|c|c|c|c|}
\hline Model ID & $\begin{array}{c}\text { Peak } \\
\text { Acceleration } \\
\text { (g) }\end{array}$ & $\begin{array}{c}\text { Peak } \\
\text { Base } \\
\text { Shear } \\
\text { (kip) }\end{array}$ & $\begin{array}{c}\text { Time } \\
\text { (s) }\end{array}$ \\
\hline cmrf/op_mass/cmu/none/ip_mass/cmu/none/syl/dbe & 1.32 & 351 & 3.14 \\
\hline cmrf/op_am/cmu/de/ip__mass/cmu/none/syl/dbe & 1.26 & 355 & 3.14 \\
\hline cmrf/op_am/cmu/tw/ip_mass/cmu/none/syl/dbe & 1.26 & 355 & 3.14 \\
\hline cmrf/op_mass/cmu/none/ip_mass/cmu/none/syl/mce & 1.77 & 524 & 3.13 \\
\hline cmrf/op_am/cmu/de/ip_mass/cmu/none/syl/mce & 1.70 & 529 & 3.13 \\
\hline cmrf/op_am/cmu/tw/ip_mass/cmu/none/syl/mce & 1.69 & 529 & 3.13 \\
\hline cmrf/op_mass/cmu/none/ip_mass/cmu/none/tar/dbe & 1.67 & 613 & 5.64 \\
\hline cmrf/op_am/cmu/de/ip_mass/cmu/none/tar/dbe & 1.57 & 606 & 5.64 \\
\hline $\mathrm{cmrf} / \mathrm{op} \_a m / \mathrm{cmu} / \mathrm{tw} / \mathrm{ip} \_m a s s / \mathrm{cmu} / \mathrm{none} / \mathrm{tar} / \mathrm{dbe}$ & 1.55 & 599 & 5.64 \\
\hline cmrf/op_mass/cmu/none/ip_mass/cmu/none/tar/mce & 2.50 & 876 & 5.64 \\
\hline cmrf/op_am/cmu/de/ip_mass/cmu/none/tar/mce & 2.35 & 889 & 5.64 \\
\hline cmrf/op_am/cmu/tw/ip_mass/cmu/none/tar/mce & 2.32 & 891 & 5.64 \\
\hline cmrf/op_mass/studs/none/ip_mass/studs/none/syl/dbe & 1.07 & 305 & 3.12 \\
\hline cmrf/op_am/studs/de_flex/ip_mass/studs/none/syl/dbe & 1.07 & 315 & 3.12 \\
\hline cmrf/op_am/studs/de_stiff/ip_mass/studs/none/syl/dbe & 1.07 & 308 & 3.12 \\
\hline cmrf/op_mass/studs/none/ip_mass/studs/none/syl/mce & 1.73 & 458 & 3.12 \\
\hline cmrf/op_am/studs/de_flex/ip_mass/studs/none/syl/mce & 1.61 & 469 & 3.12 \\
\hline cmrf/op_am/studs/de_stiff/ip_mass/studs/none/syl/mce & 1.60 & 468 & 3.13 \\
\hline cmrf/op_mass/studs/none/ip_mass/studs/none/tar/dbe & 1.44 & 697 & 4.11 \\
\hline cmrf/op_am/studs/de_flex/ip_mass/studs/none/tar/dbe & 1.38 & 688 & 4.11 \\
\hline cmrf/op_am/studs/de_stiff/ip_mass/studs/none/tar/dbe & 1.34 & 681 & 4.11 \\
\hline cmrf/op_mass/studs/none/ip_mass/studs/none/tar/mce & 2.25 & 810 & 4.30 \\
\hline cmrf/op_am/studs/de_flex/ip_mass/studs/none/tar/mce & 2.09 & 856 & 4.12 \\
\hline cmrf/op_am/studs/de_stiff/ip_mass/studs/none/tar/mce & 2.02 & 834 & 4.12 \\
\hline
\end{tabular}


Table 4.4: Comparison between the Peak Accelerations and Base Shears for the Reinforced Concrete Braced Frame, with Mass and Analytical Model Representations of the Out of Plane Wall System, and a Mass Representation of the In Plane Wall System

\begin{tabular}{|c|c|c|c|}
\hline Model ID & $\begin{array}{c}\text { Peak } \\
\text { Acceleration } \\
\text { (g) }\end{array}$ & $\begin{array}{c}\text { Peak } \\
\text { Base } \\
\text { Shear } \\
\text { (kip) }\end{array}$ & $\begin{array}{c}\text { Time } \\
\text { (s) }\end{array}$ \\
\hline cb/op_mass/cmu/none/ip_mass/cmu/none/syl/dbe & 1.02 & 296 & 3.07 \\
\hline cb/op_am/cmu/de/ip_mass/cmu/none/syl/dbe & 0.88 & 301 & 3.08 \\
\hline cb/op_am/cmu/tw/ip_mass/cmu/none/syl/dbe & 0.87 & 289 & 3.12 \\
\hline $\mathrm{cb} / \mathrm{op} \_\mathrm{mass} / \mathrm{cmu} / \mathrm{none} / \mathrm{ip} \_$mass $/ \mathrm{cmu} / \mathrm{none} / \mathrm{syl} / \mathrm{mce}$ & 1.52 & 386 & 3.12 \\
\hline cb/op_am/cmu/de/ip_mass/cmu/none/syl/mce & 1.31 & 380 & 3.12 \\
\hline cb/op_am/cmu/tw/ip_mass/cmu/none/syl/mce & 1.3 & 374 & 3.12 \\
\hline cb/op_mass/cmu/none/ip_mass/cmu/none/tar/dbe & 1.29 & 256 & 5.6 \\
\hline cb/op_am/cmu/de/ip_mass/cmu/none/tar/dbe & 1.03 & 264 & 5.6 \\
\hline $\mathrm{cb} / \mathrm{op} \_a m / \mathrm{cmu} / \mathrm{tw} / \mathrm{ip} \_m a s s / \mathrm{cmu} / \mathrm{none} / \mathrm{tar} / \mathrm{dbe}$ & 1.03 & 251 & 5.6 \\
\hline cb/op_mass/cmu/none/ip_mass/cmu/none/tar/mce & 1.55 & 404 & 5.6 \\
\hline cb/op_am/cmu/de/ip_mass/cmu/none/tar/mce & 1.34 & 389 & 5.6 \\
\hline cb/op_am/cmu/tw/ip_mass/cmu/none/tar/mce & 1.33 & 382 & 5.6 \\
\hline cb/op_mass/studs/none/ip_mass/studs/none/syl/dbe & 0.68 & 246 & 3.12 \\
\hline cb/op_am/studs/de_flex/ip_mass/studs/none/syl/dbe & 0.66 & 232 & 2.93 \\
\hline cb/op_am/studs/de_stiff/ip_mass/studs/none/syl/dbe & 0.66 & 224 & 3.09 \\
\hline cb/op_mass/studs/none/ip_mass/studs/none/syl/mce & 1.04 & 335 & 3.12 \\
\hline cb/op_am/studs/de_flex/ip_mass/studs/none/syl/mce & 1.02 & 320 & 2.93 \\
\hline cb/op_am/studs/de_stiff/ip_mass/studs/none/syl/mce & 1.02 & 315 & 3.09 \\
\hline cb/op_mass/studs/none/ip_mass/studs/none/tar/dbe & 1.28 & 202 & 5.55 \\
\hline cb/op_am/studs/de_flex/ip_mass/studs/none/tar/dbe & 1.19 & 214 & 5.56 \\
\hline cb/op_am/studs/de_stiff/ip_mass/studs/none/tar/dbe & 1.19 & 204 & 5.56 \\
\hline cb/op_mass/studs/none/ip_mass/studs/none/tar/mce & 1.51 & 316 & 5.55 \\
\hline cb/op_am/studs/de_flex/ip_mass/studs/none/tar/mce & 1.84 & 312 & 5.56 \\
\hline cb/op_am/studs/de_stiff/ip_mass/studs/none/tar/mce & 1.83 & 314 & 5.55 \\
\hline
\end{tabular}


Examination of Figure 4.1 and Tables 4.1 through 4.4 show that the frame stiffness has a significant effect on the peak acceleration experienced at both DBE and MCE ground motion levels: the stiffer the frame, the lower the peak acceleration (at least for the ground motions chosen). In addition, it appears modeling the actual behavior of the veneer wall systems can significantly reduce the peak acceleration that the supporting structural frames experience, especially for the more flexible systems. Furthermore, in general, the stiffness of the frame also has an effect on the base shear. The more flexible frames in general have a higher base shear. However, specific modeling variations show different base shear values, even though the peak accelerations are similar. This suggests a change in system motor response. These effects will be discussed further in Chapter 5 .

\subsection{Comparison of the Structural Frame Deflections}

The displacement response of the structural frame, for the range of structural frame systems, veneer system characteristics, modeling approaches and ground motions are shown in Figure 4.2. The horizontal nodal deformations of the frame were plotted at the instant of time at which one of the frame nodes reached maximum deflection, for the whole duration of the ground motion. There was a slight difference between the time instants at which the acceleration and displacement profiles were plotted, the displacement profiles being plotted at a time instant slightly later than the acceleration profiles. This is reasonable, since the frames were not infinitely stiff and it takes time for the movement to occur in the frame (deflection) due to the force that created at peak 
acceleration.In most configurations, the maximum horizontal deformation typically occurred at, or near, the top of the frame.

Figure 4.2 shows the peak frame horizontal nodal deformation for the most flexible frame system (the steel moment resisting frame (smrf/)), with the in - plane and out - of plane steel stud backed veneer walls represented by mass only (../op-mass/.../ipmass/.../stud/), under the MCE level (/mce/) of the Tarzana ground motion (/tar/). Also presented in this figure are the horizontal nodal displacements for the concrete braced frame systems $(\mathrm{cb} /)$, with in - plane and out - of - plane reinforced concrete masonry backed veneer wall systems represented by masses only (../op-mass/.../ip-mass/.../cmu/), under the DBE level (/dbe/) of the Sylmar ground motion (/syl/). These plots provide the response of the most flexible and stiffest systems analyzed, and thus define the range of system behavior. Also shown on this graph is the response of each of these systems when the out - of - plane behavior of the veneer wall system is modeled as a system, instead just masses $(/ \mathrm{op}-\mathrm{am} /)$. The values of the maximum frame horizontal nodal displacement and average displacements are tabulated in Tables 4.5 through 4.8. Average displacements are presented to indicate change in motor response in the systems that would not be obvious from changes in peak displacements. A low peak displacement but higher average displacement may indicate a greater dominance of higher modes in the response of the system for the configuration under consideration. The frame deformation plots of all the wall system and frames, with variations in out-of-plane wall system configurations and modeling are contained in Appendix B. 


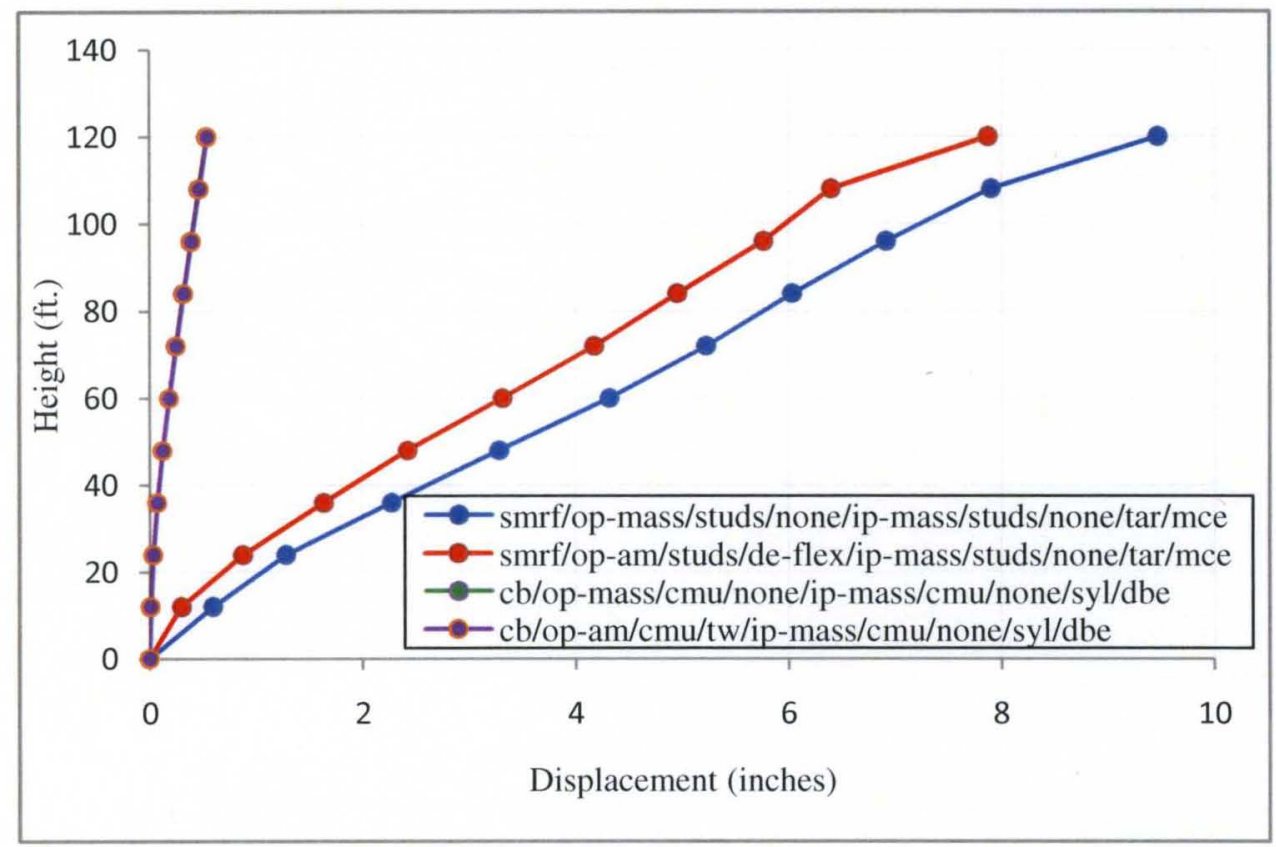

Figure 4.2: Displacement profile along the height of the main frame for the stiffest and most flexible systems analyzed, with a mass representation and an anatical model representation of the out of plane wall system, and a Mass Representation of the In Plane Wall System. 
Table 4.5: Comparison between the Peak and Average Displacements for the Steel Moment Resisting Frame, with Mass and Analytical Model Representations of the Out of Plane Wall System, and a Mass Representation of the In Plane Wall System

\begin{tabular}{|c|c|c|c|}
\hline Model ID & $\begin{array}{l}\text { Peak Disp } \\
\text { (in) }\end{array}$ & $\begin{array}{c}\text { Average } \\
\text { Disp } \\
\text { (in) }\end{array}$ & $\begin{array}{c}\text { Tim } \\
\text { e } \\
(\mathbf{s})\end{array}$ \\
\hline smrf/op_mass/cmu/none/ip_mass/cmu/none/syl/dbe & 3.13 & 1.18 & 3.26 \\
\hline smrf/op_am/cmu/de/ip_mass/cmu/none/syl/dbe & 2.49 & 0.89 & 3.15 \\
\hline smrf/op_am/cmu/tw/ip_mass/cmu/none/syl/dbe & 2.46 & 0.86 & 3.15 \\
\hline smrf/op_mass/cmu/none/ip_mass/cmu/none/syl/mce & 4.89 & 1.82 & 3.26 \\
\hline smrf/op_am/cmu/de/ip_mass/cmu/none/syl/mce & 4.05 & 1.44 & 3.15 \\
\hline smrf/op_am/cmu/tw/ip_mass/cmu/none/syl/mce & 3.71 & 1.30 & 3.15 \\
\hline smrf/op_mass/cmu/none/ip_mass/cmu/none/tar/dbe & 7.83 & 2.74 & 6.18 \\
\hline smrf/op_am/cmu/de/ip_mass/cmu/none/tar/dbe & 6.88 & 2.31 & 5.87 \\
\hline smrf/op_am/cmu/tw/ip_mass/cmu/none/tar/dbe & 6.88 & 2.31 & 5.87 \\
\hline smrf/op_mass/cmu/none/ip_mass/cmu/none/tar/mce & 11.7 & 4.07 & 6.18 \\
\hline smrf/op_am/cmu/de/ip_mass/cmu/none/tar/mce & 10.6 & 3.52 & 5.88 \\
\hline smrf/op_am/cmu/tw/ip_mass/cmu/none/tar/mce & 10.3 & 3.45 & 5.88 \\
\hline smrf/op_mass/studs/none/ip_mass/studs/none/syl/dbe & 2.53 & 1.07 & 3.24 \\
\hline smrf/op_am/studs/de_flex/ip_mass/studs/none/syl/dbe & 2.40 & 0.94 & 2.92 \\
\hline smrf/op_am/studs/de_stiff/ip_mass/studs/none/syl/dbe & 2.33 & 0.96 & 2.92 \\
\hline smrf/op_mass/studs/none/ip_mass/studs/none/syl/mce & 3.66 & 1.57 & 3.24 \\
\hline smrf/op_am/studs/de_flex/ip_mass/studs/none/syl/mce & 3.48 & 1.42 & 2.92 \\
\hline smrf/op_am/studs/de_stiff/ip_mass/studs/none/syl/mc & 3.42 & 1.40 & 2.92 \\
\hline smrf/op_mass/studs/none/ip_mass/studs/none/tar/dbe & 6.44 & 2.71 & 6.17 \\
\hline smrf/op_am/studs/de_flex/ip_mass/studs/none/tar/dbe & 5.66 & 2.50 & 5.81 \\
\hline smrf/op_am/studs/de_stiff/ip_mass/studs/none/tar/dbe & 5.24 & 2.29 & 5.81 \\
\hline smrf/op_mass/studs/none/ip_mass/studs/none/tar/mce & 10.2 & 4.36 & 6.17 \\
\hline smrf/op_am/studs/de_flex/ip_mass/studs/none/tar/mce & 7.87 & 3.43 & 5.82 \\
\hline smrf/op_am/studs/de_stiff/ip_mass/studs/none/tar/mce & 7.21 & 3.12 & 5.82 \\
\hline
\end{tabular}


Table 4.6: Comparison between the Peak and Average Displacements for the Steel Braced Frame, with Mass and Analytical Model Representations of the Out of Plane Wall System, and a Mass Representation of the In Plane Wall System.

\begin{tabular}{|c|c|c|c|}
\hline Model ID & $\begin{array}{l}\text { Peak Disp } \\
\text { (in) }\end{array}$ & $\begin{array}{l}\text { Average } \\
\text { Disp } \\
\text { (in) }\end{array}$ & $\begin{array}{c}\text { Time } \\
(\mathrm{s})\end{array}$ \\
\hline sb/op_mass/cmu/none/ip_mass/cmu/none/syl/dbe & 2.39 & 0.98 & 3.42 \\
\hline sb/op_am/cmu/de/ip_mass/cmu/none/syl/dbe & 2.52 & 0.988 & 3.23 \\
\hline sb/op_am/cmu/tw/ip_mass/cmu/none/syl/dbe & 2.47 & 0.95 & 3.23 \\
\hline sb/op_mass/cmu/none/ip_mass/cmu/none/syl/mce & 2.91 & 1.36 & 3.41 \\
\hline sb/op_am/cmu/de/ip_mass/cmu/none/syl/mce & 3.50 & 1.53 & 3.19 \\
\hline sb/op_am/cmu/tw/ip_mass/cmu/none/syl/mce & 3.55 & 1.53 & 3.19 \\
\hline sb/op_mass/cmu/none/ip_mass/cmu/none/tar/dbe & 2.66 & 0.73 & 6.13 \\
\hline sb/op_am/cmu/de/ip_mass/cmu/none/tar/dbe & 2.57 & 1.06 & 5.82 \\
\hline sb/op_am/cmu/tw/ip_mass/cmu/none/tar/dbe & 2.51 & 1.10 & 5.83 \\
\hline sb/op_mass/cmu/none/ip_mass/cmu/none/tar/mce & 3.79 & 1.04 & 6.14 \\
\hline sb/op_am/cmu/de/ip_mass/cmu/none/tar/mce & 3.95 & 1.67 & 5.83 \\
\hline sb/op_am/cmu/tw/ip_mass/cmu/none/tar/mce & 3.85 & 1.59 & 5.82 \\
\hline sb/op_mass/studs/none/ip_mass/studs/none/syl/dbe & 1.99 & 0.84 & 3.29 \\
\hline sb/op_am/studs/de_flex/ip_mass/studs/none/syl/dbe & 2.07 & 0.85 & 3.22 \\
\hline sb/op_am/studs/de_stiff/ip_mass/studs/none/syl/dbe & 2.03 & 0.85 & 3.22 \\
\hline sb/op_mass/studs/none/ip_mass/studs/none/syl/mce & 2.65 & 1.31 & 3.27 \\
\hline sb/op_am/studs/de_flex/ip_mass/studs/none/syl/mce & 2.91 & 1.43 & 3.18 \\
\hline sb/op_am/studs/de_stiff/ip_mass/studs/none/syl/mce & 3.01 & 1.42 & 3.18 \\
\hline sb/op_mass/studs/none/ip_mass/studs/none/tar/dbe & 2.08 & 0.71 & 5.89 \\
\hline sb/op_am/studs/de_flex/ip_mass/studs/none/tar/dbe & 2.25 & 1.09 & 6.04 \\
\hline sb/op_am/studs/de_stiff/ip_mass/studs/none/tar/dbe & 2.2 & 1.00 & 6.02 \\
\hline sb/op_mass/studs/none/ip_mass/studs/none/tar/mce & 3.11 & 0.99 & 5.91 \\
\hline sb/op_am/studs/de_flex/ip_mass/studs/none/tar/mce & 3.29 & 1.55 & 6.02 \\
\hline sb/op_am/studs/de_stiff/ip_mass/studs/none/tar/mce & 3.21 & 1.52 & 6.03 \\
\hline
\end{tabular}


Table 4.7: Comparison between the Peak and Average Displacements for the Reinforced Concrete Moment Resisting Frame, with Mass and Analytical Model Representations of the Out of Plane Wall System, and a Mass Representation of the In Plane Wall System

\begin{tabular}{|c|c|c|c|}
\hline Model ID & $\begin{array}{l}\text { Peak Disp } \\
\text { (in) }\end{array}$ & $\begin{array}{c}\text { Average } \\
\text { Disp } \\
\text { (in) }\end{array}$ & $\begin{array}{c}\text { Time } \\
\text { (s) }\end{array}$ \\
\hline cmrf/op_mass/cmu/none/ip_mass/cmu/none/syl/dbe & 1.37 & 0.64 & 3.15 \\
\hline cmrf/op_am/cmu/de/ip_mass/cmu/none/syl/dbe & 1.38 & 0.65 & 3.15 \\
\hline cmrf/op_am/cmu/tw/ip_mass/cmu/none/syl/dbe & 1.38 & 0.65 & 3.15 \\
\hline cmrf/op_mass/cmu/none/ip_mass/cmu/none/syl/mce & 2.07 & 0.97 & 3.15 \\
\hline cmrf/op_am/cmu/de/ip_mass/cmu/none/syl/mce & 2.08 & 0.99 & 3.15 \\
\hline cmrf/op_am/cmu/tw/ip_mass/cmu/none/syl/mce & 2.08 & 0.99 & 3.15 \\
\hline cmrf/op_mass/cmu/none/ip_mass/cmu/none/tar/dbe & 2.83 & 1.32 & 5.87 \\
\hline cmrf/op_am/cmu/de/ip_mass/cmu/none/tar/dbe & 2.81 & 1.35 & 5.87 \\
\hline cmrf/op_am/cmu/tw/ip_mass/cmu/none/tar/dbe & 2.81 & 1.35 & 5.87 \\
\hline cmrf/op_mass/cmu/none/ip_mass/cmu/none/tar/mce & 3.65 & 2.01 & 5.65 \\
\hline cmrf/op_am/cmu/de/ip_mass/cmu/none/tar/mce & 3.62 & 2.04 & 5.65 \\
\hline cmrf/op_am/cmu/tw/ip_mass/cmu/none/tar/mce & 3.07 & 2.04 & 5.65 \\
\hline cmrf/op_mass/studs/none/ip_mass/studs/none/syl/dbe & 1.04 & 0.43 & 3.14 \\
\hline cmrf/op_am/studs/de_flex/ip_mass/studs/none/syl/dbe & 1.09 & 0.49 & 3.14 \\
\hline cmrf/op_am/studs/de_stiff/ip_mass/studs/none/syl/dbe & 1.08 & 0.49 & 3.14 \\
\hline cmrf/op_mass/studs/none/ip_mass/studs/none/syl/mce & 1.77 & 0.70 & 3.14 \\
\hline cmrf/op_am/studs/de_flex/ip_mass/studs/none/syl/mce & 1.73 & 0.76 & 3.14 \\
\hline cmrf/op_am/studs/de_stiff/ip_mass/studs/none/syl/mce & 1.7 & 0.74 & 3.14 \\
\hline cmrf/op_mass/studs/none/ip_mass/studs/none/tar/dbe & 1.50 & 0.59 & 4.51 \\
\hline cmrf/op_am/studs/de_flex/ip_mass/studs/none/tar/dbe & 1.47 & 0.65 & 4.51 \\
\hline cmrf/op_am/studs/de_stiff/ip_mass/studs/none/tar/dbe & 1.46 & 0.64 & 4.51 \\
\hline cmrf/op_mass/studs/none/ip_mass/studs/none/tar/mce & 2.83 & 1.08 & 4.54 \\
\hline cmrf/op_am/studs/de_flex/ip_mass/studs/none/tar/mce & 2.76 & 1.13 & 4.54 \\
\hline cmrf/op_am/studs/de_stiff/ip_mass/studs/none/tar/mce & 2.75 & 1.12 & 4.54 \\
\hline
\end{tabular}


Table 4.8: Comparison between the Peak and Average Displacements for the Reinforced Concrete Braced Frame, with Mass and Analytical Model Representations of the Out of Plane Wall System, and a Mass Representation of the In Plane Wall System

\begin{tabular}{|c|c|c|c|}
\hline Model ID & $\begin{array}{l}\text { Peak Disp } \\
\text { (in) }\end{array}$ & $\begin{array}{c}\text { Average } \\
\text { Disp } \\
\text { (in) }\end{array}$ & $\begin{array}{c}\text { Time } \\
\text { (s) }\end{array}$ \\
\hline cb/op_mass/cmu/none/ip_mass/cmu/none/syl/dbe & 0.56 & 0.20 & 3.10 \\
\hline $\mathrm{cb} / \mathrm{op} \_a m / \mathrm{cmu} / \mathrm{de} / \mathrm{ip} \_\mathrm{mass} / \mathrm{cmu} / \mathrm{none} / \mathrm{syl} / \mathrm{dbe}$ & 0.54 & 0.21 & 3.10 \\
\hline $\mathrm{cb} / \mathrm{op} \_a m / \mathrm{cmu} / \mathrm{tw} / \mathrm{ip} \_m a s s / \mathrm{cmu} / \mathrm{none} / \mathrm{syl} / \mathrm{dbe}$ & 0.54 & 0.21 & 3.10 \\
\hline cb/op_mass/cmu/none/ip_mass/cmu/none/syl/mce & 0.83 & 0.30 & 3.13 \\
\hline cb/op_am/cmu/de/ip_mass/cmu/none/syl/mce & 0.76 & 0.30 & 3.14 \\
\hline $\mathrm{cb} / \mathrm{op} \_a m / \mathrm{cmu} / \mathrm{tw} / \mathrm{ip} \_m a s s / \mathrm{cmu} / \mathrm{none} / \mathrm{syl} / \mathrm{mce}$ & 0.76 & 0.30 & 3.14 \\
\hline cb/op_mass/cmu/none/ip_mass/cmu/none/tar/dbe & 0.49 & 0.18 & 5.82 \\
\hline cb/op_am/cmu/de/ip_mass/cmu/none/tar/dbe & 0.46 & 0.19 & 5.82 \\
\hline cb/op_am/cmu/tw/ip_mass/cmu/none/tar/dbe & 0.46 & 0.19 & 5.82 \\
\hline cb/op_mass/cmu/none/ip_mass/cmu/none/tar/mce & 0.75 & 0.28 & 5.82 \\
\hline cb/op_am/cmu/de/ip_mass/cmu/none/tar/mce & 0.72 & 0.29 & 5.82 \\
\hline cb/op_am/cmu/tw/ip_mass $/ \mathrm{cmu} /$ none $/ \mathrm{tar} / \mathrm{mce}$ & 0.72 & 0.29 & 5.82 \\
\hline cb/op_mass/studs/none/ip_mass/studs/none/syl/dbe & 0.47 & 0.18 & 3.13 \\
\hline cb/op_am/studs/de_flex/ip_mass/studs/none/syl/dbe & 0.45 & 0.18 & 3.1 \\
\hline cb/op_am/studs/de_stiff/ip_mass/studs/none/syl/dbe & 0.45 & 0.18 & 3.1 \\
\hline cb/op_mass/studs/none/ip_mass/studs/none/syl/mce & 0.71 & 0.26 & 3.13 \\
\hline cb/op_am/studs/de_flex/ip_mass/studs/none/syl/mce & 0.68 & 0.27 & 3.1 \\
\hline cb/op_am/studs/de_stiff/ip_mass/studs/none/syl/mce & 0.68 & 0.28 & 3.1 \\
\hline cb/op_mass/studs/none/ip_mass/studs/none/tar/dbe & 0.64 & 0.23 & 5.91 \\
\hline cb/op_am/studs/de_flex/ip_mass/studs/none/tar/dbe & 0.62 & 0.24 & 5.91 \\
\hline cb/op_am/studs/de_stiff/ip_mass/studs/none/tar/dbe & 0.61 & 0.24 & 5.91 \\
\hline cb/op_mass/studs/none/ip_mass/studs/none/tar/mce & 1.00 & 0.35 & 5.91 \\
\hline cb/op_am/studs/de_flex/ip_mass/studs/none/tar/mce & 1.08 & 0.39 & 5.91 \\
\hline cb/op_am/studs/de_stiff/ip_mass/studs/none/tar/mce & 1.07 & 0.39 & 5.91 \\
\hline
\end{tabular}


Examination of Figure 4.2 and Tables 4.5 through 4.8 shows that, as expected, the frame stiffness has a significant effect on the peak horizontal displacement experienced at both DBE and MCE ground motion levels. In addition, it appears modeling the actual behavior of the veneer wall systems can significantly reduce the peak frame displacements when the more flexible systems are analyzed. There appears to be little difference with stiff frames and backing systems. These effects will be discussed further in Chapter 5.

\subsection{Comparison of Structural Frame Accelerations and Deformations with the in - plane veneer walls analyzed as a mass, or analyzed as a system}

Figure 4.3 shows the peak frame accelerations for the most flexible frame system (the steel moment resisting frame (smrf/)), with the in - plane and out - of - plane steel stud backed veneer walls represented by mass only (../op-mass/.../ip-mass/.../stud/), under the MCE level (/mce/) of the Tarzana ground motion (/tar/). Also presented in this figure are the horizontal nodal accelerations for the concrete braced frame systems $(\mathrm{cb} /)$, with in plane and out - of - plane reinforced concrete masonry backed veneer wall systems represented by masses only (../op-mass/.../ip-mass/.../cmu/), under the DBE level (/dbe/) of the Sylmar ground motion (/syl/). Also shown on this graph is the response of each of these systems when the in - plane behavior of the veneer systems is modeled as a system, instead just masses (/ip-am/). The peak values of the frame acceleration and the peak base shear are tabulated in Tables 4.9 and 4.10. The frame accelerations for all the wall system and frames, analyzed with variations with in-plane wall system modeling are contained in 
Appendix C.

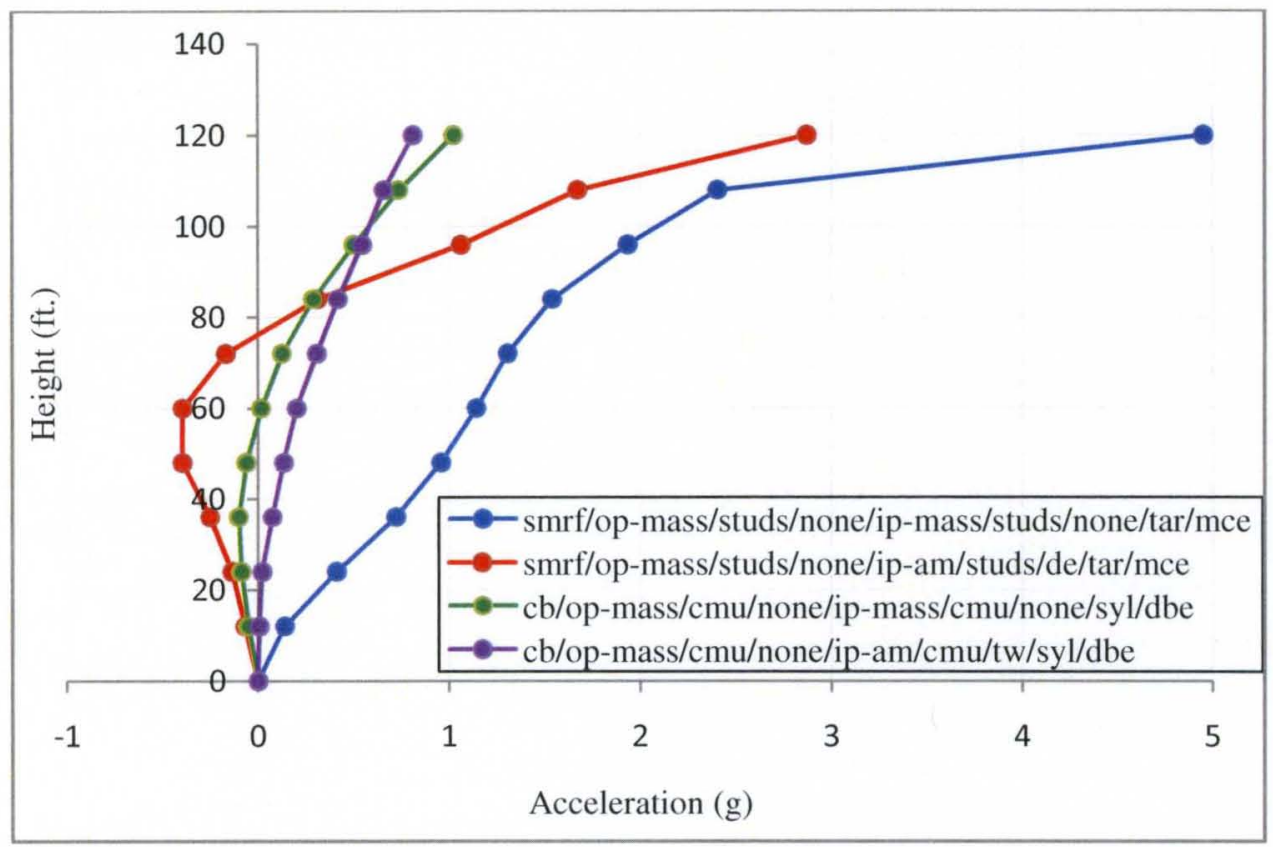

Figure 4.3: Acceleration Profile Along the Height of the Main Frame for the Stiffest and Most Flexible Systems Analyzed, With a Mass Representation and an Analytical Model Representation of the In Plane Wall System, and a Mass Representation of the Out of Plane Wall System. 
Table 4.9: Comparison between the Peak Accelerations and Base Shears for the Steel Moment Resisting Frame, with Mass and Analytical Model Representations of the In Plane Wall System, and a Mass Representation of the Out of Plane Wall System

\begin{tabular}{|c|c|c|c|}
\hline Model ID & $\begin{array}{c}\text { Peak } \\
\text { Acceleration } \\
\text { (g) }\end{array}$ & $\begin{array}{c}\text { Peak } \\
\text { Base } \\
\text { Shear } \\
\text { (kip) }\end{array}$ & $\begin{array}{c}\text { Time } \\
\text { (s) }\end{array}$ \\
\hline smrf/op_mass/cmu/none/ip_mass/cmu/none/syl/dbe & 1.53 & 289 & 3.25 \\
\hline smrf/op_mass/cmu/none/ip_am/cmu/de/syl/dbe & 0.91 & 255 & 3.13 \\
\hline smrf/op_mass/cmu/none/ip_am/cmu/tw/syl/dbe & 0.66 & 246 & 3.13 \\
\hline smrf/op_mass/cmu/none/ip_mass/cmu/none/syl/mce & 2.30 & 402 & 3.25 \\
\hline smrf/op_mass/cmu/none/ip_am/cmu/de/syl/mce & 1.26 & 378 & 3.13 \\
\hline smrf/op_mass/cmu/none/ip_am/cmu/tw/syl/mce & 1.11 & 365 & 3.13 \\
\hline smrf/op_mass/cmu/none/ip_mass/cmu/none/tar/dbe & 3.08 & 325 & 5.15 \\
\hline smrf/op_mass/cmu/none/ip_am/cmu/de/tar/dbe & 2.75 & 308 & 5.95 \\
\hline smrf/op_mass/cmu/none/ip_am/cmu/tw/tar/dbe & 2.74 & 293 & 5.48 \\
\hline smrf/op_mass/cmu/none/ip_mass/cmu/none/tar/mce & 4.97 & 450 & 5.15 \\
\hline smrf/op_mass/cmu/none/ip_am/cmu/de/tar/mce & 4.19 & 434 & 5.96 \\
\hline smrf/op_mass/cmu/none/ip_am/cmu/tw/tar/mce & 3.9 & 425 & 5.47 \\
\hline smrf/op_mass/studs/none/ip_mass/studs/none/syl/dbe & 1.5 & 203 & 3.23 \\
\hline smrf/op_mass/studs/none/ip_am/studs/de/syl/dbe & 1.25 & 179 & 2.85 \\
\hline smrf/op_mass/studs/none/ip_mass/studs/none/syl/mce & 1.88 & 303 & 3.23 \\
\hline smrf/op_mass/studs/none/ip_am/studs/de/syl/mce & 1.65 & 278 & 2.85 \\
\hline smrf/op_mass/studs/none/ip_mass/studs/none/tar/dbe & 2.55 & 255 & 5.98 \\
\hline smrf/op_mass/studs/none/ip_am/studs/de/tar/dbe & 1.91 & 210 & 5.74 \\
\hline smrf/op_mass/studs/none/ip_mass/studs/none/tar/mce & 3.94 & 428 & 5.75 \\
\hline smrf/op_mass/studs/none/ip_am/studs/de/tar/mce & 3.1 & 391 & 5.83 \\
\hline
\end{tabular}


Table 4.10: Comparison between the Peak Accelerations and Base Shears for the Reinforced Concrete Braced Frame, with Mass and Analytical Model Representations of the In Plane Wall System, and a Mass Representation of the Out of Plane Wall System

\begin{tabular}{|c|c|c|c|}
\hline Model ID & $\begin{array}{c}\text { Peak } \\
\text { Acceleration } \\
\text { (g) }\end{array}$ & $\begin{array}{c}\text { Peak } \\
\text { Base } \\
\text { Shear } \\
\text { (kip) }\end{array}$ & $\begin{array}{c}\text { Time } \\
\text { (s) }\end{array}$ \\
\hline cb/op_mass/cmu/none/ip_mass/cmu/none/syl/dbe & 1.02 & 296 & 3.07 \\
\hline cb/op_mass/cmu/none/ip_am/cmu/de/syl/dbe & 0.79 & 255 & 3.08 \\
\hline $\mathrm{cb} / \mathrm{op} \_m a s s / \mathrm{cmu} / \mathrm{none} / \mathrm{ip} \_a m / \mathrm{cmu} / \mathrm{tw} / \mathrm{syl} / \mathrm{dbe}$ & 0.81 & 248 & 3.12 \\
\hline cb/op_mass/cmu/none/ip_mass/cmu/none/syl/mce & 1.52 & 385 & 3.12 \\
\hline cb/op_mass/cmu/none/ip_am/cmu/de/syl/mce & 1.23 & 360 & 3.08 \\
\hline $\mathrm{cb} / \mathrm{op} \_m a s s / \mathrm{cmu} / \mathrm{none} / \mathrm{ip} \_a m / \mathrm{cmu} / \mathrm{tw} / \mathrm{syl} / \mathrm{mce}$ & 1.17 & 356 & 3.12 \\
\hline cb/op_mass/cmu/none/ip_mass/cmu/none/tar/dbe & 1.29 & 255 & 5.6 \\
\hline cb/op_mass/cmu/none/ip_am/cmu/de/tar/dbe & 0.95 & 219 & 5.6 \\
\hline $\mathrm{cb} /$ op_mass/cmu/none/ip_am/cmu/tw/tar/dbe & 0.91 & 211 & 5.6 \\
\hline cb/op_mass/cmu/none/ip_mass/cmu/none/tar/mce & 1.55 & 334 & 5.6 \\
\hline cb/op_mass/cmu/none/ip_am/cmu/de/tar/mce & 1.48 & 290 & 5.6 \\
\hline cb/op_mass/cmu/none/ip_am/cmu/tw/tar/mce & 1.47 & 297 & 5.6 \\
\hline cb/op_mass/studs/none/ip_mass/studs/none/syl/dbe & 0.68 & 210 & 3.12 \\
\hline cb/op_mass/studs/none/ip_am/studs/de/syl/dbe & 0.64 & 188 & 3.07 \\
\hline cb/op_mass/studs/none/ip_mass/studs/none/syl/mce & 1.04 & 324 & 3.12 \\
\hline cb/op_mass/studs/none/ip_am/studs/de/syl/mce & 0.977 & 299 & 3.07 \\
\hline cb/op_mass/studs/none/ip_mass/studs/none/tar/dbe & 1.28 & 202 & 5.55 \\
\hline cb/op_mass/studs/none/ip_am/studs/de/tar/dbe & 1.25 & 177 & 5.14 \\
\hline cb/op_mass/studs/none/ip_mass/studs/none/tar/mce & 1.51 & 305 & 5.55 \\
\hline cb/op_mass/studs/none/ip_am/studs/de/tar/mce & 1.65 & 270 & 5.38 \\
\hline
\end{tabular}


Examination of Figure 4.3 and Tables 4.9 and 4.10 indicates that modeling the actual behavior of the in - plane veneer wall systems can significantly reduce the peak acceleration that the supporting structural frames experience for the more flexible systems and have little effect for stiffer frame systems. These effects will be discussed in Chapter 5 .

Figure 4.4 shows the peak horizontal frame deformation for the most flexible frame system (the steel moment resisting frame (smrf/)), with the in - plane and out - of - plane steel stud backed veneer walls represented by mass only (../op-mass/.../ip-mass/.../stud/), under the MCE level (/mce/) of the Tarzana ground motion (/tar/). Also presented in this figure are the horizontal nodal displacements for the concrete braced frame systems (cb/), with in - plane and out - of - plane reinforced concrete masonry backed veneer wall systems represented by masses only (../op-mass/.../ip-mass/.../cmu/), under the DBE level $(/ \mathrm{dbe} /)$ of the Sylmar ground motion (/syl/). Also shown on this graph is the response of each of these systems when the in - plane behavior of the veneer systems is modeled as a system, instead just masses (/ip-am/). The values of the maximum frame horizontal nodal displacement and average displacements are tabulated in Tables 4.11 and 4.12. The peak horizontal frame deformations for all the wall system and frames, analyzed with variations with in-plane wall system modeling are contained in Appendix C. 


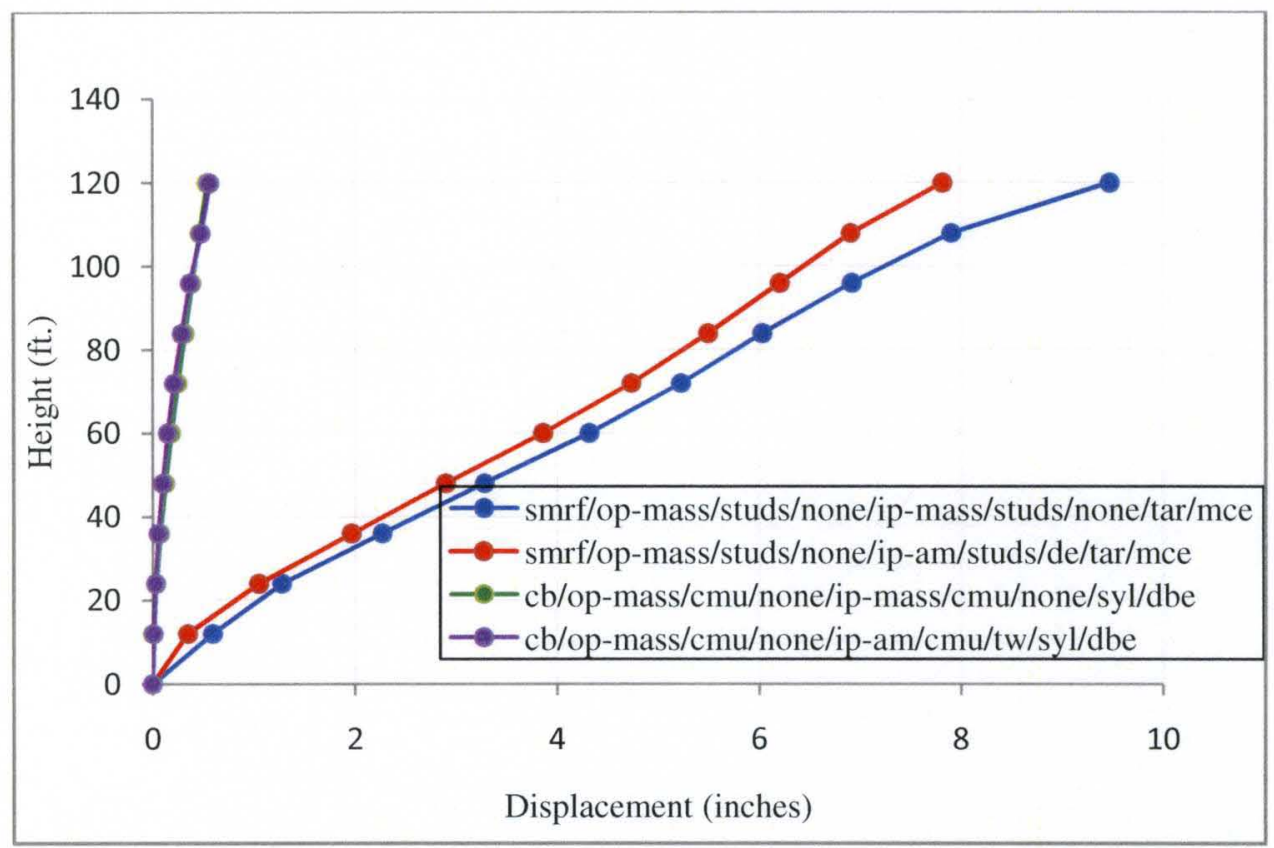

Figure 4.4: Displacement Profile Along the Height of the Main Frame for the Stiffest and Most Flexible Systems Analyzed, With a Mass Representation and an Analytical Model Representation of the In Plane Wall System, and a Mass Representation of the Out of Plane Wall System. 
Table 4.11: Comparison between the Peak and Average Displacements for the Steel Moment Resisting Frame, with Mass and Analytical Model Representations of the In Plane Wall System, and a Mass Representation of the Out of Plane Wall System

\begin{tabular}{|c|c|c|c|}
\hline Model ID & $\begin{array}{c}\text { Peak } \\
\text { Disp (in) }\end{array}$ & $\begin{array}{c}\text { Average } \\
\text { Disp } \\
\text { (in) }\end{array}$ & $\begin{array}{c}\text { Time } \\
\text { (s) }\end{array}$ \\
\hline smrf/op_mass/cmu/none/ip_mass/cmu/none/syl/dbe & 3.13 & 1.15 & 3.26 \\
\hline smrf/op_mass/cmu/none/ip_am/cmu/de/syl/dbe & 2.83 & 1.05 & 2.99 \\
\hline smrf/op_mass/cmu/none/ip_am/cmu/tw/syl/dbe & 2.15 & 0.99 & 2.99 \\
\hline smrf/op_mass/cmu/none/ip_mass/cmu/none/syl/mce & 4.89 & 1.82 & 3.26 \\
\hline smrf/op_mass/cmu/none/ip_am/cmu/de/syl/mce & 3.38 & 1.33 & 2.99 \\
\hline smrf/op_mass/cmu/none/ip_am/cmu/tw/syl/mce & 3.21 & 1.18 & 2.99 \\
\hline smrf/op_mass/cmu/none/ip_mass/cmu/none/tar/dbe & 7.83 & 2.75 & 6.18 \\
\hline smrf/op_mass/cmu/none/ip_am/cmu/de/tar/dbe & 7.08 & 2.53 & 5.84 \\
\hline smrf/op_mass/cmu/none/ip_am/cmu/tw/tar/dbe & 6.99 & 2.45 & 5.84 \\
\hline smrf/op_mass/cmu/none/ip_mass/cmu/none/tar/mce & 11.7 & 4.35 & 6.18 \\
\hline smrf/op_mass/cmu/none/ip_am/cmu/de/tar/mce & 9.45 & 3.55 & 5.84 \\
\hline smrf/op_mass/cmu/none/ip_am/cmu/tw/tar/mce & 8.59 & 3.29 & 5.84 \\
\hline smrf/op_mass/studs/none/ip_mass/studs/none/syl/dbe & 2.53 & 1.07 & 3.24 \\
\hline smrf/op_mass/studs/none/ip_am/studs/de/syl/dbe & 2.17 & 0.89 & 2.89 \\
\hline smrf/op_mass/studs/none/ip_mass/studs/none/syl/mce & 3.66 & 1.57 & 3.24 \\
\hline smrf/op_mass/studs/none/ip_am/studs/de/syl/mce & 3.18 & 1.33 & 2.89 \\
\hline smrf/op_mass/studs/none/ip_mass/studs/none/tar/dbe & 6.44 & 2.71 & 6.17 \\
\hline smrf/op_mass/studs/none/ip_am/studs/de/tar/dbe & 5.55 & 2.26 & 6.03 \\
\hline smrf/op_mass/studs/none/ip_mass/studs/none/tar/mce & 10.2 & 4.36 & 6.17 \\
\hline smrf/op_mass/studs/none/ip_am/studs/de/tar/mce & 8.96 & 3.86 & 5.83 \\
\hline
\end{tabular}


Table 4.12: Comparison between the Peak and Average Displacements for the Reinforced Concrete Braced Frame, with Mass and Analytical Model Representations of the In Plane Wall System, and a Mass Representation of the Out of Plane Wall System

\begin{tabular}{|c|c|c|c|}
\hline Model ID & $\begin{array}{l}\text { Peak Disp } \\
\text { (in) }\end{array}$ & $\begin{array}{c}\text { Average } \\
\text { Disp } \\
\text { (in) }\end{array}$ & $\begin{array}{c}\text { Time } \\
\text { (s) }\end{array}$ \\
\hline cb/op_mass/cmu/none/ip_mass/cmu/none/syl/dbe & 0.56 & 0.2 & 3.1 \\
\hline cb/op_mass/cmu/none/ip_am/cmu/de/syl/dbe & 0.54 & 0.21 & 3.1 \\
\hline $\mathrm{cb} /$ p__mass/cmu/none/ip_am/cmu/tw/syl/dbe & 0.54 & 0.21 & 3.1 \\
\hline cb/op_mass/cmu/none/ip_mass/cmu/none/syl/mce & 0.83 & 0.3 & 3.13 \\
\hline cb/op_mass/cmu/none/ip_am/cmu/de/syl/mce & 0.81 & 0.32 & 3.1 \\
\hline cb/op_mass/cmu/none/ip_am/cmu/tw/syl/mce & 0.81 & 0.32 & 3.1 \\
\hline cb/op_mass/cmu/none/ip_mass/cmu/none/tar/dbe & 0.49 & 0.18 & 5.82 \\
\hline cb/op_mass/cmu/none/ip_am/cmu/de/tar/dbe & 0.48 & 0.19 & 2.0 \\
\hline cb/op_mass/cmu/none/ip_am/cmu/tw/tar/dbe & 0.47 & 0.19 & 2.0 \\
\hline cb/op_mass/cmu/none/ip_mass/cmu/none/tar/mce & 0.75 & 0.28 & 5.82 \\
\hline cb/op_mass/cmu/none/ip_am/cmu/de/tar/mce & 0.72 & 0.29 & 5.84 \\
\hline cb/op_mass/cmu/none/ip_am/cmu/tw/tar/mce & 0.7 & 0.28 & 5.84 \\
\hline cb/op_mass/studs/none/ip_mass/studs/none/syl/dbe & 0.47 & 0.18 & 3.13 \\
\hline cb/op_mass/studs/none/ip_am/studs/de/syl/dbe & 0.46 & 0.19 & 2.95 \\
\hline cb/op_mass/studs/none/ip_mass/studs/none/syl/mce & 0.71 & 0.26 & 3.13 \\
\hline cb/op_mass/studs/none/ip_am/studs/de/syl/mce & 0.8 & 0.31 & 2.95 \\
\hline cb/op_mass/studs/none/ip_mass/studs/none/tar/dbe & 0.64 & 0.23 & 5.91 \\
\hline cb/op_mass/studs/none/ip_am/studs/de/tar/dbe & 0.67 & 0.25 & 5.27 \\
\hline cb/op_mass/studs/none/ip_mass/studs/none/tar/mce & 1.0 & 0.35 & 5.91 \\
\hline cb/op_mass/studs/none/ip_am/studs/de/tar/mce & 1.06 & 0.39 & 5.27 \\
\hline
\end{tabular}


Examination of Figure 4.4 and Tables 4.11 and 4.12 shows that, as expected, the frame stiffness has a significant effect on the peak horizontal displacement experienced at both DBE and MCE ground motion levels. In addition, it appears modeling the actual in - plane behavior of the veneer wall systems can significantly reduce the peak frame displacements when the more flexible systems are analyzed. There appears to be little difference with stiff frames and backing Systems. These effects will be discussed further in Chapter 5.

\subsection{Comparison of Out - of - Plane Veneer Wall System Responses}

Figure 4.5 shows the out - of - plane veneer nodal acceleration over the height of the frame for the most flexible system considered, at the time instant underthe MCE ground motion that produced peak veneer acceleration. The most flexible system considered was the steel moment resisting frame with a steel stud backed veneer wall system, incorporating flexible ties.

Figure 4.6 shows the veneer nodal acceleration over the height of the frame for the stiffest system considered at the time instant under MCE ground motion that produced peak veneer acceleration. The stiffest system considered was the concrete braced frame with a CMU backed veneer wall system, incorporating stiff ties. 
The stiffest and most flexible systems define the bounds of behavior within which the systems evaluated by this study were observed to lie. These plots show the variation of veneer acceleration at the different storey levels of the frame, and enable the prediction of the storey level at which the out of plane wall would have the highest likelihood of being subjected to the greatest loads. These accelerations were plotted at the time instant when the veneer acceleration reached its maximum value. The rationale for choosing the maximum veneer acceleration is that veneer acceleration serves as a good indicator of the condition or level of damage in the wall system. Higher veneer accelerationsgenerally increase tie forces, and also the likelihood of damage in the form of single or multiple cracks in the veneer. Both of the aforementioned conditions are precipitators of the ultimate failure of the wall system.It can be seen in Figures 4.5 and 4.6 , the out - of plane veneer wall system on the $10^{\text {th }}$ storey experienced the highest accelerations for both flexible and stiff frame and backing systems. Based these observations, the remainder of the discussion on the out - of - plane veneer wall systems will exclusively focus on the response of the $10^{\text {th }}$ storey veneer wall systems. 


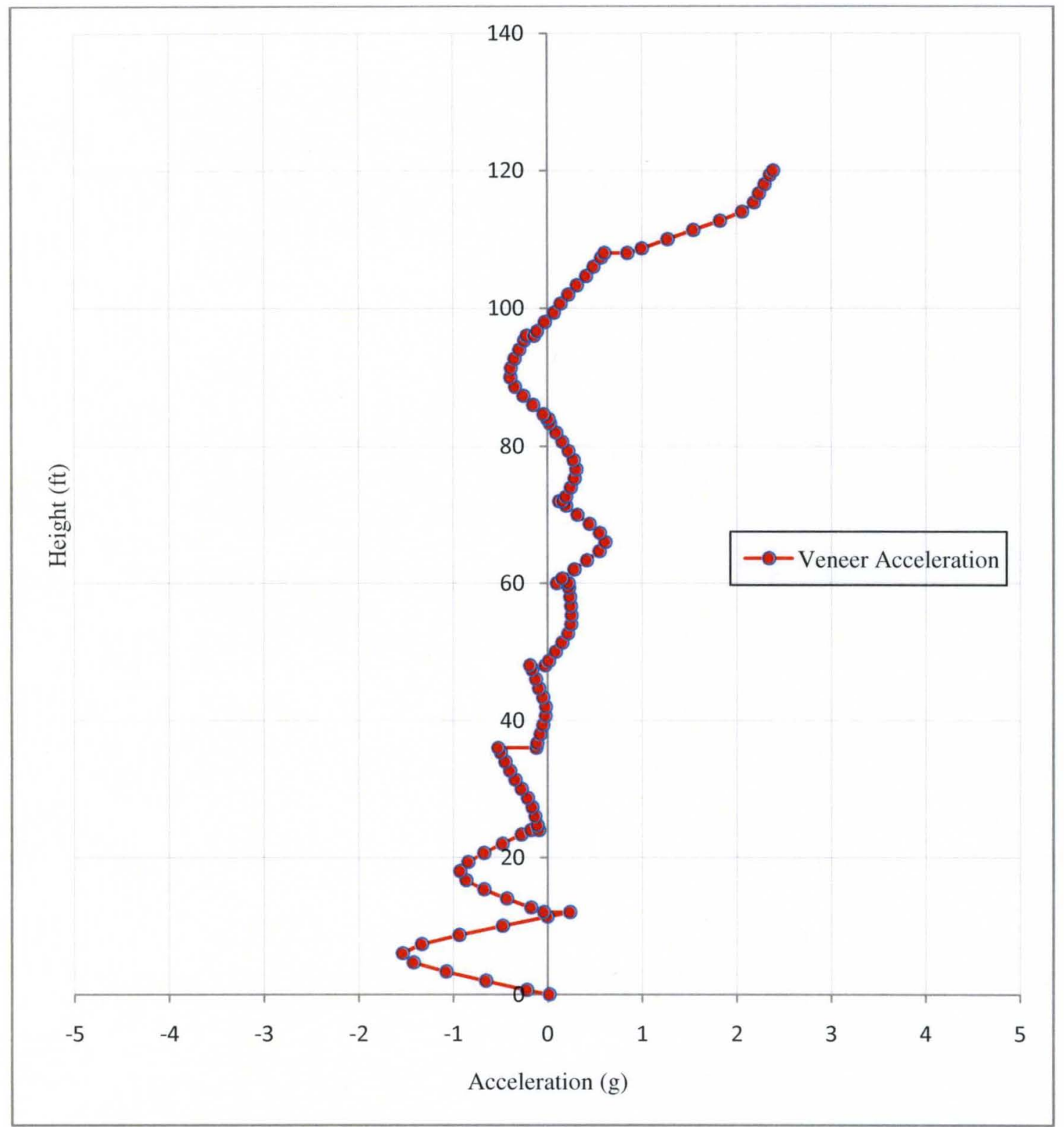

Figure 4.5: Acceleration Profile of the Out of Plane Veneer, Along the Height of the Main Frame for the Most Flexible System Analyzed, At the Time Instant At Which the Veneer Acceleration Reached Its Maximum Value. 


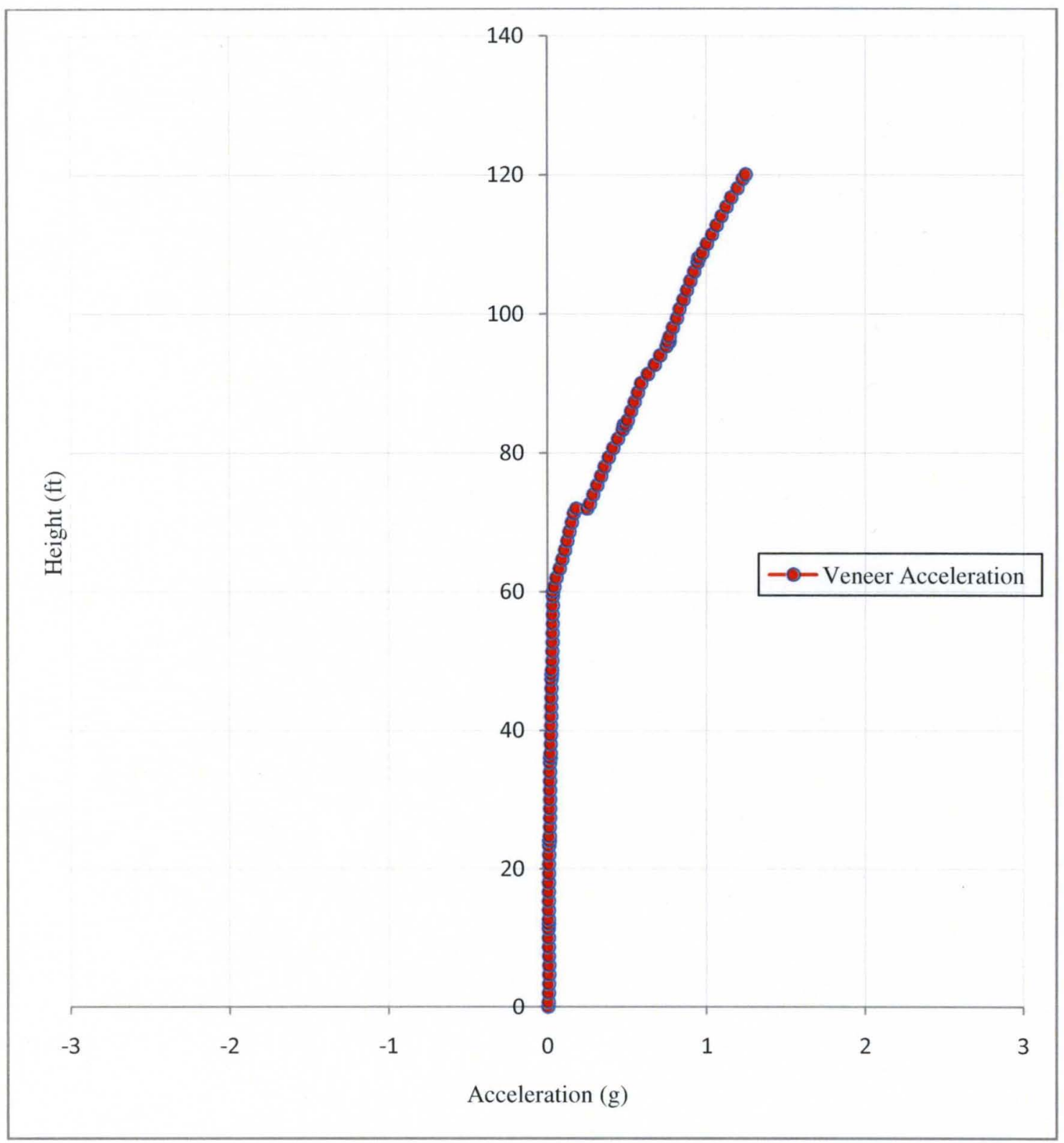

Figure 4.6: Acceleration Profile of the Out of Plane Veneer, Along the Height of the Main Frame for the Stiffest System Analyzed, At the Time Instant At Which the Veneer Acceleration Reached Its Maximum Value.

It is seen in the figures above that the veneer of the CMU backed wall systems showed a significantly stiffer response than that of the steel stud backed walls. It is also seen that the veneer on the top storey of the steel moment resisting frame had the largest 
difference in accelerations at its base and top. The high flexibility of the steel moment resisting frame and the difference in acceleration at the consecutive storey levels of the frame, coupled with the the flexibility of the steel stud backing wall and its deformed shape in bending, along the wall height, were possible factors that contributed to the difference in the two veneer acceleration profiles shown above. These effects are discussed further in Chapter 5.

As discussed in Chapter 2, the out-of-plane behavior of the masonry veneer is typically critical under seismic loading. Thus the seismic performance of the veneer wall systems was evaluated under out - of - plane loading. The peak and average veneer and backup accelerations and displacements and the tie forces at the MCE level ground motions at the time instant maximum veneer acceleration (at the top storey) for all variations in structural frame and masonry wall systems were determined. The plots of veneer and backing wall accelerations and deformations, and tie forces for all the wall systems and frame configurations are shown in Appendix D. The peak and average veneer and backing wall accelerations, peak tie forces, and veneer and backing wall deformations are summarized in Tables 4.13 to 4.22 .

Figures 4.7, 4.8, and 4.9 show the veneer and backing wall accelerations and deformations, and tie forces, for the wall systems backed by the most flexible systems, and then backed by the stiffest systems. Referring to the labeling convention described in Table 3.22, the most flexible configuration is represented by smrf/op-am/studs/de-flex/ip- 
mass/studs/none/tar/mce, and the stiffest configuration, by cb/op-am/CMU/tw/ipmass/CMU/none/syl/dbe. These plots are intended to show the range of response for the wall system configurations evaluated at, or near, collapse. (All results were therefore at the MCE ground motions).

It appears that the stiffer backing system reduces the peak accelerations and deformation of the veneer and backing walls, as well as produces a more uniform acceleration distribution over the height of the wall system. The tie force peak values are also affected, with peak tie forces occurring with the stiffer backing and tie systems. This will be discussed further in Chapter 5 . 


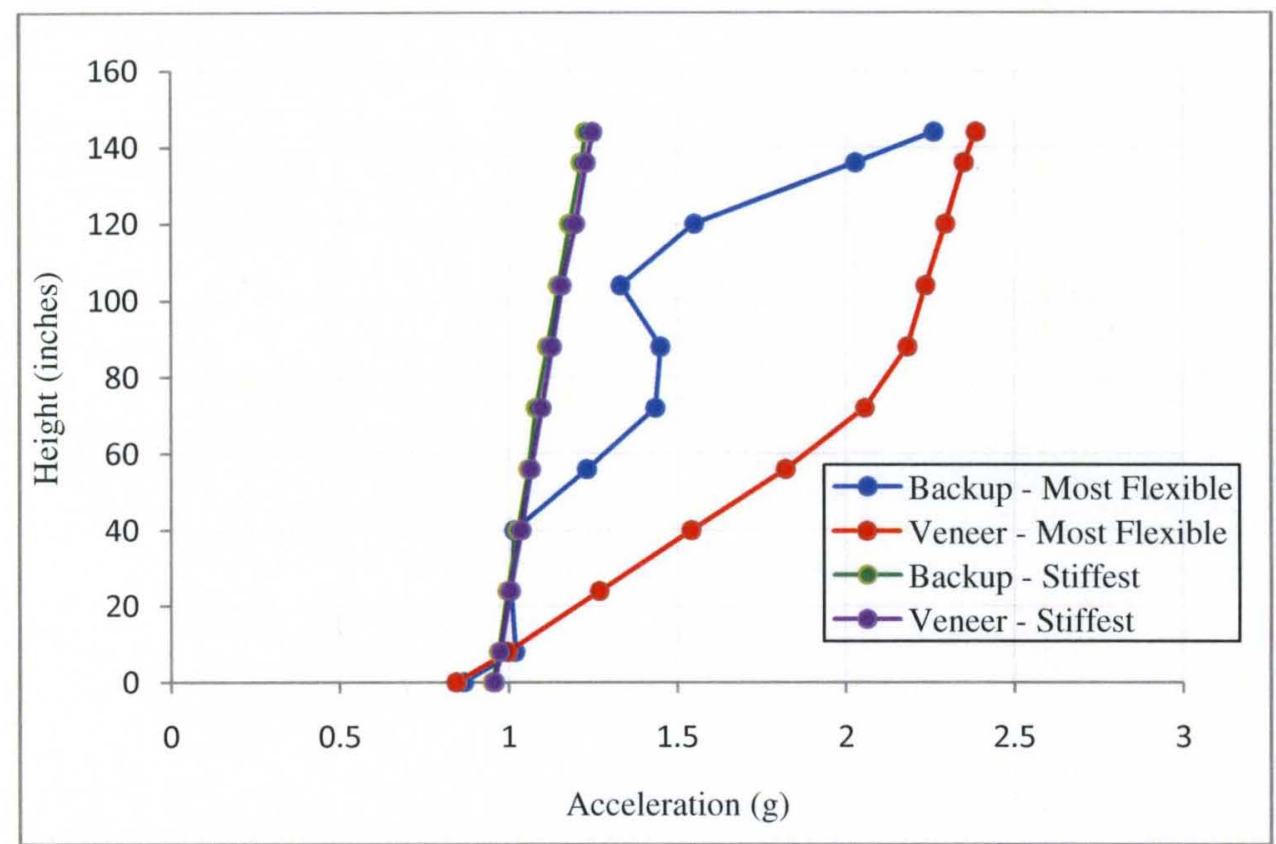

Figure 4.7: Acceleration Profiles of the Out of Plane Veneer and Backup at MCE, for the Stiffest and Most Flexible Wall Systems on the $10^{\text {th }}$ Storey of the Mainframe, at the Time Instant at Which the Veneer Acceleration Reached Its Maximum Value. 
Table 4.13: Comparison between the Peak and Average Veneer and Backup Accelerations for the Out of Plane Wall Systems In the Steel Moment Frame

\begin{tabular}{|c|c|c|c|c|}
\hline \multirow[b]{2}{*}{ Model ID } & \multicolumn{4}{|c|}{ Acceleration (g) } \\
\hline & $\begin{array}{c}\text { Peak } \\
\text { Veneer }\end{array}$ & $\begin{array}{c}\text { Peak } \\
\text { Backup }\end{array}$ & $\begin{array}{c}\text { Average } \\
\text { Veneer }\end{array}$ & $\begin{array}{l}\text { Average } \\
\text { Backup }\end{array}$ \\
\hline smrf/op_am/cmu/de/ip_mass/cmu/none/syl/mce & 1.96 & 2.10 & 1.39 & 1.28 \\
\hline smrf/op_am/cmu/tw/ip_mass/cmu/none/syl/mce & 1.78 & 1.73 & 1.15 & 1.13 \\
\hline smrf/op_am/cmu/de/ip_mass/cmu/none/tar/mce & 3.83 & 3.69 & 2.71 & 2.67 \\
\hline smrf/op_am/cmu/tw/ip_mass/cmu/none/tar/mce & 3.79 & 3.70 & 2.72 & 2.72 \\
\hline smrf/op_am/studs/de_flex/ip_mass/studs/none/syl/mce & 1.99 & 1.83 & 1.49 & 0.26 \\
\hline smrf/op_am/studs/de_stiff/ip_mass/studs/none/syl/mce & 2.12 & 2.05 & 1.61 & 1.27 \\
\hline smrf/op_am/studs/de_flex/ip_mass/studs/none/tar/mce & 2.38 & 2.26 & 1.81 & 1.38 \\
\hline smrf/op_am/studs/de_stiff/ip_mass/studs/none/tar/mce & 3.07 & 2.81 & 2.72 & 2.52 \\
\hline
\end{tabular}

Table 4.14: Comparison between the Peak and Average Veneer and Backup Accelerations for the Out of Plane Wall Systems In the Steel Braced Frame

\begin{tabular}{|c|c|c|c|c|}
\hline \multirow[b]{2}{*}{ Model ID } & \multirow[b]{2}{*}{$\begin{array}{c}\text { Peak } \\
\text { Veneer }\end{array}$} & \multicolumn{3}{|c|}{ Acceleration $(g)$} \\
\hline & & $\begin{array}{c}\text { Peak } \\
\text { Backup }\end{array}$ & $\begin{array}{c}\text { Average } \\
\text { Veneer }\end{array}$ & $\begin{array}{l}\text { Average } \\
\text { Backup }\end{array}$ \\
\hline sb/op_am/cmu/de/ip_mass/cmu/none/syl/mce & 1.63 & 1.57 & 1.45 & 1.41 \\
\hline sb/op_am/cmu/tw/ip_mass/cmu/none/syl/mce & 1.66 & 1.49 & 1.40 & 1.37 \\
\hline sb/op_am/cmu/de/ip_mass/cmu/none/tar/mce & 2.64 & 2.61 & 2.52 & 2.46 \\
\hline $\mathrm{sb} / \mathrm{op} \_a \mathrm{am} / \mathrm{cmu} / \mathrm{tw} / \mathrm{ip} \_\mathrm{mass} / \mathrm{cmu} / \mathrm{none} / \mathrm{tar} / \mathrm{mce}$ & 2.43 & 2.37 & 2.38 & 2.30 \\
\hline sb/op_am/studs/de_flex/ip_mass/studs/none/syl/mce & 1.53 & 1.41 & 1.40 & 1.18 \\
\hline sb/op_am/studs/de_stiff/ip_mass/studs/none/syl/mce & 1.68 & 1.44 & 1.52 & 1.21 \\
\hline sb/op_am/studs/de_flex/ip_mass/studs/none/tar/mce & 2.09 & 2.58 & 2.32 & 2.28 \\
\hline sb/op_am/studs/de_stiff/ip_mass/studs/none/tar/mce & 2.67 & 2.59 & 2.27 & 2.24 \\
\hline
\end{tabular}


Table 4.15: Comparison between the Peak and Average Veneer and Backup Accelerations for the Out of Plane Wall Systems In the Reinforced Concrete Moment Frame

\begin{tabular}{|c|c|c|c|c|}
\hline \multirow[b]{2}{*}{ Model ID } & \multicolumn{4}{|c|}{ Acceleration (g) } \\
\hline & $\begin{array}{c}\text { Peak } \\
\text { Veneer }\end{array}$ & $\begin{array}{c}\text { Peak } \\
\text { Backup }\end{array}$ & $\begin{array}{c}\text { Average } \\
\text { Veneer }\end{array}$ & $\begin{array}{c}\text { Average } \\
\text { Backup }\end{array}$ \\
\hline cmrf/op_am/cmu/de/ip_mass/cmu/none/syl/mce & 1.82 & 1.61 & 1.39 & 1.42 \\
\hline cmrf/op_am/cmu/tw/ip_mass/cmu/none/syl/mce & 1.72 & 1.6 & 1.15 & 1.41 \\
\hline cmrf/op_am/cmu/de/ip_mass/cmu/none/tar/mce & 3.5 & 2.26 & 2.71 & 2.0 \\
\hline cmrf/op_am/cmu/tw/ip_mass/cmu/none/tar/mce & 3.01 & 2.25 & 2.72 & 2.0 \\
\hline cmrf/op_am/studs/de_flex/ip_mass/studs/none/syl/mce & 1.79 & 1.71 & 1.49 & 1.51 \\
\hline cmrf/op_am/studs/de_stiff/ip_mass/studs/none/syl/mce & 1.69 & 1.64 & 1.61 & 1.46 \\
\hline cmrf/op_am/studs/de_flex/ip_mass/studs/none/tar/mce & 2.19 & 1.94 & 1.81 & 1.68 \\
\hline cmrf/op_am/studs/de_stiff/ip_mass/studs/none/tar/mce & 2.06 & 1.95 & 2.72 & 1.86 \\
\hline
\end{tabular}

Table 4.16: Comparison between the Peak and Average Veneer and Backup Accelerations for the Out of Plane Wall Systems In the Reinforced Concrete Braced Frame

\begin{tabular}{|c|c|c|c|c|}
\hline \multirow[b]{2}{*}{ Model ID } & \multicolumn{4}{|c|}{ Acceleration (g) } \\
\hline & $\begin{array}{c}\text { Peak } \\
\text { Veneer }\end{array}$ & $\begin{array}{c}\text { Peak } \\
\text { Backup }\end{array}$ & $\begin{array}{c}\text { Average } \\
\text { Veneer }\end{array}$ & $\begin{array}{l}\text { Average } \\
\text { Backup }\end{array}$ \\
\hline cb/op_am/cmu/de/ip_mass/cmu/none/syl/mce & 1.34 & 1.23 & 1.15 & 1.08 \\
\hline cb/op_am/cmu/tw/ip_mass/cmu/none/syl/mce & 1.25 & 1.22 & 1.1 & 1.08 \\
\hline cb/op_am/cmu/de/ip_mass/cmu/none/tar/mce & 1.3 & 1.28 & 1.17 & 1.15 \\
\hline cb/op_am/cmu/tw/ip_mass/cmu/none/tar/mce & 1.3 & 1.28 & 1.18 & 1.16 \\
\hline cb/op_am/studs/de_flex/ip_mass/studs/none/syl/mce & 1.09 & 0.99 & 0.98 & 0.77 \\
\hline cb/op_am/studs/de_stiff/ip_mass/studs/none/syl/mce & 0.98 & 0.95 & 0.88 & 0.76 \\
\hline cb/op_am/studs/de_flex/ip_mass/studs/none/tar/mce & 2.23 & 2.06 & 1.99 & 1.86 \\
\hline cb/op_am/studs/de_stiff/ip_mass/studs/none/tar/mce & 1.87 & 1.76 & 1.79 & 1.56 \\
\hline
\end{tabular}




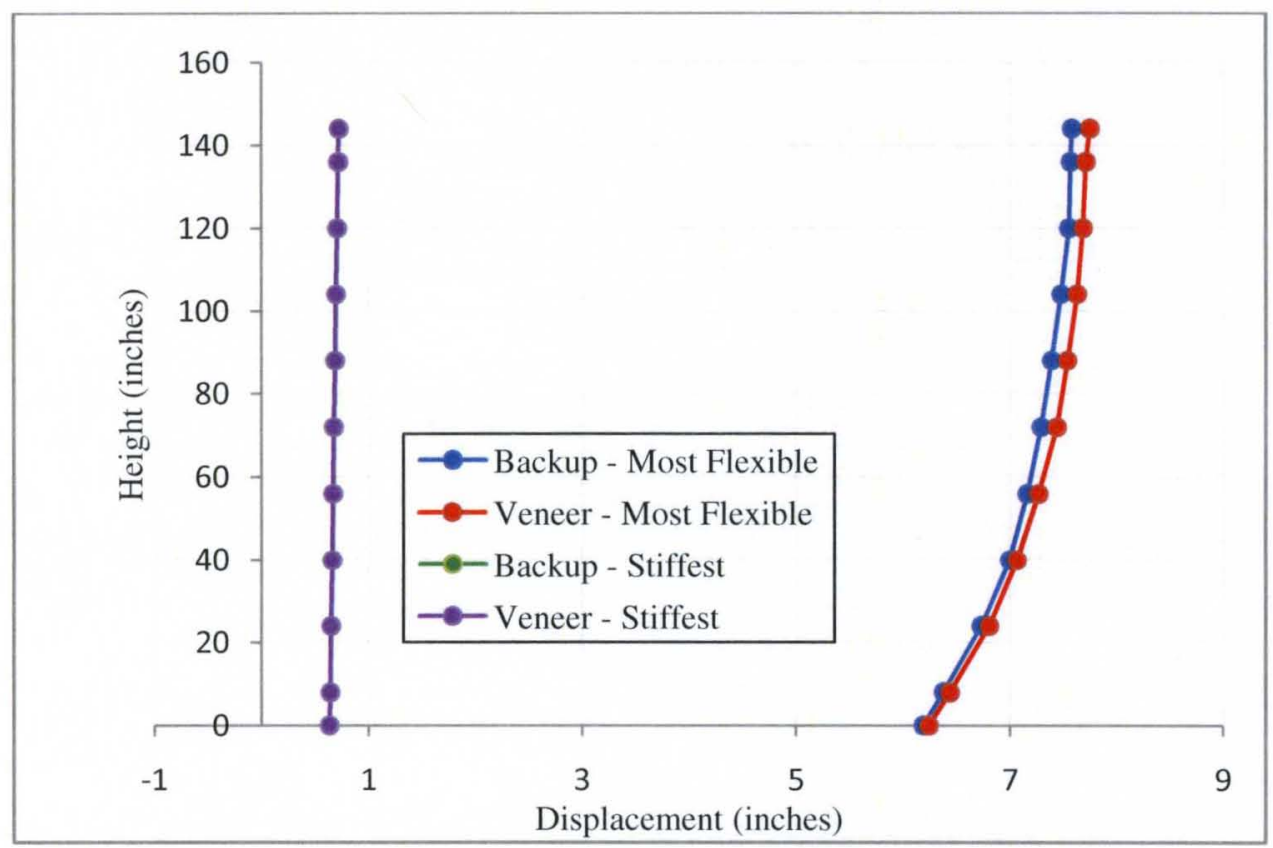

Figure 4.8: Displacement Profiles of the Out of Plane Veneer and Backup at MCE, for the Stiffest and Most Flexible Wall Systems on the $10^{\text {th }}$ Storey of the Mainframe, at the Time Instant at Which the Veneer Acceleration Reached Its Maximum Value. 
Table 4.17: Comparison between the Peak and Average Veneer and Backup

Displacements for the Out of Plane Wall Systems In the Steel Moment Frame

\begin{tabular}{|c|c|c|c|c|}
\hline \multirow[b]{2}{*}{ Model ID } & \multicolumn{4}{|c|}{ Displacement (in) } \\
\hline & $\begin{array}{c}\text { Peak } \\
\text { Veneer }\end{array}$ & $\begin{array}{c}\text { Peak } \\
\text { Backup }\end{array}$ & $\begin{array}{c}\text { Average } \\
\text { Veneer }\end{array}$ & $\begin{array}{c}\text { Average } \\
\text { Backup }\end{array}$ \\
\hline smrf/op_am/cmu/de/ip_mass/cmu/none/syl/mce & 3.64 & 3.61 & 3.18 & 3.16 \\
\hline smrf/op_am/cmu/tw/ip_mass/cmu/none/syl/mce & 3.59 & 2.57 & 3.14 & 3.12 \\
\hline smrf/op_am/cmu/de/ip_mass/cmu/none/tar/mce & 10.2 & 10.2 & 8.86 & 8.84 \\
\hline smrf/op_am/cmu/tw/ip_mass/cmu/none/tar/mce & 10.1 & 10.1 & 8.8 & 8.79 \\
\hline smrf/op_am/studs/de_flex/ip_mass/studs/none/syl/mce & 3.51 & 3.44 & 3.2 & 3.14 \\
\hline smrf/op_am/studs/de_stiff/ip_mass/studs/none/syl/mce & 3.46 & 3.4 & 3.14 & 3.11 \\
\hline smrf/op_am/studs/de_flex/ip_mass/studs/none/tar/mce & 7.75 & 7.58 & 7.23 & 7.11 \\
\hline smrf/op_am/studs/de_stiff/ip_mass/studs/none/tar/mce & 7.17 & 7.08 & 6.77 & 6.69 \\
\hline
\end{tabular}

Table 4.18: Comparison between the Peak and Average Veneer and Backup Displacements for the Out of Plane Wall Systems In the Steel Braced Frame

\begin{tabular}{|c|c|c|c|c|}
\hline \multirow[b]{2}{*}{ Model ID } & \multicolumn{4}{|c|}{ Displacement (in) } \\
\hline & $\begin{array}{c}\text { Peak } \\
\text { Veneer }\end{array}$ & $\begin{array}{c}\text { Peak } \\
\text { Backup }\end{array}$ & $\begin{array}{c}\text { Average } \\
\text { Veneer }\end{array}$ & $\begin{array}{l}\text { Average } \\
\text { Backup }\end{array}$ \\
\hline sb/op_am/cmu/de/ip_mass/cmu/none/syl/mce & 3.2 & 3.16 & 3.17 & 3.15 \\
\hline $\mathrm{sb} / o p \_a m / \mathrm{cmu} / \mathrm{tw} / \mathrm{ip} \_m a s s / \mathrm{cmu} / \mathrm{none} / \mathrm{syl} / \mathrm{mce}$ & 3.22 & 3.18 & 3.2 & 3.18 \\
\hline sb/op_am/cmu/de/ip_mass/cmu/none/tar/mce & 3.78 & 3.75 & 3.65 & 3.64 \\
\hline sb/op_am/cmu/tw/ip_mass/cmu/none/tar/mce & 3.85 & 3.85 & 3.72 & 3.72 \\
\hline sb/op_am/studs/de_flex/ip_mass/studs/none/syl/mce & 3.05 & 3.05 & 2.87 & 2.86 \\
\hline sb/op_am/studs/de_stiff/ip_mass/studs/none/syl/mce & 3.07 & 3.06 & 2.95 & 2.94 \\
\hline sb/op_am/studs/de_flex/ip_mass/studs/none/tar/mce & 3.4 & 3.43 & 3.25 & 3.23 \\
\hline sb/op_am/studs/de_stiff/ip_mass/studs/none/tar/mce & 3.35 & 3.34 & 3.17 & 3.15 \\
\hline
\end{tabular}


Table 4.19: Comparison between the Peak and Average Veneer and Backup Displacements for the Out of Plane Wall Systems In the Reinforced Concrete Moment Resisting Frame

\begin{tabular}{|c|c|c|c|c|}
\hline \multirow[b]{2}{*}{ Model ID } & \multicolumn{4}{|c|}{ Displacement(in) } \\
\hline & $\begin{array}{c}\text { Peak } \\
\text { Veneer }\end{array}$ & $\begin{array}{c}\text { Peak } \\
\text { Backup }\end{array}$ & $\begin{array}{c}\text { Average } \\
\text { Veneer }\end{array}$ & $\begin{array}{c}\text { Average } \\
\text { Backup }\end{array}$ \\
\hline cmrf/op_am/cmu/de/ip_mass/cmu/none/syl/mce & 1.96 & 1.9 & 1.83 & 1.79 \\
\hline cmrf/op_am/cmu/tw/ip_mass/cmu/none/syl/mce & 2.0 & 1.98 & 1.9 & 1.88 \\
\hline cmrf/op_am/cmu/de/ip_mass/cmu/none/tar/mce & 4.28 & 4.14 & 4.04 & 3.95 \\
\hline cmrf/op_am/cmu/tw/ip_mass/cmu/none/tar/mce & 4.14 & 4.13 & 3.95 & 3.95 \\
\hline cmrf/op_am/studs/de_flex/ip_mass/studs/none/syl/mce & 1.75 & 1.70 & 1.65 & 1.59 \\
\hline cmrf/op_am/studs/de_stiff/ip_mass/studs/none/syl/mce & 1.66 & 1.62 & 1.55 & 1.53 \\
\hline cmrf/op_am/studs/de_flex/ip_mass/studs/none/tar/mce & 2.68 & 2.64 & 2.56 & 2.53 \\
\hline cmrf/op_am/studs/de_stiff/ip_mass/studs/none/tar/mce & 2.63 & 2.6 & 2.54 & 2.51 \\
\hline
\end{tabular}

Table 4.20: Comparison between the Peak and Average Veneer and Backup Displacements for the Out of Plane Wall Systems In the Reinforced Concrete Braced Frame

\begin{tabular}{|c|c|c|c|c|}
\hline \multirow[b]{2}{*}{ Model ID } & \multicolumn{2}{|c|}{ Displacement(in) } & \multirow[b]{2}{*}{$\begin{array}{c}\text { Average } \\
\text { Veneer }\end{array}$} & \multirow[b]{2}{*}{$\begin{array}{l}\text { Average } \\
\text { Backup }\end{array}$} \\
\hline & $\begin{array}{c}\text { Peak } \\
\text { Veneer }\end{array}$ & $\begin{array}{l}\text { Peak } \\
\text { Backup }\end{array}$ & & \\
\hline cb/op_am/cmu/de/ip_mass/cmu/none/syl/mce & 0.71 & 0.69 & 0.66 & 0.65 \\
\hline $\mathrm{cb} / \mathrm{op} \_a m / \mathrm{cmu} / \mathrm{tw} / \mathrm{ip} \_\mathrm{mass} / \mathrm{cmu} / \mathrm{none} / \mathrm{syl} / \mathrm{mce}$ & 0.72 & 0.72 & 0.68 & 0.67 \\
\hline $\mathrm{cb} / \mathrm{op}$ am/cmu/de/ip_mass/cmu/none/tar/mce & 0.71 & 0.69 & 0.65 & 0.64 \\
\hline cb/op_am/cmu/tw/ip_mass/cmu/none/tar/mce & 0.73 & 0.71 & 0.66 & 0.65 \\
\hline cb/op_am/studs/de_flex/ip_mass/studs/none/syl/mce & 0.72 & 0.72 & 0.67 & 0.67 \\
\hline cb/op_am/studs/de_stiff/ip_mass/studs/none/syl/mce & 0.65 & 0.65 & 0.63 & 0.63 \\
\hline cb/op_am/studs/de_flex/ip_mass/studs/none/tar/mce & 0.95 & 0.94 & 0.9 & 0.88 \\
\hline $\mathrm{cb} / \mathrm{op}$ _am/studs/de_stiff/ip_mass/studs/none/tar/mce & 0.92 & 0.92 & 0.87 & 0.87 \\
\hline
\end{tabular}




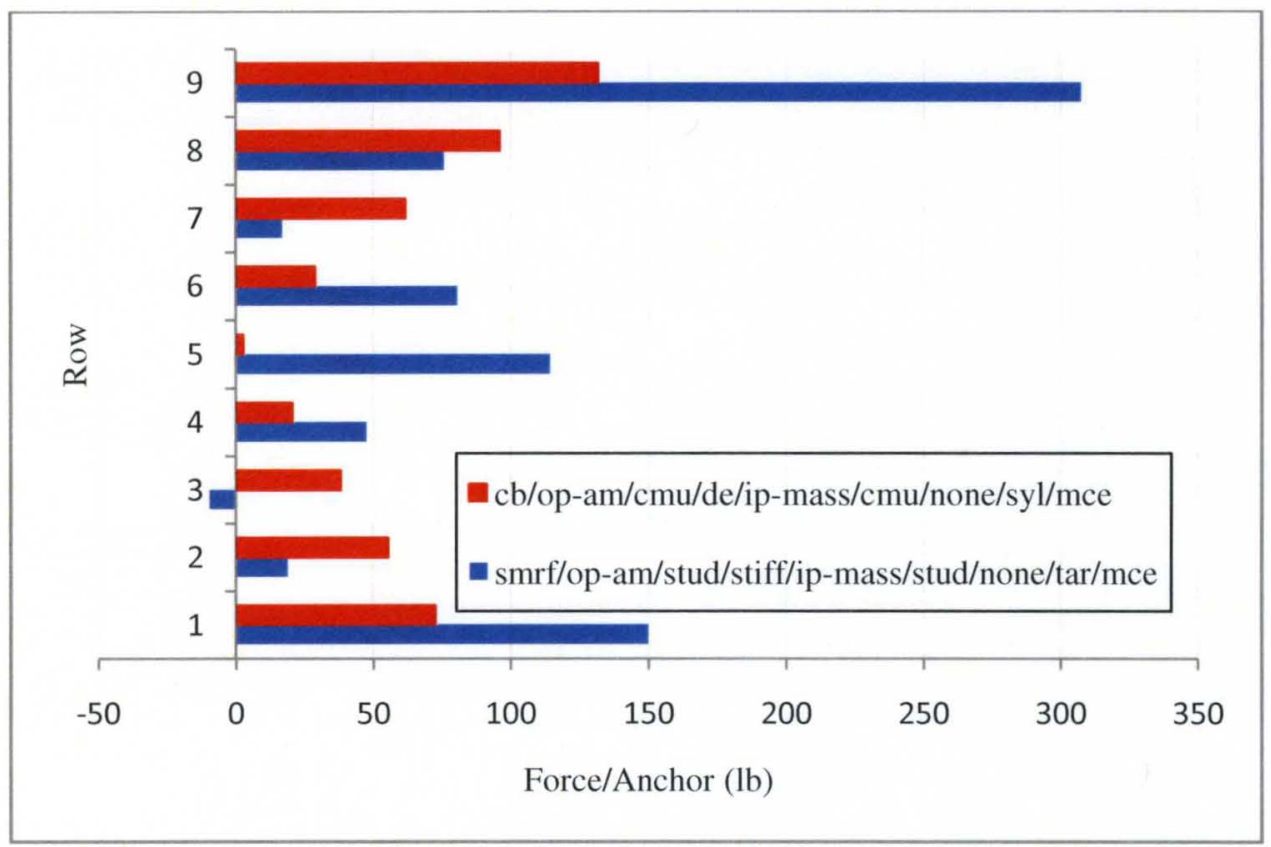

Figure 4.9: Tie Forces for the Stiffest and Most Flexible Wall Systems on the $10^{\text {th }}$ Storey of the Mainframe, at the Time Instant at Which the Veneer Acceleration Reached Its Maximum Value. 
Table 4.21: Peak Tie Forces in the Out of Plane Walls in the $10^{\text {th }}$ Storey of the Mainframes at MCE, at the Time Instant at Which the Veneer Acceleration Reached Its Maximum Value

smrf/op_am/cmu/de/ip_mass/cmu/none/syl/mce

smrf/op_am/cmu/tw/ip_mass/cmu/none/syl/mce

smrf/op_am/cmu/de/ip_mass/cmu/none/tar/mce

308

smrf/op_am/cmu/tw/ip_mass/cmu/none/tar/mce

372

smrf/op_am/studs/de_flex/ip_mass/studs/none/syl/mce

smrf/op_am/studs/de_stiff/ip_mass/studs/none/syl/mce

smrf/op_am/studs/de_flex/ip_mass/studs/none/tar/mce

307

smrf/op_am/studs/de_stiff/ip_mass/studs/none/tar/mce

$\mathrm{sb} / \mathrm{op} \_a \mathrm{am} / \mathrm{cmu} / \mathrm{de} / \mathrm{ip} \_\mathrm{mass} / \mathrm{cmu} / \mathrm{none} / \mathrm{syl} / \mathrm{mce}$

105

sb/op_am/cmu/tw/ip_mass/cmu/none/syl/mce

sb/op_am/cmu/de/ip_mass/cmu/none/tar/mce

sb/op_am/cmu/tw/ip_mass/cmu/none/tar/mce

sb/op_am/studs/de_flex/ip_mass/studs/none/syl/mce

sb/op_am/studs/de_stiff/ip_mass/studs/none/syl/mce

sb/op_am/studs/de_flex/ip_mass/studs/none/tar/mce

sb/op_am/studs/de_stiff/ip_mass/studs/none/tar/mce

285

cmrf/op_am/cmu/de/ip_mass/cmu/none/syl/mce

131

cmrf/op_am/cmu/tw/ip_mass/cmu/none/syl/mce

cmrf/op_am/cmu/de/ip_mass/cmu/none/tar/mce

170

cmrf/op_am/cmu/tw/ip_mass/cmu/none/tar/mce

cmrf/op_am/studs/de_flex/ip_mass/studs/none/syl/mce

258

cmrf/op_am/studs/de_stiff/ip_mass/studs/none/syl/mce

266

cmrf/op_am/studs/de_flex/ip_mass/studs/none/tar/mce

363

cmrf/op_am/studs/de_stiff/ip_mass/studs/none/tar/mce

cb/op_am/cmu/de/ip_mass/cmu/none/syl/mce

$\mathrm{cb} / \mathrm{op} \_a \mathrm{am} / \mathrm{cmu} / \mathrm{tw} / \mathrm{ip} \_\mathrm{mass} / \mathrm{cmu} / \mathrm{none} / \mathrm{syl} / \mathrm{mce}$

cb/op_am/cmu/de/ip_mass/cmu/none/tar/mce

$\mathrm{cb} / \mathrm{op} \_a \mathrm{~m} / \mathrm{cmu} / \mathrm{tw} / \mathrm{ip} \_\mathrm{mass} / \mathrm{cmu} / \mathrm{none} / \mathrm{tar} / \mathrm{mce}$

129

cb/op_am/studs/de_flex/ip_mass/studs/none/syl/mce

169

cb/op_am/studs/de_stiff/ip_mass/studs/none/syl/mce

157

cb/op_am/studs/de_flex/ip_mass/studs/none/tar/mce

189

cb/op_am/studs/de_stiff/ip_mass/studs/none/tar/mce

162 
Table 4.22: Time Instants at Which the Veneer Acceleration at MCE, Reached Its Maximum Value

\section{Model ID}

Time (s)

smrf/op_am/cmu/de/ip_mass/cmu/none/syl/mce

3.18

smrf/op_am/cmu/tw/ip_mass/cmu/none/syl/mce

3.18

smrf/op_am/cmu/de/ip_mass/cmu/none/tar/mce

5.57

smrf/op_am/cmu/tw/ip_mass/cmu/none/tar/mce

5.57

smrf/op_am/studs/de_flex/ip_mass/studs/none/syl/mce

2.87

smrf/op_am/studs/de_stiff/ip_mass/studs/none/syl/mce

2.87

smrf/op_am/studs/de_flex/ip_mass/studs/none/tar/mce

5.81

smrf/op_am/studs/de_stiff/ip_mass/studs/none/tar/mce

5.82

sb/op_am/cmu/de/ip_mass/cmu/none/syl/mce

3.17

sb/op_am/cmu/tw/ip_mass/cmu/none/syl/mce

3.17

sb/op_am/cmu/de/ip_mass/cmu/none/tar/mce

5.53

sb/op_am/cmu/tw/ip_mass/cmu/none/tar/mce

5.53

sb/op_am/studs/de_flex/ip_mass/studs/none/syl/mce

2.89

sb/op_am/studs/de_stiff/ip_mass/studs/none/syl/mce

3.21

sb/op_am/studs/de_flex/ip_mass/studs/none/tar/mce

5.84

sb/op_am/studs/de_stiff/ip_mass/studs/none/tar/mce

5.84

cmrf/op_am/cmu/de/ip_mass/cmu/none/syl/mce

3.17

cmrf/op_am/cmu/tw/ip_mass/cmu/none/syl/mce

3.17

cmrf/op_am/cmu/de/ip_mass/cmu/none/tar/mce

5.67

cmrf/op_am/cmu/tw/ip_mass/cmu/none/tar/mce

5.68

cmrf/op_am/studs/de_flex/ip_mass/studs/none/syl/mce

3.16

cmrf/op_am/studs/de_stiff/ip_mass/studs/none/syl/mce

3.18

cmrf/op_am/studs/de_flex/ip_mass/studs/none/tar/mce

4.35

cmrf/op_am/studs/de_stiff/ip_mass/studs/none/tar/mce

4.35

cb/op_am/cmu/de/ip_mass/cmu/none/syl/mce

3.14

cb/op_am/cmu/tw/ip_mass/cmu/none/syl/mce

3.14

cb/op_am/cmu/de/ip_mass/cmu/none/tar/mce

5.63

cb/op_am/cmu/tw/ip_mass/cmu/none/tar/mce

5.63

cb/op_am/studs/de_flex/ip_mass/studs/none/syl/mce

3.01

$\mathrm{cb} / \mathrm{op} \_a m /$ studs/de_stiff/ip_mass/studs/none/syl/mce

3.11

cb/op_am/studs/de_flex/ip_mass/studs/none/tar/mce

5.58

cb/op_am/studs/de_stiff/ip_mass/studs/none/tar/mce

5.57 
As part of the parametric study each model was subjected to increasing levels of ground motion until instability occurred. The level of ground shaking at which this failure occurred, for all the systems evaluated in the parametric study are listed in Table 4.23 for the Tarzana ground motion, and 4.24 for the Sylmar ground motion.

It was noted that the steel stud backed wall systems failed by cracking of the veneer at multiple locations and the CMU backed walls failed by pullout of the top row of ties.

The results of this analysis will be further discussed in Chapter 5.

Table 4.23: Level of Tarzana Ground Motion Corresponding to Collapse of Wall Systems

\begin{tabular}{lc}
\hline \multicolumn{1}{c}{ Model ID } & \% Tarzana \\
\hline smrf/op_am/cmu/de/ip_mass/cmu/none/tar & 105 \\
smrf/op_am/cmu/tw/ip_mass/cmu/none/tar & 120 \\
smrf/op_am/studs/de_flex/ip_mass/studs/none/tar & 95 \\
smrf/op_am/studs/de_stiff/ip_mass/studs/none/tar & 110 \\
sb/op_am/cmu/de/ip_mass/cmu/none/tar & 95 \\
sb/op_am/cmu/tw/ip_mass/cmu/none/tar & 110 \\
sb/op_am/studs/de_flex/ip_mass/studs/none/tar & 100 \\
sb/op_am/studs/de_stiff/ip_mass/studs/none/tar & 115 \\
cmrf/op_am/cmu/de/ip_mass/cmu/none/tar & 100 \\
cmrf/op_am/cmu/tw/ip_mass/cmu/none/tar & 110 \\
cmrfop_am/studs/de_flex/ip_mass/studs/none/tar & 100 \\
cmrf/op_am/studs/de_stiff/ip_mass/studs/none/tar & 110 \\
cb/op_am/cmu/de/ip_mass/cmu/none/tar & 125 \\
cb/op_am/cmu/tw/ip_mass/cmu/none/tar & 140 \\
cb/op_am/studs/de_flex/ip_mass/studs/none/tar & 125 \\
cb/op_am/studs/de_stiff/ip_mass/studs/none/tar & 135 \\
\end{tabular}


Table 4.24: Level of Sylmar Ground Motion Corresponding to Collapse of Wall Systems

\begin{tabular}{lc}
\hline \multicolumn{1}{c}{ Model ID } & \% Sylmar \\
\hline smrf/op_am/cmu/de/ip_mass/cmu/none/syl & 145 \\
smrf/op_am/cmu/tw/ip_mass/cmu/none/syl & 160 \\
smrf/op_am/studs/de_flex/ip_mass/studs/none/syl & 130 \\
smrf/op_am/studs/de_stiff/ip_mass/studs/none/syl & 145 \\
sb/op_am/cmu/de/ip_mass/cmu/none/syl & 160 \\
sb/op_am/cmu/tw/ip_mass/cmu/none/syl & 180 \\
sb/op_am/studs/de_flex/ip_mass/studs/none/syl & 140 \\
sb/op_am/studs/de_stiff/ip_mass/studs/none/syl & 155 \\
cmrf/op_am/cmu/de/ip_mass/cmu/none/syl & 150 \\
cmrf/op_am/cmu/tw/ip_mass/cmu/none/syl & 165 \\
cmrf/op_am/studs/de_flex/ip_mass/studs/none/syl & 140 \\
cmrf/op_am/studs/de_stiff/ip_mass/studs/none/syl & 160 \\
cb/op_am/cmu/de/ip_mass/cmu/none/syl & 165 \\
cb/op_am/cmu/tw/ip_mass/cmu/none/syl & 180 \\
cb/op_am/studs/de_flex/ip_mass/studs/none/syl & 155 \\
cb/op_am/studs/de_stiff/ip_mass/studs/none/syl & 175 \\
& \\
\hline
\end{tabular}

Tables 3.26 and 3.27 consist of the scaling factors applied to the ground motions in order to obtain the DBE and MCE levels of the same. Using these factors, Table 4.25 shows the ratio of the level of the ground motion at collapse to that at MCE of the Tarzana ground motion, for each of the configurations analyzed. Table 4.26 presents a similar comparison for the Sylmar ground motion. 
Table 4.25: Comparison Between the Collapse Level and MCE Level of the Tarzana Ground Motion, for all the Systems Analyzed

\begin{tabular}{lc}
\hline \multicolumn{1}{c}{ Model ID } & Ratio (Tarzana) \\
\hline smrf/op_am/cmu/de/ip_mass/cmu/none/tar & 2.13 \\
smrf/op_am/cmu/tw/ip_mass/cmu/none/tar & 2.44 \\
smrf/op_am/studs/de_flex/ip_mass/studs/none/tar & 1.93 \\
smrf/op_am/studs/de_stiff/ip_mass/studs/none/tar & 2.23 \\
sb/op_am/cmu/de/ip_mass/cmu/none/tar & 4.34 \\
sb/op_am/cmu/tw/ip_mass/cmu/none/tar & 5.03 \\
sb/op_am/studs/de_flex/ip_mass/studs/none/tar & 4.57 \\
sb/op_am/studs/de_stiff/ip_mass/studs/none/tar & 5.26 \\
cmrf/op_am/cmu/de/ip_mass/cmu/none/tar & 2.88 \\
cmrf/op_am/cmu/tw/ip_mass/cmu/none/tar & 3.17 \\
cmrfop_am/studs/de_flex/ip_mass/studs/none/tar & 2.88 \\
cmrf/op_am/studs/de_stiff/ip_mass/studs/none/tar & 3.17 \\
cb/op_am/cmu/de/ip_mass/cmu/none/tar & 6.18 \\
cb/op_am/cmu/tw/ip_mass/cmu/none/tar & 6.92 \\
cb/op_am/studs/de_flex/ip_mass/studs/none/tar & 6.18 \\
cb/op_am/studs/de_stiff/ip_mass/studs/none/tar & 6.67 \\
& \\
\hline
\end{tabular}

Table 4.26: Comparison Between the Collapse Level and MCE Level of the Sylmar Ground Motion, for all the Systems Analyzed

\begin{tabular}{lc}
\hline \multicolumn{1}{c}{ Model ID } & Ratio (Sylmar) \\
\hline smrf/op_am/cmu/de/ip_mass/cmu/none/syl & 4.08 \\
smrf/op_am/cmu/tw/ip_mass/cmu/none/syl & 4.5 \\
smrf/op_am/studs/de_flex/ip_mass/studs/none/syl & 3.66 \\
smrf/op_am/studs/de_stiff/ip_mass/studs/none/syl & 4.08 \\
sb/op_am/cmu/de/ip_mass/cmu/none/syl & 3.93 \\
sb/op_am/cmu/tw/ip_mass/cmu/none/syl & 4.43 \\
sb/op_am/studs/de_flex/ip_mass/studs/none/syl & 3.44 \\
sb/op_am/studs/de_stiff/ip_mass/studs/none/syl & 3.81 \\
cmrf/op_am/cmu/de/ip_mass/cmu/none/syl & 4.16 \\
cmrf/op_am/cmu/tw/ip_mass/cmu/none/syl & 4.58 \\
cmrfop_am/studs/de_flex/ip_mass/studs/none/syl & 3.88 \\
cmrf/op_am/studs/de_stiff/ip_mass/studs/none/syl & 4.44 \\
cb/op_am/cmu/de/ip_mass/cmu/none/syl & 4.93 \\
cb/op_am/cmu/tw/ip_mass/cmu/none/syl & 5.38 \\
cb/op_am/studs/de_flex/ip_mass/studs/none/syl & 4.63 \\
cb/op_am/studs/de_stiff/ip_mass/studs/none/syl & 5.23 \\
& \\
\hline
\end{tabular}




\section{CHAPTER 5}

\section{DISCUSSION OF THE RESULTS}

This chapter presents a discussion of the results of the parametric study described in Chapter 4. The structure of the discussion in this chapter is similar to that of the presentation of the results in the previous chapter. This chapter starts by discussing the effect that variation of the steel stud and CMU backed wall systems, tie system configurations, ground motion histories (record and load level) and modeling techniques have on the response of the four types of structural frame systems. Following this, the effects of both types building frames and wall system configuration variations on the outof-plane response of the veneer wall systems, are discussed.

\subsection{Effects of the Out-of-Plane Behavior of the CMU Backed Wall Systems on the Reinforced Concrete Moment Frame Response}


Examination of Tables 4.3 and 4.7 and Figures B.1 to B.8 in Appendix B show that modeling the $\mathrm{CMU}$ backed wall systems as opposed tojust representing them as a mass had only a minor effect on the peak frame acceleration anddisplacement response along the height of the main structural frame, at both the DBE and the MCE levels of the Sylmar and Tarzana ground motions. Furthermore, this peak response occurred at approximately the same time instant for the frames whether a mass or analytical model representation of the walls was used. This time instant was approximately between $3.0-$ 3.5 seconds into the truncated Sylmar ground motion history, and approximately $5.5-6.0$ seconds in the truncated Tarzana ground motion history, shown in Chapter 3. Changing the representation of the CMU backed wall systems from a mass representation to an analytical model representation, had a slightly more pronounced effect on the peak acceleration response of the reinforced concrete moment frame, at the DBE and MCE levels of the Tarzana ground motion, than at the same levels of the Sylmar ground motion. For the Tarzana ground motion levels, the difference between the peak accelerations varied from $6 \%-7 \%$ of the peak value at the stop storey of the mainframe, considering all the different tie types and levels of the ground motion, whereas, for the Sylmar ground motion, the difference between the peak accelerations with mass and analytical model representations of the wall systems varied between $4 \%-5 \%$ of their peak values at the top storey of the mainframe. 
Examination of Tables 4.3 and 4.7 and Figures B.1 to B.8 in Appendix B, show that the type of tie system used in the wall (stiff or flexible) did not have a significant effect on the peak acceleration and displacement response profiles along the height of the mainframe. Any difference observed, was only that the peak accelerations with the mass representation of the wall systems was very marginally less than that with the analytical model representation of the same.

The acceleration profile along the height of the mainframe (with both the mass and analytical model representations of the wall system) reflected a first mode dominated response of the building, which is consistent with the expected response of a medium rise building. The value of the peak base shear for the frames that used a mass representations of the veneer wall systems, was only slightly different from that for the frames that represented by their analytical models. This indicates that the mode of response of the frames remains unchanged when the representation of the veneer walls changed from a mass to a wall system model.

The top storey of the moment frame showed significantly higher acceleration compared to the storey below it, a consequence of the "whipping effect" seen in most flexible moment frames, due to traces of a higher modes of response. This was observed for all wall system configuration and modeling variations.

The peak displacement profile along the height of the main frame had a shape similar to the peak acceleration profile. The numerical values of the response accelerations and 
displacements along the building height were greater for the Tarzana ground motion than the Sylmar ground motion, for both the DBE and MCE levels of the motions. This is most likely because the Tarzana ground motion incorporates a wider range of frequencies at higher acceleration amplitudes than the Sylmar ground motion. This will excite a greater number of fundamental modes of response in the frame.

\subsection{Effects of the Out-of-Plane Behaviorof the Steel Stud Backed Wall Systems on the Reinforced Concrete Moment FrameResponse}

The effects of out-of-plane behavior of the steel stud backed wall system on the response of the reinforced concrete moment frame, are similar to those observed for the CMU backed wall system. Although the difference in peak acceleration and displacement response profiles along the height of the concrete frame was slightly greater for the steel stud backed wall systems modeled as a mass versus a detailed wall system model (compared to the $\mathrm{CMU}$ backed wall systems). For both the ground motions, the difference between the peak accelerations with mass and analytical model representations of the wall systems varied between approximately $7.5 \%-10 \%$ of the peak value at the stop storey of the mainframe, considering all the different tie types and levels of the ground motions.

Another difference observed was that the numerical values of the peak response accelerations and displacements of the main frame, were higher for the CMU backed wall

system attached to the main frame versus the stud backed wall system being attached to 
the same. This was likely due to the higher seismic mass of the CMU backed wall systems.

\subsection{Effects of the Out-of-Plane Behavior ofthe CMU Backed Wall Systems on the Reinforced Concrete Frame with Shear WallsResponse}

Most of the effects that changing the representation of the CMU backed wall system from a mass to an analytical wall system model had on the response of the reinforced concrete shear wall system are similar to those observed for the reinforced concrete moment frame. However, in the case of the reinforced concrete shear wall system, the "whipping effect" observed in the reinforced concrete moment frames was absent. Also, the magnitudes of the peak frame response accelerations and displacements were lower than those recorded for the reinforced concrete moment frame system. Furthermore, the analytical model representations of the wall veneer systems had a tendency to slightly increase the peak acceleration and displacement responses of points on the main frame up to approximately the $7^{\text {th }}$ or $8^{\text {th }}$ storey of the frame (compared to the mass representation of the wall systems), and slightly decreased the response of nodes on the main frame at higher storeys levels Referring to Table 4.4 , it can be seen that the values of the peak response accelerations of the reinforced concrete shear wall system at its top storey decreased by approximately $13 \%-15 \%$, (this range covers the responses of the systems with different tie types, and at the different levels of the ground motions) when the representation of the CMU backed wall system changed from mass to an analytical model representation. However, the peak base shears did not show a very large variation when 
the veneer wall system representation was changed, probably due to the fact that the introduction of the analytical model representation slightly increased the peak acceleration responses of the lower stories of the main frame, and decreased them for the upper stories.

\subsection{Effects of the Out-of-Plane Behavior ofthe Steel Stud Backed Wall Systems on the Reinforced Concrete Frame with Shear WallsResponse}

The trends observed for the effects that modeling of the out-of-plane behavior of the steel stud backed veneer wall system on the peak accelerations and displacements along the height of the main frame were similar to those observed for the CMU backed wall systems. However, the peak acceleration response at the top storey of the mainframe only showed a difference of about $2 \%-4 \%$, going from the mass to the analytical model representations of the stud backed veneer wall systems.

In a manner similar to that observed for the reinforced concrete moment frame, the reinforced concrete shear wall system also showed lower peak accelerations when the steel stud backed wall system was attached, as opposed to the CMU backed wall system. However, as in the case of the CMU backed wall system attached to the reinforced concrete shear wall system discussed previously, the peak base shears did not show a much variation when the veneer wall system representation was changed from its mass to analytical model representation. 


\subsection{Effects of the Out-of-Plane Behavior ofthe CMU Backed Wall on the Steel Braced FrameResponse}

Most of the features of the previous discussions are also applicable to the response of the steel braced frames with both mass and analytical model representations of the CMU backed veneer wall systems. However, there were some differences. The "whipping effect" observed in the reinforced concrete moment frames was largely absent with the steel braced frames. The shape of the peak accelerations and displacement response along the height of the steel braced frames was not the smooth curve observed for the reinforced concrete moment and shear wall systems. For the steel braced frames, these responses had a jagged shape. This jagged shape was probably a consequence of the way in which the pin joints between the beams and columns were modeled. These joints were modeled using zero length elements that had a very high stiffness corresponding to the vertical and horizontal translational degrees of freedom and a very low rotational stiffness, thereby approximating the behavior of a pin. Since they did not behave like an ideal pin, the acceleration and displacement profiles along the frame height changed from a smooth profile, to a slightly jagged one. Another possible reason for the observed jagged profile is that the compression braces on each storey were assigned a negligible stiffness. Since the stiffness of the compression braces was not identical to zero and had a small value, this could have led to a very small redistribution in the forces at each storey level, leading to the observed jagged profile. Furthermore, different tie types produced a noticeable change in the profiles of the peak accelerations and displacements along the building height. However, as can be seen in Figures B.33 to B.40 in Appendix B, that the peak response acceleration of the steel braced frame consisting of the wall systems 
represented by their mass is higher than that for the case in which the wall systems are represented by their analytical models, at the DBE and MCE of Sylmar. However, at the same levels of the Tarzana ground motion, the trend was reversed, in that the peak response acceleration of the steel braced frame with the wall systems represented by their masses was lower than that for the case in which the wall systems were represented by their analytical models.

When the analytical model was used to represent the veneer wall system, the peak acceleration and displacement response profiles along the frame height changed appreciably from the response profiles observed for when a mass was used to represent the wall system. The mass representation of the CMU backed wall system showed slightly higher values of acceleration on the upper storeys of the building and lower accelerations on the lower storeys of the building, when compared to those produced by the analysis that used veneer wall system models. This was observed for both DBE and MCE levels of the Sylmar ground motion. However, this trend was reversed at the DBE and MCE levels of the Tarzana ground motion.

For the steel braced frame, the peak accelerations and displacements at the DBE and MCE levels of the Tarzana ground motion were higher than the corresponding values for the Sylmar ground motion, with both the analytical model and mass representations of the veneer wall system. The change from a mass to an analytical model representation of the 
veneer wall did not significantly affect the base shear acting on the frame, thereby showing that the average force on the frame is approximately the same.

The effect of changing the mass representation of the wall system to an analytical model representation was more pronounced for the Tarzana ground motion than the Sylmar ground motion. The analytical model representations of the CMU backed wall system changed the peak acceleration response of the main frame by a range of $5.5 \%$ $7 \%$ of the value shown for the mass represented wall systems, for the different tie types and the levels of the ground motions. The corresponding range of values of the Tarzana ground motion was approximately $6 \%-10 \%$. The values of the peak displacement response for the frames with the analytical models, at DBE and MCE levels of the Sylmar and Tarzana ground motions varied within a range of about $3 \%-5 \%$ of those of the mainframe with a mass representation of the wall system. The base shear acting on the the steel braced frame did not show any significant variation between the mass and analytical model representations of the wall system.

\subsection{Effects of the Out-of-Plane Behavior ofthe Steel Stud Backed Wall Systems on the Steel Braced FrameResponse}

Similar to the observations made for the reinforced concrete frames, the frame nodal accelerations for the steel stud backed systems attached to a steel braced frame were lower than those with the CMU backed wall systems attached to a steel braced frame, under both DBE and MCE levels of the Sylmar and Tarzana ground motions. As 
mentioned earlier, this was likely due to the lower seismic mass of the steel stud backed wall systems.

At the DBE level of the Sylmar ground motion, the peak acceleration response of the structural frame with the analytical model representation of the steel stud backed system using stiff ties was about 5\% higher than with a mass representation of the wall system. For the flexible tie system, a comparison between the same quantities yielded a difference of about 3\%. At the MCE level of Sylmar ground motion, the difference for both the tie systems was approximately $8 \%$ higher for the mass versus veneer model representation (the mass representation producing a higher acceleration). At the DBE level of the Tarzana ground motion, the difference between the mainframe acceleration response using an analytical model of the veneer wall system with flexible ties and the mass representation of the same was about $6 \%$ higher, while the corresponding difference for the stiff tie system was about $1 \%$ higher. At the MCE level of Tarzana, the corresponding differences were about $9.5 \%$ and $5 \%$ (higher). It can be seen that the analytical model representation of the veneer wall system affected the accelerations experienced by the supporting structural frame system. This affect on the peak frame response accelerations was greater for wall systems with flexible tie systems than for the wall systems with a stiff tie model.

It was also observed that under the influence of the Tarzana ground motion, the peak response acceleration profiles along the mainframe height for the case of the wall systems 
represented by their analytical models, displayed higher values of response accelerations than the case of the wall system represented by its mass, at both the DBE and MCE levels of the ground motion. The mainframe peak base shear showed no significant variation for the cases of the stud backed wall system being represented by its mass, versus its analytical model.

\subsection{Effects of the Out-of-Plane Behavior ofthe CMU Backed Wall Systems on the Steel Moment FrameResponse}

The steel moment frames were the most flexible of the four building frame systems considered in this investigation. The peak response acceleration and displacement profiles are similar to those seen for the reinforced concrete moment frame, but the magnitudes of acceleration are higher, due to the flexibility of the system. The "whipping effect" is more pronounced as well, in comparison to the reinforced concrete moment frames. Furthermore, the difference between the peak response acceleration and displacement profiles along the mainframe height for the different representations of the wall system is more pronounced than in any of the other frame systems considered. When the veneer wall system was represented by its mass, higher values of peak response accelerations and displacements were observed than for analyses conducted on systems that represented the veneer systems with an analytical model, both with the flexible and stiff tie systems. Furthermore, the accelerations and displacements for systems incorporating the walls with the flexible tie systems were slightly higher from those with the walls with the stiff tie systems. The peak structural frame response accelerations and 
displacements under the Tarzana ground motion were higher than those under the Sylmar ground motion, at both the DBE and MCE levels, for both the mass representations, and analytical model representations of the veneer wall system.

The frame base shear for the systems using a mass representation of the veneer system was significantly lower than the frame base shear for those that used analytical models of the veneer wall systems. The difference was also significantly greater than that observed in any of the other structural frame systems. Most likely, this is also due to the fact that the steel moment resisting frame was the most flexible system investigated in this study.

The difference between the peak frame accelerations for different representations of the wall systems, was greater at the DBE of the Sylmar ground motion, than the corresponding level of the Tarzana ground motion. However, this pattern reversed at the MCE level of the two ground motions. The wall system represented by its mass resulted in higher peak accelerations of the steel moment resisting frame than it being represented by its analytical model, at both levels of both the ground motions considered. For the wall system model that included flexible ties, this difference was about $9 \%$, for the wall system consisting of stiff ties, it was about $14 \%$, at Sylmar DBE. The percentage differences increased to $13 \%$ for both the stiff tie and flexible tie cases, at Sylmar MCE. The corresponding differences at the DBE level of Tarzana were about $2 \%$ for both the tie systems, and about $22 \%$ at the MCE level of Tarzana. 


\subsection{Effects of the Out-of-Plane Behavior ofthe Steel Stud Backed Wall Systems on the Steel Moment Frame Response}

The patterns observed for the effects of the steel stud backed wall system on the response of the steel moment frame were similar to those observed for the CMU backed veneer wall system. However, there was a greater difference in the peak frame peak acceleration and displacement for the frames analyzed with analytical model representations of the in plane-behavior of the wall system versus mass representations.

The peak accelerations for the system models that used a mass representation of the out - of - plane behavior of the veneer wall system at the DBE Sylmar ground motion were $3 \%$ and $10 \%$ higher than the corresponding accelerations given by the more accurate wall models using flexible and stiff ties, respectively. At the MCE Sylmar ground motion, these differences increased to $5 \%$ and $8 \%$ respectively. At the DBE Tarzana level ground motion, the corresponding differences were about $2 \%$ and $13 \%$, and at the MCE level of Tarzana, they were about $20 \%$ and $25 \%$ higher. Thus, for both the CMU backed and steel stud backed wall systems, the differences between the peak response accelerations of the steel moment resisting frame, with the mass and analytical model representations of the wall systems, were the highest at with the MCE Tarzana level ground motion. The Tarzana ground motion includes higher peak ground accelerations than the Sylmar ground motion, and also includes a wider range of frequencies, from low to high, than the Sylmar ground motion. The steel moment frame 
is the most flexible system being analyzed, and thus responded more vigorously to the Tarzana ground motion.

\subsection{Effects of the CMU Backed Wall Systems Loaded in their In - Plane Direction, on the Reinforced Concrete Braced Frame Response}

The CMU backed veneer wall system loaded in its in - plane direction, effects the acceleration and displacement response of the reinforced concrete mainframe in a manner similar to the way the same wall system loaded in its out - of - plane direction did. The introduction of the analytical model representation of the CMU backed wall system loaded in its plane produced slightly larger differences in frame response (peak accelerations and displacements) when compared to its mass representation than for the out-of-plane direction. At both the DBE and MCE levels of the Sylmar and Tarzana ground motions, the peak acceleration of the reinforced concrete shear wall system was higher when the mass representation of the wall system was attached to it, versus the analytical model representation. At the DBE level of the Sylmar ground motion, the difference in the peak acceleration responses of the structural frame for the system model where the veneer wall system was represented by its mass and those produced by system models with the veneer wall system represented by an analytical model with flexible ties was about $22 \%$, and about $21 \%$ for the stiff tie condition. At the MCE level of this ground motion, these figures were approximately the same, the differences ware $19 \%$ and $23 \%$ for the flexible and stiff ties, respectively. At the DBE and MCE levels of the 
Tarzana ground motion, these differences reduced to about $13 \%$ for the flexible tie systems and $15 \%$ for the stiff tie systems.

It appears that for the reinforced concrete braced frames, the difference in the peak acceleration response of the frame were higher in the case of the Sylmar ground motion than the Tarzana ground motion,for both the mass and analytical model representations of the CMU backed veneer wall system loaded in its plane. Similar differences were observed between the base shears acting on the frames.

\subsection{Effects of the Steel Stud Backed Wall Systems Loaded in their In - Plane Direction, on the Reinforced Concrete Braced Frame Response}

As mentioned earlier, only one type of tie system was considered in the analytical models of the steel stud backed wall system loaded in the in - plane direction, a stiff double eye and pintle system. The shapes of the response acceleration and displacement profiles were similar to those seen for the reinforced concrete shear wall system discussed in the previous cases. The frame acceleration and displacement profiles, were slightly different when the in-plane behavior of the wall system was represented by an analytical model, and compared to when the wall system was represented by its mass. The shapes of the profiles were similar, but the magnitude of the response accelerations and displacements of the frame with the wall system represented by an analytical model

were higher than when the wall system was represented by its mass. This is similar to the 
trend seen for the effect of the analytical model of the wall system loaded in its out - of plane direction.

The reinforced concrete shear wall system was the stiffest system considered, and the peak response accelerations and displacements of this system with the wall represented by their masses were being lower than that in which the walls were represented by their analytical models. This contrasted with the trend observed for the steel moment frame systems, which were the most flexible of the systems analyzed.

The difference between the peak nodal frame acceleration for systems models that represented the veneer wall system as a mass, versus an analytical model, was about $6 \%$ for DBE and MCE levels of the Sylmar ground motion. For the Tarzana ground motion, the corresponding percentage differences were about $3 \%$ at DBE and about $9 \%$ at MCE ground motion levels.

\subsection{Effects of the CMU Backed Wall Systems Loaded in their In - Plane Direction, on the Steel Moment Resisting Frame Response}

The effects of incorporating the analytical models of the CMU backed wall systems loaded in their in - plane directions versus a mass representation are similar to those discussed earlier for the out - of - plane directions. However, in this case, the "whipping effect" observed earlier, becomes less pronounced for the mass representation versus the 
analytical model representations of the veneer wall systems. Furthermore, the difference between the magnitudes of the peak nodal frame accelerations and displacements along the steel moment resisting frame height for system models that had the veneer walls represented by their masses versus those where the veneer walls were represented by models, are less than those observed for the walls loaded in their out - of - plane direction.

Finally, while examining the effect of the CMU backed walls loaded in - plane on the steel moment frame response (see Figures C.16 to C.22 in Appendix C), it was seen that for all the different parameters considered the wall systems incorporating stiff ties created lower values of the response quantities than the wall systems with flexible ties. This is similar to what was observed for the same wall system loaded in its out - of - plane direction, and attached to the steel moment resisting frame.

\subsection{Effects of the Steel Stud Backed Wall Systems Loaded in their In - Plane Direction, on the Steel Moment Resisting Frame Response}

The peak nodal frame accelerations and displacements along the height of the steel moment resisting frame where the veneer wall system was represented by an analytical model loaded in its in - plane direction, were lower than those for the veneer wall system represented by its mass. The shape of the profile of the response quantities along was similar but the magnitudes differed. The mainframe peak nodal acceleration at its top storey under for both the scaling levels of both the ground motions considered was higher 
for the case of the attached wall system being represented by its mass versus its analytical model. The difference between the peak nodal frame accelerations with the veneer wall system represented as a mass, versus the wall system represented as an analytical model, at the DBE Sylmar ground motions, was approximately $16 \%$, whereas at MCE, was approximately $12 \%$. The corresponding differences at DBE and MCE levels of the Tarzana ground motion were $25 \%$ and $21 \%$. Thus, it can be seen that the wall system, loaded in - plane, had a considerable effect on the peak response accelerations of the steel moment resisting frame. The mass representation increased or decreased the fame accelerations?

\subsection{Effects of Structural Frame type on the Response of the CMU Backed Wall Systems (Stiff and Flexible Ties), Loaded in their Out - Of - Plane Direction}

For the CMU backed veneer wall systems attached to the $10^{\text {th }}$ storey of a reinforced concrete moment resisting frame and shear wall systems, with both flexible and stiff ties, loaded in their out - of - plane directions, the acceleration and displacement profiles along the heights of the veneer and backup wall showed linear increased from the midheight of the wall to its top and base, at the MCE level for both the Sylmar and Tarzana ground motions. The tie forces increased approximately linearly from the lowest value at mid - height, to the highest value at the top and bottom of the height of the wall system. These tie force distributions can be seen in Figures D.1 to D.8 in Appendix D. The top of the veneer was slightly tilted away from the backup as the veneer was only restrained by the top row of ties. Since the row of ties at the midheight of the wall carried 
a negligible force, and the forces increased away from the wall midheight (in the case of the CMU backed walls attached to the reinforced concrete frames), it is reasonable to conclude that the veneers in these walls were in their uncracked state at MCE load levels. The peak veneer accelerations for the CMU backed wall systems with both stiff and flexible ties were higher when the wall system was attached to the reinforced concrete moment resisting frame, as compared to when they were attached to the reinforced concrete shear wall system, at both the DBE and MCE levels of the Sylmar and Tarzana ground motions.

The CMU backed veneer wall systems showed a different response when attached to the steel braced and moment resisting frames. In the steel braced frames, the displacement profile for the out-of-plane response of CMU backed veneer walls with both flexible and stiff ties, suggested that veneer was likely cracked near midheight. The analysis indicates that the tie forces redistributed from the triangular profile discussed earlier, and the ties towards the mid - height supported more load than those near the top and bottom of the wall. In most, cases, the ties near mid - height had the largest loading. The shape of the veneer displacement and tie force profiles are a result of the formation of a veneer crack near its mid - height.

In the steel moment resisting frames, the acceleration and displacement profiles along the wall system heights were similar to those for the reinforced concrete moment resisting frames and shear wall systems. However, the tie force distributions along the 
wall height were different than for those where the veneer walls systems were attached to concrete frames. In fact, they were similar to those seen for the steel braced frames, and showed a redistribution of tie loads, with the ties near mid - height attracting more force, due to veneer cracks at mid-height.

The peak veneer and backup accelerations for the CMU backed wall systems with both stiff and flexible ties, were observed to be at a maximum when these veneer wall systems were attached to the steel moment resisting frame and minimum, when the walls were attached to the reinforced concrete shear wall system. For example, for the CMU backed wall systems, the highest value of the peak veneer acceleration $(3.83 \mathrm{~g})$ was observed for the configuration of a flexible tie system used in the wall, at the MCE of Tarzana, the wall being attached to the steel moment resisting frame. Correspondingly, the lowest value of peak veneer acceleration (1.25g) was observed for the configuration of a stiff tie system used in the wall, at the MCE of Sylmar, the wall being attached to the reinforced concrete shear wall system. Thus there exists a difference of approximately $67 \%$ between the highest and lowest values of peak veneer acceleration that were recorded. If these wall systems were attached to a steel braced frame system and or a reinforced concrete moment resisting frame system, the magnitudes of peak veneer accelerations were $\mathrm{X} g$ (reinforced concrete frame a) and $\mathrm{Y} g$ (steel braced frame) fell between those observed for the steel moment resisting frame and reinforced concrete shear wall system. 
It was also observed that the magnitude of the peak tie forces for all the CMU backed wall systems were the lowest when the wall systems were attached to reinforced concrete shear wall system (86 lbs in tension). These tie forces were the highest for the wall systems attached to steel moment resisting frame (373 lbs in tension). These trends are consistent with the fact that the steel moment resisting frame was the most flexible system considered, and the reinforced concrete shear wall system was the stiffest. The steel moment resisting frame, being the most flexible system under consideration would most likely show the highest values of response acceleration under the effect of the ground motions. Conversely, the reinforced concrete shear wall system, being the stiffest system investigated, would most likely show the lowest values of response acceleration under the effect of the ground motions. The mainframe accelerations are transmitted to the attached wall systems. As a consequence of this, the wall systems attached to steel moment resisting frame would be accelerated the most, and those attached to the reinforced concrete shear wall system, the least. This is the likely reason for the numerical values of the tie forces in the walls attached to the steel moment resisting frame and the reinforced concrete shear wall system constitute the upper and lower bounds of the tie forces in the walls, attached to the four different frame types.

The Tarzana ground motion produced higher veneer accelerations, tie forces and displacements than the Sylmar ground motion. The difference between the peak veneer accelerations for the wall systems in the steel moment resisting frame and the reinforced concrete shear wall system was about $32 \%$ for the system with flexible ties and about $30 \%$ for the system with stiff ties, at the MCE of the Sylmar ground motion. The 
corresponding differences under the Tarzana ground motion were about $66 \%$ and $65 \%$, for the walls with the flexible tie systems and the stiff tie systems, respectively. The differences between the peak veneer acceleration for the wall system in the steel braced frame and the steel moment resisting frame, and the reinforced concrete and steel moment resisting frames, lay within these values, with the difference between the values of the peak veneer acceleration in the steel moment and braced frames being larger than the steel and reinforced concrete moment frames. Furthermore, in general, the peak accelerations were also greater for the wall systems incorporating the flexible ties, compared to the models incorporating the stiff ties.

The peak veneer and backup accelerations and displacements occurred later than the time instant at which the structural frame reached its peak acceleration and displacement. This is consistent, since the elements that connected the veneer wall system the structural frames were not infinitely stiff, leading to a delay in the response of the veneer wall system.

The CMU backed wall systems collapsed by a pullout of the topmost row of ties. This failure occurred in the wall system attached to the top $\left(10^{\text {th }}\right)$ storey of the structural frame, for all the configurations of the CMU backed wall systems considered in this investigation. The ground motion intensity at which failure occurred can be seen in Tables 4.23 and 4.24. Referring to Tables 4.25 and 4.26, it can be seen that the wall systems remained stable at intensities of ground shaking comfortably in excess of the 
MCE, for both the Sylmar and Tarzana ground motions, for all the configurations of the CMU backed wall systems considered in this investigation. Hence, it can be seen that the current code prescriptive veneer provisions are adequate for the CMU backed wall systems.

\subsection{Effects of the Structural Frame Type on the Steel Stud Backed Wall Systems (Stiff and Flexible Ties), Loaded in their Out - Of - Plane Direction}

Unlike the CMU backed wall systems discussed in the previous section, the veneers in all the steel stud backed wall systems were cracked at the MCE level for both the Sylmar and Tarzana ground motions, in all the frame systems considered. The shape of the veneer and backup walls (the displacement profiles were similar for all the steel stud backed wall systems for all four structural frame types. Both the veneer and backup assumed a slightly curved shape, like a segment of an arc. The tie force distributions for all the stud backed walls showed a more uniform distribution of tie forces near the mid height of the wall. Since the veneer had cracked near its mid - height, the ties in that region were loaded at much higher levels than when the veneer was uncracked. Furthermore, the peak tie forces occurred at the top row of ties in each stud backed wall system investigated. These loads range from $158 \mathrm{lb}$ for the configuration cb/op_am/studs/de_stiff/ip_mass/studs/none/syl/mce to $365 \mathrm{lb}$ for the configuration smrf/op_am/studs/de_stiff/ip_mass/studs/none/tar/mce. 
The walls in the steel moment resisting frame displayed the highest peak veneer and backup accelerations and displacements, and those in the reinforced concrete shear wall system, the lowest. The peak veneer and backup accelerations were observed for the configuration represented by smrf/op_am/studs/de_stiff/ip_mass/studs/none/tar/mce, and were $3.07 \mathrm{~g}$ and $2.81 \mathrm{~g}$ respectively, and the lowest, for the configuration represented by cb/op_am/studs/de_stiff/ip_mass/studs/none/syl/mce, were $0.98 \mathrm{~g}$ and $0.95 \mathrm{~g}$ respectively. Similar to the CMU backed wall systems, the steel stud backed wall systems in the steel braced frame and the reinforced concrete moment resisting frame showed peak acceleration and displacement values that lay in between those observed in the steel moment resisting frame and the reinforced concrete shear wall system. For the reinforced concrete moment resisting frame, these values, for the configuration represented by cmrf/op_am/studs/de_flex/ip_mass/studs/none/tar/mce, were $2.19 \mathrm{~g}$ and $1.94 \mathrm{~g}$ respectively, and for the steel braced frame, represented by the configuration sb/op_am/studs/de_stiff/ip_mass/studs/none/tar/mce, they were $2.67 \mathrm{~g}$ and $2.59 \mathrm{~g}$ respectively.

Examination Tables 4.13 to 4.16 and Figures D.17 to D.32 in Appendix D, show that the peak veneer acceleration occurred at the mid - height for the steel stud backed wall systems, in almost every simulation. This is likely due to the fact that the veneer was cracked near that location. The difference between the peak veneer accelerations for the wall system incorporated in the steel moment resisting frame and the reinforced concrete shear wall system was, about $45 \%$ for the walls with flexible ties (1.99g versus $1.09 \mathrm{~g}$ ) and $54 \%$ for the walls with stiff ties $(2.12 \mathrm{~g}$ versus $0.98 \mathrm{~g})$ at the MCE Sylmar ground 
motion. The corresponding differences at the MCE Tarzana ground motion were about $12 \%(2.38 \mathrm{~g}$ versus $2.09 \mathrm{~g})$ for the flexible ties and $39 \%(3.07 \mathrm{~g}$ versus $1.87 \mathrm{~g})$ for the stiff ties. The peak veneer accelerations of the stud backed walls in the steel braced and reinforced concrete moment resisting frame systems (in the steel braced frame, $1.53 \mathrm{~g}$ and $1.68 \mathrm{~g}$ for the flexible and stiff tie systems at the MCE of Sylmar, and $2.23 \mathrm{~g}$ and $2.67 \mathrm{~g}$ at the MCE of Tarzana, and, in the reinforced concrete moment resisting frame, $1.79 \mathrm{~g}$ and $1.69 \mathrm{~g}$, and $2.19 \mathrm{~g}$ and $2.06 \mathrm{~g}$, for the same tie types and ground motions) lay in between the above mentioned bounds. The veneer and backup of the steel stud backed walls reached their peak accelerations and displacements at a time slightly later than the mainframe, for the same reasons mentioned for the CMU backed walls.

The steel stud backed wall systems collapsed by a veneer failure, characterized by cracking of the veneer at multiple locations along its height. This failure occurred in the wall system attached to the top $\left(10^{\text {th }}\right)$ storey of the structural frame, for all the configurations of the steel stud backed wall systems considered in this investigation. The ground motion intensity at which failure occurred can be seen in Tables 4.23 and 4.24. Referring to Tables 4.25 and 4.26 , it can be seen that the wall systems remained stable at intensities of ground shaking comfortably in excess of the MCE, for both the Sylmar and Tarzana ground motions, for all the configurations of the steel stud backed wall systems considered in this investigation. Hence, it can be seen that the current code prescriptive veneer provisions are adequate for the steel stud backed wall systems. 


\section{CHAPTER 6}

\section{SUMMARY AND CONCLUSIONS}

\subsection{Summary}

This investigation examined the seismic performance of steel stud backed and CMU (Concrete Masonry Units) backed masonry veneer wall systems, in medium rise building frames. Both the in and out - of - plane load deflection behavior of the wall systems was addressed. The investigation was prompted by damage to brick veneer wall systems that occurred due to recent strong earthquake and wind events. Prior research on these the veneer wall systems had focused on wall system built using older construction practices, or on residential wood stud backed veneer wall systems, or wall systems in low rise building configurations.

In this investigation, analytical models of the veneer wall systems were developed and incorporatedinto models of medium rise building frames, and the combined models were dynamically analyzed under the action of select seismic ground motion records, using the state of the art OpenSees nonlinear analysis software. 
The designs of the model building frames were obtained using the STAAD.Pro software and the International Building Code provisions. The member sizes were selected by the software using its inbuilt design algorithms, in an effort to ensure that the frames were representative of those commonly used in earthquake resistant design in the United States, in regions falling under Seismic Category D. These frame members were then modeled using the OpenSeesanalysis program, with which a nonlinear pushover and dynamic analysis was performed. For the dynamic analysis wall system models were incorporated into the frames and the Sylmar and Tarzana ground motion histories were selected and scaled to correspond to different levels of seismic events.

A parametric study was conducted in order to understand the effect of different parameters on the response of the combined system comprising the veneer walls and the main building frame. These parameters were selected to create systems that represented the range of masses and stiffnesses of the majority of systems commonly used in construction practice. For the structural frame systems, the range of systems were represented by steel moment resisting frames, steel braced frames, reinforced concrete moment resisting frames andreinforced concrete frames and shear wall systems. For the veneer wall systems, the parameters varied included the type of backing wall and tie systems. Two backing wall types were evaluated, a steel stud backing wall and a CMU backing wall. Two types were evaluated that bounded the typical range of ties systems used in commercial construction, a stiff tie system and a flexible tie system. 
An integral component of the investigation involved the calibration of the analytical models against experimental results. During the calibration process, analytical models were developed in the OpenSees program and compared to experimental observations. The model parameters were adjusted till the results predicted by the models closely matched observations and these model elements were then used to form the frames and veneer wall systems evaluated in this study.

During this investigation the effects on the structural frame system response caused by modeling the wall systems (both in and out - of - plane), as just mass, or as a detailed analytical model, at the DBE and MCE levels of the Sylmar and Tarzana ground motions were evaluated. Subsequently, the effects of the frames' response on the veneer wall systems out - of - plane behavior, at the MCE level of the same ground motions was evaluated. Finally, an analysis of the veneer wall systems under out - of - plane seismic loads that produced collapse was conducted to determine when this would and occur and the reason for the observed failure.

\subsection{Conclusions}

1) The peak frame accelerations and displacements along the height of the steel moment resisting frame with the veneer wall systems represented by detailed analytical models were noticeably lower than those recorded for the same frame in which the wall systems were represented by their masses (as is typical done in practice). The steel moment resisting frame was the most flexible frame evaluated in this investigation. As 
the stiffness of the structural frame system increased, the difference between the peak response acceleration and displacement profiles along the mainframe height for the analytical and mass representations of the veneer wall systems decreased. For the stiffest building frame system(the reinforced concrete shear wall system), the frame accelerations and displacements were actually slightly higher for the the case in which the veneer wall systems were represented by their analytical models than by masses. The peak accelerations define the peak forces that the frame must be designed for. This demonstrates that, overall, the representation of the veneer wall systems by their masses is a conservative approach for the design of the structural frames, and this approach can significantly over estimate the effect of the heavy veneers wall systems when these are incorporated into flexible structural frames such as a moment resisting steel frame. Furthermore, the approach of representing the veneer wall systems by their masses is unconservative (however, to a much lesser extent than it was conservative in the case of the steel moment resisting frames) for the frame design, in the case of the walls being attached to the stiffest reinforced concrete shear wall system.

2) The peak response acceleration and displacement profiles along the height of the frames including both the mass and analytical model representations of the wall systems indicated that the system was responding primarily in its first vibratory mode. This conclusion was also supported by the fact that the base shears recorded for the same frame consisting of the two different representations of the wall systems did not show a significant variation. However, steel and reinforced concrete moment resisting frames responses did show some traces of higher mode response in the form of the "whipping 
effect" created at the top storey of the frames. The topmost storey of the moment frames showed a peak response acceleration higher than that expected for first mode response alone.

In general, the magnitudes of the peak response accelerations and displacements along the heights of all the mainframes investigated were higher at both the DBE and the MCE levels of the Tarzana ground motion, compared to the corresponding levels of the Sylmar ground motion. This is most likely because the Tarzana ground motion incorporates a wider range of frequencies at higher acceleration amplitudes than the Sylmar ground motion. This excites a greater number of fundamental modes of response in the frames.

3) For the reinforced concrete moment resisting frame and shear wall systems, the peak response acceleration and displacement profiles along the structural frame heights, were very similar for both the stiff and the flexible tie systems when the out - of - plane behavior of the veneer wall system was modeled. In most of the cases, this was also true for the steel frames. For the steel moment resisting frames at the DBE and MCE levels of the Tarzana ground motion, the types of tie system used in the analytical model representation of the wall system did, however, have an effect on the peak response quantities of the structural frame. The veneer wall systems containing the flexible tie models produced slightly higher values of peak response accelerations and displacements along the frame height when compared to the walls containing the stiff ties. This is 
consistent, since the steel moment resisting frames were the most flexible frames considered in this investigation, and the Tarzana ground motion was expected to produce larger responses than the Sylmar ground motion, since it encompassed a wider range of frenquencies.

4) Using an in - plane analytical model representations of the veneer wall systems behavior showed a similar effect on frame behavior to that observed for the veneer walls under out - of - plane loading. However, in most of the steel moment resisting frame configurations, the difference between the magnitudes of the peak response accelerations for the two in-plane representations of the veneer wall system behavior was lower than that for the wall system representations of out - of - plane behavior. This shows that representing the veneer wall systems by their masses is a conservative approach, and is more so for the walls under out - of - plane loads.

5) For the CMU backed veneer wall systems and, the reinforced concrete moment resisting frame systems and reinforced concrete frame and shear wall systems, the veneer remained in its uncracked state at the MCE level of both the Sylmar and Tarzana ground motions. However, the veneers of the CMU backed wall systems attached to the steel moment resisting and steel braced frame for both stiff and flexible ties, were cracked at the MCE level of both the Sylmar and Tarzana ground motions.

6) In all the structural frame systems, it was observed that the peak backing wall and veneer accelerations occurred in the top $\left(10^{\text {th }}\right)$ storey of the structural frame. 
7) The Tarzana ground motion produced higher accelerations in the CMU backed wall systems than did the Sylmar ground motion.

8) All the veneers backed by steel stud walls (with both the stiff and flexible ties) loaded in their out - of - plane direction were cracked at the MCE levels of both the Sylmar and Tarzana ground motions for all four frame configurations.

9) The peak veneer and backup accelerations of both the steel stud backed and CMU backed wall systems were maximum in the walls attached to the steel moment resisting frame (Most flexible frame), and minimum for the walls attached to the reinforced concrete frame and shear wall system (Stiffest frame).

10) The top rows of ties were subjected to the maximum force in all the steel stud backed veneer wall systems. The same behavior was also observed in all the CMU backed wall systems that were uncracked. However, in a small number of the CMU backed wall systems that were cracked, the middle row of ties carried a marginally higher load than the top row.

11) At their ultimate capacity, the CMU backed wall systems failed by a pullout of the top row of ties and the steel stud backed wall systems, by cracking of the veneer at multiple locations. 
12) Both the steel stud and CMU backed wall systems, with stiff and flexible ties, collapsed at levels of ground shaking well above the MCE for the ground motions that were considered in this investigation. This shows that the current codal provisions used in the design of these wall systems are adequate when the walls are incorporated into medium rise buildings.

\subsection{Recommendations for further research}

1) This investigation emphasized the effect of the medium rise structural frames on masonry veneer wall systems attached to them and loaded in their out - of - plane direction. Additional research work needs to be performed on the interactions of structural frames on wall systems in their in - plane direction.

2) As a part of this investigation, the effect of veneer wall system in - plane behavioron the response of the structural frame was studied. In order to do this, the veneer wall system was considered only on the stiffest (the reinforced concrete frame and shear wall system) and the most flexible frames (the steel moment resisting frame). The effect of the in-plane veneer wall system behavior on the mainframes of stiffness intermediate to these, was assumed to lie in between these bounds. Analytical models of the veneer wall systems attached to medium rise building frames of intermediate stiffness need to be developed, in order to verify this assumption and obtain a better understanding of the effect of the wall systems loaded in their in - plane direction on the mainframes. 
3) The seismic behavior of wood stud and CMU backed veneer wall systems has been investigated in low rise buildings. (Okail, 2010; Jo, 2010). This investigation was focused on the seismic performance of steel stud and CMU backed veneer wall systems in medium rise buildings. Additional research needs to be conducted into the seismic performance of wood stud backed veneer wall systems in medium rise buildings, and steel stud and CMU backed wall systems in tall buildings. It is unlikely that wood stud backed veneer wall systems would be employed in tall buildings.

4) This investigation focused on the seismic response of veneer wall systems in medium rise buildings, under the influence of the Sylmar and Tarzana ground motion histories. In order to obtain a broader understanding of the performance of these wall systems, additional research needs to be performed, using the analytical models developed in this investigation, under the action of ground motion histories other than those considered in this investigation. 


\section{REFERENCES}

ACI 318-08, "Building Code Requirements for Structural Concrete (ACI 318-08) andCommentary, (ACI 318R-08)", American Concrete Institute, Farmington Hills, MI,2008.

ASCE 7-05, "Minimum Design Loads for Buildings and Other Structures, ASCE 7-05", American Society of Civil Engineers, Reston, VA, 2005.

Applied Technology Council (ATC), "Engineering Demand Parameters for Structural Framing Systems", ATC-58 Project Task Report, Phase 2, Task 2.2, 2004.

Biddah, A.M.S., "Evaluation of the Seismic Level of Protection of Steel Moment Resisting Frame Building Structures”, Ph.D Dissertation.McMaster University,1998.

Brick Industry Association, "Masonry veneer existing construction (28A)", Technical Notes on Brick Construction, Reston, VA, 1-5, 2002.

Bentley Systems Incorporated, 685 Stockton Drive, Exton, PA 19341, United States (web address: http://www.bentley.com/en-US/), 2011.

Choi, YH. and LaFave, J.M., "Performance of Corrugated Metal Ties for Brick Veneer Wall Systems", Journal of Materials in Civil Engineering, Vol. 16, No. 3,2004.

Federal Emergency Management Agency (FEMA), "FEMA 273: NEHRP Guidelines for the Seismic Rehabilitation of Buildings", Applied Technology Council, Redwood City, California, 1997. 
FEMA, "FEMA 349: Action Plan for Performance Based Seismic Design", Earthquake Engineering Research Institute, Oakland, California, 2000.

FEMA, "FEMA 461: Interim Testing Protocols for Determining the Seismic Performance Characteristics of Structural and Nonstructural Components", Applied Technology Council, Redwood City, California, 2007.

Gates, W., "Certified Life Building”, Conrad and Associates, 1973.

Hernandez, L.A.M., "Seismic Performance and Fragility Curves for Reinforced Concrete Frame and Shear Wall Residential Buildings in Puerto Rico", Ph.DDissertation. University of Puerto Rico, 2007.

Hikita, K., "Combined Gravity and Lateral Loading of Light Gauge Steel Frame / Wood Panel Shear Walls”, M.E.Dissertation.McGill University, Montreal, Canada,2006.

International Code Council (ICC), "International Residential Code for One- andTwoFamily Dwellings (IRC)", 2006.

Jo, S., "Seismic Behavior and Design of Low-rise Reinforced Concrete Masonry with Clay Masonry Veneer", Ph.D Dissertation.University of Texas, Austin, 2010.

Khatri, D., "Nonlinear Analysis of Reinforced Concrete Shear Wall Structures", Ph.DDissertation.University of Southern California, 1998.

LaFave, J.M., andReneckis, D., "Structural Behavior of Tie Connections for Residential Brick Veneer Construction”, TMS Journal, 105-119, 2005.

McGinley, W.M. and Hamoush, S., "Seismic Masonry Veneer: Quasi-Static Testingof Wood Stud Backed Clay Masonry Veneer Walls", Proceedings, ASCE StructuresCongress, Vancouver, Canada, 2008.

McGinley, W.M., et al., "Behavior of Clay Masonry Veneer Backed by Wood Stud Walls Subjected to Out - of - Plane Quasi - Static and Dynamic Loads”, Proceedings, Eleventh NAMC, Minneapolis, MN, June, 2011. 
MSJC 2008a: Building Code Requirements for Masonry Structures (TMS 402-08 /ACI 530-08 / ASCE 5-08), The Masonry Society, Boulder, Colorado, the American Concrete Institute, Farmington Hills, Michigan, and the American Society of CivilEngineers, Reston, VA, 2008.

MSJC 2008b: Specification for Masonry Structures (TMS 602-08 / ACI 530.1-08 /ASCE 6-08), The Masonry Society, Boulder, Colorado, the American ConcreteInstitute, Farmington Hills, Michigan, and the American Society of Civil Engineers,Reston, VA, 2008.

Okail, H., "Experimental and Analytical Investigation of the Seismic Performanceof Low-Rise Masonry Veneer Buildings", Ph.D dissertation.University of California, San Diego, 2010.

Okail, H., et al., "Modeling of the Dynamic Behavior of Brick Veneer Subjected to Earthquake Ground Motions", Proceedings, ECCOMAS Thematic Conference, Rhodes, Greece, June, 2009.

Pacific Earthquake Engineering Research Center, 325 Davis Hall, University of California Berkeley, CA 94720 - 1792, (web address: http://peer.berkeley.edu/products/opensees.html).

Rashidi, S., "Performance-Based Seismic Engineering of Low and Medium-Rise Steel Frames", Ph.D Dissertation. New Jersey Institute of Technology, 2000.

Reneckis, D., LaFave, J.M., and Clarke, W.M., "Out-of-plane performance of masonry veneer walls on wood frames", Engineering Structures, Vol. 26, 1027-1042, 2004.

Reneckis, D. and LaFave, J.M., "Analysis of brick veneer walls on wood frameconstruction subjected to out-of-plane loads", Construction and Building Materials, Vol. 19, 430-447, 2005.

Reneckis, D. and LaFave, J.M., "Seismic performance of anchored brick veneer", Report No. NSEL-016, Newmark structural Engineering Laboratory, University oftllinois Urbanna Champaign, IL, 2009.

Thurston, S.J., and Beattie, G.J., "Seismic Performance of Brick Veneer Houses", Proceedings, NZSEE Conference, 2008. 
Wolanski, A.J., "Flexural Behavior of Reinforced and Prestressed Concrete Beams Using Finite Element Analysis", M.Sc. Dissertation, Marquette University, Milwaukee, Wisconsin, 2004.

WIRE - BOND, 400 Roundtree Road, Charlotte, North Carolina 28224, (web address:http://wirebond.com/wp-content/uploads/2009/12/rj711 test data.pdf), 2011. 


\section{APPENDIX A \\ EQUIVALENT LATERAL FORCE CALCULATIONS}

Appendix A contains the calculations performed in obtaining the equivalent lateral force distribution assumed to act on the frames, according to the provisions of Section 12.8 of ASCE - $07-05$ (ASCE, 2005). The calculations for the steel moment resisting frame, the steel braced frame, the reinforced concrete moment resisting frame, and the reinforced concrete braced frame are provided in separate sections. 


\section{A.1. Steel Moment Resisting Frame}

Referring to Sections 3.3.2.1 and 3.3.2.2 of this dissertation, the values of the frame parameters were used in the equations, both of which were presented in these sections, to get the equivalent lateral force distribution along the height of the steel moment resisting frame. All these values have been tabulated in Table A.1. 
Table A.1:Equivalent Lateral Loads for the Steel Moment Resisting Frame

\begin{tabular}{|c|c|}
\hline Property & Value \\
\hline I & 1 \\
\hline $\mathrm{R}$ & 8 \\
\hline $\mathrm{S}_{\mathrm{DS}}$ & 0.55 \\
\hline $\mathrm{C}_{\mathrm{S}}$ & 0.06875 \\
\hline W & 10835 Kips \\
\hline V & 745 Kips \\
\hline $\mathbf{T}_{\mathrm{a}}$ & 1.2897 seconds \\
\hline $\mathrm{K}$ & 1.3948 \\
\hline$w_{1}$ to $w_{9}$ & 0.1073 \\
\hline$w_{10}$ & 0.03425 \\
\hline $\mathrm{C}_{\mathrm{v} 1}$ & 0.01 \\
\hline $\mathrm{C}_{\mathrm{v} 2}$ & 0.02645 \\
\hline $\mathrm{C}_{\mathrm{v} 3}$ & 0.04656 \\
\hline $\mathrm{C}_{\mathrm{v} 4}$ & 0.06955 \\
\hline $\mathrm{C}_{\mathrm{v} 5}$ & 0.09495 \\
\hline $\mathrm{C}_{\mathrm{v} 6}$ & 0.1224 \\
\hline $\mathrm{C}_{\mathrm{v} 7}$ & 0.1518 \\
\hline $\mathrm{C}_{\mathrm{v} 8}$ & 0.1829 \\
\hline $\mathrm{C}_{\mathrm{v} 9}$ & 0.2155 \\
\hline $\mathrm{C}_{\mathrm{v} 10}$ & 0.0797 \\
\hline$F_{1}$ & $7.5 \mathrm{Kips}$ \\
\hline $\mathrm{F}_{2}$ & 19.7 Kips \\
\hline$F_{3}$ & 34.7 Kips \\
\hline $\mathrm{F}_{4}$ & $51.8 \mathrm{Kips}$ \\
\hline $\mathrm{F}_{5}$ & 70.7 Kips \\
\hline $\mathrm{F}_{6}$ & $91.2 \mathrm{Kips}$ \\
\hline $\mathrm{F}_{7}$ & $113.1 \mathrm{Kips}$ \\
\hline $\mathrm{F}_{8}$ & $136.2 \mathrm{Kips}$ \\
\hline $\mathrm{F}_{9}$ & $160.6 \mathrm{Kips}$ \\
\hline $\mathrm{F}_{10}$ & 59.4 Kips \\
\hline
\end{tabular}




\section{A.2. Steel Braced Frame}

Referring to Sections 3.3.2.1 and 3.3.2.2 of this dissertation, the values of the frame parameters were used in the equations, both of which were presented in these sections, to get the equivalent lateral force distribution along the height of the steel braced frame. These values have been tabulated in Table A.2.

Table A.2:Equivalent Lateral Loads for the Steel Braced Frame

\begin{tabular}{|c|c|}
\hline Property & Value \\
\hline I & 1 \\
\hline $\mathbf{R}$ & 6 \\
\hline$S_{\mathrm{DS}}$ & 0.55 \\
\hline $\mathrm{C}_{\mathrm{S}}$ & 0.0916 \\
\hline W & 10799 Kips \\
\hline $\mathrm{V}$ & $990 \mathrm{Kips}$ \\
\hline $\mathrm{T}_{\mathrm{a}}$ & 0.72513 seconds \\
\hline K & 1.1125 \\
\hline $\mathrm{w}_{1}$ to $\mathrm{w}_{9}$ & 0.1073 \\
\hline $\mathrm{w}_{10}$ & 0.033 \\
\hline $\mathrm{C}_{\mathrm{v} 1}$ & 0.0169 \\
\hline $\mathrm{C}_{\mathrm{y} 2}$ & 0.0366 \\
\hline $\mathrm{C}_{\mathrm{v} 3}$ & 0.05756 \\
\hline $\mathrm{C}_{\mathrm{v} 4}$ & 0.07928 \\
\hline $\mathrm{C}_{\mathrm{v} 5}$ & 0.1016 \\
\hline $\mathrm{C}_{\mathrm{v} 6}$ & 0.1245 \\
\hline $\mathrm{C}_{\mathrm{v} 7}$ & 0.1477 \\
\hline $\mathrm{C}_{\mathrm{v} 8}$ & 0.1714 \\
\hline $\mathrm{C}_{\mathrm{v} 9}$ & 0.1954 \\
\hline $\mathrm{C}_{\mathrm{v} 10}$ & 0.0688 \\
\hline$F_{1}$ & $16.8 \mathrm{Kips}$ \\
\hline $\mathrm{F}_{2}$ & 36.3 Kips \\
\hline $\mathrm{F}_{3}$ & 57 Kips \\
\hline $\mathrm{F}_{4}$ & 78.5 Kips \\
\hline$F_{5}$ & $100.6 \mathrm{Kips}$ \\
\hline$F_{6}$ & 123.2 Kips \\
\hline $\mathrm{F}_{7}$ & 146.3 Kips \\
\hline $\mathrm{F}_{8}$ & 169.7 Kips \\
\hline $\mathrm{F}_{9}$ & 193.5 Kips \\
\hline$F_{10}$ & $68.2 \mathrm{Kips}$ \\
\hline
\end{tabular}




\section{A.3. Reinforced Concrete Moment Resisting Frame}

Referring to Sections 3.3.2.1 and 3.3.2.2 of this dissertation, the values of the frame parameters were used in the equations, both of which were presented in these sections, to get the equivalent lateral force distribution along the height of the steel braced frame. These values have been tabulated in Table A.3.

Table A.3:Equivalent Lateral Loads for the Reinforced Concrete Moment Frame

\begin{tabular}{|c|c|}
\hline Property & Value \\
\hline I & 1 \\
\hline $\mathrm{R}$ & 8 \\
\hline$S_{\mathrm{DS}}$ & 0.55 \\
\hline $\mathrm{C}_{\mathrm{S}}$ & 0.06875 \\
\hline W & 14304 Kips \\
\hline $\mathrm{V}$ & 983.4 Kips \\
\hline $\mathrm{T}_{\mathrm{a}}$ & 1.1895 seconds \\
\hline K & 1.3447 \\
\hline$w_{1}$ to $w_{9}$ & 0.1038 \\
\hline $\mathrm{w}_{10}$ & 0.0657 \\
\hline $\mathrm{C}_{\mathrm{v} 1}$ & 0.0102 \\
\hline $\mathrm{C}_{\mathrm{v} 2}$ & 0.0261 \\
\hline $\mathrm{C}_{\mathrm{v} 3}$ & 0.045 \\
\hline $\mathrm{C}_{\mathrm{v} 4}$ & 0.066 \\
\hline $\mathrm{C}_{v 5}$ & 0.0893 \\
\hline $\mathrm{C}_{\mathrm{v} 6}$ & 0.114 \\
\hline $\mathrm{C}_{\mathrm{v} 7}$ & 0.14 \\
\hline $\mathrm{C}_{\mathrm{v} 8}$ & 0.168 \\
\hline $\mathrm{C}_{\mathrm{v} 9}$ & 0.1968 \\
\hline $\mathrm{C}_{\mathrm{v} 10}$ & 0.1437 \\
\hline$F_{1}$ & 10.1 Kips \\
\hline $\mathrm{F}_{2}$ & 25.6 Kips \\
\hline $\mathrm{F}_{3}$ & $44.2 \mathrm{Kips}$ \\
\hline $\mathrm{F}_{4}$ & $65.0 \mathrm{Kips}$ \\
\hline$F_{5}$ & $87.8 \mathrm{Kips}$ \\
\hline $\mathrm{F}_{6}$ & $112.2 \mathrm{Kips}$ \\
\hline $\mathrm{F}_{7}$ & $138.0 \mathrm{Kips}$ \\
\hline$F_{8}$ & 165.2 Kips \\
\hline $\mathrm{F}_{9}$ & 193.6 Kips \\
\hline $\mathrm{F}_{10}$ & $141.3 \mathrm{Kips}$ \\
\hline
\end{tabular}




\section{A.4. Reinforced Concrete Shear Wall System}

Referring to Sections 3.3.2.1 and 3.3.2.2 of this dissertation, the values of the frame parameters were used in the equations, both of which were presented in these sections, to get the equivalent lateral force distribution along the height of the steel braced frame. These values have been tabulated in Table A.4.

\section{A.4:Equivalent Lateral Loads for the Reinforced Concrete Shear Wall System}

\begin{tabular}{|c|c|}
\hline Property & Value \\
\hline I & 1 \\
\hline $\mathrm{R}$ & 6 \\
\hline $\mathrm{S}_{\mathrm{DS}}$ & 0.55 \\
\hline $\mathrm{C}_{\mathrm{S}}$ & 0.0916 \\
\hline W & $15535 \mathrm{Kips}$ \\
\hline V & 1424 Kips \\
\hline $\mathrm{T}_{\mathrm{a}}$ & 0.7251 seconds \\
\hline K & 1.1125 \\
\hline $\mathrm{w}_{1}$ to $\mathrm{w}_{9}$ & 0.1042 \\
\hline$w_{10}$ & 0.062 \\
\hline $\mathrm{C}_{\mathrm{v} 1}$ & 0.016 \\
\hline $\mathrm{C}_{\mathrm{v} 2}$ & 0.0345 \\
\hline $\mathrm{C}_{\mathrm{v} 3}$ & 0.0542 \\
\hline $\mathrm{C}_{\mathrm{v} 4}$ & 0.0746 \\
\hline $\mathrm{C}_{55}$ & 0.0957 \\
\hline $\mathrm{C}_{\mathrm{v} 6}$ & 0.1172 \\
\hline $\mathrm{C}_{\mathrm{v} 7}$ & 0.139 \\
\hline $\mathrm{C}_{\mathrm{v} 8}$ & 0.1614 \\
\hline $\mathrm{C}_{\mathrm{v} 9}$ & 0.184 \\
\hline $\mathrm{C}_{\mathrm{v} 10}$ & 0.123 \\
\hline$F_{1}$ & 22.7 Kips \\
\hline$F_{2}$ & 49.2 Kips \\
\hline $\mathrm{F}_{3}$ & $77.2 \mathrm{Kips}$ \\
\hline $\mathrm{F}_{4}$ & 106.3 Kips \\
\hline $\mathrm{F}_{5}$ & 136.2 Kips \\
\hline$F_{6}$ & $167.0 \mathrm{Kips}$ \\
\hline $\mathrm{F}_{7}$ & 198.1 Kips \\
\hline $\mathrm{F}_{8}$ & $229.8 \mathrm{Kips}$ \\
\hline$F_{9}$ & $262.0 \mathrm{Kips}$ \\
\hline$F_{10}$ & 175.4 Kips \\
\hline
\end{tabular}




\section{APPENDIX B}

\section{EFFECT OF THE OUT OF PLANE WALL ON THE}

\section{MAINFRAME: ACCELERATION AND DISPLACEMENT}

Appendix B consists of plots that display the effect of the out of plane wall systems on the main building frame systems. These plots are derived in a manner identical to that described in the result categories 1 and 2, discussed in Chapter 4 . They compare the effect of the mass versus analytical model representation of the out of plane wall system on the acceleration and displacement responses of points on the main frame, selected as described in the aforementioned sections of chapter 4. 


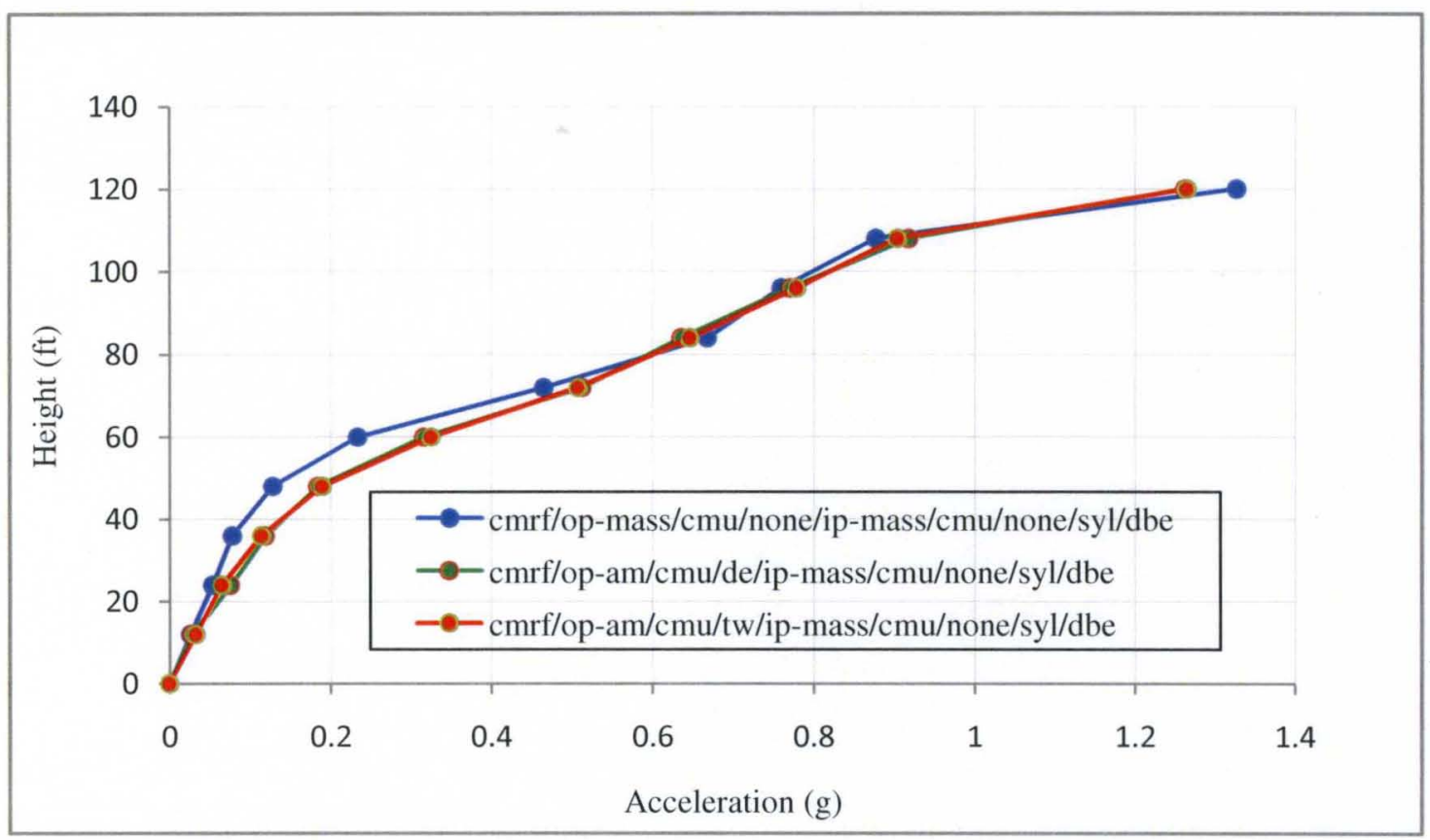

Figure B.1: Comparison of the Acceleration Profiles Going Up the Height of the Concrete Moment Resisting Frame, With a Mass Representation and Analytical Model Representations With Stiff and Flexible Ties, of the CMU Backed Out of Plane Wall System, and a Mass Representation of the In Plane Wall System, at DBE of the Sylmar Ground Motion.

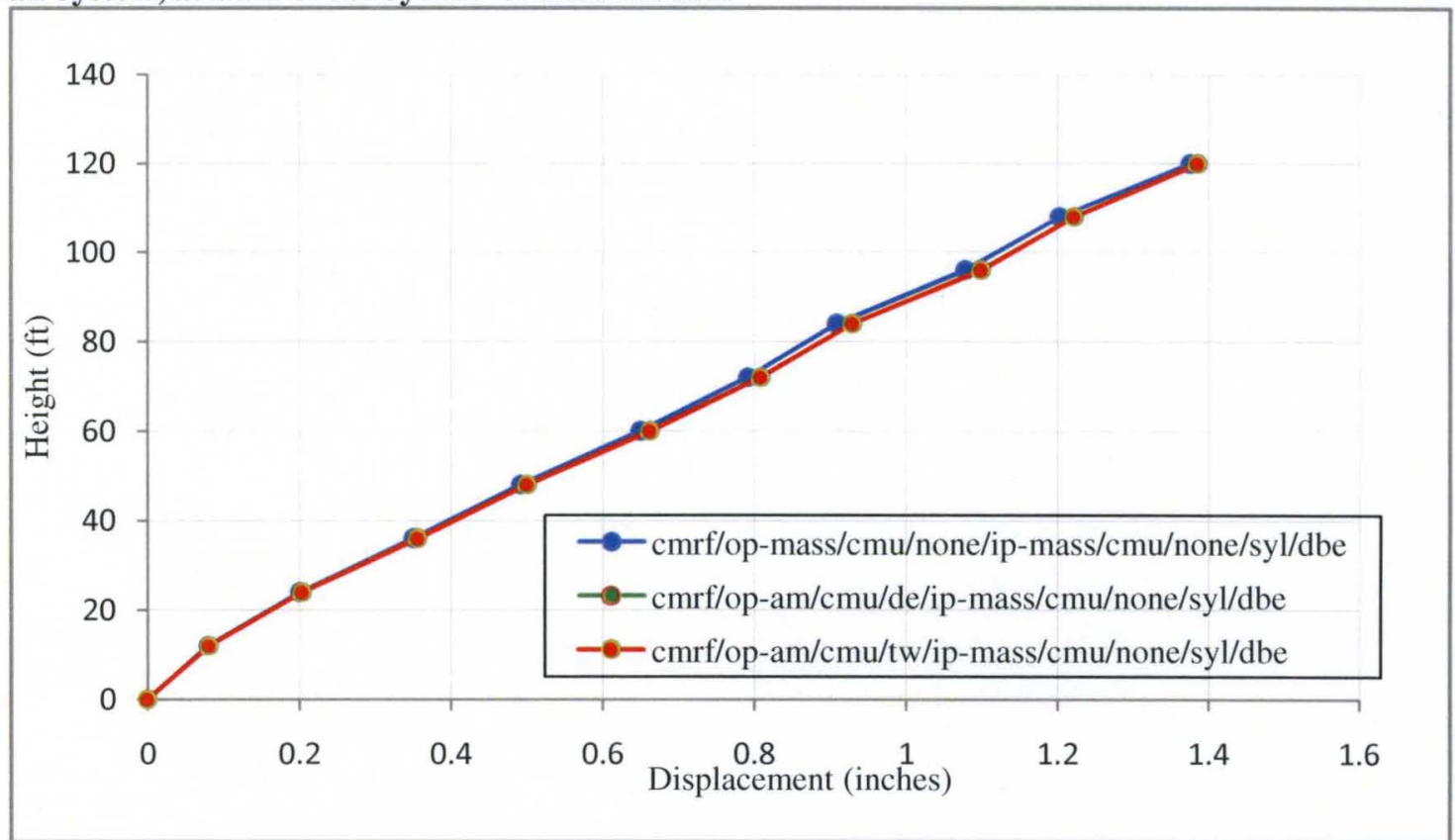

Figure B.2: Comparison of the Displacement Profiles Going Up the Height of the Concrete Moment Resisting Frame, With a Mass Representation and Analytical Model Representations With Stiff and Flexible Ties, of the CMU Backed Out of Plane Wall System, and a Mass Representation of the In Plane Wall System, at DBE of the Sylmar Ground Motion. 


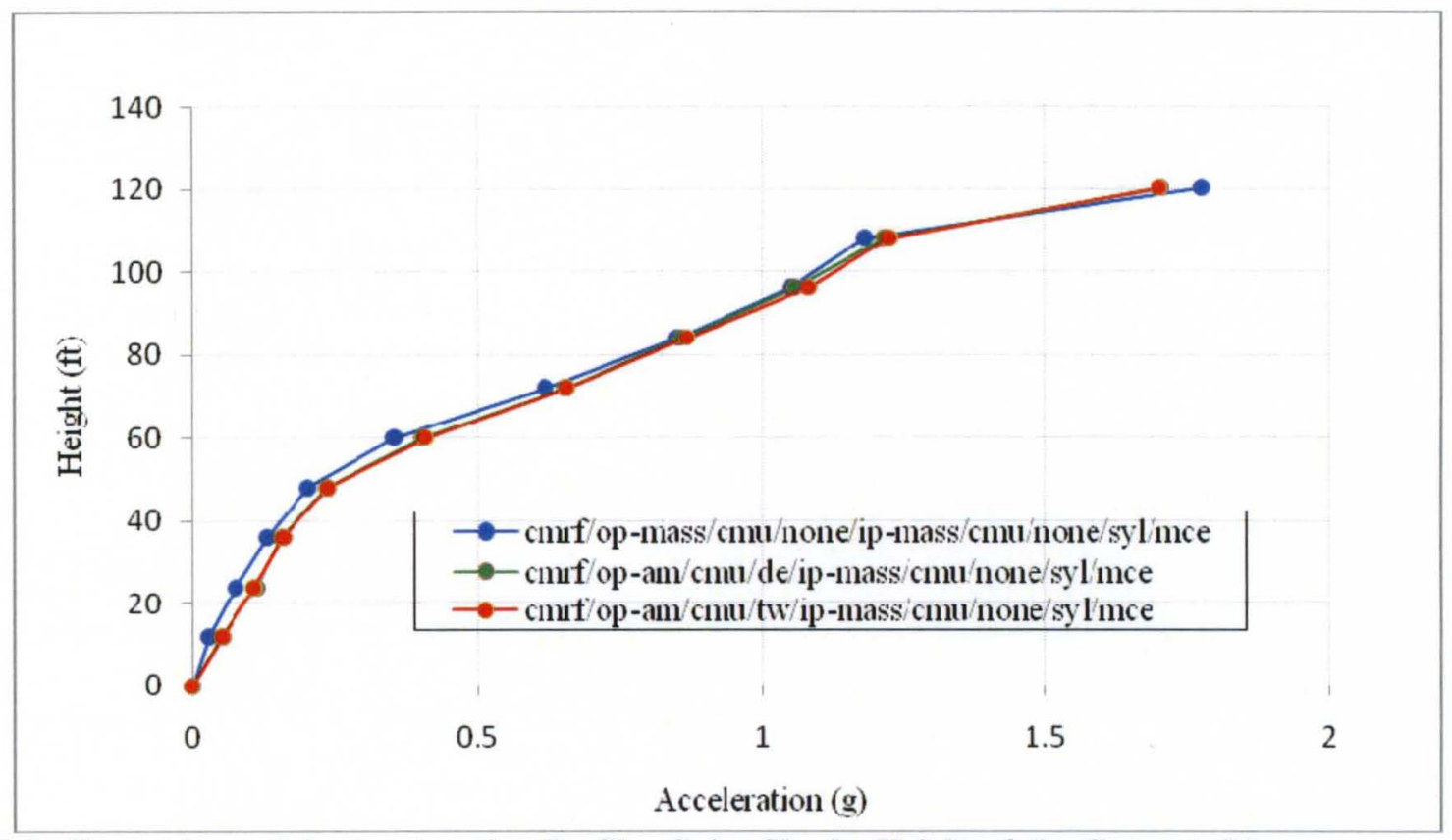

Figure B.3: Comparison of the Acceleration Profiles Going Up the Height of the Concrete Moment Resisting Frame, With a Mass Representation and Analytical Model Representations With Stiff and Flexible Ties, of the CMU Backed Out of Plane Wall System, and a Mass Representation of the In Plane Wall System, at MCE of the Sylmar Ground Motion.

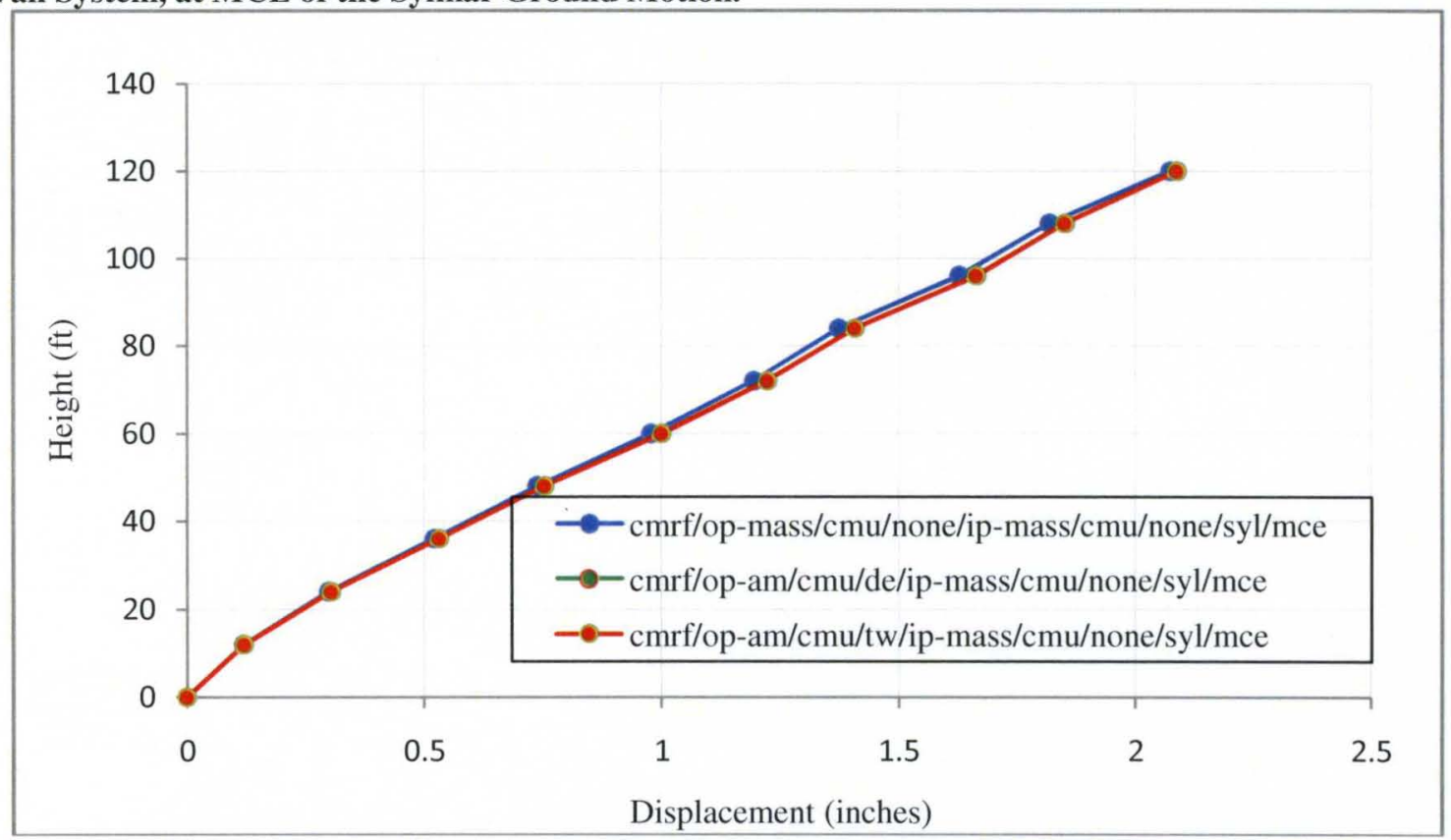

Figure B.4: Comparison of the Displacement Profiles Going Up the Height of the Concrete Moment Resisting Frame, With a Mass Representation and Analytical Model Representations With Stiff and Flexible Ties, of the CMU Backed Out of Plane Wall System, and a Mass Representation of the In Plane Wall System, at MCE of the Sylmar Ground Motion. 


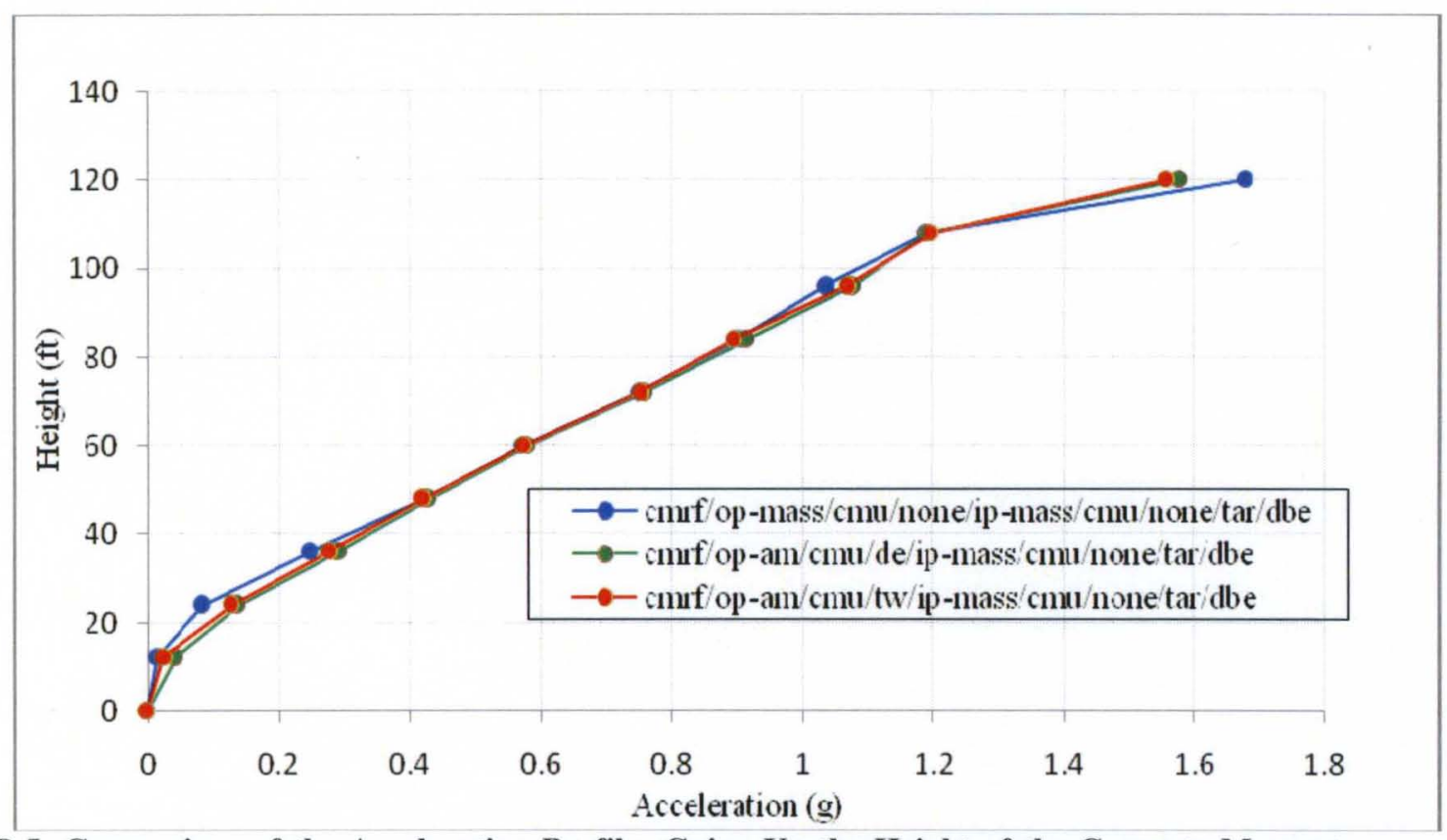

Figure B.5: Comparison of the Acceleration Profiles Going Up the Height of the Concrete Moment Resisting Frame, With a Mass Representation and Analytical Model Representations With Stiff and Flexible Ties, of the CMU Backed Out of Plane Wall System, and a Mass Representation of the In Plane Wall System, at DBE of the Tarzana Ground Motion.

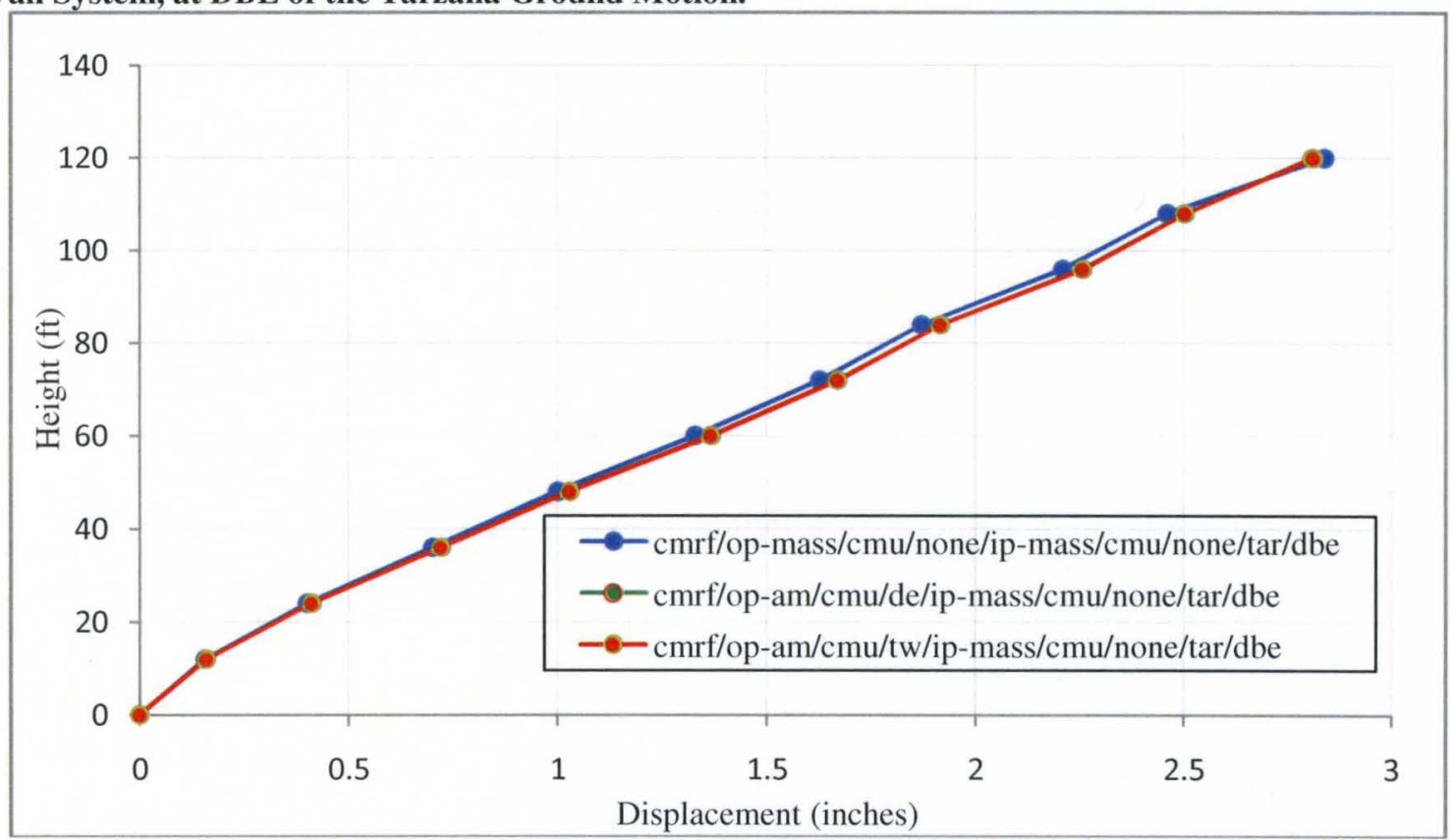

Figure B.6: Comparison of the Displacement Profiles Going Up the Height of the Concrete Moment Resisting Frame, With a Mass Representation and Analytical Model Representations With Stiff and Flexible Ties, of the CMU Backed Out of Plane Wall System, and a Mass Representation of the In Plane Wall System, at DBE of the Tarzana Ground Motion. 


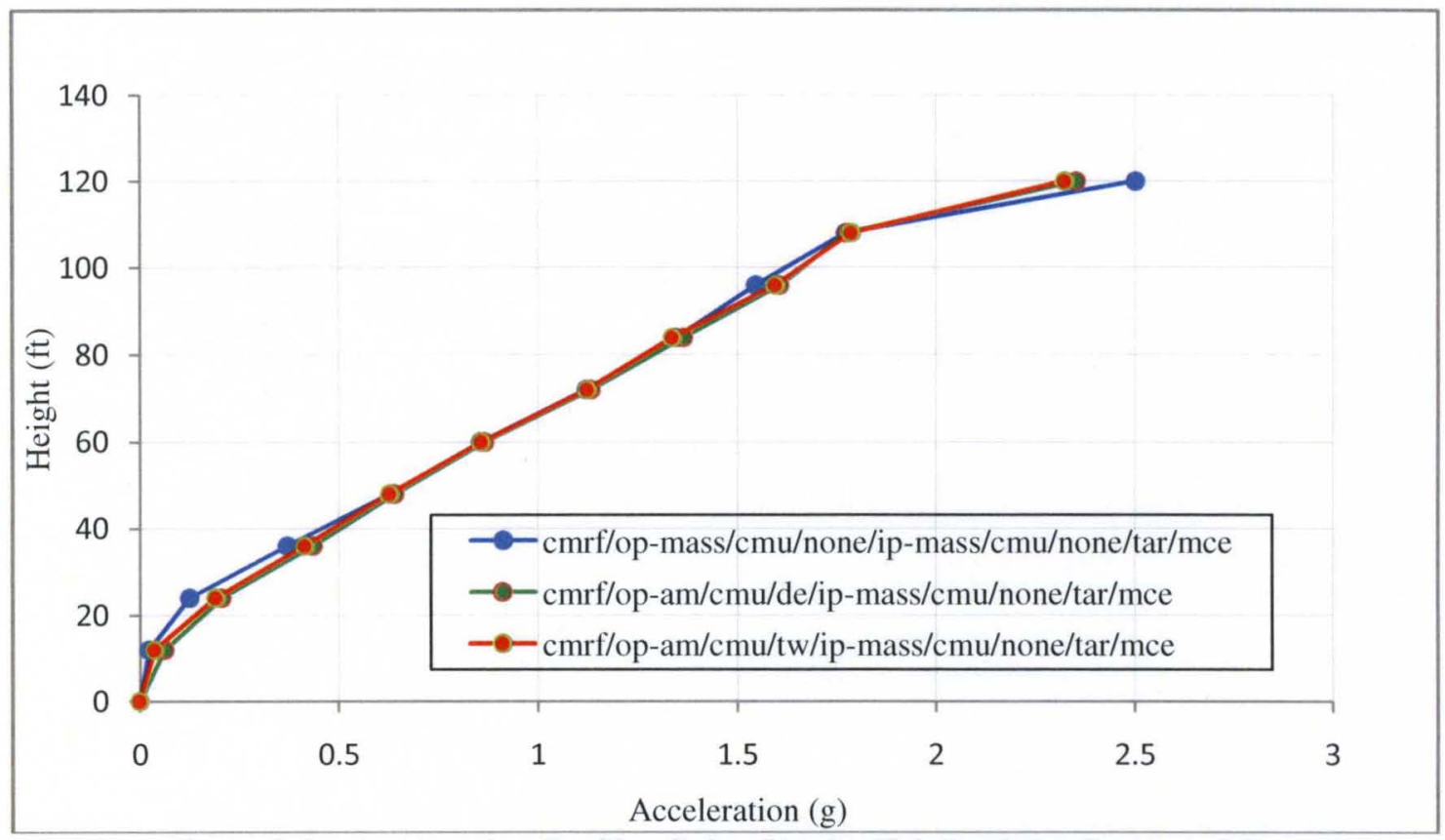

Figure B.7: Comparison of the Acceleration Profiles Going Up the Height of the Concrete Moment Resisting Frame, With a Mass Representation and Analytical Model Representations With Stiff and Flexible Ties, of the CMU Backed Out of Plane Wall System, and a Mass Representation of the In Plane Wall System, at MCE of the Tarzana Ground Motion.

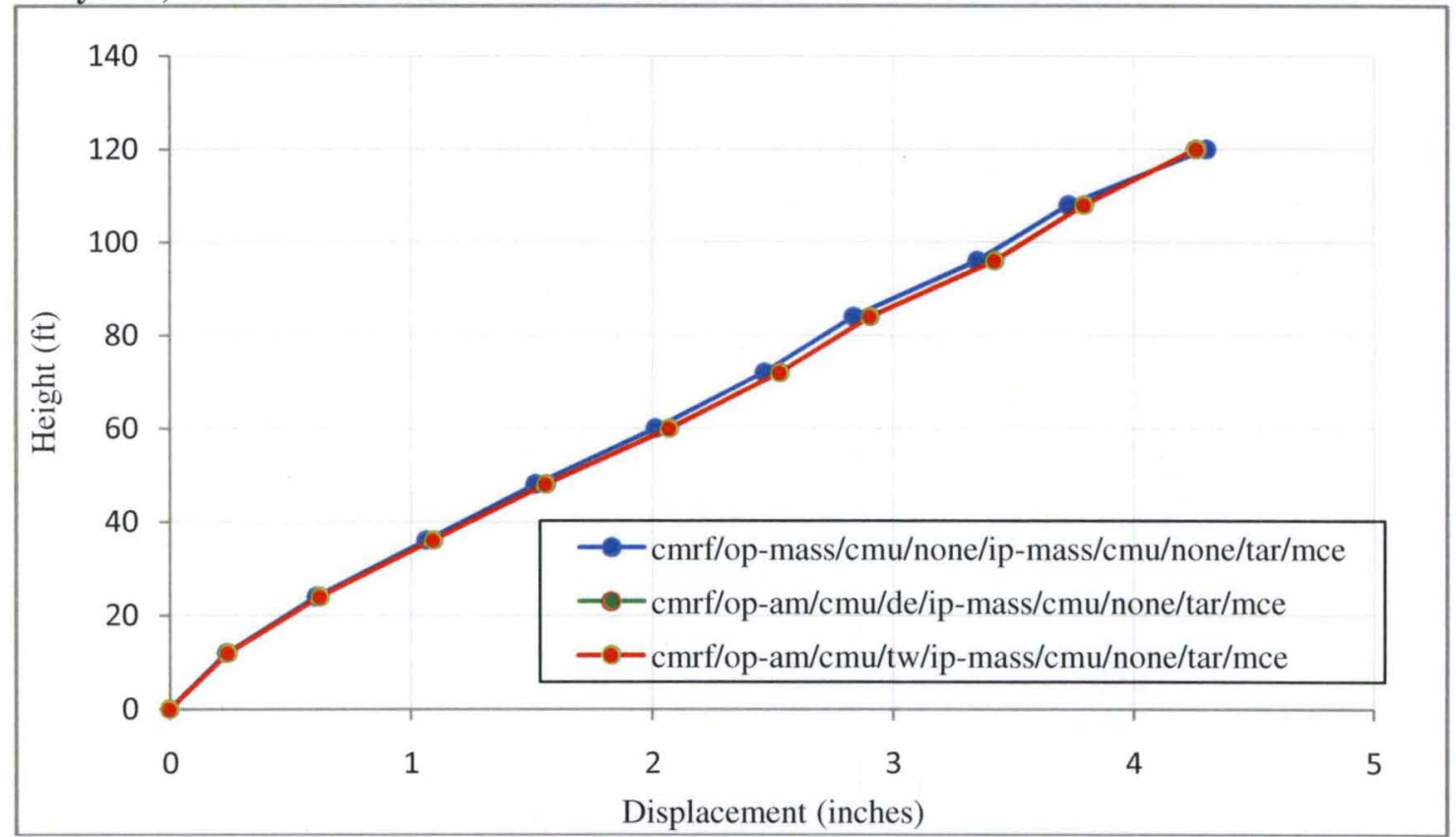

Figure B.8: Comparison of the Displacement Profiles Going Up the Height of the Concrete Moment Resisting Frame, With a Mass Representation and Analytical Model Representations With Stiff and Flexible Ties, of the CMU Backed Out of Plane Wall System, and a Mass Representation of the In Plane Wall System, at MCE of the Tarzana Ground Motion. 


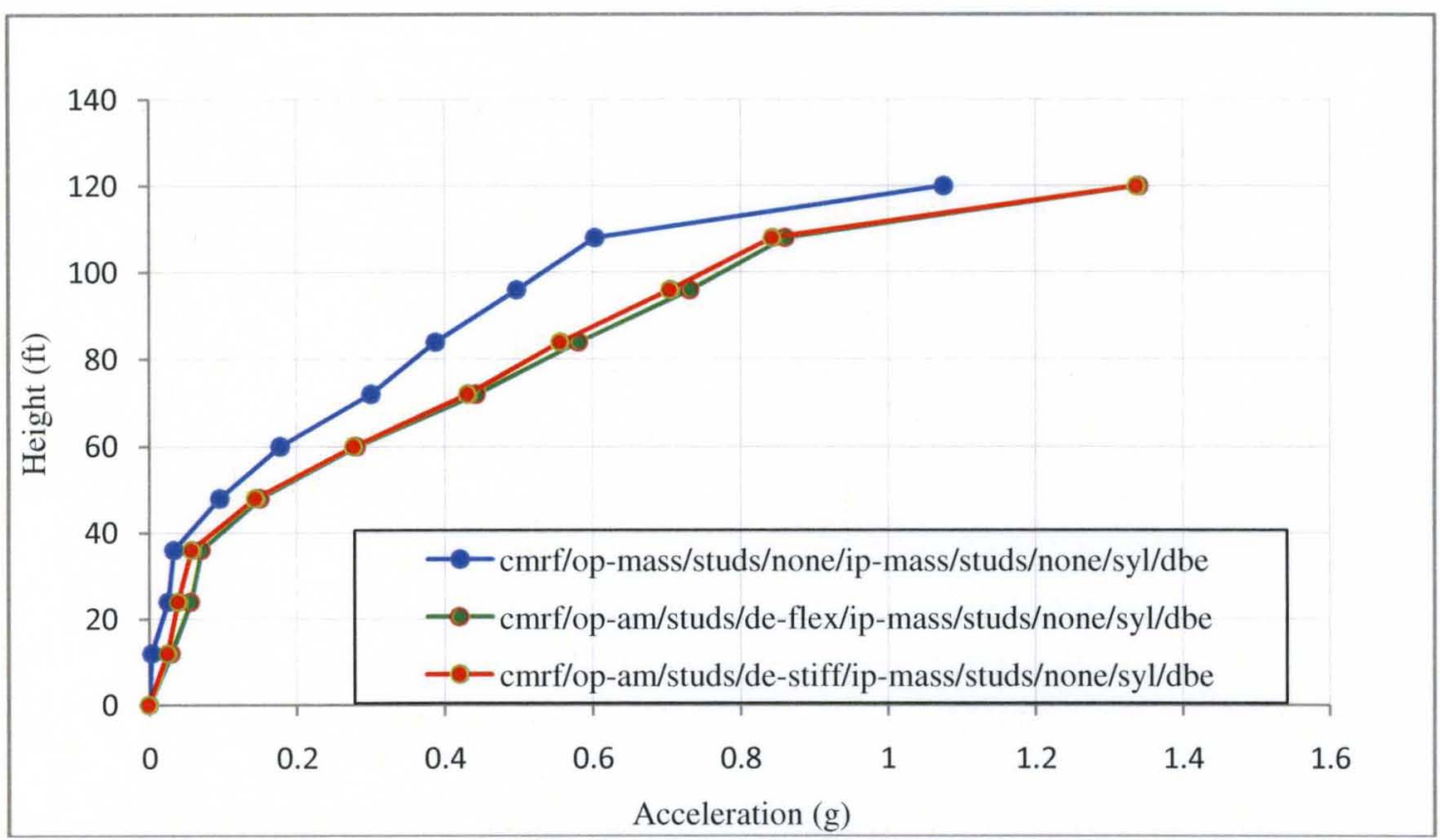

Figure B.9: Comparison of the Acceleration Profiles Going Up the Height of the Concrete Moment Resisting Frame, With a Mass Representation and Analytical Model Representations With Stiff and Flexible Ties, of the Stud Backed Out of Plane Wall System, and a Mass Representation of the In Plane Wall System, at DBE of the Sylmar Ground Motion.

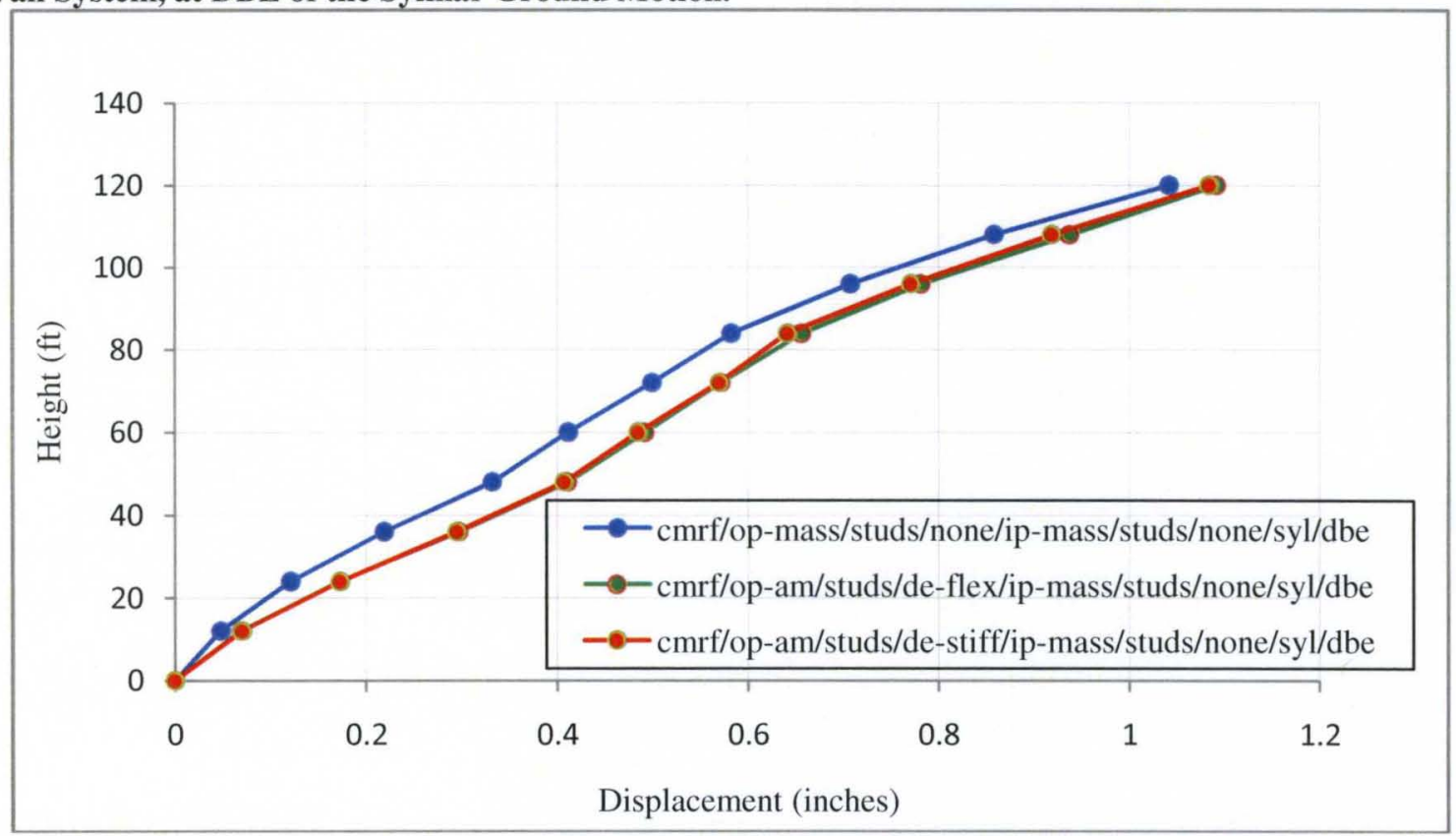

Figure B.10: Comparison of the Displacement Profiles Going Up the Height of the Concrete Moment Resisting Frame, With a Mass Representation and Analytical Model Representations With Stiff and Flexible Ties, of the Stud Backed Out of Plane Wall System, and a Mass Representation of the In Plane Wall System, at DBE of the Sylmar Ground Motion. 


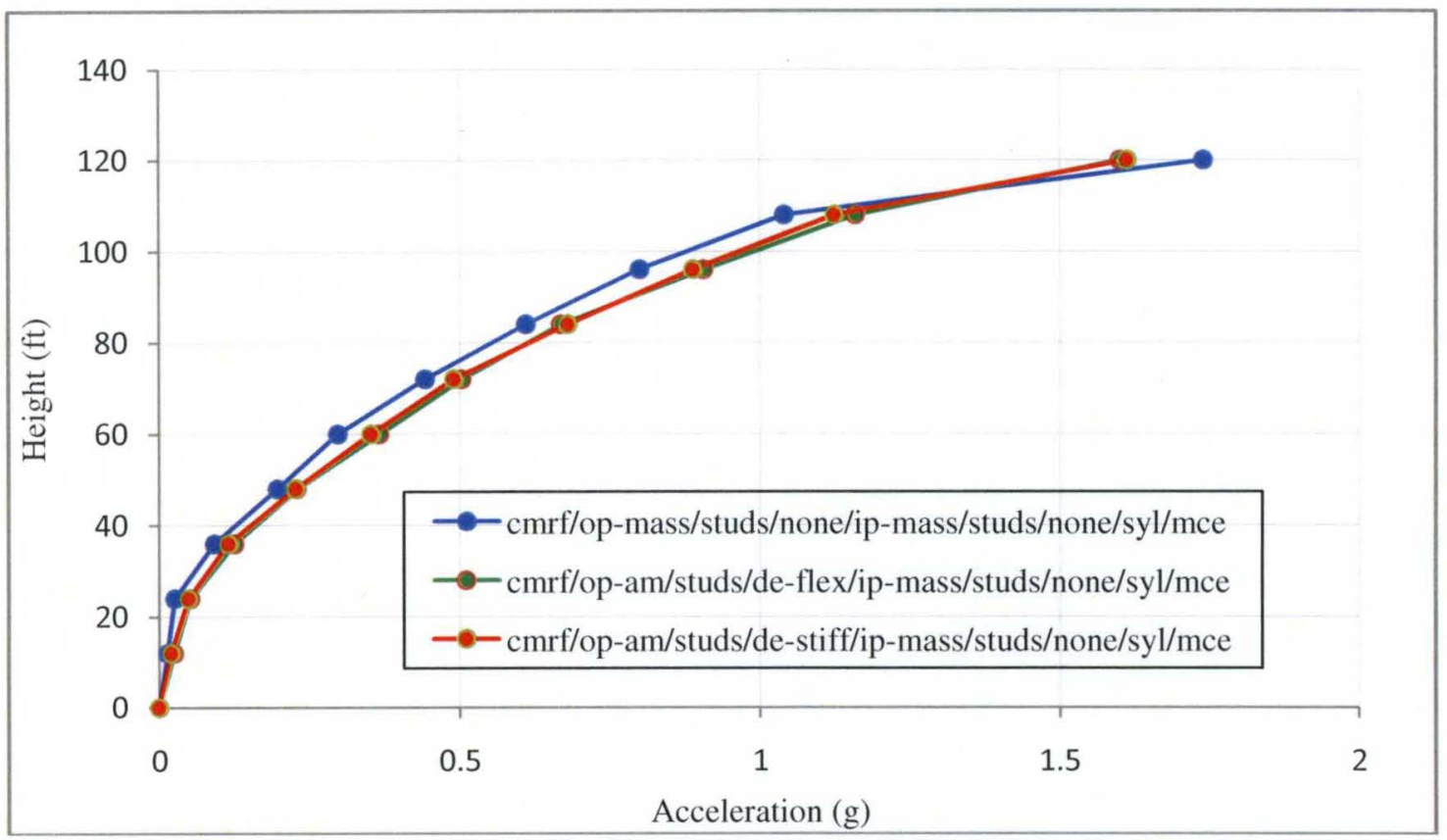

Figure B.11: Comparison of the Acceleration Profiles Going Up the Height of the Concrete Moment Resisting Frame, With a Mass Representation and Analytical Model Representations With Stiff and Flexible Ties, of the Stud Backed Out of Plane Wall System, and a Mass Representation of the In Plane Wall System, at MCE of the Sylmar Ground Motion.

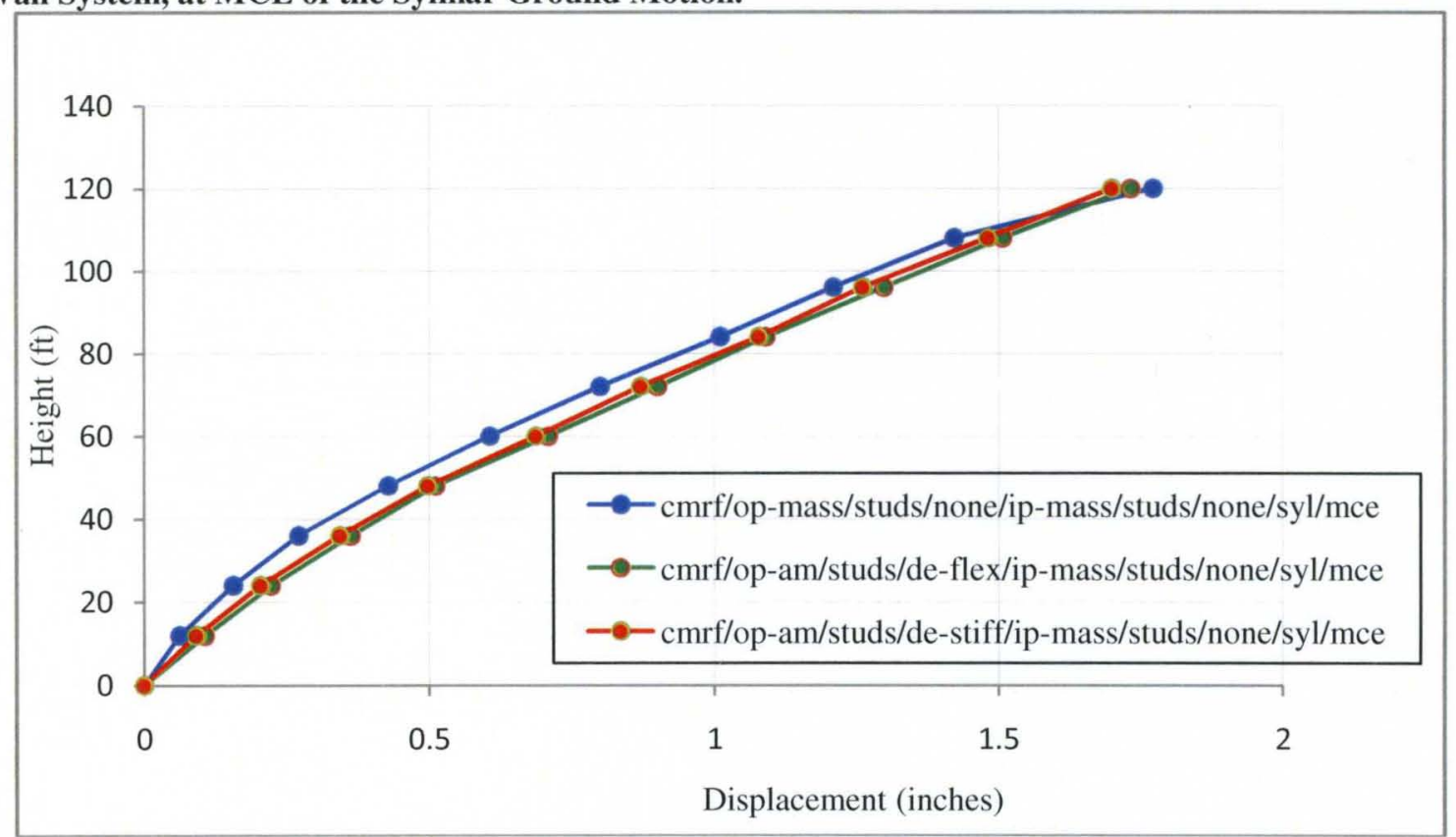

Figure B.12: Comparison of the Displacement Profiles Going Up the Height of the Concrete Moment Resisting Frame, With a Mass Representation and Analytical Model Representations With Stiff and Flexible Ties, of the Stud Backed Out of Plane Wall System, and a Mass Representation of the In Plane Wall System, at MCE of the Sylmar Ground Motion. 


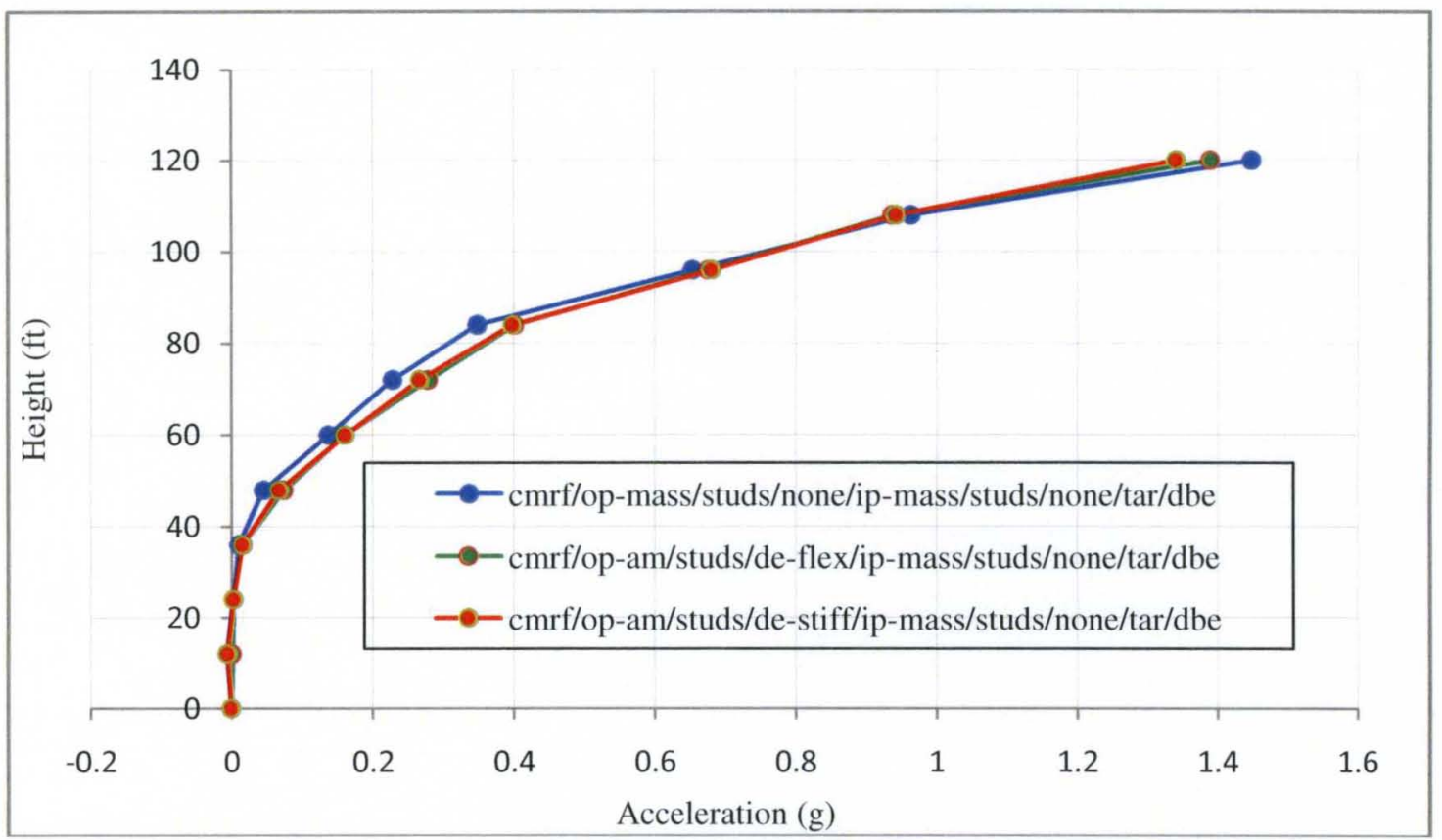

Figure B.13: Comparison of the Acceleration Profiles Going Up the Height of the Concrete Moment Resisting Frame, With a Mass Representation and Analytical Model Representations With Stiff and Flexible Ties, of the Stud Backed Out of Plane Wall System, and a Mass Representation of the In Plane Wall System, at DBE of the Tarzana Ground Motion.

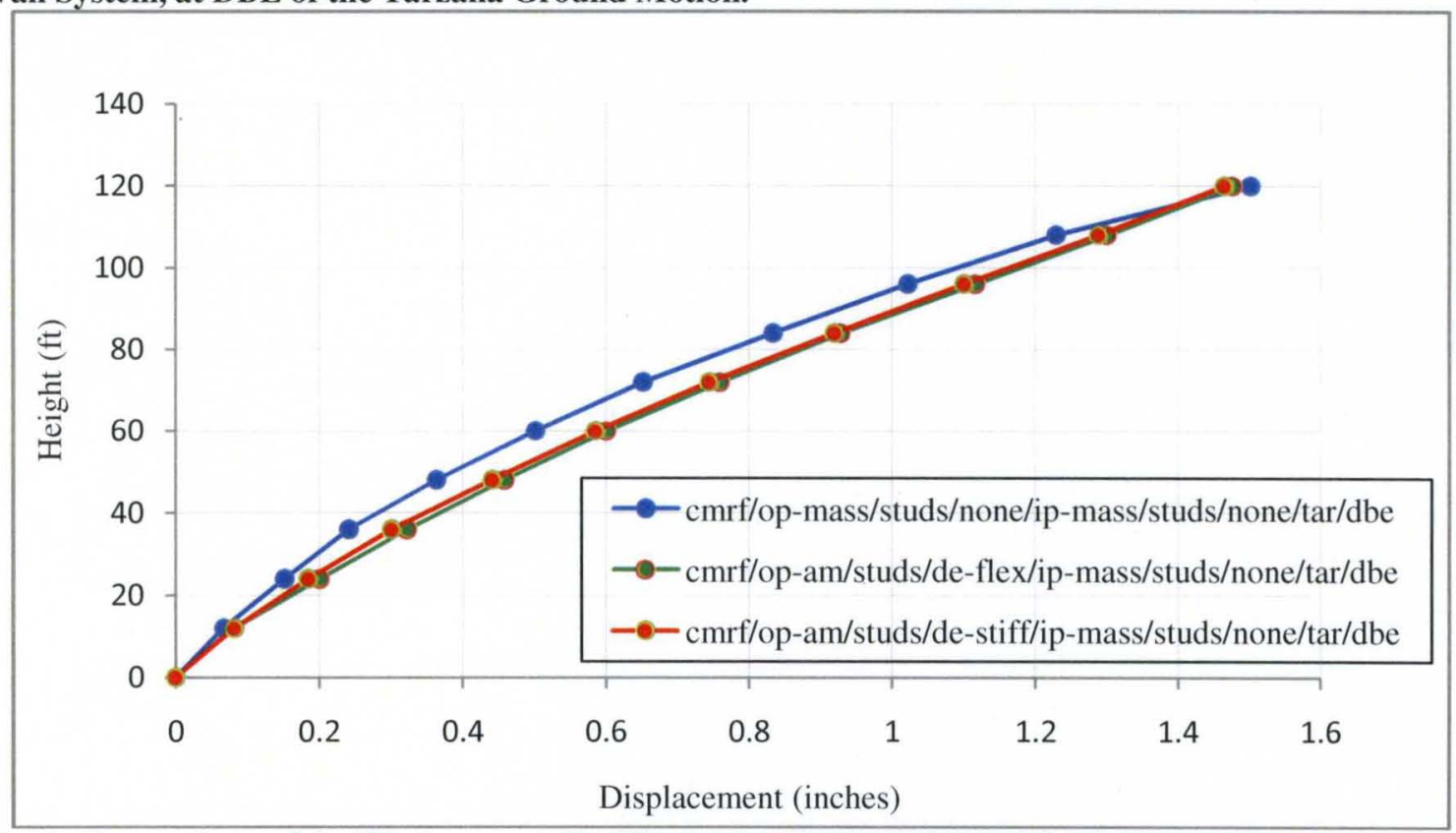

Figure B.14: Comparison of the Displacement Profiles Going Up the Height of the Concrete Moment Resisting Frame, With a Mass Representation and Analytical Model Representations With Stiff and Flexible Ties, of the Stud Backed Out of Plane Wall System, and a Mass Representation of the In Plane Wall System, at DBE of the Tarzana Ground Motion. 


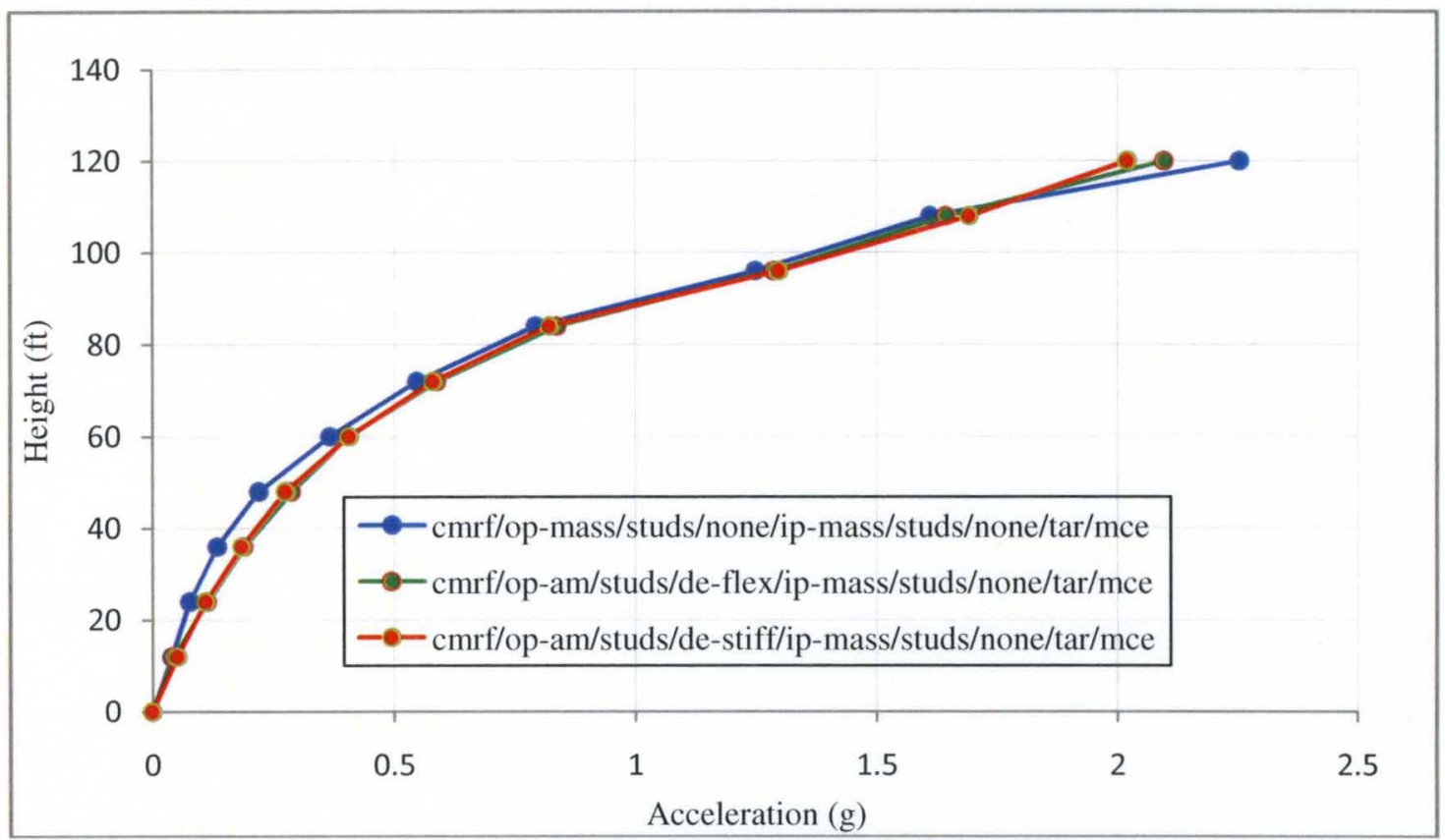

Figure B.15: Comparison of the Acceleration Profiles Going Up the Height of the Concrete Moment Resisting Frame, With a Mass Representation and Analytical Model Representations With Stiff and Flexible Ties, of the Stud Backed Out of Plane Wall System, and a Mass Representation of the In Plane Wall System, at MCE of the Tarzana Ground Motion.

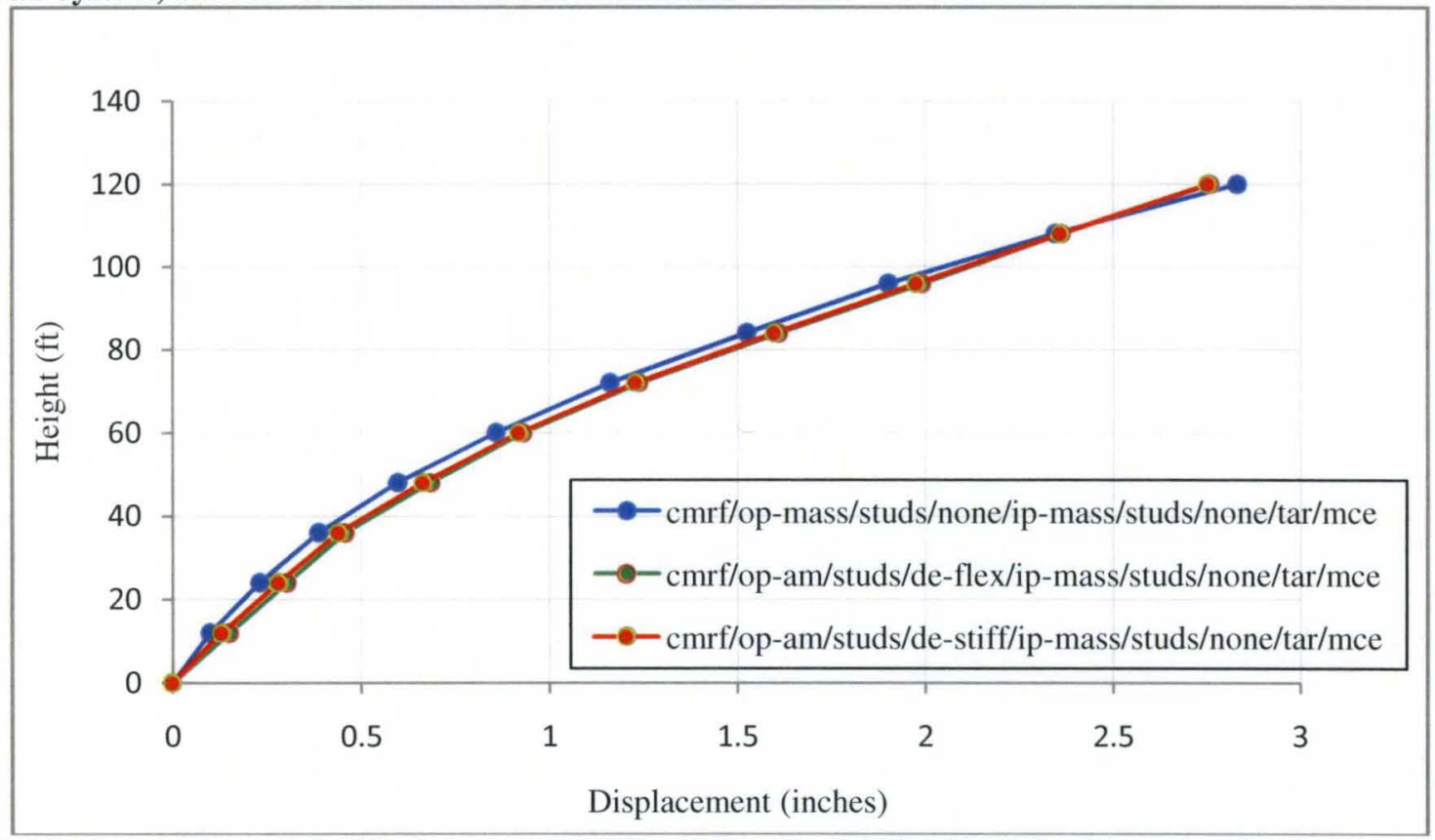

Figure B.16: Comparison of the Displacement Profiles Going Up the Height of the Concrete Moment Resisting Frame, With a Mass Representation and Analytical Model Representations With Stiff and Flexible Ties, of the Stud Backed Out of Plane Wall System, and a Mass Representation of the In Plane Wall System, at MCE of the Tarzana Ground Motion. 


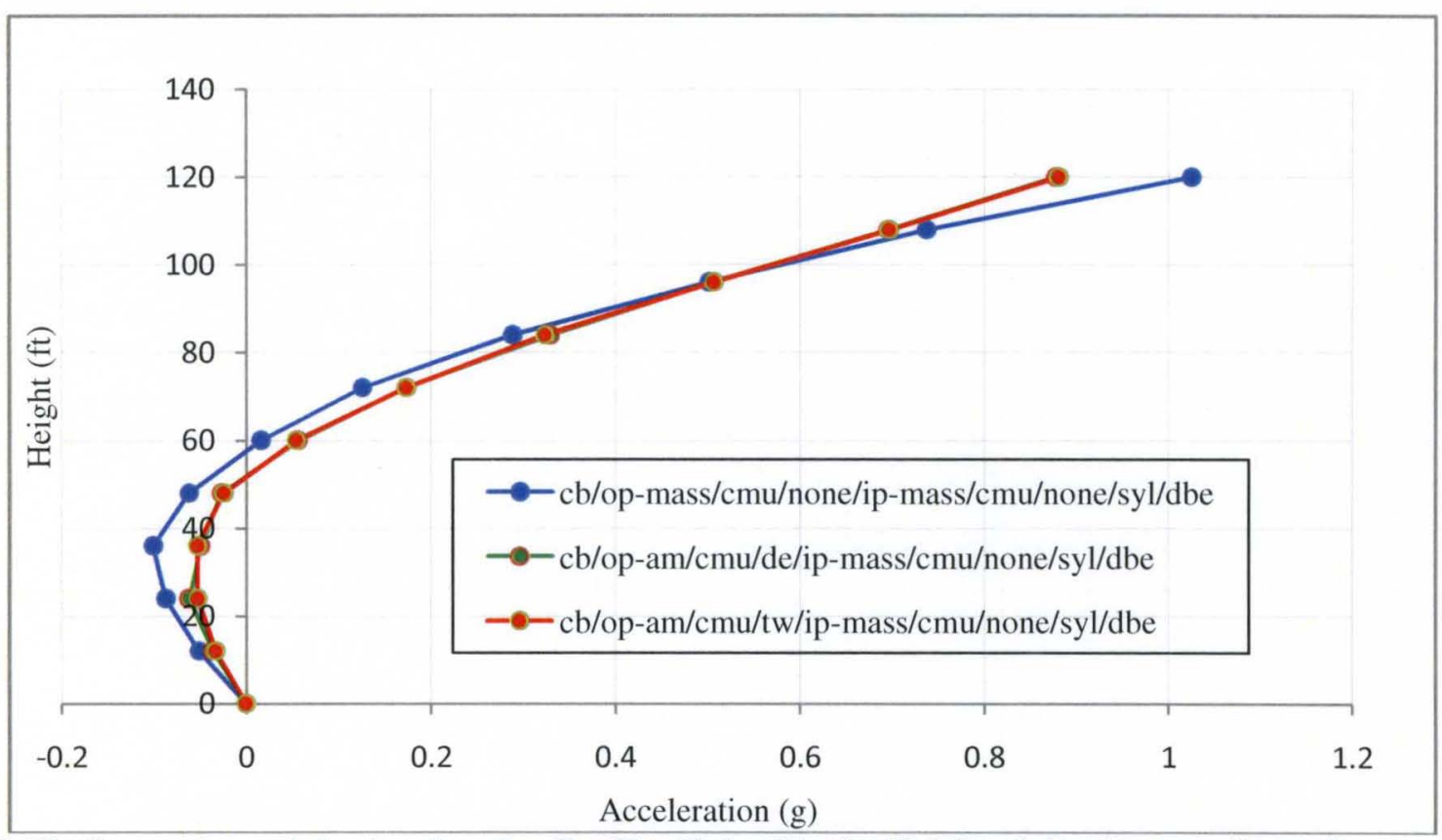

Figure B.17: Comparison of the Acceleration Profiles Going Up the Height of the Concrete Braced Frame, With a Mass Representation and Analytical Model Representations With Stiff and Flexible Ties, of the CMU Backed Out of Plane Wall System, and a Mass Representation of the In Plane Wall System, at DBE of the Sylmar Ground Motion.

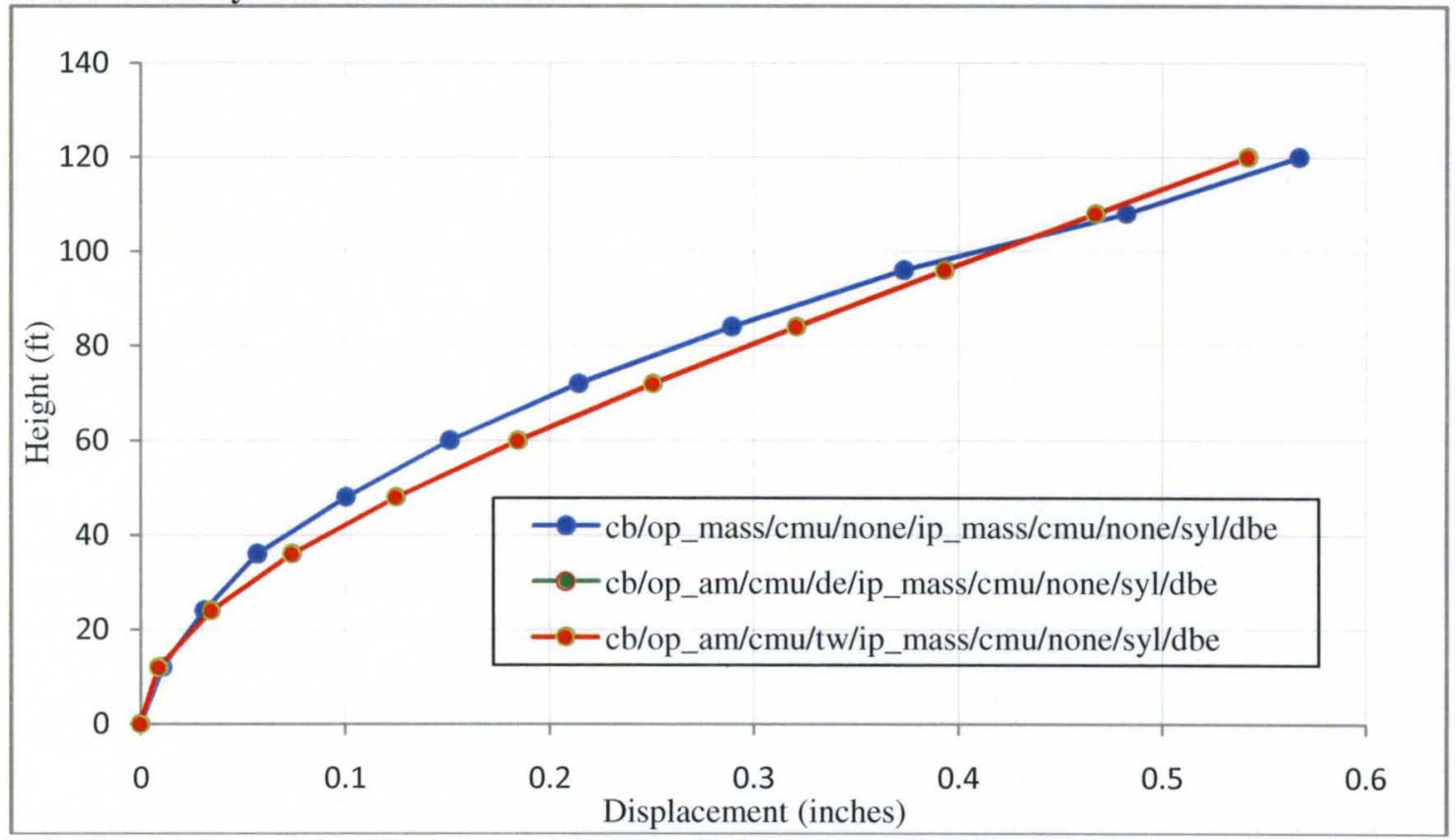

Figure B.18: Comparison of the Displacement Profiles Going Up the Height of the Concrete Braced Frame, With a Mass Representation and Analytical Model Representations With Stiff and Flexible Ties, of the CMU Backed Out of Plane Wall System, and a Mass Representation of the In Plane Wall System, at DBE of the Sylmar Ground Motion. 


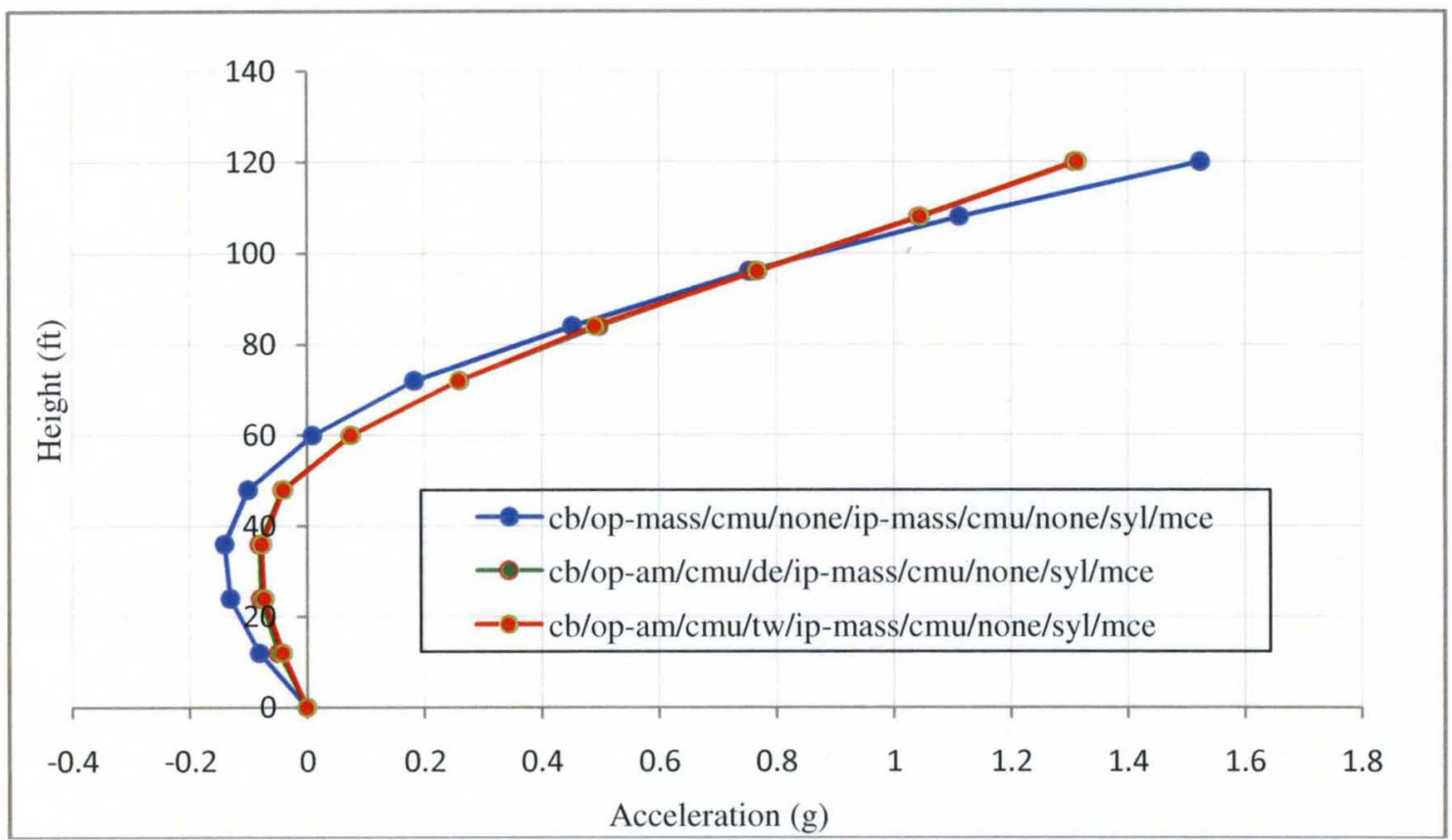

Figure B.19: Comparison of the Acceleration Profiles Going Up the Height of the Concrete Braced Frame, With a Mass Representation and Analytical Model Representations With Stiff and Flexible Ties, of the CMU Backed Out of Plane Wall System, and a Mass Representation of the In Plane Wall System, at MCE of the Sylmar Ground Motion.

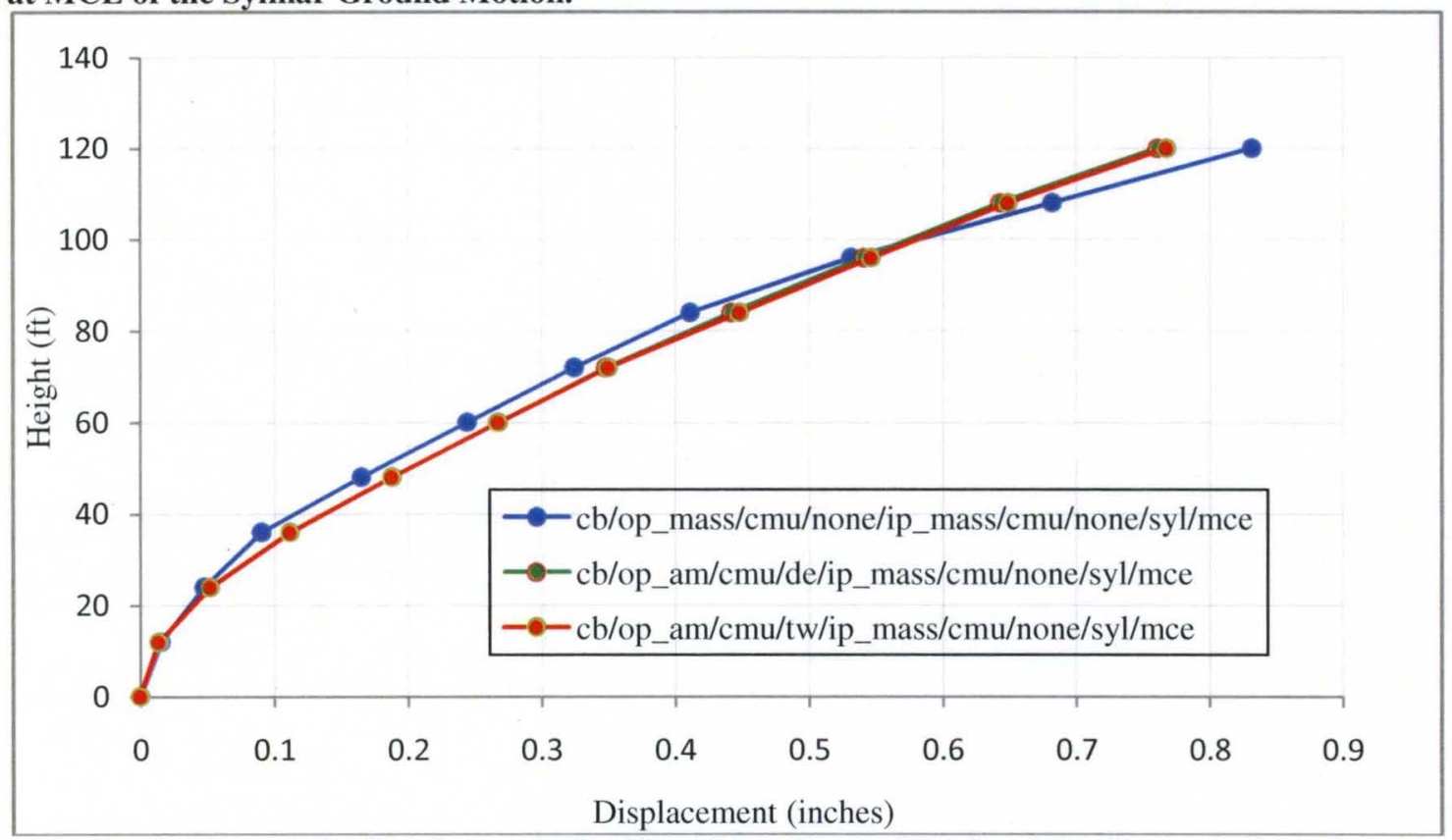

Figure B.20: Comparison of the Displacement Profiles Going Up the Height of the Concrete Braced Frame, With a Mass Representation and Analytical Model Representations With Stiff and Flexible Ties, of the CMU Backed Out of Plane Wall System, and a Mass Representation of the In Plane Wall System, at MCE of the Sylmar Ground Motion. 


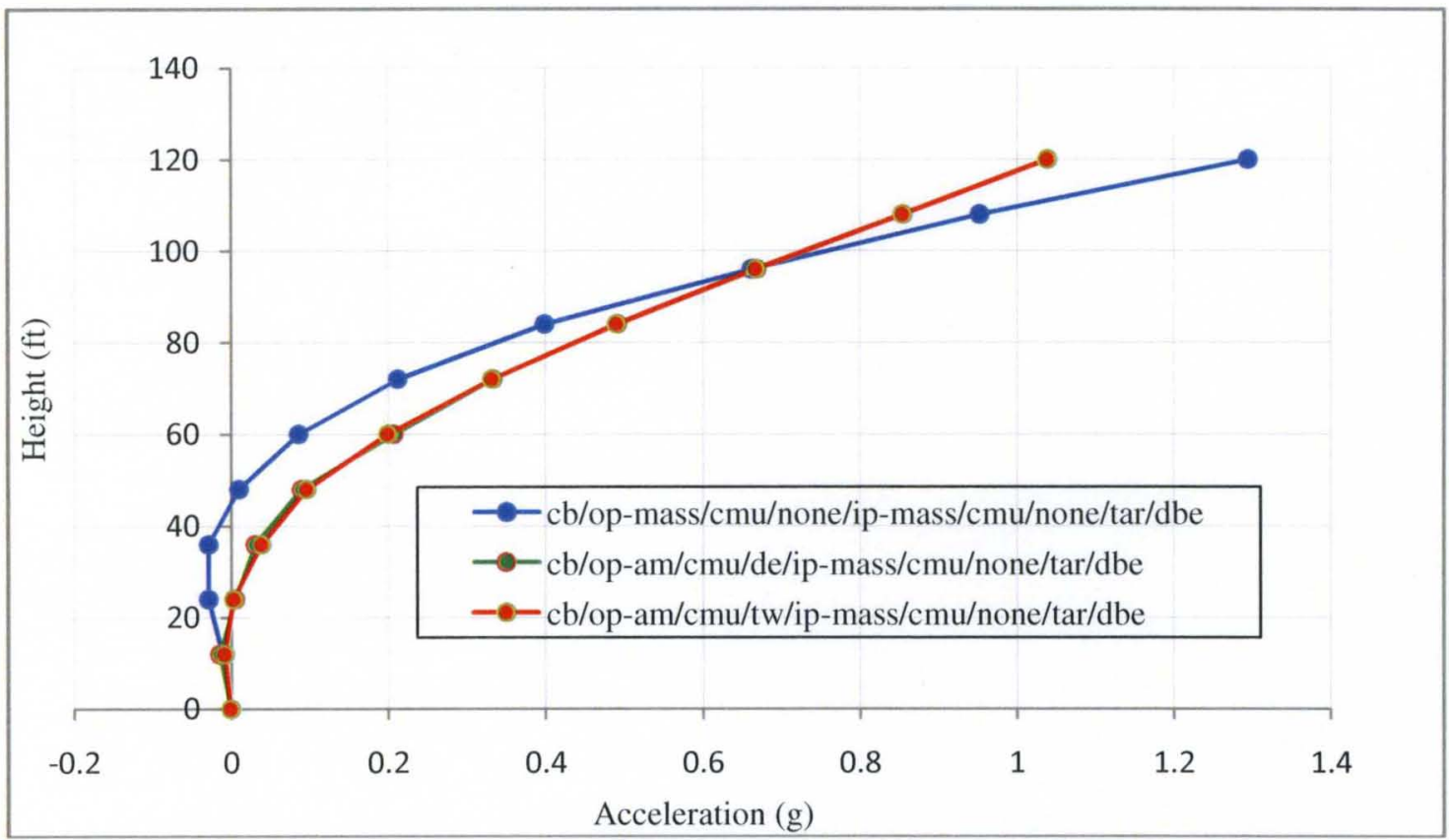

Figure B.21: Comparison of the Acceleration Profiles Going Up the Height of the Concrete Braced Frame, With a Mass Representation and Analytical Model Representations With Stiff and Flexible Ties, of the CMU Backed Out of Plane Wall System, and a Mass Representation of the In Plane Wall System, at DBE of the Tarzana Ground Motion.

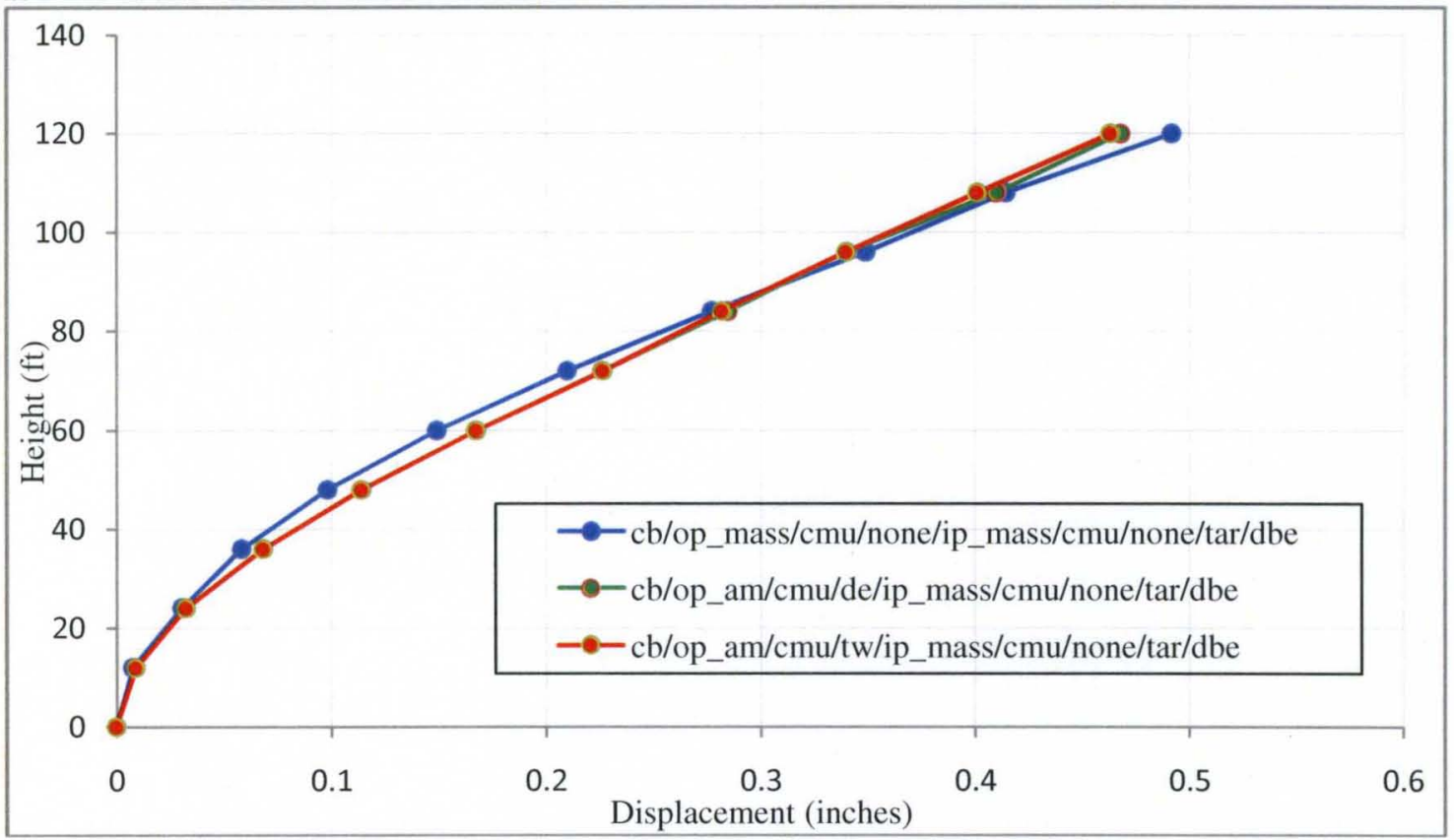

Figure B.22: Comparison of the Displacement Profiles Going Up the Height of the Concrete Braced Frame, With a Mass Representation and Analytical Model Representations With Stiff and Flexible Ties, of the CMU Backed Out of Plane Wall System, and a Mass Representation of the In Plane Wall System, at DBE of the Tarzana Ground Motion. 


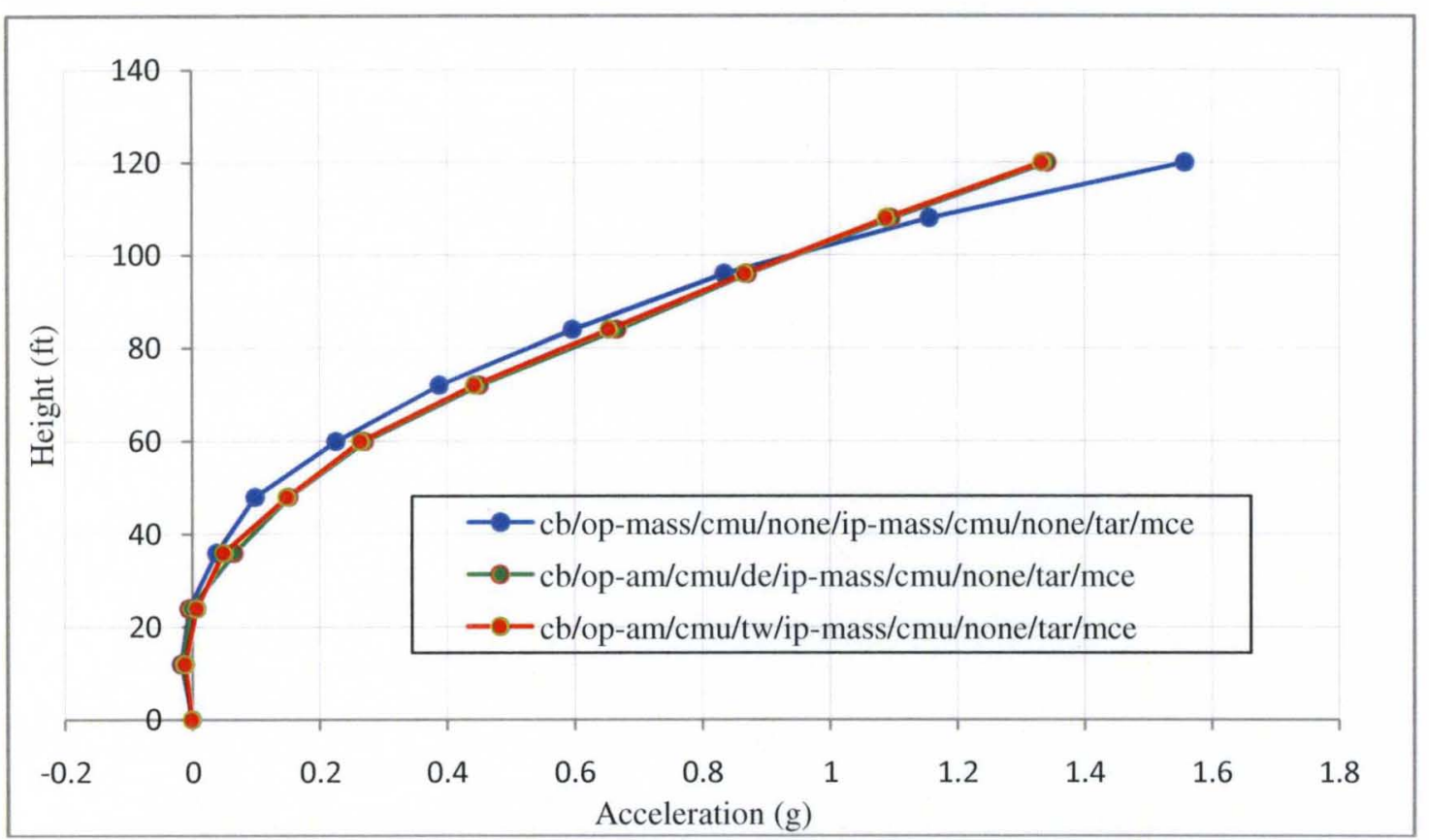

Figure B.23: Comparison of the Acceleration Profiles Going Up the Height of the Concrete Braced Frame, With a Mass Representation and Analytical Model Representations With Stiff and Flexible Ties, of the CMU Backed Out of Plane Wall System, and a Mass Representation of the In Plane Wall System, at MCE of the Tarzana Ground Motion.

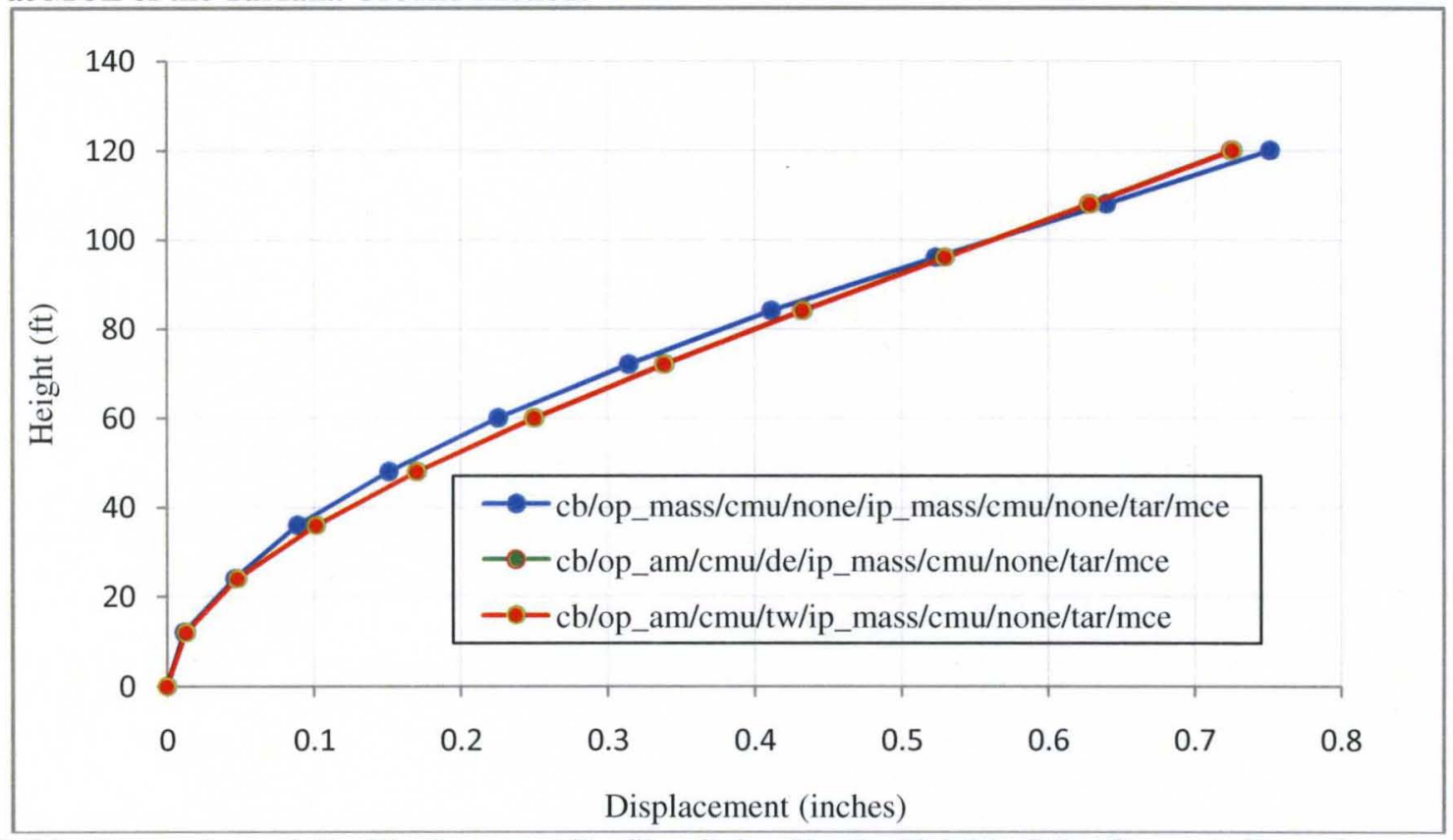

Figure B.24: Comparison of the Displacement Profiles Going Up the Height of the Concrete Braced Frame, With a Mass Representation and Analytical Model Representations With Stiff and Flexible Ties, of the CMU Backed Out of Plane Wall System, and a Mass Representation of the In Plane Wall System, at MCE of the Tarzana Ground Motion. 


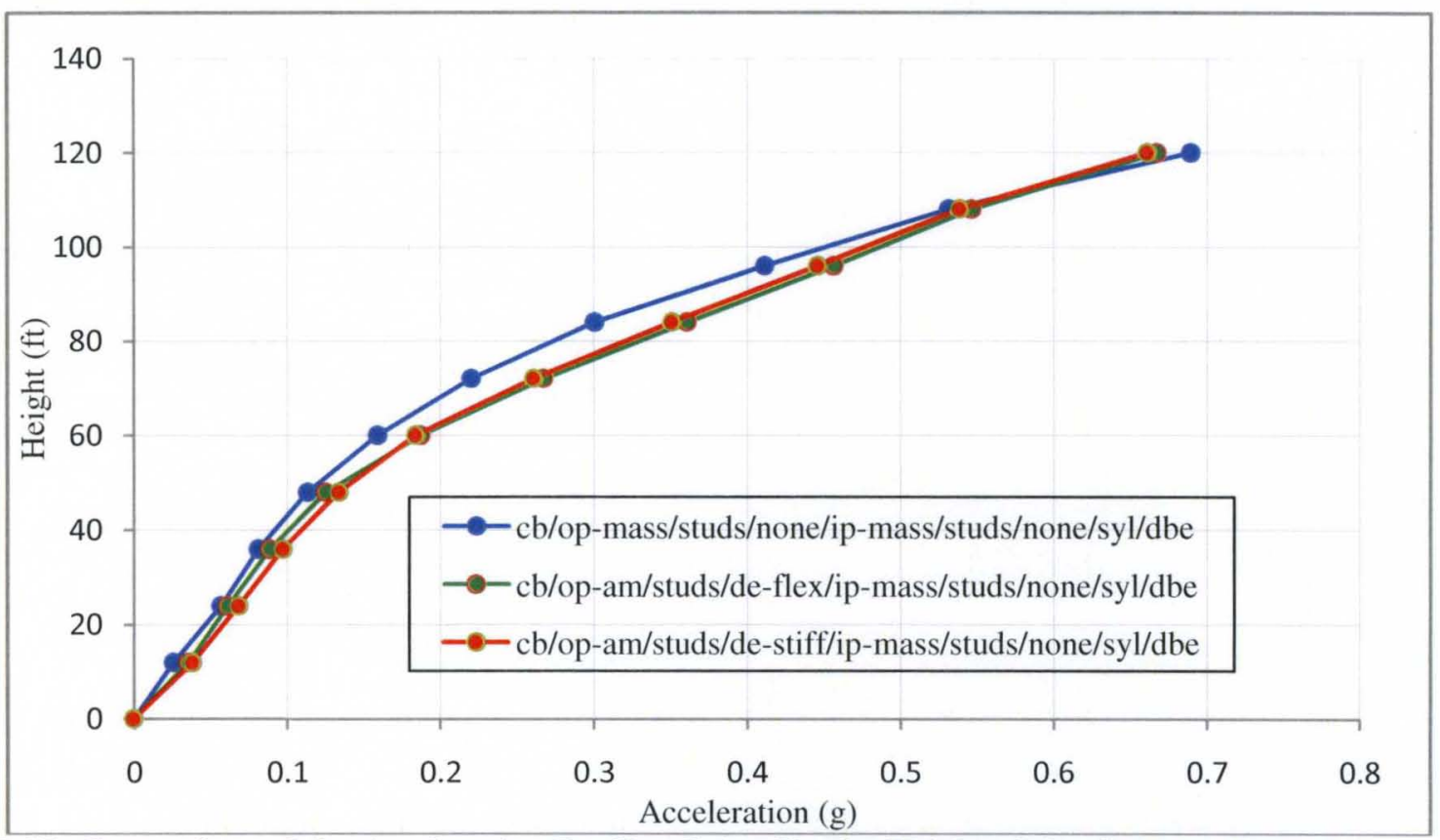

Figure B.25: Comparison of the Acceleration Profiles Going Up the Height of the Concrete Braced Frame, With a Mass Representation and Analytical Model Representations With Stiff and Flexible Ties, of the Stud Backed Out of Plane Wall System, and a Mass Representation of the In Plane Wall System, at DBE of the Sylmar Ground Motion.

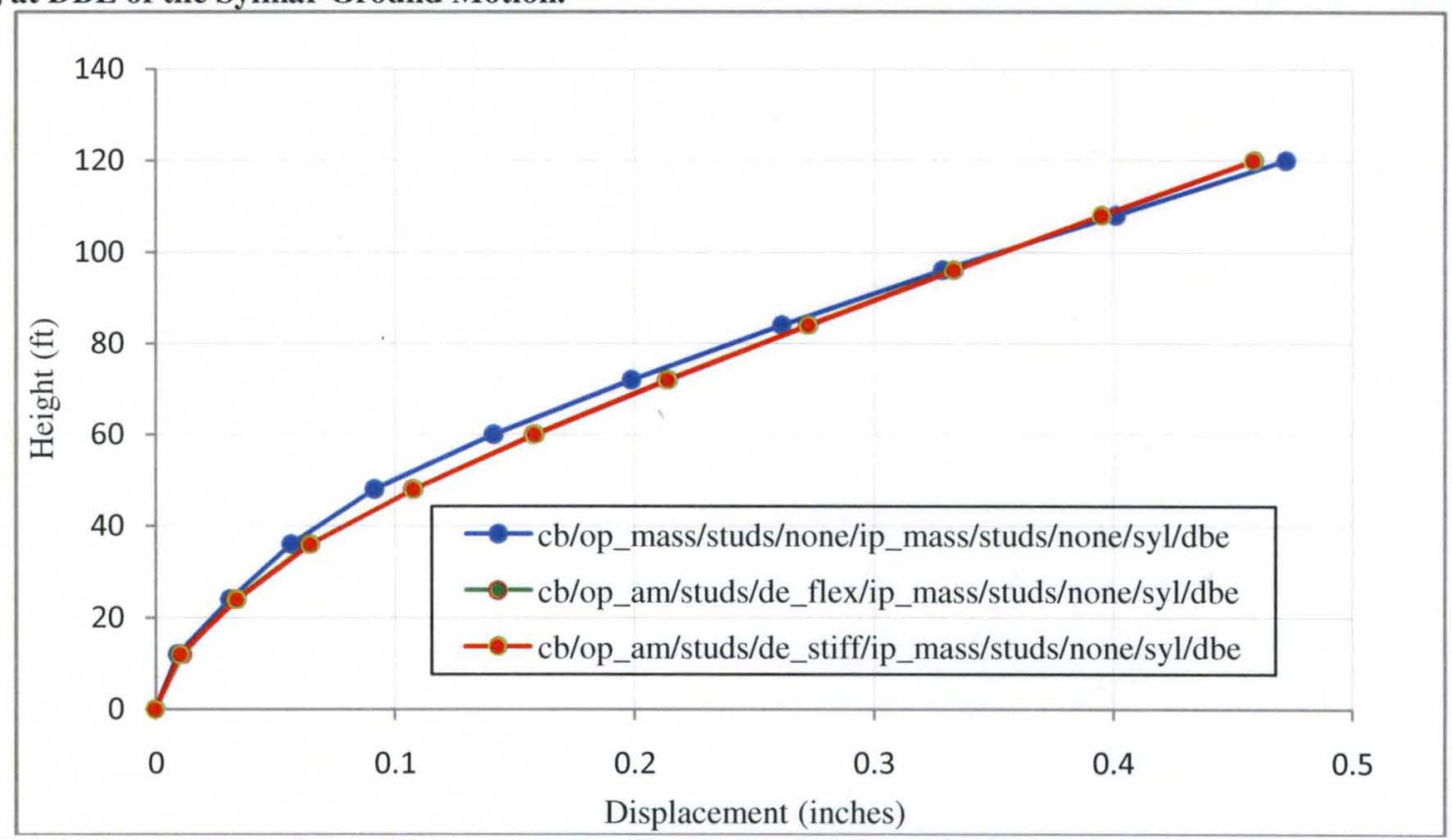

Figure B.26: Comparison of the Displacement Profiles Going Up the Height of the Concrete Braced Frame, With a Mass Representation and Analytical Model Representations With Stiff and Flexible Ties, of the Stud Backed Out of Plane Wall System, and a Mass Representation of the In Plane Wall System, at DBE of the Sylmar Ground Motion. 


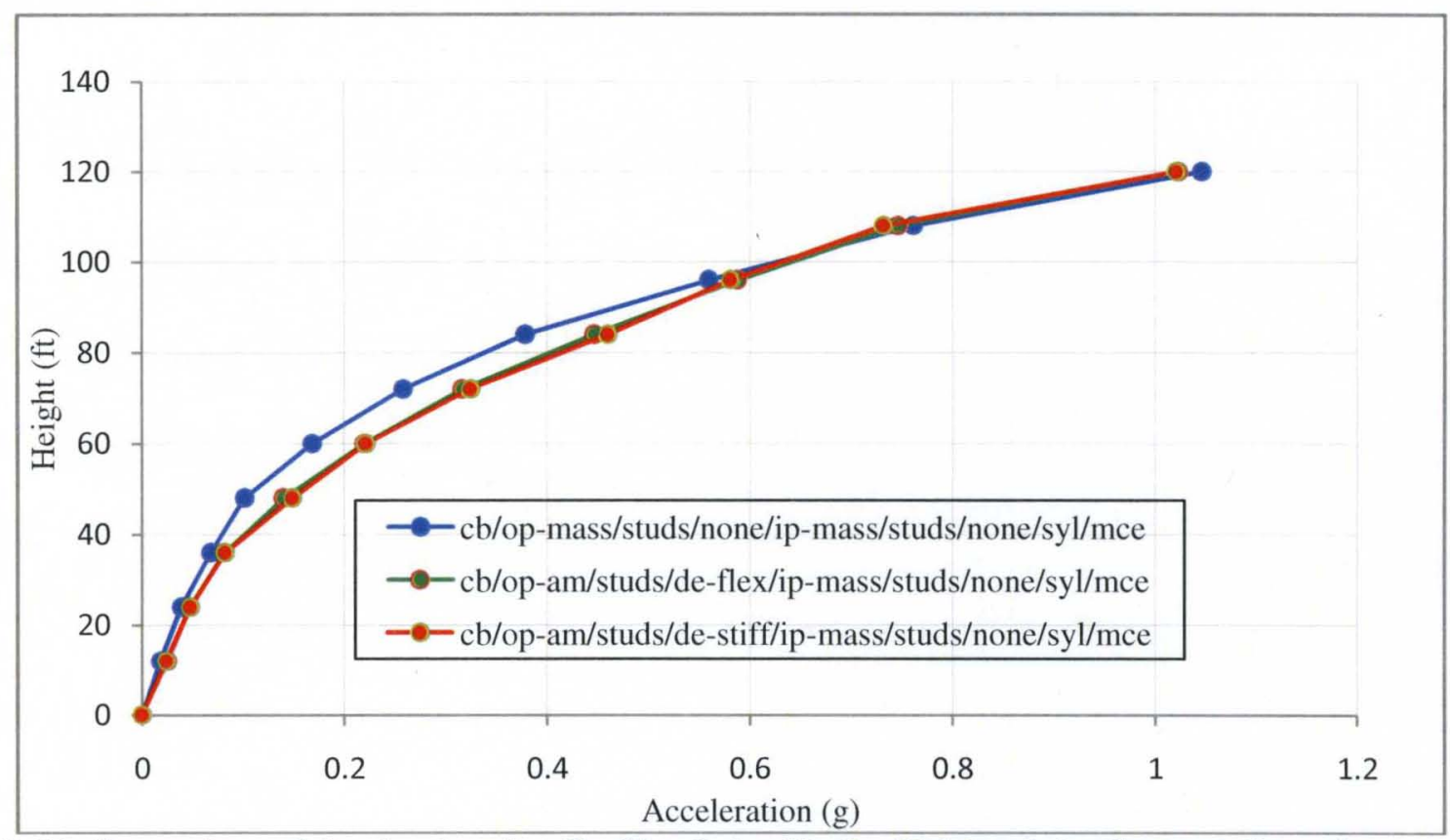

Figure B.27: Comparison of the Acceleration Profiles Going Up the Height of the Concrete Braced Frame, With a Mass Representation and Analytical Model Representations With Stiff and Flexible Ties, of the Stud Backed Out of Plane Wall System, and a Mass Representation of the In Plane Wall System, at MCE of the Sylmar Ground Motion.

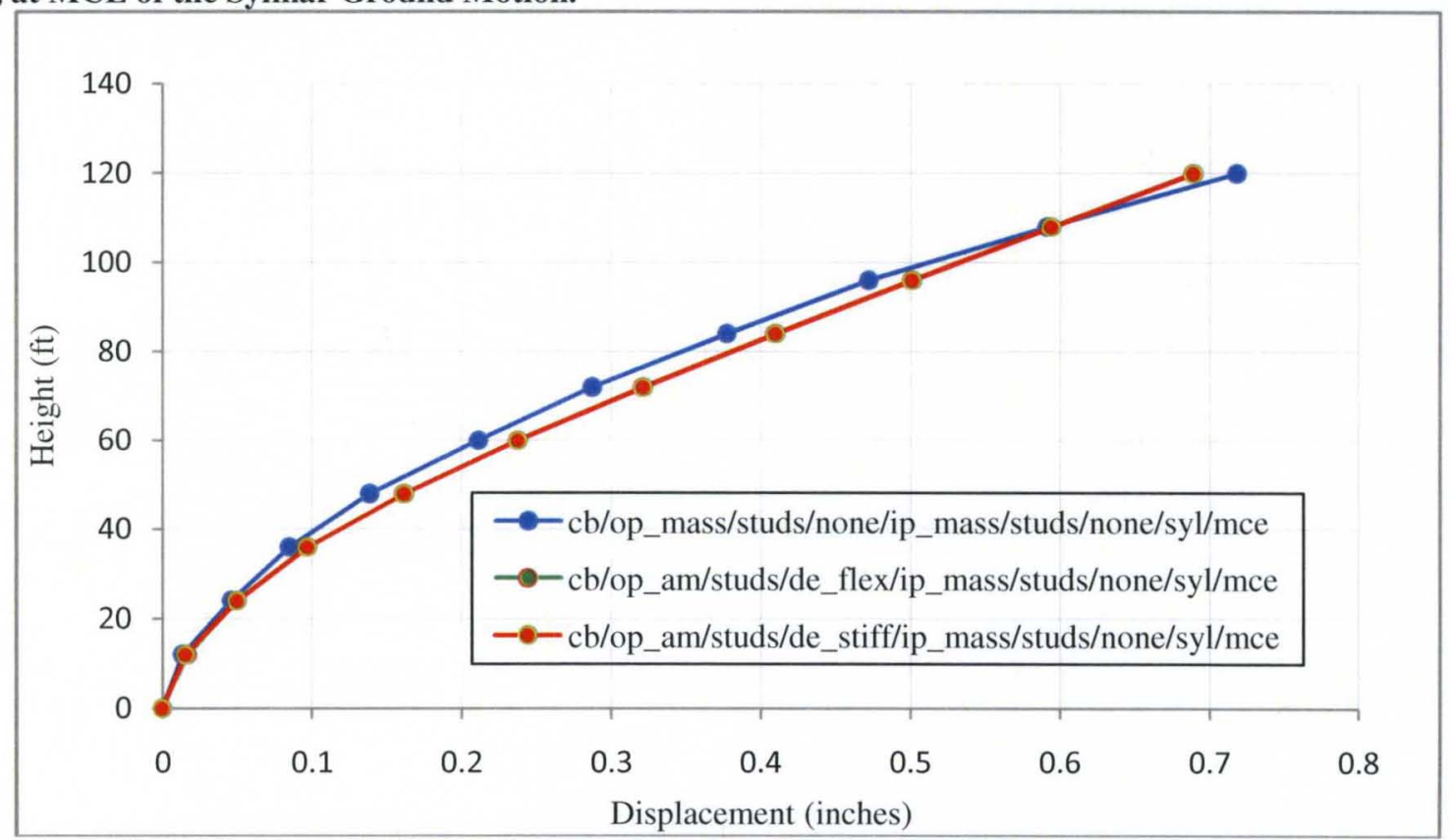

Figure B.28: Comparison of the Displacement Profiles Going Up the Height of the Concrete Braced Frame, With a Mass Representation and Analytical Model Representations With Stiff and Flexible Ties, of the Stud Backed Out of Plane Wall System, and a Mass Representation of the In Plane Wall System, at MCE of the Sylmar Ground Motion. 


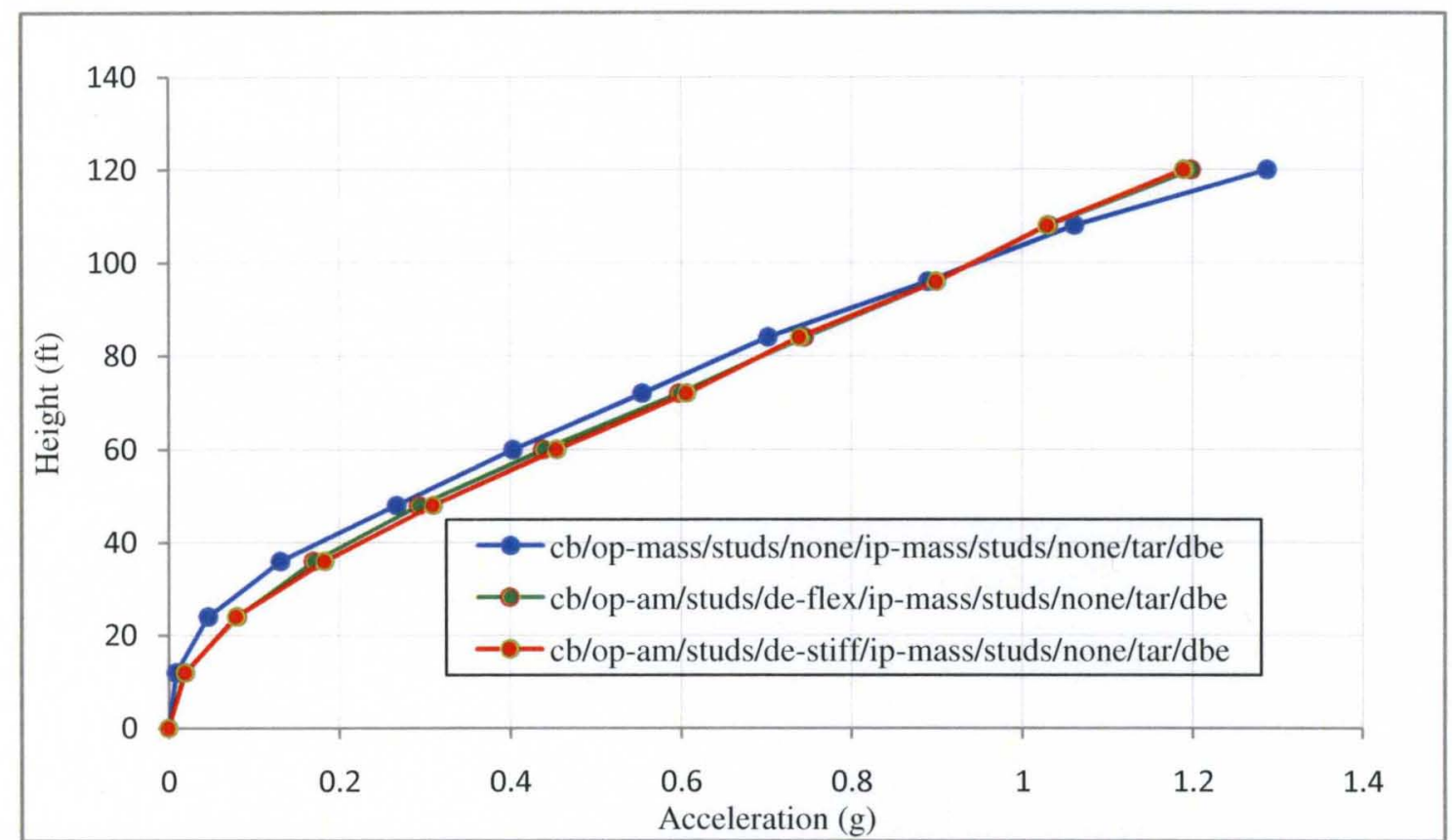

Figure B.29: Comparison of the Acceleration Profiles Going Up the Height of the Concrete Braced Frame, With a Mass Representation and Analytical Model Representations With Stiff and Flexible Ties, of the Stud Backed Out of Plane Wall System, and a Mass Representation of the In Plane Wall System, at DBE of the Tarzana Ground Motion.

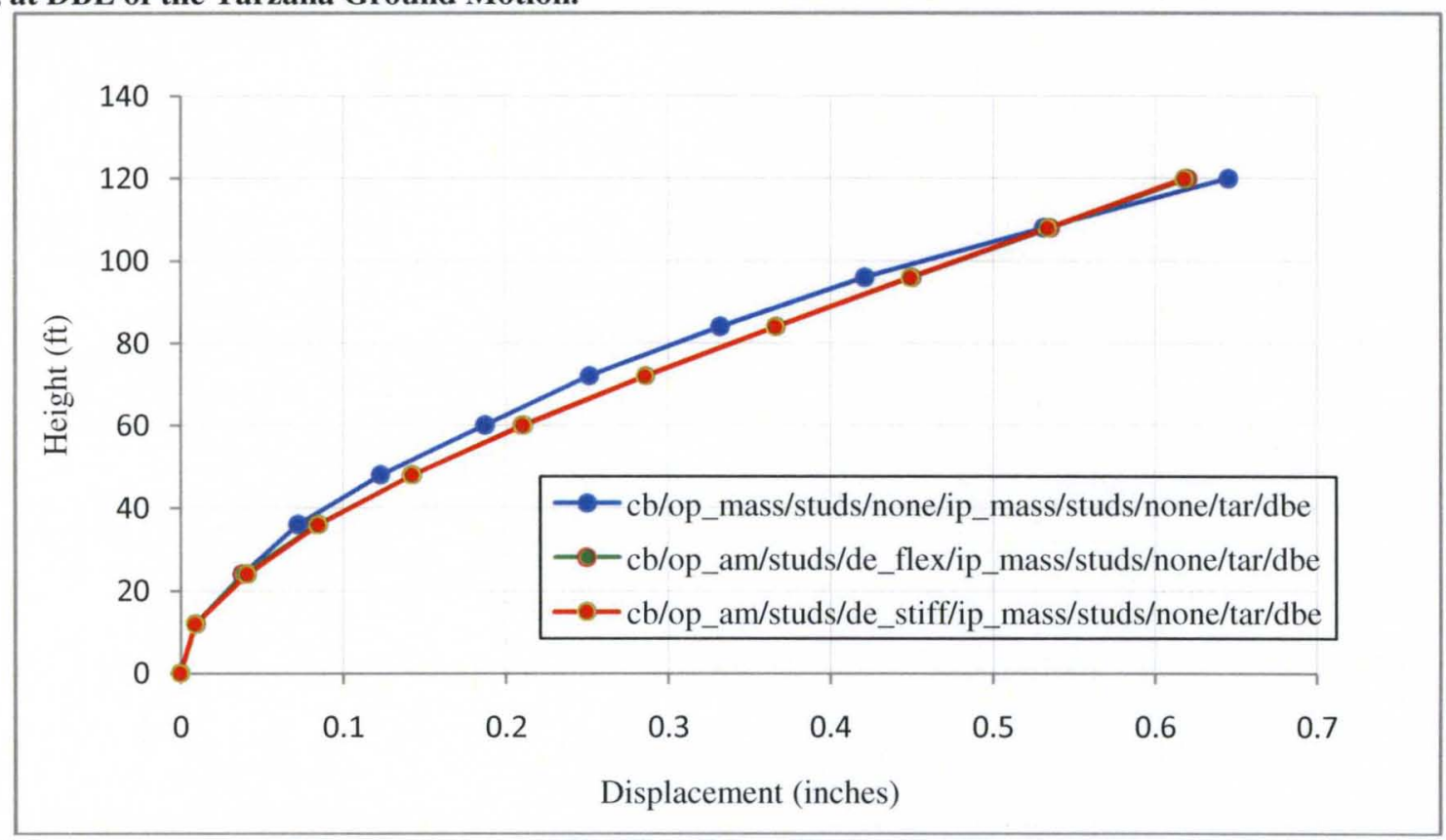

Figure B.30: Comparison of the Displacement Profiles Going Up the Height of the Concrete Braced Frame, With a Mass Representation and Analytical Model Representations With Stiff and Flexible Ties, of the Stud Backed Out of Plane Wall System, and a Mass Representation of the In Plane Wall System, at DBE of the Tarzana Ground Motion. 


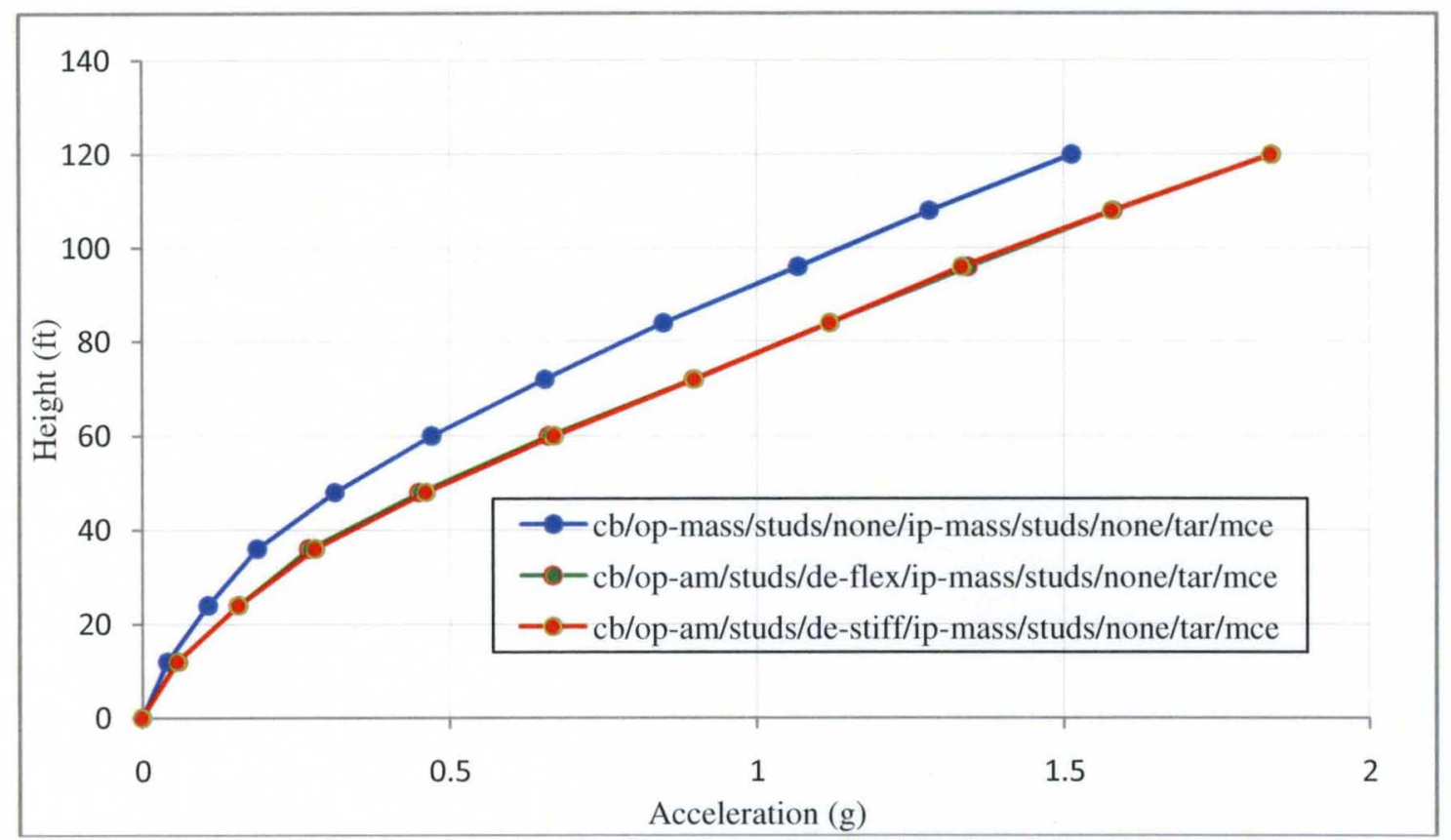

Figure B.31: Comparison of the Acceleration Profiles Going Up the Height of the Concrete Braced Frame, With a Mass Representation and Analytical Model Representations With Stiff and Flexible Ties, of the Stud Backed Out of Plane Wall System, and a Mass Representation of the In Plane Wall System, at MCE of the Tarzana Ground Motion.

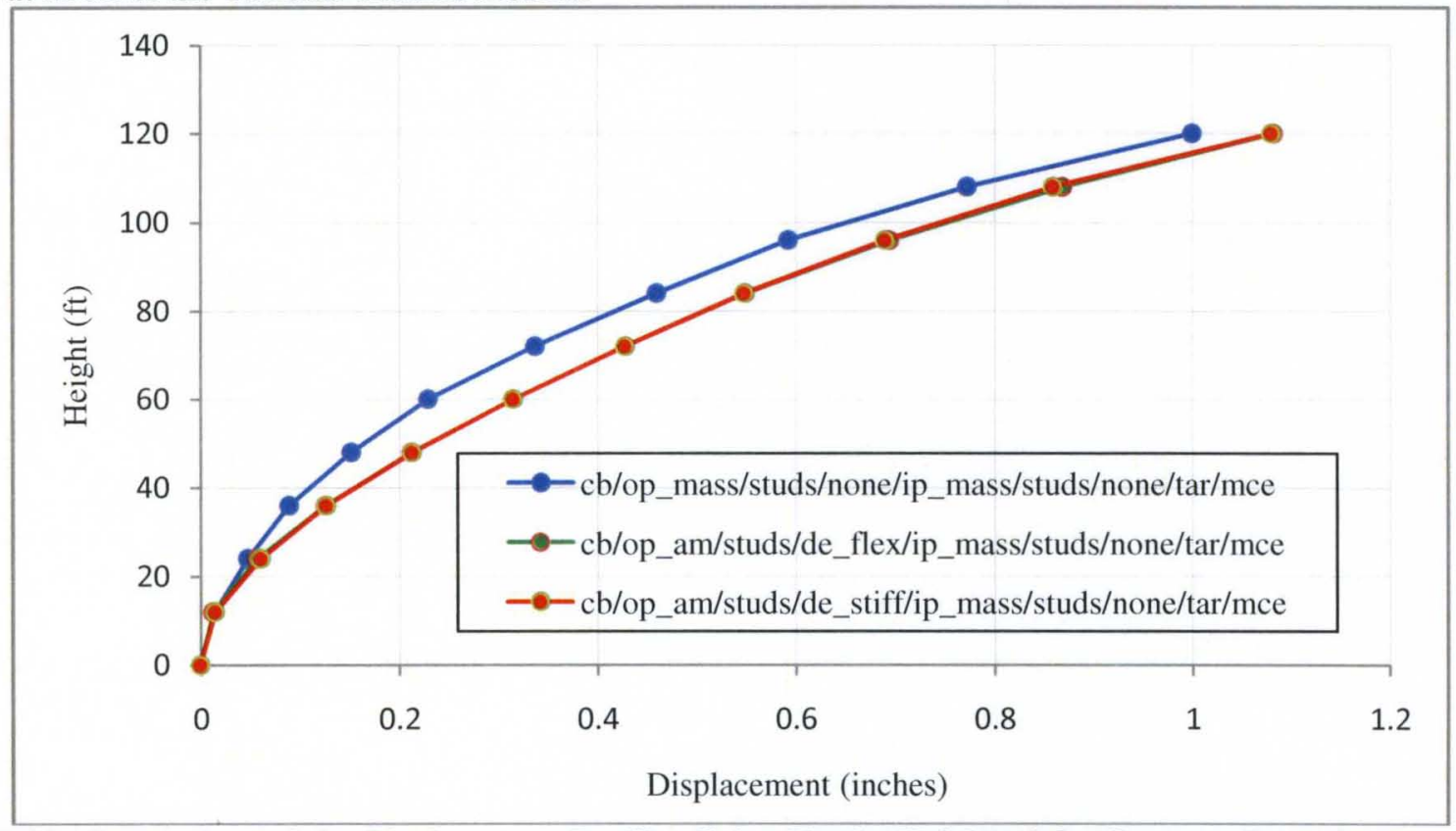

Figure B.32: Comparison of the Displacement Profiles Going Up the Height of the Concrete Braced Frame, With a Mass Representation and Analytical Model Representations With Stiff and Flexible Ties, of the Stud Backed Out of Plane Wall System, and a Mass Representation of the In Plane Wall System, at MCE of the Tarzana Ground Motion. 


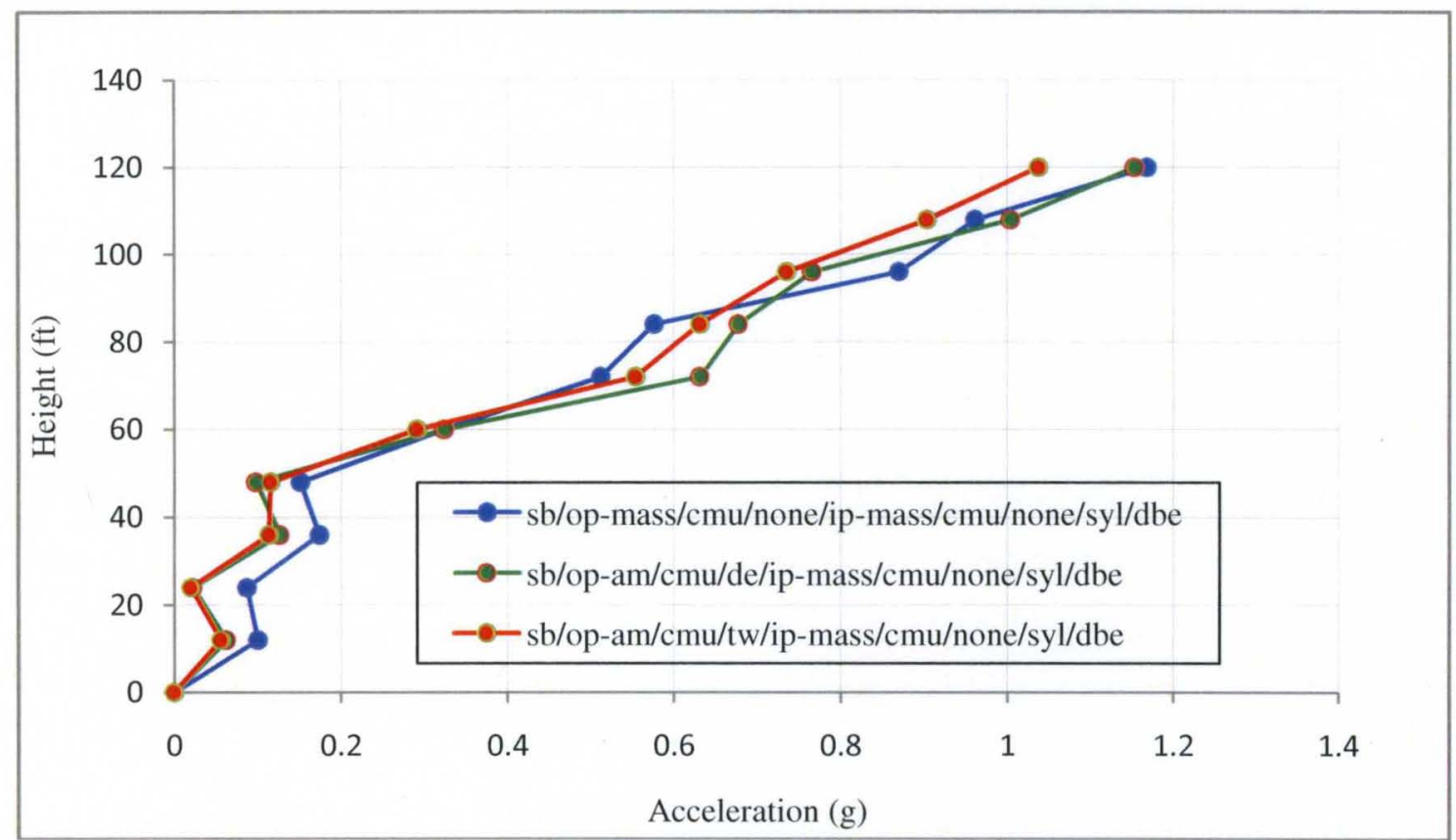

Figure B.33: Comparison of the Acceleration Profiles Going Up the Height of the SteelBraced Frame, With a Mass Representation and Analytical Model Representations With Stiff and Flexible Ties, of the CMU Backed Out of Plane Wall System, and a Mass Representation of the In Plane Wall System, at DBE of the Sylmar Ground Motion.

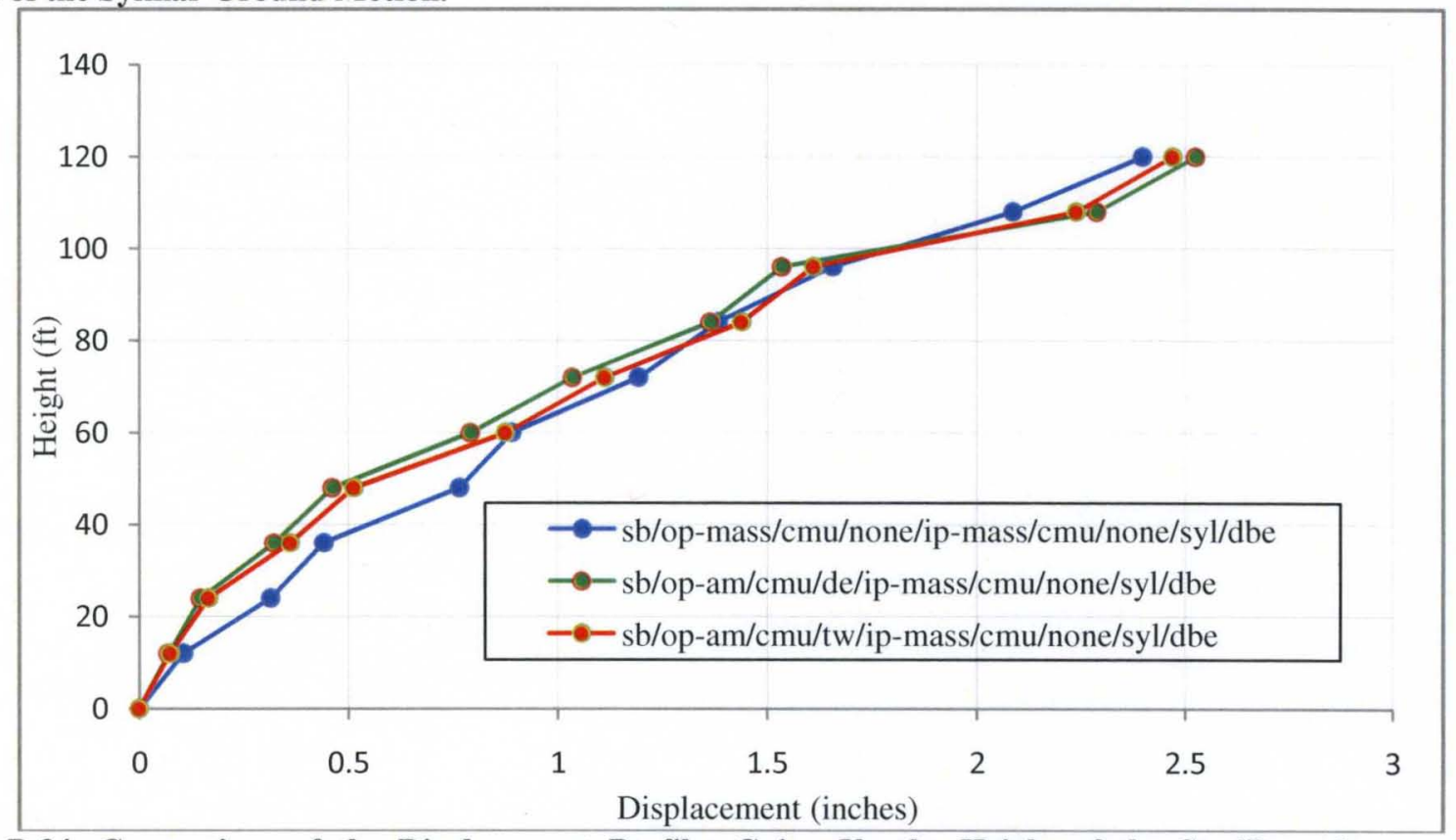

Figure B.34: Comparison of the Displacement Profiles Going Up the Height of the SteelBraced Frame, With a Mass Representation and Analytical Model Representations With Stiff and Flexible Ties, of the CMU Backed Out of Plane Wall System, and a Mass Representation of the In Plane Wall System, at DBE of the Sylmar Ground Motion. 


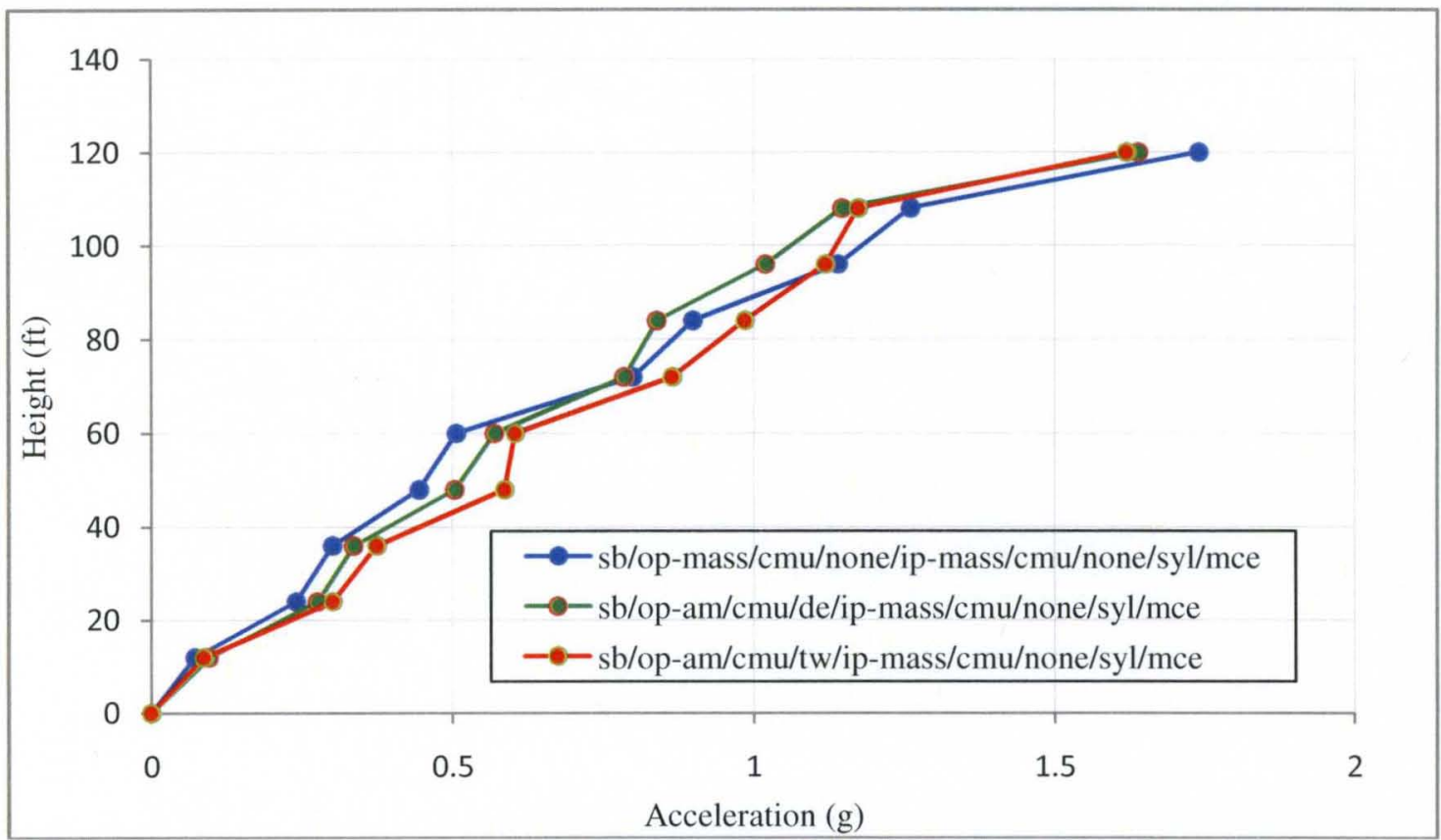

Figure B.35: Comparison of the Acceleration Profiles Going Up the Height of the SteelBraced Frame, With a Mass Representation and Analytical Model Representations With Stiff and Flexible Ties, of the CMU Backed Out of Plane Wall System, and a Mass Representation of the In Plane Wall System, at MCE of the Sylmar Ground Motion.

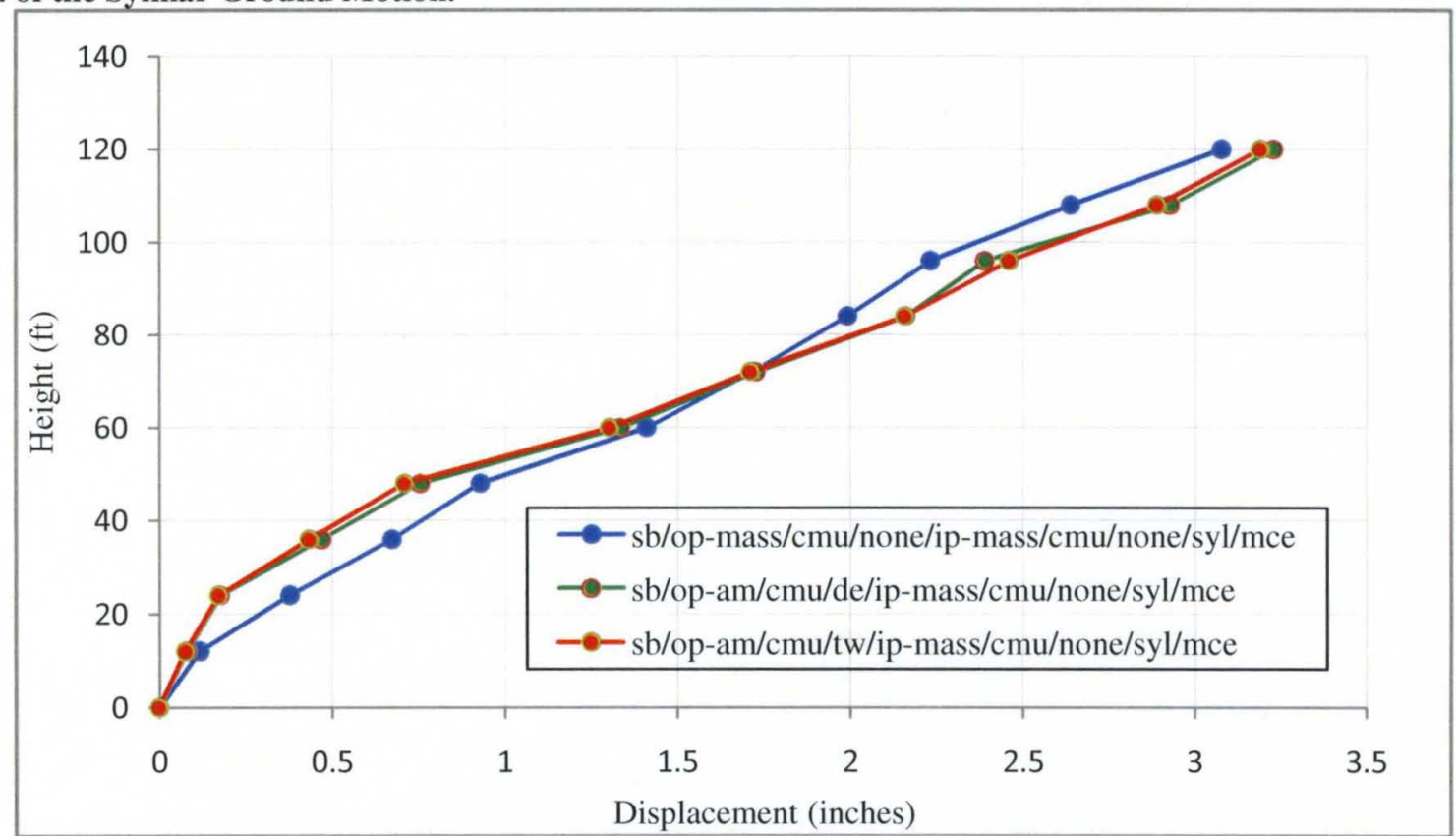

Figure B.36: Comparison of the Displacement Profiles Going Up the Height of the SteelBraced Frame, With a Mass Representation and Analytical Model Representations With Stiff and Flexible Ties, of the CMU Backed Out of Plane Wall System, and a Mass Representation of the In Plane Wall System, at MCE of the Sylmar Ground Motion. 


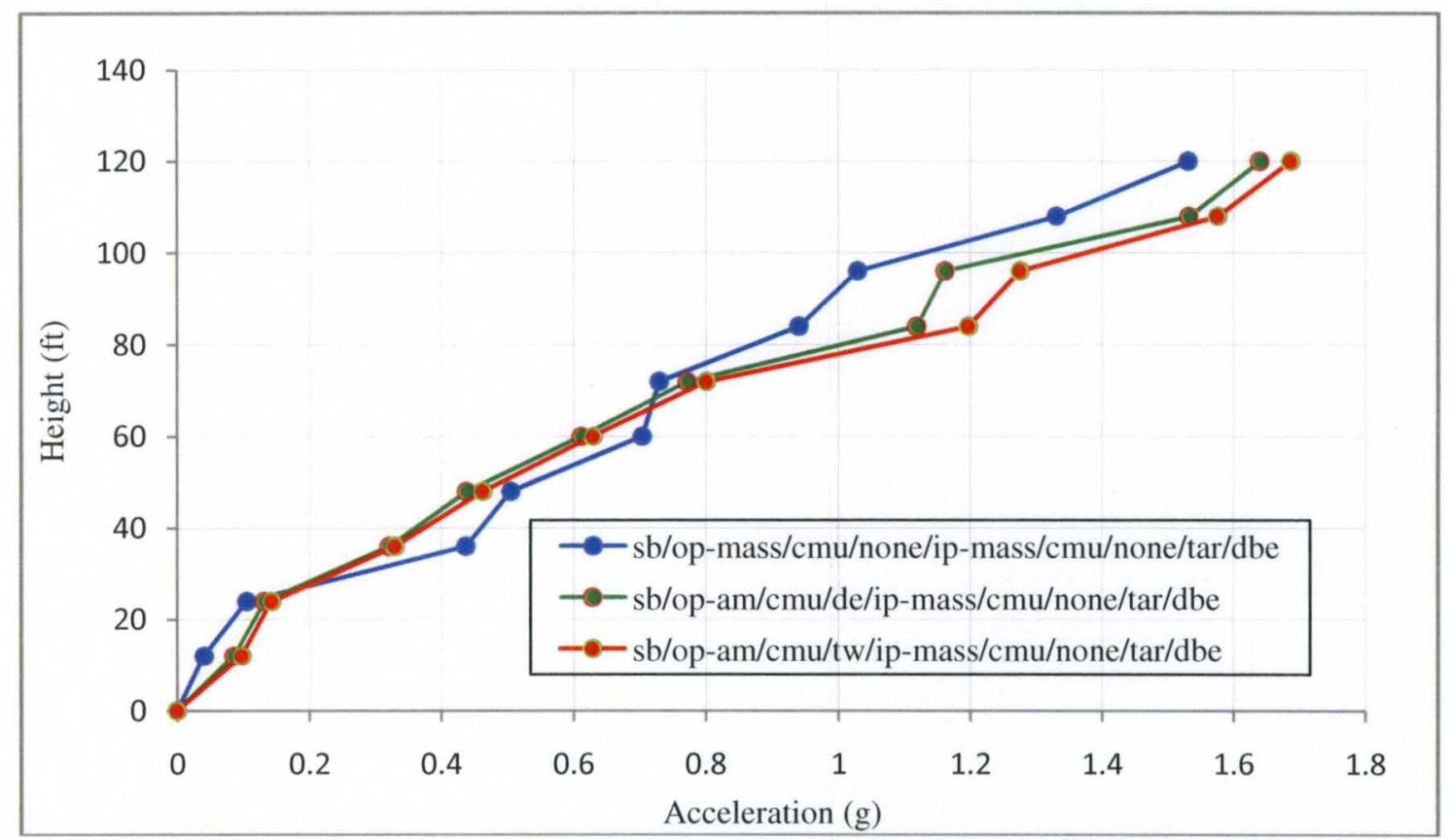

Figure B.37: Comparison of the Acceleration Profiles Going Up the Height of the SteelBraced Frame, With a Mass Representation and Analytical Model Representations With Stiff and Flexible Ties, of the CMU Backed Out of Plane Wall System, and a Mass Representation of the In Plane Wall System, at DBE of the Tarzana Ground Motion.

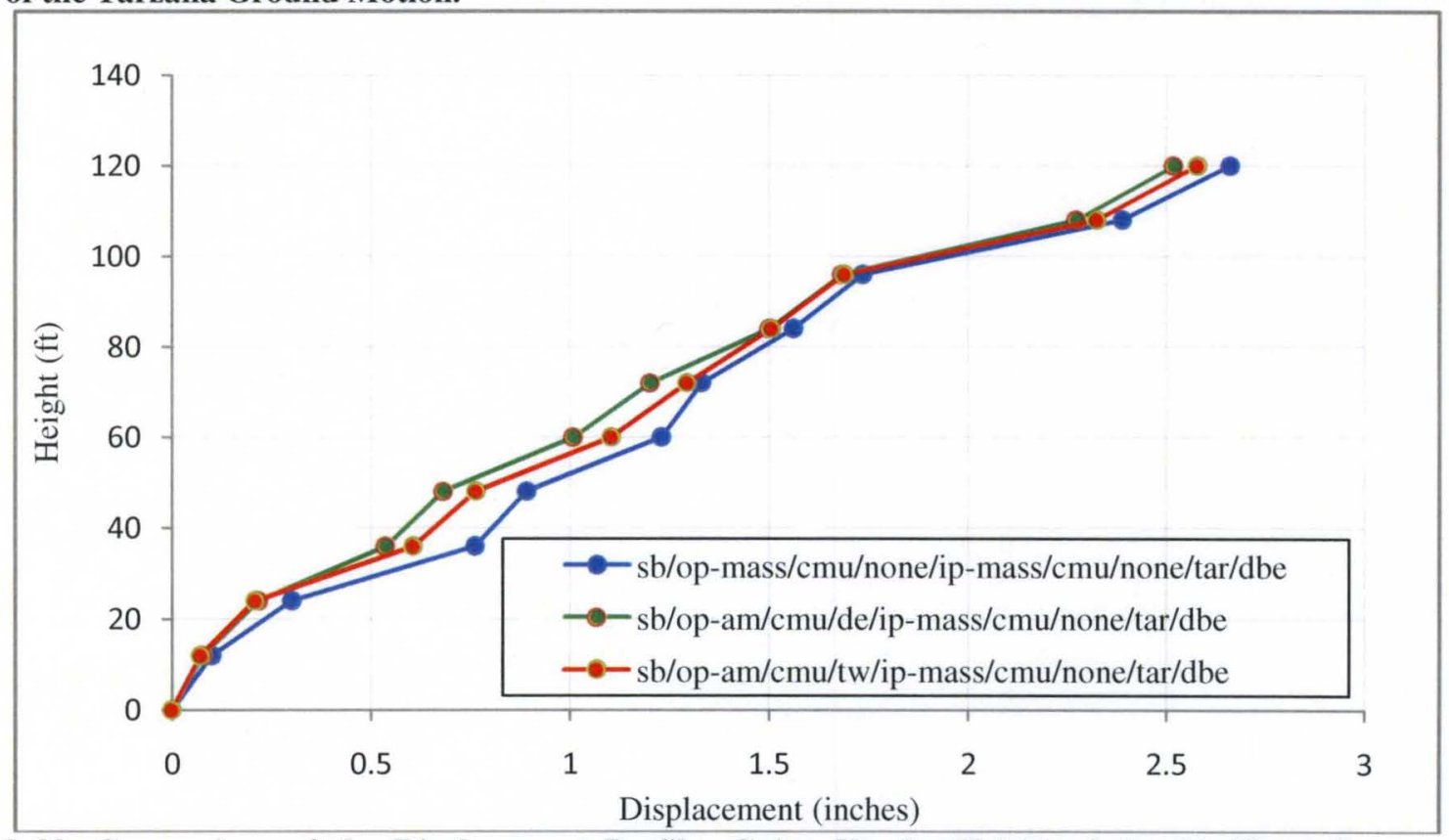

Figure B.38: Comparison of the Displacement Profiles Going Up the Height of the SteelBraced Frame, With a Mass Representation and Analytical Model Representations With Stiff and Flexible Ties, of the CMU Backed Out of Plane Wall System, and a Mass Representation of the In Plane Wall System, at DBE of the Tarzana Ground Motion. 


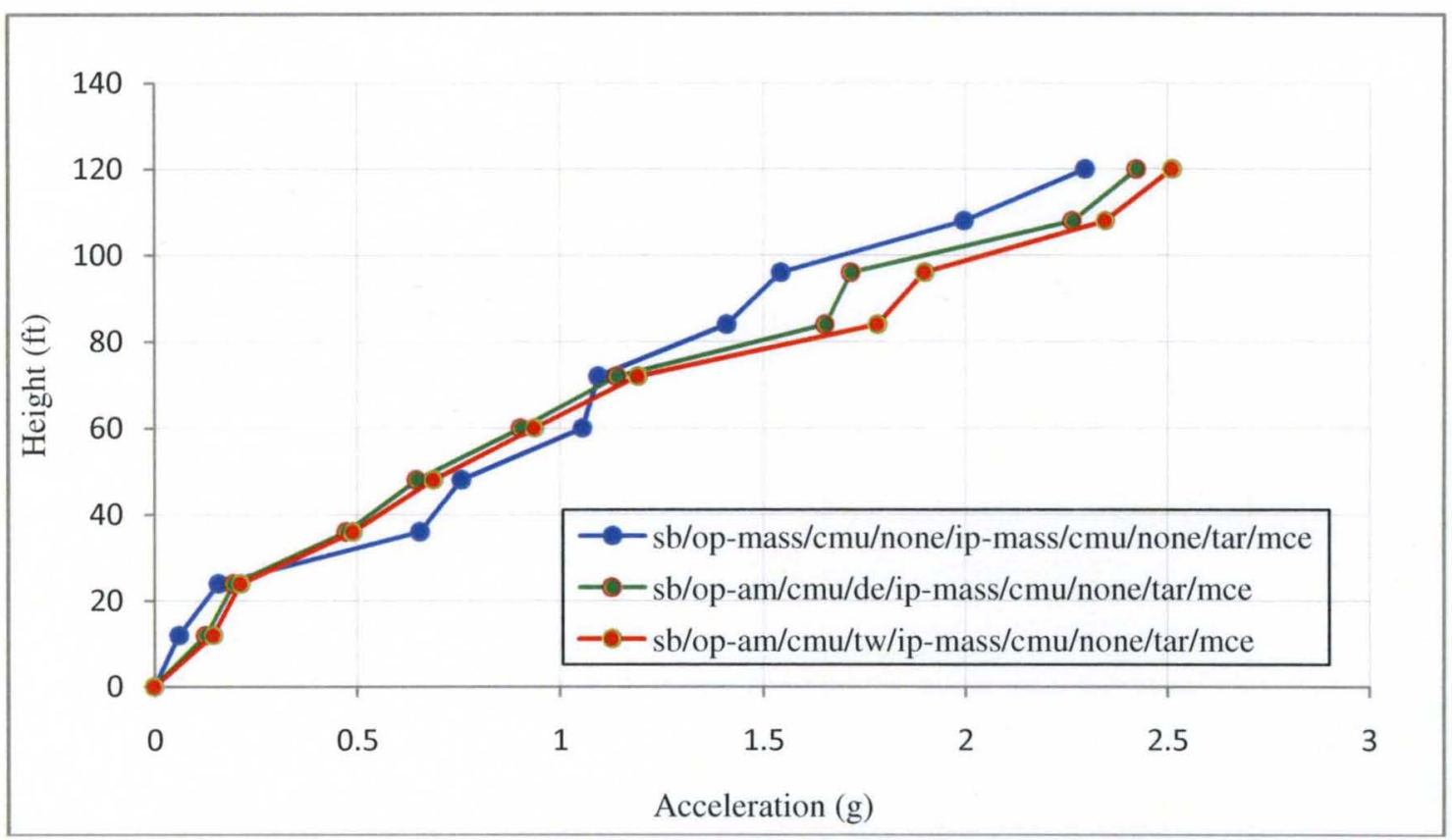

Figure B.39: Comparison of the Acceleration Profiles Going Up the Height of the SteelBraced Frame, With a Mass Representation and Analytical Model Representations With Stiff and Flexible Ties, of the CMU Backed Out of Plane Wall System, and a Mass Representation of the In Plane Wall System, at MCE of the Tarzana Ground Motion.

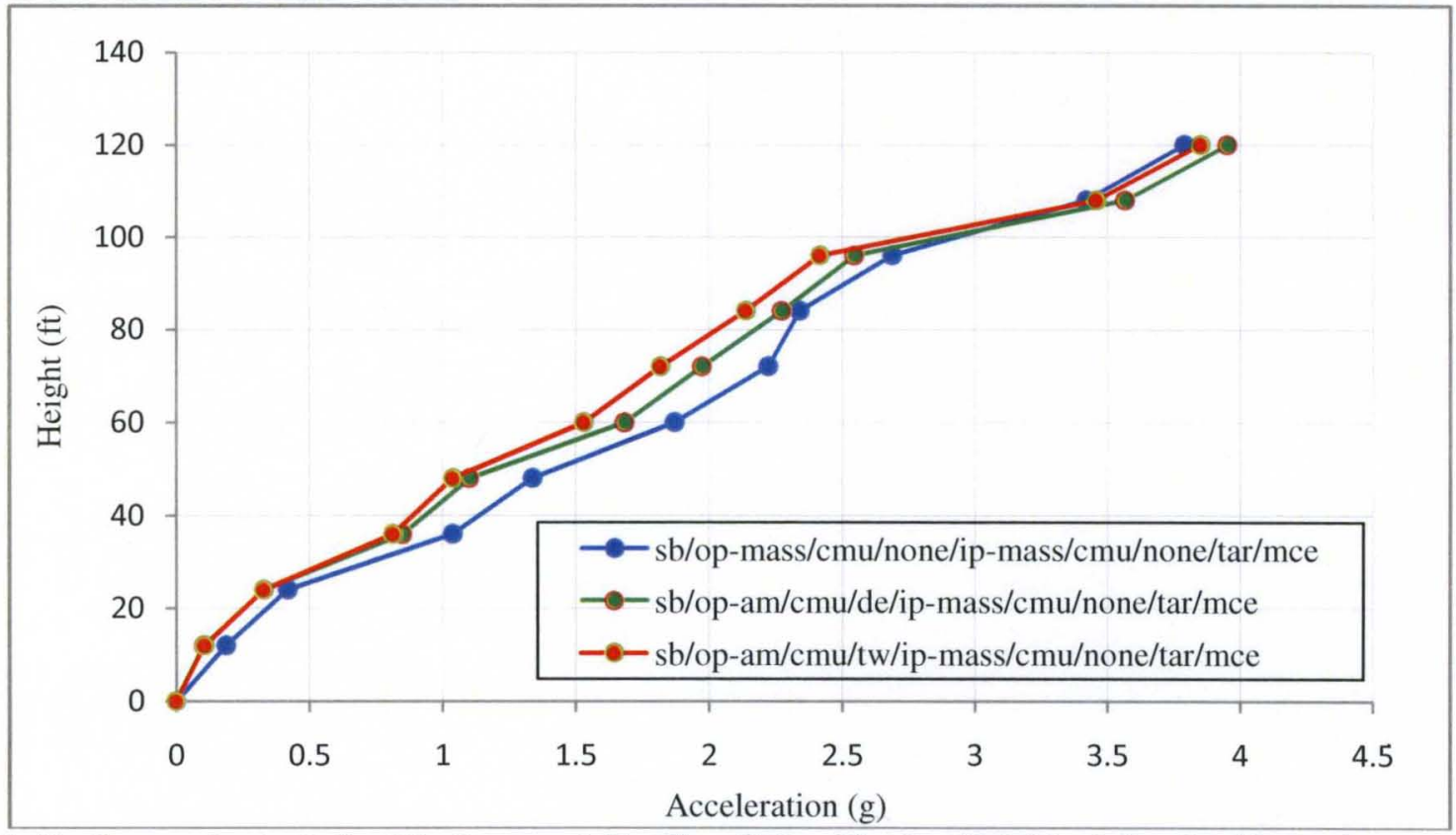

Figure B.40: Comparison of the Displacement Profiles Going Up the Height of the SteelBraced Frame, With a Mass Representation and Analytical Model Representations With Stiff and Flexible Ties, of the CMU Backed Out of Plane Wall System, and a Mass Representation of the In Plane Wall System, at MCE of the Tarzana Ground Motion. 


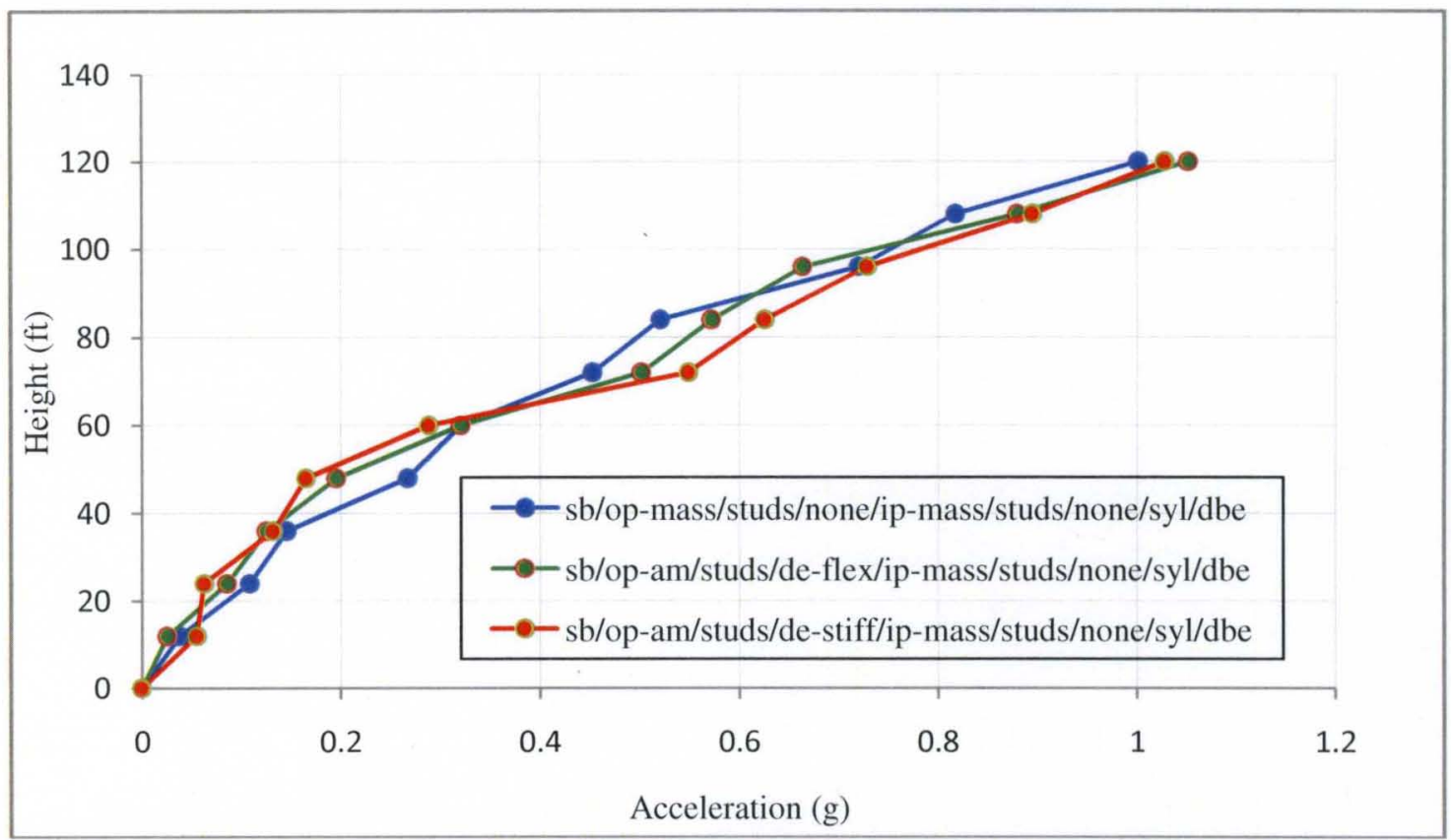

Figure B.41: Comparison of the Acceleration Profiles Going Up the Height of the SteelBraced Frame, With a Mass Representation and Analytical Model Representations With Stiff and Flexible Ties, of the Stud Backed Out of Plane Wall System, and a Mass Representation of the In Plane Wall System, at DBE of the Sylmar Ground Motion.

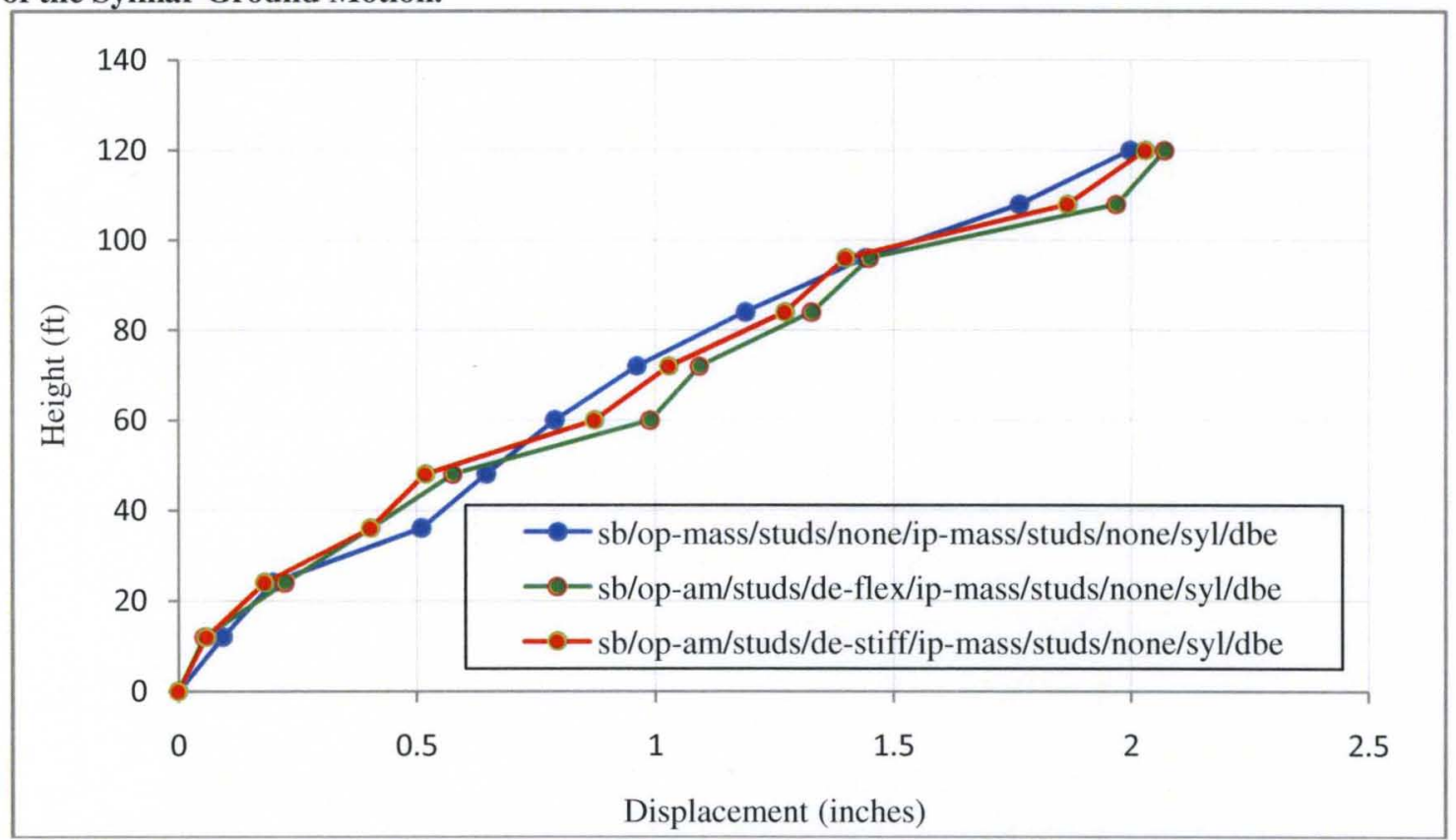

Figure B.42: Comparison of the Displacement Profiles Going Up the Height of the SteelBraced Frame, With a Mass Representation and Analytical Model Representations With Stiff and Flexible Ties, of the Stud Backed Out of Plane Wall System, and a Mass Representation of the In Plane Wall System, at DBE of the Sylmar Ground Motion. 


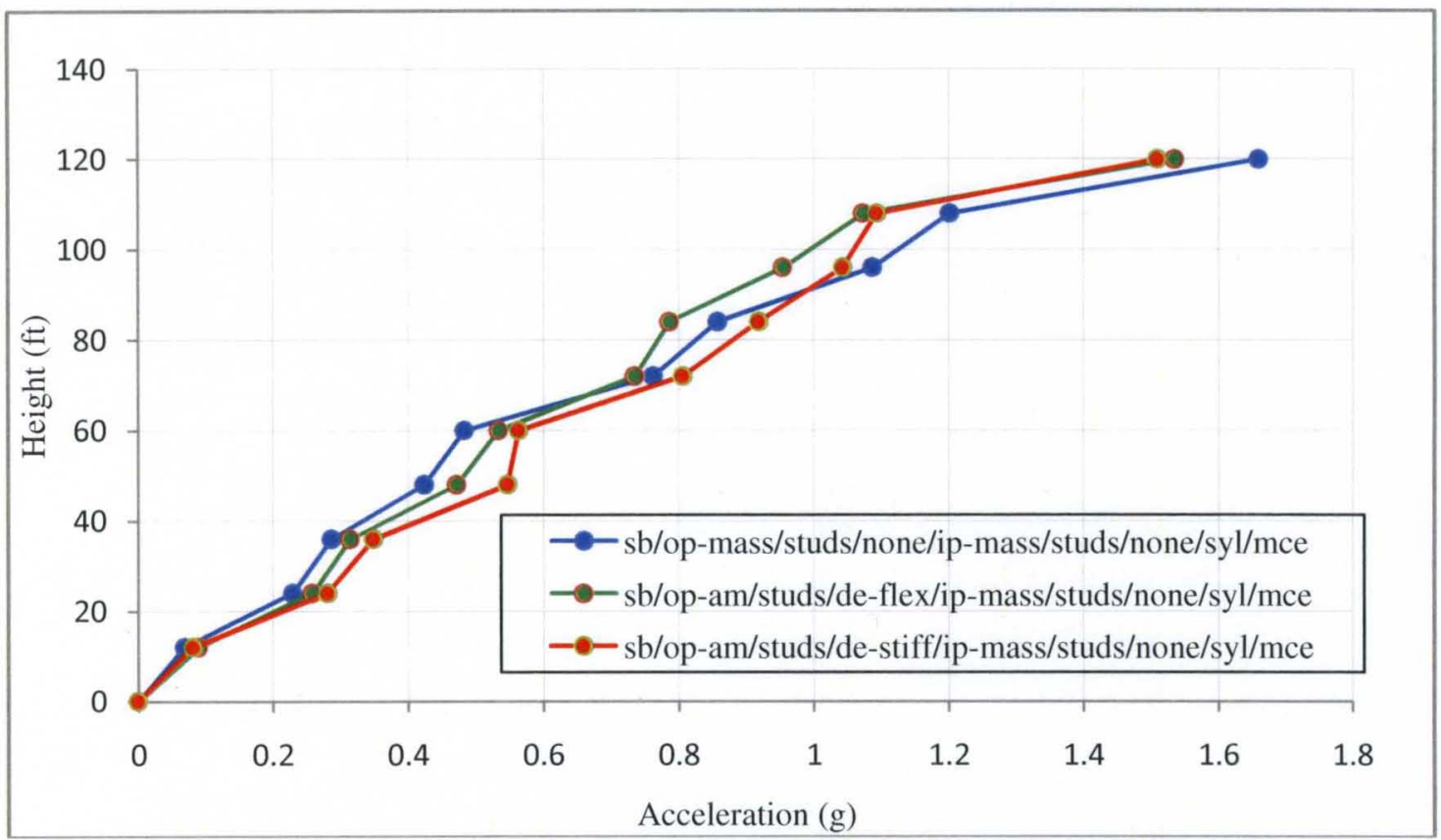

Figure B.43: Comparison of the Acceleration Profiles Going Up the Height of the SteelBraced Frame, With a Mass Representation and Analytical Model Representations With Stiff and Flexible Ties, of the Stud Backed Out of Plane Wall System, and a Mass Representation of the In Plane Wall System, at MCE of the Sylmar Ground Motion.

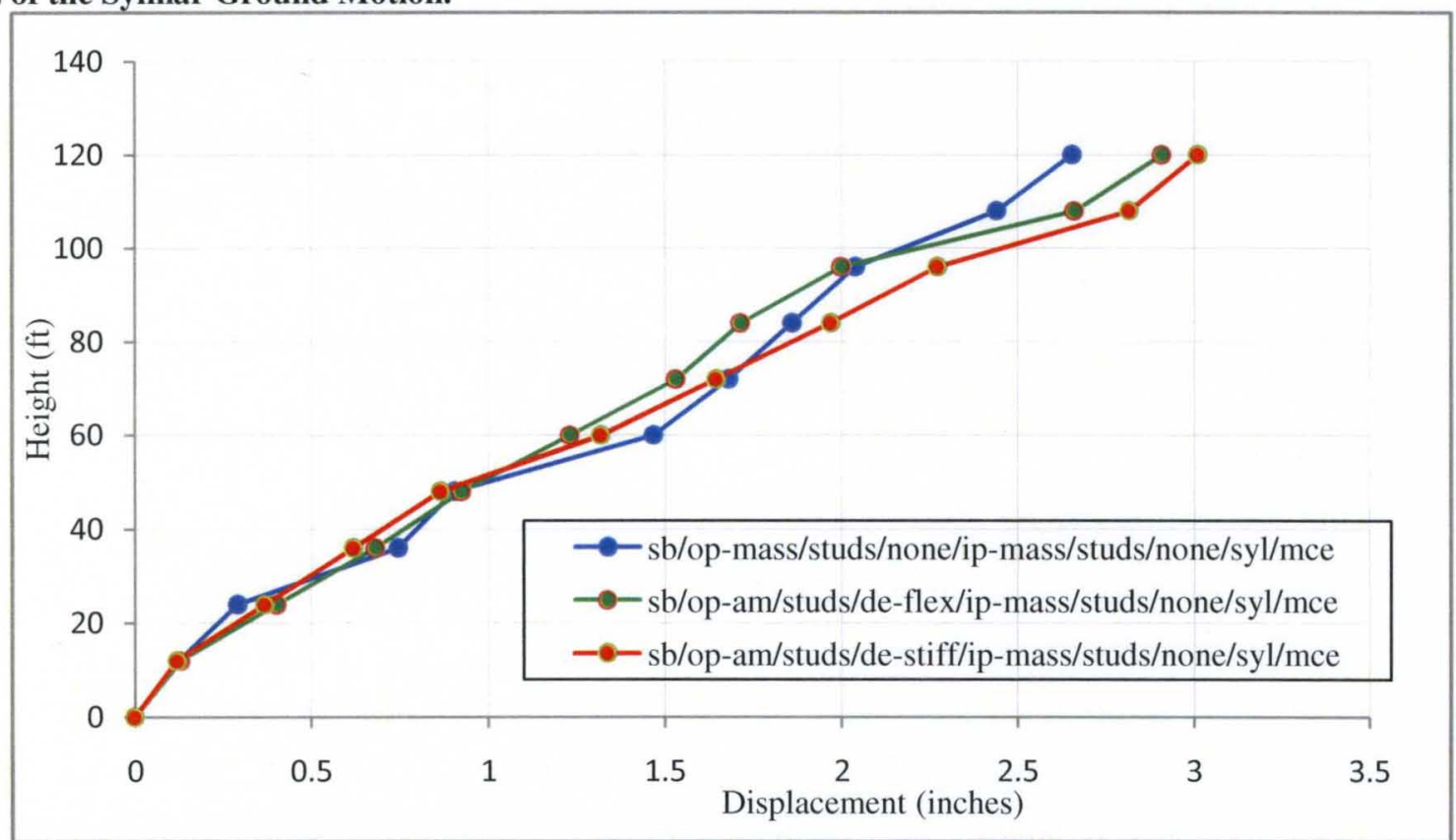

Figure B.44: Comparison of the Displacement Profiles Going Up the Height of the SteelBraced Frame, With a Mass Representation and Analytical Model Representations With Stiff and Flexible Ties, of the Stud Backed Out of Plane Wall System, and a Mass Representation of the In Plane Wall System, at MCE of the Sylmar Ground Motion. 


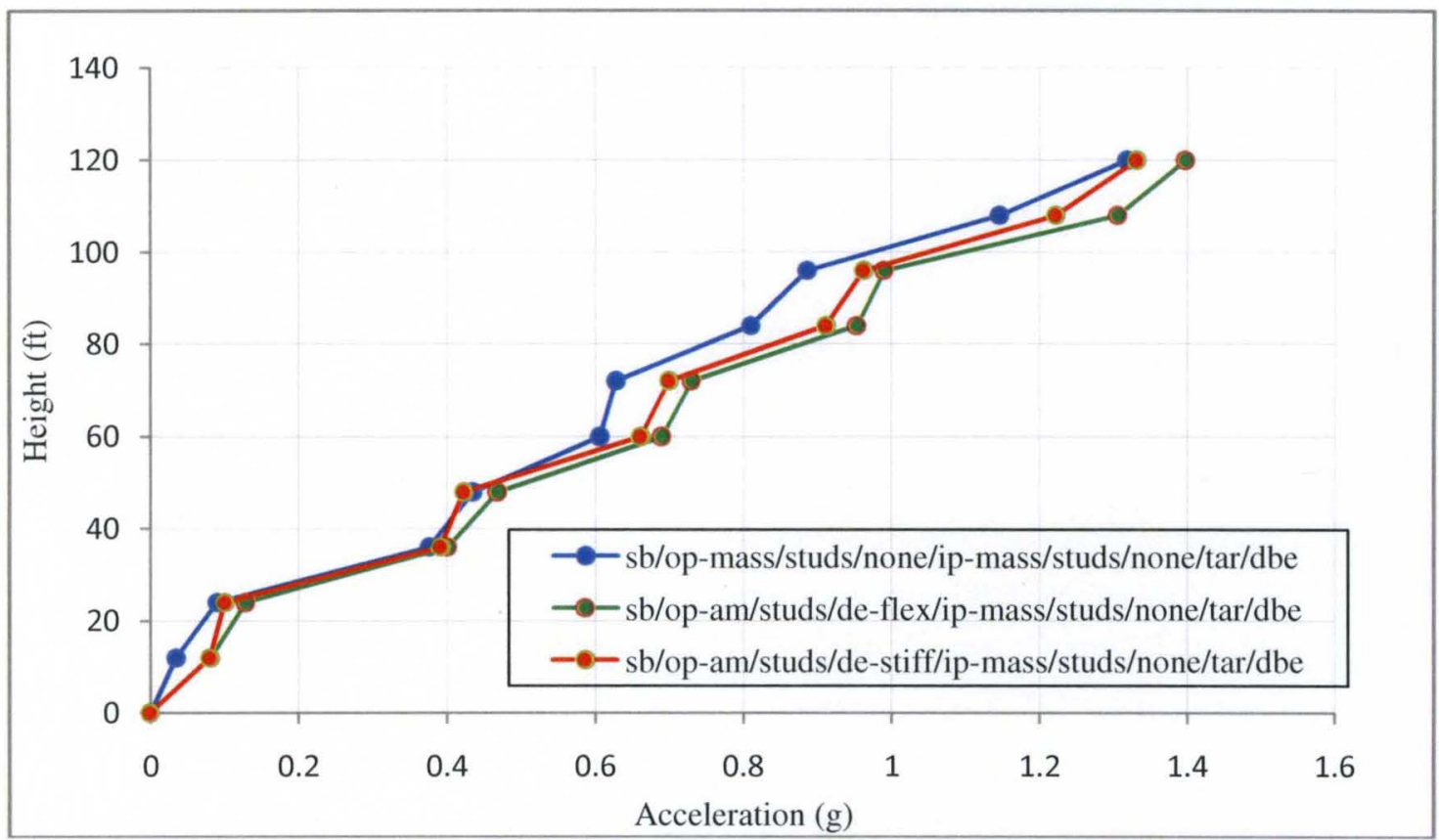

Figure B.45: Comparison of the Acceleration Profiles Going Up the Height of the SteelBraced Frame, With a Mass Representation and Analytical Model Representations With Stiff and Flexible Ties, of the Stud Backed Out of Plane Wall System, and a Mass Representation of the In Plane Wall System, at DBE of the Tarzana Ground Motion.

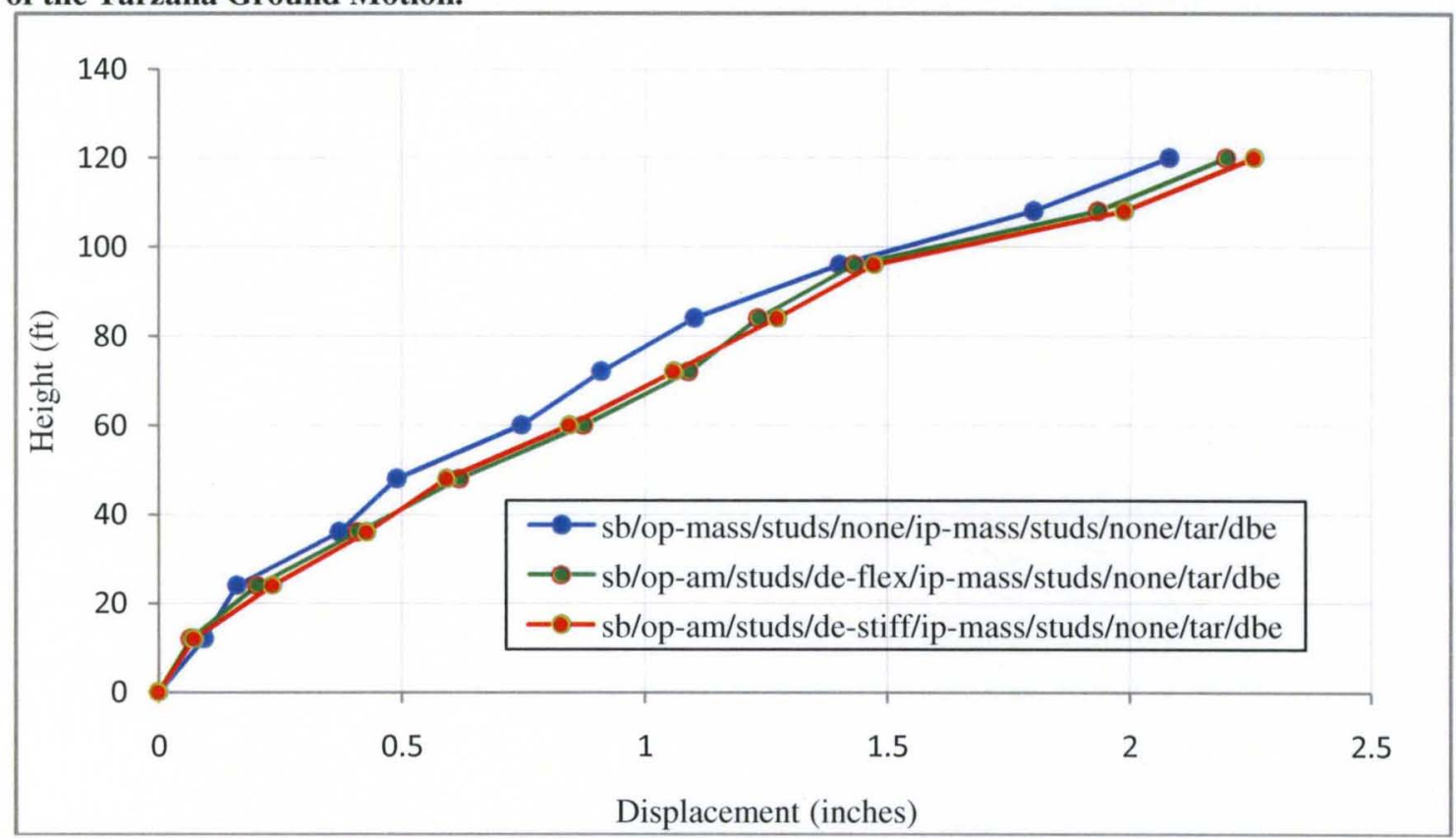

Figure B.46: Comparison of the Displacement Profiles Going Up the Height of the SteelBraced Frame, With a Mass Representation and Analytical Model Representations With Stiff and Flexible Ties, of the Stud Backed Out of Plane Wall System, and a Mass Representation of the In Plane Wall System, at DBE of the Tarzana Ground Motion. 


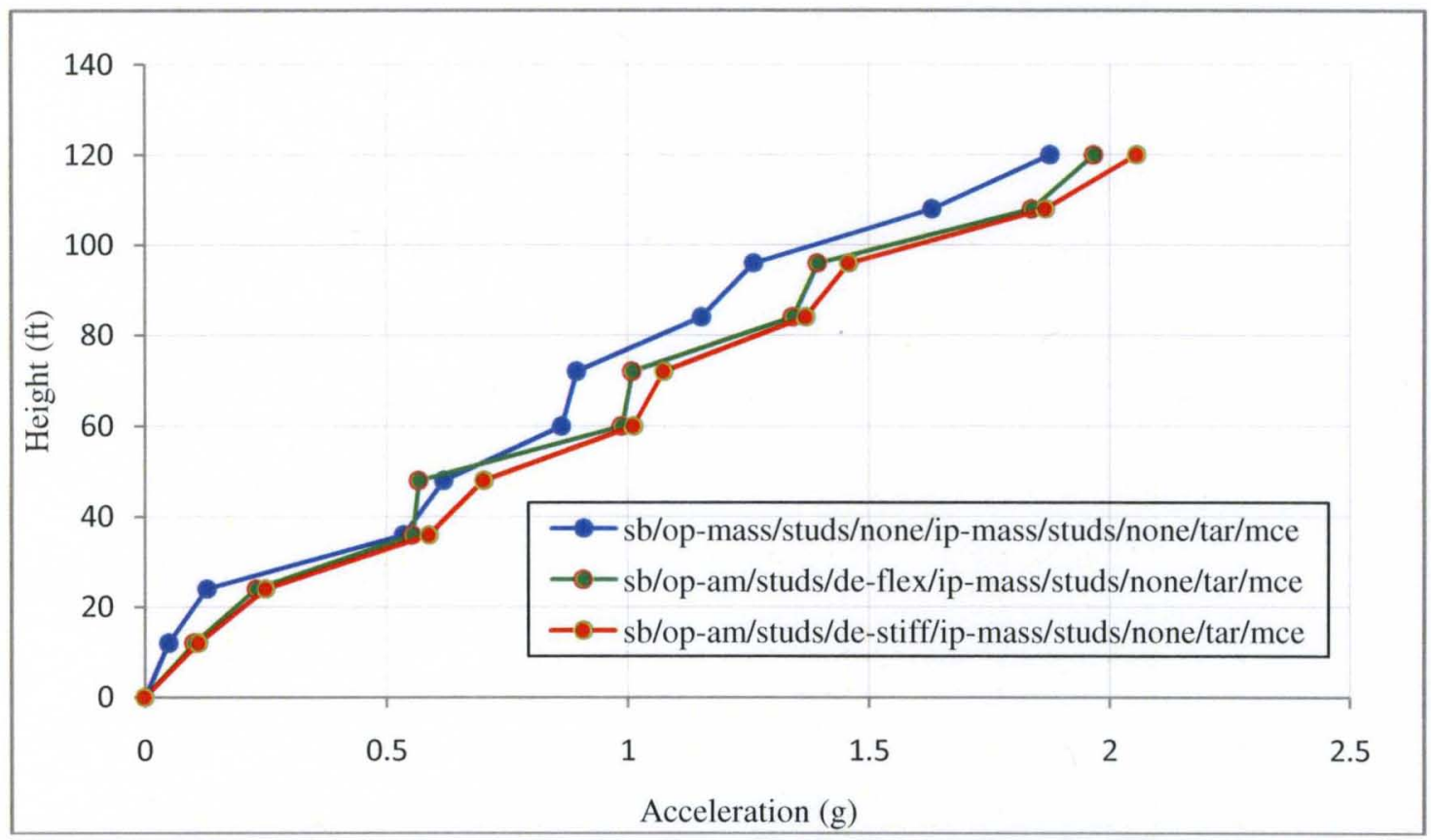

Figure B.47: Comparison of the Acceleration Profiles Going Up the Height of the SteelBraced Frame, With a Mass Representation and Analytical Model Representations With Stiff and Flexible Ties, of the Stud Backed Out of Plane Wall System, and a Mass Representation of the In Plane Wall System, at MCE of the Tarzana Ground Motion.

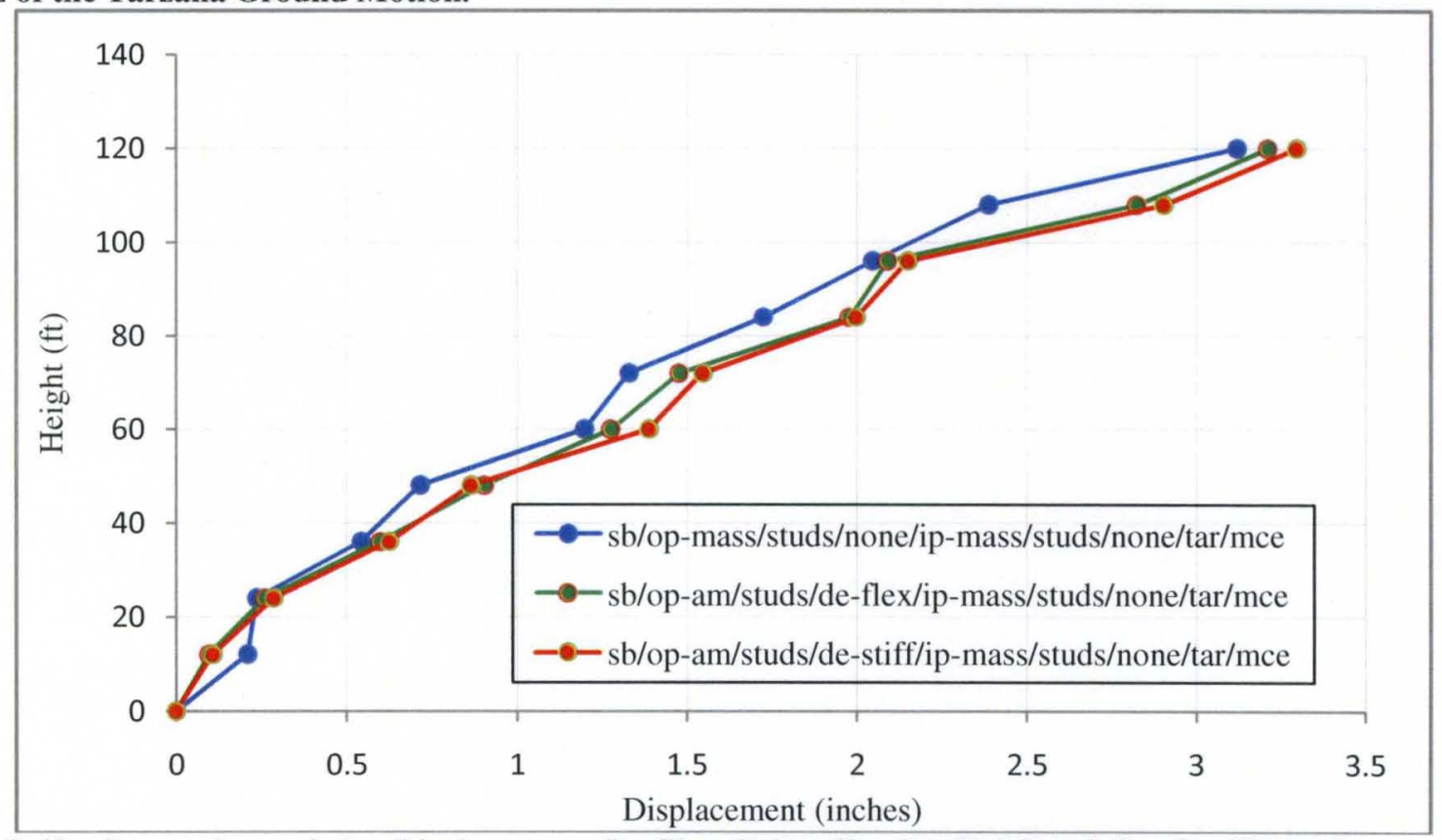

Figure B.48: Comparison of the Displacement Profiles Going Up the Height of the SteelBraced Frame, With a Mass Representation and Analytical Model Representations With Stiff and Flexible Ties, of the Stud Backed Out of Plane Wall System, and a Mass Representation of the In Plane Wall System, at MCE of the Tarzana Ground Motion. 


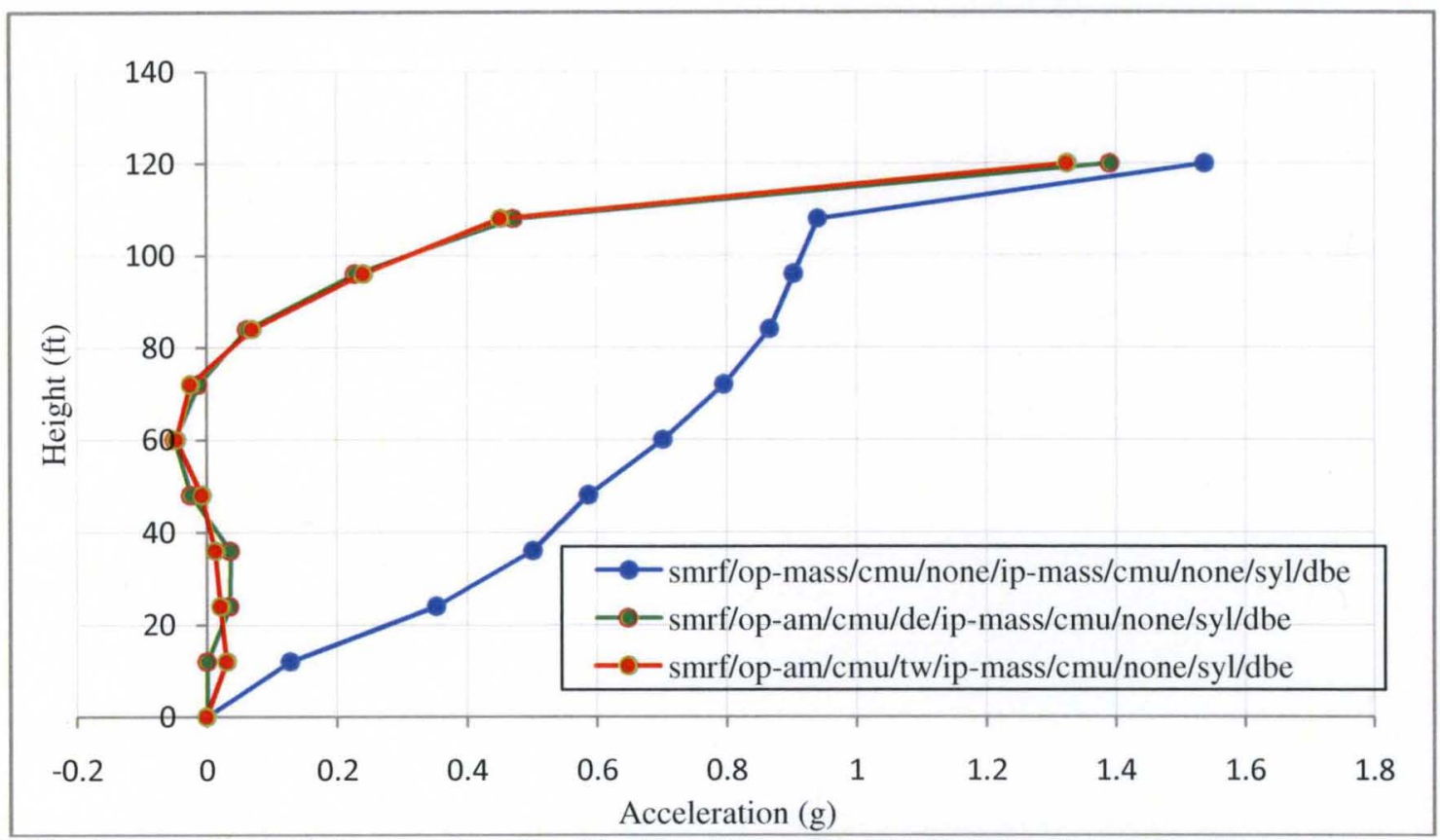

Figure B.49: Comparison of the Acceleration Profiles Going Up the Height of the SteelMoment Resisting Frame, With a Mass Representation and Analytical Model Representations With Stiff and Flexible Ties, of the CMU Backed Out of Plane Wall System, and a Mass Representation of the In Plane Wall System, at DBE of the Sylmar Ground Motion.

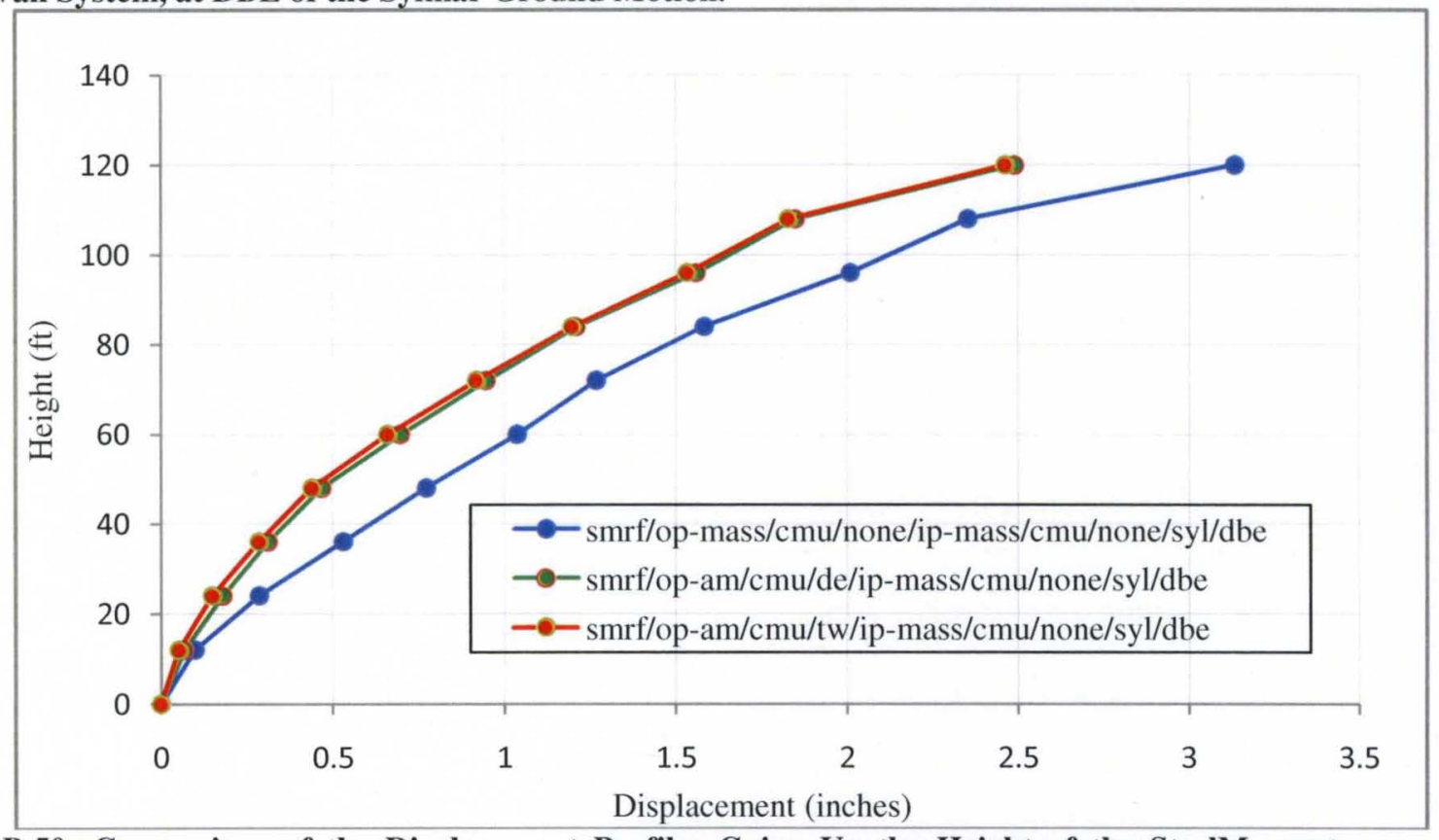

Figure B.50: Comparison of the Displacement Profiles Going Up the Height of the SteelMoment Resisting Frame, With a Mass Representation and Analytical Model Representations With Stiff and Flexible Ties, of the CMU Backed Out of Plane Wall System, and a Mass Representation of the In Plane Wall System, at DBE of the Sylmar Ground Motion. 


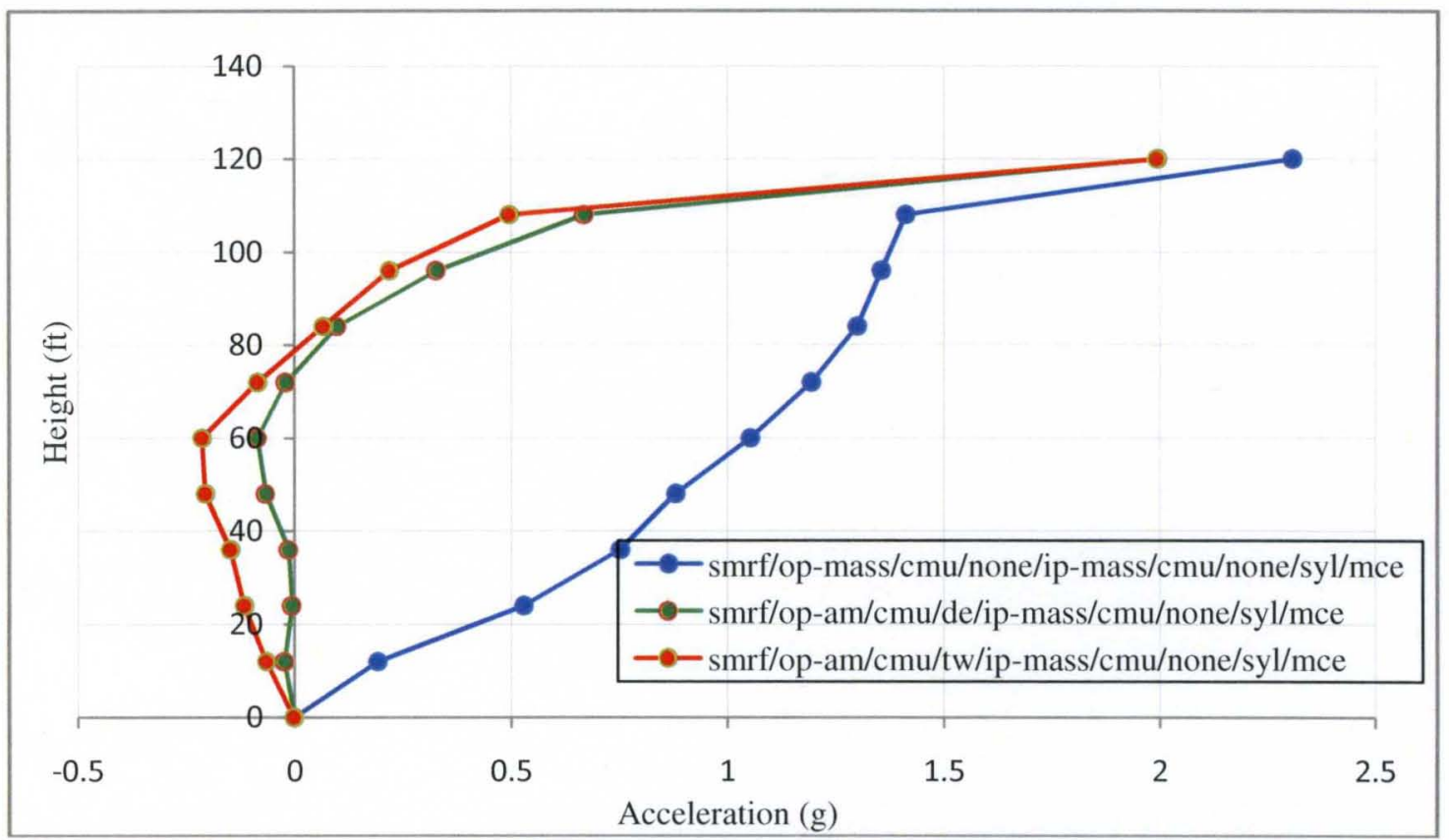

Figure B.51: Comparison of the Acceleration Profiles Going Up the Height of the SteelMoment Resisting Frame, With a Mass Representation and Analytical Model Representations With Stiff and Flexible Ties, of the CMU Backed Out of Plane Wall System, and a Mass Representation of the In Plane Wall System, at MCE of the Sylmar Ground Motion.

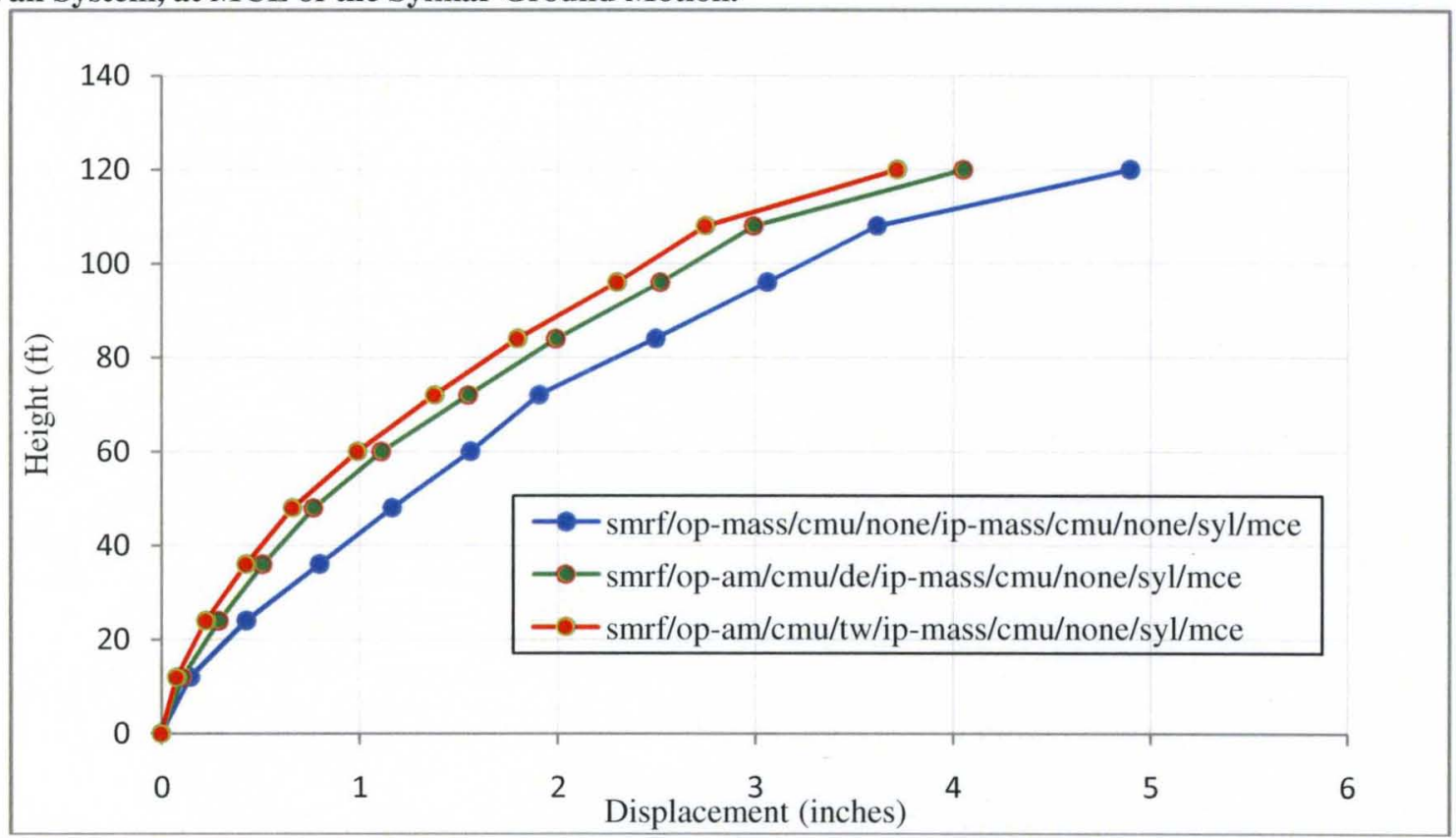

Figure B.52: Comparison of the Displacement Profiles Going Up the Height of the SteelMoment Resisting Frame, With a Mass Representation and Analytical Model Representations With Stiff and Flexible Ties, of the CMU Backed Out of Plane Wall System, and a Mass Representation of the In Plane Wall System, at MCE of the Sylmar Ground Motion. 


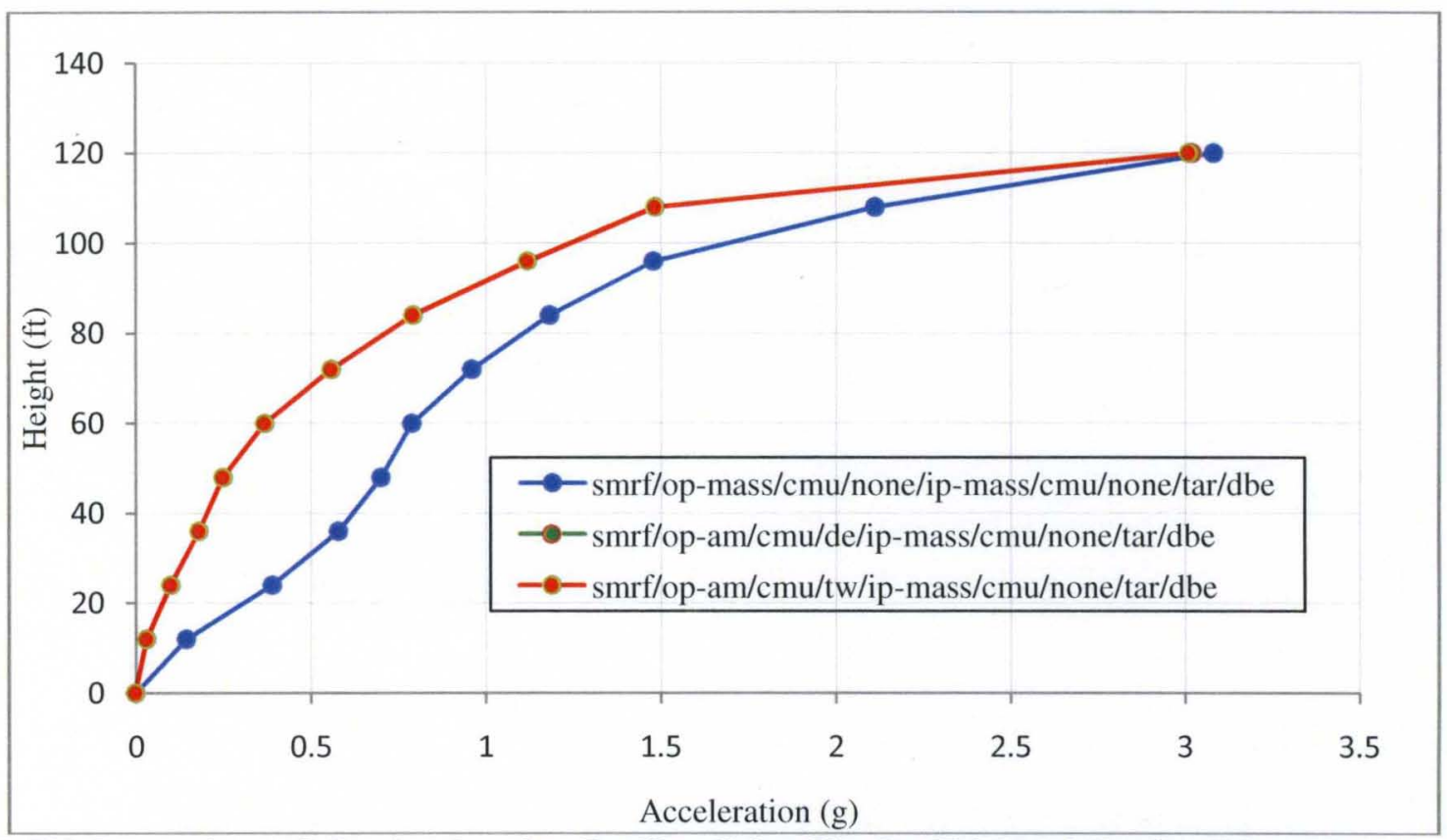

Figure B.53: Comparison of the Acceleration Profiles Going Up the Height of the SteelMoment Resisting Frame, With a Mass Representation and Analytical Model Representations With Stiff and Flexible Ties, of the CMU Backed Out of Plane Wall System, and a Mass Representation of the In Plane Wall System, at DBE of the Tarzana Ground Motion.

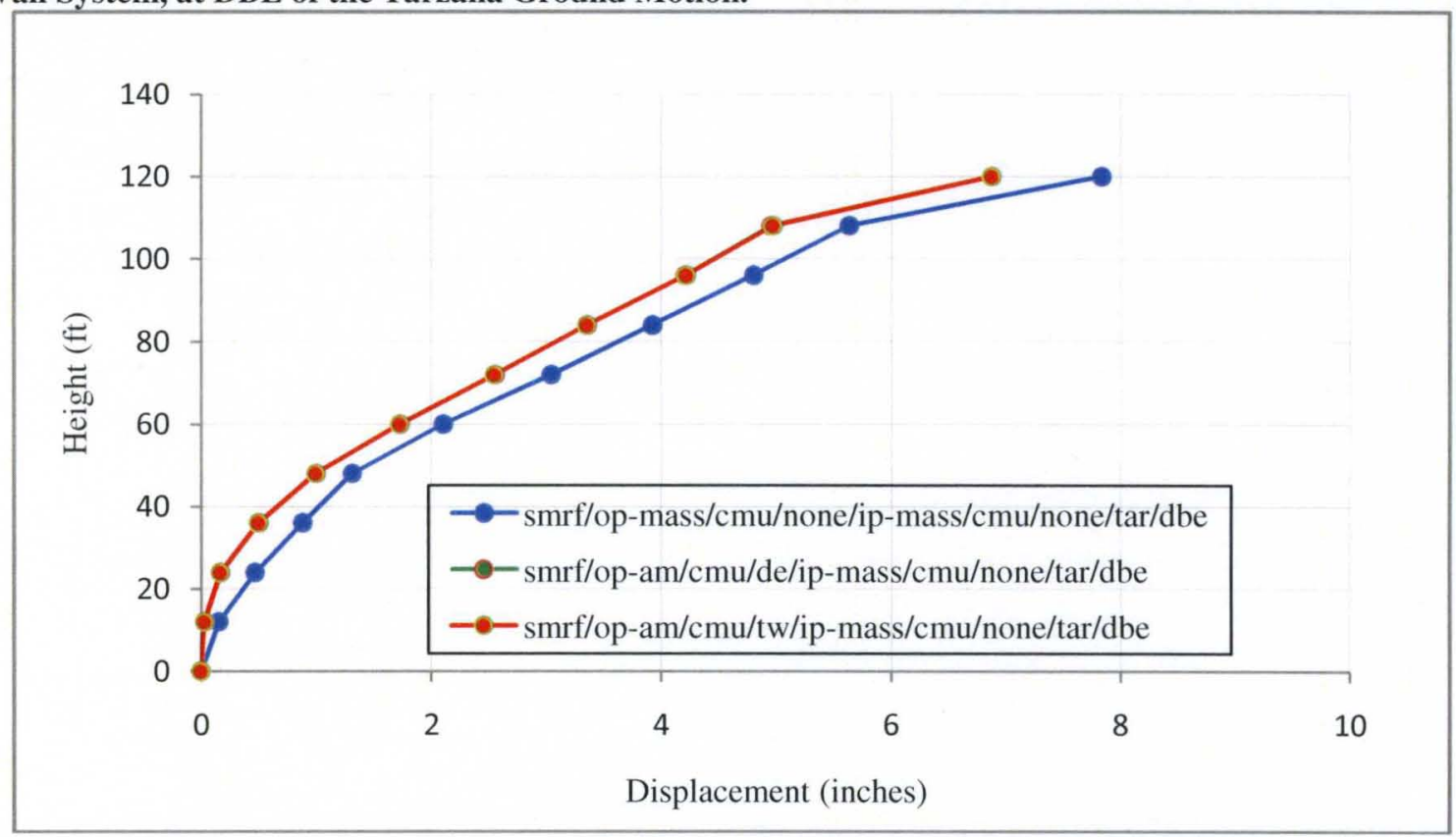

Figure B.54: Comparison of the Displacement Profiles Going Up the Height of the SteelMoment Resisting Frame, With a Mass Representation and Analytical Model Representations With Stiff and Flexible Ties, of the CMU Backed Out of Plane Wall System, and a Mass Representation of the In Plane Wall System, at DBE of the Tarzana Ground Motion. 


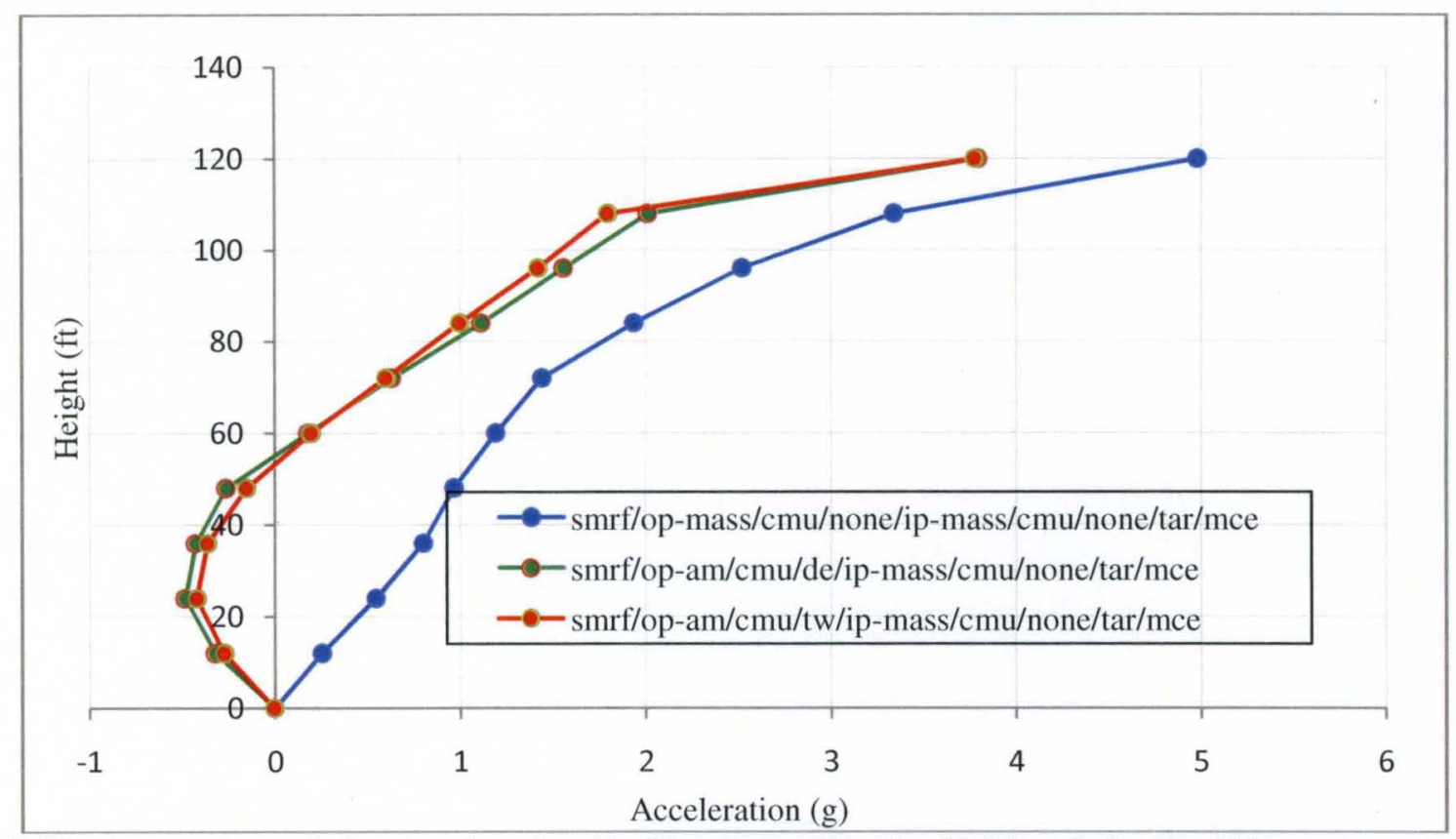

Figure B.55: Comparison of the Acceleration Profiles Going Up the Height of the SteelMoment Resisting Frame, With a Mass Representation and Analytical Model Representations With Stiff and Flexible Ties, of the CMU Backed Out of Plane Wall System, and a Mass Representation of the In Plane Wall System, at MCE of the Tarzana Ground Motion.

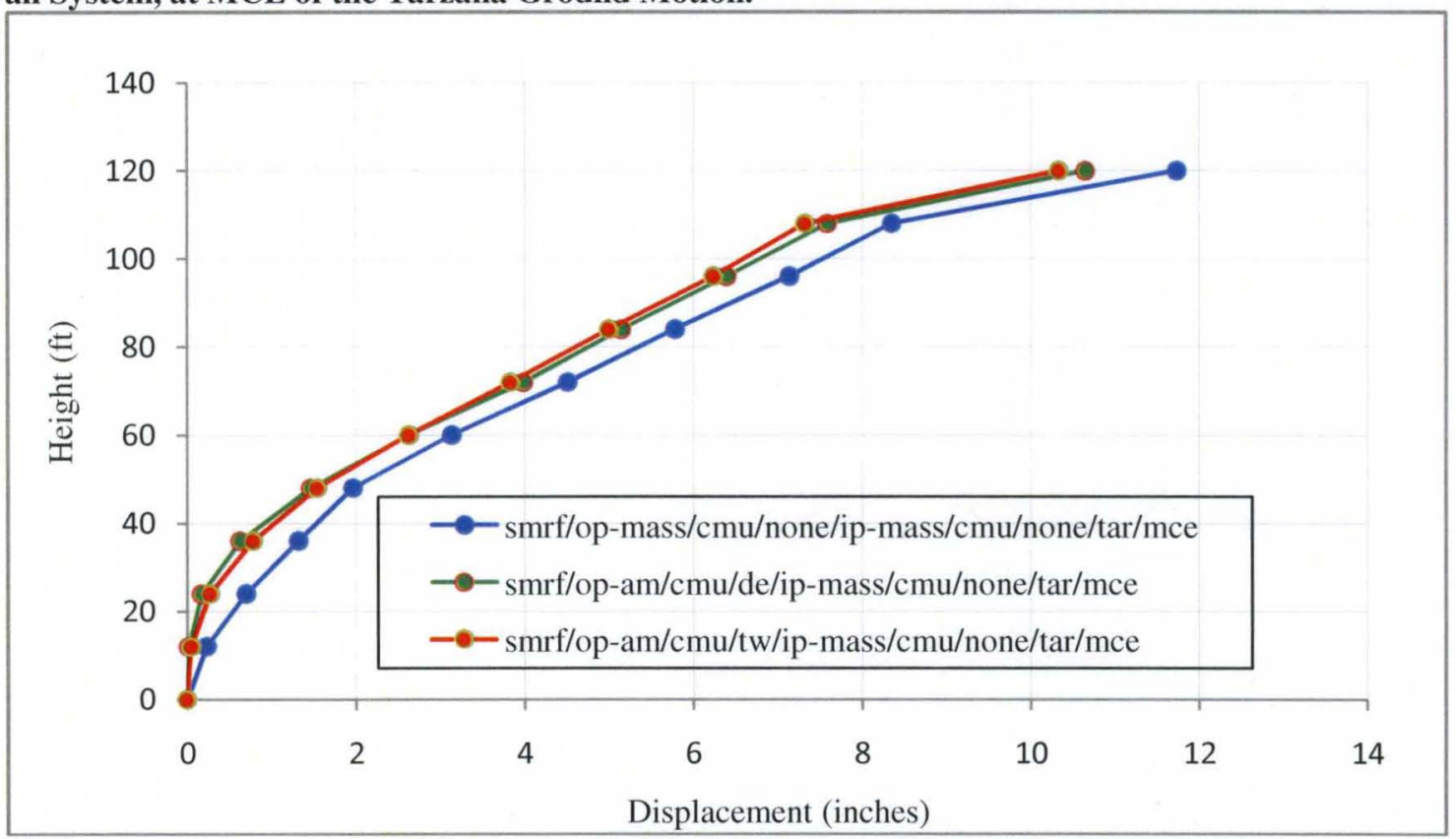

Figure B.56: Comparison of the Displacement Profiles Going Up the Height of the SteelMoment Resisting Frame, With a Mass Representation and Analytical Model Representations With Stiff and Flexible Ties, of the CMU Backed Out of Plane Wall System, and a Mass Representation of the In Plane Wall System, at MCE of the Tarzana Ground Motion. 


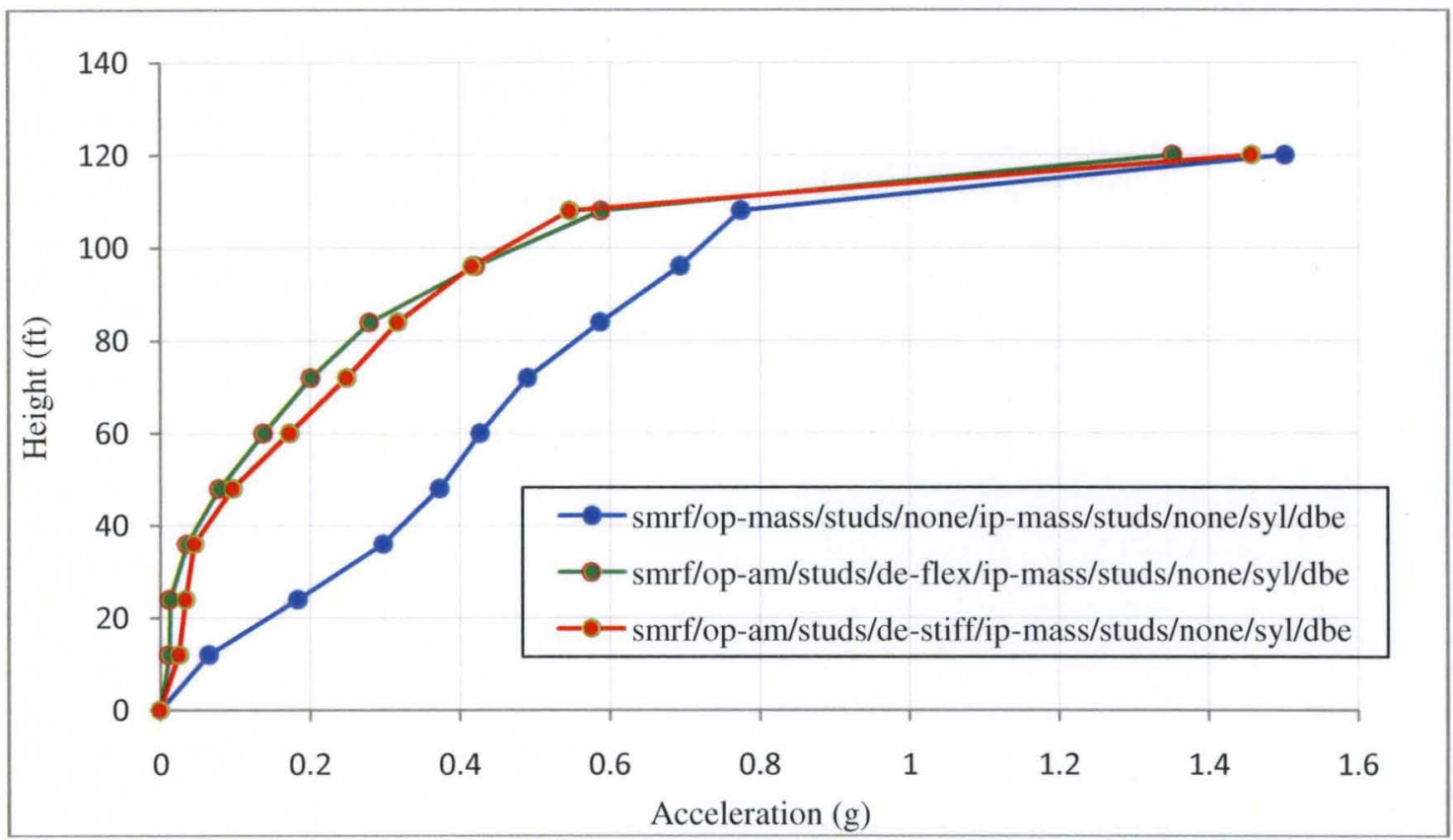

Figure B.57: Comparison of the Acceleration Profiles Going Up the Height of the SteelMoment Resisting Frame, With a Mass Representation and Analytical Model Representations With Stiff and Flexible Ties, of the Stud Backed Out of Plane Wall System, and a Mass Representation of the In Plane Wall System, at DBE of the Sylmar Ground Motion.

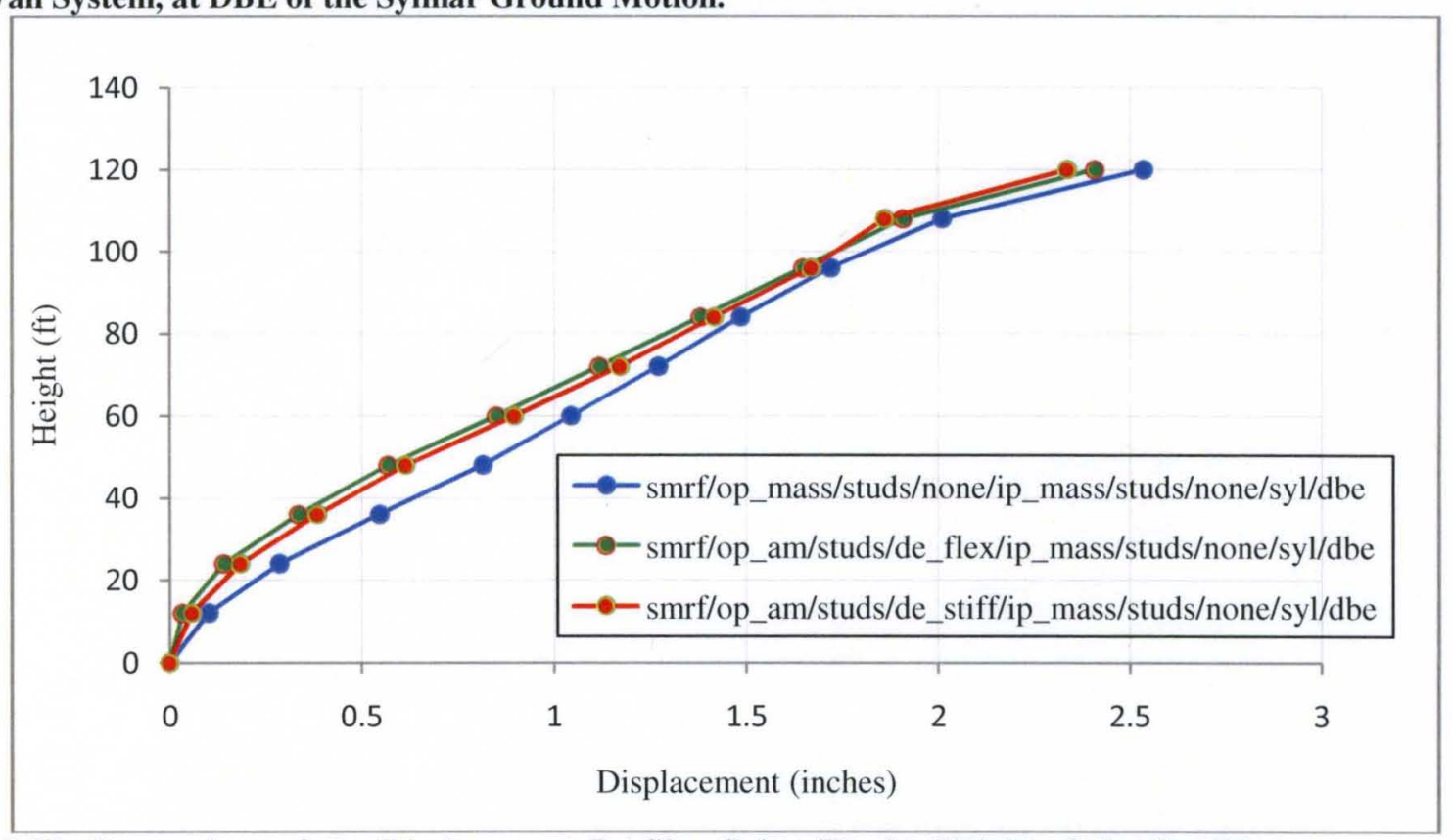

Figure B.58: Comparison of the Displacement Profiles Going Up the Height of the SteelMoment Resisting Frame, With a Mass Representation and Analytical Model Representations With Stiff and Flexible Ties, of the Stud Backed Out of Plane Wall System, and a Mass Representation of the In Plane Wall System, at DBE of the Sylmar Ground Motion. 


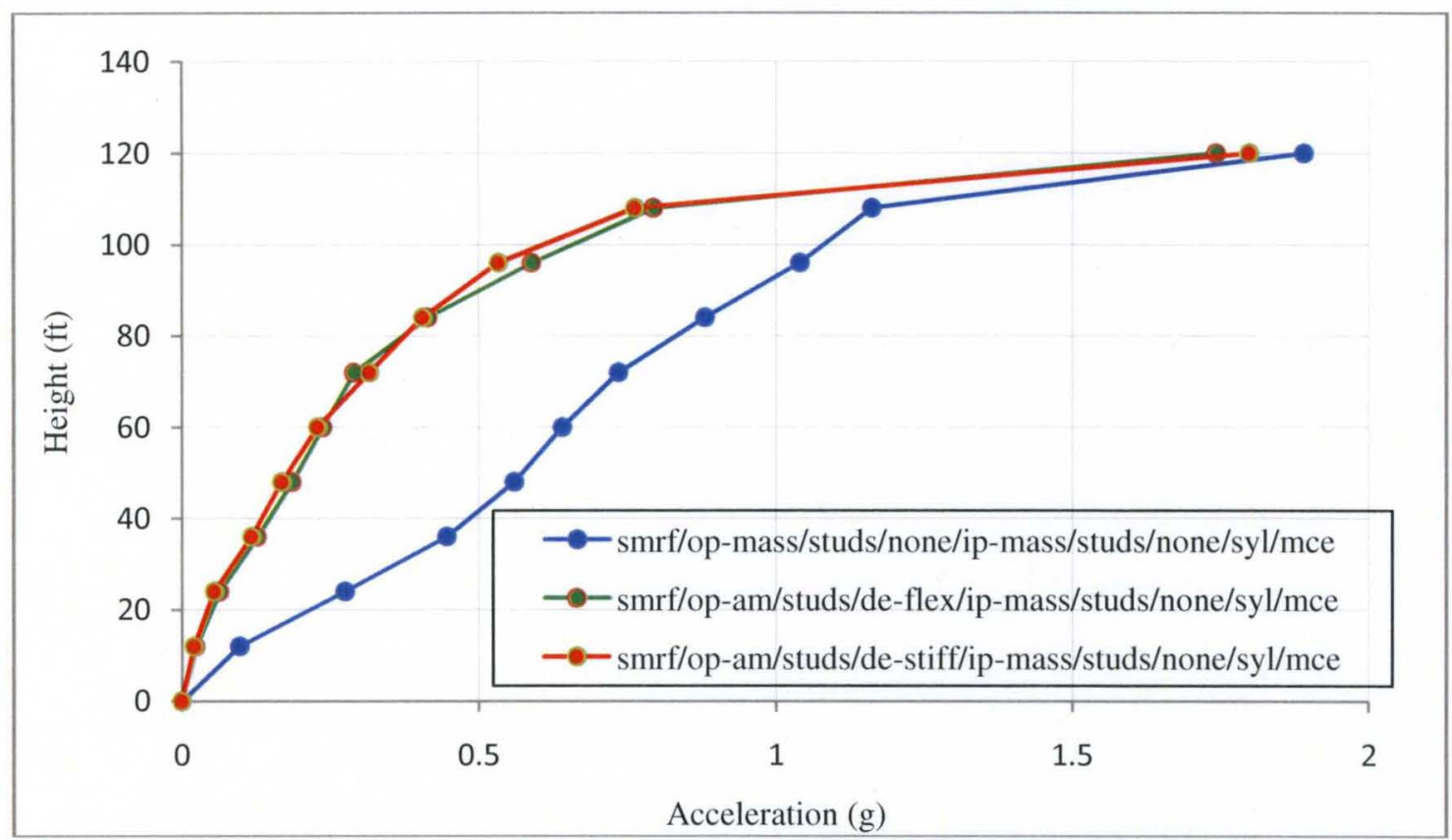

Figure B.59: Comparison of the Acceleration Profiles Going Up the Height of the SteelMoment Resisting Frame, With a Mass Representation and Analytical Model Representations With Stiff and Flexible Ties, of the Stud Backed Out of Plane Wall System, and a Mass Representation of the In Plane Wall System, at MCE of the Sylmar Ground Motion.

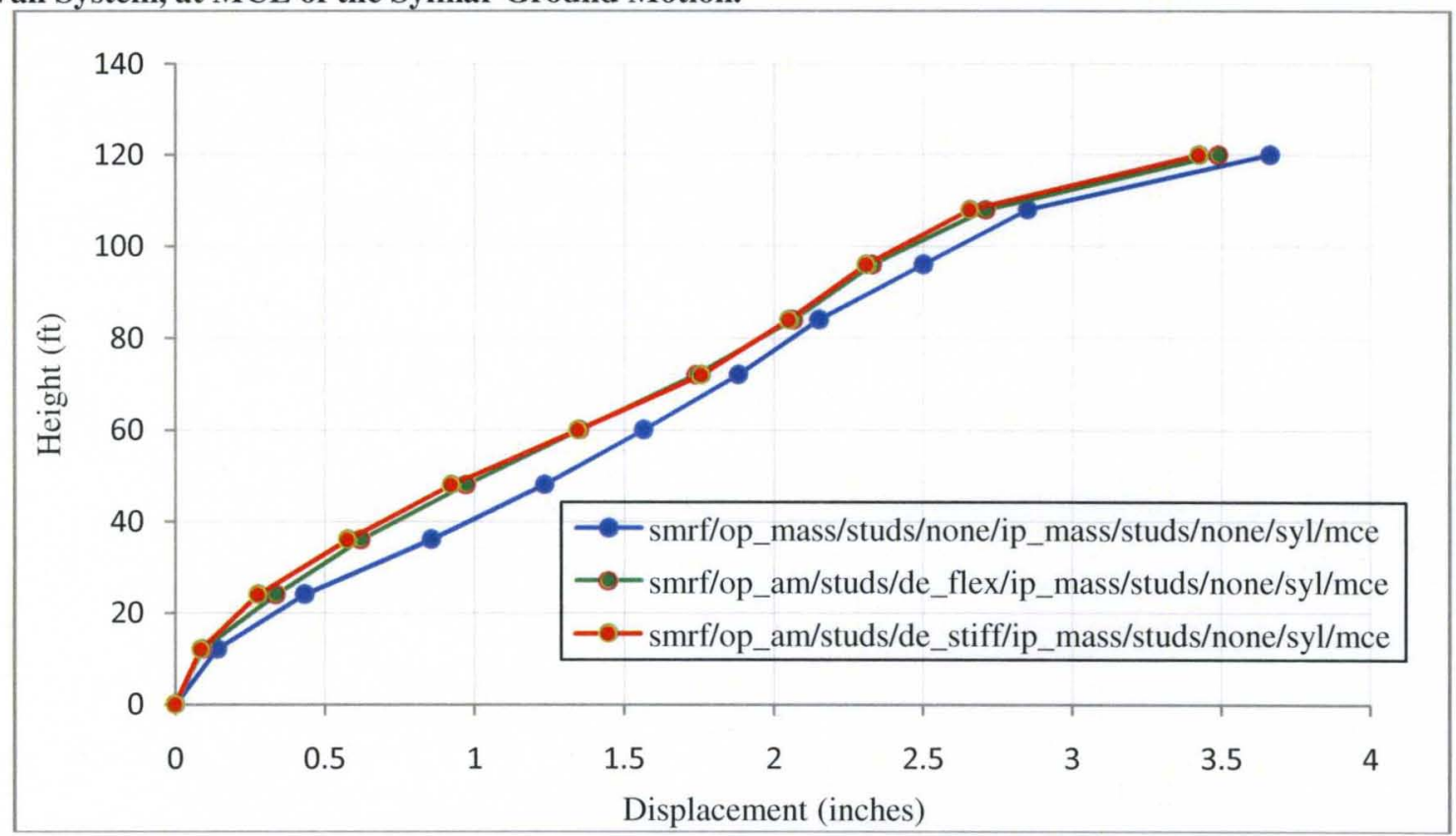

Figure B.60: Comparison of the Displacement Profiles Going Up the Height of the SteelMoment Resisting Frame, With a Mass Representation and Analytical Model Representations With Stiff and Flexible Ties, of the Stud Backed Out of Plane Wall System, and a Mass Representation of the In Plane Wall System, at MCE of the Sylmar Ground Motion. 


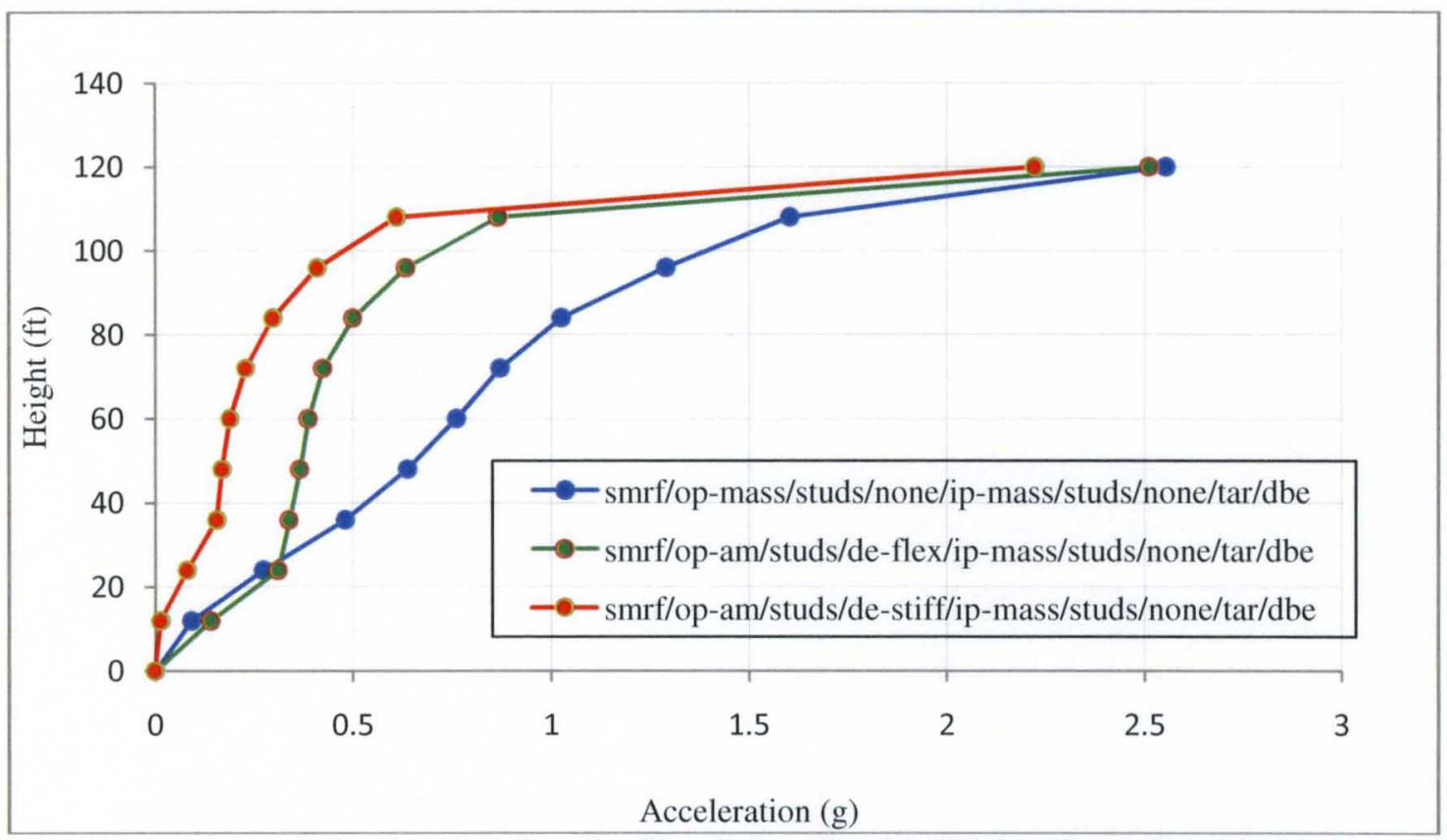

Figure B.61: Comparison of the Acceleration Profiles Going Up the Height of the SteelMoment Resisting Frame, With a Mass Representation and Analytical Model Representations With Stiff and Flexible Ties, of the Stud Backed Out of Plane Wall System, and a Mass Representation of the In Plane Wall System, at DBE of the Tarzana Ground Motion.

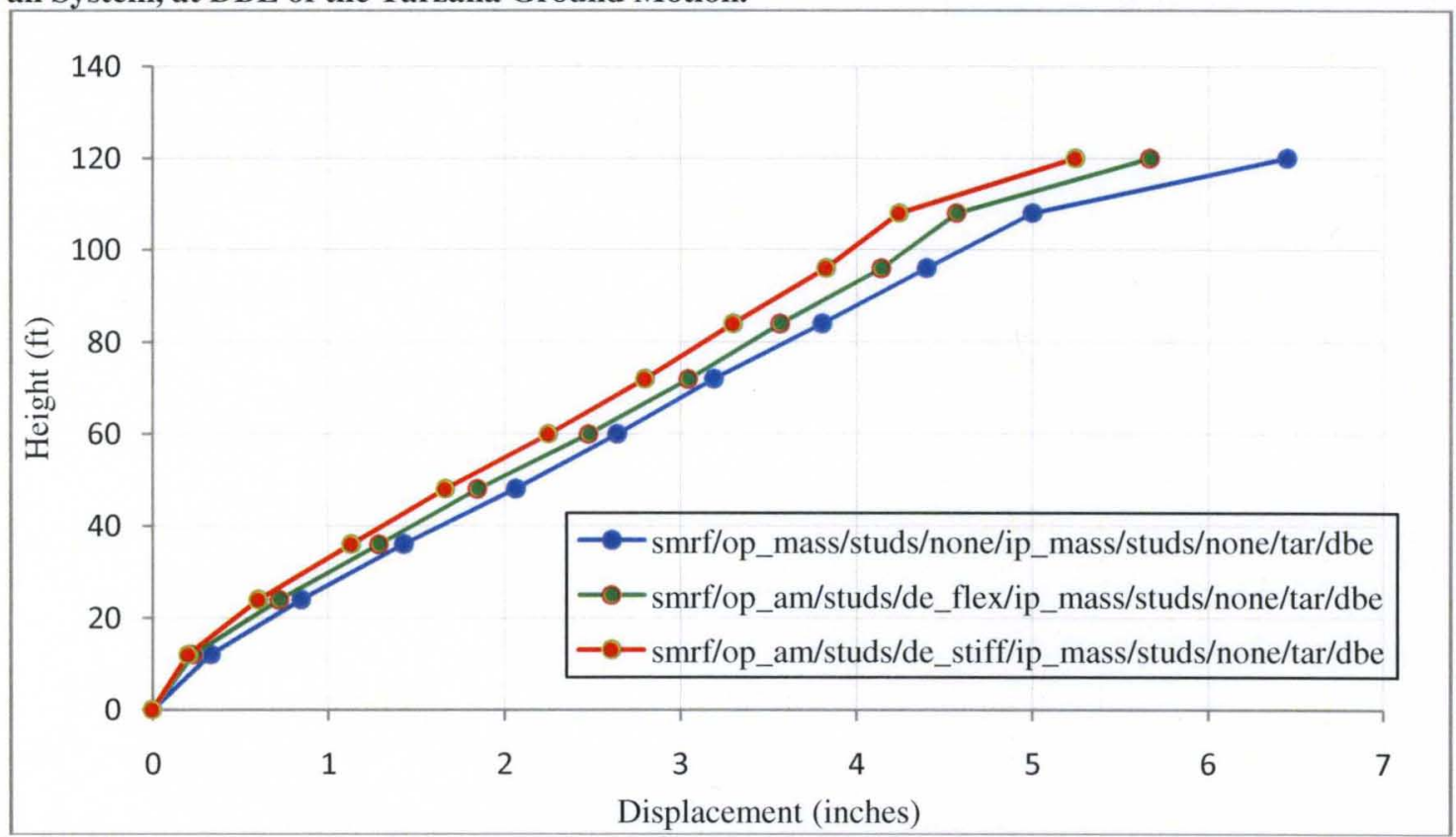

Figure B.62: Comparison of the Displacement Profiles Going Up the Height of the SteelMoment Resisting Frame, With a Mass Representation and Analytical Model Representations With Stiff and Flexible Ties, of the Stud Backed Out of Plane Wall System, and a Mass Representation of the In Plane Wall System, at DBE of the Tarzana Ground Motion. 


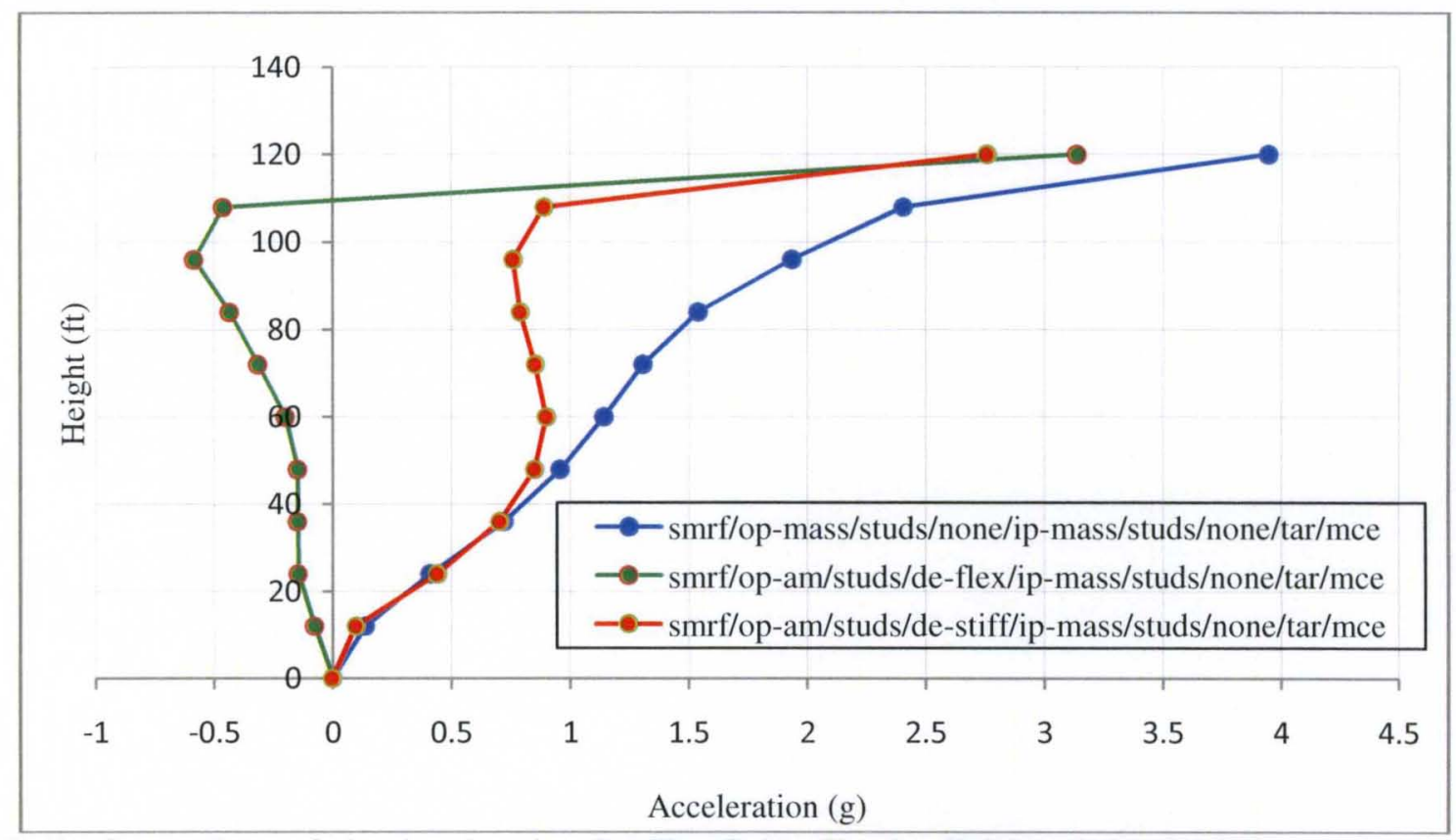

Figure B.63: Comparison of the Acceleration Profiles Going Up the Height of the SteelMoment Resisting Frame, With a Mass Representation and Analytical Model Representations With Stiff and Flexible Ties, of the Stud Backed Out of Plane Wall System, and a Mass Representation of the In Plane Wall System, at MCE of the Tarzana Ground Motion.

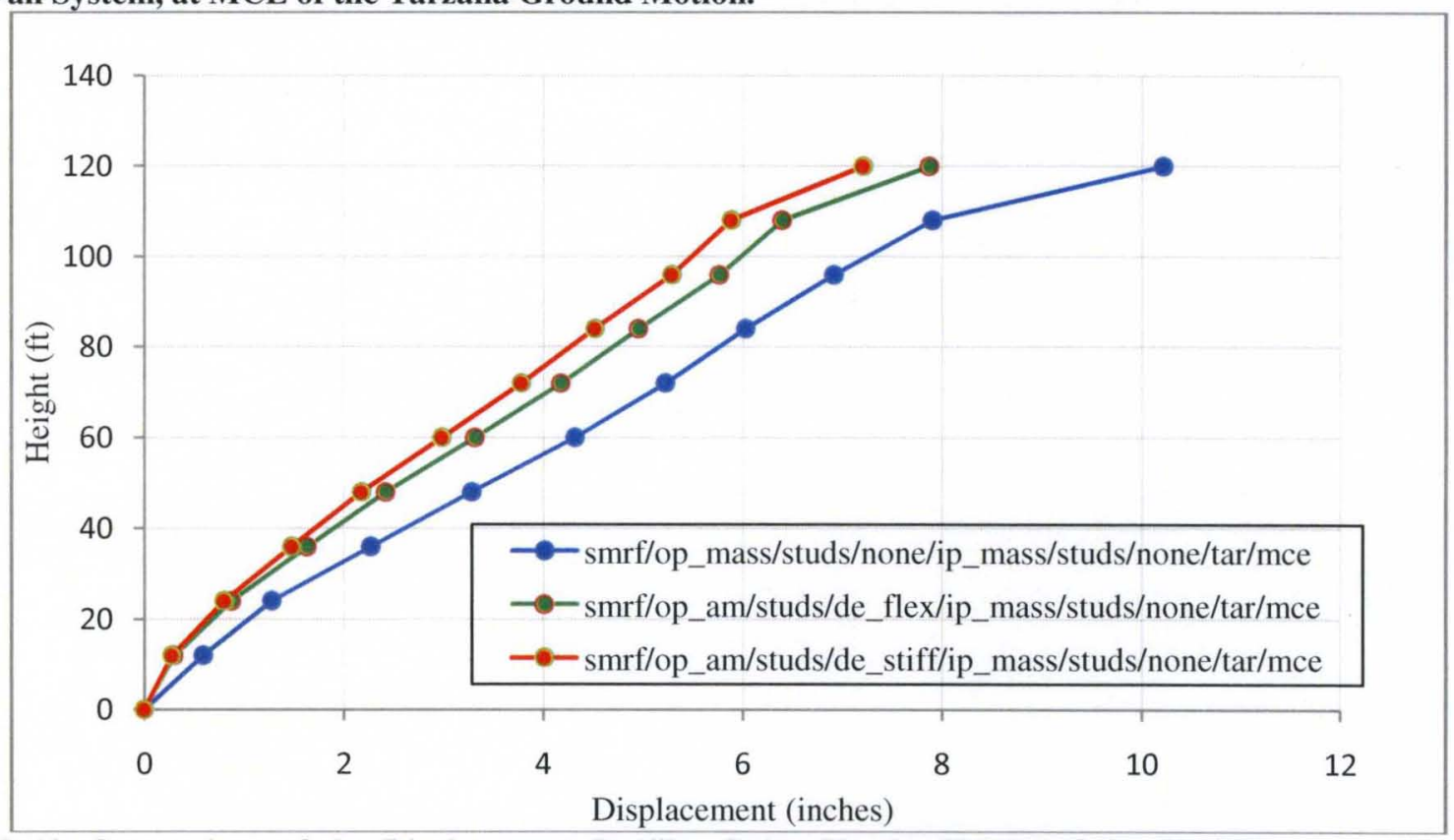

Figure B.64: Comparison of the Displacement Profiles Going Up the Height of the SteelMoment Resisting Frame, With a Mass Representation and Analytical Model Representations With Stiff and Flexible Ties, of the Stud Backed Out of Plane Wall System, and a Mass Representation of the In Plane Wall System, at MCE of the Tarzana Ground Motion. 


\section{APPENDIX C}

\section{EFFECT OF THE IN PLANE WALL ON THE}

\section{MAINFRAME: ACCELERATION AND DISPLACEMENT}

Appendix $\mathrm{C}$ consists of plots that display the effect of the in plane wall systems on the main building frame systems. These plots are derived in a manner identical to that described in the result categories 3 and 4, discussed in Chapter 4. They compare the effect of the mass versus analytical model representation of the in plane wall system on the acceleration and displacement responses of points on the main frame, selected as described in the aforementioned sections of chapter 4. 


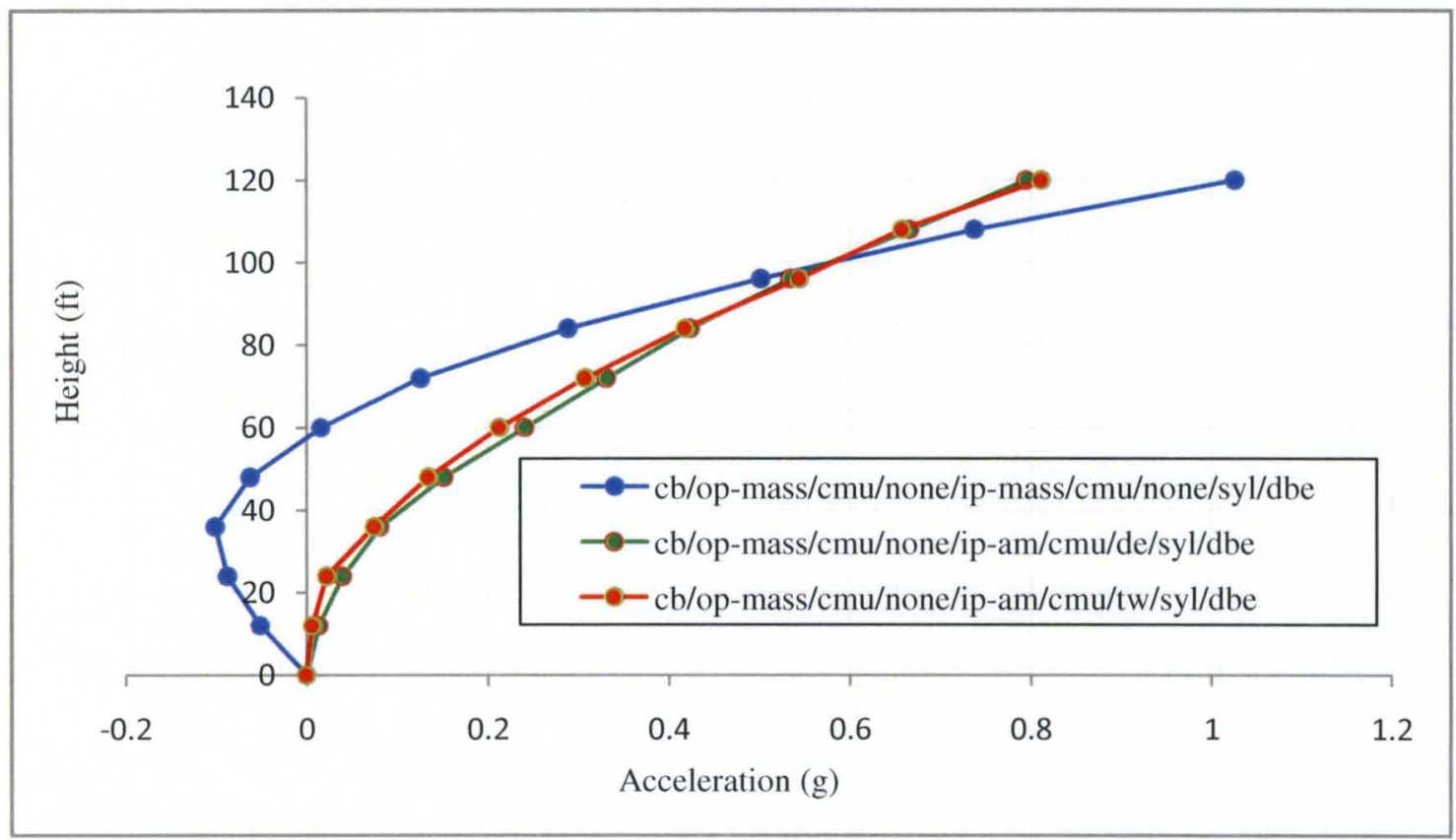

Figure C.1: Comparison of the Acceleration Profiles Going Up the Height of the Concrete Braced Frame, With a Mass Representation and Analytical Model Representations With Stiff and Flexible Ties, of the CMU Backed In Plane Wall System, and a Mass Representation of the Out Of Plane Wall System, at DBE of the Sylmar Ground Motion.

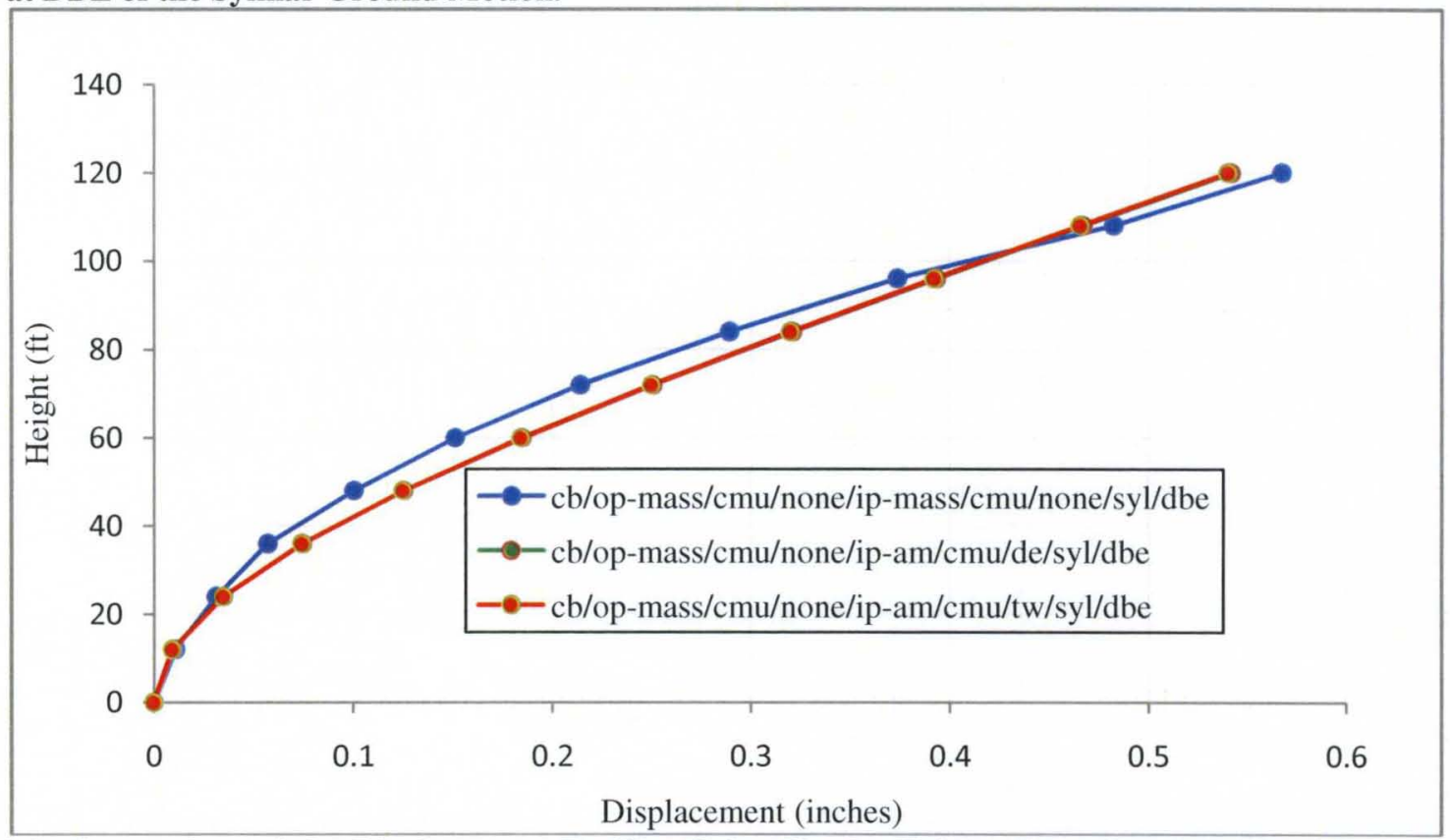

Figure C.2: Comparison of the Displacement Profiles Going Up the Height of the Concrete Braced Frame, With a Mass Representation and Analytical Model Representations With Stiff and Flexible Ties, of the CMU Backed In Plane Wall System, and a Mass Representation of the Out Of Plane Wall System, at DBE of the Sylmar Ground Motion. 


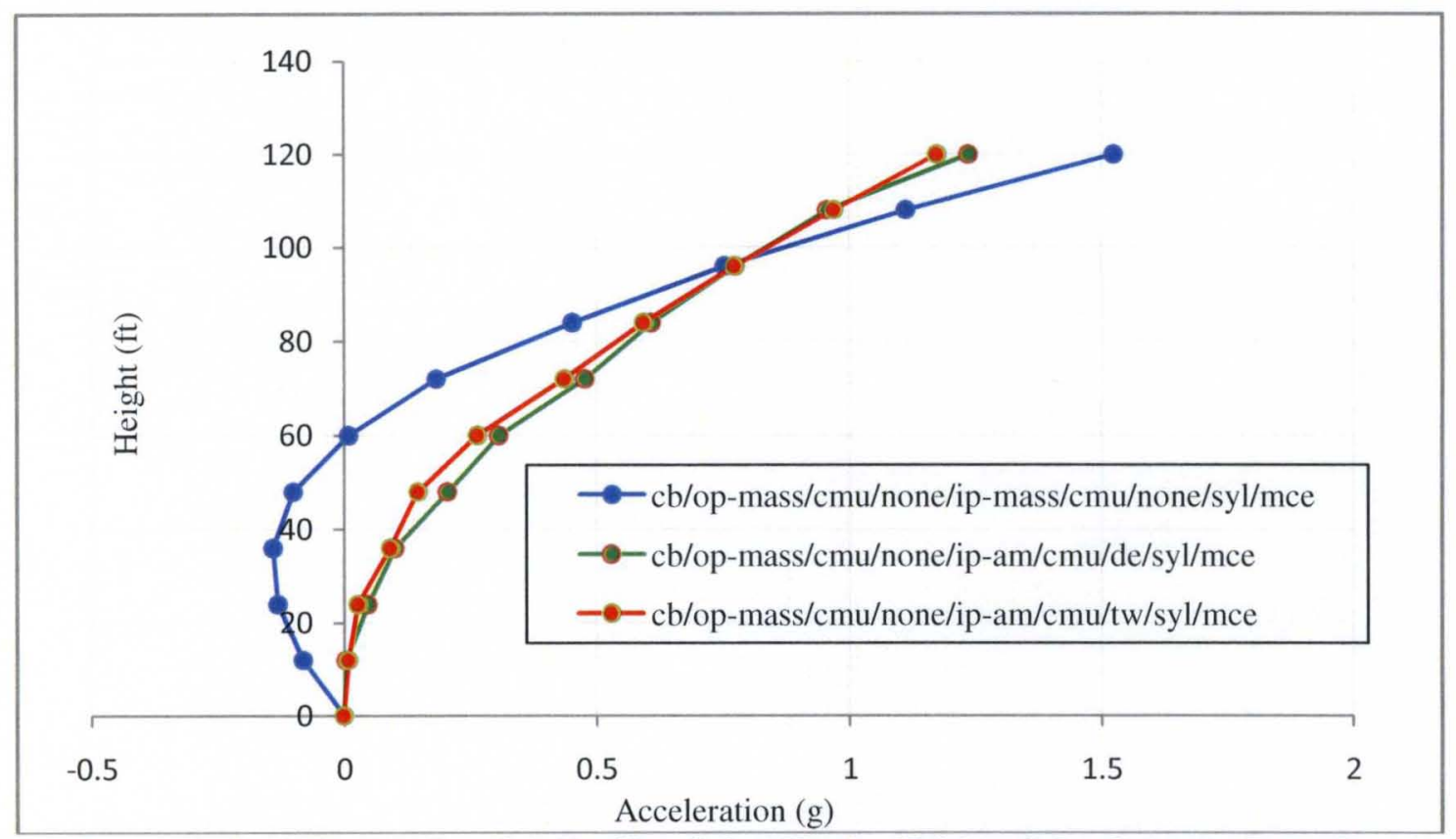

Figure C.3: Comparison of the Acceleration Profiles Going Up the Height of the Concrete Braced Frame, With a Mass Representation and Analytical Model Representations With Stiff and Flexible Ties, of the CMU Backed In Plane Wall System, and a Mass Representation of the Out Of Plane Wall System, at MCE of the Sylmar Ground Motion.

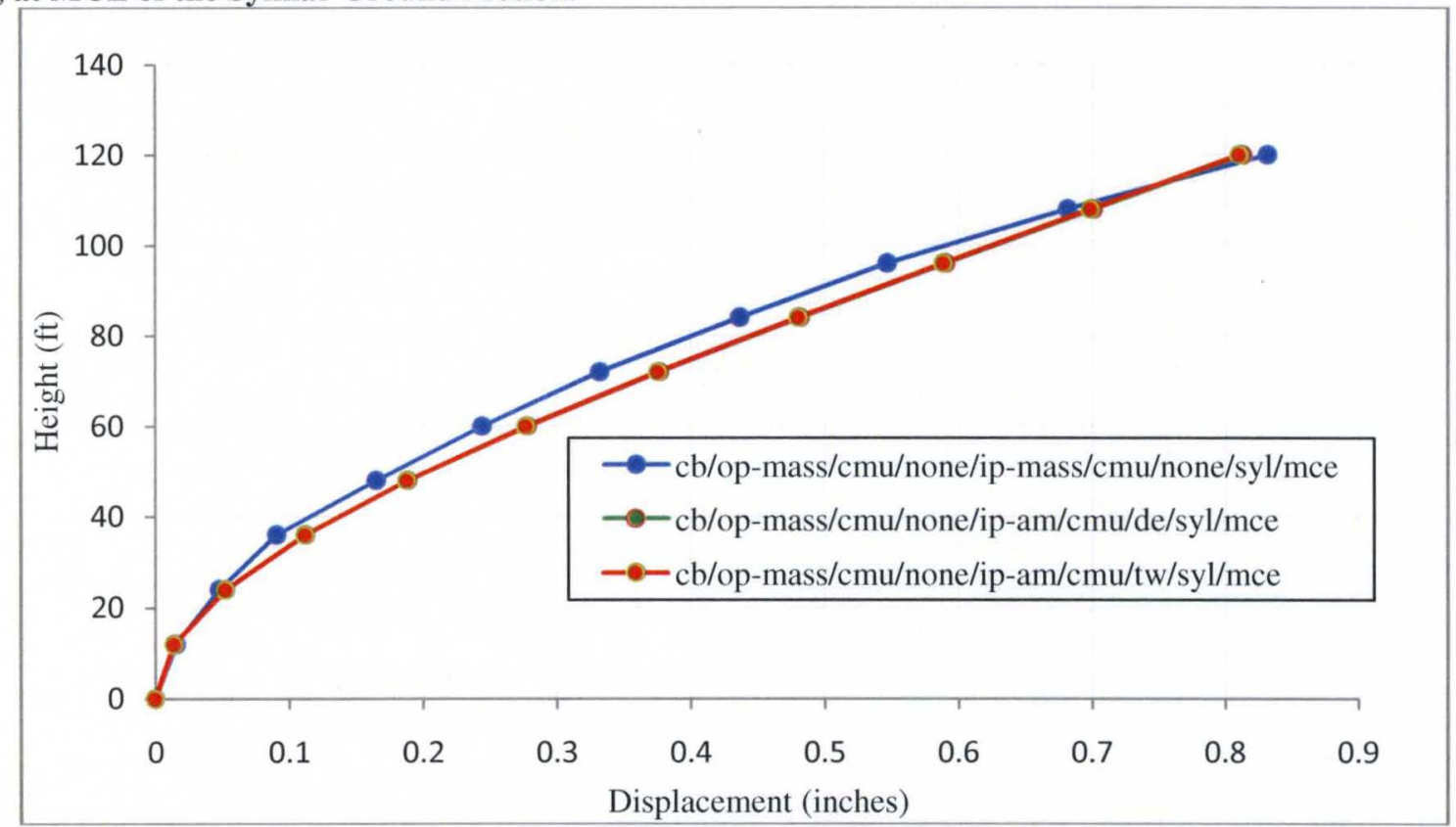

Figure C.4: Comparison of the Displacement Profiles Going Up the Height of the Concrete Braced Frame, With a Mass Representation and Analytical Model Representations With Stiff and Flexible Ties, of the CMU Backed In Plane Wall System, and a Mass Representation of the Out Of Plane Wall System, at MCE of the Sylmar Ground Motion. 


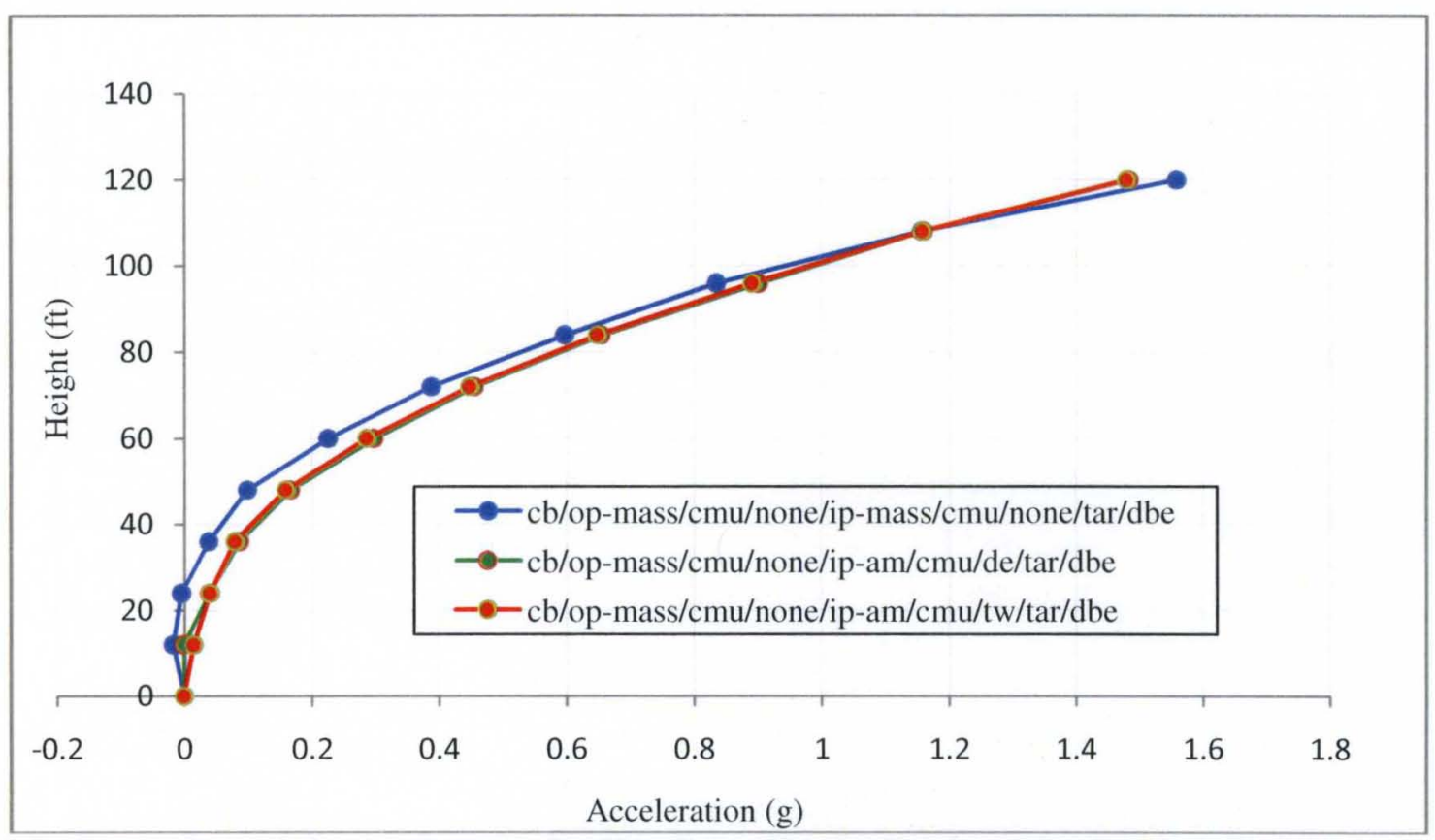

Figure C.5: Comparison of the Acceleration Profiles Going Up the Height of the Concrete Braced Frame, With a Mass Representation and Analytical Model Representations With Stiff and Flexible Ties, of the CMU Backed In Plane Wall System, and a Mass Representation of the Out Of Plane Wall System, at DBE of the Tarzana Ground Motion.

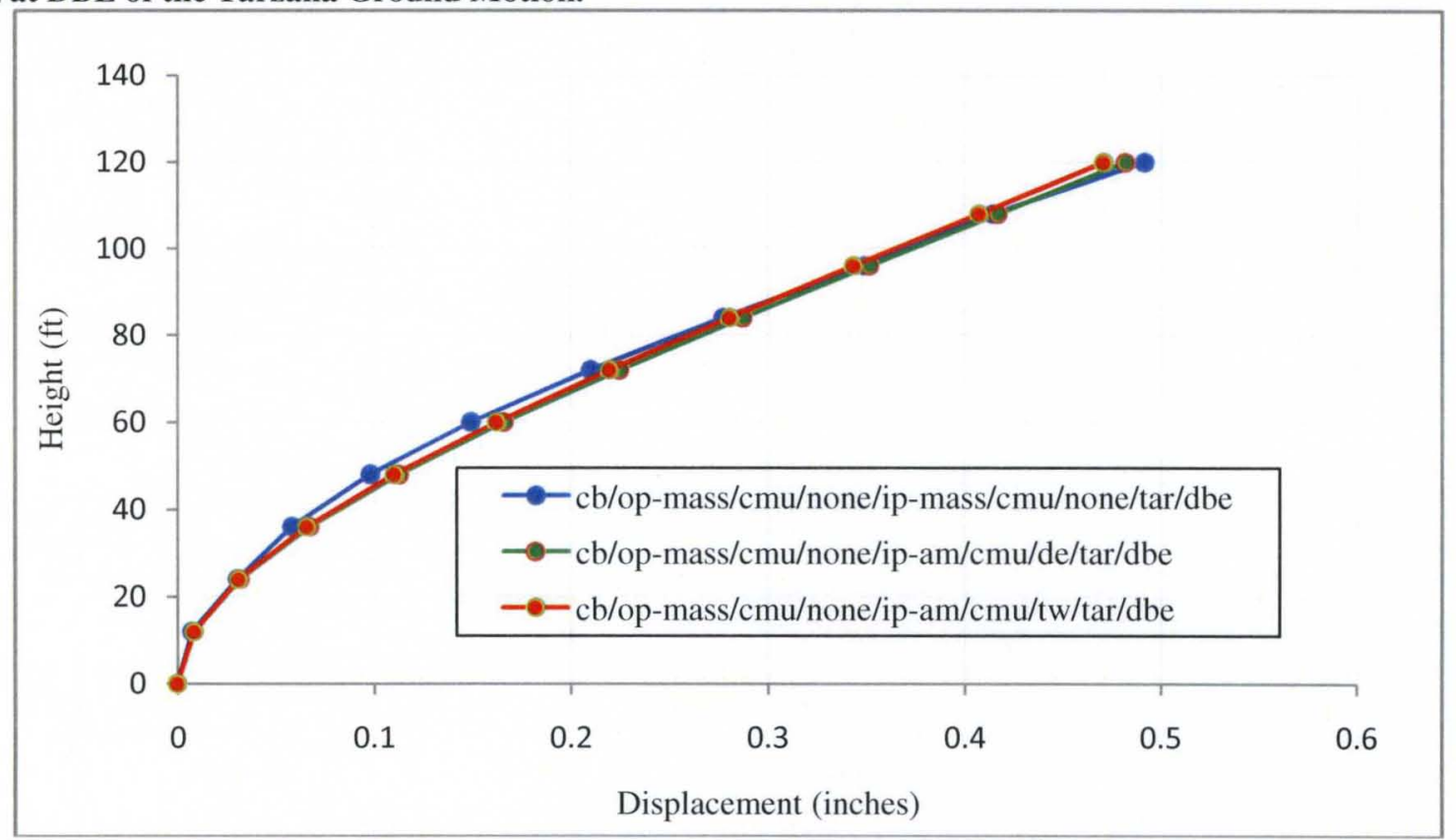

Figure C.6: Comparison of the Displacement Profiles Going Up the Height of the Concrete Braced Frame, With a Mass Representation and Analytical Model Representations With Stiff and Flexible Ties, of the CMU Backed In Plane Wall System, and a Mass Representation of the Out Of Plane Wall System, at DBE of the Tarzana Ground Motion. 


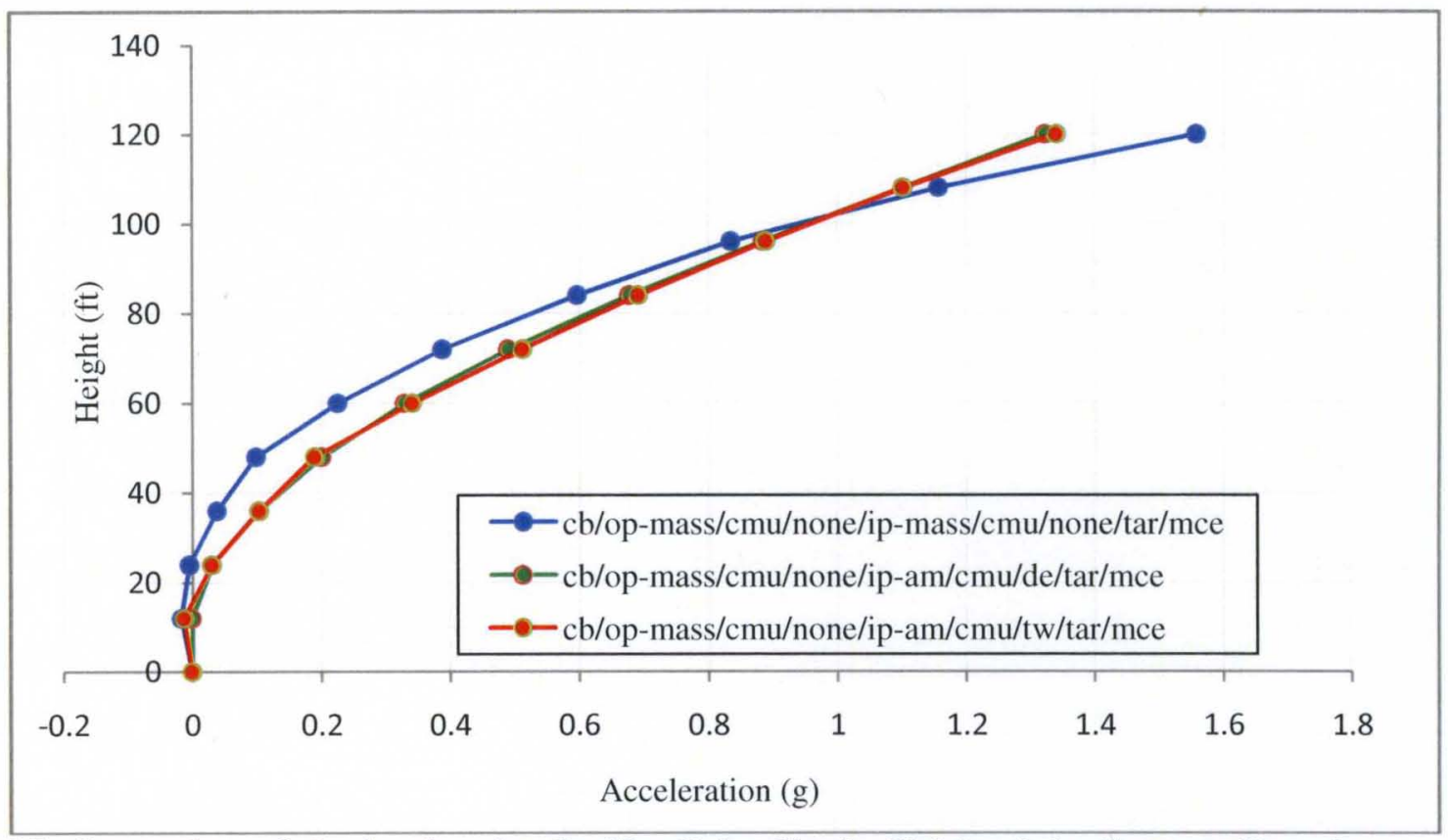

Figure C.7: Comparison of the Acceleration Profiles Going Up the Height of the Concrete Braced Frame, With a Mass Representation and Analytical Model Representations With Stiff and Flexible Ties, of the CMU Backed In Plane Wall System, and a Mass Representation of the Out Of Plane Wall System, at MCE of the Tarzana Ground Motion.

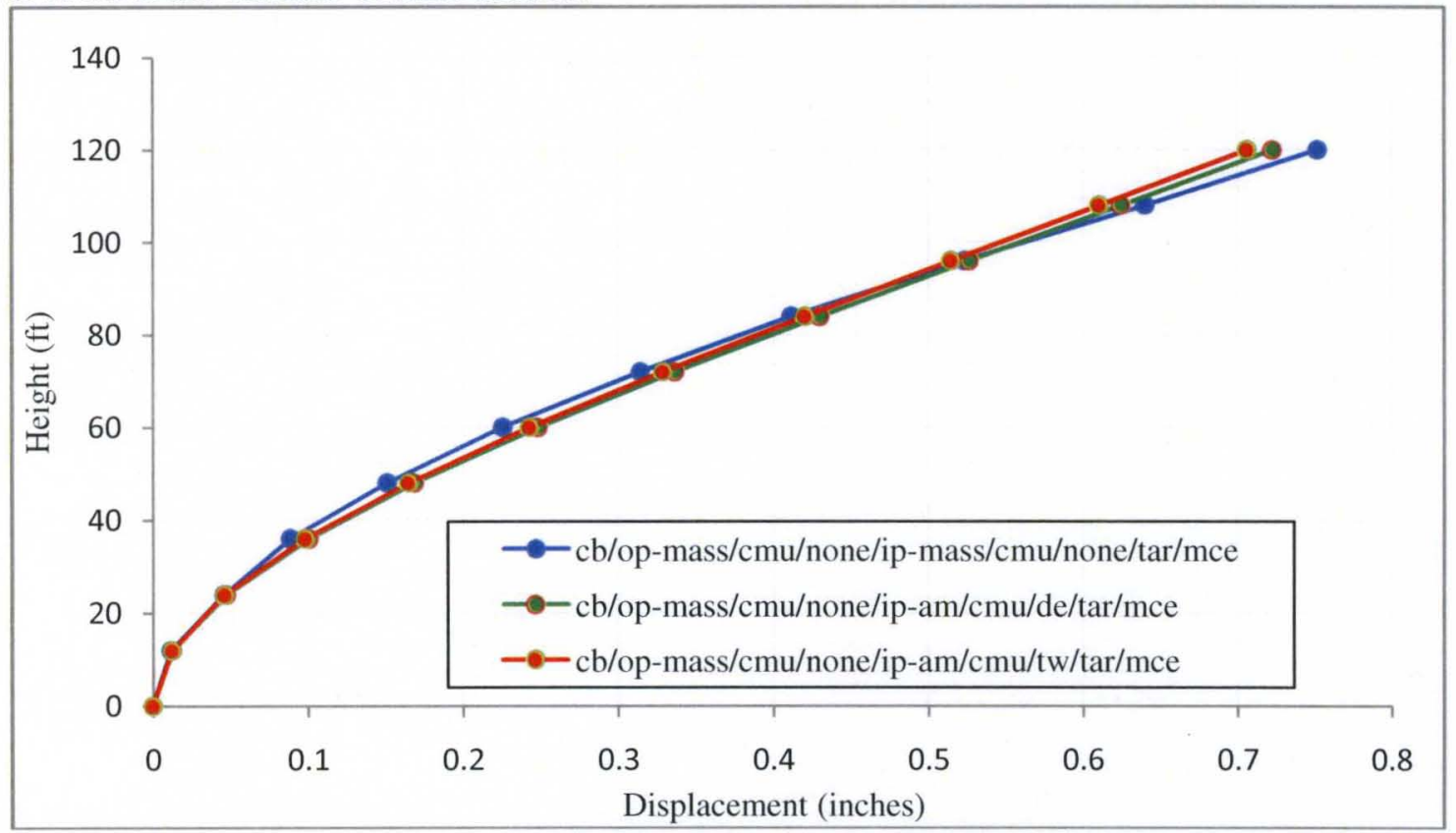

Figure C.8: Comparison of the Displacement Profiles Going Up the Height of the Concrete Braced Frame, With a Mass Representation and Analytical Model Representations With Stiff and Flexible Ties, of the CMU Backed In Plane Wall System, and a Mass Representation of the Out Of Plane Wall System, at MCE of the Tarzana Ground Motion. 


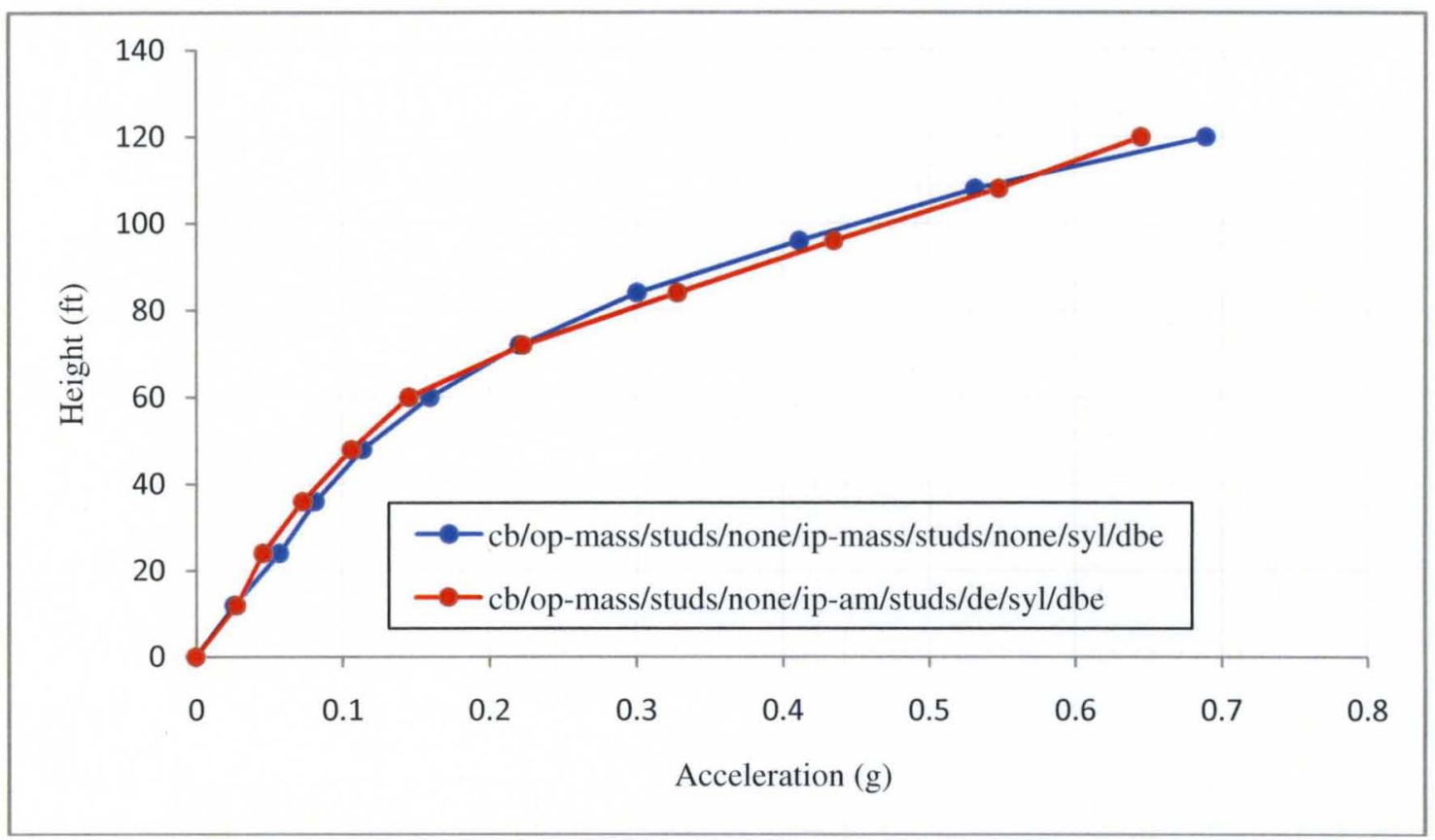

Figure C.9: Comparison of the Acceleration Profiles Going Up the Height of the Concrete Braced Frame, With a Mass Representation and Analytical Model Representations With Double Eye and Pintle Ties, of the Stud Backed In Plane Wall System, and a Mass Representation of the Out Of Plane Wall System, at DBE of the Sylmar Ground Motion.

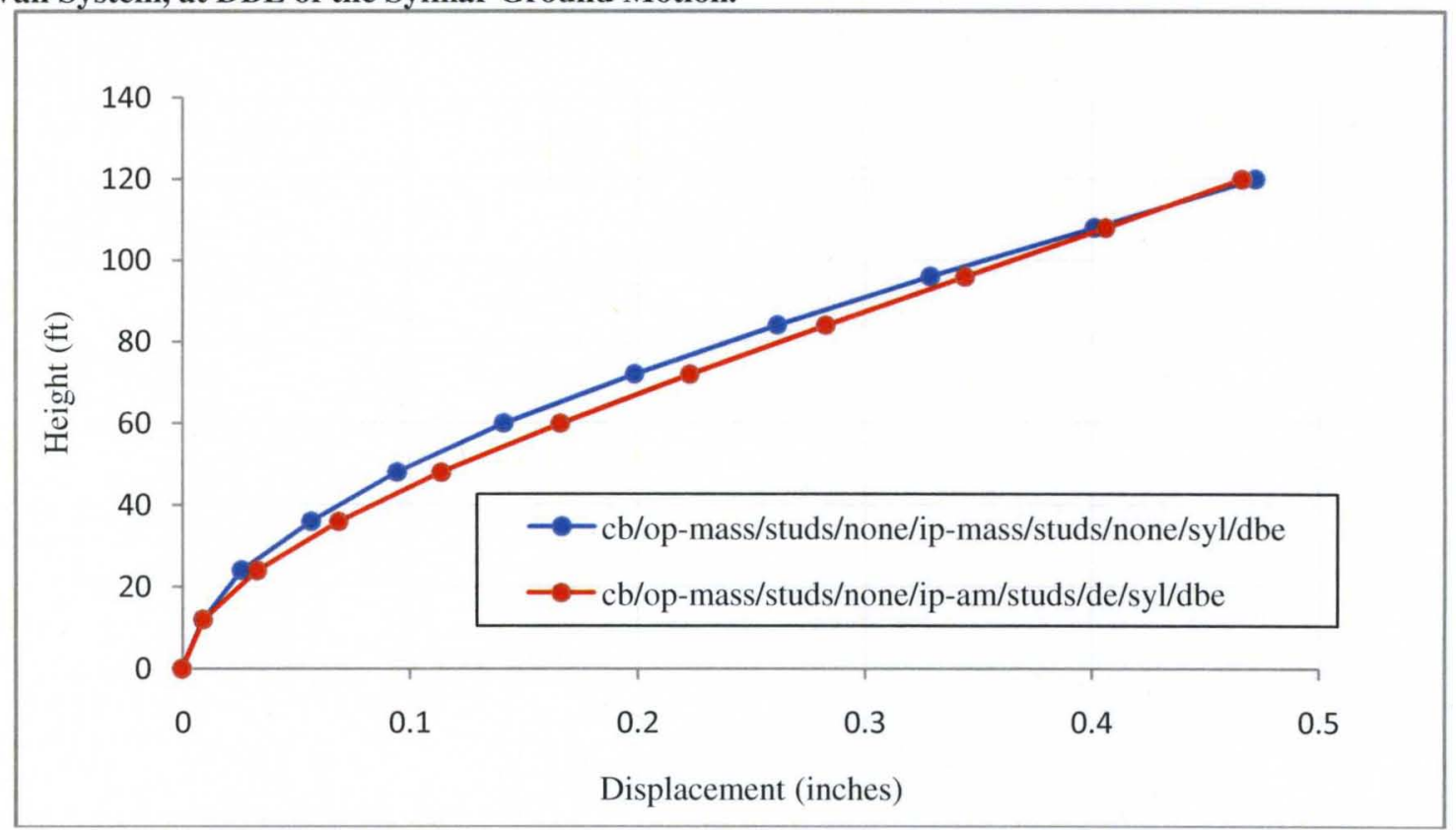

Figure C.10: Comparison of the Displacement Profiles Going Up the Height of the Concrete Braced Frame, With a Mass Representation and Analytical Model Representations With Double Eye and Pintle Ties, of the Stud Backed In Plane Wall System, and a Mass Representation of the Out Of Plane Wall System, at DBE of the Sylmar Ground Motion. 


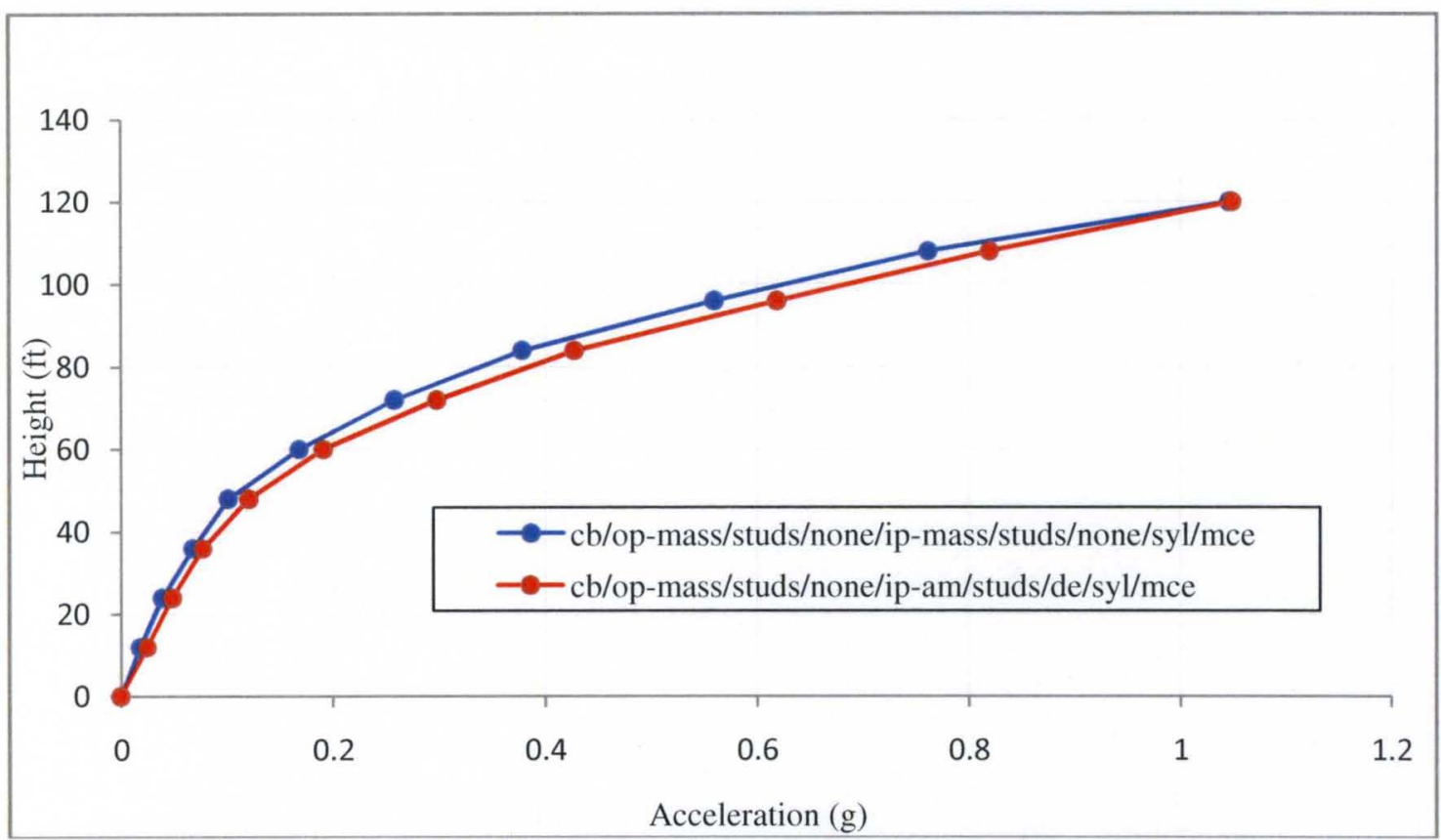

Figure C.11: Comparison of the Acceleration Profiles Going Up the Height of the Concrete Braced Frame, With a Mass Representation and Analytical Model Representations With Double Eye and Pintle Ties, of the Stud Backed In Plane Wall System, and a Mass Representation of the Out Of Plane Wall System, at MCE of the Sylmar Ground Motion.

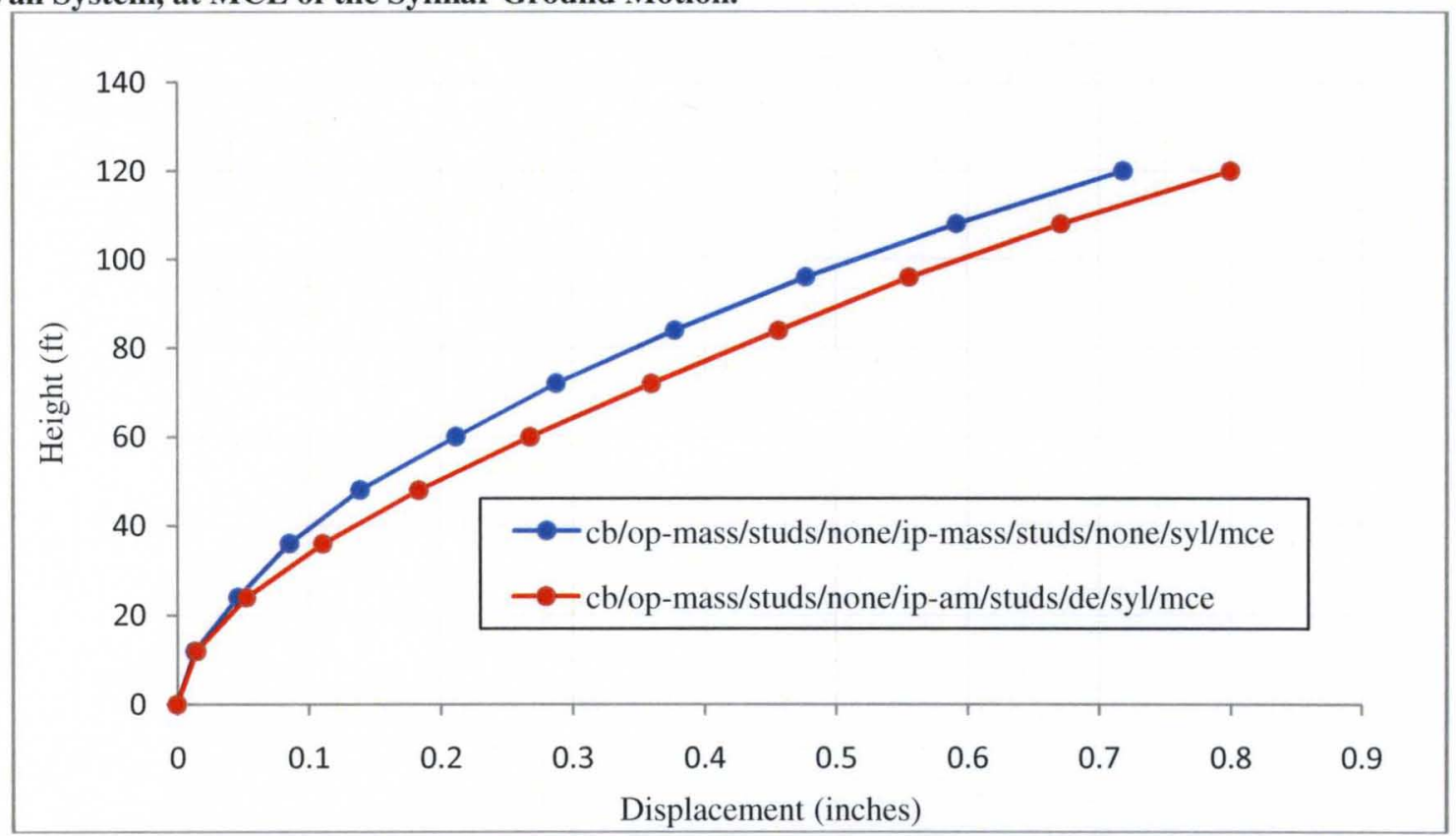

Figure C.12: Comparison of the Displacement Profiles Going Up the Height of the Concrete Braced Frame, With a Mass Representation and Analytical Model Representations With Double Eye and Pintle Ties, of the Stud Backed In Plane Wall System, and a Mass Representation of the Out Of Plane Wall System, at MCE of the Sylmar Ground Motion. 


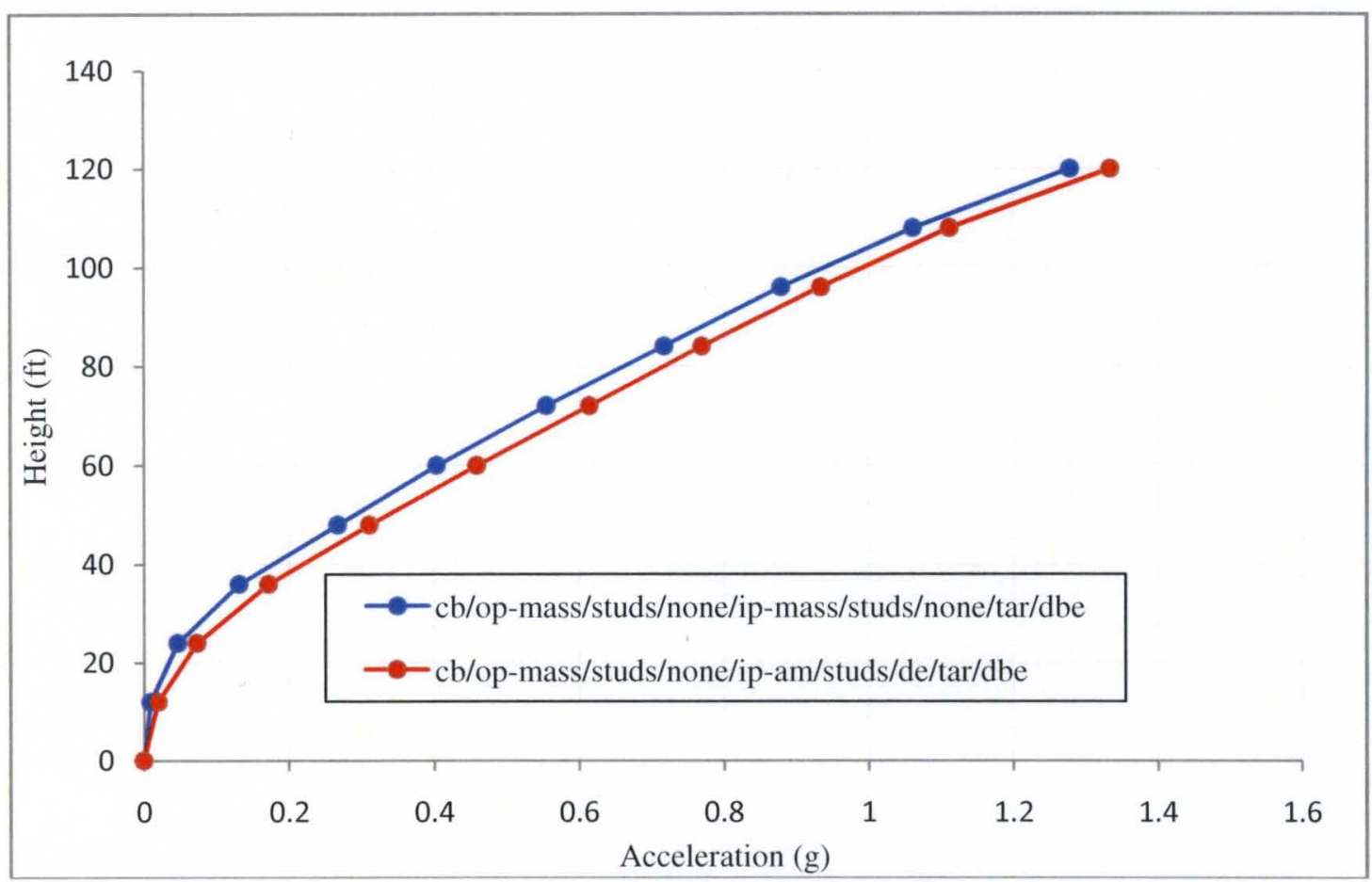

Figure C.13: Comparison of the Acceleration Profiles Going Up the Height of the Concrete Braced Frame, With a Mass Representation and Analytical Model Representations With Double Eye and Pintle Ties, of the Stud Backed In Plane Wall System, and a Mass Representation of the Out Of Plane Wall System, at DBE of the Tarzana Ground Motion.

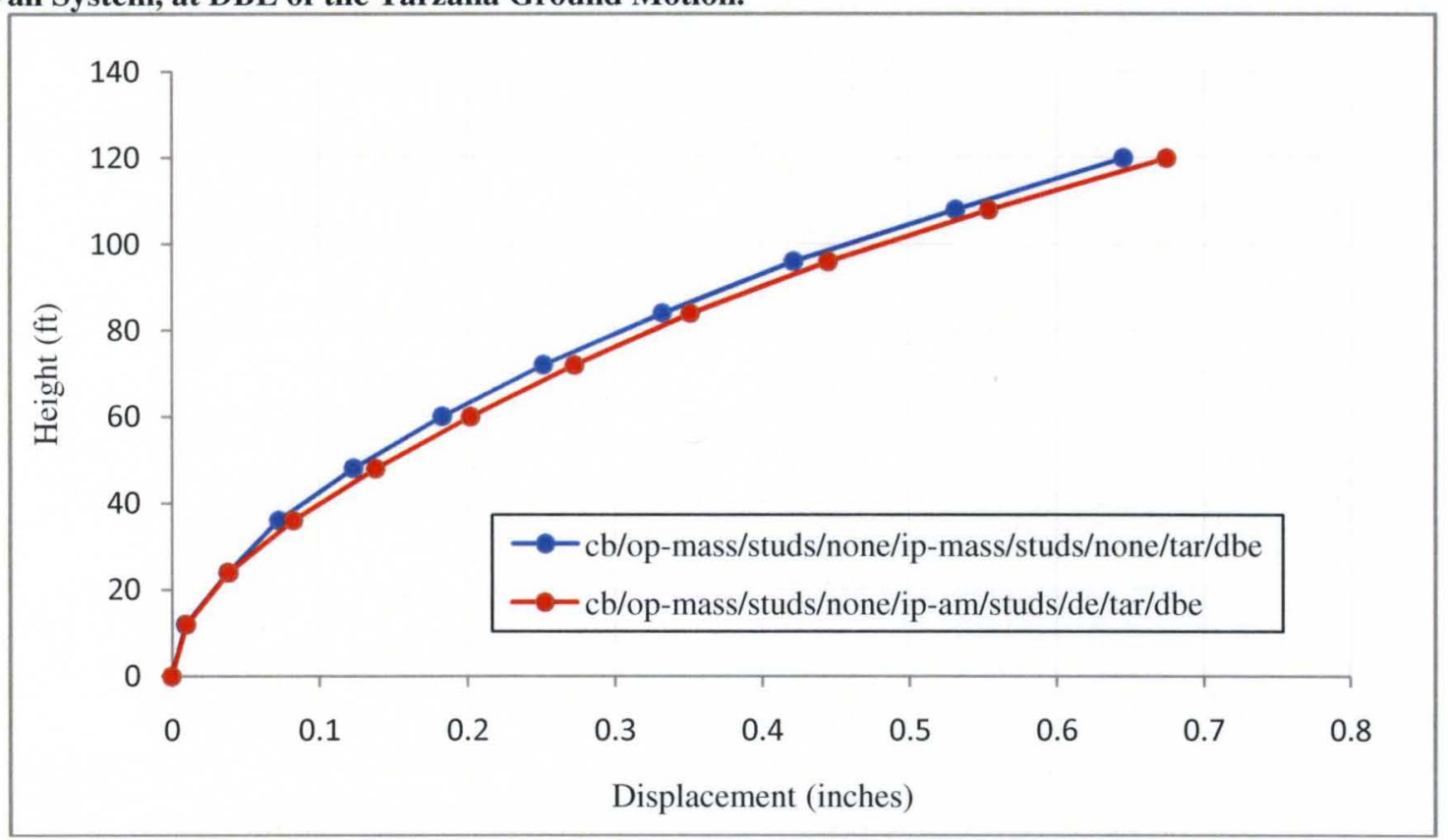

Figure C.14: Comparison of the Displacement Profiles Going Up the Height of the Concrete Braced Frame, With a Mass Representation and Analytical Model Representations With Double Eye and Pintle Ties, of the Stud Backed In Plane Wall System, and a Mass Representation of the Out Of Plane Wall System, at DBE of the Tarzana Ground Motion. 


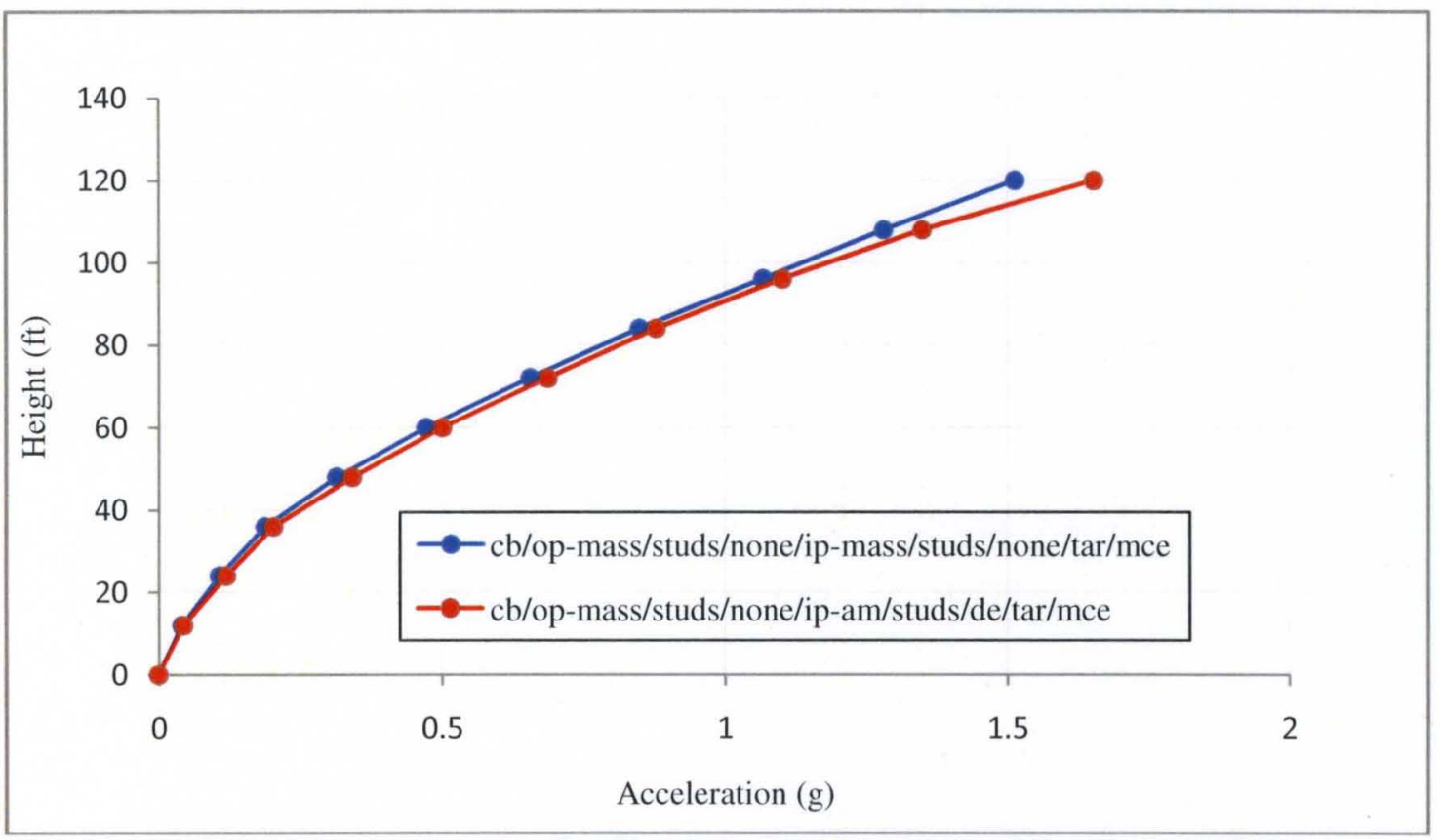

Figure C.15: Comparison of the Acceleration Profiles Going Up the Height of the Concrete Braced Frame, With a Mass Representation and Analytical Model Representations With Double Eye and Pintle Ties, of the Stud Backed In Plane Wall System, and a Mass Representation of the Out Of Plane Wall System, at MCE of the Tarzana Ground Motion.

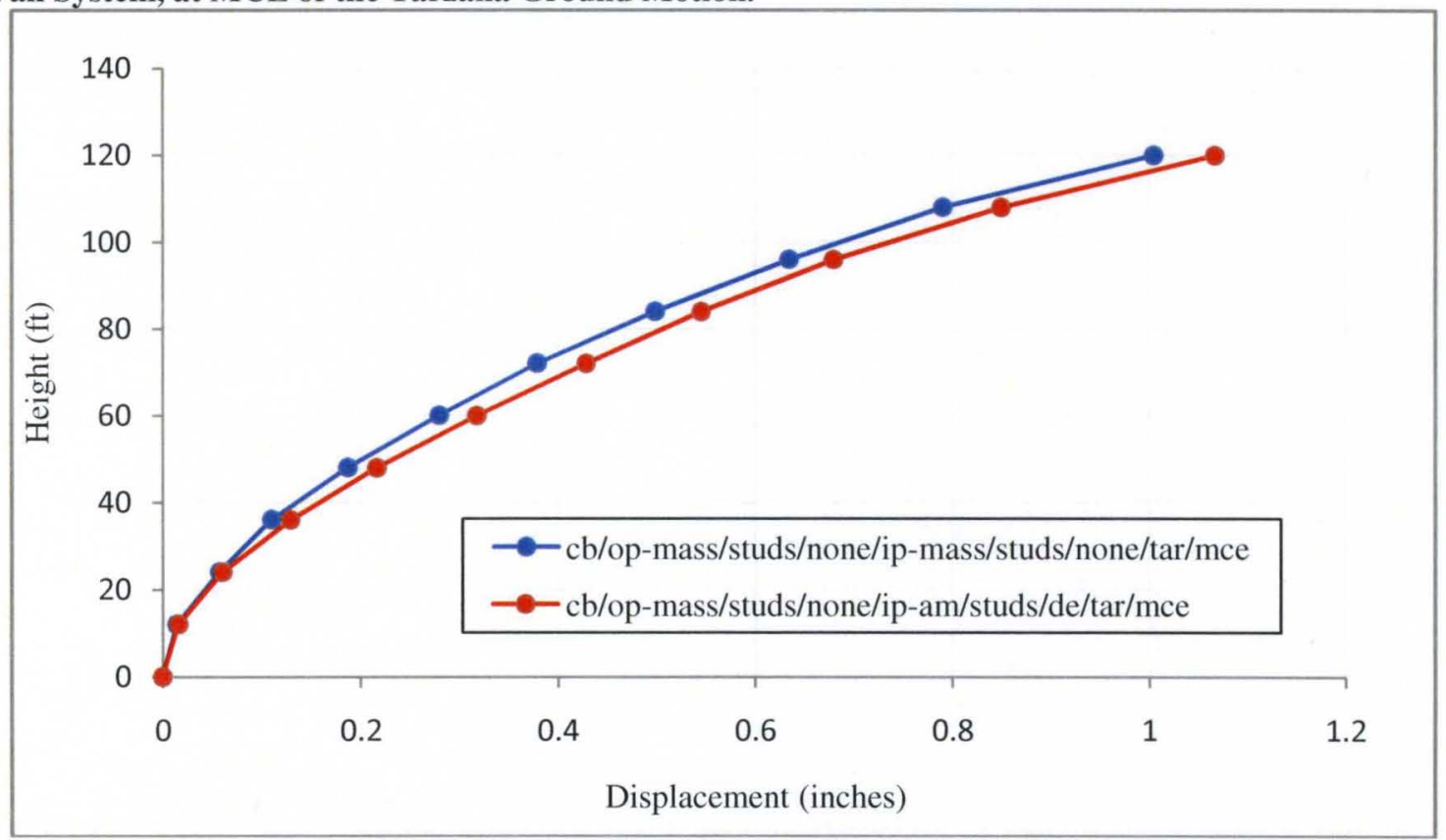

Figure C.15: Comparison of the Displacement Profiles Going Up the Height of the Concrete Braced Frame, With a Mass Representation and Analytical Model Representations With Double Eye and Pintle Ties, of the Stud Backed In Plane Wall System, and a Mass Representation of the Out Of Plane Wall System, at MCE of the Tarzana Ground Motion. 


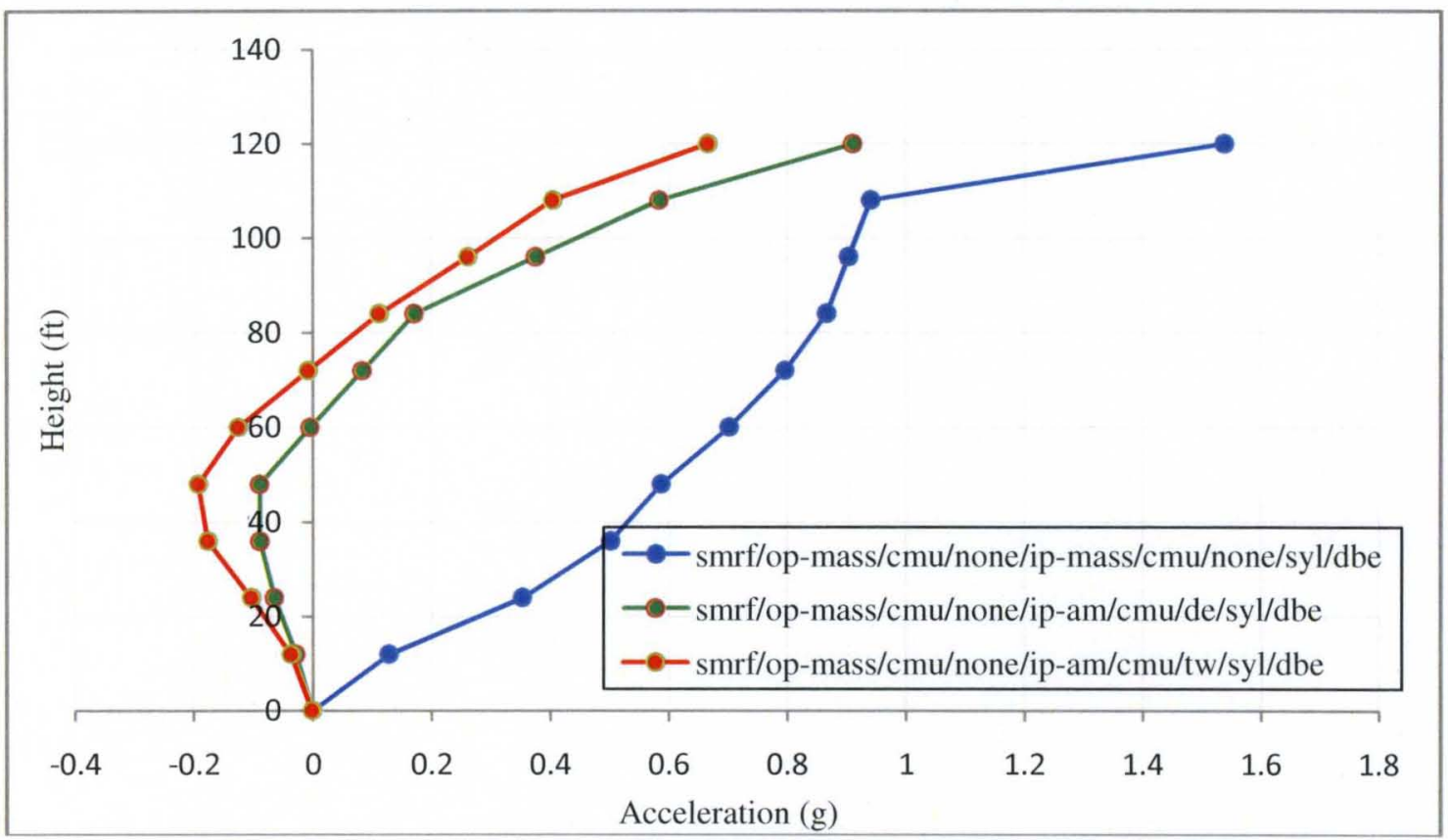

Figure C.16: Comparison of the Acceleration Profiles Going Up the Height of the Steel Moment Resisting Frame, With a Mass Representation and Analytical Model Representations With Stiff and Flexible Ties, of the CMU Backed In Plane Wall System, and a Mass Representation of the Out Of Plane Wall System, at DBE of the Sylmar Ground Motion.

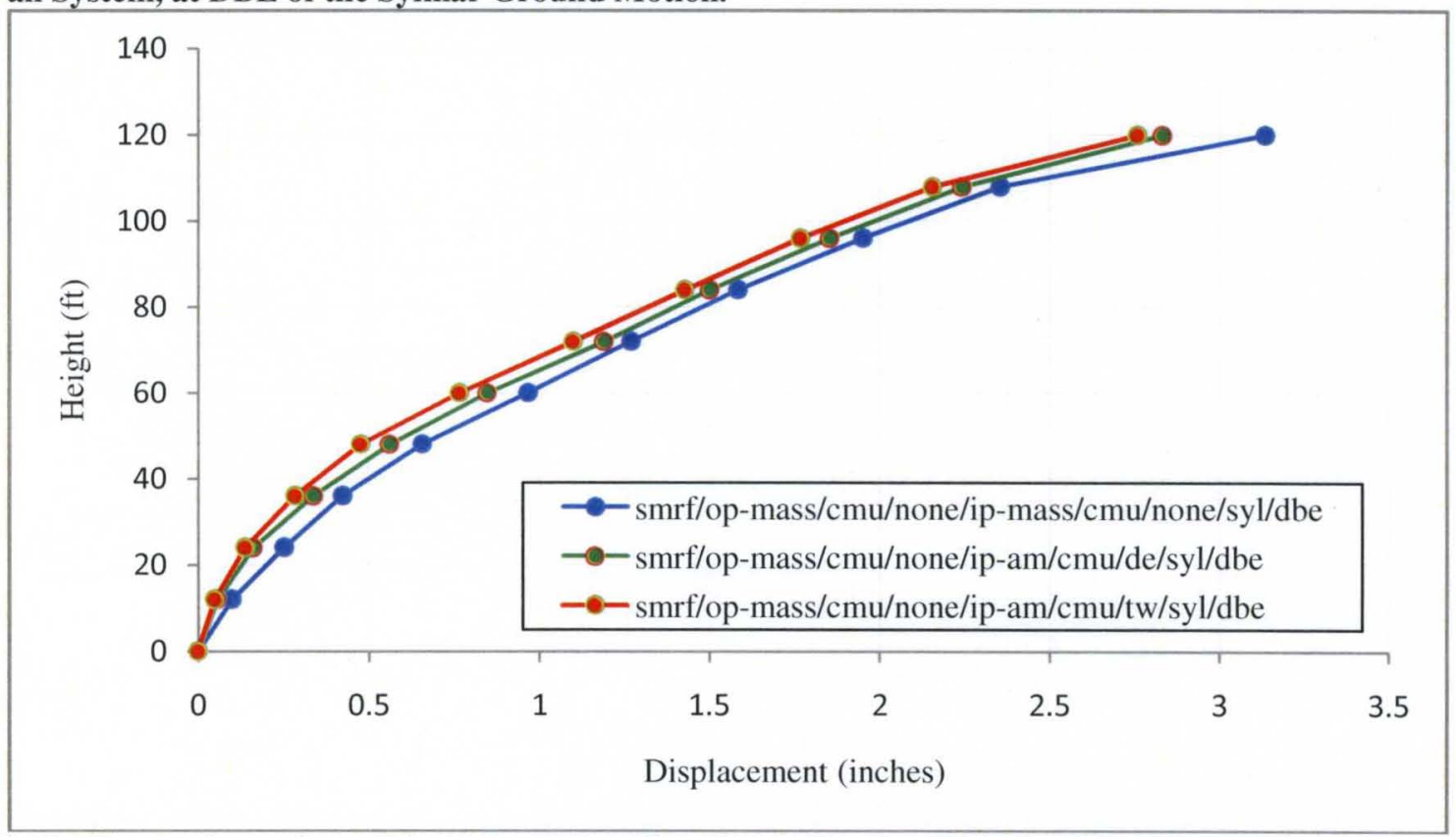

Figure C.17: Comparison of the Displacement Profiles Going Up the Height of the Steel Moment Resisting Frame, With a Mass Representation and Analytical Model Representations With Stiff and Flexible Ties, of the CMU Backed In Plane Wall System, and a Mass Representation of the Out Of Plane Wall System, at DBE of the Sylmar Ground Motion. 


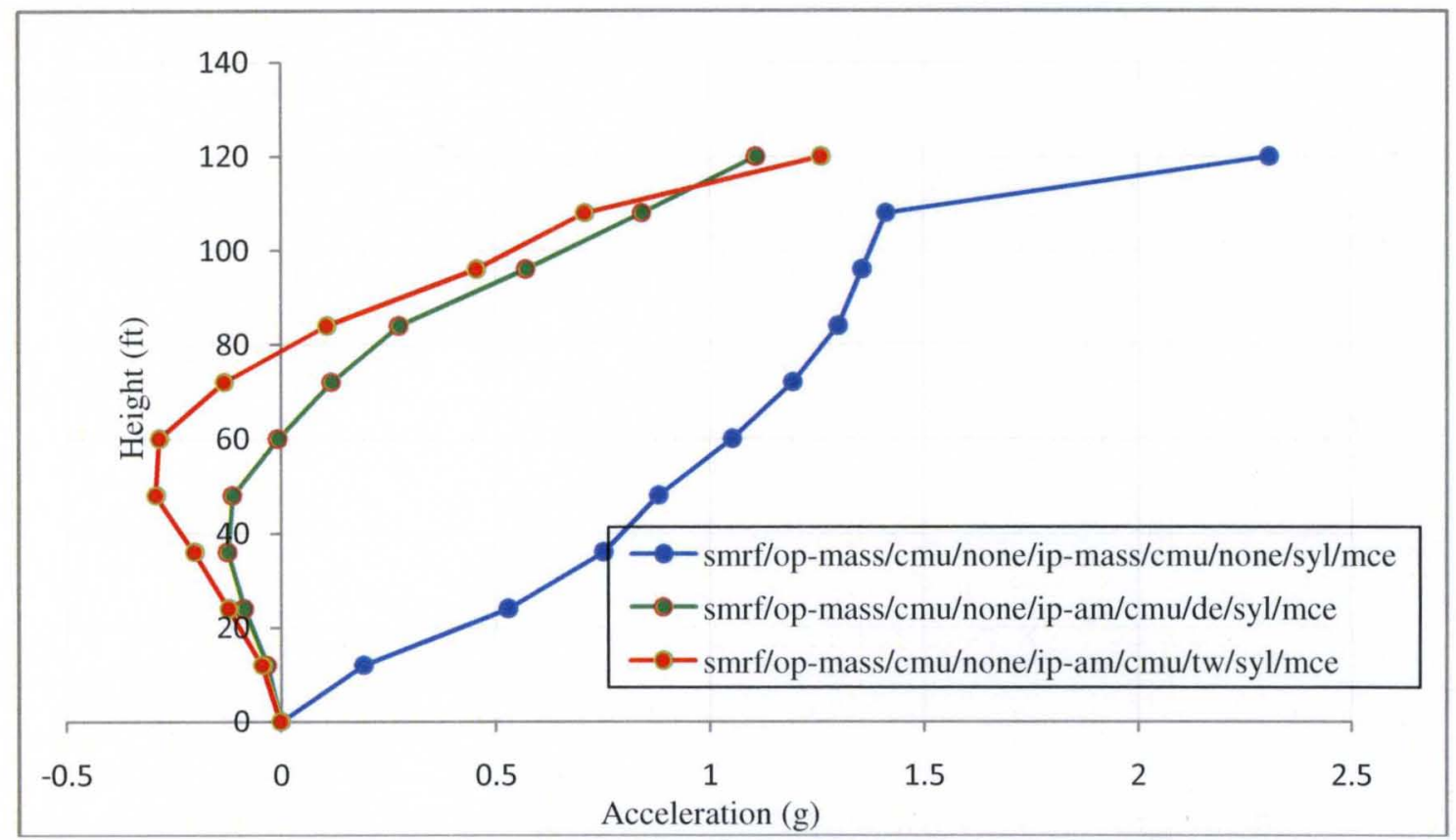

Figure C.18: Comparison of the Acceleration Profiles Going Up the Height of the Steel Moment Resisting Frame, With a Mass Representation and Analytical Model Representations With Stiff and Flexible Ties, of the CMU Backed In Plane Wall System, and a Mass Representation of the Out Of Plane Wall System, at MCE of the Sylmar Ground Motion.

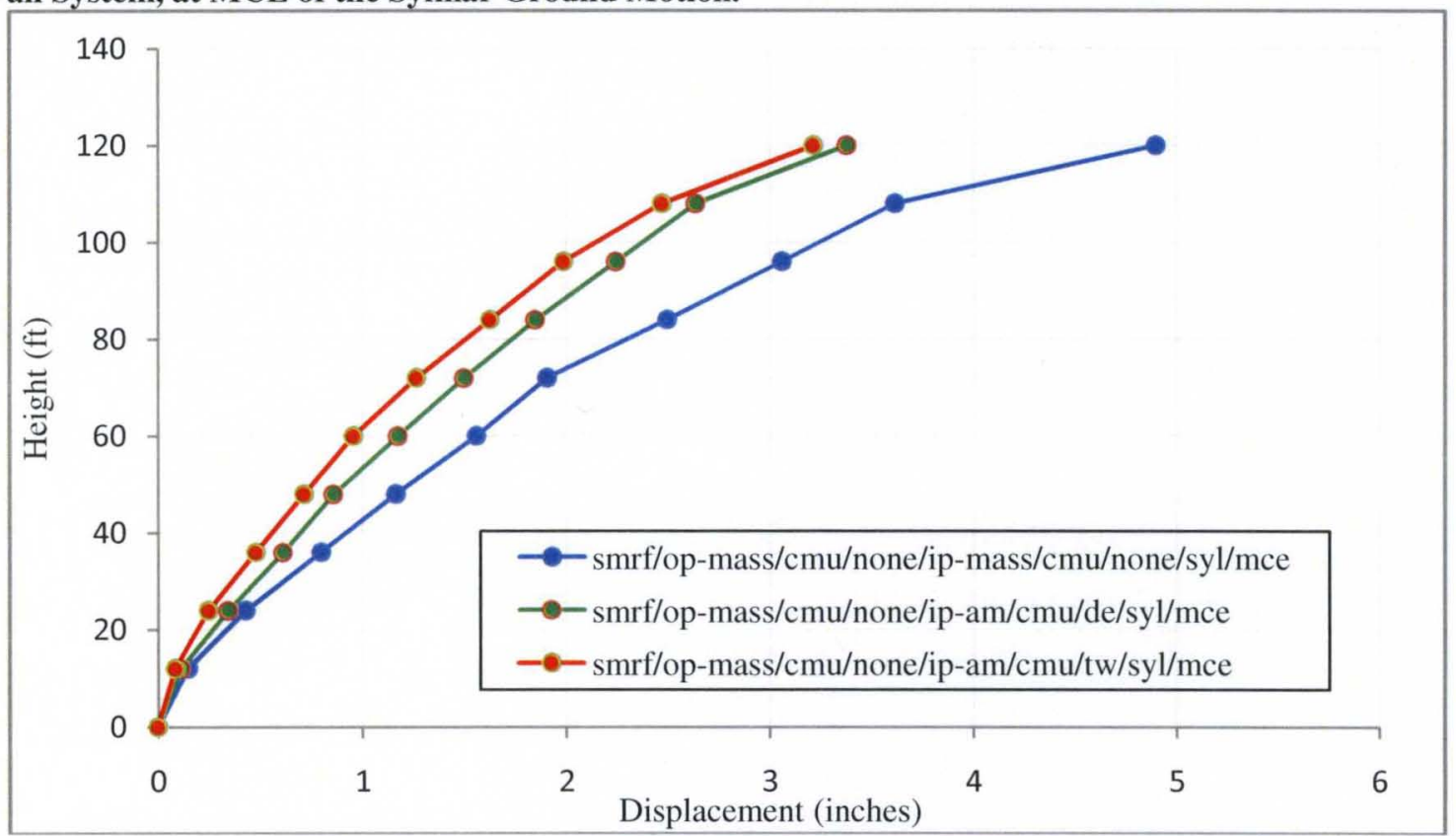

Figure C.19: Comparison of the Displacement Profiles Going Up the Height of the Steel Moment Resisting Frame, With a Mass Representation and Analytical Model Representations With Stiff and Flexible Ties, of the CMU Backed In Plane Wall System, and a Mass Representation of the Out Of Plane Wall System, at MCE of the Sylmar Ground Motion. 


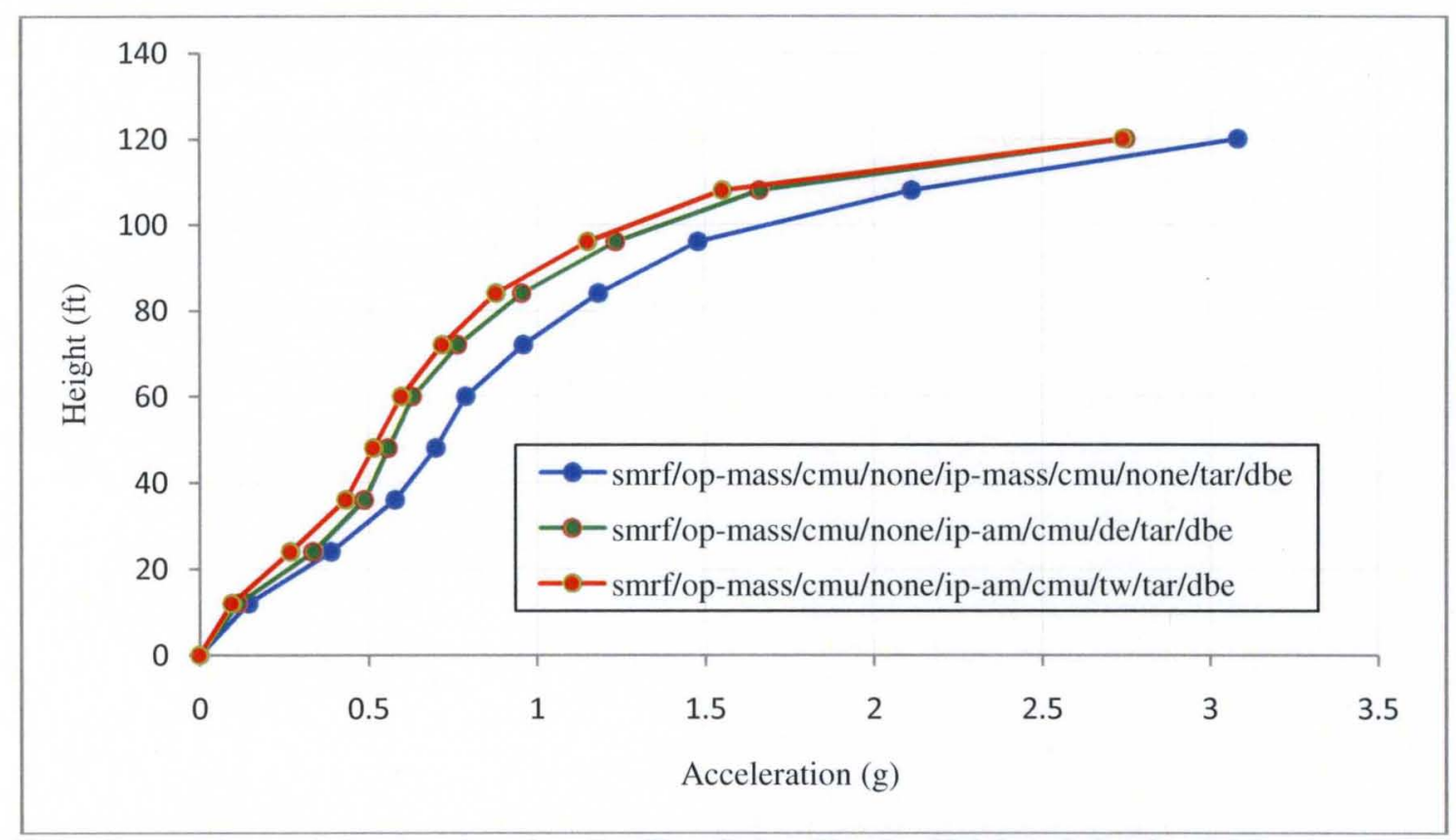

Figure C.20: Comparison of the Acceleration Profiles Going Up the Height of the Steel Moment Resisting Frame, With a Mass Representation and Analytical Model Representations With Stiff and Flexible Ties, of the CMU Backed In Plane Wall System, and a Mass Representation of the Out Of Plane Wall System, at DBE of the Tarzana Ground Motion.

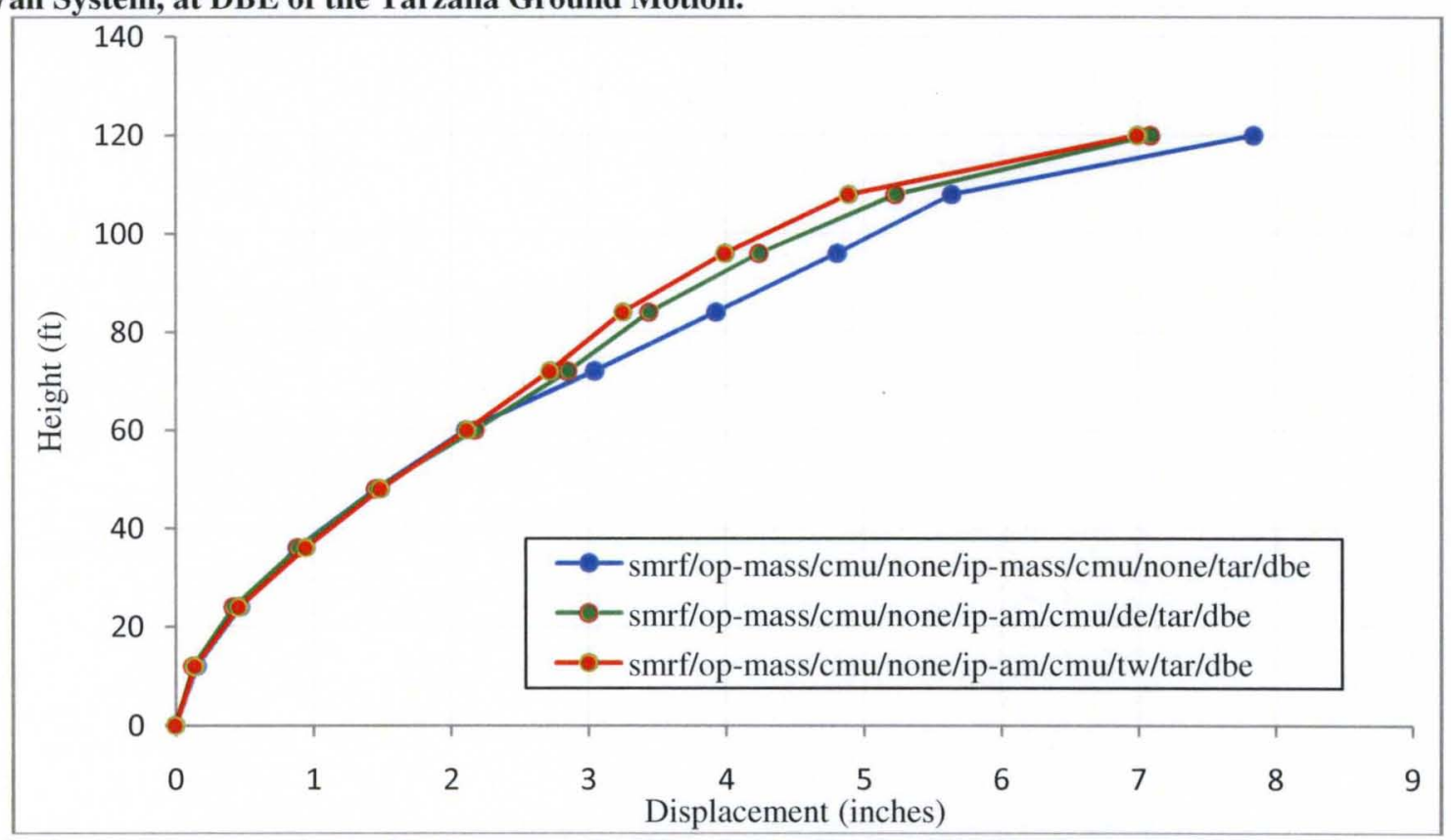

Figure C.21: Comparison of the Displacement Profiles Going Up the Height of the Steel Moment Resisting Frame, With a Mass Representation and Analytical Model Representations With Stiff and Flexible Ties, of the CMU Backed In Plane Wall System, and a Mass Representation of the Out Of Plane Wall System, at DBE of the Tarzana Ground Motion. 


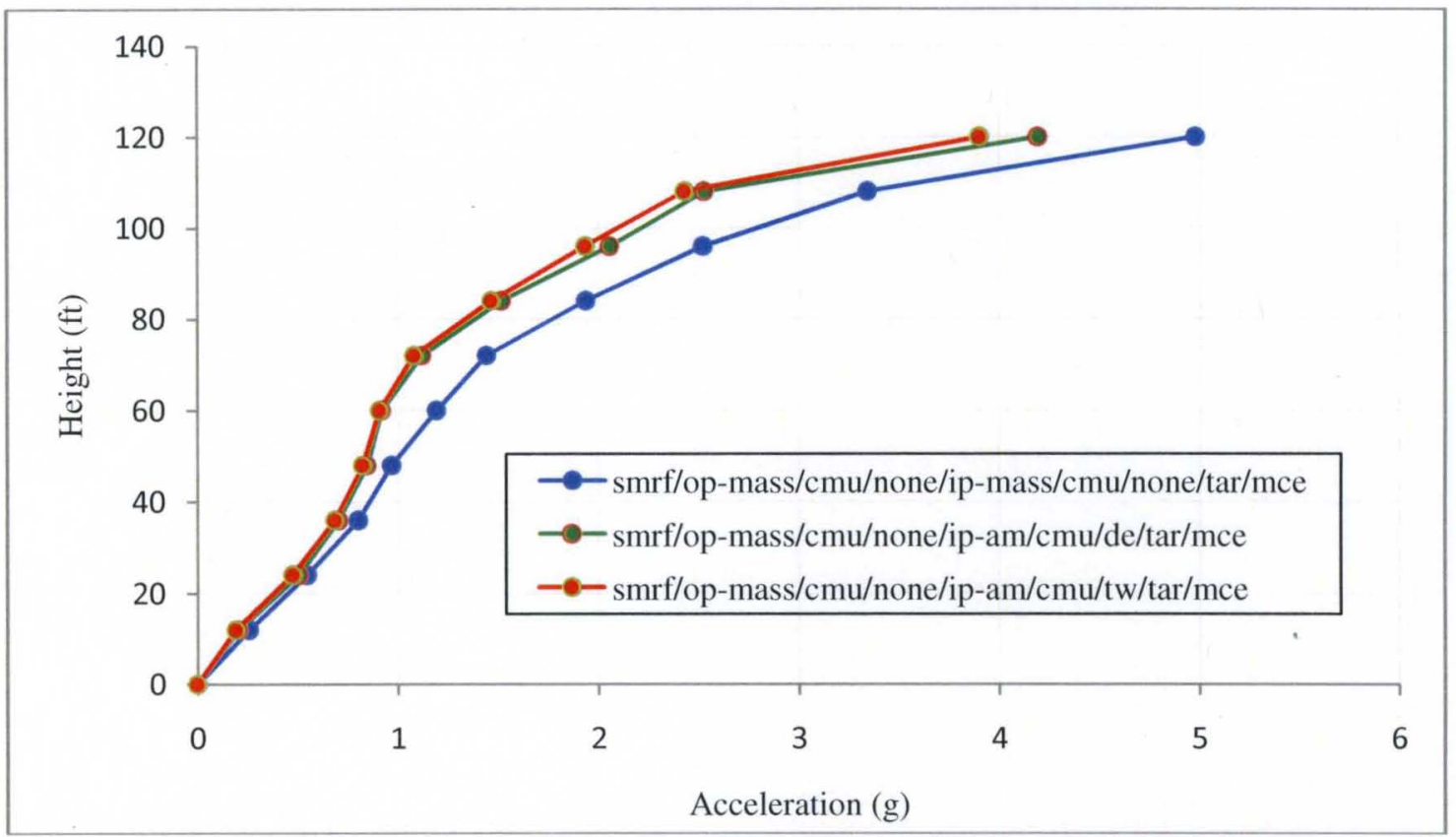

Figure C.22: Comparison of the Acceleration Profiles Going Up the Height of the Steel Moment Resisting Frame, With a Mass Representation and Analytical Model Representations With Stiff and Flexible Ties, of the CMU Backed In Plane Wall System, and a Mass Representation of the Out Of Plane Wall System, at MCE of the Tarzana Ground Motion.

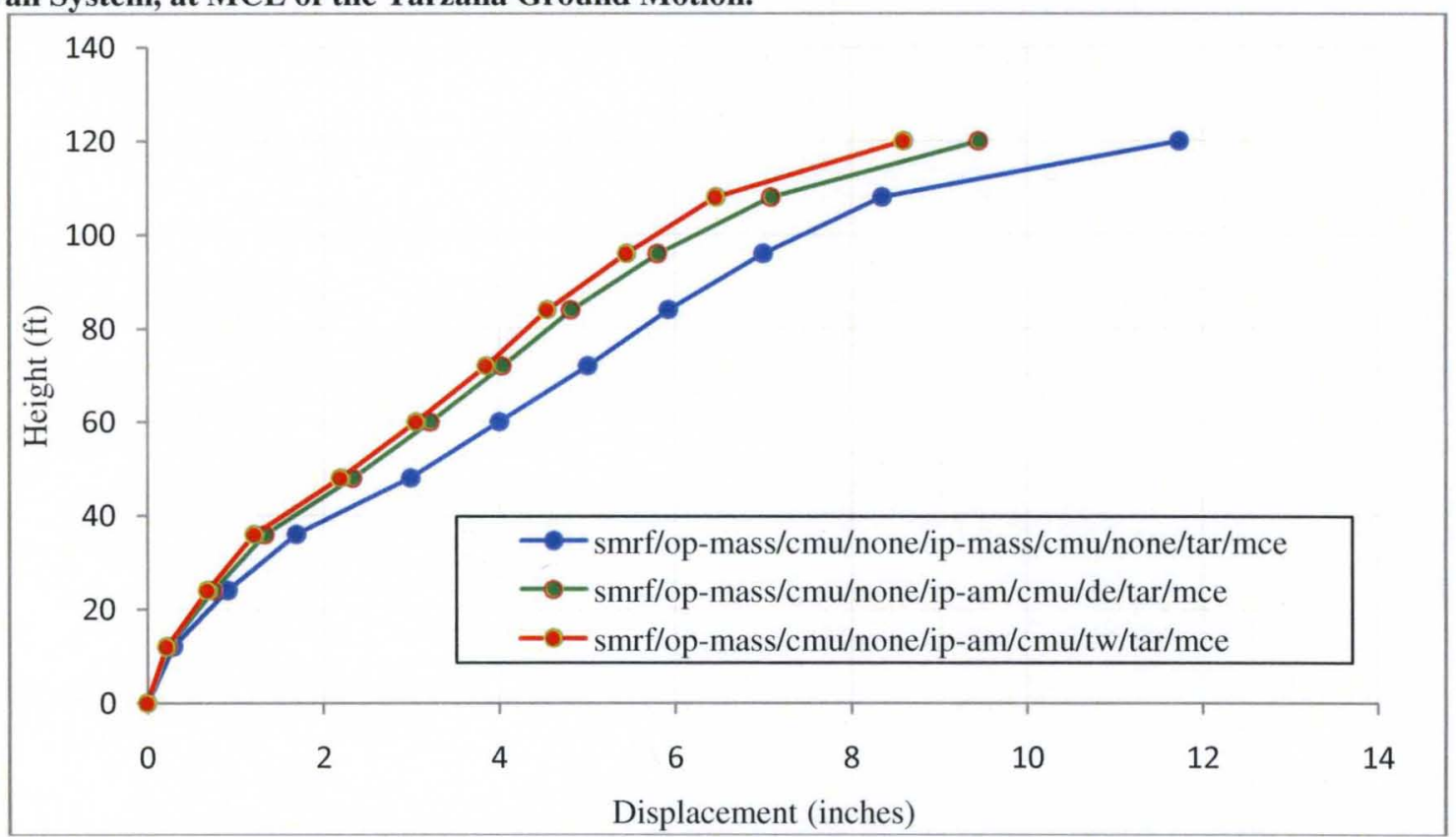

Figure C.23: Comparison of the Displacement Profiles Going Up the Height of the Steel Moment Resisting Frame, With a Mass Representation and Analytical Model Representations With Stiff and Flexible Ties, of the CMU Backed In Plane Wall System, and a Mass Representation of the Out Of Plane Wall System, at MCE of the Tarzana Ground Motion. 


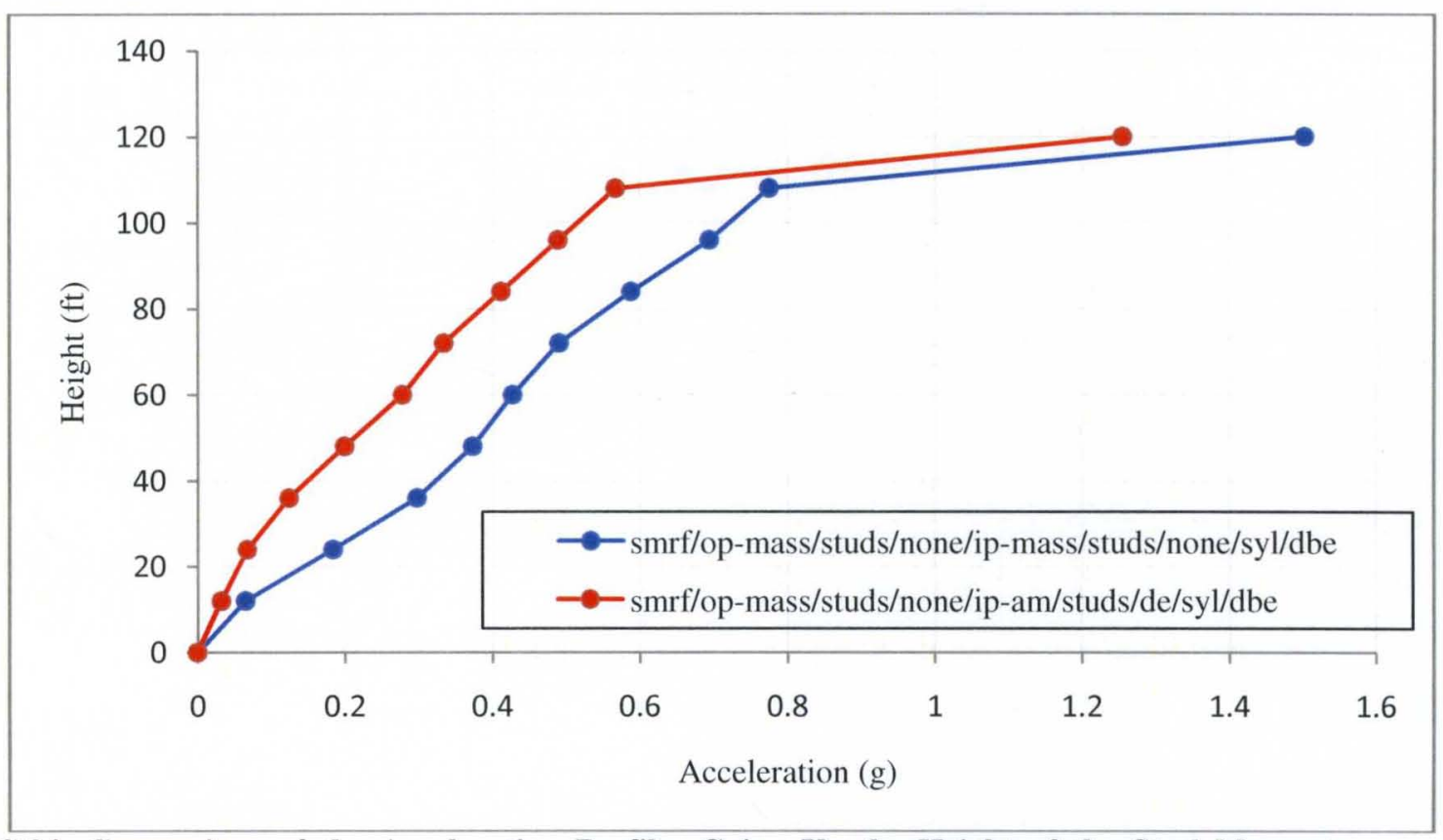

Figure C.24: Comparison of the Acceleration Profiles Going Up the Height of the Steel Moment Resisting Frame, With a Mass Representation and Analytical Model Representations With Double Eye and Pintle Ties, of the Stud Backed In Plane Wall System, and a Mass Representation of the Out Of Plane Wall System, at DBE of the Sylmar Ground Motion.

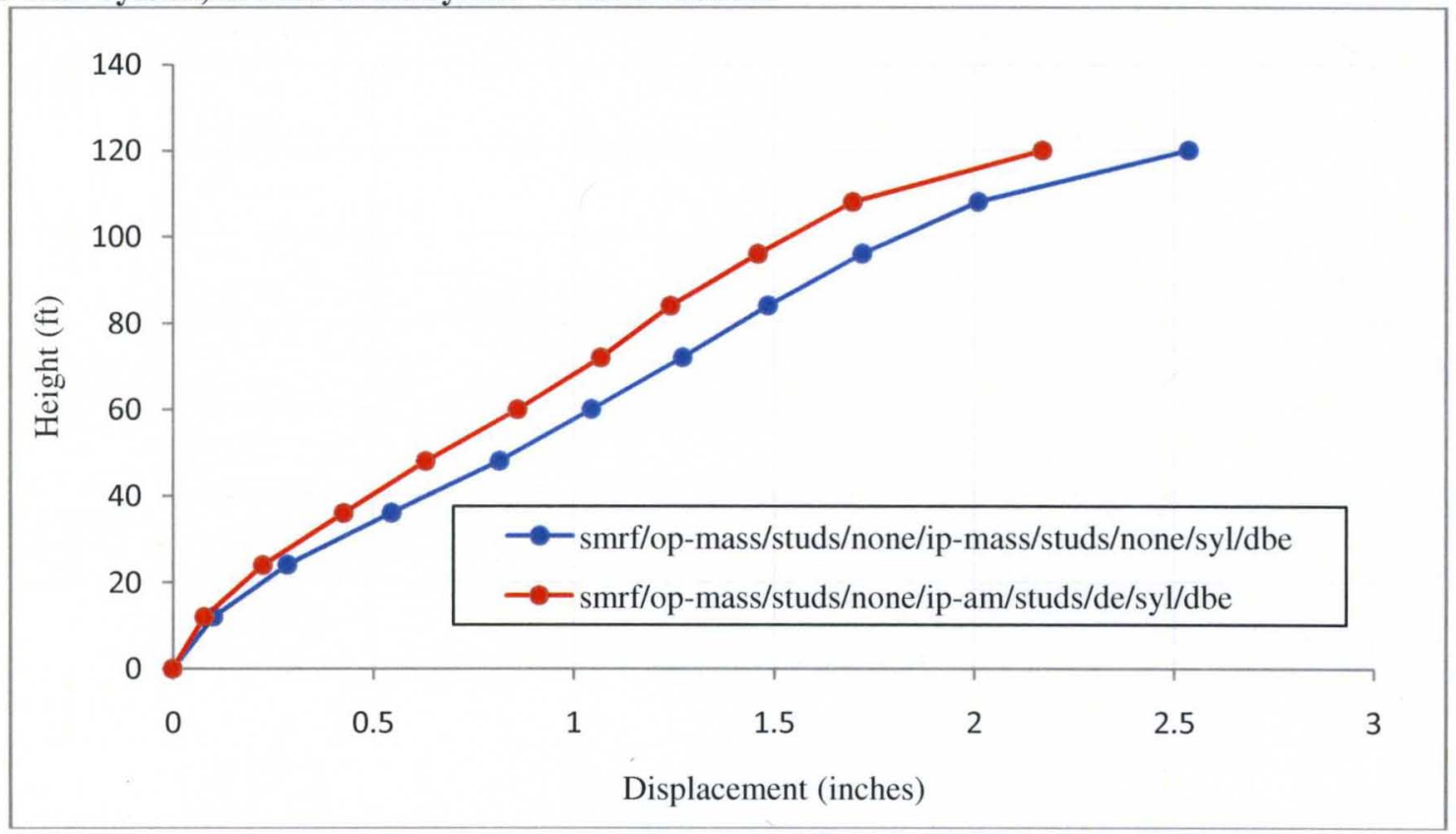

Figure C.25: Comparison of the Displacement Profiles Going Up the Height of the Steel Moment Resisting Frame, With a Mass Representation and Analytical Model Representations With Double Eye and Pintle Ties, of the Stud Backed In Plane Wall System, and a Mass Representation of the Out Of Plane Wall System, at DBE of the Sylmar Ground Motion. 


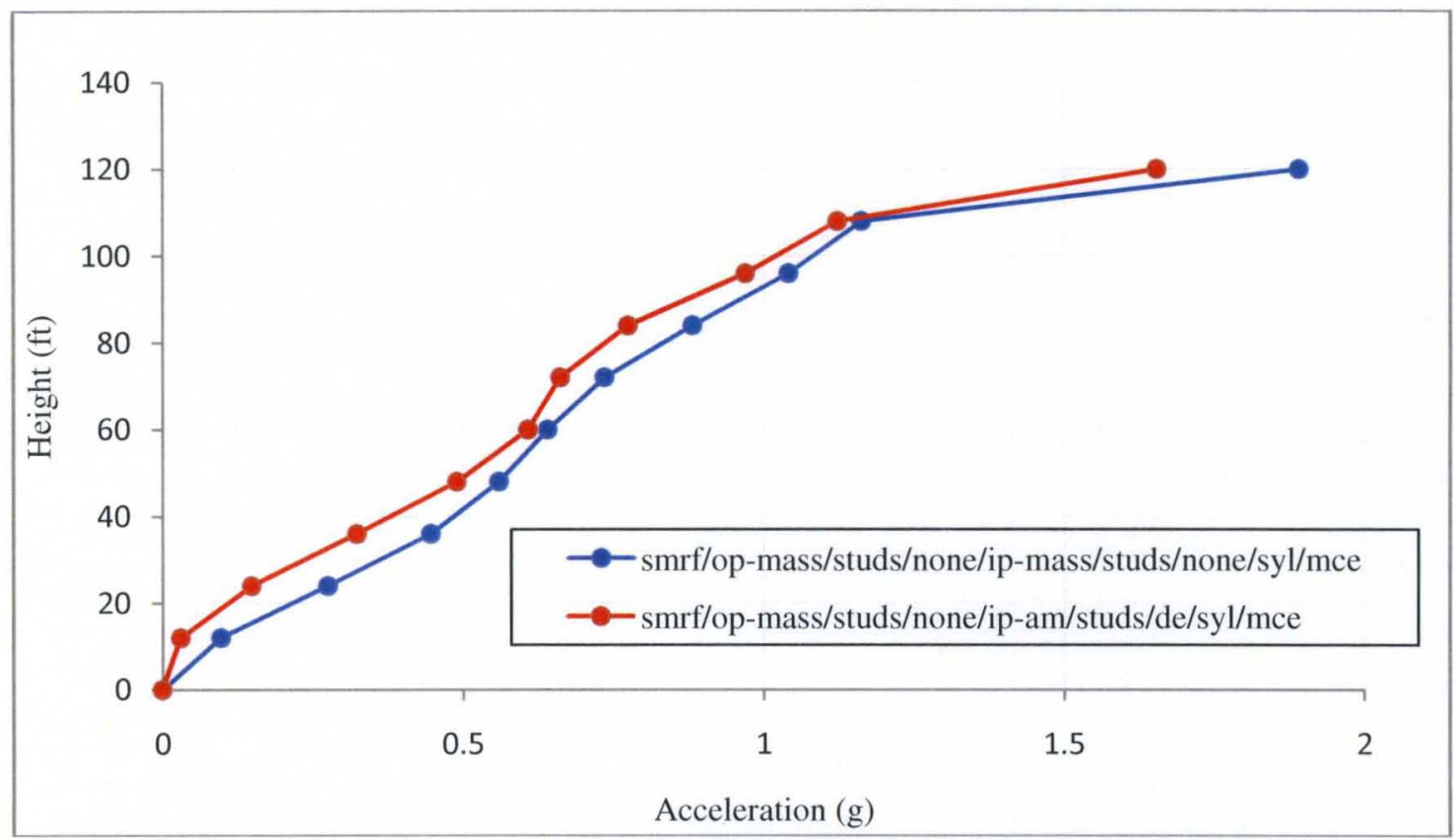

Figure C.26: Comparison of the Acceleration Profiles Going Up the Height of the Steel Moment Resisting Frame, With a Mass Representation and Analytical Model Representations With Double Eye and Pintle Ties, of the Stud Backed In Plane Wall System, and a Mass Representation of the Out Of Plane Wall System, at MCE of the Sylmar Ground Motion.

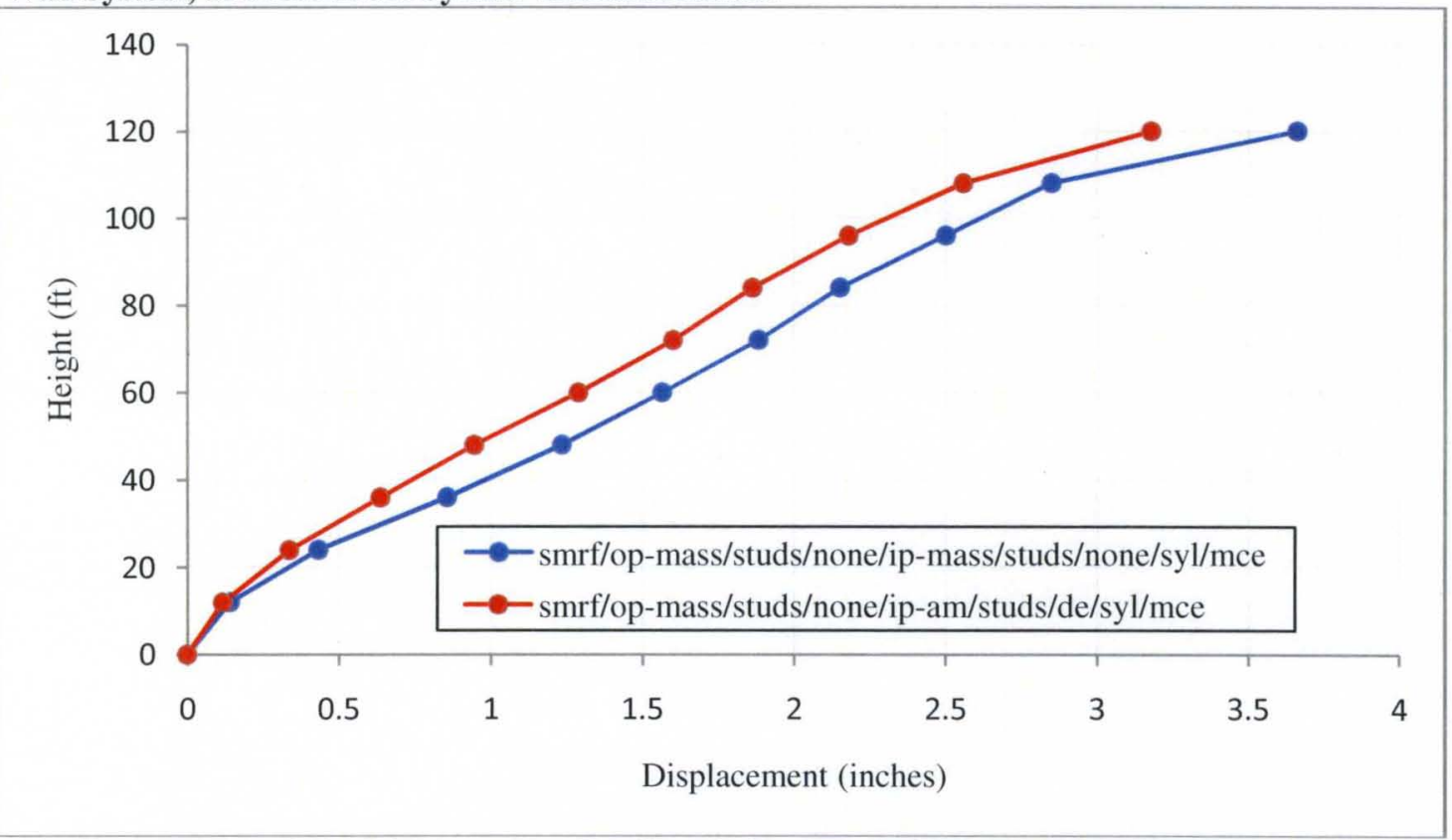

Figure C.27: Comparison of the Displacement Profiles Going Up the Height of the Steel Moment Resisting Frame, With a Mass Representation and Analytical Model Representations With Double Eye and Pintle Ties, of the Stud Backed In Plane Wall System, and a Mass Representation of the Out Of Plane Wall System, at MCE of the Sylmar Ground Motion. 


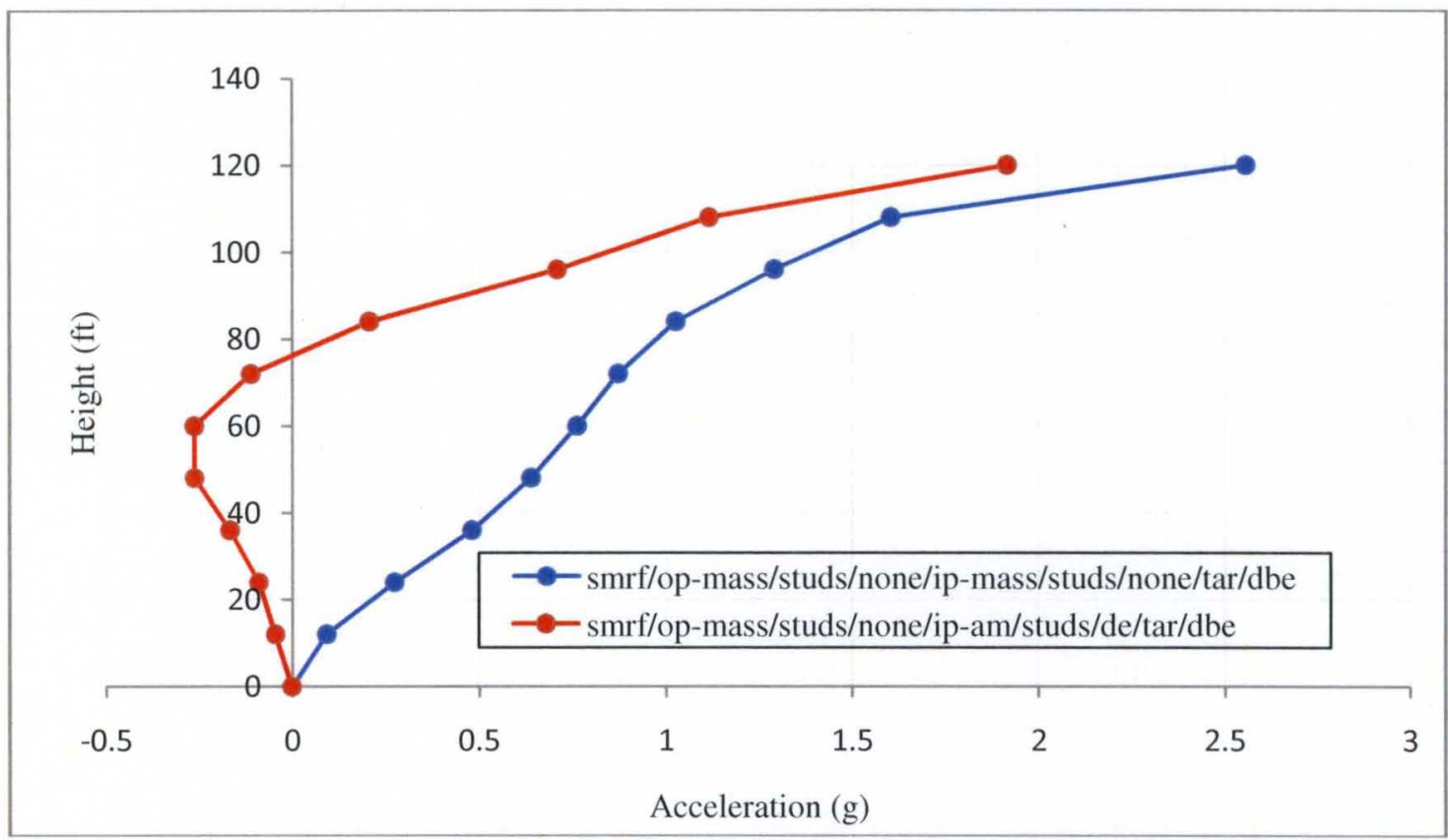

Figure C.28: Comparison of the Acceleration Profiles Going Up the Height of the Steel Moment Resisting Frame, With a Mass Representation and Analytical Model Representations With Double Eye and Pintle Ties, of the Stud Backed In Plane Wall System, and a Mass Representation of the Out Of Plane Wall System, at DBE of the Tarzana Ground Motion.

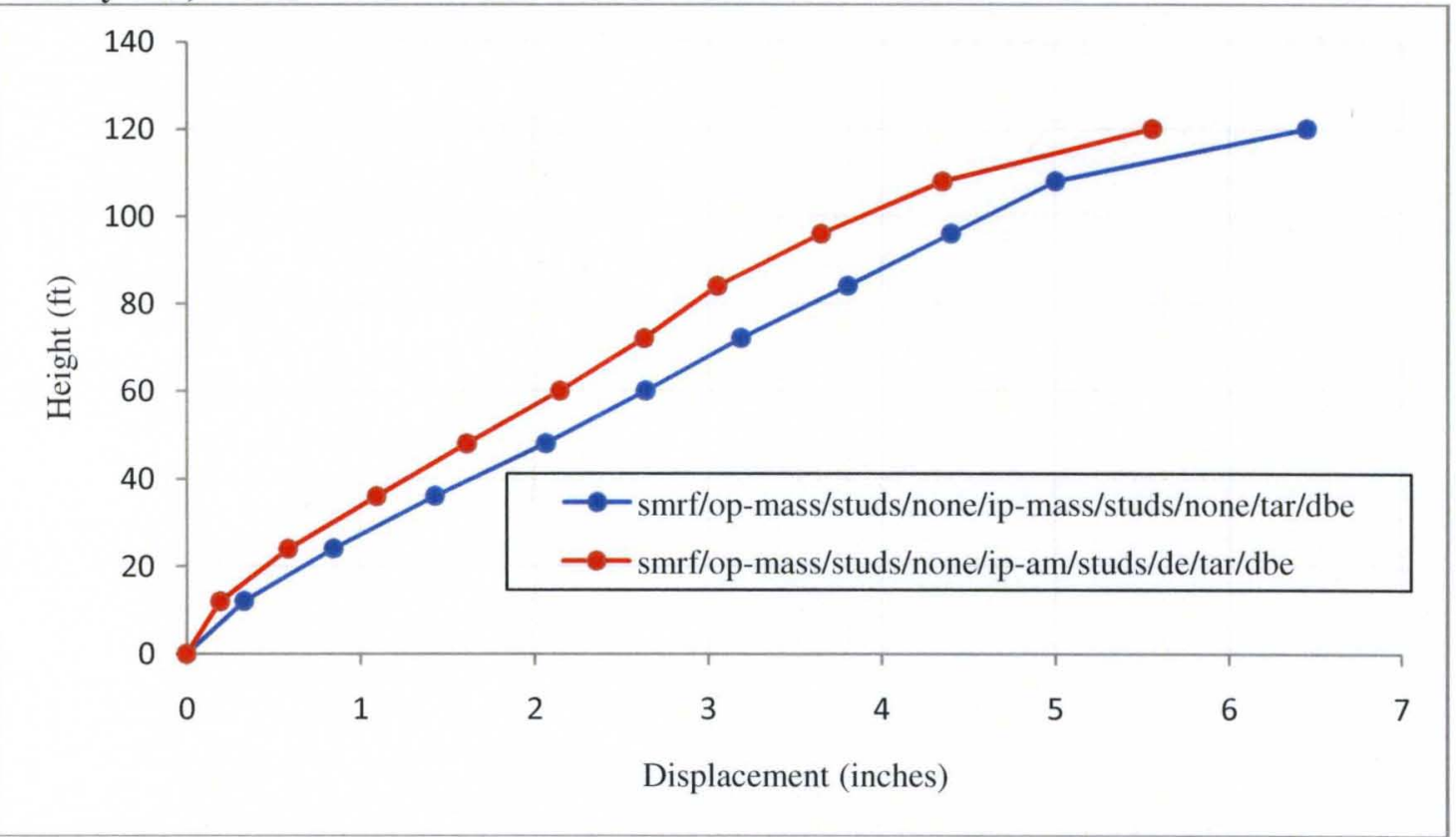

Figure C.29: Comparison of the Displacement Profiles Going Up the Height of the Steel Moment Resisting Frame, With a Mass Representation and Analytical Model Representations With Double Eye and Pintle Ties, of the Stud Backed In Plane Wall System, and a Mass Representation of the Out Of Plane Wall System, at DBE of the Tarzana Ground Motion. 


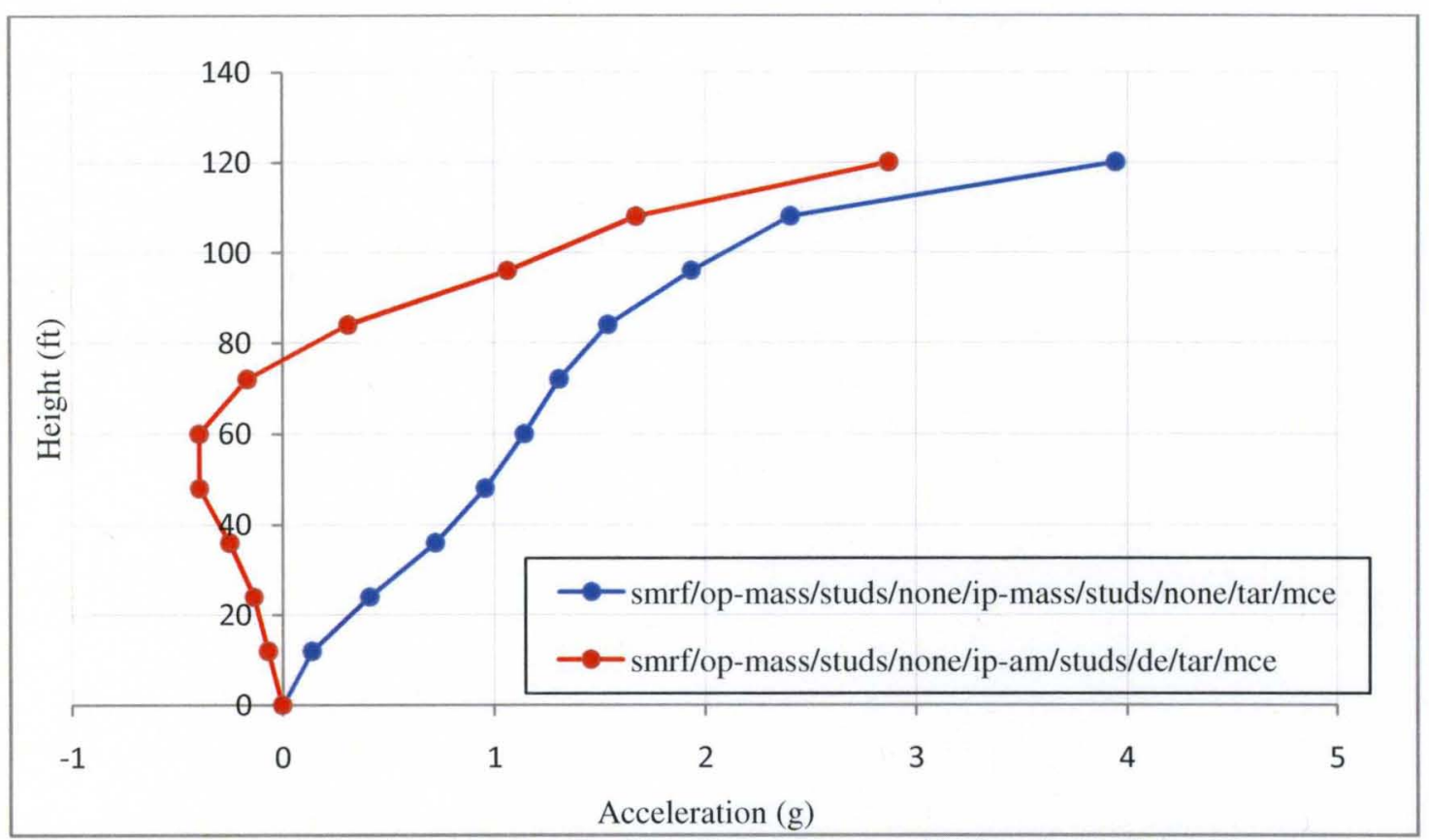

Figure C.30: Comparison of the Acceleration Profiles Going Up the Height of the Steel Moment Resisting Frame, With a Mass Representation and Analytical Model Representations With Double Eye and Pintle Ties, of the Stud Backed In Plane Wall System, and a Mass Representation of the Out Of Plane Wall System, at MCE of the Tarzana Ground Motion.

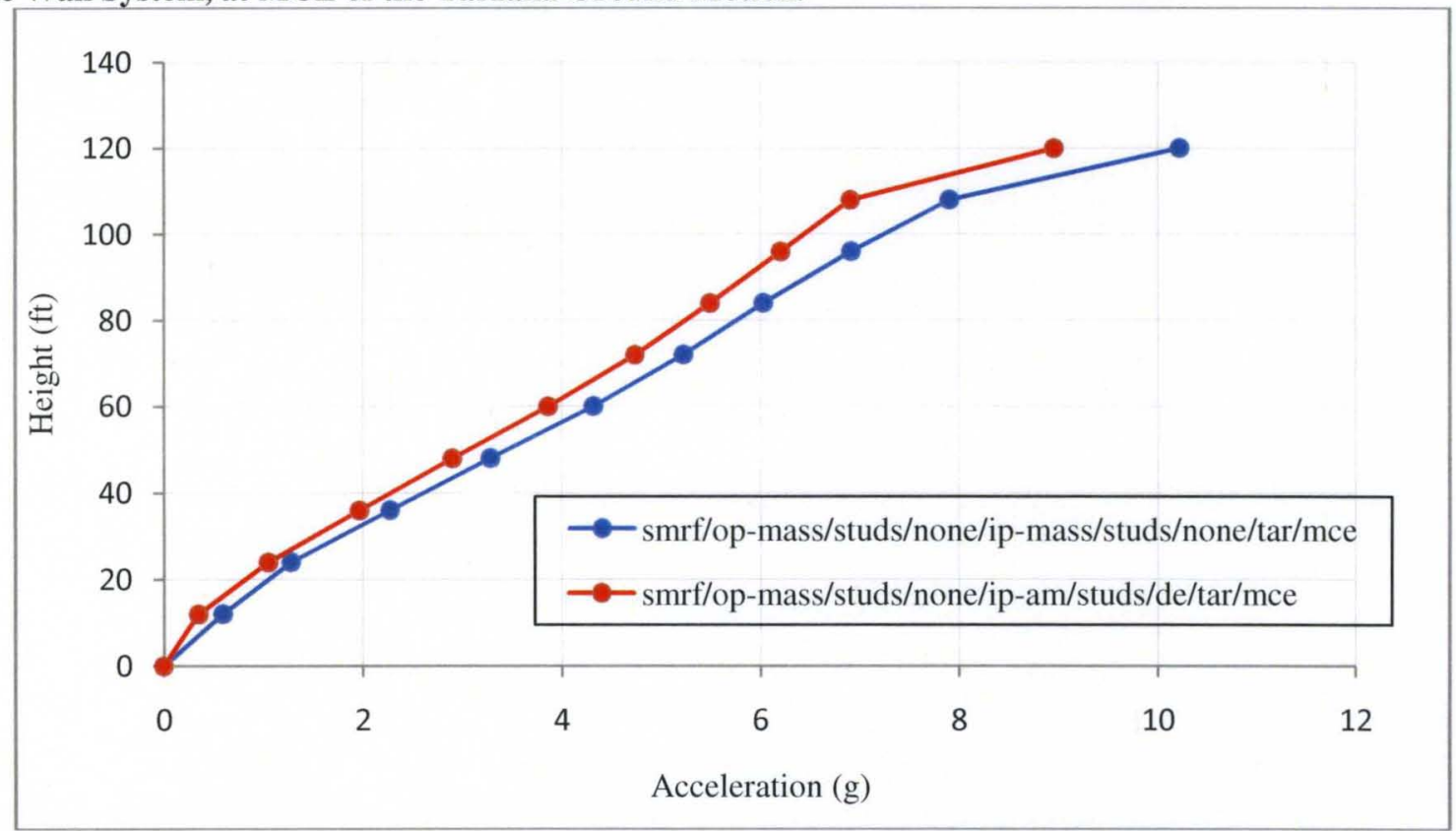

Figure C.31: Comparison of the Displacement Profiles Going Up the Height of the Steel Moment Resisting Frame, With a Mass Representation and Analytical Model Representations With Double Eye and Pintle Ties, of the Stud Backed In Plane Wall System, and a Mass Representation of the Out Of Plane Wall System, at MCE of the Tarzana Ground Motion. 


\section{APPENDIX D}

\section{THE OUT OF PLANE RESPONSE OF THE}

\section{MASONRY VENEER WALLS: TOP STOREY VENEER \\ AND BACKUP ACCELERATIONS AND \\ DISPLACEMENTS, AND TIE FORCES}

Appendix D consists of plots that display the response of the masonry veneer wall systems under out of plane loading. These plots are derived in the manner as discussed in Chapter 4. They display the veneer and backup accelerations and displacements, and the tie forces, in the top storey out of plane masonry wall systems in all the frames analyzed in this investigation at a time instant at which the veneer reached its maximum acceleration. 

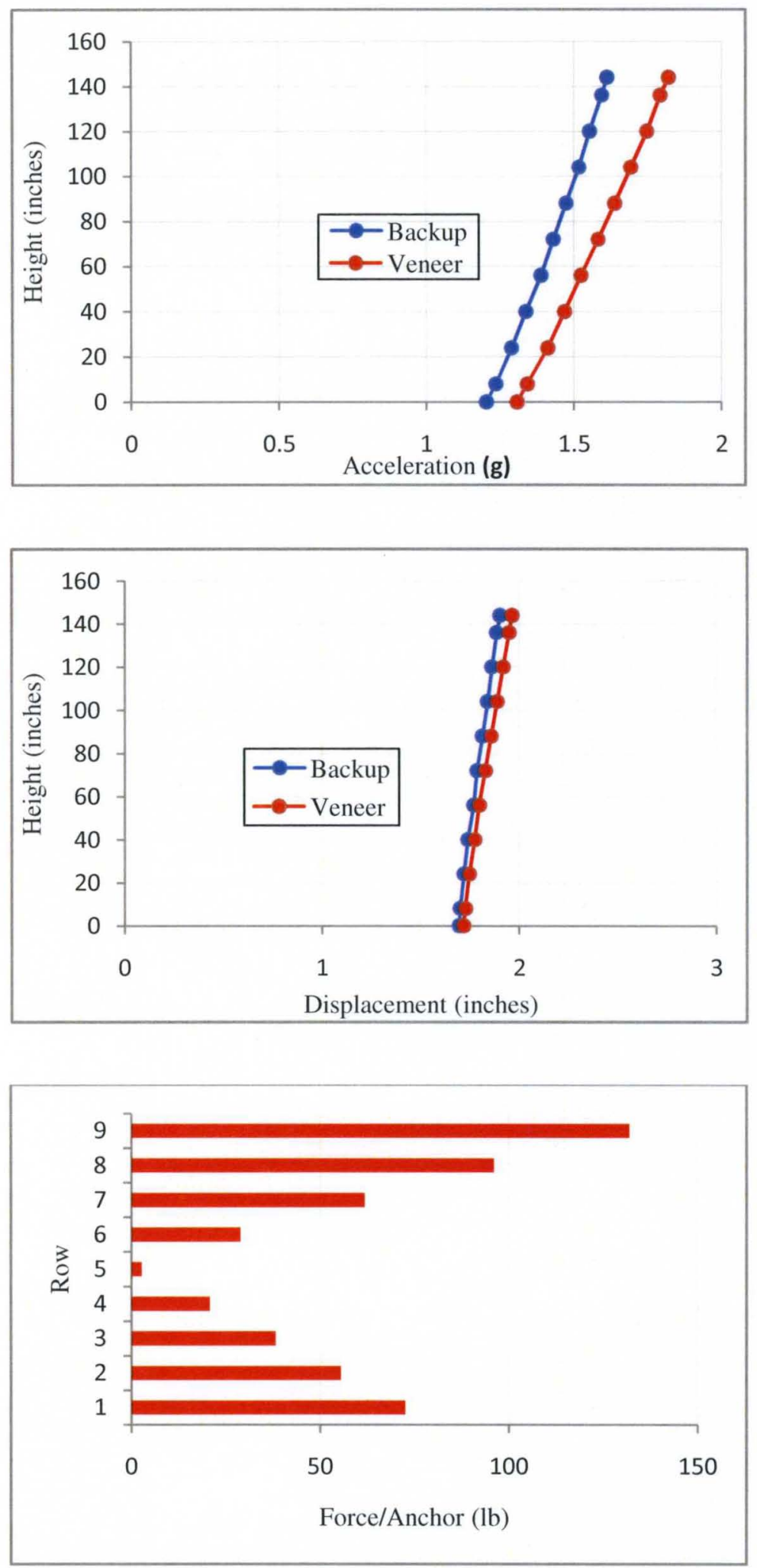

Figure D.1: Backup and Veneer Accelerations and Displacements, and Tie Forces for model id. cmrf/op-am/cmu/de/ip-mass/cmu/none/syl/mce. 

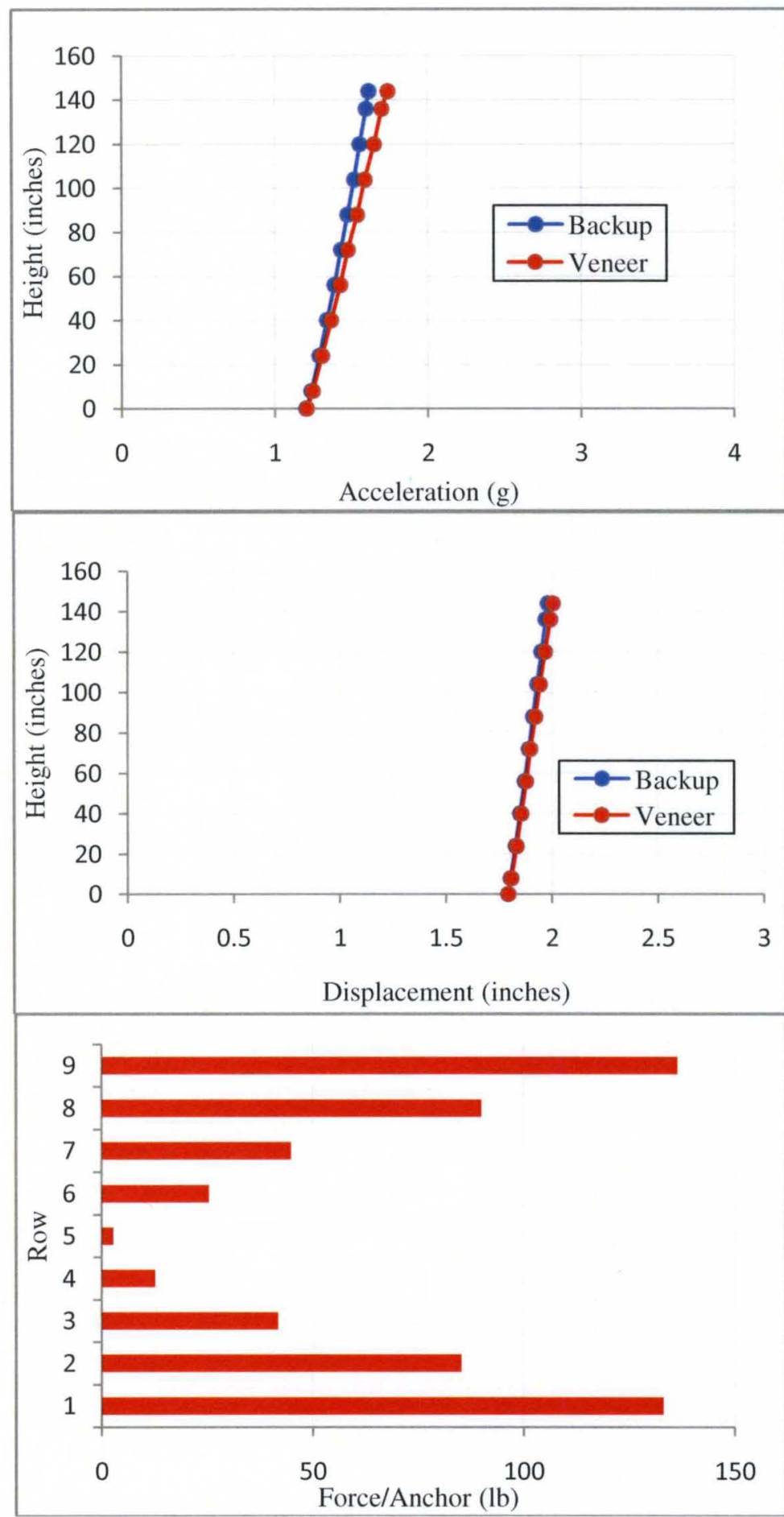

Figure D.2: Backup and Veneer Accelerations and Displacements, and Tie Forces for model id. cmrf/op-am/cmu/tw/ip-mass/cmu/none/syl/mce 

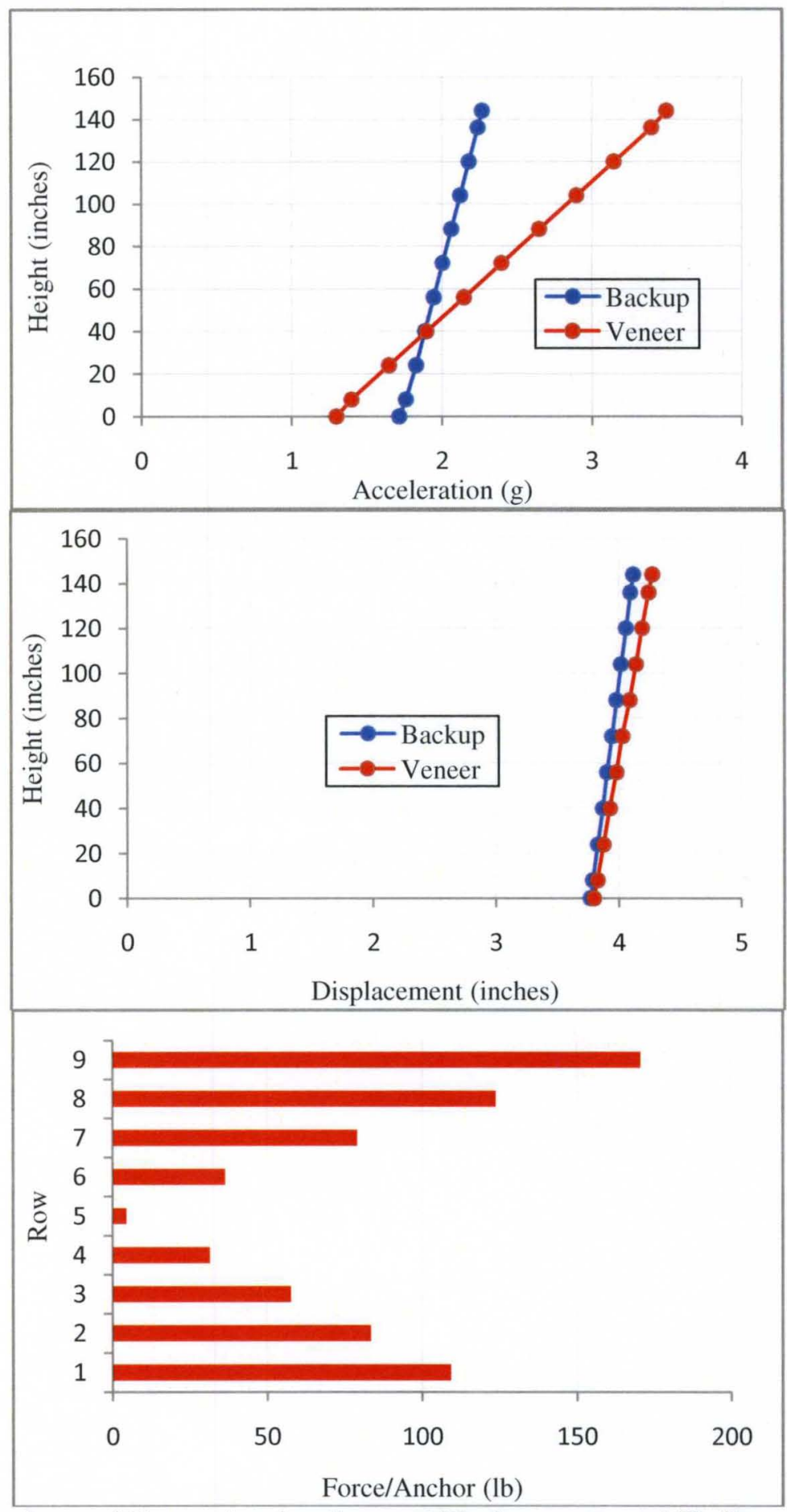

Figure D.3: Backup and Veneer Accelerations and Displacements, and Tie Forces for model id. cmrf/op-am/cmu/de/ip-mass/cmu/none/tar/mce 

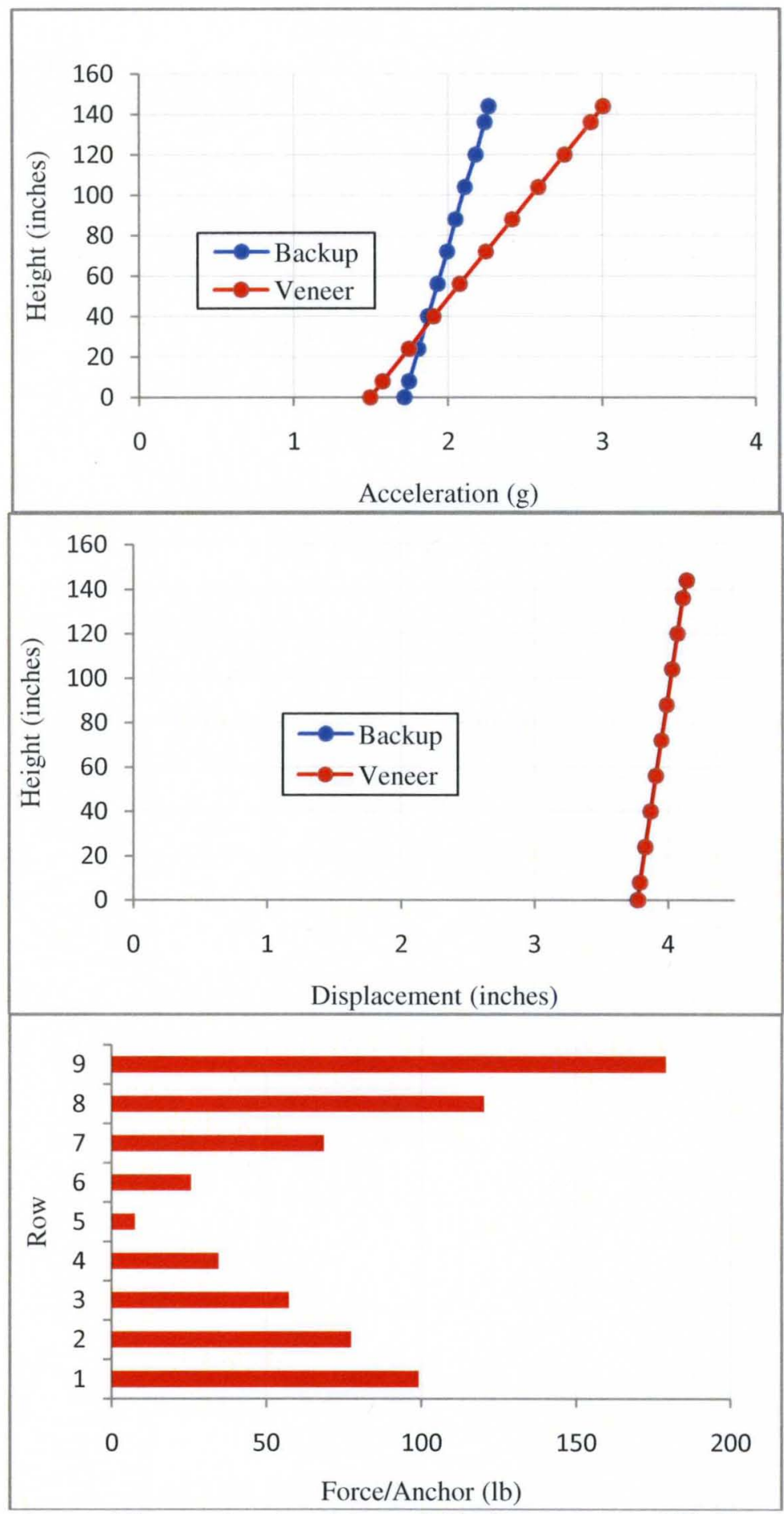

Figure D.4: Backup and Veneer Accelerations and Displacements, and Tie Forces for model id. cmrf/op-am/cmu/tw/ip-mass/cmu/none/tar/mce 

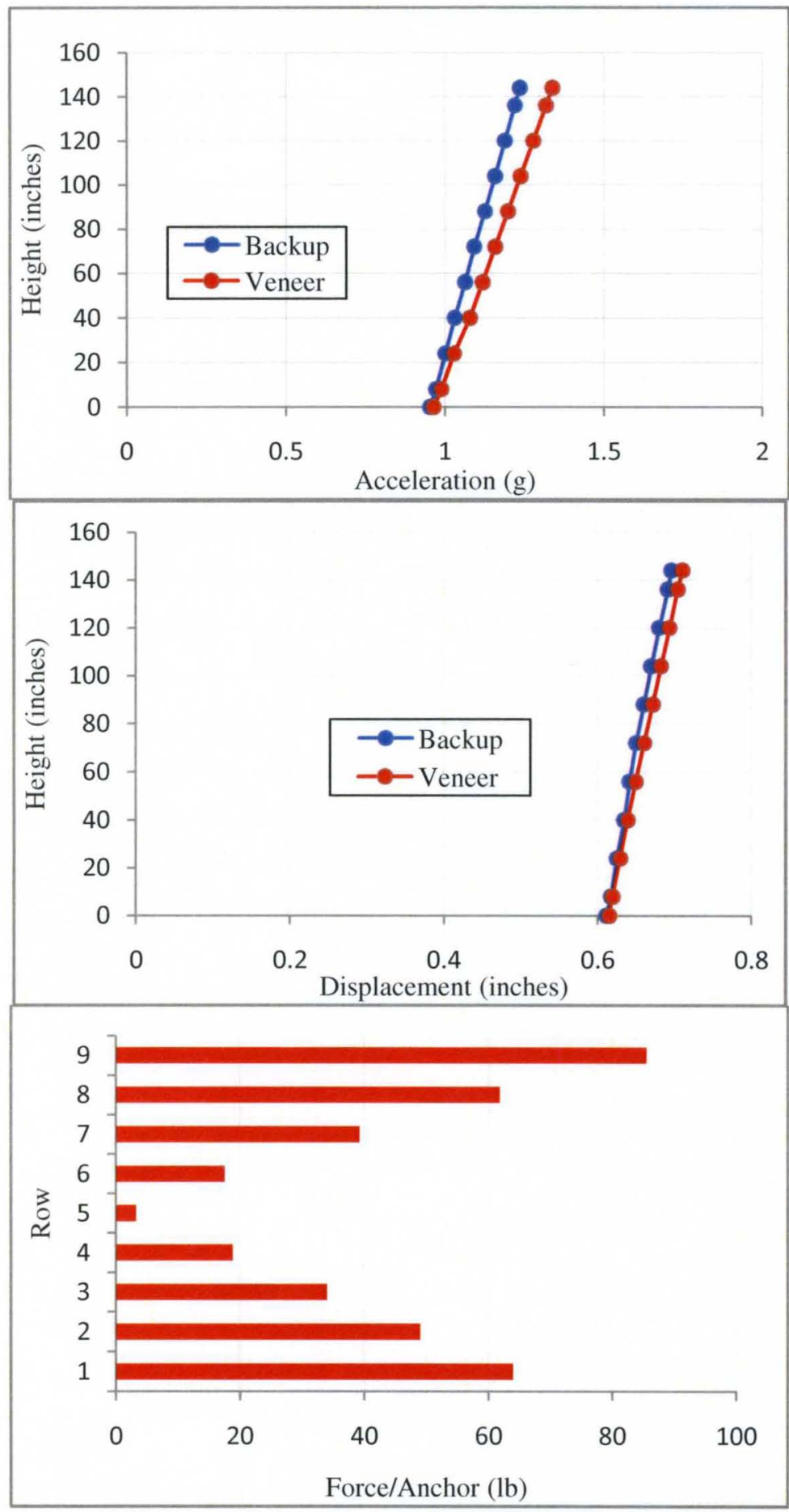

Figure D.5: Backup and Veneer Accelerations and Displacements, and Tie Forces for model id. cb/op-am/cmu/de/ip-mass/cmu/none/syl/mce 

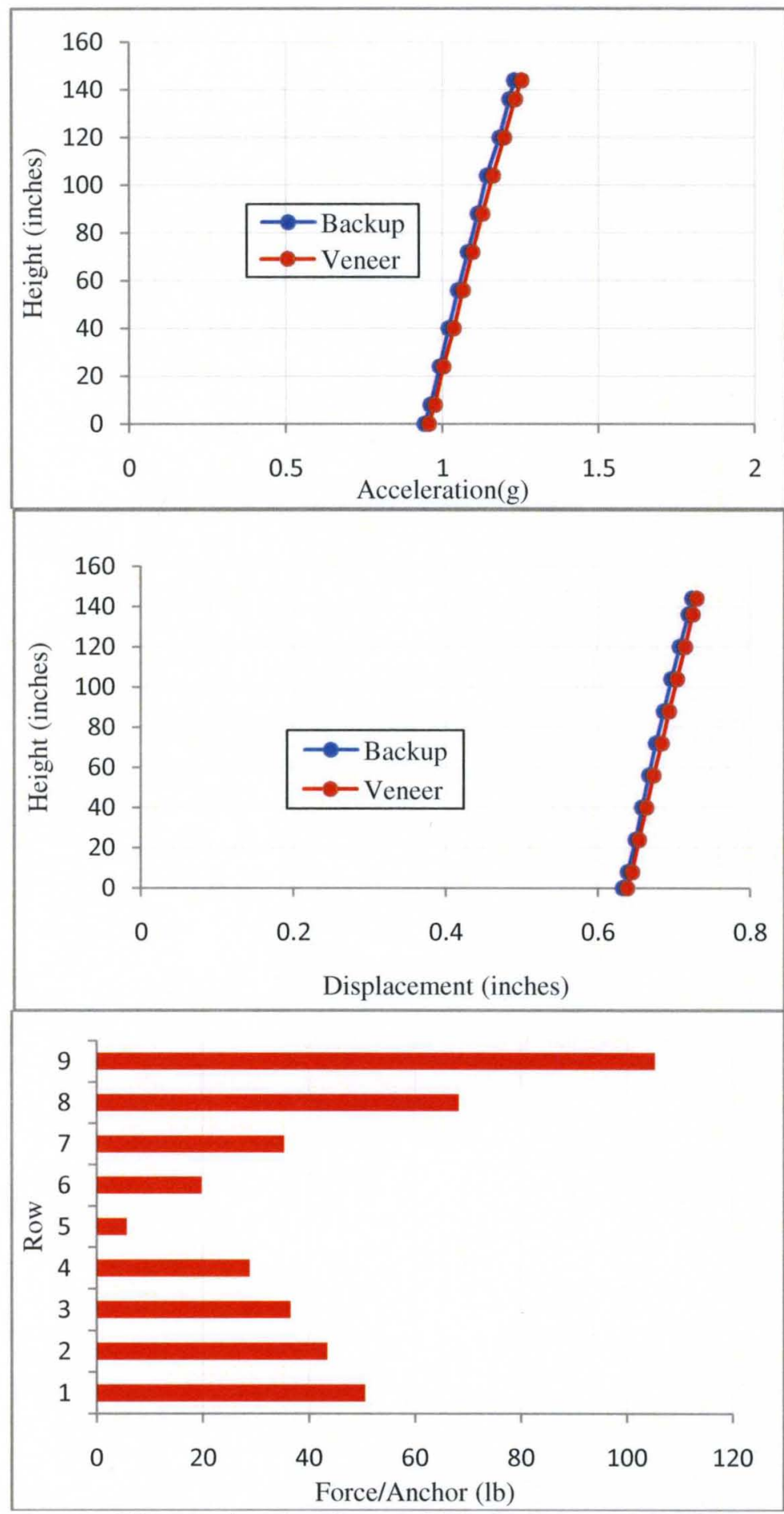

Figure D.6: Backup and Veneer Accelerations and Displacements, and Tie Forces for model id. cb/op-am/cmu/tw/ip-mass/cmu/none/syl/mce 


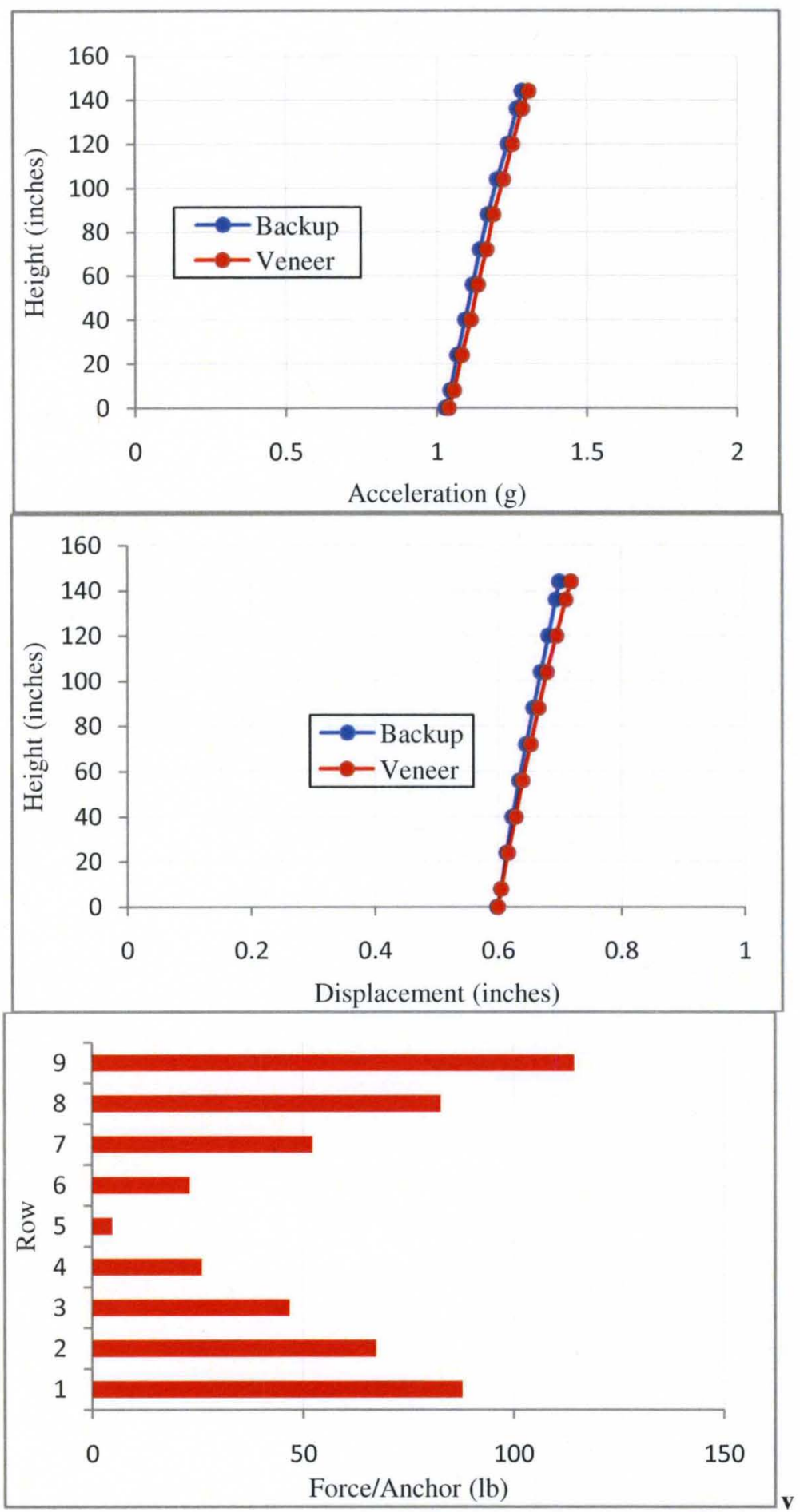

Figure D.7: Backup and Veneer Accelerations and Displacements, and Tie Forces for model id. cb/op-am/cmu/de/ip-mass/cmu/none/tar/mce 

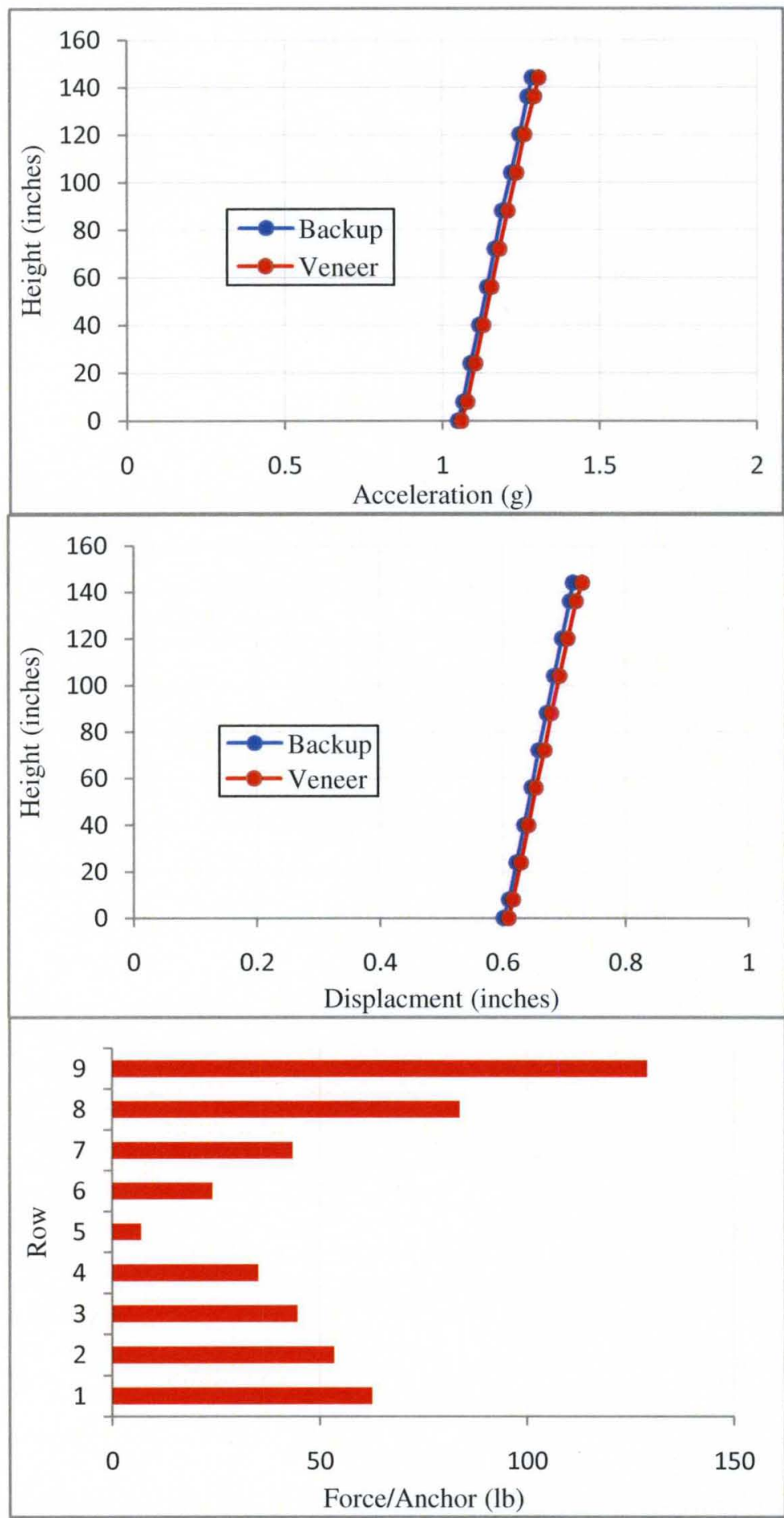

Figure D.8: Backup and Veneer Accelerations and Displacements, and Tie Forces for model id. cb/op-am/cmu/tw/ip-mass/cmu/none/tar/mce 

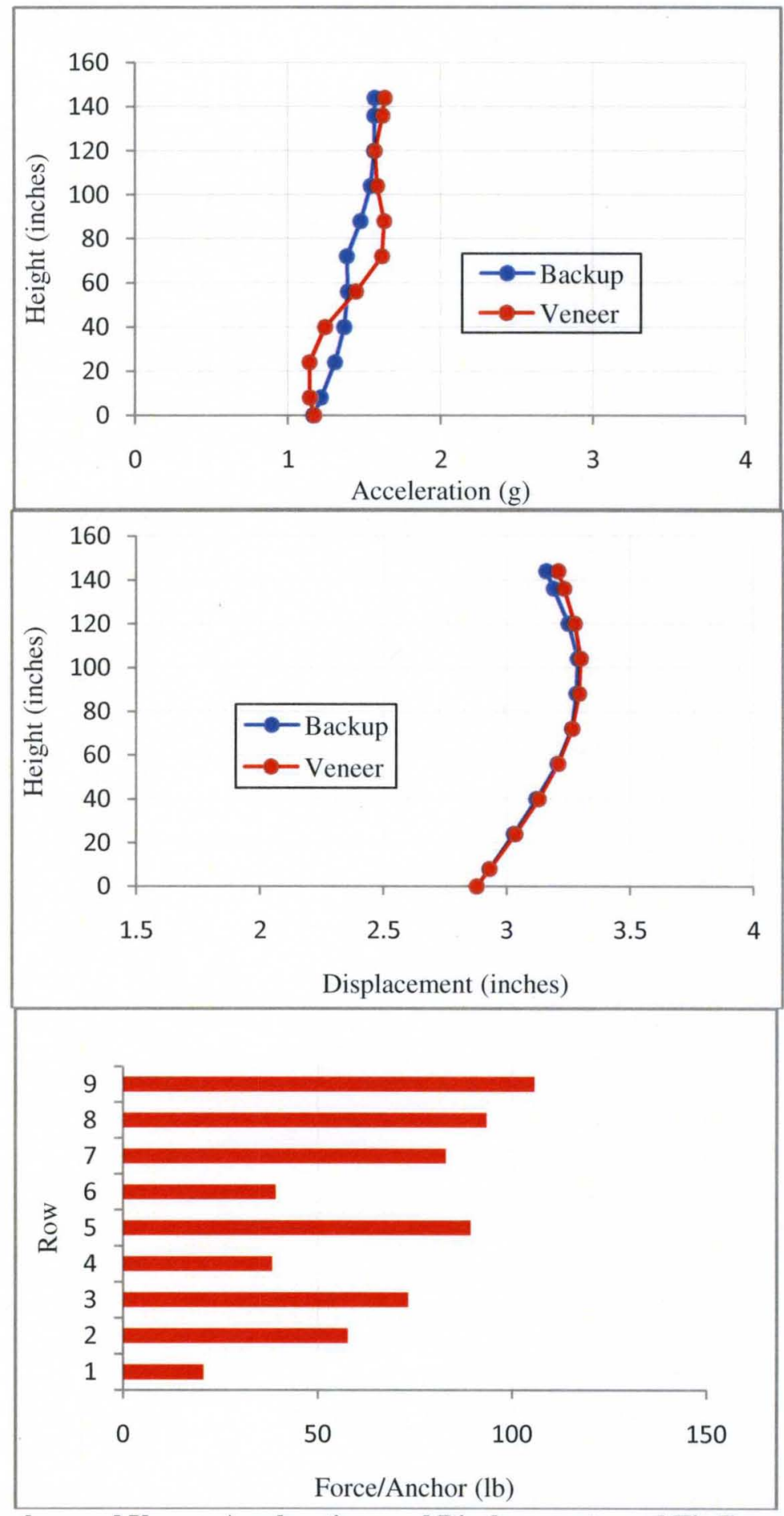

Figure D.9: Backup and Veneer Accelerations and Displacements, and Tie Forces for model id. sb/op-am/cmu/de/ip-mass/cmu/none/syl/mce 

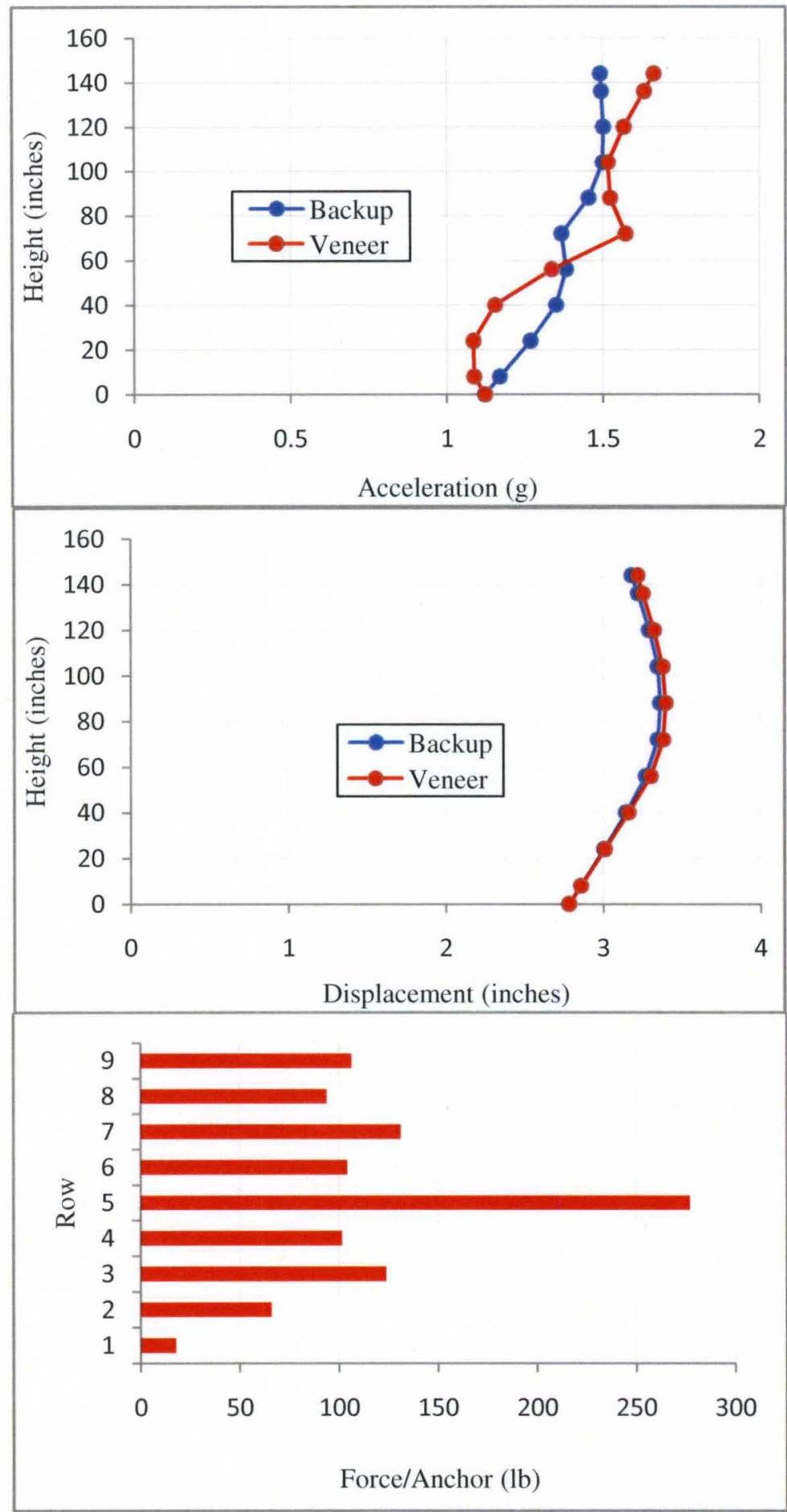

Figure D.10: Backup and Veneer Accelerations and Displacements, and Tie Forces for model id. sb/op-am/cmu/tw/ip-mass/cmu/none/syl/mce 


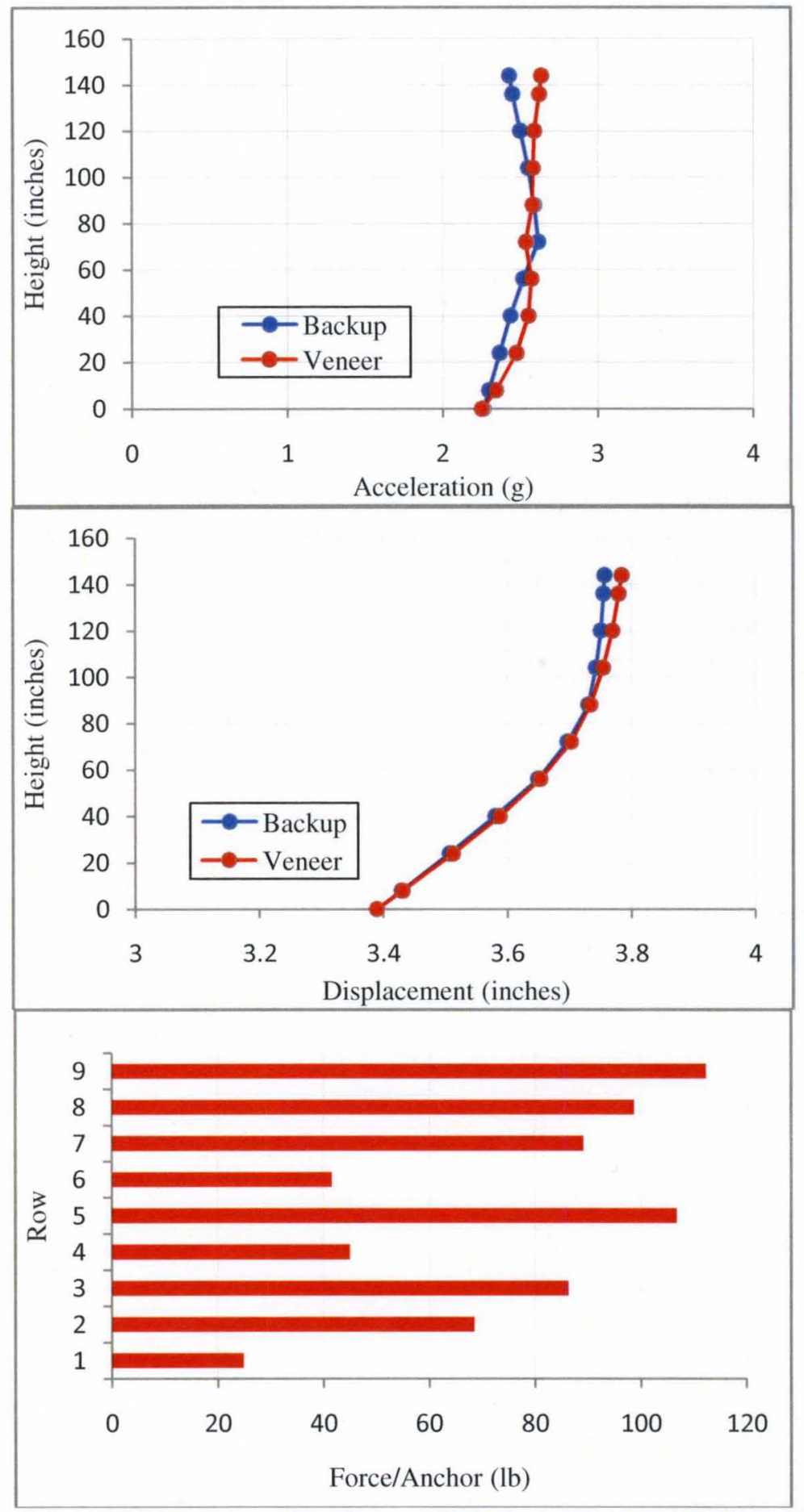

Figure D.11: Backup and Veneer Accelerations and Displacements, and Tie Forces for model id. sb/op-am/cmu/de/ip-mass/cmu/none/tar/mce 

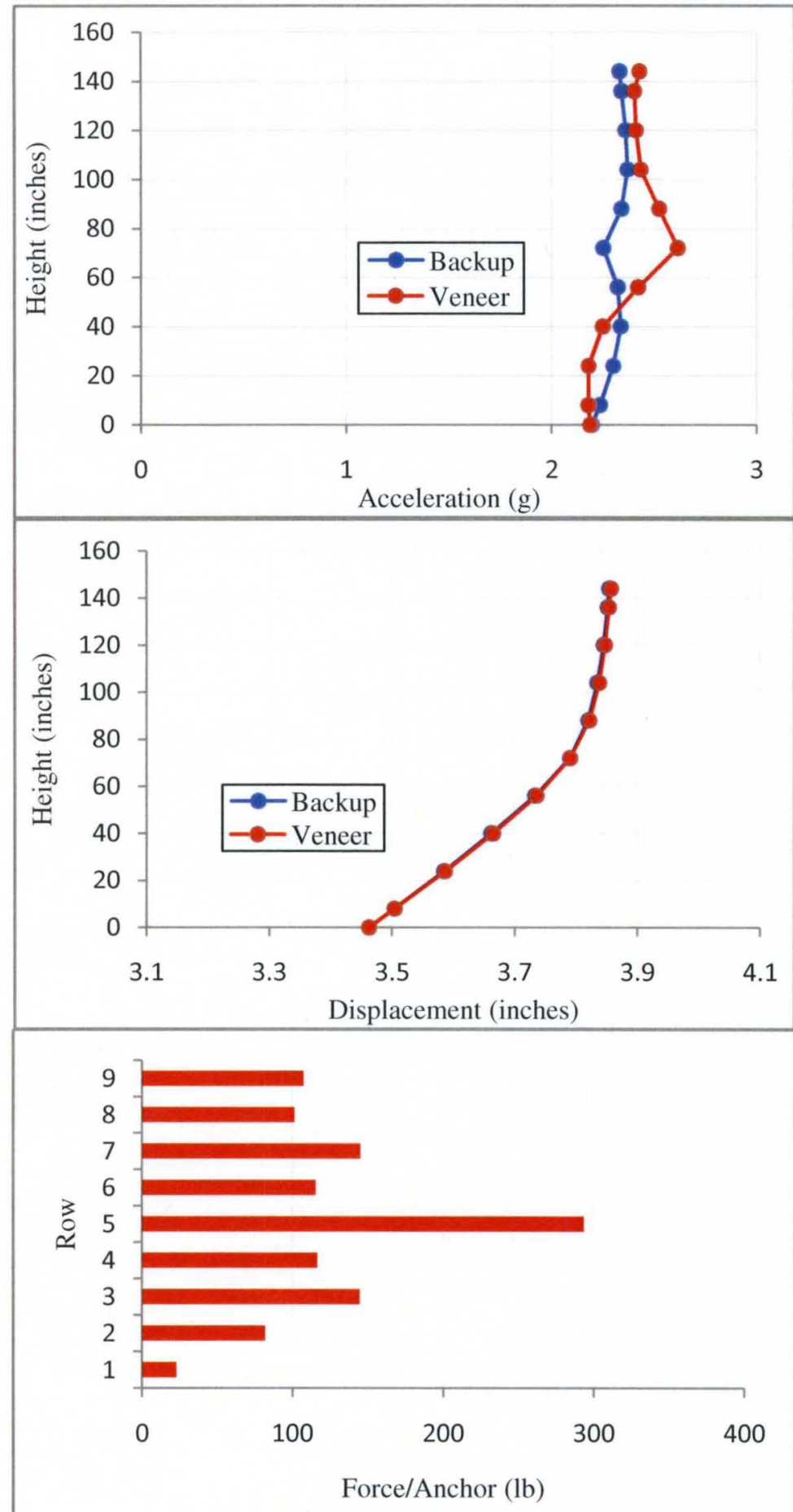

Figure D.12: Backup and Veneer Accelerations and Displacements, and Tie Forces for model id. sb/op-am/cmu/tw/ip-mass/cmu/none/tar/mce 

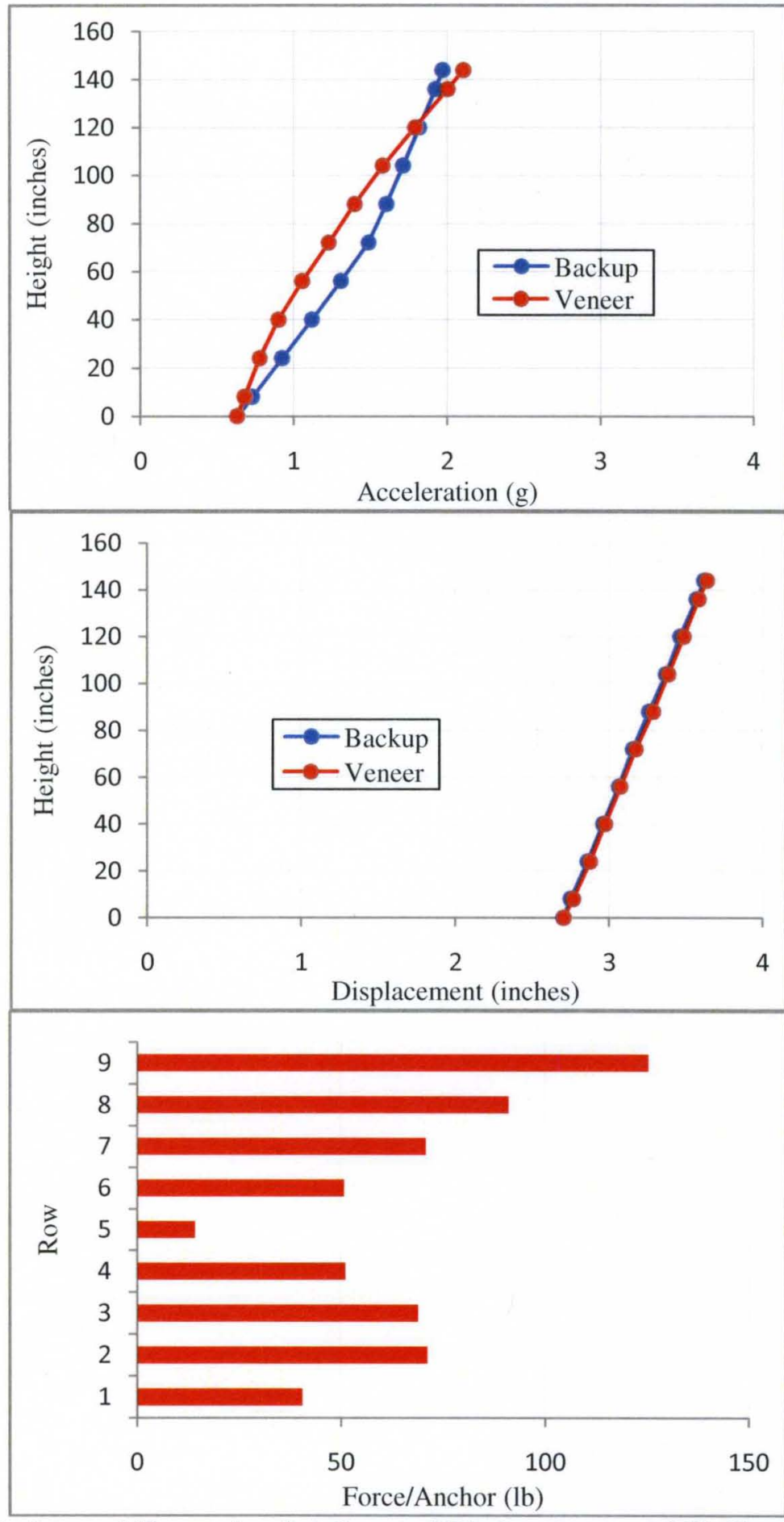

Figure D.13: Backup and Veneer Accelerations and Displacements, and Tie Forces for model id. smrf/op-am/cmu/de/ip-mass/cmu/none/syl/mce 

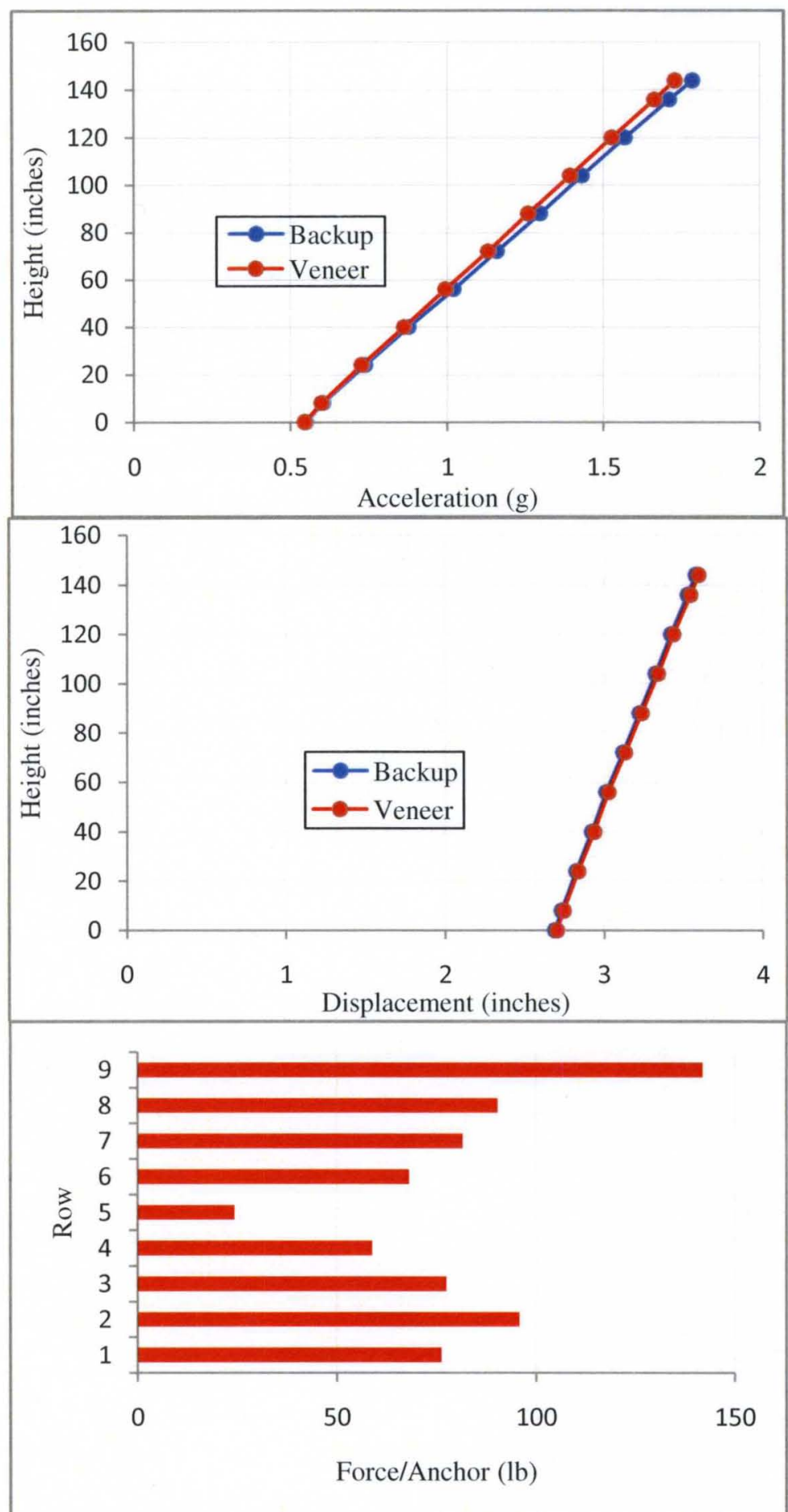

Figure D.14: Backup and Veneer Accelerations and Displacements, and Tie Forces for model id. smrf/op-am/cmu/tw/ip-mass/cmu/none/syl/mce 

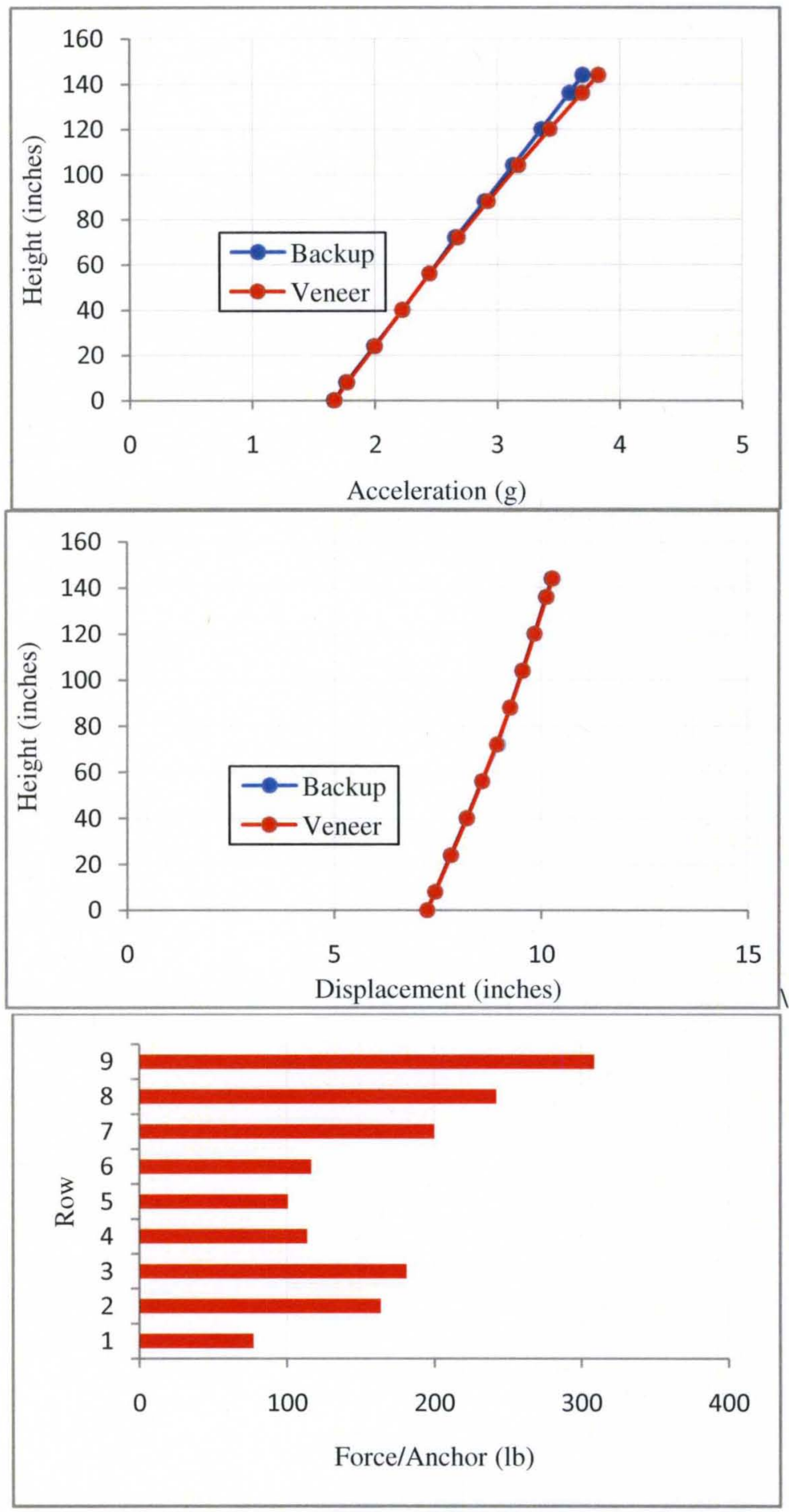

Figure D.15: Backup and Veneer Accelerations and Displacements, and Tie Forces for model id. smrf/op-am/cmu/de/ip-mass/cmu/none/tar/mce 


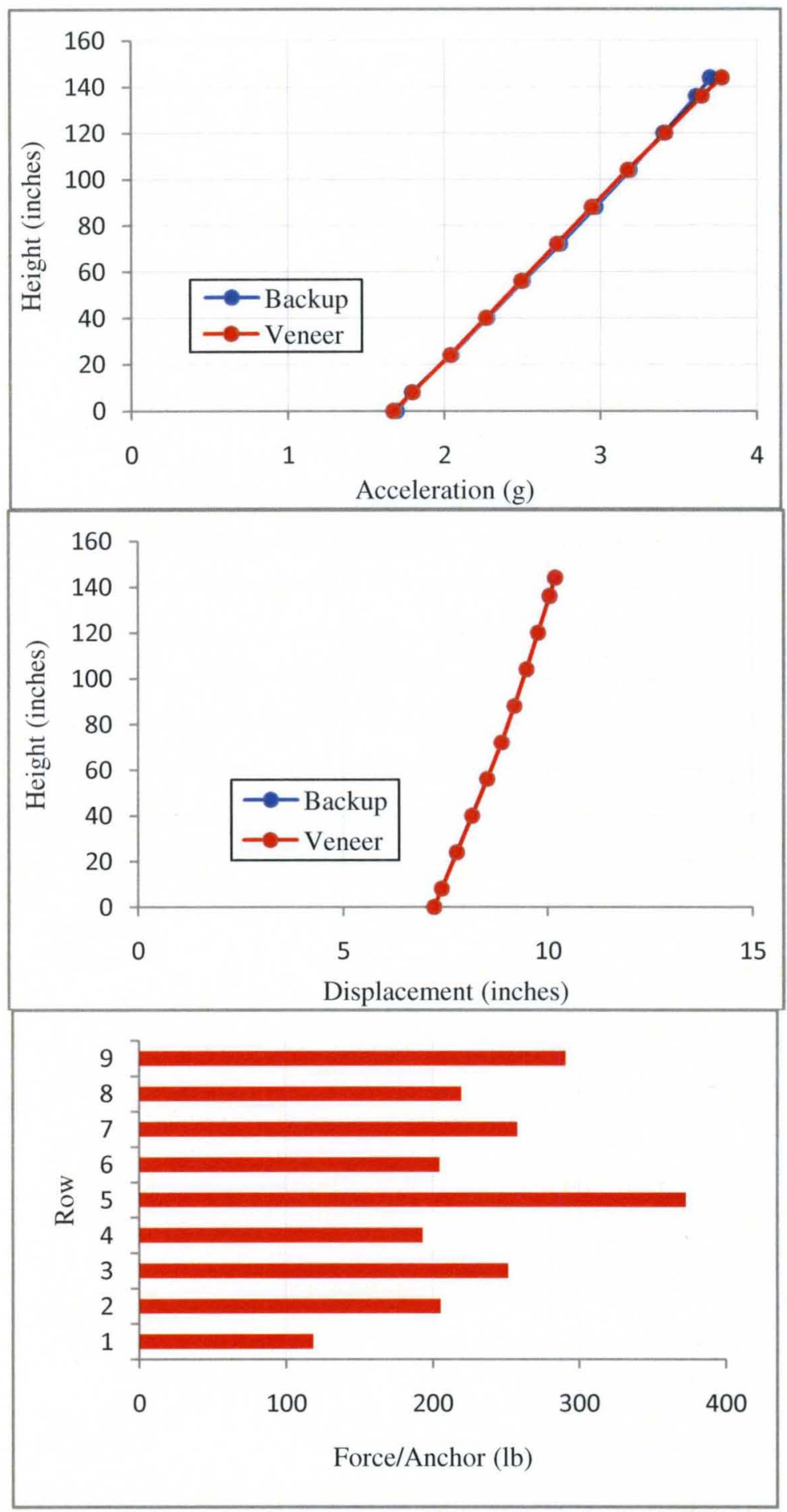

Figure D.16: Backup and Veneer Accelerations and Displacements, and Tie Forces for model id. smrf/op-am/cmu/tw/ip-mass/cmu/none/tar/mce 

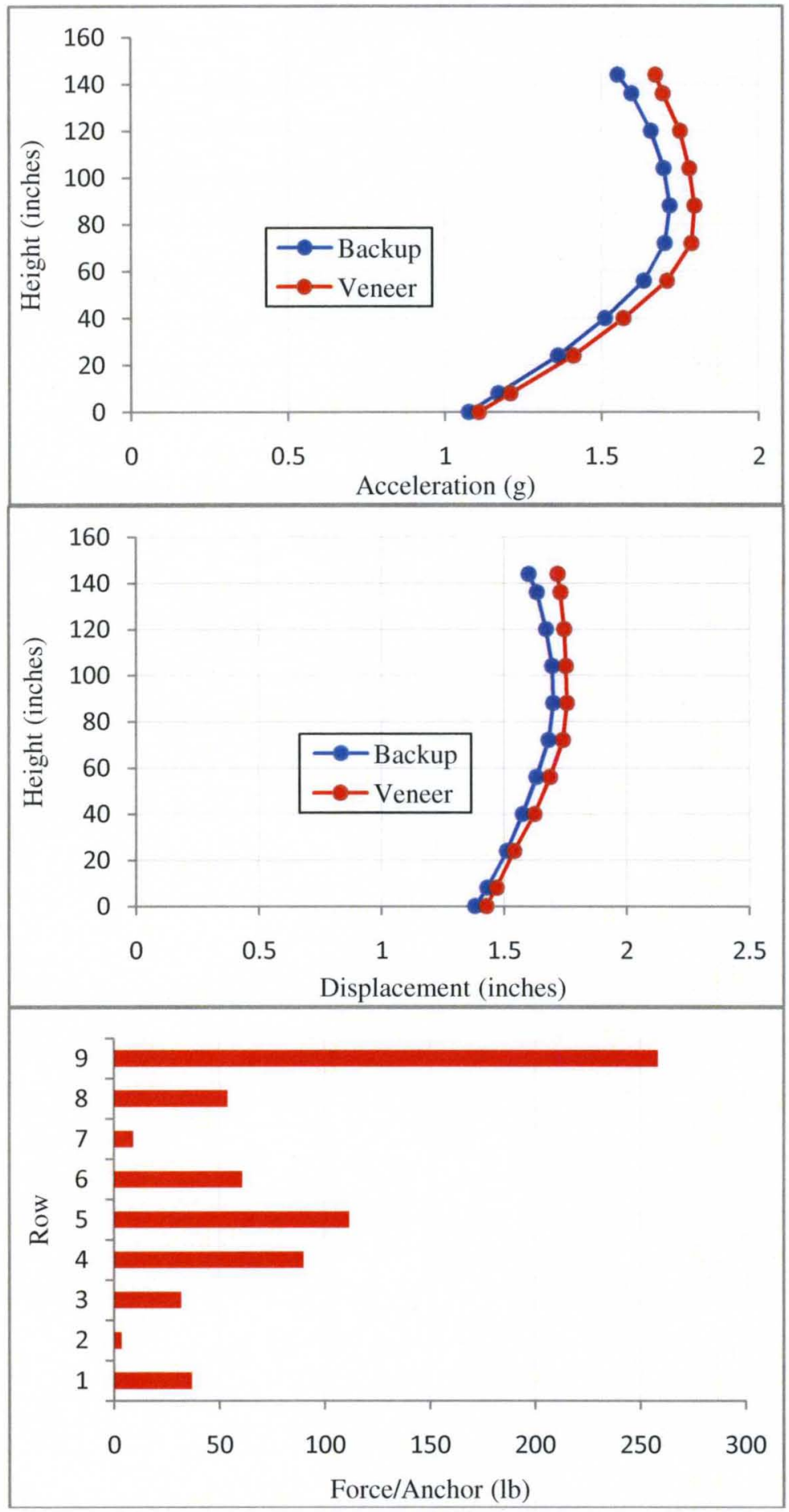

Figure D.17: Backup and Veneer Accelerations and Displacements, and Tie Forces for model id. cmrf/op-am/studs/de-flex/ip-mass/studs/none/syl/mce 


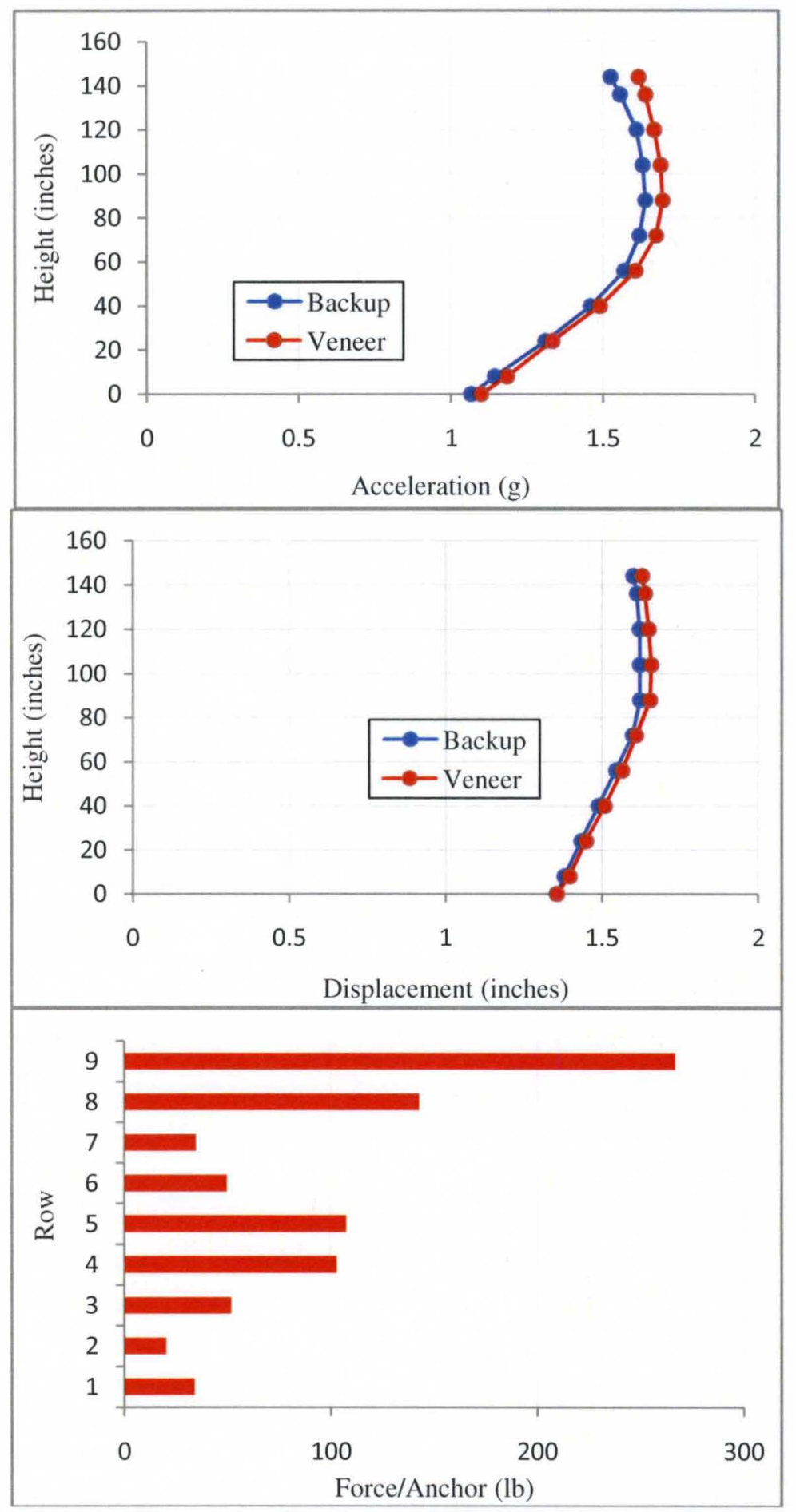

Figure D.18: Backup and Veneer Accelerations and Displacements, and Tie Forces for model id. cmrf/op-am/studs/de-stiff/ip-mass/studs/none/syl/mce 

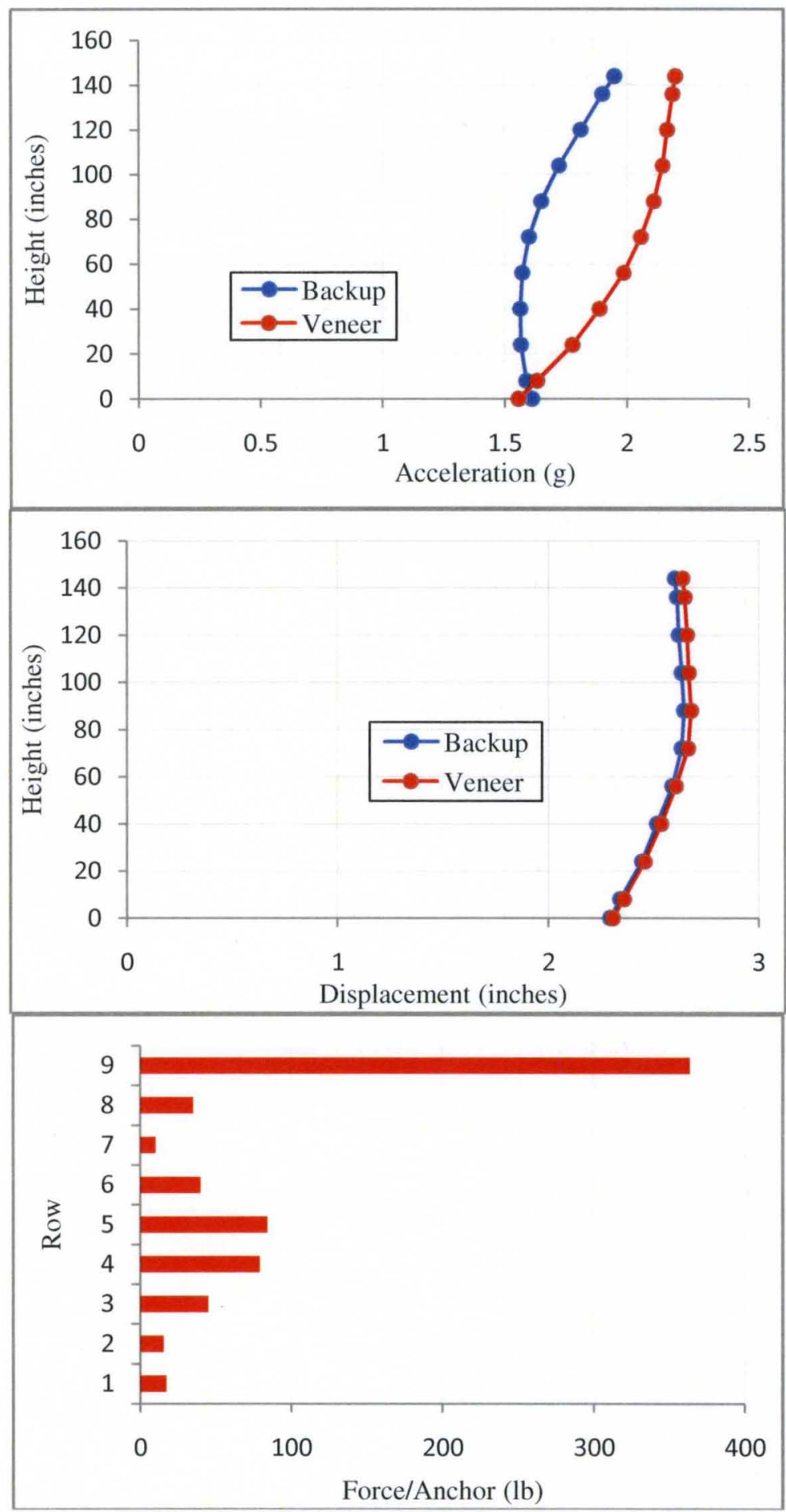

Figure D.19: Backup and Veneer Accelerations and Displacements, and Tie Forces for model id. cmrf/op-am/studs/de-flex/ip-mass/studs/none/tar/mce 


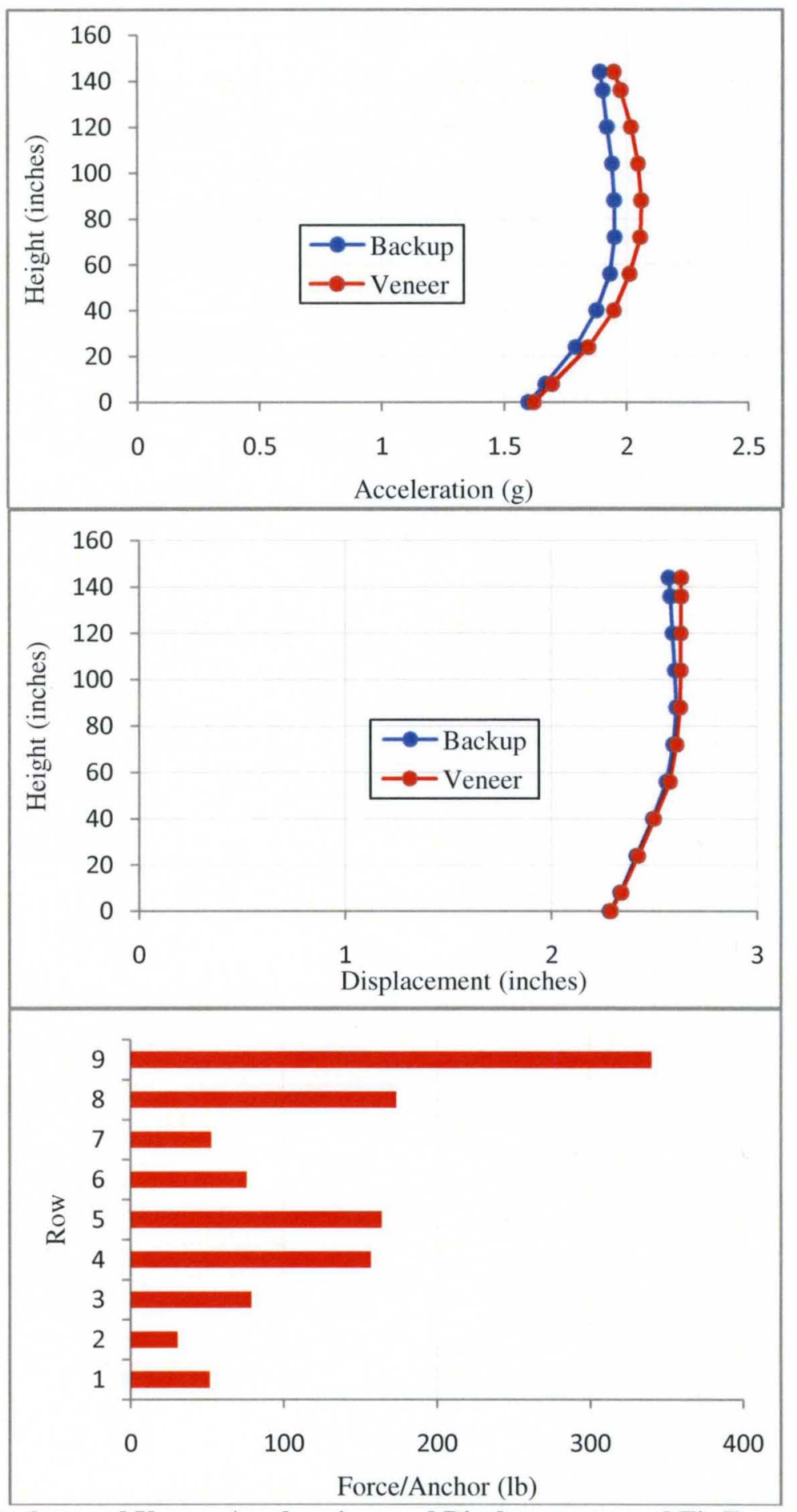

Figure D.20: Backup and Veneer Accelerations and Displacements, and Tie Forces for model id. cmrf/op-am/studs/de-stiff/ip-mass/studs/none/tar/mce 

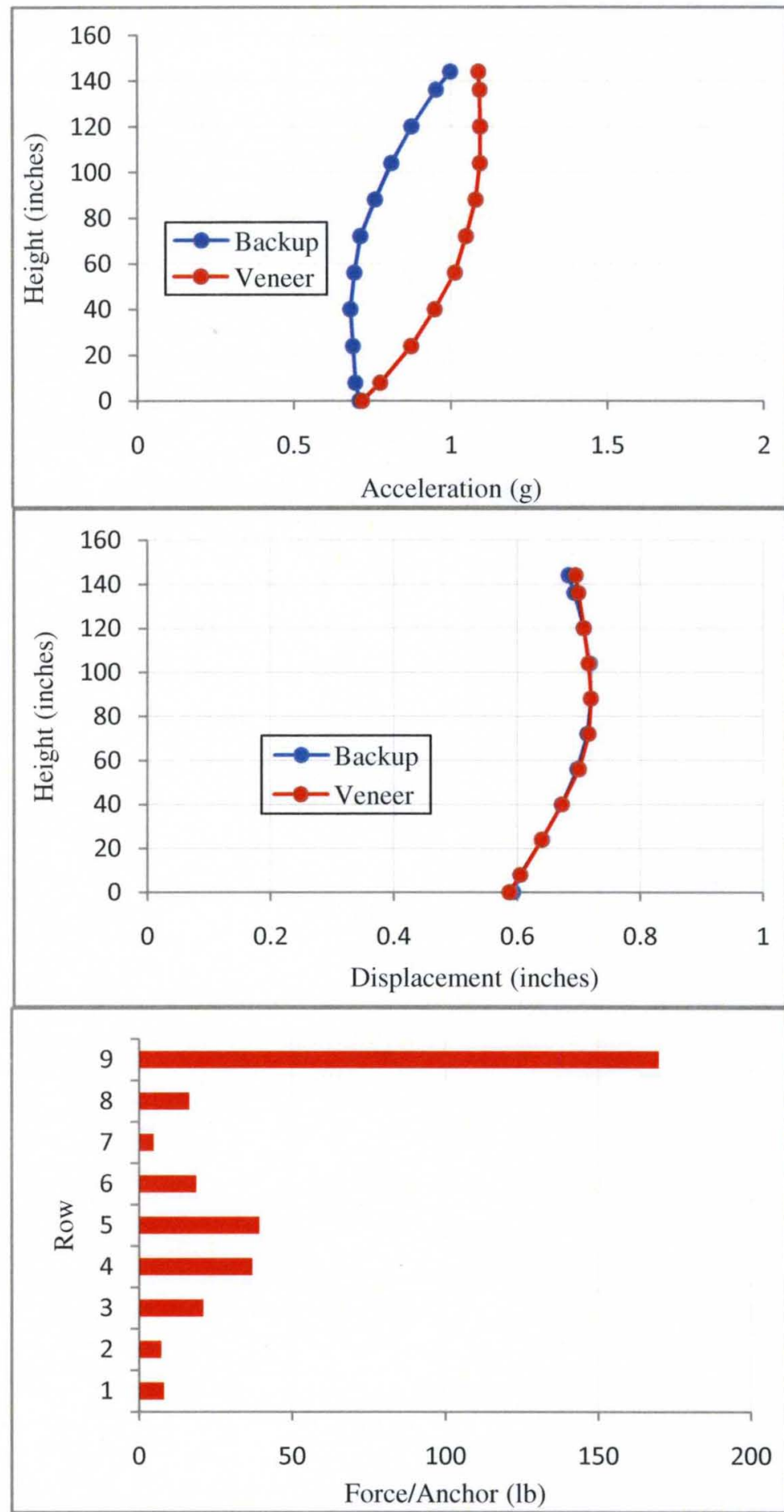

Figure D.21: Backup and Veneer Accelerations and Displacements, and Tie Forces for model id. cb/op-am/studs/de-flex/ip-mass/studs/none/syl/mce 

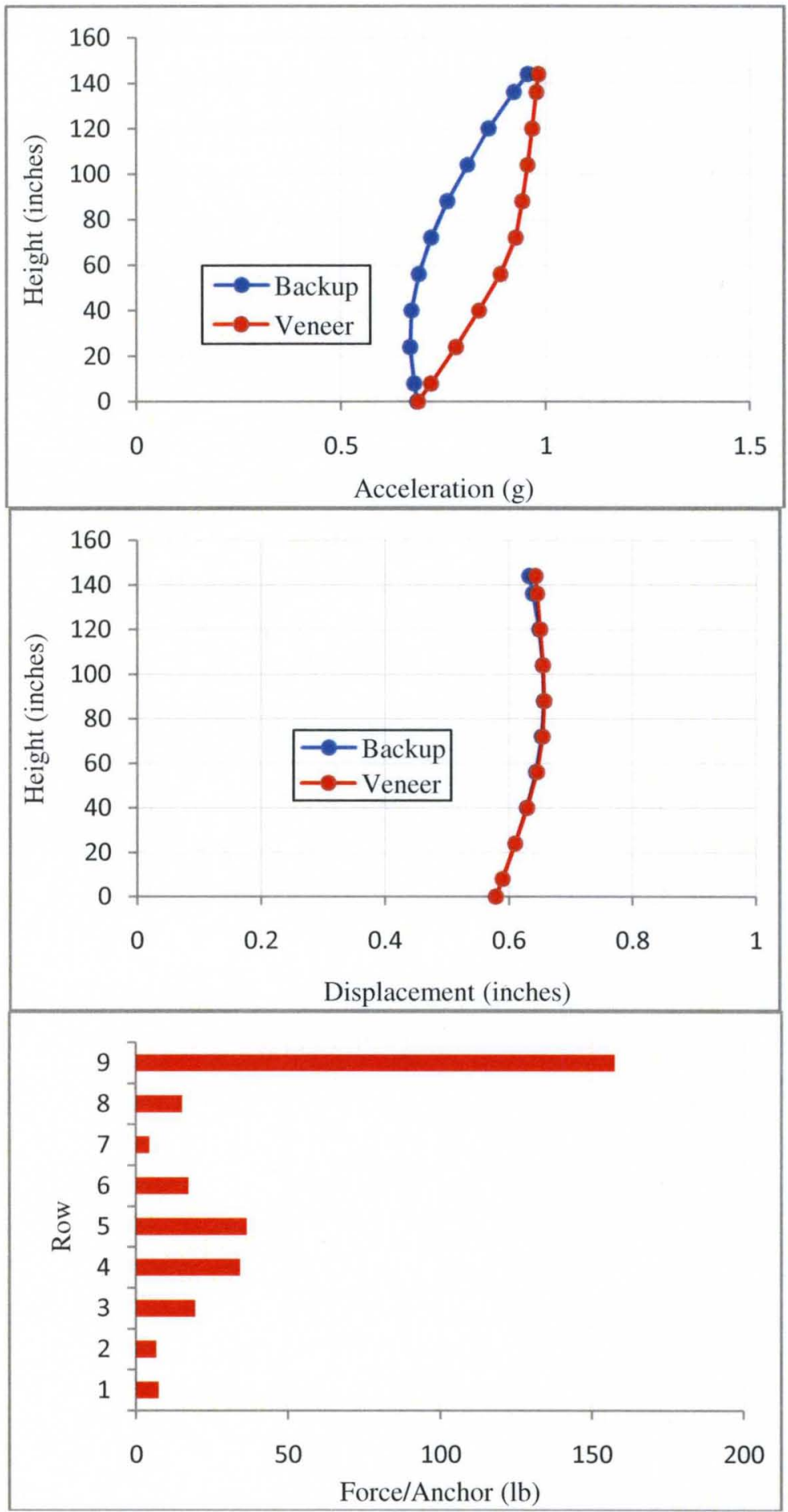

Figure D.22: Backup and Veneer Accelerations and Displacements, and Tie Forces for model id. cb/op-am/studs/de-stiff/ip-mass/studs/none/syl/mce 

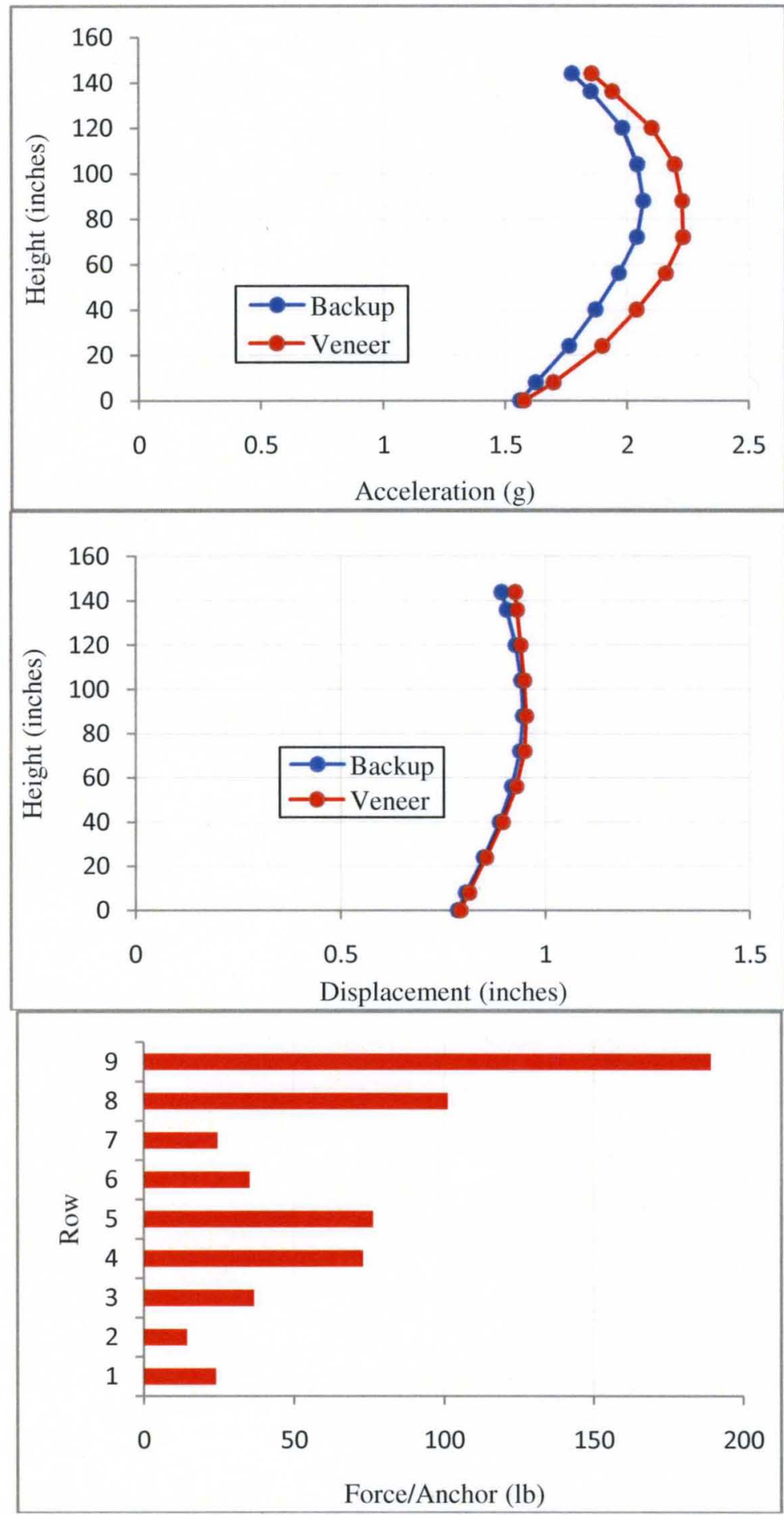

Figure D.23: Backup and Veneer Accelerations and Displacements, and Tie Forces for model id. cb/op-am/studs/de-flex/ip-mass/studs/none/tar/mce 


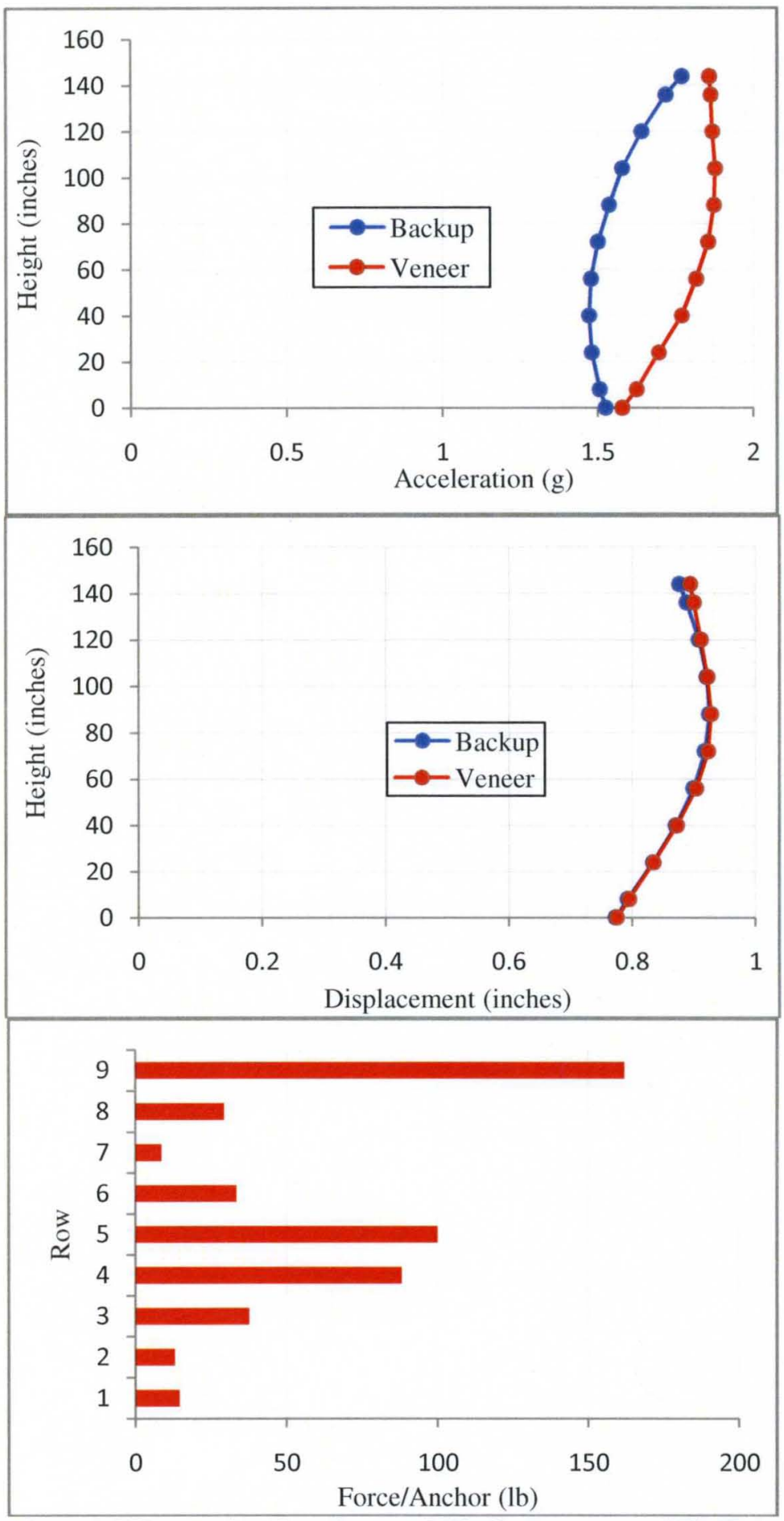

Figure D.24: Backup and Veneer Accelerations and Displacements, and Tie Forces for model id. cb/op-am/studs/de-stiff/ip-mass/studs/none/tar/mce 

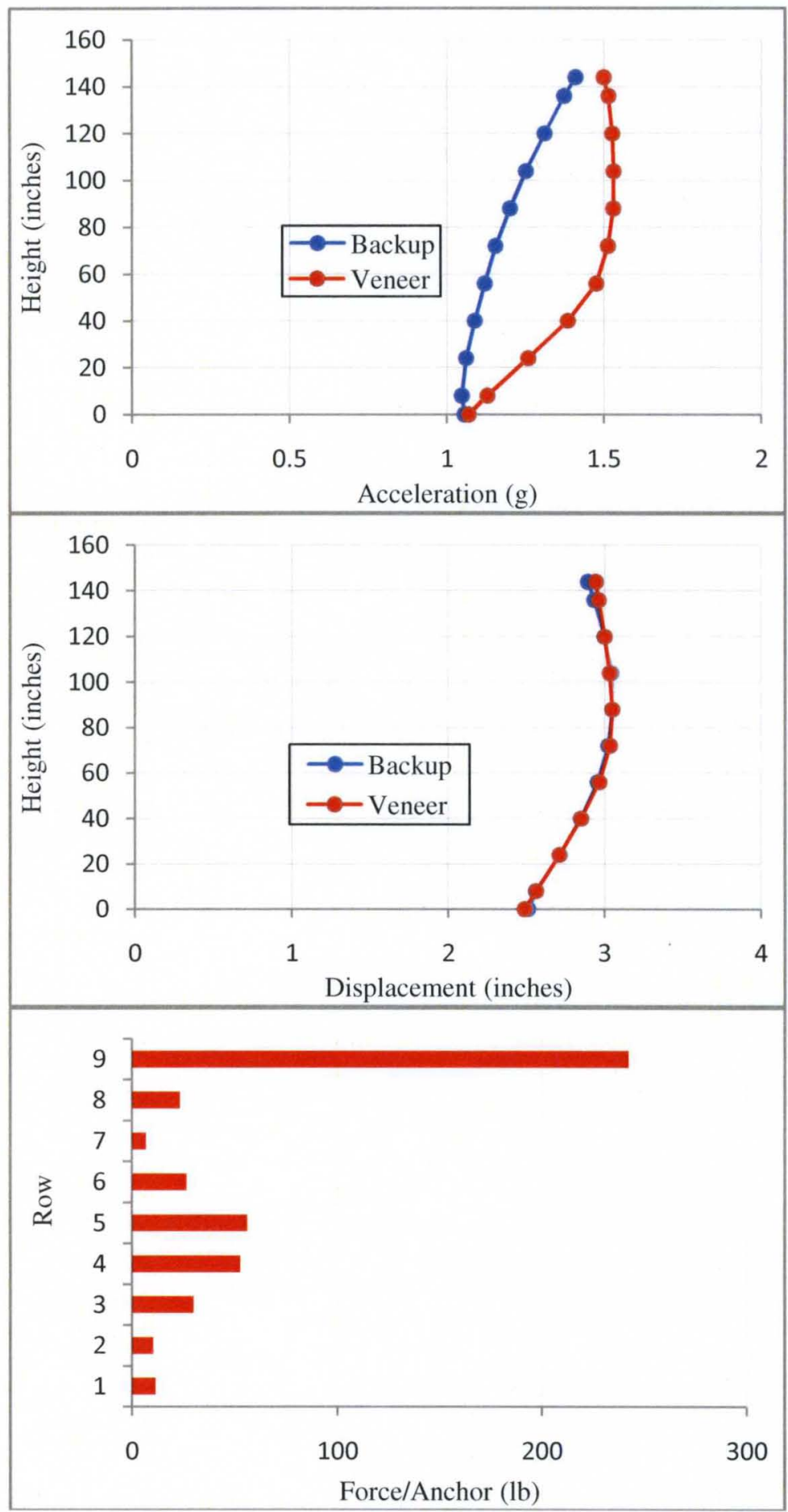

Figure D.25: Backup and Veneer Accelerations and Displacements, and Tie Forces for model id. sb/op-am/stud/flex/ip-mass/stud/none/syl/mce 

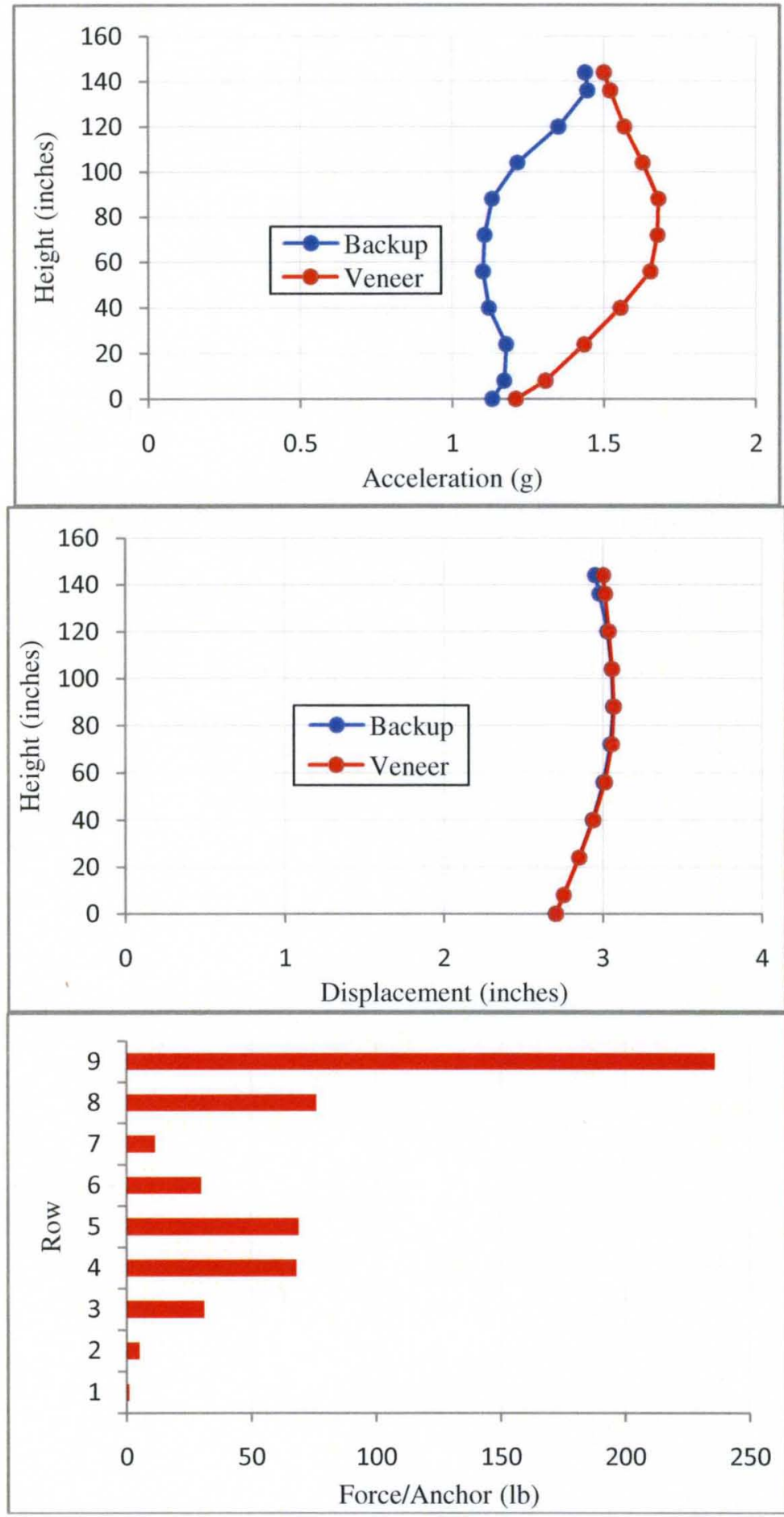

Figure D.26: Backup and Veneer Accelerations and Displacements, and Tie Forces for model id. sb/op-am/stud/stiff/ip-mass/stud/none/syl/mce 


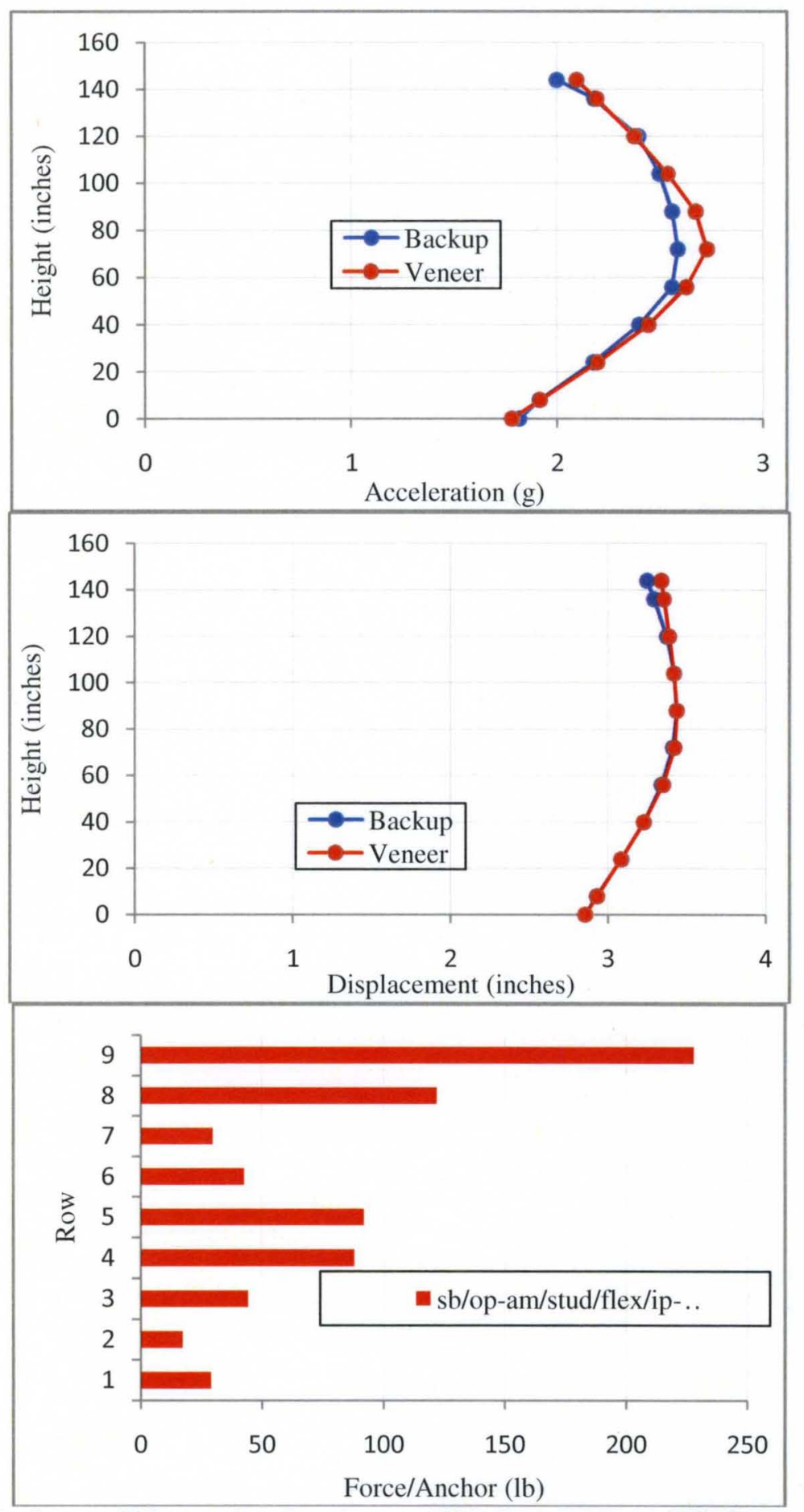

Figure D.27: Backup and Veneer Accelerations and Displacements, and Tie Forces for model id. sb/op-am/stud/flex/ip-mass/stud/none/tar/mce 

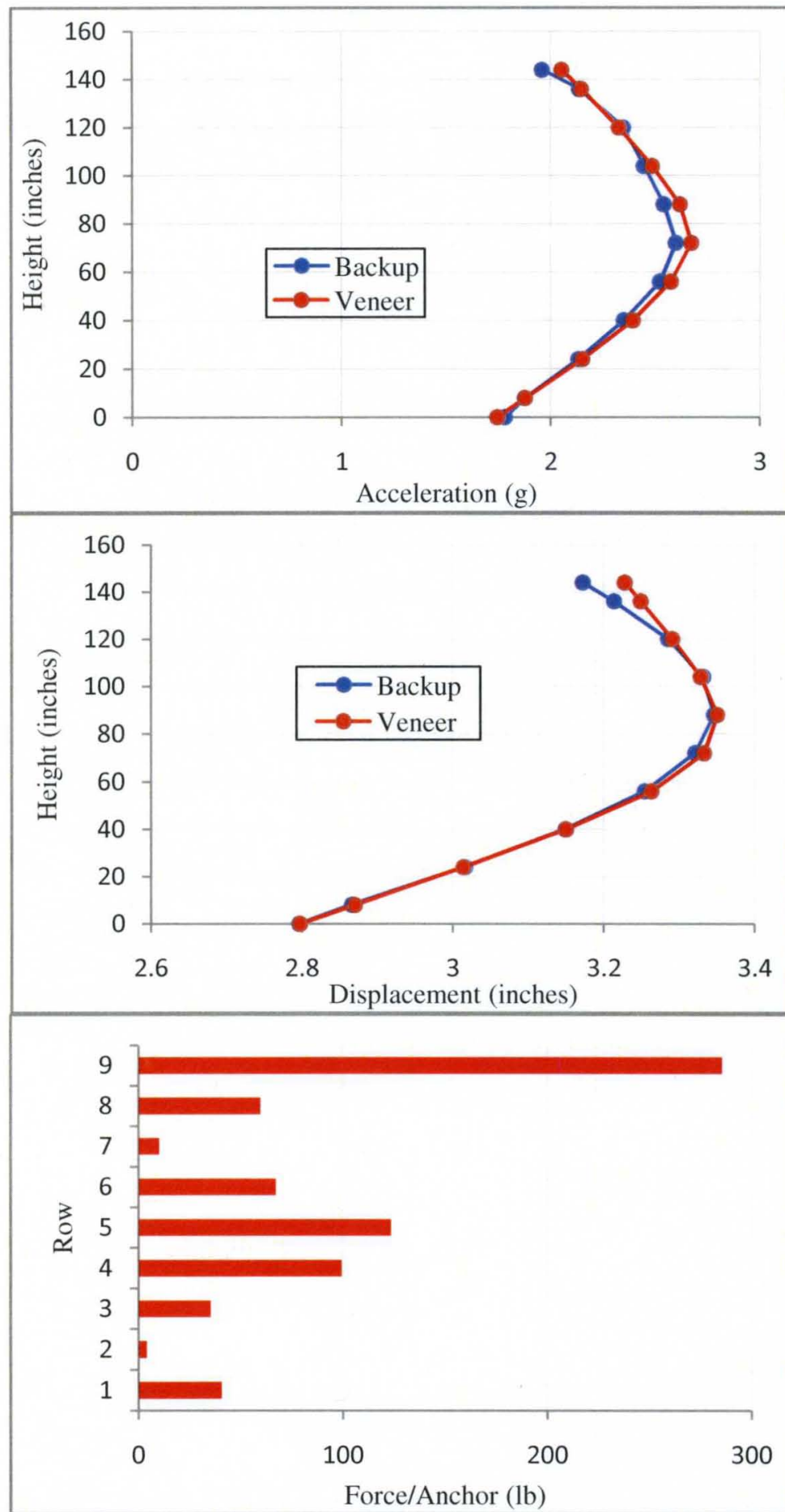

Figure D.28: Backup and Veneer Accelerations and Displacements, and Tie Forces for model id. sb/op-am/stud/stiff/ip-mass/stud/none/tar/mce 

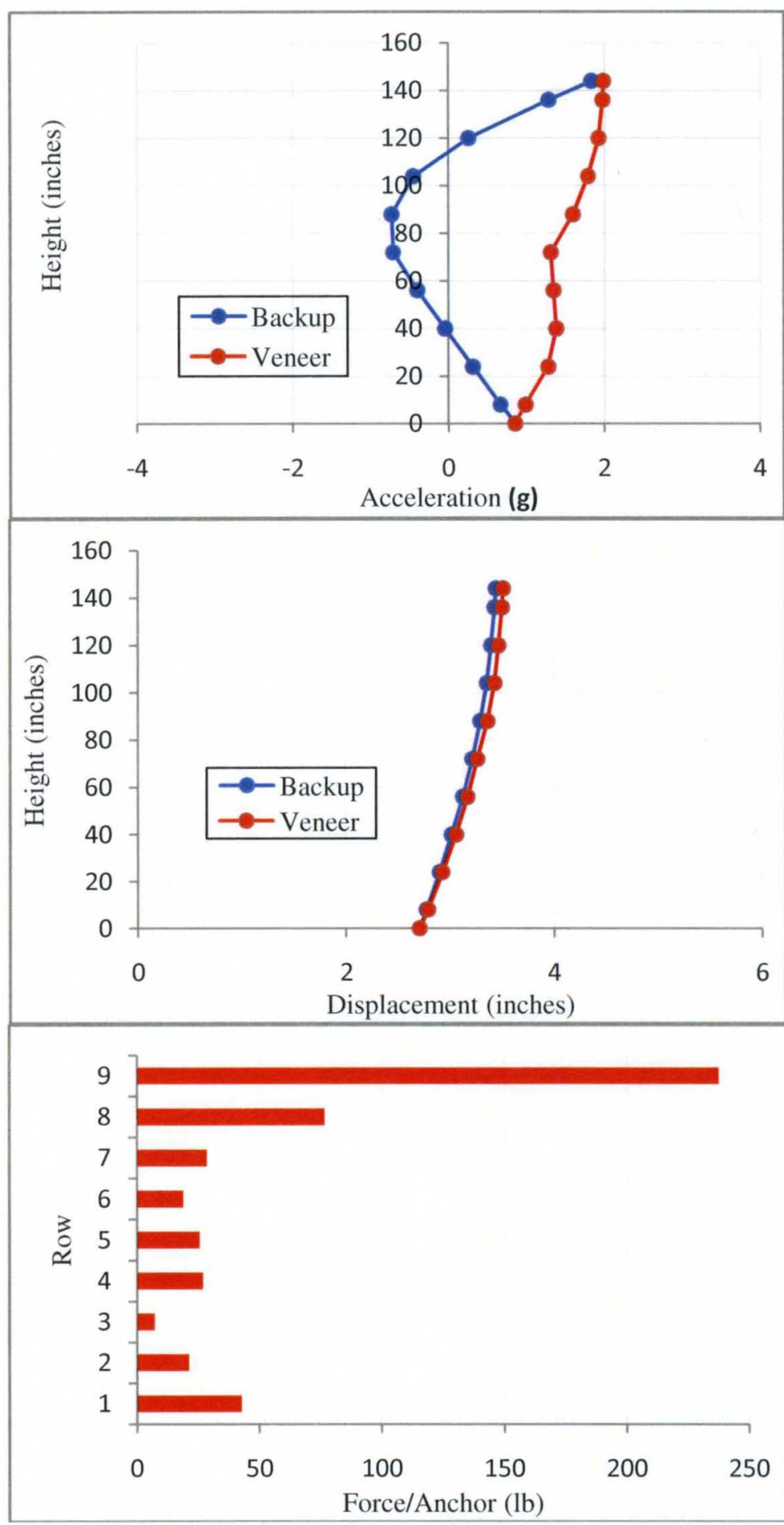

Figure D.29: Backup and Veneer Accelerations and Displacements, and Tie Forces for model id. smrf/op-am/stud/flex/ip-mass/stud/none/syl/mce 

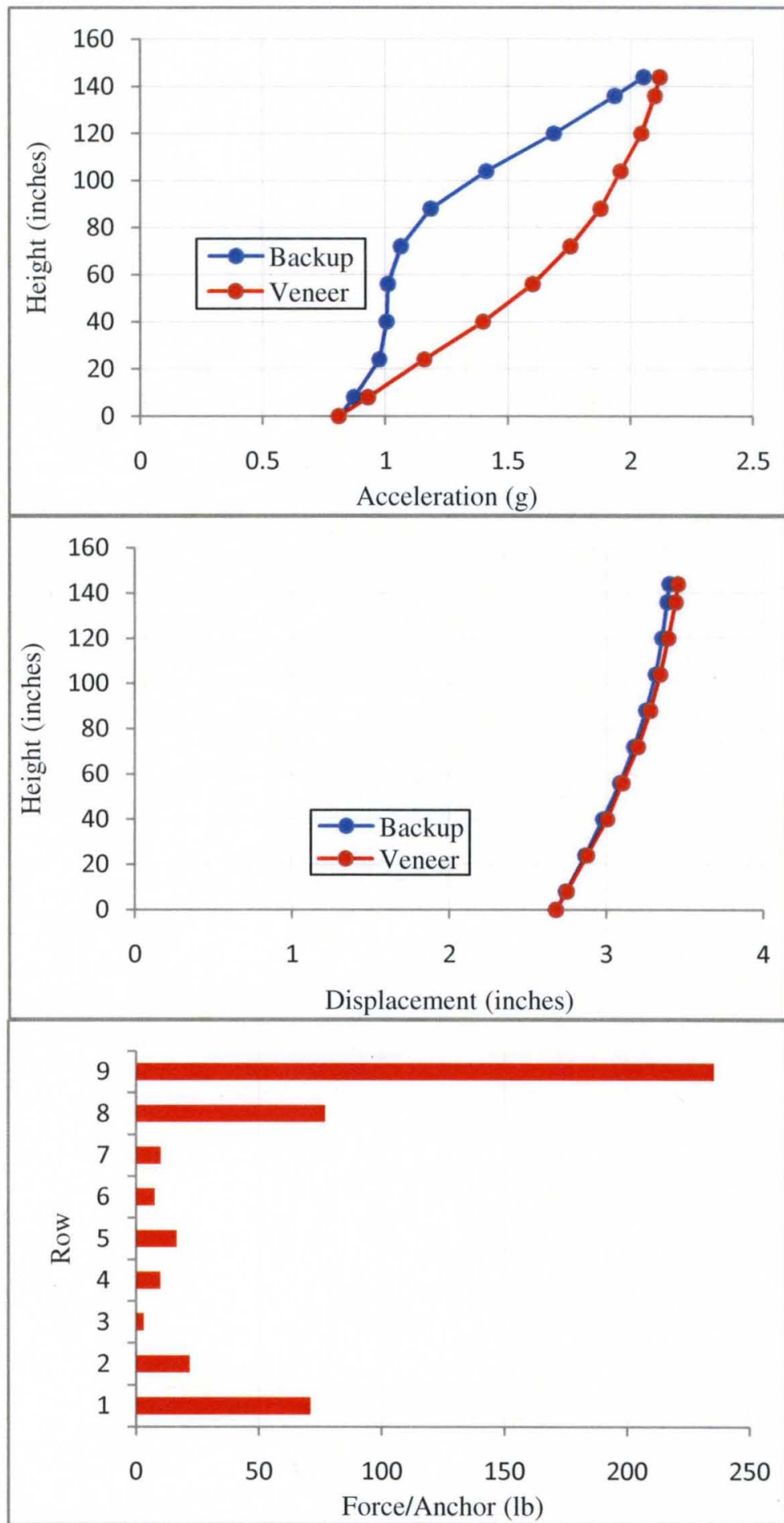

Figure D.30: Backup and Veneer Accelerations and Displacements, and Tie Forces for model id. smrf/op-am/stud/stiff/ip-mass/stud/none/syl/mce 


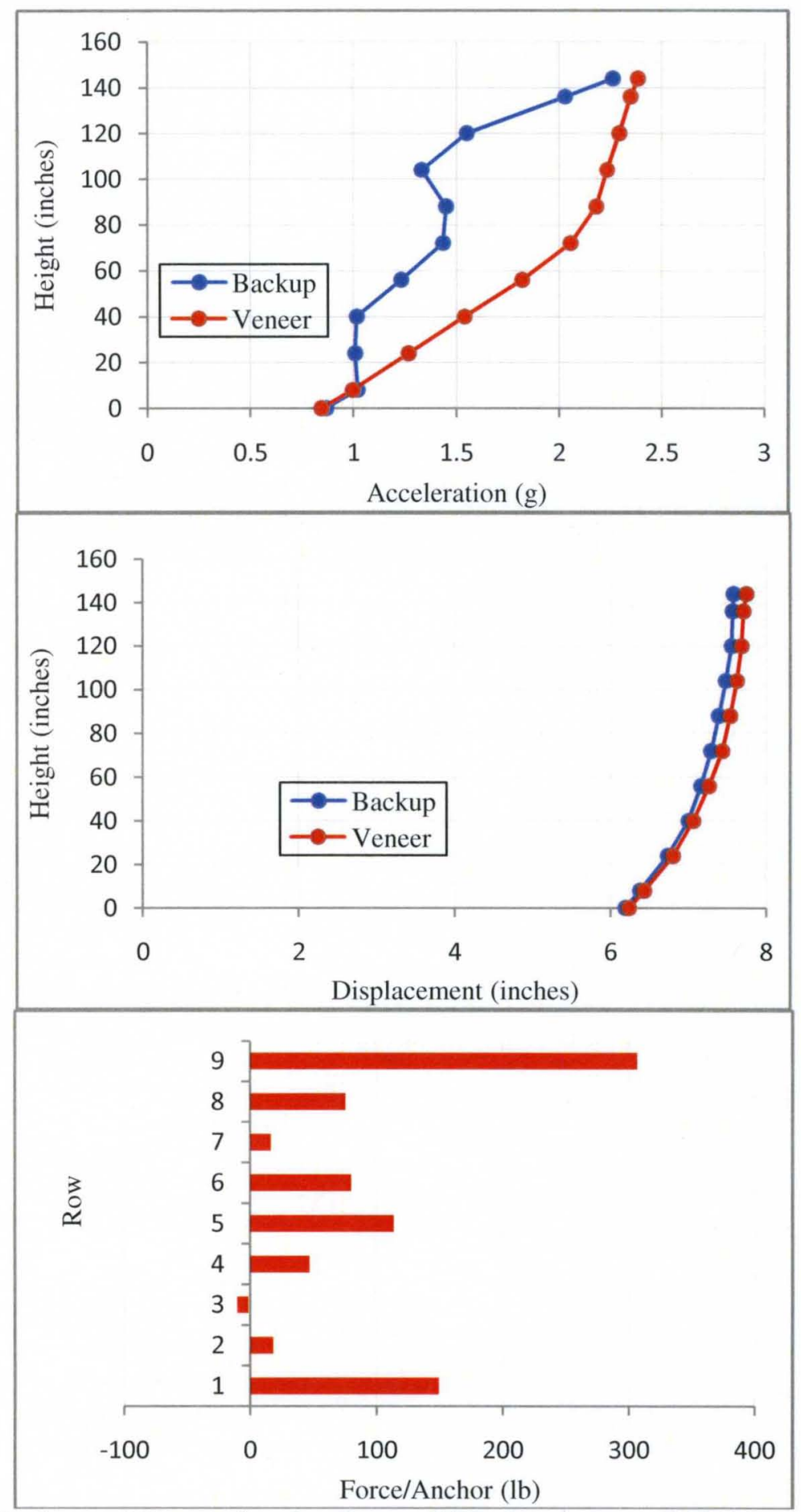

Figure D.31: Backup and Veneer Accelerations and Displacements, and Tie Forces for model id. smrf/op-am/stud/flex/ip-mass/stud/none/tar/mce 

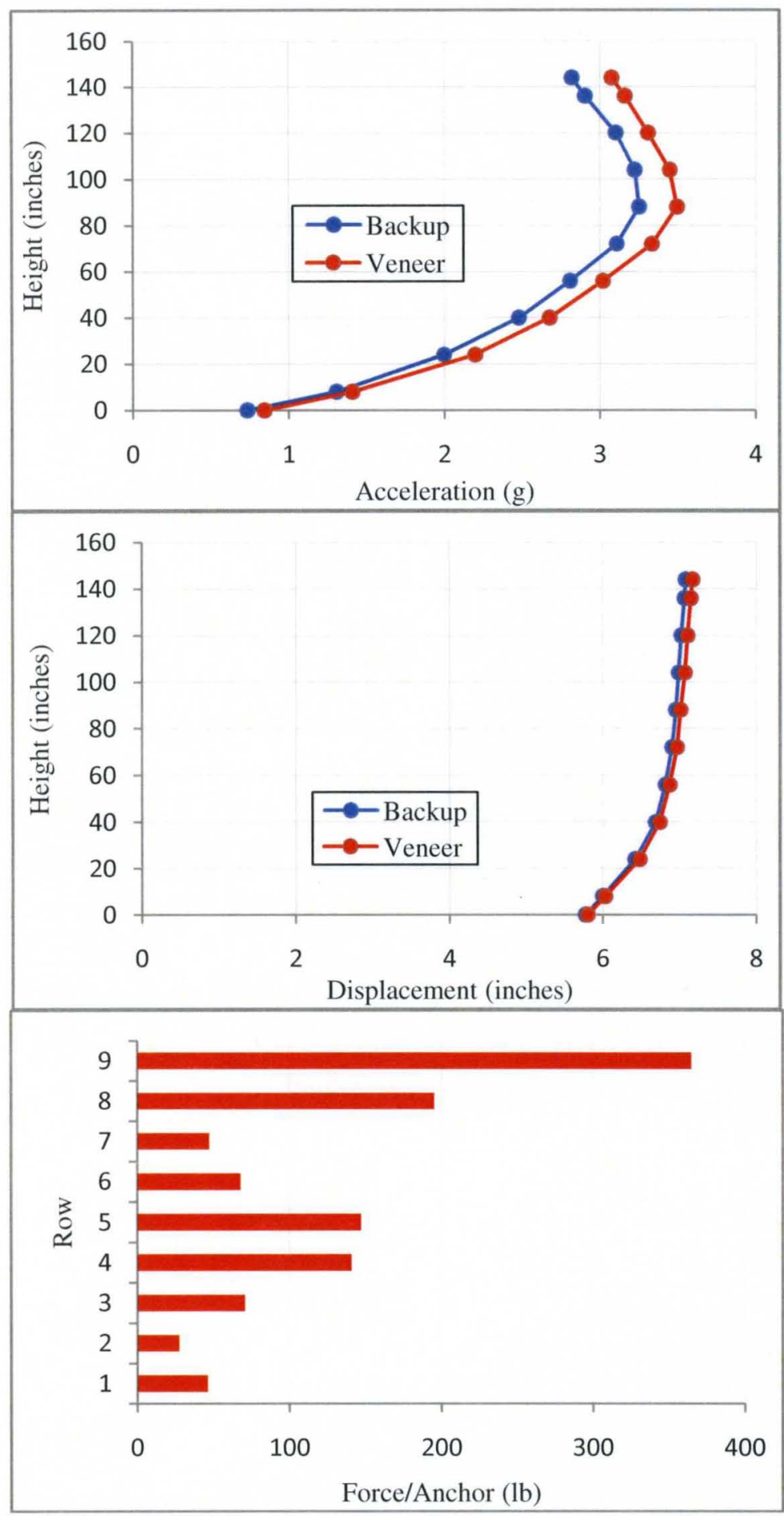

Figure D.32: Backup and Veneer Accelerations and Displacements, and Tie Forces for model id. smrf/op-am/stud/stiff/ip-mass/stud/none/tar/mce 


\section{CURRICULUM VITAE}

NAME: Niranjan Desai

ADDRESS: $\quad$ The Department of Civil and Environmental Engineering

J. B. Speed School of Engineering

University of Louisville

Louisville, Kentucky 40292, USA.

DOB: $\quad$ Mumbai, India - November 19, 1979

EDUCATION

AND TRAINING: $\quad$ B.TECH., Civil Engineering

Indian Institute of Technology - Delhi, 2003

M.E.S., Structural Engineering

University of Sydney, Australia, 2004

Ph.D., Structural Engineering

University of Louisville, USA, 2011 